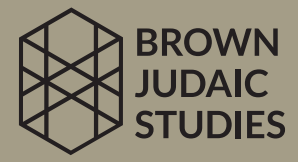

\title{
A History of the Mishnaic Law of Agriculture: Kilayim
}

Translation and Exegesis

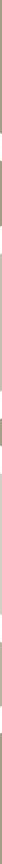

IRVING MANDELBAUM 

A History of the Mishnaic Law of Agriculture: Kilayim 


\title{
BROWN UNIVERSITY \\ BROWN JUDAIC STUDIES
}

Edited by

\author{
Jacob Neusner
}

Wendell S. Dietrich, Ernest S. Frerichs, Sumner B. Twiss, Alan Zuckerman

Board of Editors

David Altshuler, George Washington University

David R. Blumenthal, Emory University

Baruch M. Bokser, University of California, Berkeley

Joel Gereboff, Arizona State University

David Goldenberg, Dropsie University

Robert Goldenberg, State University of New York, Stony Brook

David Goodblatt, Haifa University

William Scott Green, University of Rochester

Peter Haas, Vanderbilt University

Martin Jaffee, University of Virginia

Shamai Kanter, Temple Beth El, Rochester, New York

Jack L. Lightstone, Concordia University

lrving Mandelbaum, University of Texas

Alan Mintz, University of Maryland

Alan J. Peck, Tulane University

Gary G. Porton, University of Illinois

Marc L. Raphael, Ohio State University

Richard S. Sarason, Hebrew Union College-Jewish Institute of Religion

Tzvee Zahavy, University of Minnesota

Editorial Committee:

Roger Brooks

Louis Newman

Number 26

\author{
A History of the Mishnaic Law \\ of Agriculture: Kilayim \\ Translation and Exegesis
}

by Irving Mandelbaum 


\title{
A HISTORY OF THE MISHNAIC LAW OF AGRICULTURE: KILAYIM
}

\section{Translation and Exegesis}

\author{
by \\ IRVING MANDELBAUM
}

Scholars Press 


\section{A History of the Mishnaic Law of Agriculture: Kilayim:}

Translation and Exegesis

by

Irving Mandelbaum

Copyright @ 2020 by Brown University

Library of Congress Control Number: 2019953439

Open access edition funded by the National Endowment for the Humanities/ Andrew W. Mellon Foundation Humanities Open Book Program.

The text of this book is licensed under a Creative Commons Attribution-NonCommercial-NoDerivatives 4.0 International License: https://creativecommons.org/licenses/ by-nc-nd/4.0/. To use this book, or parts of this book, in any way not covered by the license, please contact Brown Judaic Studies, Brown University, Box 1826, Providence, RI 02912. 
For My Parents 
Publication of this book is made possible with the support of The Max Richter Foundation, in honor of Professor David R. Blumenthal. 
PREFACE - . . . . . . . . . . . . . . . . . . . . . . . . ix

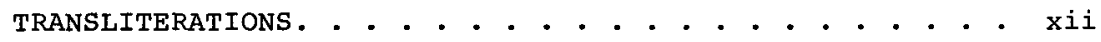

ABBREVIATIONS AND BIBLIOGRAPHY. . . . . . . . . . . . . . xiii

INTRODUCTION . . . . . . . . . . . . . . . . . . . . . . . . . . . 1

i. The central thesis of the tractate . . . . . . . . 1

ii. The structure and contents of the tractate... . 4

iii. Goals and methods of exegesis. . . . . . . . . . 17

CHAPTER

I. KILAYIM CHAPTER ONE. . . . . . . . . . . . . . . 25

II. KILAYTM CHAPTER TWO. . . . . . . . . . . . . . . 71

III. KILAYIM CHAPTER THREE. . . . . . . . . . . . . . 115

IV. KILAYIM CHAPTER FOUR . . . . . . . . . . . . . 145

V. KILAYIM CHAPTER FIVE . . . . . . . . . . . 163

VI. KILAYIM CHAPTER SIX. . . . . . . . . . . . . . . 201

VII. KILAYIM CHAPTER SEVEN. . . . . . . . . . . . . . 229

VIII. KILAYIM CHAPTER EIGHT. . . . . . . . . . . . . . . 251

IX. KILAYIM CHAPTER NINE . . . . . . . . . . . . . . 283

NOTES

INTRODUCTION . . . . . . . . . . . . . . . . . 315

Chapter I. . . . . . . . . . . . . . . . . . 316

II. . . . . . . . . . . . . . . 333

III. . . . . . . . . . . . . . . . 347

IV. . . . . . . . . . . . . . . . . 358

V. . . . . . . . . . . . . . . 364

VI. . . . . . . +. . . . . , . . . 371

VII. . . . . . . . . . . . . . . . . 378

VIII. . . . . . . . . . . . . . , . . . . 384

IX. . . . . . . . . . . . . . . . . 390

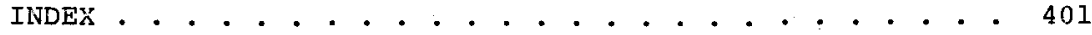





\section{PUBLISHERS ${ }^{\prime}$ PREFACE}

Brown Judaic studies has been publishing scholarly books in all areas of Judaic studies for forty years. Our books, many of which contain groundbreaking scholarship, were typically printed in small runs and are not easily accessible outside of major research libraries. We are delighted that with the support of a grant from the National Endowment for the Humanities/Andrew W. Mellon Foundation Humanities Open Book Program, we are now able to make available, in digital, open-access, format, fifty titles from our backlist.

Irving Mandelbaum's A History of the Mishnaic Law of Agriculture: Kilayim: Translation and Exegesis (1982) examines a complex tractate of the Mishnah dealing with the biblical prohibition against mixing sees or species. In addition to commenting on each part of the Mishnah, Mandelbaum considers the logic of the tractate as a whole and the intent of its composers.

This edition contains typographical corrections of the original text.

Michael L. Satlow Managing Editor October, 2019 

This study examines Mishnah-Tractate Kilayim (Diverse-Kinds), the fourth treatise in Mishnah's Division of Agriculture (Seder Zeracim). The tractate presents an extended essay concerning the scriptural prohibitions against commingling different categories of plants, animals, or fibers (Lv. 19:19, Dt. 22:9-11). For each of these types of agricultural items Mishnah supplements Scripture's rulings in three ways: 1) by establishing criteria for distinguishing among different classes, 2) by defining what constitutes the commingling of such classes, and 3 ) by determining how to keep these categories separate and distinct from one another. Although Mishnah's regulations clearly depend upon their scriptural antecedents, the conception of the law which they express is distinctive to Mishnah. In the tractate's view it is man, using his powers of observation, who determines what is orderly and what lies in confusion. Unlike Scripture, which takes for granted the existence of an established and immutable order, Mishnah calls upon man to create order based upon his own perception of the world around him.

My purpose in presenting a translation and exegesis of Mishnah-Tractate Kilayim is to discover the original meaning of the tractate. What I want to know is the sense which the formulators of the tractate's laws wished their rules to convey. I make no attempt to establish what laws pertaining to diverse-kinds meant either prior to their formulation in Mishnah or afterwards, in the course of the long history of Mishnah-exegesis. Since my work does not take into account these possible earlier or later layers of meaning, I am able to focus upon those issues which are of greatest concern to the actual framers of the tractate, the rabbis of the second century, A.D. My search for the original meaning of Mishnah Kilayim thus contributes towards the larger task of describing and interpreting early rabbinic Judaism.

Both the translation and exegesis of Mishnah Rilayim are directed towards this goal of discovering the original neaning of the tractate's laws. The translation closely renders into English the formulait language and syntactic patterns of the Hebrew text. My exegesis then opens with a careful analysis of these formal and literary traits which are underlined by the translation. Here I show how the formulation of the tractate's rules araws our attention to those issues which the authorities behind the rules deem to be of central importance. At this stage it becomes 
possible to explain the substance of the laws in terms of these larger issues. This I maintain brings me to those points which Mishnah's framers intended to make through their rulings. Once I have made clear these larger concerns, moreover, I am able to identify the one central issue, or problematic, which has generated them, and so stands behind the tractate as a whole.

Although my study is primarily concerned with Mishnah"s Tractate Kilayim, I also present a translation and exegesis of Tosefta kilayim, an early commentary to our treatise. I include Tosefta in this study because among rabbinic documents it bears a unique relationship to Mishnah. Although it is separate from Mishnah, it totally depends upon the latter for its redactional order, and often employs Mishnah's own formal traits and legal principles in formulating its rulings. Tosefta therefore deserves to be treated in accord with its implicit claim to be a companiondocument to Mishnah. For this reason I insert a translation and discussion of Tosefta's pericopae after the mishnaic pericope to which they refer. The purpose of this treatment of Tosefta is simply to explain the latter's exegesis of Mishnah.

It is with deep and heartfelt gratitude that I express my appreciation to those people who helped make this work possible. Foremost among these stands Professor Jacob Neusner, who has patiently guided this study from its inception to its present form. His searching questions, incisive criticism, and insightful suggestions have stimulated me to produce a work far more thorough and lucid than would otherwise have been the case. Dr. David Goodblatt (Haifa University) and Dr. Geza Vermes (University of Oxford) served as readers for the dissertation, and I greatly value their comments and suggestions. My teachers in the Department of Religious Studies at Brown University have contributed immeasurably to my personal and intellectual growth, and so merit thanks for their substantial (if often intangible) influence upon the present work. For their continuing interest in me I would like to thank Professors Wendell s. Dietrich, Ernest S. Frerichs (Dean of the Graduate School), Horst R. Moehring, John P. Reeder, Jr., Sumner B. Twiss, Jr., J. Giles Milhaven, and B. Barry Levy (now of McGill University). Mrs. Lois Atwood, Administrative Assistant, has also helped in many ways towards making my graduate career a pleasant one.

I have also benefitted from the comments, criticism and collegiality of fellow students in the Brown University graduate seminar in Judaic Studies, in which the present work was originally 
read (1974-77, 79-30). These include: Professors Charles Primus, University of Notre Dame; Tzvee Zahavy, University of Minnesota; Jack N. Lightstone, Concordia University; Richard S. Sarason, Hebrew Union College-Jewish Institute of Religion; Joel Gereboff, Arizona State University; Martin Jaffe, University of Virginia; Peter Haas, Vanderbilt University; Rabbi David Eisenman, Mr. Leonard Gordon, Mr. Avi Habibi, Mr. Alan Peck, Mr. Michael Rosen, and Mr. Howard Essner.

In the course of writing the present work I have been fortunate to have had the opportunity to spend several years at the university of oxford. My teachers there introduced me to new areas of study and in many ways enriched my academic and personal life. I am grateful to Dr. Geza Vermes, Dr. Sebastian Brock, Rev. Symeon Lash (now of the University of Newcastle), and Professor Mary Boyce (University of London) for all that they have taught me.

I an grateful as well to the various institutions which helped support me during my career as a graduate student. Brown University offered me tuition scholarships in 1974-76, and a teaching assistantship in 1976-77. The Memorial Foundation of Jewish Culture awarded me a Doctoral Dissertation Grant in 1976-77, and the National Foundation for Jewish Culture provided a Comprehensive Examination Grant for the summer of 1977. In addition, the Oxford Centre for Postgraduate Hebrew studies awarded me Junior Fellowships for the years 1978-30. I greatly appreciate the generosity of the Centre and its principal, Dr. David Patterson, in this regard.

Mrs. Elaine Haste and Mrs. Dody Giletti carefully typed a difficult manuscript, and are to be commended for their efforts. Mr. Douglas Rose skillfully drew the illustrations which appear in the work. My thanks also go to Jenny Godfrey, now my wife, who provided assistance and personal support during the closing stages of the preparation of this study. I am further grateful to the Max Richter Foundation and its president, Dr. Jacob Neusner, for a grant making possible the publication of this work.

Finally, I cannot adequately express the thanks which I owe to my parents, Alice and Myer Handelbaum. Through their continuous support and encouragement they have taught me much concerning the value of learning and scholarship. This work stands as a tribute to their patience and understanding. 
TRAINSLITERATIONS

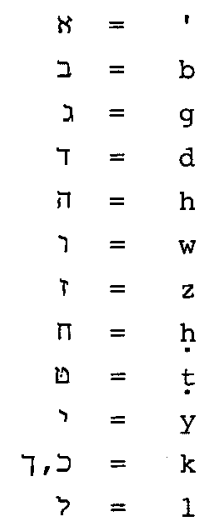

$\square, b=\mathrm{m}$

$7,3=n$

$0=s$

$y=c$

ด,, $\mathrm{P}$

$\gamma, y=s$

$p=q$

$7=r$

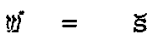

iii $=s$

$\Omega=t$ 


\section{ABBREVIATIONNS AND BIBLIOGRAPHY}

Ah.

Albeck

\section{Albrecht}

Alcalay

Arak.

Avi-Yonah, Carta's Atzas

Avi-Yonah, Historical Geography

A. Z.

B

B.

B.B.

$\mathrm{BDB}$
$=$ 'Ahilot

$=\mathrm{H}$. Albeck, The Six Orders

of Mishnah. I. The

Order of seeds [Heb.]

(Jerusalem and Tel Aviv:

Bialik Institute and

$D^{e}$ vir, 1957).

= see Beer-Holtzmann

= R. Alcalay, The Complete

Hebrew-English Dictionary

(Tel. Aviv: Massadah, 1965).

$=$ Arakin

= M. Avi-Yonah, Carta's

Atzas of the Period of the

Second Temple, the Mishnah,

and the Talmud [Heb.]

(Jerusalem: Carta, 1966).

= Historical Geography of Palestine from the End of

the Babyzonian Exile up

to the Arab Conquest

[Heb.] (2nd ed; Jerusalem:

Bialik Institute, 1951).

$={ }^{C}$ Abodah Zarah

$=$ Mishnah $2 e r a^{c} i m$, Ms. Berlin 93; see Zachs, I, pp. 7778 .

= Babylonian Talmud

= Baba' Batra'

= F. Brown, S.R. Driver, and C.A. Briggs, eds., A Hebrew and English Lexicon of the old Testament (1907; rpt. Oxford: Clarendon Press, 1952), 
Beer-Holtzmann

Bek.

Ber:

Bert.

Bes.

Bik.

Blackman

B.M.

Bokser

B. Q.

C

Cant.

$\mathrm{Cn}$
$=$ G. Beer and O. Holtzmann, eds., Die Mischna: Text, vbersetzung und ausfuhrliche Erkzarung (Giessen: A. Töpelmann, 1912- ). I. 4. seder Zeraim: Kil'ayim: Text, Übersetzung und Erkzarung, by K. Albrecht (1914).

= Bekorot

= Berakot

= Obadiah of Bertinoro, Mishnah commentary; in the Romm ed. of Mishnah.

$=$ Besah

= Bikkurim

= P. Blackman, trans., Mishnayot. I. order Zeraim (2nd. ed; New York: Judaica Press, 1964).

$=$ Baba'Meșica'

= B.M. Bokser, Samuel's Commentary on the Mishnah: Its Nature, Forms and Content. I. Mishnayot in the Order of Zeracim (Leiden: E.J. Brill, 1975).

$=$ Baba' Qamma'

= Mishnah, MS. Cambridge 470.1 , printed in W.H. Lowe, The Mishnah on which the Palestinian Talmud Rests (1883; rpt. Jerusalem: 1967); see Zachs, I, p. 67.

= Canticles

= Mishnah, early printed edition of unknown origin, probably constantinople or Pisaro, c. 1516 (photocopy: Jerusalem: Makor, 1970). see Zachs, I, pp, 82-83. 
Columella

Dalman

Danby

Dem.

Douglas

Dt.

Eben-Shoshan

Ed.

Epstein, IAL

Epstein, ITM

Erfurt

Erub.

Ex.
= Columella, De Re Rustica, trans. H.B. Ash, E.S. Forster, and E. Heffner. The Loeb Classical Library (London and Cambridge, Mass,: W. Heinemann Ltd., Harvard University Press, 1941-55). Three volumes.

= G. Dalman, Arbeit und Sitte in Palastina (1928-42; rpt. Hildesheim: Georg Olms, 1964). Eight volumes; Seven parts.

= H. Danby, trans., The Mishnah (London: Oxford University Press, 1933).

$=$ Dema'i

= M. Douglas, Purity and Danger: An Analysis of the Concepts of Pollution and Taboo (London: Routledge and Kegan Paul, 1966)

$=$ Deuteronomy

= A. Eben-Shoshan, HaMizon HaḤadash (Jerusalem: Kiryat-Sefer, 1969), Seven volumes.

$=\mathrm{C}_{\text {Eduyyot }}$

= Y,IN. Epstein, Introduction to Amoraitic Literature [Heb.] (Jerusalem: Magnes Press, 1962).

= Y.N. Epstein, Introduction to the Text of Mishnah

[Heb.] (2nd ed.; Jerusalem: Magnes Press, 1964). Two volumes.

$=$ Tosefta, Ms. Erfurt; cf. Lieberman, $T Z$, pp. 8-11.

$=$ CErubin

$=$ Exodus 


\section{Feldman}

Feliks, Agriculture

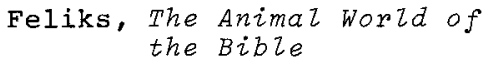

Feliks, HaHai BaMishnah

Feliks, Mar'ot HaMishnah

Feliks, Mixed Sowing

Feliks, Plant World of the Bible

Finkelstein, Sifre Dt.

First printed ed.

Forbes

Geniza fragments
= Feldman, Șimḥe HaMishnah

(Tel Aviv: 1962).

$=$ J. Feliks, Agriculture in Palestine in the Period of the Mishna and the Talmud. [Heb.] (Jerusalem: Magnes Press, 1963).

= J. Feliks, The Animal World of the Bible, trans. Pinhas Irsai (Tel Aviv: Sinai, 1962).

= J. Feliks, Haţai BaMishnah (Jerusalem: Institute for Mishnah Research, 1972).

= J. Feliks, Mar'ot HaMishnah (Jerusalem: Midrash Bnei Siyon, 1967).

= J. Feliks, Mixed Sowing, Breeding and Grafting [Heb.] (Tel Aviv: $\mathrm{D}^{\mathrm{e}} \mathrm{vir}$, 1967).

= J. Feliks, Plant World of the Bible [Heb.] (Tel Aviv: Massadah, 1057).

= L. Finkelstein, ed., Sifre on Deuteronomy (Berlin, 1939; rpt. New York: Jewish Theological Seminary, 1969).

= Tosefta, editio princeps. Venice, 1521.

= R.J. Forbes, Studies in Ancient Technology, IV (2nd ed.; Leiden, E.J. Bril1, 1964).

= Mishnah Mss. Eragments from the Cairo Genizah; listed by Zachs, I, pp. 87-112. 
Gereboff

Ginzberg

Git.

Gn.

GRA

Graser

Green

Hag.

Hal.

Harrison, Masefield, and Wallis
= J. Gereboff, Rabbi Tarfon

(Missoula: Scholars

Press, 1979) (page numbers refer to Brown University Ph.D. dissertation, 1977).

= L. Ginzberg, "Beiträge zur Lexikographie des Aramaischen," in Samuel Krauss, ed. Festschrift Adolf Schwartz (Berlin: R. Löwit, 1917).

$=$ Gittin

$=$ Genesis

$=$ Elijah b. Solomon Zalman ("Hagaon Rabbi Eliyahu" or "Vilna Gaon"; Lithuania 1720-1797), Mishnah commentary in Romm edition of Mishnah (Vilna, 1908, and numerous reprints); Tosefta emendations, in Romm ed. of Babylonian Talmud (Vilna, 1886, and numerous reprints)

= S.R. Graser, trans., The Edict of Diocletian, in Tenney Frank, ed., An Economic Survey of Ancient Rome (Baltimore: Johns Hopkins Press, 1940), volume 5, pp. 305-421.

= W.S. Green, The Traditions of Joshua b. Hananiah. Unpublished Brown University Ph.D. dissertation, 1974 .

= Hagigah

$=$ Hallah

= S.G. Harrison, G.B. Masefield, and Michael Wallis, The oxford Book of Food plants (London: Oxford University Press, 1969). 
Hartmann and Kester

Hazon YehezqueI

HD

Hill

Hillel

Hor.

Hul.

Ish-Shalom

Israelstam
$=$ Hudson T. Hartmann and Dale E. Kester, Plant Propagation: Principles and Practices (2nd ed.; Englewood Cliffs: PrenticeHa11, 1968).

= Yehezquel Abramsky (18361976), Tosefta Hazon Yehezquel I. Zeracim (1925; rpt. Jerusalem, 1971).

= Hasde David. David Samuel b. Jacob Pardo (1718-1790), Sefer Hasdé David [Tosefta Commentary]. I. Seder Zeracim (Livorno, 1776 ; rpt. Jerusalem, 1971).

= Albert F. Hill, Economic Botany: A Text-Book of Useful plants and Plant Products (2nd ed.; New York: McGraw-Hi11, 1952).

= Hillel b. Eliaqim, Commentary to sifre, in Sifré. . with the Commentary. . . of Rabbenu HizzeZ b. EZiaqim, ed. s. Koleditsky (Jerusalem, 1958).

$=$ Horayyot

$=$ Ḥullin

$=$ M. Ish-Shalom (Friedman), ed., Sifré debe Rab (Vienna, 1864 ; rpt. Jerusalem, 1967).

= The Babyzonian Talmud: Seder Zeracim II, translated into English with notes, glossary, and indices under the editorship of Rabbi Dr. I. Epstein (London: Soncino Press, 1948). Kilayim is the work of J. Israelstam. 
Jastrow

Jones

Josephus

K

Kel.

Ker.

Ket.

$\mathrm{Ki} 1$.

KM

Knowles
$=$ M. Jastrow, A Dictionary of the Targumim, the Talmud Babli and Yerushalmi and the Midrashic Literature (1904; rpt. New York: Pardes Press, 1950).

= A.H.M. Jones, "The cloth Industry in the Roman Empire," in P.A. Brunt, ed., The Roman Economy. (Oxford: Basil Blackwell, 1974), pp. 350-364.

= Flavius Josephus, The Jewish War, trans. H. st. J. Thackeray, in Josephus, Loeb Classical Library (London and New York: W. Heinemann and G.P. Putnam's Sons, 1927). volumes 2 and 3 .

$=$ Mishnah, Ms. Kaufmann A50; photocopy: G. Beer, Faksimize-Ausgabe des Mischnacodex Kaufmann A50 (The Hague, 1929; rpt. Jerusalem: Makor, 1969); cf. Zachs, I, pp. 65-66.

$=$ Kelim

$=$ Keritot

$=$ Ketubot

= Kilayim

= Joseph b. Ephraim Karo (1488-1575), Keseph Mishnah. Commentary to Maimonides, Mishnah Torah; in standard editions of latter.

= P.F. Knowles, "Safflower-Production, Processing and Utilization," in Economic Botany 9 (1955), pp. 273299. 


\section{Kosowsky}

Kosowsky, Tosefta

KP

Krauss

I

LV .

Lewin

Iieberman, Greek

Lieberman, HeZlenism

Lieberman, $T K$
= C.Y. Kosowsky, Thesaurus Mishnae [Heb.] (Jerusalem: Massadah, 1956). Four volumes.

= C.Y. Kosowsky, Thesaurus Tosephtae [Heb.] (Jerusalem, 1932-61). Six volumes.

= Estori Parhi (ca. l4th century), Kaftor VaPerah, work on medieval Palestine and its agriculture. Cited by Lieberman, $T K$.

= S. Krauss, TaZmudische Archäologie (Leipzig: G. Fock, 1910). Two volumes.

= Palestinian Talmud, Ms. Leiden (Codex Scali 3); photocopy: Jerusalem: Makor, 1976; see Zachs, I, p. 72 .

$=$ Leviticus

= B.M. Lewin, ed., Otzar HaGeonim (Haifa: 1930).

= S. Lieberman, Greek in Jewish Palestine (New York: Jewish Theological Seminary, 1942).

= S. Lieberman, HeZZenism in Jewish Palestine (New York: Jewish Theological Seminary, 1950).

= S. Lieberman, Tosefta Kifshutah: A Comprehensive Commentary on the Tosefta. I. Order Zeracim (New York: Jewish Theological Seminary, 1955). Two volumes. 
Lieberman, $T M$

Lieberman, T2

Löw

Lv .

M.

Macas.

Maim., Code

Maim., Comm.

Mak.

Makh.

MB
= S. Lieberman, ed., The Tosefta According to Codex Vienna, with variants from Codices Erfurt, London, Genizah Mss. and Editio Princeps (Venice 1521). II. The order of $\mathrm{Mo}^{\mathrm{C} e d}$ (New York: Jewish Theological Seminary, 1962).

= S. Lieberman, ed. The Tosefta According to codex Vienna, with Variants from Codex Erfurt, Genizah Mss. and Editio Princeps Venice 1521. I. The order of Zeracim (New York: Jewish Theological Seminary, 1955).

= I. Löw, Die Flora der Juden (Vienna: R. Löwit, 1926). Four volumes.

$=$ Leviticus

= Mishnah

= Macaserot

$=$ Maimonides (Moses $b$. Maimon, 1135-1204), Mishnah Torah. Standard edition, six volumes; particularly Laws of Diverse-Kinds, in The Book of Agricuzture.

= Maimonides, Mishnah Commentary, in J. Qappah, trans. and ed., Mishnah with the Commentary of $R$. Moses b. Maimon. I. Zerac ${ }^{c}$ m-Moced (Jerusalem: Mossad HaRav Kook, 1963).

$=$ Makkot

$=$ Makhshirin

= Samuel Avigdor b. Abraham Karlin, Minhat Bikkurim. Tosefta commentary (1842); in Romm ed. of Babylonian Talmud. 
Me.

Meg .

Me'iri

Mekilta de Rabbi Ishmael

Men.

Mid.

Miq.

Mn

Morinaga

M.Q.

MR

Ms .

M.S.

MS
= Mecilah

= Megillah

$=$ Menahem b. Solomon Meiri (1249-1306), Beth HaBehirah on the Talmudical Tractate Shabbat, ed. Isaak S. Lange (1965; rpt. Jerusalem, 1971) .

= J.z. Lauterbach, ed., Mekizta de-Rabbi Ishmael (Philadelphia: Jewish Publication Society, 193549). Three volumes.

$=$ Menahot

$=$ Middot

$=$ Miqua'ot

= Babylonian Talmud, Codex Munich 95; photocopy: Hermann L. Strack, Talmud Babyzonium Codicis Hebraica Monatensis (Leiden, 1912; rpt. Jerusalem: Makor, 1971). See Zachs, I, pp. 69-70.

= Toshitaro Morinaga, "Germination of Seeds under Water," American Journal of Botany 13 (1926), pp. 126-140.

$=$ Mo ${ }^{\mathrm{C}}$ d Qațan

= Ephraim Isaac of Premsyla, Mishnah Rishonah. Mishnah commentary (1382) in Romm edition of Mishnah.

= Manuscript (plural: Mss.).

$=$ MaCaser Sheni

= Solomon b. Joshua Adeni. (1567-1625), Melekhet Shezomoh. Mishnah Commentary in Romm edition of Mishnah. 
Mt.

N.

Naz.

Ned.

Neg,

Nesiv

Neusner, Eliezer

Neusner, HMLHT

Neusner, HMLP

Neusner, Pharisees

Nia.

Noth

$\mathrm{Nu}$.

o
$=$ Matthew

= Mishnah, editio princeps (Naples, 1492; photocopy: Jerusalem: Makor, 1970). See Zachs, I, pp. 81-82.

= Nazir

$=$ Nedarim

$=N e g a^{C} i m$

= Naftali Sevi Yehudah Berlin (1817-1893), commentary to sifre, in sifre... ${ }^{c}$ Emeq HaNeṣiv (Jerusalem, 195961). Three volumes.

$=\mathrm{J}$, Neusner, Eliezer b. Hyrcanus: The Man and the Tradition (Leiden: E.J. Brill, 1973). Two volumes.

$=\mathrm{J}$. Neusner, A History of the Mishnaic Law of Holy Things (Leiden: E.J. Brill, 1978-), Four volumes thus far.

= J. Neusner, A History of the Mishnaic Law of Purities (Leiden: E.J. Brill, 1974-77), 22 volumes.

= J, Neusner, Rabbinic Traditions about the Pharisees before 70 (Leiden: E,J. Brill, 1971). Three volumes.

$=$ Niddah

= M. Noth, Leviticus, trans. J.S. Anderson, The old Testament Library (Philadelphia: Westminster Press, 1965).

$=$ Numbers.

$=$ Mishnah, Ms. Oxford 393, order Zeracim; with Maimonides' commentary, autograph. See Zachs, I, pp. 76-77. 


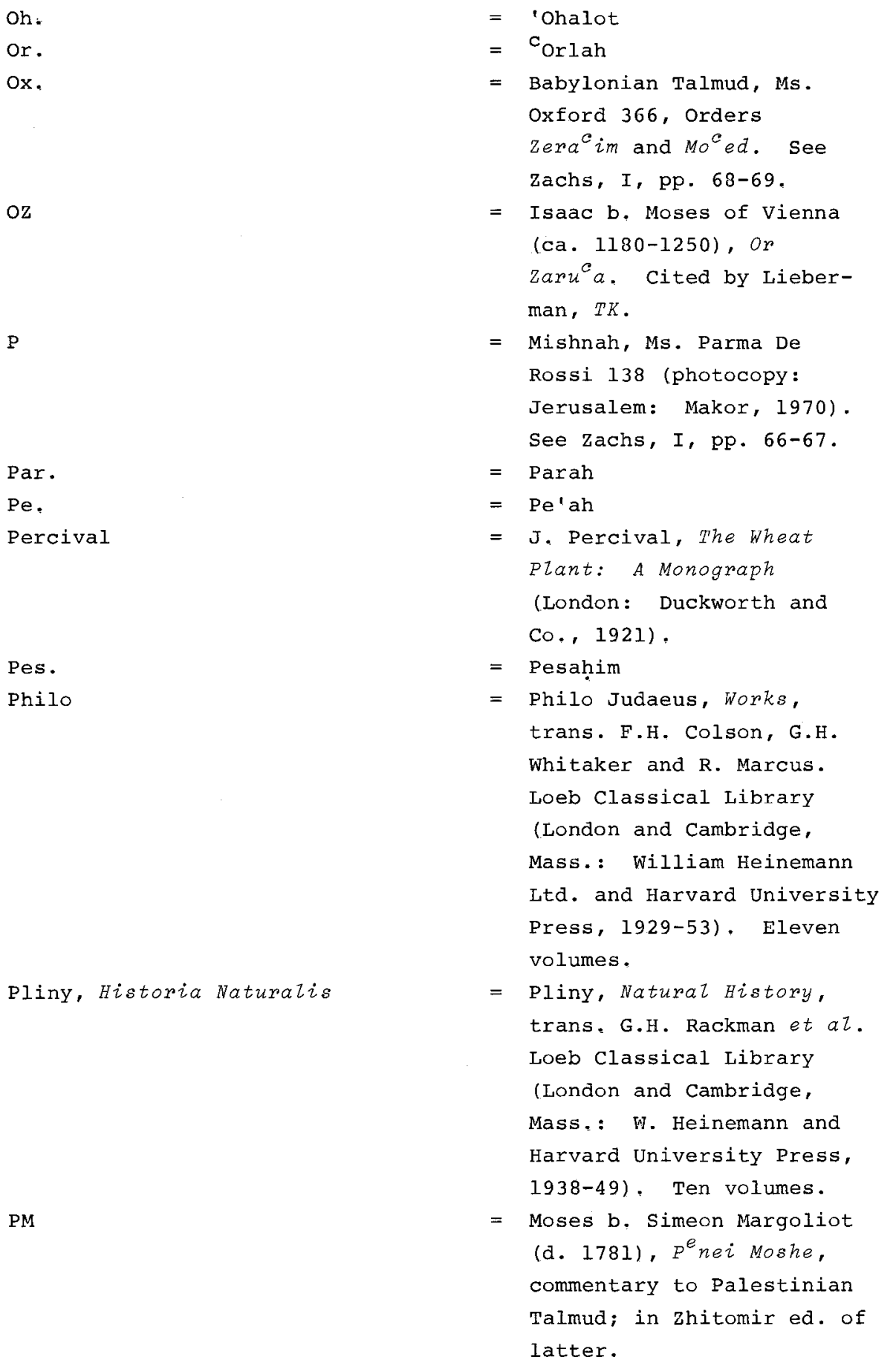


Porton

Post

$\operatorname{Pr}$

Primus

$Q A$

Qappạ

Qid.

Qin.

$\mathrm{R}$

Rabad

R.H.

Ribmas
= G. Porton, The Traditions of Rabbi Ishmael (Leiden: E,J. Brill, 1976- ). Three volumes thus far.

= George E. Post, Flora of Syria, Palestine and Sinai, ed. J.E. Dinsmore (2nd ed,; Beirut: Armenian Press, 1932). Two volumes.

= Mishnah, Ms. Paris 328-329 (photocopy: Jerusalem: Makor, 1970), See Zachs, I, p. 79.

= C. Primus, ${ }^{C}$ Aqiva's Contribution to the Law. I. Zeracim (Leiden: E.J. Brill, 1977).

= Aaron Ibu H̦ayyim (d. 1632), Qorban Aharon, Perush LaSefer Sifra (Dessau, 1749; rpt. Jerusalem, 1970).

= See Maim., Comm.

$=$ Qiddushin

= Qinnim

= Palestinian Talmud, Ms. Rome 133, Order Zerac ${ }^{c}$ m and tractate soțah. See zachs, I, p, 73.

= Abraham b. David of Posquières (twelfth century) glosses to Maimonides, Mishneh Torah; in standard edition of latter.

= Rosh Hashanah

$=$ Isaac $b$. Melchizedek of Siponto (c. 1090-1160), Mishnah commentary; in Romm edition of Babylonian Talmud. 
Ridbaz

Rosh

RSV

S

Sanh.

Sarason, Demai

Sarason, "Mishnah and Scripture"

Sefer Ha'Eshkoz
$=$ David b. Solomon ibn Abi Zimra (1479-1573) Ridbaz (more commonly known as Radbaz), commentary to the books of Asservations, Seeds, Holiness and Judges in Maimonides, Mishneh Torah; in standard editions of latter.

$=$ Asher b. Yehiel (ca. 12501327), Mishnah commentary; in Romm ed. of Babylonian Talmud,

= Revised standard Version of the old Testament.

= Palestinian Talmud, according to $R$. Solomon Sirillo, Ms. British Museum 403. See Zachs, I, pp. 73-75.

$=$ Sanhedrin

= R.S. Sarason, A History of the Mishnaic Law of Agriculture. III. $A$ study of the Tractate Demai. Part I: Commentary (Leiden: E.J. Brill, 1979).

= R.S. Sarason, "Mishnah and Scripture: Preliminary Observations on the Law of Tithes," published in W.S. Green, ed., Approaches to the study of Ancient Judaism, II (Missoula: Scholars Press, 1980).

$=$ Abraham $\mathrm{b}$. Isaac of Narbonne (ca. 1110-1179), Sefer Ha'Eshkol, work of halakic codification. Cited by Lieberman, $T K$. 
Sens

Shab.

Shav.

sheq.

Shev.

Sifra

Sifré Dt.

Sirillo

$\mathrm{Sn}$

Soler

Sot.

Suk.

T

T.

Ta.

Tam.

TAS

Tem.

Ter.
$=$ Samson b. Abraham of Sens (twelfth-thirteenth centuries), Mishnah commentary; in Romm ed. of Babylonian Talmud.

= Shabbat

$=$ Shavuot

= Sheqalim

$=$ Shevicit

= cf. Weiss, Sifra.

$=$ cf. Finklestein, sifré Dt.

= Solomon b. Joseph Sirillo (died ca. 1558), commentator on Palestinian Talmud; cited by Lieberman, $T K$.

$=$ Mishnah Zeracim, Ms. Sassoon 531. See Zachs, I, p. 68 .

= J. Soler, "The Dietary Prohibitions of the Hebrews," New York Review of Books, June 14,1979 (26:10), pp. 24-30.

$=$ Sotah

= Sukkah

$=$ Mishnah Zera $a^{c} i m$, Yemenite ms. of J. Qappah. See Zachs, I, pp. 80-81.

= Tosefta

$=\mathrm{Ta}^{\mathrm{C}}$ anit

$=$ Tamid

= Tosafot Anshe Shem, anonymous nineteenth century Mishnah commentary; in Romm edition of Mishnah.

= Temurah

$=$ Terumot 
Theophrastus, Historia Plantarum

$T K$

$\mathrm{Tm}$

Toh.

Tos.

T.Y.

TYB

TYT

TYY

Uqs .

$\mathrm{V}$

Varro
= Theophrastus, Enquiry into Plants, trans. A. Hort (London and New York: W. Heinemann and G.P. Putnam's Sons, 1916). Two volumes.

= See Liebermann, $T K$.

$=$ Mishnah Zeracim, Yemenite ms. of R. Maimon. See Zachs, I, pp. 80-81.

$=$ Tohorot

= Tosafot

= Tebul Yom

= Baruch Isaac b. Israel Lipschütz (1812-1877), Tif'eret Yisra'el $B 0^{C} a z$, supercommentary to TYY; in Romm edition of Mishnah.

$=$ Yom ToV Lipman Heller, (1579-1694), Tosafot yom Tov, Mishnah commentary; in Romm ed. of Mishnah.

= Israel b. Gedaliah Lipschütz (1782-1360), Tif'eret yisra'el yakhin, Mishnah commentary; in Romm edition of Mishnah.

$=\mathrm{C}_{\text {Uqsin }}$

= Babylonian Talmud, editio princeps, Venice 1520-23 (photocopy: Jerusalem: Makor, 1967-72). See Zachs, I, pp. 83-84.

= Varro, On Agriculture, trans. W.D. Hooper, rev.

H.B. Ash. Loeb Classical Library (1934; revised and reprinted, London and Cambridge, Mass.: w. Heinemann and Harvard University Press, 1967). 
Vienna

Weiss, Sifra

White

wilson, Clothing

Wild, "Flax-hackle"

Wild, Textile Manufacture

Windfuhr

$\mathrm{Y}$.

Yad.

Yev.

Y.T.

$\mathrm{Zab}$.

Zachs
= Tosefta, Ms. Vienna Heb. 20. See Lieberman, $T Z$, pp. 11-12 .

= I.H. Weiss, ed., Sifra debe Rab (1862; rpt. New York: Om, 1846).

= White, E.B., Roman Farming (Ithaca: Cornell University Press, 1970).

= L.M. Wilson, The Clothing of the Ancient Romans (Baltimore: Johns Hopkins Press, 1938).

= J.P. Wild, "The Roman Flax-hackle (AENA)", in Museum Helveticum 25 (1968), pp. 139-142.

= J.P. Wild, Textile Manufacture in the Northern Provinces (Cambridge: Cambridge University Press, 1970) .

$=$ G. Kittel and K.H. Rengstorf, eds., Die Tosefta: Text, Übersetzung und Erklärung Vi.l. KelimAhilot-Negaim, by W. Windfuhr (Stuttgart: Kohlhammer, 1960).

= Yerushalmi, Palestinian Talmud

= Yadayim

= Yevamot

= Yom Tob

= Zabbim

$=$ N. Zachs, ed., M. Zerac $i m$ (Jerusalem: Makhon HaTalmud HaYisraeli HaShalem 1972-75). Two volumes. 
Zeb.

zohary

Zuckermandel
= Zebahim

= M. Zohary, A New Anazytical Flora of Israel [Heb.]

(Tel Aviv: Am Oved, 1976).

= M.S. Zuckermandel, ed., Tosephta, based on the Erfurt and Vienna Codices (Trier, 1881-82; revised edition with supplement by Saul Lieberman, Jerusalem, 1936-39; rpt. Jerusalem: Wahrmann, 1970). 
i. The central thesis of the tractate

Mishnah Kilayim examines the scriptural prohibitions against commingling different classes of plants, animals, or fibers. While agreeing with Scripture's basic premise that different classes must be kept separate from one another, the tractate brings to its subject a conception of the law which is unknown to Scripture but distinctive to Mishnah as a whole. Specifically, Mishnah Kilayim maintains that it is man who both defines what constitutes a class and determines how to keep the different classes distinct from one another. Man thus imposes upon an otherwise disorderly world limits and boundaries which accord with human perception of order and regularity. In the tractate's view, then, what appears to man as orderly becomes identified with the objective order of the world. In presenting this conception of the law of diverse-kinds, the tractate Kilayim expresses views which are paralleled elsewhere in Mishnah. The tractate's interest in the human role in the ordering of mundane and ordinary things mirrors the emphasis placed by other mishnaic treatises ${ }^{1}$ upon the part played by man in defining the boundaries of the sacred. These other tractates claim that human thought and action affect the susceptibility of objects to either holiness or its opposite, uncleanness. As I shall explain below, Mishnah Kilayim applies the same principles to the ordering of the mundane realm that other mishnaic tractates apply to demarcating the bounds of the sacred.

Mishnah's divergence from Scripture becomes striking when we turn to the actual texts of the biblical rules. These laws are found in two sources:

Lv. $19: 19$

"You shall keep my statutes. You shall not let your cattle breed with a different kind ( $\left.k l^{\prime} y m^{2}\right)$; you shall not sow your field with two kinds of seed; nor shall there come upon you a garment of cloth made of two kinds of stuff (k $\tau^{\prime} y m$ şctnz 3$)$."

Dt. $22: 9-11$

"You shall not sow your vineyard with two kinds of seed, lest the whole yield be sanctified (tqd $\vec{s}$ ), the crop which you have sown and the yield of the vineyard. You shall not plow with an ox and an ass 
together. You shall not wear a mingled stuff $(\breve{s} \subset \operatorname{t} n z)$, wool and linen together."

Although there are differences between the two sources, both versions of the rules agree that it is prohibited to commingle plants, animals, or fibers of different kinds. First, both Leviticus and Deuteronomy prohibit the sowing of different classes of seeds among one another (the topic of Chapters one through Three of Mishnah), although Deuteronomy prohibits only the sowing of seeds in a vineyard (the topic of Chapters Four through Seven of Mishnah). Second, both sources prohibit the joining together of animals of different kinds (the topic of Chapter Eight of Mishnah). Leviticus, however, refers specifically to the mating of such animals, while Deuteronomy speaks of yoking them together to pull a plow. Finally, the wearing of a garment composed of commingled kinds of fibers is also prohibited by both sources, although Deuteronomy takes "mingled stuff" to refer to a mixture of wool (an animal product) and linen (a plant product) alone (as discussed in Chapter Nine of Mishnah). In each case, then, the two sources agree in prohibiting the commingling of different classes, while differing as to the specific act of commingling which is forbidden.

A comparison of the different formulations of the law, in any event, adds little to our investigation of the larger meaning of the scriptural laws of diverse-kinds. What we do want to know, on the other hand, is how each of the pentateuchal sources interprets the significance and purpose of these laws. It is difficult to learn anything about the views of $D$, for the context of its laws, a catalogue of rules dealing with unrelated topics, offers no insight into D's understanding of these laws. By contrast, a study of the context of the rules in the Holiness code of Leviticus yields important knowledge of P's views of the laws of diverse-kinds. Leviticus 19 consists of a list of rules headed by the command You shall be holy; for I the Lord your God am holy (Lv. 19:2). According to the catalogue's redactor, then, observance of the laws of diverse-kinds, like observance of the other rules of the catalogue, makes Israel holy. The laws are therefore to be interpreted in the context of the priestly understanding of the relationship between order and holiness. By examining this relationship we shall be able to put into perspective Mishnah's divergence from the views of Scripture.

In the view of the priestly circles which stand behind $P$, order is a precondition of holiness. This notion is clearly reflected in $\mathrm{P}^{\prime} \mathrm{s}$ account of the creation (Gn. 1:1-2:4a). P describes the making of a well-ordered, hierarchical world, Each 
type of creation is brought forth in order of ascending importance, with (among living things) plant life appearing first (Gn. 1:11-12), then animal life (Gn. 1:20-25), and finally man (Gn. 1:26-27). All living things, furthermore, were created each according to its kind (Gn. $1: 11-12,21,24-25) .{ }^{4}$ Creation is thus an act of ordering, the purpose of which is to make the world perfect and thus prepare it to be made holy. The actual act of the sanctification of the world then takes place on the Sabbath (Gn. $2: 1-3$ ). The point of $\mathrm{P}^{\prime} \mathrm{s}$ laws in Leviticus, then is to prevent the confusion of those classes and categories which were established at the creation. $P$ thus commands man to restore the world from its present condition of chaos to its original orderly state, and so to make the world ready once again for sanctification.

Although Mishnah takes up $\mathrm{P}^{\prime}$ 's general interest in order, it clearly diverges from $P^{\prime} s$ view that the task of man is to restore the original order of creation. For, as we have already stated, Mishnah claims that it is man, and not a set of already established rules, who decides what is orderly and what is confused. This claim leads the tractate to examine issues which are wholly unknown to $P$. For example, scripture would maintain that wheat and barley may not be grown together in the same field, for the growth of two kinds in a single field would confuse the distinctions between these two kinds. By contrast, according to Mishnah the commingling of different classes is prohibited only if the resultant mixture appears to man to contain a confusion of kinds, but not if the different kinds are arranged in an orderly manner. Mishnah thus permits one to grow wheat and barley in the same field, provided that each kind is allowed a substantial amount of area, and so appears to be sown in a separate area unto itself (cf. especially M. 2:6 and 2:9). Unlike Scripture, then, which is concerned with the absolute separation of different classes, Mishnah attempts to determine how different kinds may be kept distinct from one another as they grow together. Mishnah's views concerning the role of man in establishing order thus raise new and interesting issues in the law of diverse-kinds.

Mishnah's divergence from $P$ becomes even more interesting when one takes into account the historical context of the two documents. Both $\mathrm{P}$ and Mishnah take shape in the aftermath of historical catastrophes. P was compiled during and after the exile which followed the destruction of the First Temple, while Mishnah was redacted primarily after the failure of the Bar Kokhba rebellion (132-135 A.D.), a disaster which erased 
the Jews' last hope of regaining and rebuilding the Temple. It is thus noteworthy that both $\mathrm{P}$ and Mishnah respond to these similar historical circumstances with an interest in restoring order to a world which to them appears to lie in utter confusion. It is striking, therefore, that these two documents should disagree concerning the nature of the order which they intend to restore. What is important to $\mathrm{P}$ is that the world should be returned from its present condition of confusion to its original, ordered state, as God had created it. P thus responds to the crisis it perceives by calling for a return to an unchanging, perfect world. By contrast, Mishnah underlines man's power to impose order upon the world, a capacity which is unaffected by historical events. In spite of the occurrence of catastrophes and disasters, man retains the ability to affect the world around him through such ordinary activities as sowing a field. While $P$ thus has man confront confusion by reconstructing the ideal order of creation, Mishnah regards man as imposing his own order upon a world in a state of chaos, and so, in effect, as participating in the process of creation.

ii. The structure and contents of the tractate

The first stage in the analysis of Mishnah Kilayim is a consideration of the tractate as a whole. By examining the logic which governs the organization of the tractate's materials, we may understand how the redactors of the tractate viewed the relationships among the themes and topics which they present, and so identify the central propositions which they develop. Having determined first how the tractate's redactors related one idea to the other, we may begin the exegesis of the text with the same understanding of the tractate as a whole which is held by the redactors themselves.

Mishnah Kilayim is organized topically, considering in turn plants (Unit I), animals (Unit II), and fibers (Unit III). In each case Mishnah discusses permitted and prohibited ways of commingling different classes. The most important unit is the first, which develops the tractate's thesis that a mixture is prohibited only if it produces the appearance of a confusion of diverse-kinds. The tractate's redactors, in fact, could have completed their treatise at the conclusion of this unit, for, as we shall see, Units II and III do not introduce into the tractate any major principles dealing with the laws of diversekinds. These two units serve only to include in the tractate Scripture's remaining two topics, the commingling of animals or 
fibers of different kinds. It appears, then, that the primary interest of the tractate's redactors concerns issues relating to the commingling of different classes of plants alone.

I. Plants: Growing together different kinds of plants. $1: 1-7: 8$

A. Plants which are or are not considered diverse-kinds with one another. 1:1-6

1:1 Wheat and tares, etc., are not considered diverse-kinds with one another (six pairs in all).

1:2 A chate melon and a musk melon, etc., are not considered diverse-kinds with one another (eight pairs in al1).

1:4A-C Fruits of the tree: Pears and crustaminum pears, etc., are not considered diverse-kinds with one another (two pairs in all).

1:4D-F Apples and Syrian pears, etc., even though they resemble each other, are considered diverse-kinds with one another (three pairs in all).

1:5 A radish and a rape etc., even though they resemble each other, are considered diverse-kinds with one another (three pairs in all).

1:6 A wolf and a dog, etc., even though they resemble each other, are considered diverse-kinds with one another (seven pairs in all).

Unit I opens at A with a catalogue listing different kinds of plants which may or may not be commingled. This catalogue sets the stage for the remainder of the unit, which discusses various types of commingling. B discusses grafting, an act which Scripture neglects to prohibit. $C$ and $D$, respectively, discuss sowing together different classes of plants in a field (Lv. 19:19), or growing such plants together in a vineyard (Dt. 22:9). The unit as a whole, therefore, consists of a proem (A), a nonscriptural prohibition against commingling different kinds of plants (B), and discussions of two scriptural prohibitions (C-D). As we shall see below, Units II and III continue C-D's treatment of the scriptural prohibitions of diverse-kinds.

A's catalogue lists pairs containing items which resemble one another. At issue in $A$, therefore, is whether one may commingle items, which, when mingled together, do not produce the appearance of confusion. A presents two opposing views of this question, with $M .1: 1-4 \mathrm{C}$ maintaining that such plants may be commingled, while M. 1:4D-6 disagrees. We shall take up 
in our commentary the problems relating to the interpretation of these sublists. Both M. $1: 1-4 \mathrm{C}$ and $\mathrm{M}$. $1: 4 \mathrm{D}-6$ are organized topically, as the former treats, grain, vegetables, and fruits, while the latter deals with fruits, vegetables, and animals. This last, anomalous category is surprising, for we would have expected grain to follow vegetables and so form the pattern $a-b-c-c-b-a$. I cannot explain why the catalogue of animals is included in A's list. It may serve simply to signify the completion of the list as a whole.

B. Grafting one kind of plant onto another. 1:7-9D

1:7 Prohibition of grafting a tree or vegetable of one kind onto a tree or vegetable of another kind, vs. Judah: They do graft a vegetable onto a tree.

1:8 Illustrations of the above prohibition.

1:9A-D He who buries turnips or radishes under a vine does not scruple lest he has transgressed the laws of diverse-kinds, etc.

As pointed out above, B's discussion of the prohibition of grafting is not mentioned by scripture. The unit is placed here so as not to interrupt Mishnah's discussion of the four scriptural prohibitions of diverse-kinds: 1) sowing different kinds of plants in a field (C), 2) sowing grain or vegetables in a vineyard (D), 3) mating or yoking together animals of different kinds (Unit II), 4) commingling wool and flax (Unit III). M. 1:7 opens B with a general prohibition against grafting trees or vegetables onto one another, which M. 1:8 then illustrates. M. 1:9A-D appropriately closes the section with a discussion of an ambiguous case, a graft which appears to take place but does not actually occur.

C. Sowing together different kinds of crops. 1:9E-3:7

1. Sowing together different kinds of crops in the same space. $1: 9 \mathrm{E}-2: 5$

1:9E-H Sowing two kinds of seed simultaneously: He who sows a grain of barley together with a grain of wheat, this is considered diverse-kinds, vs. Judah.

2:1-2 A se'ah consisting of seeds of one kind and containing a quarter-qab of seeds of another kind-- 
he shall lessen the quantity of the latter kind, vs. Yose: He shall sift them out completely. 2:3-5 Sowing two kinds of seed sequentially: If his field was sown with wheat, and he decided to sow it with barley, he waits for the wheat to take root, overturns it, and sows the barley + two further cases.

2. Sowing together different kinds of crops in adjacent spaces. $2: 6-3: 3$

2:6 He who wishes to lay out his field in narrow beds of every kind + Houses-dispute: How large must the beds be?

2:7 If a row of wheat enters an adjacent field of barley, it is permitted, since the row looks like the end of the field of wheat + two further cases concerning the borders of fields.

2:8 They do not flank a field of grain with mustard or safflower, but only a field of vegetables.

2:9 He who wishes to lay out his field in patches of every kind--he lays out twenty-four patches per bet se'ah, one to a bet rovac, and sows a different kind in each. Dispute between Meir, sages, and Eliezer b. Jacob: How many patches may be sown with mustard?

2:10 Everything contained in a bet rovac is reckoned as part of it: the ground required for a vine, etc. Grain of one kind sown in a field of grain of another kind requires a bet rovac of area, etc.

2:11 Grain which leans over grain of another kind, etc., is permitted, except for the Greek gourd (which becomes tangled up with the other kind) + Meir.

3:1 A garden-bed measuring six handbreadths square-they sow five kinds in it, four along the sides and three in the middle, vs. Judah.

3:2 They do not sow seeds of grain, but only those of vegetables in a garden-bed.

A border which became diminished in height is fit, since it was fit from its inception.

$3: 3$ If a row of vegetables enters an adjacent field of vegetables of another kind, etc.

If his field was sown with one kind of vegetable, and he wished to plant in it a row of vegetables of another kind + dispute between Ishmael and 


CAqiva: How large must the row be? + Judah,
3. Sowing together different kinds of crops in
adjacent spaces. Special case: Trailing plants.
$3: 4-7$
He who plants two rows each of chate melons,
gourds, etc.,--it is permitted. One row each--it
is prohibited, since they do not appear to be
planted in autonomous fields.
A man plants a chate melon and a gourd in the same
hollow provided that each leans to a different side.
If his field was sown with onions and he wishes
to plant in it rows of gourds + dispute between
Ishmael and Aqiva: How much space must be left
between the two kinds? + sages,
Gourds planted in a field of vegetables require
the same area as vegetables planted in a vegetable-
field of another kind. A row of gourds planted in
a field of grain requires an area of tillage of six
handbreadths vs. Yose: Four amot + debate: Do
gourds require more area of tillage than does a vine?

C's treatment of the sowing of different kinds of crops in a field (Lv. 19:19) begins the tractate's discussion of the scriptural prohibitions of diverse-kinds. At issue in $\mathrm{C}$ is the manner in which crops belonging to different kinds may be commingled without violating the laws of diverse-kinds. This problem is treated in two parts, with $\mathrm{Cl}$ considering the sowing together of different kinds of crops in the same space, and $\mathrm{c} 2$ considering the sowing together of such crops in adjacent spaces. C3 then goes over the ground of $\mathrm{C} 2$, this time with regard to the special case of trailing plants. These plants differ from other crops in that they tend to spread out over adjacent plants, and so must be separated from the latter by a fixed distance. C3 thus serves to introduce D's discussion of sowing crops among vines, which similarly must be distanced from adjacent plants.

Let us now examine each of $\mathrm{C}^{\prime} \mathrm{s}$ subunits in detail. Cl's discussion of sowing seeds of different kinds in the same area opens at M. I:9E-H, with a general rule concerning the number of such seeds which, if sown together, render the sower liable under the laws of diverse-kinds, M. 2:1-2 then proceeds to the more complex case of sowing a mixed assortment of seeds at the same time. Mishnah now asks an entirely separate question, viz., whether one may sow different kinds of seeds together if one does 
not thereby produce the appearance of confusion. Once we have considered the sowing of different kinds of seeds at the same time, M. 2:3-5 turns to discuss the question of sowing different classes of seeds in sequence.

From $\mathrm{Cl}^{\prime} \mathrm{s}$ treatment of sowing different classes of plants in the same space $\mathrm{C} 2$ turns to a discussion of sowing such plants in adjacent spaces. This section is constructed from two formal subunits, M. 2:6+2:9, concerning various ways of arranging many different kinds of plants in a field, and $M .2: 7+3: 3$, dealing with the case of a row of one kind of plants which extends into a field containing another kind. M. 2:7 has been separated from M. 3:3 and inserted between M. 2:6 and M. 2:9 because of M. 2:8. The latter glosses both M. 2:7's discussion of the borders of a field and M. 2:9's treatment of the mustard plant, and so had to be placed in close proximity to both pericopae. M. 2:7-8 could not, however, have been placed after M. 2:9, for the latter is closely followed by M. 2:10-11. M. 2:10 glosses M. 2:9's discussion of a bet rovac, while M. 2:11 supplements M. 2:10's own treatment of different kinds growing in adjacent spaces. M. 2:7-8 therefore could only have been placed immediately before M. 2:9. M. 3:1-2 turns from M. 2:6-11's discussion of sowing different kinds of plants in a field to consider sowing such plants, vegetables in particular (M. 3:2), in a garden-bed, a miniature version of a field. Reverting to the issues of the opening of the section, M. $3: 3$ supplements $M .3: 1-2$ 's discussion of vegetables with a reprise of $M .2: 7$, dealing this time with vegetables instead of grain. M. 3:3 thus serves to tie together the entire section.

As we have already mentioned, C3 offers a reprise of C2, dealing this time with trailing plants. C3 consists of two parts, M. 3:4-5, considering the planting of different kinds of trailing plants with one another, and $\mathrm{M}$. 3:6-7, discussing the planting of a single kind of trailing plants among grain or vegetables. The debate at M. 3:7, comparing the distance which must separate a gourd from adjacent plants to that which must set off a vine from nearby plants of other kinds, provides a smooth transition to D's discussion of sowing crops among vines.

D. Sowing crops among vines. $4: 1-7: 8$

1. Permitted sowing of crops in a vineyard. 4:1-5:4 $4: 1-4$ Sowing within or around a vineyard: Houses-disputes: How large must bald spot, outer space be in order to be sown with grain or vegetables. Definition of various areas and structures in a vineyard. 
4:5 Definition of a vineyard: Houses-disputes: He who plants a row of five vines-House of Shammai: It is considered a vineyard. House of Hillel: It is not a vineyard unless it contains two rows + further Houses-dispute making same point.

4:6-7 Rulings concerning particular arrangements of vines, all presupposing the view of the House of Hillel.

4:8-9 He who plants two rows of vines--How much space must separate the rows if one wishes to sow between them? + further cases dealing with three rows, vineyard.

5:1 Special cases of vineyards: A vineyard laid waste, or irregularly planted: Under what circumstances are they considered vineyards?

5:2 A vineyard which is planted with less than four amot separating the rows + dispute between simeon and sages: Is it considered a vineyard?

5:3-4 Autonomous areas within a vineyard: A ditch, winepress, etc.: Is one permitted to sow grain or vegetables in them?

2. Prohibited sowing of crops in a vineyard. 5:5-5:8

5:5 He who plants vegetables in a vineyard or allows them to grow renders liable to destruction fortyfive vines. Under what circumstances? Etc.

5:6 He who sees vegetables in the vineyard--he need not pluck them until he reaches them; but he may not leave them and return, since he would thereby indicate his approval of their growth.

5:7 If seeds accidentally enter a vineyard, the vines are not liable to destruction as long as the owner does not actually see the seeds go into the vineyard.

5:8 He who allows thorns to grow in a vineyard + dispute between Eliezer and sages: Does he render the vines liable to destruction? Discussion concerning the status in a vineyard of other plants not usually grown for food.

3. Permitted sowing of crops near vines: special cases. $6: 1-7: 2$

$6: 1$ Definition of an espalier and determination of its area of tillage + Houses-disputes: From what part of the espalier is the area of tillage measured? + Yohanan b. Nuri. 
6:2 An espalier which projects from a terrace--how much of the ground below may not be sown? Eliezer b. Jacob: If he can harvest it from the ground, it is regarded as if it were on the ground, etc. + Eliezer.

6:3-5 He who trains a vine ovex some laths of latticework, he shall not put seed under the remainder of the laths. Further cases of barren and fruit trees serving to support the vine. Definition of a barren tree.

6:6 Gaps of an espalier--they must measure eight amot and a little more in order to be sown. Definition of a gap of an espalier.

6:7 An espalier which projects along a wall from a corner and stops--they allow its area of tillage and sow the rest, vs. Yose.

6:8-9 Reeds, blossoms, etc., which project from an espalier: Is it permitted to sow opposite them?

$7: 1$ He who sinks a vine-shoot into the ground--if there are not three handbreadths of soil on top of it, he may not put seed upon it.

$7: 2 \mathrm{~A}-\mathrm{C}$ He who sinks three vine-shoots, and their roots are visible--Eleazar b. Sadoq: If there are from four to eight amot between them, they combine to form a vineyard, etc.

7:2D-F Discussion of items near which it is prohibited to sow but which do not render liable to destruction the grain or vegetables sown near them.

4. Prohibited sowing of erops near vines: Special cases. $7: 3-8$

7:3 These prohibit but do not render liable to destruction: The remainder of the waste-state of the vineyara, etc. (four items in all). But the area under the vine, etc. do render liable to destruction (three items in a1l).

7:4-5 He who trellises his vine over his neighbor's grain, he has rendered it liable to destruction, etc., vs. Yosé and simeon: A man does not render liable to destruction that which is not his own + Yosé $m a^{c} a \xi e h$ attributing rule to ${ }^{c}$ Aqiva.

7:6 The usurper who sowed a vineyard, and it left his possession--the rightful owner must cut down the sown crop immediately, etc. 
$7: 7$

A wind which hurled vines on top of grain--he shall cut down the vines at once, + further cases. At what point in their growth do grain, grapes become liable for destruction?

7:8 A perforated pot containing seeds of vegetables or grain, but not an unperforated pot, vs. Simeon: Both unperforated and perforated pots are prohibited from being placed in a vineyard, but they do not render the vines liable for destruction.

D discusses a second scriptural prohibition, the rule against sowing grain or vegetables in a vineyard (Dt. 22:9). D presents a balanced treatment of this rule, dealing first with the permitted ways of sowing crops in a vineyard (D1), and then with the consequences of sowing crops in a vineyard in a prohibited manner (D2). D3 and D4 then respectively supplement D1 and D2 with a discussion of special cases, and so form an appropriate conclusion to the section.

Let us now consider each part of $D$ in detail. At the center of Dl stand two sets of Houses-disputes. M. $4: 1$ (heavily glossed at M. 4:1-4) deals with the minimum size required of areas in or around a vineyard in order to be sown with grain or vegetables without creating the appearance of confusion. M. 4:5 then discusses the number of rows, and the number of vines within these rows, that are required to form a vineyard. Although this definition of a vineyard is logically prior to M. 4:1's discussion of areas in or around a vineyard, DI's redactors chose to place M. 4:1 first because M. 4:5 introduces a new subunit concerning the rows of a vineyard. M. 4:6-7 supplements $M, 4: 5$ with a discussion of secondary questions relating to the number of rows and vines required to form a vineyard, while $M$. 4:8-9 turns to the question of sowing between the rows of a vineyard. Dl thus first discusses the question of sowing grain or vegetables in areas in or near the vineyard (M. 4:1-4), and then considers the problem of sowing such plants among the actual rows of the vineyard (M. 4:5-9). M. 5:1-2 further supplements M. 4:5-9's treatment of the rows of a vineyard with a discussion of irregular arrangements of vineyards. Finally, M. 5:3-4 returns to the concerns of the opening of the section, asking again whether certain areas within a vineyard may be sown with grain or vegetables. In this instance, however, the spaces are set apart from the vineyard not by their size, as in M, 4:1-4, but by their height or depth.

From DI's treatment of permitted ways of sowing crops in a vineyard, D2 turns to discuss the consequences of sowing crops 
in a vineyard in a prohibited manner. D2 opens at M. 5:5 with a rule concerning the number of vines which must be destroyed when grain or vegetables (which must also be destroyed [Dt. 22:9]) have been sown nearby in a prohibited manner. M. 5:6-8 then qualifies this rule, asking whether one must take into account the intentions of the owner (M. 5:6-7) or the presumed purpose for which the crops have been grown (M. 5:8),

D3 returns to the concerns of Dl, considering again the sowing of crops near vines in a permitted manner. In this case, however, the vines do not grow in a vineyard, but are arranged in other patterns. D3 discusses two such arrangements of vines, with M. 6:1-9 dealing with vines trained upon a supporting structure, while M. 7:1-2 treats vines which have been sunk into the ground to create new plants. M. 6:1-9 asks whether crops may be sown in the vicinity of vines which are trained upon a supporting structure. Dealing with both an espalier (a row of trained vines; M. $6: 1-2+6-9)$ and an individual trained vine (M. 6:3-5), this subunit systematically considers the possibility of sowing crops in various areas around the vine. M. 6:1-2 opens the subunit with a discussion of the areas directly opposite (M. 6:1) and under (M. 6:2) the supporting structure of an espalier. Interpolated into this discussion of a row of trained vines, M. 6:3-5 supplements M. 6:2 with a discussion of sowing under a structure which supports a single vine. At issue in M. 6:3-5 is whether the vine takes over the aspect of the entire supporting structure, so that one cannot sow crops even under that part of the structure which does not support the vine. Having thus treated the areas surrounding the vines and their supporting structure, we then proceed at $M, 6: 6-7$ to discuss those areas which are actually aligned with the vines, whether in the midale (M. $6: 6$ ) or at the end (M. 6:7) of a row. M. 6:8-9 concludes the subunit with an ambiguous case, asking whether reeds or blossoms which project outward from an espalier are regarded as integral to the latter, so that it is prohibited to sow under them.

D3's second subunit, M, 7:1-2, discusses a pattern of vines which is created by sinking vine-shoots into the ground to grow new roots. Like M. 6:1-9, this subunit deals with both a single vine (M. $7: 1$ ) and a row of vines (M. $7: 2 \mathrm{~A}-\mathrm{C}$ ). At issue in $M .7: 1$ is whether one may sow crops above a sunken shoot without allowing the roots of the crops to become attached to the sunken vine and so create a prohibited graft. $M .7: 2 \mathrm{~A}-\mathrm{C}$ then turns to a separate question, asking whether a row of new vines may combine with their parent vines to form a vineyard. M. 7:2D-F 
closes the subunit by introducing the concern of D4, viz., prohibited means of sowing crops near vines which do not render the latter liable to destruction. Although M. 7:2D-F thus turns to an entirely new problem, the pericope is linked to $\mathrm{M}, 7: 1-2 \mathrm{C}$ in two ways. First, both $M .7: 2 \mathrm{D}-\mathrm{F}$ and $M, 7: 1-2 \mathrm{C}$ contain sayings attributed to Eleazar b. Sadoq (M. $7: 2 \mathrm{~F}, \mathrm{M}, 7: 2 \mathrm{~A}-\mathrm{C}$ ). More importantly, however, Eleazar b. Sadoq's saying at M, 7:2D-F supplements $M, 7: 1^{\prime}$ s discussion of the sunken vine-shoot, and so provides an even stronger link to the rest of the subunit.

Reverting to the concerns of D2, D4 presents a series of exceptions to the latter's general rule that one must destroy crops and vines which grow together in a prohibited manner. In D4's cases, by contrast, one need not destroy such crops and vines, even though it is prohibited to grow them together in the first place. D4 presents three different types of cases where this rule holds. First, M. 7:3 lists specific areas in the vicinity of vines which may not be sown with crops but which do not render these crops liable to destruction. M, 7:4-7 then discusses cases in which either human (M. 7:4-6) or non-human (M. 7:7) agents cause diverse-kinds to grow without the owner's knowledge or permission. In these instances the crops do not render the vines liable to destruction, but the owner may not maintain the growth of diverse-kinds once he discovers them. Finally, having considered at $M, 7: 1-7$ cases in which the crops actually grow together with the vines, we turn at $M, 7: 8$ to a case in which this point is ambiguous. Now the crops grow in a perforated pot which is placed in a vineyard. At issue, therefore, is whether the crops are regarded as growing in the vineyard, so that the vines are liable to destruction, or whether it is prohibited to place the pot in the vineyard, but the vines need not be destroyed. With this case of doubt, M. 7:8 concludes both D4 and $D$ as a whole.

To summarize, Unit I is laid out in a highly logical manner. A presents a catalogue of plants which may or may not be commingled, and so serves to introduce $B-D^{\prime} s$ discussion of the various ways of commingling plants which clearly belong to two different classes, This latter subunit first considers a method of commingling which is not mentioned in Scripture (B), and then turns to its primary concern, the scriptural prohibitions against commingling different kinds of plants in a field (C) or in a vineyard (D). C and $D$ are themselves well-structured. C asks how different classes of plants may be sown together in a field, whether in the same space (C1) or in adjacent spaces (C2). C3 then goes over the ground of $\mathrm{C} 2$, but this time dealing with the 
special case of trailing plants, and so serving to introduce D's discussion of a similar plant, the grapevine. D presents both sides of the question of sowing crops in a vineyard, considering first the permitted ways of sowing crops and vines together (DI), and then the consequences of commingling such plants in a prohibited manner (D2). D3 and D4 then repeat the same sequence. Unit $I$ is thus arranged in a thoroughly rational way, with both the unit as a whole and each of its primary subunits structured according to their own respective principles of organization.

II. Animals: Mating or yoking together animals of different kinds. $8: 1-6$

8:1 General rules concerning the different types of diverse-kinds: Diverse-kinds of the vineyard differ from diverse-kinds of seeds in that one may not derive benefit from them. Diverse-kinds of garments are prohibited only from being worn. Diverse-kinds of animals are permitted to be reared and maintained, and are prohibited only from being bred.

8:2 Prohibition against joining together domesticated and wild, clean and unclean animals with one another to plow, draw a vehicle, or be led.

8:3 Both he who leads a wagon drawn by animals of different kinds, and he who sits in it incur forty lashes, vs. Meir, who exempts the one who sits. A third animal may not be tied to the harness of a wagon drawn by a different kind of animal, even if the third animal does not actually draw the wagon.

8:4A-B Further discussion of this last principle.

8:4C-E Judah: All offpsring of a female horse, and a male ass are permitted with one another, and vice-versa. But the offspring of a female horse are not permitted to be mated with the offspring of a female ass.

8:5A-B Special types of mules: The mule of unknown parentage, etc.

8:5C-6 Classification of special cases of animals: Are they considered man or animal, wild or domesticated?

Unit II's discussion of commingling different kinds of animals opens the tractate's brief treatment of the two remaining scriptural prohibitions of diverse-kinds. As we shall shortly see, Unit III takes up the last such prohibition, the rule against commingling different classes of fibers. At the head of 
Unit II stands a list of rules relating to each of the four scriptural prohibitions of diverse-kinds (M. 3:1). This catalogue serves to link Unit II to Unit $I$, for the first of its rules deals with diverse-kinds of the vineyard, the subject of ID, while the last concerns the topic of Unit II, diverse-kinds of animals. The remainder of Unit II is organized according to the two scriptural rules against commingling different kinds of animals. M. 8:2-4B discusses the yoking together of different classes of animals to do work (Dt. $22: 10$ ), while M. 8:4C-G deals with the mating of animals of different kinds (Lv. 19:19).

\section{Fibers: Mingling wool andilinen. 9:1-10}

9:1A-C Three rules concerning wool and linen: The laws of diverse-kinds prohibit only a garment composed of wool and linen; only garments composed of wool or linen are susceptible to uncleanness through plagues; priests wear only garments composed of either wool or linen to serve in the Temple.

9:1D-H Camel's hair and sheep's wood which were hackled together--if the majority is camel's wool, they may be mixed with flax, etc:

9:2 Items which are not subject to the laws of diversekinds, because they only resemble wool and linen, or because they are not designed to serve as garments. Prohibition against wearing garments of diversekinds either temporarily or without intending them to serve as garments.

9:3 Hand-towels, etc. (three items in all) are not subject to the laws of diverse-kinds, since they are not made to serve as garments, vs. Eliezer. But barber's towels are prohibited.

9:4 Shrouds and a pack-saddle of an ass, items not usually worn by man, are not subject to the laws of diversekinds. One may not, however, place a pack-saddle on his shoulder and use it for carrying items, as it then functions like a garment.

9:5-6 Clothes-dealers and tailors may bear garments of diverse-kinds in the course of their work, provided that they do not intend to use them as garments.

9:7 Garments (presumably of foreign provenance) which must be examined for diverse-kinds before being worn: A birrus, bardaicus, etc., (four items in all) + Yosé. 
$9: 8$

A further general rule: Nothing is prohibited on account of the laws of diverse-kinds except wool and flax which have been spun or woven together + exegesis of "shacatnez" in Dt. 22:11 + homiletical exegesis by Simeon b. Eleazar.

9:9 Felted stuffs composed of wool and linen are prohibited, because they are hackled together. A fringe of wool fastened onto a garment of flax is prohibited, because the wool interlaces the web of the garment, + Yose, and further discussion of different types of fastening (three cases in all).

9:10 Further discussion of fastening--three cases.

Unit III takes up the remaining scriptural prohibition of diverse-kinds, the law against commingling different classes of fibers (Lv, 19:19, Dt. 22:11). M. 9:1A-C introduces the unit with three rules concerning wool and flax, the only two fibers which may not be commingled (Dt. 22:11). The unit then considers, in logical sequence, commingling fibers of different kinds (M. 9:1D-H) and wearing garments of diverse-kind (M. 9:2-7). M. 9:810 concludes the unit with a discussion of the secondary issue, asking whether items of wool and linen which are connected to one another in various ways combine to form a mixture of diversekinds .

In summary, we have seen that while Mishnah Kilayim follows a topical agendum established by scripture, it treats these topics in accord with its own approach to the laws of diversekinds. Although the tractate discusses all of the scriptural prohibitions against commingling different kinds, it chooses fully to examine only those laws which are of interest to it, viz., rules concerning the commingling of different kinds of plants (I). By contrast, the units concerned with animals (II) and garments (III) are brief, and appear in the tractate only because they are found in scripture. We have earlier seen that the tractate's discussion of the law begins from a distinctively mishnaic conception of order, and so raises issues which are entirely unknown to Scripture, Within its scriptural framework, therefore, Mishnah Kilayim presents its own treatment of the law of diverse-kinds.

iii. Goals and Methods of Exegesis

A. Commentary to Mishnah

In my commentary to Mishnah Kilayim I present both a new translation of the tractate and a fresh exegesis of its rulings. 
To consider the former first, the translation attempts to render each pericope of the tractate into intelligible English, while at the same time replicating its literary and formal traits. With this translation, then, the reader is able to follow my analysis of the literary and formal traits of each pericope, from which, as we shall shortly see, the exegesis of the law directly follows.

To translate a pericope I first divide the Hebrew text into its smallest intelligible units of thought. These units I label with the letters of the alphabet $(A, B, C, \ldots)$, thus enabling the reader both to see the component parts in which the pericope expresses its thoughts, and to follow my analysis of these parts in the exegesis. In translating each unit of the pericope I also attempt to find terms in English which correspond to the text's formulaic language, and to maintain as well the syntax of the pericope's rulings, thus rendering in English the pericope's formal traits. Finally, to ensure that my rendering is readable as well as accurate, I frequently insert explanatory language into my translation, placing such interpolations into square brackets. Through these methods I arrive at a translation which reproduces in a lucid manner the style and substance of the Hebrew text. I thus enable the reader immediately to see the layout of each pericope and to determine what exegetical difficulties are posed by the pericope's formal and literary traits. These difficulties I discuss in the exegesis which follows the translation of each pericope.

In my exegesis I aim to discover what the rules of each pericope of the tractate meant to the authorities who formulated them. What I want to know is simply the basic point which the framers of these rules intended their words to express. To gain such an understanding of these rules I first observe the pericope's formal traits, for it is through these traits that the authorities behind the unit attempt to draw our attention to those issues which are of primary concern to them. These larger issues generally are not stated in the pericope itself, but rather implicitly inform the unit's rules. It is thus only by noting the use of formal characteristics by the framers that $I$ am able to draw out the unit's central issue and so gain a point of entry into the exegesis of the pericope as a whole.

The formulators of a pericope use several techniques to highlight those issues which are important to them. For one thing, they may present two balanced rules containing matching but opposing apodoses. In this manner these authorities draw our attention to the contrast between the two apodoses and hence to 
the issue which produces that contrast. In my exegesis I explain the position taken by these two rules with regard to this issue. Alternatively, the main issue of a pericope may become clear through the repetition or variation of syntactic patterns on the part of the formulators of the small units. By repeating a distinctive syntactic pattern, the creators of a pericope implicitly indicate that a single principle applies to all of the diverse cases exhibiting that arrangement. These authorities thus lead us to ask what the different cases all have in common. Having determined this common factor, I then explain in my exegesis the meaning of each rule cast in this single pattern. Finally, by repeating a syntactic pattern and then varying it, a pericope's framers point out an exception to the previously-stated principle. In so doing they indicate to us that their interest centers about this exceptional case and the issue which it raises. With the identification of this issue I am able in my exegesis to explain each rule of the pericope in terms of its relationship to this central concern. It is through the use of repetition and contrast that the pericope's formulators underline the key issues of their construction. 5

In addition to using balanced formulations and recurrent syntactic patterns, as we have just seen, a pericope's formulators underline their main point by presenting their materials in certain standard forms. Of particular importance to our tractate, with its frequent discussion of plants or animals belonging to different species of the same genus, is the list, a catalogue of different items sharing a certain trait or common status. By enumerating these items in a list, the tractate's formulators effectively draw our attention to that unstated feature which these items have in common, namely, their genus. It is through reference to this common characteristic that my exegesis explains the presence on the list of its diverse members.

Another form which frequently appears in our tractate is the dispute. In its primary formulation the dispute consists of a superscription followed by two opposing opinions, although it may also be produced by a rule followed by an opposing gloss. In either case the point of the dispute emerges through the contrast of its two opinions, both of which relate to some larger, unstated issue. This issue reveals not only what stands at the center of the dispute but also what is not contested by the two sides, that is, the premises which the two parties to the dispute hold in common. It is this common ground which makes possible the dispute, a discussion of a gray area of law. In my exegesis 
I explain both the issue under dispute and what the two sides take for granted.

Finally, we note that in a few instances the disputes of our tractate are followed by debates. These debates serve to raise questions concerning the logical consistency within Mishnah's law as a whole of the positions of the antecedent dispute. As in the case of the dispute, the issue of the debate emerges through the contrast of the opposing opinions. In my exegesis I interpret the positions of both sides with reference to this central issue.

Having followed the formulation of a pericope to its main issue, I turn my attention to those rules which stand outside of the small unit's primary formal construction. What I want to know is whether these rules serve the pericope's main point, e.g., by introducing or illustrating it, or whether they are related only tangentially to the pericope's central concern, By first identifying this important issue, I am able to explain each of the pericope's rules in terms of its relationship to this issue and its function within the small unit.

To summarize, what I present in my commentary is the original meaning of each pericope of the tractate, the sense which the small unit held for the authorities who created it. By paying close attention to the pericope's formulation, I am able to discover the issue which stands at the center of the small unit, and which thus informs each of this unit's rules. With the identification of this issue I am able to explain each pericope solely in its own terms, within the limits of its own language and syntax. Drawing the meaning of a rule from the latter's own formulation alone, my exegesis offers the sense which the rule's formulators intended their words to convey,

In addition to explaining the meaning of the tractate's individual pericopae, I analyze how these small units have been redacted together to form larger thematic units and, ultimately, the tractate as a whole. I want to discover the principle by which the redactors of the tractate shaped their materials into well-ordered structures of ideas. To understand the organization of these constructions I first determine how discrete pericopae are arranged to corstitute formally coherent units dealing with a single theme. Discussing this one theme, such units are marked by the distinctive syntactic pattern which recurs throughout it. I then attempt to discover the logic by which the redactors of the tractate have linked these thematic units together in order to develop a single principle or topic. I present this analysis of thematic units at the beginning of my commentary to each chapter of the tractate. Although these 
chapters of the printed editions of the tractate frequently do not correspond to the thematic units constructed by the tractate's redactors, for the reader's convenience my commentary here follows the traditional divisions of the standard Hebrew text. In introducing each chapter I simply indicate how its materials are divided into the redactors' thematic units.

To analyze the tractate as a whole, I stand back from its discussions of larger principles and topics and consider its overall structure. My goal here is twofold. First, I want to know whether a single, generative issue, or problematic, stands behind the rulings of the tractate. Second, I attempt to discover whether the tractate's discussion of this problematic, as well as its treatment of secondary issues, unfolds in a logical and orderly way. In raising these questions my aim is to determine whether the tractate has a single, major point which it wishes to express in a cogent and articulate manner. This analysis of the tractate, which I have already presented earlier in the Introduction, shows that our tractate does present a disciplined treatment of a single problematic. Like its thematic units, the tractate constitutes a well-ordered and coherent treatment of its subject.

It remains for me to discuss the importance of earlier commentaries to the tractate for my study. I frequently make use of these earlier works, which both explain difficult passages in the text and render explicit the larger principles which stand behind Mishnah's rulings. I am able to draw upon these commentaries even though I differ with classical exegetes in my understanding of how Mishnah was composed. We must now determine what this difference is, and why it does not prevent me from using these commentaries, Classical exegetes regard Mishnah as a seamless, unitary document, and so pay little attention to the manner in which its rules have been formulated and then redacted together. By contrast, I do not assume that Mishnah is the product of a single hand. For this reason I carefully observe the text's forms and formulary paterns, which indicate to us how the tractate's different pericopae were composed and so enable us to interpret each of these small units in its own terms. In spite of taking this approach to Mishnah I am able to engage in discourse with the classical exegetes. What makes this dialogue possible is the nature of Mishnah's own composition. Each pericope of the document has its own logic, and so can be explained without reference to any other small units. Because these pericopae are autonomous of one another, I am able to agree with classical exegetes concerning the interpretation of a pericope even though I disagree concerning its relationship to the rest of the tractate. For 
this reason I am able to incorporate into my own work the results of their efforts.

What enables me to make use of classical exegesis, however, also determines the limits of such use. Although each of the tractate's pericopae may be explained in its own terms, classical exegetes frequently fail to confine their explanations to the issues raised by these small units themselves. Rather, these commentators seek to understand what a rule means in relation to laws found in other rabbinic documents, such as Tosefta, the legal midrashim, and the Babylonian and Palestinian Talmuds. Since they consider all rabbinic rulings to belong to a single, wholly-consistent body of law, these exegetes attempt to harmonize each of the tractate's rulings with laws found in these other sources. What they want to know is how a rule informs the meaning of laws belonging to these other compilations, and how these latter rules in turn affect our understanding of the tractate's rulings. Because of this goal, classical commentators often introduce into their explanation of a rule issues drawn from other sources, and so frequently do not explain a rule in terms of its own formulation. For this reason classical exegesis does not always offer me what I want to know, namely, the meaning which a rule held for its creators. What earlier commentaries do provide, however, is a range of possible meanings of a law. From among these possibilities I may select that meaning which, following my own exegetical methods, I consider to be the sense which the rule's formulators intended it to convey. It is in this manner that classical exegesis offers valuable assistance to my work of exegesis.

B. Commentaries to Tosefta, Sifra and Sifré Dt.

Together with my commentary to Mishnah Kilayim I present a translation and exegesis of the corresponding tractate of Tosefta, with each pericope of Tosefta following the pericope in Mishnah to which it relates. A commentary to Mishnah, Tosefta relies upon that document for its redactional order, agendum of issues, and many of its legal principles as well. Tosefta may therefore be understood only when read together with Mishnah. Since my commentary to Mishnah provides the most appropriate context for an investigation of Tosefta, I have taken it upon myself to treat the latter document as well.

My commentary to Tosefta differs from my discussion of Mishnah principally in that its primary aim is to make clear the relationship between these two documents, To this end, in 
translating Tosefta's pericopae I italicize those passages which cite Mishnah, placing in square brackets the references to the original source. My exegesis then aims to interpret each rule of Tosefta as it relates to Mishnah's laws. For the most part Tosefta's rules either cite and gloss Mishnah's laws or complement these rulings with related materials which carry them forward in a new way. In only a few cases does Tosefta present pericopae which are autonomous of Mishnah, and these I interpret in their own terms. In all of these cases my interpretation of Tosefta applies to the document the same methods that I employ in explaining Mishnah, and makes use of the classical commentaries to Tosefta in the same way that my study of Mishnah uses earlier exegesis. Among the classical exegetes of Tosefta I make extensive use of the work of $\mathrm{s}$. Lieberman. ${ }^{6}$ Like the classical exegetes to Mishnah, Lieberman serves the purpose of my commentary by presenting a broad range of possibilities for the meaning of Tosefta's rules.

In addition to the commentary to Tosefta I include a translation and exegesis of those pericopae from sifra (to Leviticus) and Sifre to Deuteronomy (Sifre Dt.) which are relevant to certain pericopae of Mishnah Kilayim. These documents aim to demonstrate that even if a Mishnaic rule does not appear to be based upon scripture, it may be deduced only through a highly formalized exegesis of the biblical text. In line with this goal Sifra and Sifre Dt. often cite Mishnah's rulings, which rarely appear with scriptural support, and attempt to link these to scriptural proof-texts, Because the point of these pericopae cannot be understood without a knowledge of Mishnah's rulings, I treat them along with my commentary to Mishnah. As in the case of Tosefta, my commentary to Sifra and Sifre Dt. attempts simply to explain the point which these documents make with regard to Mishnah. In my translation I underline the citations of Mishnah with a dotted line, while my exegesis explains the principles of scriptural exegesis by which Mishnah is linked to Scripture.

\section{c. Texts and Editions}

My translations of Mishnah and Tosefta Kilayim depend primarily upon the texts and translations of modern scholars. My rendering of Mishnah follows the text edited by H. Albeck. ${ }^{7}$ I insert into this translation (in parentheses) variant readings from manuscripts and early printed editions as recorded by $N$. Zachs in his critical edition of $2 e r a^{c} i m .{ }^{8}$ Foremost among the English translations which I regularly consult, and often cite (in 


\section{4/ KILAYIM}

brackets), is that of H. Danby. 9 I also make occasional use of the renderings of $P$. Blackman ${ }^{10}$ and $J$. Israelstam. ${ }^{11}$

In translating Tosefta I follow Ms. Vienna, which has been published by $\mathrm{S}$. Lieberman. ${ }^{12}$ Lieberman's critical apparatus provides variant readings from Ms. Erfurt and the first printed edition, while in his commentary he frequently cites alternate readings found in other rabbinic documents and in the classical commentaries. I cite other important readings from the commentaries of Samson of sens and GRA (found in the Romm edition of the Babylonian Talmud).

For my translation of Sifra pericopae I use the text of I.H. Weiss; ${ }^{13}$ while for sifre Dt. I rely on the edition of $\mathrm{L}$. Finkelstein. ${ }^{14}$ I cite the biblical verses which occur in these two documents in the translation of the Revised standard Version (RSV), modifying this rendering only when it is necessary to clarify a particular point of scriptural exegesis. All scriptural citations are consistently italicized. 


\section{CHAPTER ONE}

\section{KILAYIM CHAPTER ONE}

Chapter One of M. Kilayim opens with lists (M. 1:1-6) which state whether or not certain plants or animals are considered diverse-kinds with one another. The redactor presents these lists as an introduction to chapters 1-7 of the tractate, which concern the prohibition of sowing diverse-kinds. The outline of the lists is as follows. M. 1:1-3 presents a list of twenty pairs of plants which are not considered diverse-kinds with each other, and thus may not be planted or cross-bred with one another. M. I:I concerns grains and legumes, while M. $1: 2$ and M. $1: 3$ deal with a variety of vegetables. It is clear that this list is a composite, for M. $1: 3$ contains a short sublist attributed to CAqiva, while the rest of $\mathrm{M} .1: 1-3$ is given anonymously. It is possible that this anonymous part of the list is a composite as well. M. 1:4 is then set apart from the foregoing catalogue by its superscription, which reads, "And [in regard to the fruit of] the trees." M. $1: 4$ contains two sublists, with the first describing fruits which are not considered diverse-kinds with one another, and the second discussing fruits which are so considered. By placing M. 1:4 between M. 1:1-3 and M. 1:5-6, the redactor thus links the former's list of items which are not considered diverse kinds with the latter's catalogue of items which are regarded as diverse-kinds. M. 1:5 proceeds to list vegetables which are considered diverse-kinds, and M. 1:6 describes animals which may not be cross-bred with one another. Although the subject matter of M. 1:6 (animals) differs from that of $M \cdot 1: 1-5$ (plants), M. 1:6 is similar to the other lists in respect to both form and substance.

M. 1:7-8 is a brief, autonomous unit concerning prohibited grafts. The redactor has placed this unit as an appendix to M. 1:1-6, apparently because he wanted to present his briefer material before the more lengthy section on sowing diverse-kinds (Chapters Two and Three). M. 1:7 describes four general categories of prohibited grafts, three of which M. 1:8 then illustrates with specific examples. M. 1:9A-D, although apparently autonomous of M. 1:7-8, actually supplements the unit with an additional example of a graft. However, the case involves only an apparent graft rather than a real one, so that the actions described in 
M. 1:9A-D are actually permitted. The redactor has then ended the discussion of grafts by presenting an exception to the general law.

The chapter ends with M. 1:9E-G, which is autonomous of M. 1:9A-D. M. 1:9E-G presents a fundamental law (glossed and opposed by Judah) defining the minimum act for which one is liable for sowing diverse-kinds of seeds, and so introduces Chapter Two, which opens with a discussion of sowing mixed seeds.

$1: 1$
A. (I) Wheat ${ }^{1}$ and tares $^{2}$
B. are not [considered] diverse-kinds with one another.
C. (2) Barley ${ }^{3}$ and two-rowed barley, ${ }^{4}$
(3) rice-wheat ${ }^{5}$ and spelt, 6
(4) the broad bean ${ }^{7}$ and the French vetch, 8
(5) the red grasspea ${ }^{9}$ and the grasspea, 10
(6) and the hyacinth bean $(p w \tau h 2 b n)^{11}$ and the Nile cowpea 12 $\left(\breve{s}^{c} w^{c} y t ; \mathrm{R}: \breve{s}^{c} w^{c} y m, 0: \breve{s}^{c} \omega^{c} y n\right)$,

D. are not [considered] diverse-kinds with one another.

M. Kil. $1: 1$

Chapter one presupposes the prohibition of Iv. 19:19, which states that one may not sow different kinds of seeds in the same field. M. 1:1-3 lists pairs of plants which are exempt from this prohibition. Each pericope deals with a different group (or groups) of plants and may be considered independently.

M. $1: 1$ consists of two lists ( $A$ and $C$ ), each followed by the same subscription. A-B contains a single pair, while C-D includes five pairs, five being a good mnemonic number. As we shall see, however, it is more likely that we have a single list composed of two groups of three, for the plants may be divided in this way according to botanical families. The subscription then belongs only at $D$, and $B$ is unnecessary. It is possible that the subscription was placed after the first two plants named in $M$. in order to inform us that the law applies to pairs of plants (TYT, GRA). Without $B$ we might have thought that all of the plants of $M$. are not considered diverse-kinds with one another. The subscription is repeated at $B$ in order to tell us that only the members of one pair may be planted together.

We turn now to the law of $M$. Before we may consider the significance of the particular plants listed in M., we must first discuss the underlying conception of the pericope as a whole. Why are the members of each pair of plants not considered to be 
diverse-kinds with one another? This question may be answered in one of two ways. According to one explanation (following Maim., Comm. ${ }^{13}$ ) the point of $M$. is that, although the members of each pair belong to two different kinds, they are similar in appearance and thus are not considered to be diverse-kinds with one another. This interpretation maintains, then, that it is necessary only that a field not appear to be sown with diversekinds, whether or not it is actually sown with seeds of different kinds. Alternatively, Maimonides presents the opposite view in his Code (Diverse-Kinds $3: 1-2$ ) as follows:

There are kinds (mynyn) among seeds where one kind will become separated into many forms (swrwt) because of a difference in locations and [in] the type of work [i.e. cultivation] which they do [in] the land; until it [i.e. the single kind] appears as two kinds. And although [the two forms] are not similar to one another, because they [belong] to one kind they are not [considered] diverse-kinds with one another.

And there are among seeds two kinds which are similar to one another, and the forms of both of them are almost a single form; and even so, because they [constitute] two kinds, 10, these are prohibited [to be sown] with one another.

Maimonides then proceeds to illustrate the first rule with the lists of M. 1:1-3, and the second with the catalogue of M. 1:5. Maimonides here apparently interprets M. 1:1-3, which gives no reason for its ruling, together with $M$. 1:5, which explicitly states that, although the members of each of its pairs resemble one another, they are considered to be diverse-kinds with each other. M. 1:1-3 is thus understood as presenting a contrasting list of plants which are not considered to be diverse-kinds with one another even though they do not resemble one another. According to this interpretation, then, it is important that a field not actually be sown with diverse-kinds, regardless of its appearance. It is not necessary, however, to read M. 1:1-3 together with M. 1:5. In addition, we shall immediately see that the members of each pair actually do resemble one another. ${ }^{14}$ We therefore prefer the first interpretation given above.

The plants of pairs (1)-(3) all belong to Graminae, or the grass family. Wheat and tares (1) belong to different genera (Triticum and Lolium, respectively), but they resemble each other in both their seeds and their leaves. ${ }^{15}$ Tares are often found growing in wheat fields. ${ }^{16}$ Its seeds may germinate even several years after having been planted, so that its growth could not always be prevented. This may help explain why it was not prohibited to have wheat and tares growing in the same field. 17 
The members of the pair (2) are types of barley (genus Hordeum). Ordinary barley has four or six rows, as opposed to the two rows of two-rowed barley. The difference between them lies in the fertility of the spikelets (the small ears of grain). Each node on a barley stalk has three spikelets, each of which produces two seeds. In two-rowed barley, only the middle spikelet is fertile, while in ordinary barley, either two or all three of the spikelets produce seeds. ${ }^{18}$ The plants are similar in all other respects.

Rice-wheat and spelt (3) are both types of wheat (genus Tritioum), though they are presumably both considered diversekinds with the wheat of pair (1). The stalks and pales (the leaves covering the seeds) of rice-wheat and spelt are similar. ${ }^{19}$

The plants of pairs (4)-(6) belong to Papilionaceae, or the pea family. All of the plants of these pairs have their seeds in pods. The broad bean and the French vetch belong to the same genus (Vicia) and, according to Feliks, are "systematically and morphologically close." 20 The red grasspea and the grasspea (5) belong to the same genus (Lathyrus) and therefore presumably resemble each other. The hyacinth bean (or variety thereof) and the Nile cowpea ( 6 ) belong to different genera, and Feliks does not explain how they resemble each other. In Y. 1:1 (27a) they are both considered type of beans ( $p w l$ ) (cf. GRA, long commentary).

\section{$1: 2$}

A. (7) A chate melon 21 and a musk melon 22

B. are not [considered] diverse-kinds with one another.

C. R. Judah says "[They are considered] diverse-kinds."

D. (8) Lettuce ${ }^{23}$ and hill-lettuce ${ }^{24}$ (hart glym; alternatively: hzrt gnym [garden-lettuce ${ }^{25}$ ]),

(9) chicories ${ }^{26}$ and wild chicories, 27

(10) leeks ${ }^{28}$ and wild leeks, 29

(11) coriander 30 and wild coriander, 31

(12) mustard ${ }^{32}$ and Egyptian mustard, 33

(13) and an Egyptian gourd ${ }^{34}$ and a remusah, 35

(14) and a cowpea ${ }^{36}$ (lit.: Egyptian bean) and an asparagus bean $^{37}$ [omitted by B. Pes. $39 \mathrm{a}^{38}$ ],

E. are not [considered] diverse-kinds with one another.

$$
\begin{aligned}
& \text { M. Kil. } 1: 2 \text { (A-C: Y. Kil } 1: 2 \text { (27a) } ; 39 \\
& \text { D (8) }-(13)+\text { E: B. Pes. 39a) }
\end{aligned}
$$


M. 1:2 continues the list of plants which may grow together. A presents a single pair, followed by the subscription at $B$. C glosses $A-B$ and creates a dispute. D presents seven pairs of plants, which may be divided into groups of one (8),40 three ((9)-(11): cultivated v. wild species), and three ((12)(14): one plant in each pair is known as an Egyptian variety). If wild mustard is read for Egyptian mustard in (12), then we have a list of five (8)-(12) and two (13)-(14). If (14) is dropped, as it is in B. Pes. 39a, then we have a list of five and one.

The chate melon and the musk melon (7) belong to the same genus and species (Cucumis me 20 ) of Cucurbitaceae, or the gourd family. Feliks argues that they produce good hybrids and therefore are not considered diverse-kinds. ${ }^{41}$ Judah in $C$ considers the chate melon and the musk melon to be diverse-kinds with one another (cf. M. Ter. 2:6, where he expresses the same opinion).

The plants of pairs (8)-(11) belong to various different families of plants. As we have noted, though, each pair is made up of a cultivated and wild species ( 8 ) may or may not stand alone). The plants of pairs (8)-(9) belong to compositae, or the composite family. Lettuce and hill-lettuce belong to a single genus (Lactuca), as do chicory and wild chicory (Cicorium), so that there is presumably a resemblance between the members of each pair. The leek and the wild leek (10) belong to the genus Allium of Liliaceae, or the lily family. Coriander and wild coriander (11) belong to different genera (Coxiandrum and Bifora, respectively) of Umbrellifrae, or the parsley family. They resemble each other in several respects, however, including height ( $\left.\frac{1}{2} \mathrm{~m}.\right)$, the shape of their leaves, their white flowers, smell, and taste. They differ only in the shape of their seeds. ${ }^{42}$

Each of the pairs (12)-(14), as we mentioned, contains an Egyptian plant. Mustard and Egyptian mustard (12) belong to different genera (Brassica and Sinapsis, respectively), of Cruciferae, or the mustard family. The plants are similar in appearance, ${ }^{43}$ with the major differences being that the Egyptian mustard plant is shorter than the mustard plant and has larger white seeds, while the seeds of the latter plant are smaller and are black. ${ }^{44}$ Both the Egyptian gourd and the remusah (13) are identified as varieties of the calabash gourd (Lageneria vulgaris, of cucurbitaceae, or the gourd family). 45 The cowpea and the asparagus bean (14) both belong to the same genus (Vigna) of the Papilionaceae, or the pea family, and therefore presumably resemble each other. 
A. All of the pairs which the sages enumerated--

B. one kind with its own kind (myn bmynw) are not [considered] diverse-kinds with one another.

c. And the rest of the wild vegetables (yrqwt sdh; Erfurt: yrqwt ["vegetables"]) and garden vegetables--

D. one kind with its own kind (myn bmynw) are not [considered] diverse-kinds with one another.

T. Kil. l:la (p. 203, 11. 1-2)

(Remainder of T. $1: 1$ cited below and at p. 39)

T. consists of two apocopated sentences, $A-B$ and $C-D$, which have identical apodoses and thus form a unitary composition. A-B comments on the list begun in $M .1: 1$, and it tells us to read that list by pairs. The phrase myn bmynw (B) apparently means that both members of a single pair are considered to be of the same myn, or kind, and therefore are not considered diverse-kinds with one another. This implies that two plants which belong to different pairs are not of the same kind and are considered diverse-kinds. It should be noted that the concept of myn is introduced by T., for this term does not appear in the list of M. $1: 1-3$.

C-D offers a generalized law based on M. 1:2D, pairs (9)-(11). Each of these pairs contains one cultivated and one wild species of the same plant. C generalizes and adds all similar pairs to the list of specific pairs of $M$.

H. "(I) Chate melons and gourds, 46

"(2) and watermelons 47 and musk melons,

I. "are not [considered] diverse-kinds with one another;

J. "and they give heave-offerings and tithes from one for the other,"

K. the words of R. Meir [Erfurt: R. Meir and R. Judah].

L. R. Judah and R. Simeon [Erfurt: R. Yosé and R. Simeon] say,

M. "They are [considered] diverse-kinds with one another,

N. "and they do not give heave-offerings and tithes from one to the other."

T. Kil. $1: 1 \mathrm{c}$ (p. 203, 11. 3-6)

T. $1: 1 \mathrm{C}$ is related to $M .1: 2$ and we shall compare the two pericopae below. T. presents an Ushan dispute about a doublet consisting of two pairs of gourds. H presents the plants at issue. I contains the same subscription as those of the list 
begun in M. 1:1. J introduces a new legal consideration (cf. M. Ter. $2: 6$ ). M-N opposes and balances I-J.

H lists four plants which belong to different genera of the gourd family (Cucurbitaceae). The members of each pair are somewhat similar to each other, although it is not clear to me to what extent this is the case. There is certainly no close resemblance, and this may be the reason for the dispute as to whether or not the members of each pair are considered diversekinds with one another.

Let us now compare T. to M. 1:2A-C, using the following chart:

$$
\text { M. } 1: 2 A-C
$$

1. The chate melon and the musk melon

2. are not [considered] diversekinds with one another.

3.

4 .

5. R. Judah says,

6. "They are [considered] diverse-kinds."

7 .

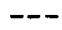

T. $1: 1 \mathrm{c}$

1. "The chate melons and the gourds and the watermelons and the musk melons

2. "are not [considered] diverse-kinds with one another;

3. "and they give heaveofferings and tithes from one for the other,"

4. the words of R. Meir.

5. R. Judah and R. Simeon say,

6. "They are [considered] diverse-kinds with one another,

7. "and they do not give heave-offerings and tithes from one for the other."

T. differs from M. in three ways. First, the list of $T$. at (1) includes the gourds and the watermelons, which are not found in M. Second, T. mentions the law concerning heave-offerings and tithes, which M. lacks, at (3) and (7). Finally, T. has attributions to Meir, simeon and Judah at (4) and (5), while M. has only the attribution to Judah. 48 We see, then, that $T$. presents an alternate version of M., including additional plants, a secondary legal consideration, and additional attributions.

We now turn to the law of T. Meir's opinion in T. H-K conflicts with the law of M. Kil. on two separate points. First, Meir states that the chate melons and the gourds are not 
considered diverse-kinds. M. Kil. 3:4-5, however, implies that they are so considered. ${ }^{49}$ This conflict may be explained in one of two ways. It is probably that M. Kil. 3:4-5 simply agrees with the view of Judah (T. L-N) rather than that of Meir. Alternatively, the gourds do not belong at all on the list of T. ${ }^{50}$ The gourds may have been mistakenly included in the 1 ist of the three melons only because the same four plants are grouped together elsewhere in M. T. ${ }^{51}$ According to this explanation Meir does not oppose the law of M. Kil. 3:4-5, for he does not discuss the gourds at all.

The second legal problem concerns the status of the musk melon and the chate melon.. T. H places the chate melon and the musk melon in different pairs, so that Meir's ruling implies that they are considered diverse-kinds with one another. For it is only if two plants belong to the same pair that they are not considered diverse-kinds. If, however, they belong to different pairs, the implication is that they are so considered. ${ }^{52}$ Meir then opposes the law of M. l:2A-B, which states that the chate melon and the musk melon are not considered diverse-kinds. Again this conflict may be explained in one of two ways. It is probable that Meir simply opposes the law of $M$. Alternatively, Lieberman 53 suggests that $\mathrm{H}$ be read not as a list of two pairs but as adding gourds and watermelons to the list of $\mathrm{M}$. $1: 2 \mathrm{~A}-\mathrm{C}$. In effect, therefore, Lieberman maintains that each of the first three items is paired with the fourth. In other words, Meir says that neither chate melons nor gourds nor watermelons are considered diverse-kinds with musk-melons. According to this explanation, then, Meir agrees with the law of M. $1: 2 \mathrm{~A}-\mathrm{B} .{ }^{54}$ This reading is difficult, however, for it assumes that $T$. is read differently than M. (i.e. so as not to concern pairs). We therefore prefer the first interpretation presented above.

$$
1: 3
$$

A. (15) A turnip 55 and a rape (npws; many mss.: npws), 56

(16) and a $\mathrm{kale}^{57}$ and a garden cabbage ${ }^{58}$ (trwbtwr; Danby, Israelstam, Albeck: cauliflower),

(17) the spinach beets 59 and garden sorrels, 60

B. are not [considered] diverse-kinds with one another [Missing in many mss. $\left.{ }^{61}\right]$.

C. Added (hwsyp) R. Aqiva, "(18) A garlic ${ }^{62}$ and a chive, 63

(19) an onion, 64 and a shallot, 65

(20) and a lupine ${ }^{66}$ and a yellow lupine, 67 
D. "are not [considered] diverse-kinds with one another."

M. Kil. $1: 3$

M. $1: 3$ concludes the list begun in $M .1: 1.68$ It adds two groups of three to this list, making the sum total twenty pairs of grains and vegetables. M. 1:3 consists of two sublists, $A$ and $C$, each followed by the same subscription. $B$ is missing in many mss. Epstein ${ }^{69}$ also deletes $B$, maintaining that $C$ was inserted parenthetically into the list consisting of $\mathrm{A}+\mathrm{a}$ subscription, so that only one subscription is necessary.

A is actually composed of a pair $((15)-(16))$ and a single item (17), for the former is given in the plural, while the latter appears in the singular. The plants of pairs (15)-(16) all belong to the genus Brassica of Cruciferae, or the mustard family. The turnip and the rape (15) are similar in respect to their leaves, bulbs, and taste. ${ }^{70}$ The kale and the garden cabbage (16), both leafy cabbages, are varieties of the same species (Brassica oleracea) and resemble each other. Feliks is not certain of the identification of trwbtwr as the garden cabbage, and othersidentify it as the cauliflower, another variety of the same species.

Each of the two plants of pair (17) belongs to a different family. The spinach beet belongs to Chenopodiaceae (the goosefoot family) while garden sorrel belongs to Polygonaceae (the buckwheat family). The two plants, however, are similar in appearance. 71 I can see no botanical relationship between this pair and the other two pairs of $A$.

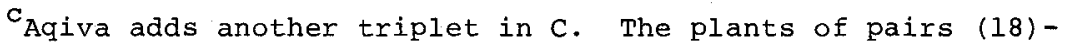
(19) all belong to the genus Allium of Liliaceae, or the lily family, and therefore resemble each other. The plants of pair (20) both belong to the genus Lupinus of Papilionaceae, or the pea family, and are similar in appearance. The main difference between them is that the lupine has white flowers, in contrast to the yellow flowers of its counterpart. ${ }^{72}$ Again, I can see no botanical connection between the third pair of the list and the other two pairs. Perhaps both pairs (17) and (20) are single items which are attached to the end of their respective lists.

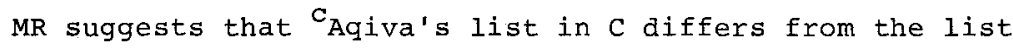
which ends at M. 1:3A. C actually lists plants which do not resemble each other but are still not considered diverse-kinds. In this way MR attempts to explain why ${ }^{C}$ Aqiva would add to an existing list (as hwsyp implies). It is more likely, however,

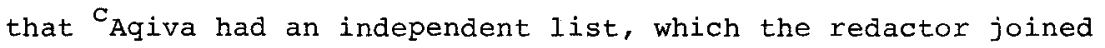
to $M$. with hwsyp. The redactor apparently understood the list 
to contain plants with the same characteristics (i.e. that they are not diverse-kinds) as the plants listed in M. 1:1-3A.

A. Added (hwsyp) R. CAqiva,

"(1) The garlic and the chive,

(2) and the onion and the shazzot,

(3) and the lupine and the yellow lupine

[yellow lupine omitted in Erfurt] [= M. 1:3C]."

B. Said R. Simeon, "R. CAqiva repeated the tradition only ( $l$ ' hyh $r$ [by] 'qyb' šwh ' $z$ ') [GRA omits ' $z$ ' and reads:

R. ${ }^{C}$ Aqiva did not repeat the tradition] in regard to these [first] two pairs,

c. "But (' 2 ') the lupine and the yellow lupine are not [considered] diverse-kinds with one another."

$$
\text { T. Kil. } 1: 2 \text { (p. 203, 11. 6-8) }
$$

A cites CAqiva's list of M. 1:3C, but without a subscription. Simeon then glosses $\mathrm{A}$ in $\mathrm{B}-\mathrm{C}$, thus attesting it to Usha. Simeon's comment is somewhat difficult. He maintains that ${ }^{{ }^{A q i v a}}$ repeated the tradition only with respect to the first two pairs (B), but that, by contrast, the plants of the third pair are not considered to be diverse-kinds with one another (C). Simeon thus

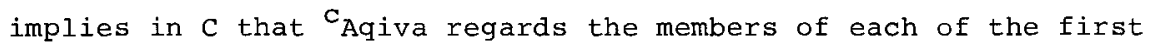
two pairs to be diverse-kinds with each other. M. I:3C-D, how-

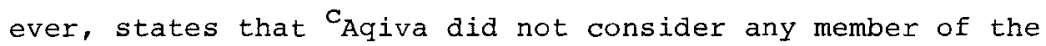
three pairs to be diverse-kinds with its counterpart. Simeon

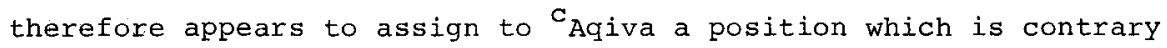
to the one attributed to him in M. $1: 3 \mathrm{C}-\mathrm{D}$.

This difficulty may be resolved in one of two ways. It is possible that simeon had before him a different version of the subscription, one which read "are [considered] diverse-kinds with one another."73 simeon then states in $T$. that this ruling applies only to the first two pairs on the list, while the contrary ruling (.e., that they are not considered diverse-kinds with one another) holds for the last one. Alternatively, GRA ${ }^{74}$ omits ' $l$ ' from $B$, and so reads the latter as: "R. "Aqiva did not repeat the tradition in regard to these first two pairs." According to this interpretation simeon maintains that ${ }^{\text {Aqiva }}$ did not rule at all concerning the first two pairs on the list, so that M.'s subscription (M. 1:3D) applies to the third pair alone. Now although both of these explanations are possible, we prefer the first one, for it allows us to interpret the pericope as it stands, and, unlike the second, does not require us to emend the text of $T$. 
The only other possibility of explaining $\mathrm{T}$. involves reading $B$ and $C$ as independent of each other. Simeon only says $B$, and argues that only the first two pairs belong on Aqiva's list, but not the third. $C$ then contradicts simeon, for it says that the third pair is also not considered diverse-kinds, and also belongs on Aqiva's list. According to this interpretation, we have a saying (B) which is immediately glossed by a contradicting statement $(C)$. This would be an unusual way of transmitting a tradition, and it is therefore unlikely that this interpretation is correct.

$1: 4$

A. And in [regard to] the tree:

B. (1) Pears ${ }^{75}$ and crustaminum pears, 76

(2) and quinces ${ }^{77}$ (pryšym) and hawthorns ${ }^{78}$ (cwzrrym),

C. are not [considered] diverse-kinds with one another.

D. (1) An apple ${ }^{79}$ and a Syrian pear 80 (hzrd: B, C, L, K are corrected to read hzrr; $\mathrm{V}, \mathrm{Cn}, \mathrm{N}, \mathrm{S}$ read ḩzrt; $\mathrm{O}, \mathrm{P}$ read ${ }^{c}$ ward; Geniza fragments ${ }^{81}$ read ${ }^{c}{ }_{z r r}$ or $\left.{ }^{c}{ }_{w z r}\right)$,

(2) peaches 82 and almonds, 83

(3) jujubes 84 and wild jujubes, 85

E. even though they are similar to one another,

F. they are [considered] diverse-kinds with one another.

M. Kil. $1: 4$

As the superscription (A) shows, our chapter now proceeds to a new issue, the grafting of diverse-kinds of fruit-trees. M. 1:4 presupposes the prohibition of grafting a bud from one fruit-tree onto a fruit-tree of another kind (cf. T. 1:34, M. 1:7, and Maimonides, Code, Diverse-Kinds 1:5). M. consists of a statement of its theme (A) and two lists of fruit (B-C and $D-F)$. B-C contains two pairs which are not considered diverse-kinds, and D-F lists three pairs which are so considered, making a total of five pairs of fruits. B-C has the same literary structure as the 1ist of M. 1:1-3, with a list followed by a subscription. The structure of $\mathrm{D}-\mathrm{F}$ is similar to that of the list of $\mathrm{M}$. 1:1-3 except for $\mathrm{E}$, which glosses $\mathrm{D}+\mathrm{F}$. The two opposing subscriptions, $\mathrm{C}$ and $\mathrm{F}$, balance each other.

The trees represented by the fruits of pairs ${ }^{86} \mathrm{~B}(1)-(2)$ all belong to the rose family (Rosaceae). The two members of $B(1)$ belong to the same genus (Pirus) and resemble each other. The quince and the hawthorn (B(2)) belong to different genera (Cydonia and (rataegus respectively). There is some question as to the 
identification of the prys as the quince, since the latter is larger than the hawthorn, and the two do not closely resemble each other.$^{37}$ Löv ${ }^{88}$ maintains that the pry $\breve{s}$ is a medlar, which is similar to the hawthorn. Feliks, ${ }^{89}$ however, rejects this identification because of descriptions of the fruit in various sources (cf. B. Ber. 43b, T. Suk. 2:9, and B. Suk. 3la-b). Following R. Jonah's identification of the pry $\breve{s}$ as 'sprglyn (= Arabic 'sprgl) (Y. Kil. 1:4), Feliks suggests that the hawthorn may have been considered an inferior variety of the quince. 90

Although we have assumed that $B$ lists two pairs, this is not necessarily the case. Y. 1:4 (27a) presents a dispute between Rav and Joshua $b$. Levi as to whether $B$ contains two pairs or $a$ single group of four. Y. apparently concludes that B speaks of two pairs. However, the four fruits are grouped together in other contexts in M. - T. Zera ${ }^{C}$ im (M. Macas. 1:3, T. Shev. 7:16), and it is possible that $B$ should be read as a list of four.

$D+F$ presents three pairs of fruitrtrees which are considered diverse-kinds, even though, as $E$ notes, the members of each pair resemble each other. The fruit-trees of pairs $D(1)-(2)$ belong to the rose family (Rosaceae; cf. B (1)-(2)). Feliks identifies the hard of $\mathrm{D}(1)$ as the syrian pear, although he admits that he is uncertain about this identification. 91 Both the syrian pear and the apple belong to the genus Pirus, and therefore resemble each other. According to Feliks the syrian pear is not edible, and it would make sense to graft an apple bud onto its tree. ${ }^{92}$ Peaches and almonds ( $D$ (2)). belong to the same genus (Prunus) and are similar in appearance (e.g., certain varieties of peaches have a smooth peel like the shell of an almond). The jujube and the wild jujube (D (3)) belong to the genus ziayphus of the buckthorn family (Rhamnaceae), and resemble each other. I do not see any botanical relationship between this pair and the first two pairs of this list.

Following E, Maimonides (Code, Diverse-Kinds 3:4) explains the law of M. $1: 4 \mathrm{D}-\mathrm{F}$ as follows:

And thus [i.e., it is the same as we saw above in the case of seeds] in [regard to] the tree, where there are two kinds which are similar to one another in [their] leaves or fruits, [but] since they are two kinds, Io, they are [considered] diverse-kinds.

Maimonides then lists the fruits of M. $1: 4$ as examples. ${ }^{93}$

A. In the district (thum) of Ariah ${ }^{94}$ they used to graft apple [buds] onto Syrian pear ('zrd; Lieberman corrects to 'zrr = Y.'s harr) [trees]. 
B. A certain student [once] found them [performing this grafting].

C. He said to them, "You are forbidden [to do this]."

D. They went and cut them [i.e., the buds] off.

E. And they came and asked at Yavneh.

F. They [i.e., the sages] said, "Correctly (yph) did that student say."

$$
\begin{aligned}
& \text { T. Kil. } 1: 3 \text { (p.203, 11. 8-10) } \\
& \text { (Y. } 1: 4 \text { (27a)) }
\end{aligned}
$$

G. In the irrigated fields (šwqy) of sepphoris they used to graft crustaminum pear [buds] onto pear [trees].

H. A certain student [once] found them [performing this grafting].

I. He said to them, "You are forbidden [to do this]."

J. They went and cut them [i.e., the buds] off.

K. [Erfurt, first printed ed.: And] they came and asked at Yavneh.

L. They [i.e., the sages] said, "Whoever met you was none other than [one] of the students of the house of study (by $r b$ ) of Shammai."

T. Kil. $1: 4$ (pp. 203-204,

11. 11-13) (Y. $1: 4 \quad(27 a))$

T. 1:3-4 presents two stories which give precedents for the law of M. $1: 4$. T. $1: 3$ concerns the law of M. $1: 4 \quad D(1)$, while T. $1: 4$ deals with $M .1: 4 \mathrm{~B}(1)$. The two stories clearly were formulated together, for they have the same literary structure, and the language of $\mathrm{B}-\mathrm{E}$ is identical to that of $\mathrm{H}-\mathrm{K}$. The two stories differ mainly in $F$ and $L$, for in the former the student's words are praised, while in the latter the student is called a Shammaite. The student's ruling in F follows M. 1:4 D-F, while that of $L$ opposes that of M. 1:4 B-C. T. thus supports the view of M. I: 4 by praising one who agrees with it and calling a Shammaite one who opposes the rule.

A. (1) A radish ${ }^{95}$ and a rape ${ }^{96}$ (npws; many mss. ${ }^{97}$ npws), (2) mustard 98 and wild mustard, 99

(3) a Greek gourd ${ }^{100}$ with an Egyptian [gourd] ${ }^{101}$ and [Geniza fragments ${ }^{102}$ add: with] the remuṣa, 103

B. even though they are similar to one another,

C. they are [considered] diverse-kinds with one another. 
M. Kil. 1:5 offers the same type of list as that found in M. 1:4D-F, for it lists plants which are diverse-kinds with each other in spite of a similarity in appearance. $M$, presents two pairs and a group of three (= two pairs), making the total number of plants seven. We note that one plant of each pair also appears on the list of M. 1:1-3, We shall first discuss the characteristics of the plants of M. $1: 5$ and then determine the relationship between $M, 1: 5$ and $M, 1: 1-3$.

All of the plants of pairs (1)-(2) belong to the mustard family (Cruciferae). The radish and the rape belong to different genera (Raphanus and Brassica, respectively). In Y. 1:5 (27a) Jonah maintains that while the two vegetables are similar in respect to both their leaves and their fruits, they are considered diverse-kinds because of a difference in taste. Accordingly, taste becomes the ultimate criterion for determination of diversekinds (Cf. MR to M. $1: 1^{104}$ ).

Mustard and wild mustard (pair (2)) also belong to different genera (Brassica and Sinapsis, respectively). The latter is similar to the former (and, incidentally, to Egyptian [or white] mustard as well) in its yellow flowers, leaves and taste. ${ }^{105}$ Feliks says that the wild mustard differs from white mustard in the shape of its root, 106 although he does not say whether it differs in this respect from ordinary (= black) mustard as well.

All plants of group (3) are varieties of the calabash gourd (Lageneria vulgaris, of the gourd family [Cucurbitaceae]). 107 The Greek gourd is an African variety while the Egyptian gourd and presumably the remusah are Asian. Although the two varieties are presumably similar to each other, ${ }^{108}$ there are important differences between them. The stalks of the African variety spread out 10-15 m., while those of the Asian variety extend only 3-10 m. In addition, the leaves of the latter are split into lobes, while the leaves of the former are not. ${ }^{109}$ These differences probably account for M.'s ruling that the two varieties are considered diverse-kinds, We may note that, according to M., the Egyptian gourd and the remusah are not considered diverse-kinds (following GRA; Cf. M, 1:2D). Nehemiah opposes this ruling in T. 1:5, as we shall shortly see.

Let us now compare the plants listed in M. 1:5 to those of M. 1:1-3, using the following chart: 


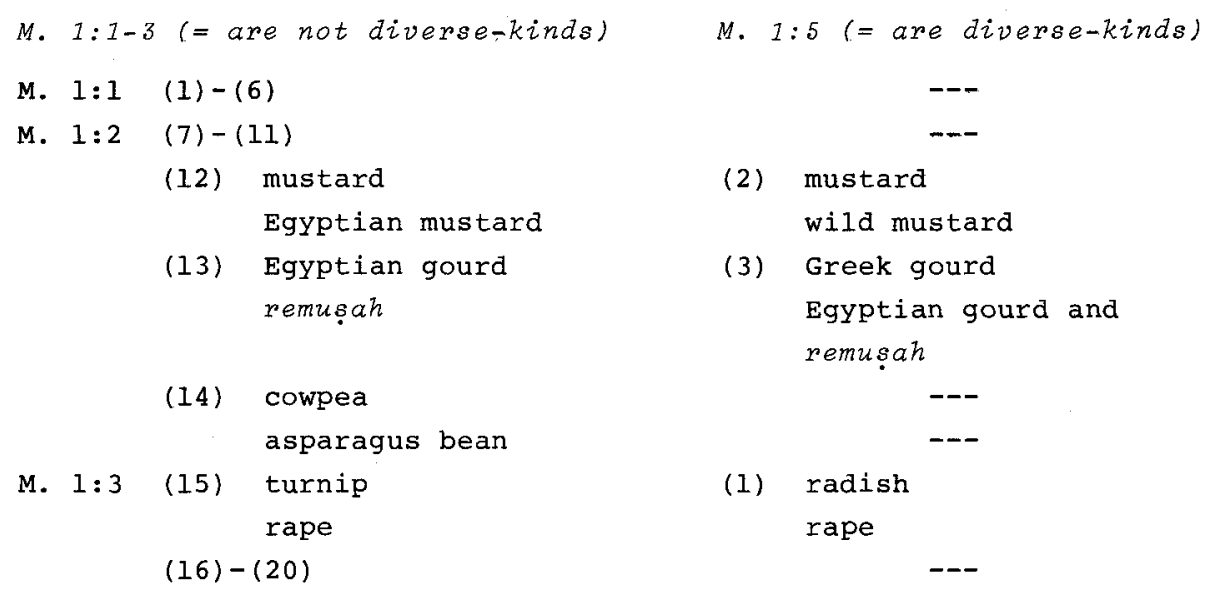

The 1ist of M. 1:5 corresponds to pairs (12), (13), and (15) of M. 1:1-3. One plant from each of these pairs (or in the case of (13), both plants) is combined with another plant to form a pairing of diverse-kinds. In effect, M. 1:5 supplements M. $1: 1-3$, for it states that while plant $A$ of $M .1: 1-3$ is not considered diverse-kinds with plant $B$, it is considered diversekinds with plant $C$. If we are correct in supposing the underlying rule of $M .1: 1-3$ to be that plants which resemble each other are not considered diverse-kinds, then M. 1:5 provides a list of exceptions to that rule. That is, M. 1:5 lists those plants which do resemble each other but are nevertheless considered diversekinds. 110
E. (1) Dill $1^{111}$ and fennel, 112
(2) coriander and celery, 113
F. even though they are similar to one another,
G. they are [considered] diverse-kinds [when they grow] with one another.

$$
\text { T. Kil. } 1: 1 \mathrm{~b} \text { (p. 203, 11. 2-3) }
$$

T. $1: 1 \mathrm{~b}$ adds two pairs to M. 1:5's list of plants which resemble each other but are still considered diverse-kinds. The plants of these pairs were all used as spices, and thus are similar to (and, in the case of coriander, identical with) some of the plants listed in M. 1:2. T. thus links M. 1:5 to M. 1:2. All four plants belong to different genera of Umbellifrae, ${ }^{114}$ or the parsley family. Dill and fennel resemble each other, although the latter is taller and has larger leaves. ${ }^{115}$ Celery appears somewhat similar to coriander, but according to Feliks ${ }^{116}$ there 
are important differences between them (e.g., smell). The law of E-F states that these plants, in spite of their similarities, are considered diverse-kinds. We note that, although this list is presumably also to be read in pairs, as we have done, it is also possible that we have a list of four separate items, which may be read differently (cf. T. $1: 1 \mathrm{c}$ ).

A. R. Nehemiah says, "Aramean and (w) Egyptian gourd[s] are [considered] diverse-kinds with the remuṣah." [first printed ed.: "Aramean and Egyptian gourd[s] and a Greek gourd are [considered] diverse-kinds with the remugah." Erfurt and GRA: "Aramean and Egyptian gourd[s] are [considered] diverse-kinds [Lieberman adds: with] the Greek gourd, and are [considered] diverse-kinds with the remusah." B. and Y.: "[The] Aramean gourd [L: The desert gourd], which is the Egyptian gourd, is [considered] diverse-kinds [with] the Greek gourd, and is [considered] diverse-kinds with the remusah."]

$$
\begin{aligned}
& \text { T. Kil. } 1: 5 \text { (p. 204, 13-14) } \\
& \text { (B. Ned. 5la, Y. Kil. 1:2 (27a)) }
\end{aligned}
$$

T. I:5 presents a saying of Nehemiah which opposes the law of M. 1:5 in regards to at least one pair of gourds. We shall follow Lieberman and take Erfurt's reading as the best one. 117 The saying then reads that both the Aramean and the Egyptian gourds are considered diverse-kinds with both the Greek gourd and the remuşah. As for the gourds themselves, we have already identified all but the Aramean gourd, which does not appear in M. 1:5. The only identification of it which we could find appears in the versions of $B$. and $Y$. , where it is said to be identified with the Egyptian gourd. It is also possible, however, that the Aramean gourd is another Asian variety of the calabash gourd. If this is so, then Nehemiah says that the Asian varieties (Aramean and Egyptian) of the calabash gourd are diverse-kinds with the African variety (Greek) and the remusch.

We shall now compare Nehemiah's opinion in M. $1: 2$ and M. 1:5. The following chart shows how the law differs in respect to each pairing of the Egyptian gourd, the Greek gourd and the remusah. 
Pairs of Gourds

M. $1: 2$

not diverse-

kinds

(2) Greek Egyptian

(3) Greek remugah

(1) Egyptian remusah

--

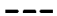

M. $1: 5$

T. 1:5 (Nehemiah)
$--$

diverse-kinds

diverse-kinds diverse-kinds

diverse-kinds

not diverse-kinds

We first note that the rule of M. $1: 2$ and M. 1:5 are consistent with one another. The Greek and Egyptian gourds are considered to be diverse-kinds with each other (M. 1:5), and so the remusah, which is not considered to be diverse-kinds with the Egyptian gourd (M. 1:2), is regarded as being diverse-kinds with the Greek gourd (M. 1:5). Now Nehemiah agrees that Greek and Egyptian gourds are considered diverse-kinds with one another. He disagrees, however, concerning the status of the remusah, maintaining that the latter is regarded as diverse-kinds with the Egyptian gourd, rather than with the Greek variety. Nehemiah perhaps reasons that both the remusah and the Greek gourd have a bitter taste, 118 and that it is this characteristic, rather than any traits shared by the remusah and the Egyptian gourd, which determines the status of the remugah. If this interpretation is correct, then Nehemiah apparently follows the principle that taste is a criterion for determining diverse-kinds (cf. our discussion of the radish and the rape of $M .1: 5)$.

A. Five things were said concerning the Greek gourd:

(1) It is prohibited to train it ('swrh bsykwk; Y.: 'yn mskkyn 'wth) over plants $\left(z r^{c} y m\right)$,

(2) its stalk [is considered its handle up to a] handbreadth,

(3) it prohibits in any amount,

(4) and it conveys uncleanness and interposes before uncleanness,

(5) and [= omitted by Erfurt and Sens] he who prohibits [himself] by a vow [lit.: he who vows] from [eating] the gourds, is only prohibited from [eating] the Greek gourd alone.

$$
\begin{aligned}
& \text { T. Kil. } 1: 6 \text { (p. 204, 11. 14-17) } \\
& \text { (Y. Kil. } 2: 11 \text { (28b) 119) }
\end{aligned}
$$

T. supplements M. 1:5 with a list of five different rules which pertain to the Greek gourd. (1) states that one may not train (i.e., guide the growth of) the plant of the Greek gourd over other plants. This ruling refers to M. 2:11, which states 
that the only plant which must not be allowed to hang over or lean on other plants is the Greek gourd. The Greek gourd is a climbing plant which may spread out 10-15 m. (see above, p. 38), and, if it is trained over other plants, it may easily become entangled with them. One would then not be able to tell how close to the other plants the Greek gourd is actually planted, ${ }^{120}$ and the field would appear to be planted with diverse-kinds. 121

(2) refers to the statement in M. Uqs. 1:6 that "the stalk of a gourd [is considered its handle up to a] handbreadth." Following T. Ned. $3: 6$ (see item (5) below), Lieberman ${ }^{122}$ maintains that this law applies specifically to Greek gourds. The Iaw concerns the stalk of an unclean gourd. The part of the stalk which is within a handbreadth of the gourd is considered its handle $(y d)$, as it is reasoned that one must grasp a handbreadthlength of the stalk in order to take hold of the gourd. As the handle of the gourd, this part of the stalk may convey uncleanness to the gourd or receive uncleanness from it, although it is not considered part of the actual gourd. ${ }^{123}$ The part of the stalk which is more than a handbreadth away from the gourd is not considered its handle and is not affected by its uncleanness.

(3) refers to $M$. Orl. 3:7. The sages there list the Greek gourd as one of six items, which, if they are prohibited and become mixed up in a larger group of permitted items, cause the entire group to be burnt. These prohibited items are not neutralizec in the larger group because such items are usually sold individually and not in large quantities (Maimonides, Comm., ad. Loc.). According to $M$. the Greek gourd becomes prohibited if it is grown in a vineyard. ${ }^{124}$ The gourd must then be burnt, because according to the laws of diverse-kinds of the vineyard one must burn both that which is planted in the vineyard as well as the surrounding vines. 125

M. Oh. 8:1 lists the Greek gourd among those things which convey uncleanness and interpose before it (4). Neusner ${ }^{126}$ explains that the plants listed in $M$. are inedible, are attached to the ground (and so insusceptible [TYT]), and have large leaves which may form tents. We shall see that Bar Qappara, in another list of rulings cited in $\mathrm{Y}$. (see below), regards conveying uncleanness and interposing before it as two separate properties. 127

(5) cites T. Ned. 3:6. The law concerns to which gourds one refers when he vows not to eat "gourds." T. says that "gourds" refer only to Greek gourds and that the vow does not prohibit other types of gourds. In ordinary usage, then, "gourd" means the Greek gourd. 128 
Bar Qappara, cited in Y. 2:11 (28b), presents a different version of a list of rulings concerning the Greek gourds. His list contains seven items:

A. Bar Qappara teaches (tny) [lit. repeats] seven [rulings concerning the Greek gourd]:

(1) They do not train it over plants,

(2) and it conveys uncleanness,

(3) and interposes before uncleanness,

(4) and [the length of] its handle is a handbreadth,

(5) and they give it [the full area required for] its tillage,

(6) and it is [considered] diverse-kinds with the Aramean gourd,

(7) and it is [considered] diverse-kinds with the remușah.

B. And he does not teach [that the Greek gourd] prohibits [in any amount];

c. and he does not teach [concerning] vows.

Bar Qappara thus includes T.'s (1), (4) (counted as two rulings), and (2), in the same order that Y. cites T. He omits (3) and (5) (cf. Y. B-C) and includes three other laws. The first is at $Y$. (5), which says that one allows the Greek gourd the full area required for its tillage. This ruling refers to M. Kil. 3:7 (PM), which states that a single gourd must be given an area the size of fourth of a $q b$ (so that it should not spread over other plants; cf. M. Kil. 2:11). ${ }^{129}$ Bar Qappara also adds (Y. (6)-(7)) that the Greek gourd is considered diverse-kinds with both the Aramean [= Egyptian (?)] gourd and the remugah (= M. 1:5). This ruling is counted as two laws, so that the list totals seven. We may note, however, that since the two laws concerning diversekinds (Y. (6) $-(7)$ ) and the two which concern uncleanness (Y. (2)(3)) may each also be considered as one law, Bar Qappara's list may be reduced to five items.

$$
1: 6
$$

A. (1) A wolf 130 and a dog, 131

(2) a wild $\operatorname{dog}^{132}$ (hklb hkpry) [Geniza fragments, ${ }^{133} \mathrm{o:}$ hkwpry; S, K: kwpry] [alt. translation (Blackman): village dog] and the jackal, 134

(3) goats $^{135}$ and gazelles, 136

(4) Nubian ibexes ${ }^{137}$ and fat-tailed sheep, 138 
(5) a horse $e^{139}$ and a mule, 140

(6) a mule and an ass, 141

(7) an ass and an Arabian onager, 142

B. even though they are similar to one another,

C. they are [considered] diverse-kinds with one another.

$$
\text { M. Kil. 1:6 }
$$

M. Kil. 1:6 presents seven pairs of animals which are considered diverse-kinds in spite of a similarity in appearance. This list of animals augments M. 1:4D-5's discussion of fruits and vegetables to which the same rule applies. M. apparently refers only to the breeding of animals of diverse-kinds, and so presupposes the prohibition of Lv. 19:19 (Maim. Code, Diverse-Kinds 9:4). According to some commentaries (MS, TYT), however, M. also refers to the law of Dt. 22.10, which prohibits the driving or leading together of two different kinds of animals (cf. M. 8:2).

In terms of literary structure, $\mathrm{M}$. is identical to $\mathrm{M}$. 1:4D-F and M. 1:5, for it consists of a list (A), subscription (C) and gloss (B). Pairs (5)-(7) alone, however, form a list which differs structurally from the other lists, for the last animal of each of the first two pairs is the first animal listed in the next pair. The list then has the form of $A-B, B-C, C-D$. This may be seen as an elegant way to end the list of $M .1: 6$, and it is perhaps also intended as an ending to the entire construction of M. 1:1-6, which now contains thirty-five items in all.

We may note that all of the animals named in $A$ are listed in the singular, except for those belonging to pairs (3)-(4), which are given in the plural. The list of $\mathrm{A}$ may thus be divided into three parts, (1)-(2), (3)-(4), and (5)-(7). This division is also on sound taxonomical grounds, since each group represents a different family of animals. We shall now consider each of these families separately.

All of the animals of pairs (1)-(2) belong to the genus canis of the dog family (Canidae). Feliks maintains that we cannot accurately identify the dogs mentioned in M., but suggests that they may be similar to the dogs of the present day. One type of dog has long legs and a rolled-up tail, and is similar in these respects to the wolf. Another type is smaller and has pointed ears along with a hanging, heavy tail. This type of dog also walks with its head low, keeps its distance from man, and is considered almost wild. On account of these characteristics, this dog is said to be similar to the jackal. 143 
All of the animals of pairs (3)-(4) belong to the ox family (Bovidae). The animals are not grouped together according to any similarities in overall appearance, for, although the goat and the Nubian ibex belong to the same genus (Capra) and resemble each other, they are placed in different pairs. Rather, the animals are apparently paired according to similarities between their horns. All four of the animals have permanent, hollow horns. However, the horns of both the goat and gazelle are short and slender, while those of the Nubian ibex and the sheep are broad and have grooves. 144 Feliks ${ }^{145}$ notes that no mating between any two animals of pairs (3)-(4) actually produces offspring, except for the mating of the goat and Nubian ibex (since they belong to the same genus). All of the animals, though, can mate with each other, "particularly in captivity with the aid of man."146 The mating of these animals is thus prohibited, even though they cannot actually produce an animal of diverse-kinds. 147 This rule is consistent with the general principle that one cannot allow even the appearance of diverse-kinds to take place.

All of the animals of pairs (5)-(7) belong to the horse family (Equidae) and are similar to each other. Matings between any two of these animals may produce offspring, except where one of the animals is a mule, which is sterile. ${ }^{148}$ MR explains that the mule is considered to be diverse-kinds with both the horse and the ass because it is the offspring of their mating.

Maimonides (Code, Diverse-Kinds 9:4) interprets M. to concern wild and domesticated animals which are similar to one another:

[Concerning] two kinds (myny) of domesticated or wild animals which are similar to one another--even though they conceive fxom one another and are similar to one another, 10, they are [considered] diversekinds and it is forbidden to cross-breed them (2hrkybn).

Maimonides then lists the animals of M. 1:6 as examples (cf. also MR). It is not clear, however, that pairs (2) and (5)-(6) each include one wild and one domesticated animal. We therefore prefer the interpretation given above.

A. (1) A cock ${ }^{149}$ [and a] peacock, 150

(2) a cock [and a] pheasant ${ }^{151}$ (psy'ny) [first printed ed.: $p s ' n y$ ] [Erfurt, B. B.Q.: The cock and the peacock and the pheasant (psywny); Y. Kil. and Y. B.Q.:

The cock with the pheasant (pysywyn), the cock with the peacock (twws; Y. B.Q.: twwst)], 
B. even though they are similar to one another,

C. they are [considered] diverse-kinds with one another.

$$
\begin{aligned}
& \text { T. Kil. } 1: 7 \text { (p. } 204,11.17-18 \text { ) } \\
& \text { (Y. Kil. } 1: 6(27 a), \text { B. B.Q. 55a, } \\
& \text { Y. B.Q. } 5: 8(5 a))
\end{aligned}
$$

T. adds a group of birds to M. 1:6's list of animals which may not be mated with one another (cf. M. B.Q. 5:7). We shall first deal with the different readings of $T$. As it stands, $A$ consists of two pairs made up of three birds (Y. Kil and Y. B.Q. reverse the order of the pairs). We have inserted the conjunction "and" between the members of each pair, for otherwise the list would make no sense. ${ }^{152}$ The law thus reads that the cock is considered diverse-kinds with both the peacock and the pheasant. The readings of Erfurt and $B$. list a group of three instead of two pairs. They differ in law with the previous reading only in that now the peacock and the pheasant are presumably considered diversekinds with each other. ${ }^{153}$ This fact is not clear from the other reading of $\mathrm{T}$.

The three birds belong to different genera of the pheasant family (Phasianidae). Feliks ${ }^{154}$ explains (following Erfurt and B.) that the female pheasant resembles the hen (of the domestic fowl, or chicken) while the male pheasant, with its long and colorful tail, is similar to the peacock. The reading of two pairs at $A$ may be explained by noting that the female pheasant is similar to the hen of a chicken ( $A(2))$, and that the peahen presumably resembles the hen as well (A(1)). Feliks ${ }^{155}$ comments that no mating of these birds produces offspring, for the birds belong to different genera.

A. R. Judah said [B.: says], "A female mule which craved $\left(\breve{s}^{t} b^{c} h\right.$ ) a male [mule] [= omitted in B.]--

B. "they do not mate with it ('yn mrbycyn) either [one] of [= omitted in B.] the horses or [one] of the asses, but only [one] of the male mules [B.: of its own kind]." [Entire pericope omitted in Vienna.]

T. Kil. $1: 8 \mathrm{a}$ (p. 204, 11. 18-19)

(B. Hul. $79 a=$ B. Ket. $111 b$ )

T. Kil. 1:8a presents an opinion of Judah which agrees with M. $1: 6$ as to which animals may not be mated with the mule. Judah assumes that it is permissible to satisfy the mule's sexual desires 
by mating another animal with it, even though no offspring can result from such a mating. He rules, however, that, although the female mule cannot produce offspring, it still may not be mated with a horse or an ass, but only with another mule. ${ }^{156}$ Judah thus again illustrates the principle that animals of different kinds may not be mated with each other, even when no offspring of diverse-kinds can be produced. We note that Judah agrees with the law of M. Kil. 1:6 A(5)-(6), which states that both the horse and the ass are considered diverse-kinds with the mule. He thus attests the substance of M. to Usha.

c. (1) An ox ${ }^{157}$ and a wild ox [= omitted in vienna, 158

(2) an ass and a wild ass, 159

(3) a hog ${ }^{160}$ and a wild boar [= omitted in Y.], 161

D. even though they are similar to one another [= omitted in Y.], E. they are [considered] diverse-kinds with one another.

T. Kil. $1: 8 \mathrm{~b}$ (p. 204, 11. 19-20)

(Y. B.Q. $5: 8(28 b))$

T. Kil. $1: 8 \mathrm{~b}$ adds three pairs of animals to the list of M. 1:6.162 T.'s three pairs of animals respectively belong to the ox (Bovidae), horse (Equidae), and hog (Suidae) families. Each pair consists of one wild and one domesticated species of the same animal. 163 The point of $T$. is that, although the members of each pair resemble each other and differ only as to how and where they were raised, they are still considered diverse-kinds with each other. We may point out that Maimonides (Code, Diverse-Kinds 9:5) disagrees with the law of T., maintaining that the wild and domesticated species of the same animal are not considered diversekinds with each other.

A. Five things were said concerning the wild ox:

(1) It is prohibited because of [the law prohibiting the slaughter of both] it and its offspring [on the same day],

(2) and its fat is prohibited,

(3) and it is offered on the altar,

(4) and it is liable for the gifts [which must be given to the priests],

(5) and it is bought with [second] tithe-money for peaceofferings, but not for meat [to satisfy] the appetite [i.e., for use as food $\left.{ }^{164}\right]$.

B. And 10 , it is [considered] like a domesticated animal (bhmh) in all respects. 
C. R. Yosé says, "This is the $t^{\prime} w$ which is written [Erfurt, first printed ed.: said $\left(h^{\prime}(m w r)\right]$ in the Torah, 165

D. "(I) and it is permitted because of [i.e., in respect to] [the law prohibiting the slaughter of both] it and its offspring [on the same day],

"(2) and its fat is permitted,

"(3) and it is disqualified $(p s w l)$ from [= omitted by First printed ed.: Erfurt: for] the altar,

$"(4)$ and it is exempt from the gifts [which must be given to the priests],

" (5) and it is bought with [second] tithe-money for meat [to satisfy] the appetite [i.e., for use as food], but not for peace-offerings.

E. "And lo, it is [considered] like a wild animal (hyh) in all respects."

F. And the sages say, "The $t$ ' $w$ is a creature unto itself, and the wild ox is a creature unto itself."

$$
\text { T, Kil. } 1: 9 \text { (pp. 204-205, 11. 20-26) }
$$

T. presents a dispute between an anonymous opinion and Yose concerning certain rulings which pertain to the wild ox. The central issue of the dispute concerns whether the wild ox is considered a domesticated or wild animal. T. 1:9 thus supplements T. 1:8b. While the latter states that the ox and the wild ox are considered diverse-kinds, T. 1:9 deals with the related question of whether or not the wild ox is treated like a domesticated animal (i.e., like an $o x$ ) in differing legal contexts. As the redactor sees them, then, both pericopae are concerned with the difference between a wild ox and an ox. ${ }^{166}$

A lists five rulings which concern the wild ox, and $B$ glosses A with the general principle behind the list. In $C$, Yose introduces a new issue, the identification of the $t^{\prime} w$ with the wild ox. D-E then opposes and balances A-B. F opposes C, as the sages say that the $t^{\prime} w$ and the wild ox are two separate animals. ${ }^{167}$ We now see that $T$. is actually composed of two disputes. A-B and D-E differ as to whether the wild ox is a domesticated or wild animal ( $b h m h$ vs. hyh), and $F$ disagrees with $C$ concerning the identification of the $t^{\prime} w$ as the wild ox.

Now the issues of these two disputes are somewhat related (we shall see below to what extent this is the case). By identifying the $t^{\prime} w$ as the wild ox in $c$, Yose implies that the latter is a wild animal, for the $t^{\prime} w$ is listed among the clean wild animals in Dt. 14:5. In fact, Yosé explicitly states in M. Kil. 8:6 
that the wild ox is a wild animal. D-E is then consistent with $C$. Moreover, since $D-E$ is autonomous of $C$, and since it perfectly balances $A-B$, it is possible that $D-E$ was attached to $C$ in order to relate the issue of $C+F$ to that of $A-B$. That is, D-E spells out C's implication that the wild ox is a wild animal, and at the same time brings Yose, who originally disputes only with the sages in $F$, into dispute with the anonymous opinion of $A-B$ as well. T. thereby combines two related issues into a single pericope.

Let us now turn to the law of $T$. We shall begin with the dispute over the five laws in $A-B$ and $D-E$. As $B$ and $E$ indicate, the dispute concerns whether the wild ox is a domesticated or wild animal. 168 All five laws apply only to domesticated animals, so that $A$ maintains that they do apply in the case of the wild ox, while D says that they do not. We shall briefly discuss these five laws, and, by referring to their sources, indicate why they apply only to domesticated animals.

The first four laws are all based on biblical verses. Each of these verses refers only to domesticated animals, and therefore may be understood as applying to that class of animals alone. $A(1)$ and $D(1)$ discuss whether or not it is prohibited to slaughter a wild ox and its offspring on the same day. The relevant law is based on Lv. 22:28, which reads: And whether it is an ox or a sheep, you shall not slaughter both it and its young on the same day. The phrase an ox or a sheep may be taken to exclude wild animals, so that the law would not apply to them. 169

$A(2)$ and $D(2)$ disagree as to whether or not it is permissible to eat the fat of a wild ox. The prohibition of eating the fat of an animal is stated in Lv. 7:23: You shall not eat any of the fat of an ox, sheep or goat. Again, since the verse mentions only domesticated animals, the law is understood to apply only to them. 170

Similarly, A(3) and D(3) concern whether or not the wild ox is an acceptable sacrifice. The law referred to is based on Lv. 1:2, which states: speak unto the Israelite people and say to them: When any of you presents an offering to the Lord, you shall bring your offering of cattle from the herd (bqr) or from the flock (ș'n). The terms "herd" and "flock" clearly exclude wild animals, and the law does not apply to them. ${ }^{171}$

$A(4)$ and $D(4)$ dispute whether or not the wild ox is liable for gifts. The gifts are the portions of the sacrifice which one is obligated to give the priest (cf. Maimonides, Code, First-Fruits 9:1). The law is stated in Dt. 18:3 as follows: And this shall be the priests' due from the people: Everyone 
who offers a sacrifice, whether an ox or a sheep, must give the shoulders, the cheeks and the stomach to the priest. Once more, the verse mentions only domesticated animals, so that only when one sacrifices such animals is he liable for the gifts. Of course, the fact that this law applies only to domesticated animals may be inferred from our understanding of Lv. $1: 2$. If a wild animal is not an acceptable sacrifice, it clearly is not going to be liable for the gifts.

$A(5)$ and $D(5)$ deal with what one is allowed to purchase with second tithe-money which he has brought to Jerusalem. M. M.S. 1:3-4 and T. M.S. 1:9 all assume that domesticated animals may be purchased only for peace-offerings, while wild animals may be bought only for use as food. A(5) therefore says that the wild ox may be purchased only for peace-offerings, while $D(5)$ states the opposite view.

We now turn to the second dispute of the pericope in $C$ and $F$, which concerns the identification of the $t^{\prime} w$ with the wild ox. The $t^{\prime} w$ is listed among the clean wild animals in Dt. 14:5: The deer and the gazelle and the antelope and the wild goat and the adax and the $t^{\prime} w$ and the wird sheep. 172 In $C$, Yose identifies the $t^{\prime} w$ as the wild ox, ${ }^{173}$ while in $F$ the sages distinguish between the two animals. The legal significance of the dispute is not clear. It is possible that the two sides simply disagree as to the identification of the $t^{\prime} w$. It is more likely, however, that the dispute concerns the wild ox, and is related to the dispute as to whether the wild ox is a domesticated or wild animal. 174 Yose identifies the $t^{\prime} w$ with the wild ox, and would maintain that the latter is a wild animal. The sages, on the other hand, maintain that the $t^{\prime} w$ and the wild ox are two separate animals, and presumably would say that the latter is a domesticated animal. If the dispute of C+F does concern the wild ox, then it parallels the dispute of M. Kil. 8:6, where an anonymous opinion says that the wild ox is a $b h m h$, while yose maintains that it is a hyh. This means that the dispute of $C+F$ is also parallel to that of $A-B+D-E$, even though the two disputes are phrased in different terms.

$1: 7$

A. They do not graft (mby'yn; lit.: bring) [B: mrkybyn] 175

B. [either] a tree onto a tree [of a different kind],

C. [or] a vegetable onto a vegetable [of a different kind],

D. and neither [do they graft] a tree onto a vegetable, 
E. nor a vegetable onto a tree.

F. R, Judah permits [the grafting of] a vegetable onto a tree.

$$
\text { M, Kil. } 1: 7
$$

M. Kil, 1:7-8 forms an autonomous subunit within Chapter One and introduces a new issue, the prohibition of grafting. M. 1:7 presents a general statement of the law, which M. I:8 then illustrates with specific examples. We first turn to a discussion of M. 1:7.

M. 1:7 has a tight literary structure. A serves as the protasis for each of the clauses of B-E. B-E is formed from the four possible pairings of the words "tree" ('y $2 n$ ) and "vegetable" $(y r q)$. Each clause, then, has the same number of syllables (five, omitting $w l^{\prime}$ in $\left.\mathrm{D}-\mathrm{E}\right)$, and it is clear that $\mathrm{B}-\mathrm{E}$ has been constructed with mnemonic considerations in mind. Furthermore, the four pairings may be divided into two groups, $B-C$ and $D-E$. The members of each pair of $B-C$ are identical with each other (i.e.,tree-tree, vegetable-vegetable). D-E, though, differs from $B-C$ in that wl' is added to each clause, and in that the members of its pairs are not identical with each other (i.e., treevegetable, vegetable-tree). This grouping of the pairs is probably also intended as a mnemonic aid. $F$ then glosses and opposes $\mathrm{E}$, and attests it to Usha.

$A$ indicates that $M$, concerns the practice of grafting, which is prohibited when it results in diverse-kinds growing together. We note that $M$, nowhere relates the prohibitions of grafting to the prohibition of diverse-kinds $\left(k l^{\prime} y m\right)$. Feliks ${ }^{176}$ suggests that $A$ uses the general term $m b y$ 'yn, "they bring," and not mrkybyn, "they graft," in order to include different methods of uniting two plants which may not be technically termed "grafting."177 We shall discuss these methods in M. $1: 8$ and T., where various examples of them are given.

$B-C$ prohibits the grafting of trees onto trees 178 and vegetables onto vegetables. We assume that the prohibitions apply only when one of the trees or vegetables is considered diversekinds with the other, ${ }^{179}$ D-E prohibits the grafting of trees and vegetables onto one another. In $F$, Judah disagrees with $\mathrm{E}$, saying that it is permitted to graft a vegetable onto a tree. The reasons for Judah's ruling are not clear, and we offer two possible explanations. Y. 1:7 (27a) implies that Judah permits this type of graft because the vegetable and the tree do not actually unite to form one plant. Rather, the vegetable only derives its nourishment from the tree, and it is possible that, 
according to Judah, this is not prohibited by the laws of diversekinds. 180 Alternatively, Feliks explains Judah's position with reference to botanical considerations. A vegetable may be successfully grafted onto a tree only when the two plants have compatible structures of cambium tissue (a single cell layer between the bark and the core). The only vegetables which have a cambial structure compatible to that of a tree are certain "grass-like" (i.e., having a soft stem) perennials. However, even the graft of such a vegetable onto a tree is only temporary, for it is successful only until the branches of the tree harden into wood. It is posible, then, that Judah permits the graft of a vegetable onto a tree because it does not often succeed, and even when it does succeed, the graft is only temporary. ${ }^{181}$

A. Whence [do I know] that they do not graft

(1) a barren tree upon a fruit tree,

(2) nor a fruit tree upon a barren tree,

(3) nor a fruit tree upon a fruit tree [Y. adds: one kind upon one not of its kind]?

B. Scripture says, You shall keep my statutes (Lv. 19:19). Sifra Qedoshim 4:17 (ed. Weiss, 89a) (Y. Kil. $1: 7$ (27a))

A-B takes the clause you shall keep my statutes, which immediately precedes the prohibition concerning diverse-kinds of crops, to include the prohibition of grafting one kind of tree on another (which is not stated in scripture). We note that unlike M. 1:7B, which states simply that one may not graft one kind of tree on another, sifra prohibits only the three possible grafts which involve at least one fruit tree. 182

\section{$1: 8$}

A. They do not plant vegetables in the stump (sdn: Geniza fragments: $s d n ; 183 \mathrm{P}: s n d n)$ of a sycamore tree, 184

B. $[S:$ and $]$ they do not graft rue ${ }^{185}$ onto a trifoliate orange $(q y a h 2 b n h)^{186}$ [alt. translation: peganum ${ }^{187}$ ] tree

c. because these are [lit.: it is] [grafts of] a vegetable onto a tree.

D. They do not plant a shoot of a fig $[\text { tree }]^{188}$ in squill, 189

E. So that [the latter] might cool [the former];

F. $[B, S$ : and $]$ they do not insert a vine shoot ${ }^{190}$ into a watermelon,

G. So that [the latter] might pour [lit.: throw] its water into [the former], 
H. because these are [lit.: it is] [grafts of] a tree onto a vegetable.

I. They do not place [lit.: give] a seed of a gourd in mallow, 191

J. so that it might protect it,

$K$. because it is [a graft of] a vegetable onto a vegetable [of a different kind].

$$
\text { M. Kil. } 1: 8
$$

M. Kil. 1:8 presents five examples of the categories of grafts which are prohibited by M. 1:7. M. 1:8 discusses the last three of the four categories of M. $1: 7$ in reverse order, and provides no illustration of the first. ${ }^{192} \mathrm{M}$. may then be divided, according to these categories, into three parts, $\mathrm{A}-\mathrm{C}, \mathrm{D}-\mathrm{H}$, and I-K. Each of the first two parts contains two examples, while the third has only one. All three parts have a similar structure, consisting of a description of the example(s) (A-B, D-F, I) and an apodosis linking the example(s) to M. 1:7. Both the descriptions and the apodoses follow set patterns (the former begin with 'yn + plural participle, the latter with mpny $\breve{s})$. In addition, each of the examples of $\mathrm{D}-\mathrm{H}$ and $\mathrm{I}-\mathrm{K}$ is glossed by a clause explaining the purpose of the graft ( $E, G, J)$.

A states that one may not plant a vegetable on the stump of a sycamore tree, and $C$ explains that this act falls under the prohibition of grafting a vegetable onto a tree. Feliks ${ }^{193}$ says that when a sycamore tree was cut down, it was a common practice to leave a stump (up to ten handbreadths high) and cover it with dirt. It would therefore be possible to plant a vegetable on the stump or in the surrounding area. ${ }^{194}$ This planting was prohibited because the vegetable planted on the stump would receive nourishment from it. ${ }^{195}$ The vegetable would then, in effect, be grafted onto the tree.

$B$ states that one is not allowed to graft rue onto a $q y d h \quad 2 b h h$, again because of the prohibition of grafting a vegetable onto a tree. Rue is a perennial shrub of the rue family (Rutaceae), which has split, pinnate ${ }^{196}$ leaves and yellow flowers. It is probably considered a vegetable, rather than a tree, on account of its soft stem. ${ }^{197}$ Feliks is uncertain as to the identification of $q y d h 2 b n h$, and presents two alternative interpretations. 198 one possibility is that the qydh $2 b n h$ is the trifoliate orange. This plant also belongs to the rue family and has flowers similar to those of rue. The trifoliate orange commonly serves as understock (i.e., a plant onto which a graft is made) for several citrus fruits, and could conceivably perform 
the same function for rue as well. However, the identification of qydh $2 b n h$ with the trifoliate orange is uncertain, for the latter originated in China, and it is not known whether it had already reached Palestine by the time of $\mathrm{M} .199$

Alternatively, qydh $2 b n h$ may correspond to peganum, a plant which has white flowers but resembles rue in its split leaves. Since its family (Simaribeae) is systemically close to the rue family, a graft is botanically feasible. This identification, though, also poses a problem, for the peganum is a low plant, and it is not clear whether $M$. would describe it as a tree (which qydh $2 b n h$ certainly is). The problem of the identification of qydh $2 b n h$ therefore remains unresolved.

D states that one may not plant a fig-shoot in squill, because of the prohibition of grafting a tree onto a vegetable (H). E explains that the purpose of such a planting is to keep the fig-shoot cool. 200 According to Feliks 201 a common means of spreading the growth of trees involves planting their shoots in the ground, so that they may strike new roots. In order for this procedure to be effective, the shoots mustobtain a certain amount of moisture (but also no more). D then describes one method of assuring that the shoots gain this moisture, namely the planting of the shoots in squill. Squill is a wild plant of the lily family (Liliaceae). It has large bulbs with roots which dig deep into the earth and absorb moisture. 202 Therefore, by planting a fig-shoot in squill, one could be sure it would receive the necessary moisture 203 and strike root faster. 204 The planting is prohibited, though, as the fig-shoot is nourished from the squill, and it is as if the two are grafted together.

F describes another example of a tree grafted onto a vegetable. One may not insert a vine-shoot into a watermelon, so that the latter might provide water for the former. Feliks (following Y. 1:8 (27b)) ${ }^{205}$ maintains that the vine-shoot is not cut off from the vine, but rather is bent and inserted into the watermelon. It is not clear, though, whether the vine-shoot is inserted into the watermelon plant (i.e., at the stem or the roots), or into the watermelon itself. There are, then, two possible interpretations. Sens and sirillo (both cited by Feliks ${ }^{206}$ ) both maintain that the vine-shoot is inserted into the watermelon plant at a depth of three handbreadths 207 below the ground (following Y.). Feliks rejects this possibility, arguing that it describes an actual graft of a vine-shoot onto a watermelon plant, and such a graft would be unlikely to succeed. Since M. Kil. consistently deals only with cases which are practically feasible, it is doubtful that $F$ refers to an actual 
graft. Furthermore, the language of F-G ("insert," "throw") is not that which is usually employed in describing a graft. 208 We therefore turn to Feliks, who offers an alternative explanation. Feliks 209 maintains that the vine-shoot is inserted into the watermelon itself. ${ }^{210}$ This may have been done for one of two purposes. It is possible that the procedure was performed so that the vine might draw moisture from the watermelon and also become sweeter from it. Feliks, however, thinks that the act was done in order to better the taste of the watermelon, by having the vine pour its liquids into it. 211 we tend to favor the first alternative, if only because it seems more likely that the procedure was developed to improve the vine, which is presumably a more important plant than the watermelon. As to whether the vine is inserted into the watermelon plant or the watermelon itself, we lean towards the latter alternative, but only because the graft described by the former is not likely to succeed. If, however, M. is not speaking in practical terms (and there is no reason to think that it must) either interpretation is possible.

I-K states that one may not plant a gourd-seed in mallow in order to protect it, because this is considered a graft of a vegetable onto a vegetable. Feliks ${ }^{212}$ explains that the gourd is usually a summer plant, for it needs a certain amount of warmth. It was also grown in winter, though, because it could then obtain a higher price. In order to keep the gourd-seed warm, it was necessary to place it in a winter plant, such as mallow. This, then, is the procedure which is prohibited by $M$.

A. They do not plant [either] the shoot (šbyt) of a pomegranate $[\text { tree }]^{213}$ or the stalk of pomegranates beside the stump of a sycamore tree;

B. and they do not place [lit.: give] [Erfurt: nor (do they plant)] a shoot between two beams [of a trunk],

c. so that it might absorb $\left(\breve{s} t b \imath^{c}\right.$; Erfurt: $\left.\breve{s} t y b l^{c}\right)$ [lit.: swallow] [nourishment] between them [alt. translation: so that it might be absorbed between them];

D. and they do not place two kinds [of tree-seeds] $]^{214}$ in a single tube (spwprt)

E. so that they might absorb [nourishment] from one another;

$F$. and they do not graft the branch $(r k b)$ of a palm tree ${ }^{215}$ onto olive [trees] ${ }^{216}$ [lit.: they do not graft olive [trees] with the $r k b$ of a palm tree];

G. because [these are grafts] of a tree onto a tree [of a different kind].

T. Kil. $1: 10$ (pp. 204-205, 11. 27-30)

(F-G: Y. Kil. $1: 7$ (27b)) 
T. Kil. 1:10-12 comments on $M .1: 7$ in the manner of $M .1: 8$, i.e., by providing examples which illustrate the categories of prohibited grafts listed in $M$. T. presents seven examples for the first, second, and fourth categories of $\mathrm{M}$. , and comments on the third as well. We shall present and discuss each pericope of $\mathrm{T}$. individually, and then sumarize in a chart the relationship of $T$. to $M$.

T. 1:10 describes four examples of a tree grafted onto another tree. The pericope has basically the same literary structure as that of M. 1:8, with descriptions of the examples (A, B, D, F), and an apodosis (G) relating them to $M .1: 7 \mathrm{~B}$. Two of the examples, $B$ and $D$, are glossed by clauses (C, E) which explain, in similar language (both use the verb $b l^{c}$ ), the purpose of the graft. B and $D$ also differ from $A$ and $F$ in that the former deal with general methods, while the latter are concerned with specific cases. B-E may then form an autonomous unit within the pericope. The pericope may be composed of three separate units, A, B-E, and $F$, together with the apodosis, G.

A states that one may not plant a pomegranate-shoot or the stalks of pomegranates beside a sycamore stump. Following GRA and HD Feliks 217 prefers to read btwk ("in") in A rather than bsd ("beside"), since it makes more sense to have the shoot planted within the stump itself. Feliks suggests that A refers to the area surrounding the stump, which, along with the stump, is covered with dirt when the sycamore tree is cut down (cf. M. 1:8). It is possible for a pomegranate-shoot to take root there, and since the area contains some of the trunk's sap, the shoot will be nourished by the trunk. This planting is therefore prohibited. Alternatively, Feliks ${ }^{218}$ suggests that $T$. may refer to the stalk of the pomegranate, which may have been planted in the dirt which is on top of the stump itself, for there it could take root and be nourished by the trunk.

$$
B \text { states that one may not place a shoot }{ }^{219} \text { between two }
$$
beams, which presumably are two halves of a trunk. C, which states the purpose of $B$, may be explained in one of two ways, depending on whether $t b l^{c}$ is understood as an active or passive verb. 220 If it is taken to be active, then $C$ states that the shoot absorbs nourishment from the trunk because it was placed between two beams. Alternatively, C says that the shoot will be absorbed between the two beams, meaning that it will be united with the trunk. Either way, it is clear that the shoot will absorb nourishment from the trunk, and therefore placing it between the beams is prohibited as a graft of a tree onto a tree. 
D-E states that one may not place two kinds in a single tube $^{221}$ so that they may nourish each other. Lieberman 222 states that $D$ refers to two kinds of tree-seeds. He further notes that while different kinds of tree-seeds may be planted next to each other (cf. T. Kil. 1:15), they may not be planted in such a way that they derive nourishment from each other, as is the case here.

The meaning of $\mathbf{F}$ is unclear, for the term $r k b$ may be understood in various ways. We shall present three interpretations of $F$, each of which explains this word differently. Lieberman 223 (whom our translation follows), explains that $r k b$ refers to a branch of the palm tree. F then says that one may not graft a palm branch onto an olive tree. Lieberman maintains (following Y. $1: 7$ (27a)) that the purpose of such a graft is to sweeten the taste of the olives. Löw, ${ }^{224}$ on the other hand, takes $r k b$ to refer to the trunk of a palm tree which lies on the ground. Accordingly, $F$ says that one may not graft an olive-shoot onto the trunk of a palm tree. Löw explains the palm tree was laid on the ground so that the shoots coming out of its trunk would strike roots in the soil. Therefore, one may not graft an oliveshoot onto the trunk, for fear that the palm-shoots would take root and the olive-shoot would be nourished from them.

Finally, Feliks ${ }^{225}$ rejects both of these interpretations, for both entail an actual graft involving olive and palm trees. He maintains that such a graft could not succeed, for the two trees differ considerably in structure. Rather, says Feliks, the rkb does not refer to a part of the palm tree at all. It refers to a structure of earth which surrounds the tree in such a way that shoots coming out of the trunk of the tree will take root in it. $F$ then prohibits the bending of olive-shoots into this earth so that they may strike roots, for the olive-shoots would then be nourished by the roots of the palm tree (i.e., the roots of its shoots). ${ }^{226}$ Feliks's interpretation depends on accepting a new meaning for $r k b$, and it is not clear whether one can legitimately understand the word in this way. If, however, an actual graft between olive and palm trees cannot take place, then it is equally difficult to see how Lieberman or Löw could be correct (unless, again, M. need not refer to grafts which are actually practicable). The problem of understanding $r k b$ and interpreting $\mathrm{F}$ must therefore remain unresolved. 
A. They do not graft dodder 227 onto alhagi,228

B. nor [do they graft] a spinach beet onto an amaranth, 229

C. because [these are grafts] of a vegetable onto a vegetable [of a different kind].

$$
\text { T. Kil. 1:11 (p. 205, 11. 30-31) }
$$

T. Kil. $1: 11$ continues T.'s illustration of $M .1: 7$ with two examples of a vegetable grafted onto a vegetable. T. has the same literary structure as that of M. 1:8 and T. 1:10, with descriptions of the examples (A-B) followed by an apodosis (C) linking them to M. $1: 7 \mathrm{C}$.

A states that one may not graft dodder onto an alhagi plant. Dodder is a wild, parasitic plant of the convolvulus family (Convolvulaceae). It has a unique seed which lacks both a rootlet and cotyledons (the earliest leaves of a plant). Dodder grows in the shape of a thread, and waves in the air until it finds a host plant, around which it then wraps itself. It then sends "suckers" into the stalk of the plant in order to obtain nourishment. At the same time, the dodder is cut off from the ground and becomes entirely dependent on its host. ${ }^{230}$ Feliks ${ }^{231}$ points out that dodder was actually grafted onto host plants and thereby cultivated (even though the graft destroyed the host), for it had medicinal uses. One of these host plants was alhagi, a low perennial plant of the pulse family (Leguminosae). Alhagi could serve as a host for several types of dodder. 232 It is clear why A prohibits the graft of dodder onto alhagi, for one plant nourishes another of a different kind..

$B$ states that one may not graft a spinach beet onto an amaranth. Feliks ${ }^{23}$ points out that the two plants belong to related families (goosefoot [Chenopodiaceae] and amaranth [Amarantaceae], respectively), and therefore B prohibits a feasible graft.

A. They do not graft dodder onto a calycotome (' $g$ '), 234

B. because [it is a graft] of a vegetable onto a tree.

C. R. Judah permits [the grafting of] a vegetable onto a tree $[=\mathrm{M} .1: 7 \mathrm{~F}]$.

D. [Concerning the graft of] a tree onto a vegetable --

E. R. Simeon $b$. Gamaliel permits in the name of $R$. Judah $b$. 'Agra [B.: Gamdah] from Kefar ${ }^{\mathrm{Akk}}$.

T. Kil. $1: 12$ (p. 205, 11. 31-33)

(D-E [with slight changes]: $B$. Sot. $43 \mathrm{~b}$ ) 
T. Kil. $1: 12$ concludes T.'s illustration of M. 1:7 with an example of a vegetable grafted onto a tree. A describes the example and B relates it to M. 1:7E. Citing Judah's opinion of M. 1:7F, C glosses and opposes B. D-E presumably complements $C$, for it discusses the case of the tree grafted onto the vegetable, while $\mathrm{C}$ concerns the issue of the vegetable grafted onto a tree. D-E opposes M. 1:7D. 235

A states that one may not graft dodder onto the ' $g$ '. We have already discussed the characteristics of the parasitic dodder (cf. T. 1:11). From B we learn that the ' $g$ ' is considered a tree. ${ }^{236}$ Feliks says that it is probably the calycotome, a wild, thorny bush of the pulse family (Leguminosae). The calycotome can serve as a host plant for several types of dodder. ${ }^{237}$

$C$ cites Judah's opinion, which we have already discussed (cf. M. 1:7). In D-E, Simeon b. Gamaliel, in the name of Judah b. 'Agra, opposes the prohibition of M. 1:7D and permits the grafting of a tree onto a vegetable. His view may be explained in the same way that we explained Judah's position. That is, it is possible that simeon $b$. Gamaliel permits the grafting of a tree onto a vegetable because he does not consider the result a true graft (since the plants do not actually unite). Alternatively, he permits such a graft because it is often unsuccessful, and even when it does succeed, the graft is only temporary in nature. 238

We shall now summarize T.'s relationship to $M .1: 7$ with the following chart:
M. $1: 7$
T. $1: 10-12$

A. They do not graft:

B. a tree onto a tree,

T. 1:10A Planting of pomegranate shoots or stalks in a sycamore tree.

$B-C$ Placing a shoot between two beams.

$D-E$ Placing two kinds of tree-seeds in a single tube.

F-G Grafting a palm tree onto an olive tree. 
c. a vegetable onto a
vegetable,

D. a tree onto a vegetable,

E. a vegetable onto a tree,

F. Judah permits the grafting of a vegetable onto a tree.
T. 1:11A $(+C)$ Grafting dodder onto alhagi.

T. 1:11B(+C) Grafting a spinach beet onto an amaranth.

T. 1:12D-E Simeon b. Gamali$e l$, in the name of Judah b. 'Agra, permits the grafting of a tree onto a vegetable. T. 1:12A-B Grafting dodder onto calycotome. T. $1: 12 \mathrm{C}=\mathrm{M} \cdot 1: 7 \mathrm{~F}$.

Except for T. 1:12D-E, then, T. 1:10-12 follows exactly the order of $M$. in systematically illustrating each of its clauses.

A. He who places a seed $\left(m^{c} h\right)^{239}$ of lupine beside a seed of a gourd,

B. so that the earth might be broken open (stybq $q^{c}$ ) before it, C. is liable.

$$
\text { T. Kil. } 1: 13 \text { (p. 205, 11. 33-34) }
$$

T. supplements $M .1: 8 \mathrm{I}-\mathrm{K}$, for it describes another procedure designed to stimulate the growth of gourds. T. follows the basic structure of $M .1: 8$ and $T$. $1: 10 \mathrm{~A}-\mathrm{C}+\mathrm{D}-\mathrm{E}$, for it consists of a description of the act (A), a gloss explaining its purpose (B), and an apodosis (C). T. 1:13 differs from these pericopae, 240 however, in that its apodosis states only that one who performs the act is liable, and does not relate the act to one of the categories of prohibited grafts listed in $M .1: 7$. We shall see below that this allows for two possible interpretations of $T$. According to A-C one may not plant a lupine-seed next to a gourd-seed so that the former might break up the soil for the latter. Feliks ${ }^{241}$ explains that a gourd must grow in loose soil. The lupine-seed was well known in ancient times for the way in which it would vigorously bore through the soil. 242 Therefore, if a lupine-seed were to be planted next to a gourd-seed, the latter would be able to grow in the soil loosened by the former. Now the act prohibited by $T$. does not actually involve grafting, for the two kinds of seeds are simply planted next to one another. Taken by itself, therefore, T. may refer to the prohibition not of 
grafting one kind on another, but of sowing seeds of different kinds together. The redactor of $\mathrm{T}$. has placed it as a comment on M. I:8I-K because, like the latter, it involves the seeds of a gourd. Alternatively, Lieberman ${ }^{243}$ maintains that, although the act described in $T$. does not involve grafting, it still falls in the same category as that of a graft of one vegetable onto another (M. 1:7C). There is little reason, however, to regard the case of $T$. as having any similarity with an act of grafting, and we therefore prefer the first interpretation given above.

$$
1: 9
$$

A. He who buries turnips or (w) radishes [B. Erub. 77a-b: a turnip or a radish] under the vine --

B. if [B. Erub.: when $\left(\right.$ bamn)] some of its leaves $\left(^{c} \eta_{y w}\right.$; Geniza fragments, ${ }^{244}$ Geonim and early commentaries: 245 he $h^{c} w n$

["the upper part"]) were exposed,

c. he does not fear [that he has transgressed (Danby)],

(1) either because of ( $m \check{s} w m$; Geniza fragments, K, Ox.: $m \breve{s} m$ ) [the laws of] diverse-kinds,

(2) or because of [the laws of] the Seventh Year [= omitted in a Geniza fragment],

(3) or because of [the laws of] tithes [= omitted in s] [Geniza fragments, K, B. Erub., reverse (2) and (3)];

D. and they are removed (wnytlyn; $\mathrm{C}, \mathrm{K}$ (before correction), Mn of B. Shab. 50b-5la; wnwt tyn, ["and they remove them"]) on the Sabbath.

E. He who sows wheat and barley together [lit.: as one],

F. lo, this is [considered a sowing of] diverse-kinds.

G. R. Judah says, "It is not [considered a sowing of] diversekinds,

H. "(1) until there are [either] two [grains of] wheat and [one of] barley,

"(2) or [one of] wheat and two [of] barley,

"(3) or [one each of] wheat, barley, and rice-wheat."

$$
\begin{aligned}
& \text { M. Kil. } 1: 9 \text { (A-D: B. Erub. 77a-b, } \\
& \text { B. Shab. 50b-5la, 13a) }
\end{aligned}
$$

M. is composed of two autonomous subunits, $A-D$ and $E-H$. The former concerns the case of one who buries turnips or radishes under a vine. This pericope thus supplements $M .1: 7-8^{\prime}$ 's discussion of prohibited grafts. E-H then deals with the separate issue of sowing together different kinds of seeds. Since the 
two subunits deal with such entirely different questions, we shall deal with each of them separately.

The basic unit of $A-D$ consists of the declarative sentence formed by $A+C$, with the apodosis $C$ consisting of three parts. $B$ was then inserted into this completed sentence. This is clear from the fact that $B$ interrupts the smooth construction of the sentence, for the subject of $B$ is not that of $A$ and $C$ (i.e., "he who buries"), but the "turnips or radishes" of $A$. $D$, which also refers to the subject of $\mathrm{B},{ }^{246}$ then augments the list of $\mathrm{C}$. We shall see below that $D$ could not have been added to the pericope without $B$, so that it was included in M. 1:9 either together with $B$ or after the latter had already been inserted into $\mathrm{A}+\mathrm{C}$.

A describes the case of one who buries turnips or 247 radishes 248 under a vine, presumably in order to protect them from heat and dryness (Feliks ${ }^{249}$ ). According to $C$ one who thus buries these vegetables is exempt from three prohibitions, all of which apply only to crops which are actually planted, and not simply buried. We note that the fact that the vegetables are buried specifically under a vine is relevant only to $\mathrm{C}(1)$, which concerns the prohibition of diverse-kinds, and not to $C(2)$ or $C(3)$ (Seventh Year and tithes), which need presuppose only that the vegetables are buried. The pericope has thus been formulated with special regard to the law of diverse-kinds, and so concerns the other two prohibitions only secondarily.

Let us now take each of C's rules in turn. $C(1)$ states that the action described in $A$ is not prohibited by the laws of diverse-kinds. As we have already indicated, the relevant law is probably the prohibition against grafting a vegetable onto a tree (M. 1:7E; cf. Hai Gaon, ${ }^{250}$ Maim., Code, DiverseKinds 2:11, Rabad [ad. Zoc.], MR, and Feliks 251, 252 According to this law it is prohibited to plant a vegetable near a tree in such a way that it would gain nourishment from the latter. Since in this instance the turnips or radishes are only buried and are not actually planted, they will not be nourished by the roots of the vine, and the action described in $A$ is therefore permitted. Alternatively, $C(1)$ may refer to the law of diversekinds of the vineyard (Dt. 22:9), which prohibits the planting of another kind near a vine (Sens, Maim., Comm., Rashi, 253 Me:iri ${ }^{254}$ ). Again, since the vegetables are not actually planted, the law does not apply. While both of these explanations are plausible, the redactor, by placing M. 1:9A-D immediately after M. 1:7-8, appears to understand the pericope according to the first interpretation. 
C(2) concerns the prohibition of planting during the Seventh Year (Ex. 23:10-11, Iv, 25:4), One is permitted to bury the turnips or radishes because he is not considered thereby to plant them (Maim., Code, Seventh Year and Jubilee 1:15, according to the interpretation of Ridbaz). Alternatively, $\mathrm{C}(2)$ may concern the prohibition of eating that which grows of itself (spyh) in the Seventh Year (Sens, Bert., TYY, GRA; Cf. M. Shev. 9:1). Since the vegetables were buried rather than planted, one is permitted to eat any aftergrowth which may be produced by the vegetables during this period.

C(3) refers to the obligation of tithing one's crops ( $\mathrm{Lv}$. $27: 30$, Nu. 18:21-24). One who buries turnips or radishes need not tithe them after removing them from the ground, 255 since he is obligated to tithe only that which he has planted (Maim., Comm. $i^{256} \mathrm{cf}$. also Bert.). Alternatively, the relevant law may again concern the aftergrowth which the turnips or radishes may produce. Since no planting has taken place, one is not obligated to tithe the aftergrowth. 257

According to $B$ the rule of $A+C$ holds only if the leaves of the turnips or radishes are visible aboveground. It is not clear, however, why one should be exempt from the laws of $\mathrm{C}$ only if the leaves of the vegetables are exposed. Three different interpretations have been advanced to explain this difficulty. Some commentaries (Maim., Code, Diverse-Kinds 2:11, Rabad [ad. Zoc.], Maim., Code, Seventh year and Jubilee 1:15) maintain that one must expose the leaves ${ }^{258}$ in order to show that he intends only to bury the vegetables, but not to plant them. 259 Feliks, ${ }^{260}$ however, disagrees, maintaining that if the leaves are visible aboveground the vegetables actually appear to be growing. The point of $B$, rather, is that the owner is exempt from the laws of $C$ even if the turnips or radishes appear to have been planted. This interpretation, though, does not follow from the language of the text, which reads "if some of its leaves were exposed," and not, as Feliks wishes to take it, "even if some of its leaves are exposed." B therefore clearly implies that the rule of $A+C$ holds only when the leaves are visible. Finally, a third interpretation maintains that B applies only to D, and that the rule of $A+C$ holds whether or not the leaves are exposed (Rashi, ${ }^{261}$ Sens, Maim., Comm.). This interpretation, however, is also difficult. It is true that this explanation is supported by the fact that $B$ and $D$ may have been added together to the pericope. Even if this is the case, though, one must still explain why $B$ was inserted into the pericope in such a way that it must be read with $C$ as well as with $D$. If the glossator had 
wished to read $B$ with $D$ alone, he could have placed the former after $C$, and not before it. According to its position in the pericope, then, the point of $B$ can only be that one is exempt from the laws of $C$ and $D$ solely when the leaves of the vegetables are exposed. We therefore prefer the first interpretation given above.

D states that, if their leaves are visible, the buried turnips or radishes may be removed on the Sabbath. Several commentaries (Sens, Maim., Comm., Code, Sabbath 25:14-15, Bert., TYY) state that the point of $\mathrm{D}$ is that one may remove the vegetables by their leaves even though he may also move some soil (which one is not permitted to move on the Sabbath) in the process. Since he moves the soil only indirectly, the one who picks up the vegetables is not considered to violate the sabbath. ${ }^{262}$ we note that, according to this interpretation, $B$ is clearly necessary to $D$, for one cannot remove the vegetables without violating the sabbath unless he can pull them out by their leaves.

We now turn to $E-H$. Like $A+C, E-F$ opens with a singular present participle $\left(h z w r^{c}\right)$. In contrast to the former, however, E-F does not form a smooth declarative sentence, for the subject of $F$ is not the sower of $E$, but the act of sowing itself. Judah glosses and opposes $F$ at $G$, which balances the former ( $k l$ 'ym vs. 'ynw kl'ym). G in turn is glossed and expanded at $\mathrm{H}$.

According to E-F one who sows a grain of barley and a grain of wheat together is liable for sowing diverse-kinds. ${ }^{263}$ At $G$ Judah disagrees with this rule, maintaining that one is not liable for sowing only two grains of different kinds. H explains that one is liable only if he sows together three grains, with at least two of the grains being considered diverse-kinds with the third. Judah and the anonymous rule of $E-F$ thus dispute concerning the number of grains which one must sow before becoming liable for sowing diverse-kinds. The issue of the dispute may concern the definition of the "field" mentioned in the poohibition against sowing diverse-kinds, which reads: you shall not sow your field with diverse-kinds (LV. 19:19). E-F takes "field" to mean simply an area of land, so that the verse prohibits one from sowing $k l$ 'ym, i.e., two grains (as indicated by the dual form) in an empty space. Judah, on the other hand, apparently understands field to refer to land which has already been sown. 264 Judah therefore maintains that the verse prohibits one from sowing kl'ym, i.e., two grains, in land which has already been sown, i.e., containing at least one grain. Accordingly, one is not liable until he has sown three kinds together (Sens, Maim, Comm., Bert.). 
A. He who sows something [i.e., a kind of seed] which sprouts [by nature], 265

B. over $\left(c_{l} g b y\right)$ swamps or over rushes $(h y l t), 266$

C. is liable.

D. [If he sows it] over a rock or over a water-channel ('mt mym),

E. he is free of liability.

F. and [he who sows] something [i.e., a kind of seed] which does not sprout [by nature],

G. Whether over swamps, over rushes [Erfurt, first printed ed. add: over a rock], or over a water-channel [= omitted by Lieberman], 267

H. he is free from liability.

T. Kil. $1: 14$ (p. 205, 11. 35-37)

T. Kil. 1:14 supplements M. 1:9E-G, for both pericopae discuss the conditions under which one becomes liable for sowing diverse-kinds. While $M$. discusses the number of seeds one must sow before becoming liable, T. concerns how such factors as the condition of the seed and the land determine liability, We note that $T$. nowhere explicitly mentions diverse-kinds, and could just as easily relate to another area of law (e.g., laws of the Seventh-Year). Our understanding of the pericope here follows that of the redactor, who has placed the pericope in the context of T. Kil., and has thus indicated that he interprets it as a rule of diverse-kinds.

T. consists of three statements, $A-C, D-E$, and $F-H . D-E$, which depends on $A$, balances and opposes $B-C$ (swamps and rushes vs. rock and water channel [B vs. D]; hyyb vs. ptwr [C vs. E]). $\mathrm{F}+\mathrm{H}$ balances $\mathrm{A}+\mathrm{C}$ (hmṣmyh vs. S'ynw mṣmyh [A vs. F]; hyyb vs. pțwr [C vs. H]), but $G$ does not correspond to $B$, for the former contains an additional item, the water-channel. According to Lieberman, however, this item has been mistakenly inserted into $G$ from $D$, so that $G$ does correspond to $B$, and $F-H$ balances and opposes A-C. Alternatively, Erfurt and the first printed edition add a fourth item, the rock, to $G$, so that the latter includes the kinds of land listed in both $B$ and $D$. It is not likely, though, that $C$ would list all of these types of land, when, as we shall see, it need list only those of $B$. We therefore prefer the reading suggested by Lieberman.

A describes a case in which one sows diverse-kinds which sprout by nature, i.e., seeds which readily germinate. In B-C seeds are sown over swamps and rushes. Although these areas contain too much moisture and do not have adequate drainage, 268 it is 
sometimes possible for a seed to germinate in the soil found in them. The actual growth of diverse-kinds thus may result from the sowing of the seeds, and the sower is therefore liable (following $\mathrm{HD}^{269}$ ). According to $\mathrm{A}$, then, one is liable for sowing diverse-kinds even if there is only a slight possibility that the seeds will actually grow. In D-E, on the other hand, the seeds are sown over a rock or a water-channel. Both such areas are totally unsuitable for sowing, for the rock offers no moisture at all, while the water-channel presumably contains too much water. The seeds will not germinate when sown in such areas, and therefore the sower is not liable. 270 F-H similarly presents a case which contrasts with $A-D$, only this time the case differs in that the sower uses a different type of seed. In this instance the seeds of diverse-kinds will not germinate at all, so that the sower is not liable even if he sows them over swamps or rushes (or, it logically follows, over a rock or a water-channel as wel1). The point of $\mathrm{T}$. , then, is that although one is liable for sowing diverse-kinds, when there is even the slightest possibility that the growth of diverse-kinds will result, he is not liable if such growth is not at all likely to occur. It is therefore not the act of sowing itself, but its probable outcome, which determines liability. 271

A. He who sows, weeds, or covers of (hmnph; Lieberman, 272 following Erfurt, corrects to hmhph; first printed ed.: $h h w p h)$ [Erfurt: He who sows, covers over, or weeds] [seeds of diverse-kinds], transgresses a negative commandment ( ${ }^{c} w b r b l$, $\left.t^{c} s h\right)$.

B. R. CAqiva says, "Even ('p) he who allows [plants of diversekinds] to grow transgresses a negative commandment."

c. And they sow seeds [i.e., either seeds of vegetables, or grains] and tree-seeds together [lit.: as one] [Erfurt: And they sow tree seeds together].

D. He who sows grape-seeds (hrsnym) with wheat [= omitted in Y.], 10, he receives forty stripes ( $w q h^{\prime}{ }^{\prime} t h^{\prime} r b^{c} y m$ ).

T. Kil. 1:15 (pp. 205-206, 11. 37-40)

(A-B: B. M.Q. 2b, B. Mak. 21b,

B. A.2. $64 \mathrm{a} ; \mathrm{C}-\mathrm{D}:$ Y. Peah $1: 4$ $(16 c)^{273}$ )

T. is composed of two separate subunits, $A-B$, which concerns activities related to the care of sown seeds, and C-D, dealing with the sowing together of certain kinds of seeds. 
Although these two parts are autonomous of $M .1: 9 \mathrm{E}-\mathrm{G}$ they seem to supplement the latter. A-B expands M.'s prohibition of sowing diverse-kinds to include related activities as well, and C-D discusses a situation which is analogous to M.'s care of sowing wheat and barley together.

$A-B$ consists of a declarative sentence at $A$, which is glossed by CAqiva's statement at $B$. The two sayings clearly have been formulated together, for they each consist of one or more singular present participles and the apodosis "transgresses a negative commandment." Since $A$ and $B$ share the same apodosis, it is likely that the latter was added to ${ }^{A q i v a ' s ~ s a y i n g ~ f r o m ~} A$, and that B originally read simply, "Even he who allows [them] to grow" (cf. the formulation of $B$, cited below). In fact, it is possible that "even" ('p) is standard joining-language which may have been used here to connect an independent saying of CAqiva (e.g., He who allows [them] to grow + apodosis) with A. B may thus have not been originally formulated as a gloss of $\mathrm{A}$ at all. We note that the phrase "transgresses a negative commandment" appears nowhere else in M.-T. Kil., and in fact gives no indication that the prohibition concerns diverse-kinds (and not, for example, laws of the seventh-Year) at all. We understand A-B to pertain to diverse-kinds only on account of the work of the redactor, who has placed $A-B$ in $T$. Kil.

According to $A$ one is prohibited not only from sowing diversekinds, as Scripture itself indicates (Lv. 19:19), but also from performing any other action, such as weeding or covering with soil, which may aid the growth of diverse-kinds. A thus extends the prohibition against sowing diverse-kinds to include the care of the seeds which have already been sown. In B $C_{\text {Aqiva }}$ states that one may not allow diverse-kinds to grow. When taken by itself CAqiva's saying simply restates the point of $A, v i z .$, that one may not further the growth of diverse-kinds which have already been sown. When read together with $A$, however, $B$ may be taken to add that one may not allow diverse-kinds to grow, even if he does not do anything himself to aid their growth. In this context, then, B may be understood to say that one is liable for acts of omission (e.g., failing to uproot the diverse-kinds) as well as acts of commission (e.g., actually aiding the growth of diverse-kinds). 274

Let us now compare T.'s version of $A-B$ with that of $B$. : 


$$
\text { T. KiZ. } 1: 15
$$

1. He who sows, weeds or covers over

2. transgresses a negative commandment.

3. R. CAqiva says "Even he who allows [plants of diversekinds] to grow

4. "transgresses a negative commandment."
B. M.Q. (et al.)

1. He who weeds or covers over diverse-kinds,

2. receives stripes [Mn. of B. Mak.: transgresses a negative commandment].

3. R. CAqiva says, "Even he who allows [plants of diverse-kinds] to grow."

4 .

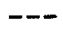

B. differs from $T$. in several ways. First, B. mentions "diversekinds" in (1), and so presents the context of the rule. B. does not mention sowing in (1), presumably because this action is expressly prohibited by scripture ( $\mathrm{VV}$. 19:19). B. also reads "receives stripes," for T.'s "transgresses a regative commandment" at (2), and so perhaps specifies the punishment connected with the prohibition. 275 Finally, B. omits the apodosis at (4), because it is redundant. B. thus both clarifies the laws of $T$. (at (1) and (2)) and simplifies its formulation (at (4)).276 $C$ and $D$ are formally autonomous of one another, for the subject of $C$ is given in the singular (and is prefaced by the definite article), while that of $D$ appears in the plural. $D$, however, seems to supplement $C$, as we shall immediately see. C states that one may sow tree-seeds together with other kinds of seeds. The point of $\mathrm{C}$ is that the prohibition of sowing diversekinds does not apply to trees, perhaps because the latter are not mentioned in the scriptural formulation of the laws of diversekinds (Lv. 19:19, Dt. 22:9). According to Erfurt's reading C permits the sowing of different kinds of tree-seeds together, again because the laws of sowing diverse-kinds do not apply to trees. 277 We note that sirillo 278 derives both of the above rules from our initial reading of $\mathrm{C}$. Maimonides (Code, DiverseKinds $1: 6$ ) also presents both laws:

And it is permitted to sow [other kinds of] seeds and tree-seeds together; and similarly it is permitted to mix tree-seeds [of different kinds] and sow them together, for [the laws of] diversekinds concern trees only in respect to grafting alone (s'yn $i k$ k'ym b'ylnwt ' $\left.\iota^{\prime} h r k b h \quad b i b d\right)$. 
D states that one may not sow wheat together with grapeseeds, since the sowing of diverse-kinds in a vineyard is expressly prohibited by scripture (Dt. 22:9). In this context the point of $D$ is that although vines are regarded as trees (cf. M. $1: 8 \mathrm{~F}-\mathrm{H})$, one is not permitted to sow other kinds with them. $D$ thus presents an exception to the rule of $c$. We note that, while D supplements M. 1:5 E-G's case of sowing wheat and barley together, $C$ bears no connection to $M .$, and so has been placed here only on account of D. If, on the other hand, Erfurt's reading of $C$ is followed, $D$ is not related to $C$ at all, so that the latter is autonomous of $\mathrm{D}$ as well as of $\mathrm{M}$. 

Chapter Two concerns the various means by which different kinds of plants may be sown together without being sown as diverse-kinds. The chapter actually begins at M. 1:9E-G, which states that the sowing of two seeds of different kinds (or, according to Judah, three seeds of two different kinds) at the same time constitutes a sowing of diverse-kinds. M. 2:1-2 then discusses how one may sow two or more different kinds of seeds which have been mixed together. M. 2:1 opens with a rule stating that if a $s e^{\prime a h}$ of one kind of seeds contains a rovac of seeds of another kind, then the $s e^{\prime} a h$ may not be sown until the quantity of seeds in the rova ${ }^{c}$ is lessened. That is, a field may contain two different kinds if one kind is present only in very small quantities, and so does not produce the appearance of diversekinds. Yosé, on the other hand, rules that all of the seeds of the rova $a^{c}$ must be removed from the $s e^{\prime} a h$, for one may not cause the actual growth of diverse-kinds, regardless of whether or not the appearance of diverse-kinds would result. As we shall see, the rest of the chapter presupposes $M .2: 1 A^{\prime} s$ view that it is the appearance of diverse-kinds which must be avoided.

M. 2:3-2:5C forms a subunit dealing with the problem of sowing one kind in a field already sown with another kind. In M. 2:3 a man wishes to sow one kind of grain in a field already sown with grain of another kind, while M. 2:4 has the owner wishing to plant trees in a field already sown with grain or vegetables (and vice-versa). M. 2:5A-C concerns one who wishes to sow grain or vegetables in a field already sown with carum. or arum (which produce fruit for several years after they are sown). In each case $M$. rules that the plants already in the field must be removed before, rather than after, the new plants are sown. The new plants may not be allowed to grow alongside of the old ones, for, although the owner intends to remove the latter, he appears to be sowing diverse-kinds. The subunit thus agrees with M. 2:1A that it is the appearance of diverse-kinds which determines liability, and not their actual growth.

M. 2:5D-F deals with wild plants which come up together with plants that have been sown, and so forms an appropriate appendix to the foregoing. The issue now is not that of sowing diversekinds, but of allowing them to remain. M. again follows the theory 
of M. 2:1A, ruling that since one did not appear to wish the growth of the diverse-kinds, he is not required to weed out the wild plants. Once he begins to weed, however, he must uproot all of the wild plants, for if he were to stop weeding, he would appear to allow diverse-kinds to grow.

M. Kil. 2:6-9 forms a new subunit which concerns sowing different kinds together (i.e., in the same field or in adjacent fields) without producing the appearance of diverse-kinds. The subunit as a whole follows the theory of M. 2:1A. M. 2:6 has a Houses-dispute concerning the minimum width which the rows of different kinds must have in order to be considered autonomous from one another. M. 2:7-8 then interrupts the discussion of sowing different kinds in the same field with a subunit concerning the sowing of different kinds in adjacent fields. According to M. 2:7 the corner of a field of one kind may enter a field of a different kind, and the edge of a field of one kind may be sown with the kind of an adjacent field, for in each instance, the kind which enters the field of another kind appears to mark the end of its own field, so that no appearance of diverse-kinds results. M. 2:8 concerns the related problem of flanking a field of one kind with another kind (in this instance, mustard or safflower) in such a way that the appearance of diverse-kinds is not produced. M. 2:9 reverts to M. 2:6, for it opens with the same sentence-structure ("He who wishes to lay out his field.. ."). Now the field is to be laid out in patches of different kinds. M. again deals with the minimum size a patch must be in order to be considered an autonomous field. A dispute between Meir and the sages, concerning the sowing of mustard patches, is then interpolated into $M$. The insertion of this dispute may represent an attempt by the redactor to link M. 2:9 and M. 2:8 (which also concerns mustard) together, and so to consolidate the two parts of the subunit (M. $2: 6+2: 9$, M. 2:7-8). M. $2: 10 \mathrm{~A}-\mathrm{B}$, which concerns measuring the area within a patch, is then appended to the subunit.

M. 2:10C-2:11 closes the chapter with rules about sowing different kinds among one another. Both pericopae are tightly constructed, for both describe the ways in which the different kinds may be sown with each other by listing the four possible combinations of the words $t b w^{\prime} h$ and yrq. M. 2:10C-F defines, for each combination, the minimum area which a secondary kind must cover when it is sown in a field of a primary kind. A space the size of this minimum area constitutes an autonomous field, so that the presence of the secondary kind in the field does not produce the appearance of diverse-kinds. M. 2:11 rules that all plants may be allowed to lean over other kinds of plants, except 
for the Greek gourd. The Greek gourd tends to become entangled in adjacent plants, and so could cause the appearance of diversekinds if it were allowed to lean over other kinds. M. 2:10C-2:11 then also follows M. 2:1A's emphasis on the appearance of diverse-kinds.

\section{$2: 1-2$}

A. [Concerning] every $s e^{\prime} a h$ [of one kind of seeds] which contains a quarter [-qqab] [most mss. ${ }^{1}$ add: of seeds] of another kind (mmyn ' $h r$; $\mathrm{B}, \mathrm{C}$, Geniza fragments, ${ }^{2} \mathrm{~K}, \mathrm{Pr}, \mathrm{V}$ : of one kind [mmyn 'hid] $]^{3}$ ) -- he shall lessen [the quantity of seeds of the other kind, so that those seeds form less than a quarter-qab].

B. R. Yose says, "He shall sift [out the other kind completely]."

C. [And it makes no difference] whether [the quarter-qab consists] of one kind or two.

D. R. Simeon says, "They only said [that he must lessen the quantity of seeds in the quarter-qab when the latter consists solely] of one kind."

E. And the sages say, "Everything which is [considered] diversekinds with [the seeds of] the se'ah combines (mstrp) to [form] the quarter $[-q a b] . "$

$$
\begin{aligned}
& \text { M. Kil. } 2: 1 \text { (A: B. M.Q. 6a; } \\
& \text { A-B: M. B.B. } 94 a \text { ) }
\end{aligned}
$$

F. Under what circumstances?

G. (1) When grain [is mixed] with grain,

(2) and pulse with pulse,

(3) grain with pulse,

(4) and pulse with grain.

H. But they said (b'mt ' $m r w)$ [C, K, L, O, P, Pr omit: said], "Garden-seeds which are not eaten combine (mstrpyn) [to form an amount sufficient to prohibit the sowing of the when they total] one twenty-fourth of [the volume] which is sown ${ }^{4}$ in a bet se'ah."

I. R. Simeon says, "Just as they said [this ruling in order] to make [the law] more stringent [in one case], so did they say [the same ruling in order] to make [the law] more lenient [in another]:

J. "Flax ${ }^{5}$ [which has been mixed] with [a se'ah of] grain combines [to form an amount sufficient to prohibit the sowing of the $s e^{\prime a h}$ when it totals] one twenty-fourth of [the volume] which 
is sown in a bet se'ah."

M. Kil. $2: 2$

M. Kil.2:1-2 deals with the problem of sowing seeds of diverse-kinds which have been mixed together, thus continuing the discussion of sowing diverse-kinds which began at M. 1:9E-G.

M. consists of four parts, A-B, concerning the sowing of different kinds of seeds with one another, $C-E$, dealing with the combining of seeds to form a minimum quantity, F-G, glossing A-B, and H-J, dealing with mixtures containing garden-seeds or flax. We shall consider each of these sections in turn. A describes a situation where a $s e^{\prime a h}$ of one kind of seeds (henceforth: principal seeds) contains a quarter-qab (= one twenty-fourth of a $s e^{\prime} a h^{6}$ ) of another kind of seeds (henceforth: secondary seeds). According to A one must lessen the quantity of secondary seeds before sowing the se'ah. Y. understands A to mean that one must reduce the proportion of secondary seeds to principal seeds. Therefore one may either lessen the quantity of secondary seeds or add to the amount of principal seeds (Y. Kil. 2:1 (27c), Maim., Comm., Code, Diverse-Kinds $2: 1$, GRA). The purpose of this action is to avoid presenting the appearance of sowing diverse-kinds (TYY, GRA, MR). It is apparently assumed that the diverse-kinds would be noticed (later, when the plants actually grew) only if the secondary seed comprised at least one twenty-four of the se'ah.

In $B$, Yosé disagrees with $A$ and says that one must remove all of the secondary seeds from the $s e$ 'ah. Yose apparently reasons that one may not sow any amount of diverse-kinds, and therefore one may not leave any secondary seeds in the se'ah. The issue of the dispute thus concerns whether the appearance or actual sowing of diverse-kinds determines liability. While A apparently maintains that one need only be concerned about the appearance of diverse-kinds, Yosé says that the actual sowing of diverse-kinds is prohibited, even when the appearance of diversekinds will not result.

$C-E$ glosses $A-B$ with a dispute concerning whether or not several different kinds of secondary seeds may join together to form the quarter-qab mentioned in $A$. The dispute consists of three opinions. C states that different kinds of seeds may combine to form the quarter-qab. Simeon, on the other hand, says in $\mathrm{D}$ that the quarter-qab may consist of only one kind. In $\mathrm{E}$ the sages basically restate the position of $C$ in the language of A ("se'ah" and "rovac"), for they maintain that every kind of seed which is considered diverse-kinds with the principal seeds combines to form the quarter-qab. The dispute then poses a 
problem, for it contains two different versions of the same position. We may resolve this difficulty by noting that $\mathrm{C}$ is only necessary to $A$ because of $D$. In other words, it is only necessary to specify that the quarter-qab of $A$ may consist of either one or two kinds because simeon says that it must be composed of one kind. Therefore $\mathrm{C}$ was added to the pericope together with D. E, which, without the attributive formula, restates $C$ as an autonomous rule, was then added to the dispute of C-D.

The issue of the dispute concerns whether or not the quarter$q a b$ of seeds must be lessened even when it consists of more than one kind. According to $\mathrm{C}$ and $\mathrm{E}$ such a quarter-qab must be lessened, presumably because such a quantity of seeds will produce the appearance of diverse-kinds even if the seeds themselves are of different kinds. Simeon, however, disagrees in $D$, maintaining the seeds will produce the appearance of diverse-kinds only when the quarter $q a b$ consists entirely of one kind.

F-G glosses $A-B$, stating that the law of that unit (i.e., that one may not sow a $s e$ 'ah which contains a quarter-qab of another kind of seeds) applies only to mixtures involving grain and/or pulse. G then simply consists of the four possible combinations of the words tbw'h and qtnyt. Feliks explains that the grains involved are probably wheat, barley, two-rowed barley, rice-wheat and spelt (all belonging to the grass family [Graminae]). ${ }^{7}$ Pulse refers to certain plants of the pea family (Papilionaceae). The particular grain and pulse of which $M$. speaks have large seeds which are usually sown close together, so that a relatively high volume of seeds is sown in a given area (or, they are sown at a high rate [= volume/area]). ${ }^{8}$ According to $G$, therefore, the law of A-B applies only when all of the seeds in the mixture are sown at this rate. MR points out that $M$. assumes this rate to be a se'ah per bet se'ah.9

$\mathrm{H}-\mathrm{J}$ concerns the measure in which garden-seeds $(\mathrm{H})$ and flax (I-J) prohibit the sowing of a se'ah. H is connected to $G$ by the phrase $b$ 'mt 'mrw, which, according to Lieberman, 10 should simply read $b^{\prime} m t$. This phrase usually introduces a particular case which does not follow a foregoing general rule. 11 In this instance, then, $H$ is contrasted with $G$, for the law of $A-B$, which applies to grain and pulse, does not apply to garden-seeds, as we shall now see.

H states that garden-seeds which are not eaten combine at one twenty-fourth of the volume sown in a bet se'ah. The gardenseeds referred to here are those seeds which are not produced as the fruits of their plants (e.g., seeds of onions, turnips, etc.; 
cf. M. Macas. 5:8). These seeds are said to combine to form a certain measure. Now the meaning of "combine" in this context is not clear. It is likely that "combine" has the sense of "combine to prohibit," or simply "prohibit" (GRA, cited by Feliks, Mixed Sowing, p. 197).12 H then says that garden-seeds prohibit the sowing of a se'ah at one twenty-fourth of the volume sown in a bet se'ah. Garden-seeds are then distinguished from grain and pulse, which prohibit the sowing of a se'ah at a quarter-qab. $(A+G)$.

Alternatively, the statement may mean that different kinds of garden-seeds combine to prohibit the sowing of a se'ah at the given measure (Maim., Comm., Sirillo, TAS, MR [latter three cited by Feliks, Mixed Sowing, p. 196]). H then refers back to $E$, its point being that while different kinds of grain and pulse ${ }^{13}$ combine to form a quarter-qab, different kinas of garden-seeds combine to form one twenty-fourth of the volume sown in a bet $s e^{\prime} a h$. According to this interpretation $\mathrm{H}$ assumes that the garden-seeds prohibit the sowing of a $s e^{\prime} \alpha h$ when they amount to the latter measure.

In any event, both of the above interpretations of $\mathrm{H}$ agree that garden-seeds prohibit the sowing of a $s e$ tah when they amount to one twenty-fourth of the volume (of garden-seeds) sown in a bet $s e^{\prime a h}$. We must now determine why the law of A-B does not apply to garden-seeds. The reason for this, in my view, is as follows. A apparently assumes that every kind of seed in the $s e ' a h$ is sown at the same rate. It is only under this condition that each kind's proportion of the total volume equals the proportion of area which it will cover. A can then say that a quarter-qab of seeds prohibits the sowing of a selah. For a quarter-qab (= one twenty-fourth of a se'ah) of seeds will cover one twenty-fourth of the area sown, and A apparently determines that this sowing will result in the appearance of diverse-kinds (cf. Maim., Code, Diverse-Kinds 2:7). Now garden-seeds are smaller than grain or pulse (all commentaries) and so are sown at a lower rate (i.e., less volume per area). If garden-seeds are mixed with grain or pulse, their proportion of the total volume will not correspond to the proportion of area which they will cover. For example, a quarter-qab of garden-seeds will cover more than one twenty-fourth of the area sown. The law of A then cannot be applied in this case, for that law does not consider seeds with different rates of sowing.

The law of $\mathrm{H}$, however, does take the garden-seeds" rate of sowing into account. As we have already seen, H says that the measure in which garden-seeds prohibit the sowing of a se'ah 
is one twenty-fourth of the volume sown in a bet se'ah. In other words, a se'ah of grain or pulse may not be sown when there are enough garden-seeds in it to cover one twenty-fourth of the area sown by the se'ah, for then the garden-seeds will produce the appearance of diverse-kinds (as in A). Since the rate of sowing for garden-seeds is less than that for grain or pulse, the amount described in $\mathrm{H}$ is less than a quarter-qab. 14 $\mathrm{H}$ then states that the principle of $\mathrm{A}$ (that the secondary seeds may not cover one twenty-fourth of the area sown) also applies to garden-seeds, only with a different measure.

In I, Simeon glosses $\mathrm{E}$ with the comment that, while the method of calculation used in $\mathrm{H}$ results in a stringent ruling in one case, the same method produces a lenient ruling in another. That is, it takes less than a quarter-qab of garden-seeds to prohibit the sowing of a se'ah of grain or pulse, and this ruling is more stringent than the law of $A$, which says that it takes a full quarter-qab of seeds to do the same. Simeon then states in $\mathrm{J}$ that $\mathrm{flax}$, like garden-seeds, combines (i.e., prohibits) at one twenty-fourth of the volume sown in a bet se'ah. Now although the law for flax is the same as that for garden-seeds, the two kinds of seeds prohibit the sowing of a $s e^{\prime}$ ah in different amounts. Flax-seeds, although they are the same size as garden-seeds, are sown closer together because their plants do not spread out. 15 Therefore flax-seeds are sown at a rate which is not only higher than that of garden-seeds, but higher than that of grain and pulse as well. 16 Consequently, it takes more than a quarter-qab of $\mathrm{flax}$-seeds to prohibit the sowing of a $s e ' a h$. The principle of $\mathrm{A}$, when applied to flax, thus produces a lenient ruling.

A. [Concerning] every se'ah [of one kind of seeds] which contains a quarter [-qab] [Erfurt, first printed ed. add: of seeds] of another kind (mmyn ' hro; first printed ed.: of one kind [mmyn 'ha]) -- he shall lessen Ethe quantity of seeds of the other kinds, so that those seeds form less than a quarter-qab] [= M. $2: 1 \mathrm{~A}]$.

B. Under what circumstances?

C. With seeds [lit.: things] which [are sown at the rate of] three or $(w)$ four qabs per bet se'ah [first printed ed.: per $\left.s e^{\prime} a h\right]$.

D. But (b'mt) [Erfurt adds: they said] garden-seeds combine [to form an amount sufficient to prohibit the sowing of the se'ah when they total] one twenty-fourth of [the volume] which [is sown] according to its own kind (bnwpl Imynw) [= M. 2:2H]. 
E. [And this amount prohibits the sowing of the $s e^{\prime} a h$ ] whether it [i.e., the garden-seeds] fell into other [kinds of seeds] or other [kinds of seeds] fell into it.

$$
\text { T. Kil. } 1: 16 \mathrm{a} \text { (p. 206, 11. 40-43) }
$$

T. cites and glosses M. 2:1-2. A cites M. 2:1A, and B-C states that the law of M. applies to seeds which are sown at the rate of three or four qabs per bet se'ah. T. then qualifies M. 1:la in a way different from the way in which M. explains itself. While M. 2:2F-G states that M. 2:lA concerns particular kinds of seeds (grain or pulse), T. says that the law applies to seeds sown at particular rates. 17

D cites M. $2: 2 \mathrm{H}$, but the two statements differ in that the latter ends with the phrase bnwpl $2 b y t s^{\prime} h$ ("of [the volume] which falls [i.e., is sown] in a bet se'ah"), while the former concludes with bnwp 2 lmynw. According to Feliks bnwp 2 lmynw means "according to the measure in which they are accustomed to sow the given kind," 18 so that both phrases refer to the rate at which garden-seeds are sown. 19

$E$ then comments that the same measure (one twenty-fourth of the volume sown in a bet se'ah) prohibits the sowing of a $s e^{\prime} a h$ both where the garden-seeds are mixed with a larger volume of seeds of other kinds, and where other kinds of seeds are mixed with a larger volume of garden-seeds. E clarifies M. 2:2H, which says only that the law applies to garden-seeds, but does not describe the composition of the relevant mixtures.

$2: 3$

A. [If] his field was sown [with] wheat, and he decided to sow it [with] barley,

B. he shall wait until [the wheat] sprouts radicles $\left(^{c} d \vec{s} t t \imath y^{c}\right.$; $\left.\mathrm{L}: \quad s y t \imath y^{c}\right), 20$

C. and overturn [the soil], and afterwards sow [the barley].

D. If [the wheat] has [already] sprouted [aboveground ${ }^{21}$ ],

E. he should not say, "I shall sow [the barley] and afterwards overturn [the soil];"

F. rather, he overturns [the soil], and afterwards sows [the barley].

G. How much [of the field] should he plow [up] (hwrš; K, L, P; hrys; Geniza fragment, ${ }^{22}$ ox: hhrys ["How much should the plowing be?"])

$\mathrm{H}$. [He should make furrows] like the furrows [= omitted by $\mathrm{N}$ ] [plowed after ${ }^{23}$ ] a rainfall (ktımy $\left.h r b y^{c} h ; C, C n, M n, V: b t \imath_{m y}\right)$. 
I. Abba Saul says, "[He should plow enough] so that he shall not leave [alt. trans.: so that there will not be left] [unplowed the area which is sown by] a quarter[-qab of grain] in a bet se'ah."

M. Kil. $2: 3$

M. Kil. 2:3-4 continues the discussion of sowing diversekinds. While $M$. 1:9E-2:2, however, concerns sowing seeds of diverse-kinds together, M. 2:3-4 deals with sowing one kind of seeds in a field which has already been sown with another kind. In M. 2:3, the owner wishes to sow one kind of grain in a field already sown with a different kind. M. 2:4 then has the owner wishing either to plant vines in a field of vegetables or grain, or to sow grain or vegetables in a field already planted with vines. M. 2:3-4 is probably a unitary composition, for the main protases of both M. $2: 3$ and M. 2:4 (M. 2:3A, M. 2:4A+D) are constructed in a similar way (if his field + passive participle + and he decided + infinitive) and several of the apodoses differ only in their choice of verbs (M. 2:3E-F, M. $2: 4 \mathrm{~B}-\mathrm{C}+\mathrm{E}-\mathrm{F}:$ "He shall not say, 'I shall do $X$ and afterwards do $Y$;' rather, he does $Y$ and afterwards does $X "$ ). We shall discuss $M .2: 3$ and M. $2: 4$ in turn.

M. 2:3 presents two cases, $A-C$ and D-F, which, when supplied with "if," are in declarative sentences. D-F depends on A. G-I then has a dispute between an anonymous opinion and Abba Saul on a secondary issue.

A presents the case of one who wishes to sow barley in a field already sown with wheat. B-C states that, before one may sow the barley, he must first wait for the wheat to sprout radicles (i.e., small roots), and then he must overturn the soil. Following Feliks, we may explain the law of B-C as follows. The point of $\mathrm{M}$. is that in order to avoid sowing diverse-kinds, one must destroy the wheat before sowing the barley. ${ }^{24}$ Now one can only destroy the wheat if he overturns the soil after the wheat sprouts radicles. For if he were to overturn the soil before the wheat sprouted radicles, the seed would simply begin to grow wherever it came to rest. Once the radicles sprout, however, the seeds are attached to the soil and are nourished by it. Therefore when the soil is overturned, the seeds are cut off from their source of nourishment and consequently die. ${ }^{25}$ By overturning the soil after the radicles sprout, one destroys the previously-sown wheat, and one may sow the barley without being liable for sowing diverse-kinds. 26 
D-F differs from $\mathrm{A}-\mathrm{C}$ only in that now the wheat has already sprouted aboveground. E-F states that one may not say that he will sow the barley before overturning the soil, but he must still overturn the soil first, as in A-C. According to TYT one may reason that since the wheat is now visible, he will be able to destroy all of it at any time. He may then wish to sow the barley first, and overturn the soil later when he covers the grains of barley. Therefore the point of $M$. is that even when one may be certain that he can destroy all of the wheat, he must still overturn the soil before sowing. For otherwise he would actually be sowing barley in a wheatfield, and so would be liable for sowing diverse-kinds.

G asks how much of the field must be plowed up, and so introduces a secondary issue into the pericope. H presents a dispute in response to $\mathrm{G}$. H states that when one plows up his field, he must make furrows like those which are made after a rainfall. These particular furrows are wide and deep, for they are made to hold rain water. More importantly, these furrows do not lie right next to each other. Between every two furrows there is an area of unplowed land, upon which dirt is piled to prevent erosion. 27 The point of $\mathrm{H}$ is that when one plows his field, he need not make the furrows right next to one another, even though the wheat will remain in the unplowed areas and may still grow (cf. Maim., Code, Diverse-Kinds 2:13). Y. explains that by sowing in this manner one indicates that he does not want the wheat which he had previously sown in the field, and so he need not plow up the entire field. ${ }^{28}$

In I Abba Saul says that one must plow up enough of the field so that less than one twenty-fourth of the area sown by a quarter-qab remains unplowed in a bet $s e^{\prime} a h$. If we assume that grain is sown at the rate of a se'ah per bet se'ah (cf. M. 2:1-2), then Abba Saul says that one may not leave one twenty-fourth or more of a bet se'ah unplowed. ${ }^{29}$ Abba Saul apparently reasons that if the previously-sown wheat were to grow in a one twentyfourth of a bet se'ah, the field would appear to be sown with diverse-kinds (as in M. 2:1-2). Abba Saul differs with $H$ in that he requires a fixed proportion of the land to be plowed, while $\mathrm{H}$ presumably requires only that the furrows cover most of the land. It appears, though, that $\mathrm{H}$ and $I$ are not really in dispute at all, for their answers to $G$ are phrased in entirely different terms. H speaks of a type of furrow, while Abba saul discusses a proportion of land. It is likely, therefore, that $H$ and $I$ are two autonomous statements which have been redacted together to form a dispute (see $\mathrm{T}$. below). 
F. [If] his field was sown [with] wheat, and he decided to sow it [with] barley [= M. 2:3A],

G. he shall not sow [the barley] until he overturns [the soil; HD: the wheat-grains].

H. [If] he did not overturn [the soil; HD: the wheat-grains],

I. he shall wait until [the wheat] sprouts radicles [= M. 2:3B].

J. How long [does it take] until $\left({ }^{c} d k m h\right)$ it [i.e., the wheat] sprouts radicles $\left(m t \tau^{c} t\right.$; Y.: $\left.m z x^{c} t^{30}\right)$ ?

K. [The wheat does not sprout radicles] until it has stayed ( $\breve{h} t$; first printed ed.: yšhh) in the place [Y.: in the earth] for three days [Erfurt: [Not] until three days];

L. [that is, when the wheat is sown] in a moist place (mqwm htynh), but not in a dry place (mqum hgryd);

M. for ( $\zeta)$ part of the day [is considered] like a whole [day] [i.e., one may assume that the wheat has already sprouted radicles by the third day itself].

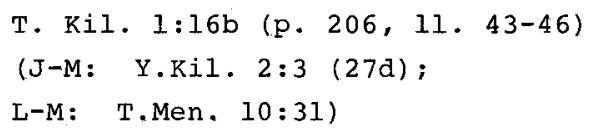

N. They do not require him to plow a fine plowing (hry $\breve{s} d q$ ) [i.e., to make narrow furrows], but rather (' 2 ') he plows [= omitted by first printed ed.] a coarse plowing ${ }^{31}$ (hrys gs) [i.e., he makes wide furrows] [Erfurt: but rather a coarse (plowing)] like [the plowing of] the furrows [after] a rainfall [Y.: They do not require (him) to plow finely (Zhywt $h w r \breve{s} d q$ ), only (to make furrows) like the furrows (plowed after) a rainfall].

o. Rabban Simeon b. Gamaliel says, "[The appearance of the furrows which are plowed after a rainfall] was called 'the horse's tail[-end],' [for] the end [of the mound] of dirt this [furrow] touches the [mound of] dirt of that [i.e., the next] [furrow] [First printed ed.: the end (of the mound) of dirt touches the (mound of) dirt of that (furrow); Y.: so that the end (of the mound) of dirt of this (furrow) touches that (furrow), and the end (of the mound) of dirt of that (furrow) touches this (furrow)].

P. If [the wheat] has [already] sprouted [aboveground] [=M. 2:3D], and he brought an animal down into [= omitted by Erfurt] [the field], and [the animal] plucked out (wlyqttw; Erfurt: wlyqth; Y.: wqyrtmth) [the wheat], 10, this is permitted 
[i.e., one is then allowed to sow without overturning the soil].

T. Kil, $1: 17$ (pp. 206-207, 11. 46-49)

(Y. Kil. $2: 3$ (27d))

T. Kil. $1: 16 \mathrm{~b}-17$ concerns issues similar to those raised by M. 2:3. We shall postpone a consideration of T.'s relationship to $M$. until after we have discussed each section of $T$. T. consists of four subunits, F-G, presenting the case of one who wishes to sow barley in a field already sown with wheat, J-M and $\mathrm{N}-\mathrm{O}$, which discuss secondary issues, and $\mathrm{P}$, which, reverting to $A-D$, deals with a case in which the wheat has already grown aboveground.

F-I consists of two cases, $F-G$ and $H-I$, with the former citing and glossing $M .2: 3 \mathrm{~A}$ and the latter citing and glossing M. 2:3B. According to T., therefore, M. 2:3B supplies the apodosis not to M. 2:3A, but to a different case. F-G states that if one wishes to sow barley in a field already sown with wheat, he first overturns the soil and then sows. It is only if he did not overturn the soil, and the wheat has (presumably) started to grow, that he must wait for the seeds to sprout radicles, overturn them, and then sow the barley (H-I). This interpretation of $T$. is difficult, however, for it is not evident how overturning the wheat before the radicles sprout would in any way destroy it. Furthermore, if the overturning of the soil is supposed to be effective even before the radicles sprout, why should one wait for them to sprout at all? It is not at all clear how T. understands the procedure discussed in $M$.

Since the above interpretation, which follows the plain sense of the text, presents certain difficulties, we must turn to a different explanation of the pericope. We shall here offer the views of HD. According to the latter $B$ does not refer to the overturning of soil, for such an action is effective only when the wheat has already sprouted radicles. Rather, T. means that one overturns (i.e., shakes) the seeds themselves until they are destroyed and can no longer grow. ${ }^{32}$ It is only once the wheat is destroyed that one is allowed to sow the barley. H-I then presents the law of M. 2:3B. If one did not overturn the seeds he waits for the wheat to sprout radicles, overturns the soil, and sows. According to this interpretation T. supplements M. by presenting a case in which one may sow the barley without waiting for the radicles to grow.

$J-M$ refers to $D$, and concerns how long it takes for wheat to sprout radicles. J states the question, $K$ responds, and 
L-M glosses $K$. We note that $H$ begins with "for" ( $\zeta)$, which makes no sense in this context. Lieberman ${ }^{33}$ points out that L-M also appears in T. Men. 10:31, where $\breve{s}$ is appropriate. Therefore L-M may be primary to $T$. Men.

$J-K$ states that it takes three days for wheat to sprout radicles. This statement is botanically sound, for wheat begins to germinate within a three-day period, and the radicles are the first parts to emerge from the seed. ${ }^{34} \mathrm{~L}$ adds that this is true only where the seed is sown in a moist place, for in a dry place it presumably takes longer. I's point stands to reason, for the seed must imbibe water before it begins to germinate. ${ }^{35}$ Therefore a seed sprouts radicles faster if it is sown in wet ground. ${ }^{36}$ M introduces a separate issue, stating that part of the day is considered like a whole day. In this context, the point of $M$ is that one may assume that the wheat sprouts radicles by the third day itself, and therefore, one may sow the barley on that very day.

$\mathrm{N}-\mathrm{O}$ discusses the method of plowing which is used in overturning the soil. I states that one does not have to plow finely when overturning the soil, for one may make a coarse plowing like that which is plowed after a rainfall. This means that one need not carefully make smooth narrow furrows throughout the field. Rather, one may plow quickly and make wide furrows even though he will not overturn all of the soil in the field. In $O$, Simeon b. Gamaliel glosses this rule, saying that the appearance of the furrows described in $\mathrm{N}$ was called "the horse's tail[-end]," for one furrow's mound of dirt touched that of the next furrow. That is, the two mounds of dirt, when viewed in cross-section, resemble the backside of a horse.

We shall now compare $T$. N with $M$. 2:3G-I:

$$
\text { M. } 2: 3 G-I
$$

1. How much [of the field] should he plow [up]?

2. [He should make furrows] like the furrows [plowed after] a rainfall (ktImy hrbych).

\section{T. $1: 17 N$}

1 .

2. They do not require him to plow a fine plowing, but rather he plows a coarse plowing like [the plowing of] the furrows [after] a rainfall (kt lmy $h r b y^{c} h$ ). 

3. Abba Saul says, "[He shall plow enough] so that he does not leave [unplowed the area which is sown by] a quarter [-qab] of grain] in a bet se'ah.

M. and $T$. both say in (2) that one plows furrows like those which are plowed after a rainfall, but each places this law in a different context. M. presents the law as concerning how much of a field one must plow up, while T. mentions it in reference to methods of plowing. It is clear that $T$. has the law in the more appropriate context, for the phrase $k t l m y$ $h x b y{ }^{c} h$ describes a type of furrow, and does not deal with an amount of land (as, for example, (3) does). T. therefore clarifies M., for it explains the type of plowing to which ktlmy $h r b y^{c} h$ refers.

$P$ cites M. 2:3D, and concerns a case in which the wheat has already sprouted aboveground. $P$ states that if one brings an animal into his field to pluck out the wheat, he may afterwards sow the barley. The point of $\mathrm{P}$ is that by bringing an animal into the field, one shows that he does not want the wheat which grows there. ${ }^{37}$ Therefore one may afterwards sow the barley without being liable for sowing diverse-kinds. 38

Let us now review the relationship of $T$. to $M$. F cites M. 2:3A (the protasis of the case), which G-H then supplements. I cites M. $2: 3 \mathrm{~B}$ and depends on $M .2: 3 \mathrm{C}$, for the citation of $B$ alone is meaningless. N clarifies M, 2:3H (ktlmy $\left.h r b y^{c} h\right)$, and $P$ cites and supplements $M .2: 3 D$. T. thus provides a running commentary to $M$. while at the same time slightly rearranging the order of its topics, placing the discussion of the furrows $(\mathrm{N}, \mathrm{M} .2: 3 \mathrm{H})$ before that of the wheat growing aboveground $(P$, M. $2: 3 \mathrm{D}-\mathrm{F})$.

\section{$2: 4$}

A. [If his field] was sown [with vegetables or grain] and he decided to plant it [with vines ${ }^{39}$ ],

B. he shall not say, "I shall plant and afterwards overturn [the soil];"

C. rather, he overturns [the soil] and afterwards plants.

D. [If his field] was planted [with vines] and he decided to sow it [with vegetables or grain],

E. he shall not say, "I shall sow and afterwards uproot [the vines]; 
F. rather, he uproots [the vines] and afterwards sows.

G. If he wanted (rșh; K: rwṣh) [however, to sow first (PM)], he cuts (gwmm; K: gwms; Mn: gyms) [the vines] until they are less than a handbreadth [high], and sows, and afterwards uproots [the vines].

\section{Kil. $2: 4$}

M. Kil. 2:4 concerns the planting of a field which is already sown and the sowing of a field which is already planted. M. may be divided into three parts, $A-C, D-F$, and $G . A-C$ and $D-F$ present two cases in perfectly balanced declarative sentences. The two protases ( $A$ and $D$ ) are identical except for the reversal of $n t^{c}$ and $z r^{c}$. The apodoses both follow the same pattern (as given above), so that $B-C$ balances $E-F$. Furthermore, each apodosis consists of two clauses which balance each other. The second clause of each apodosis ( $C$ and $F$ ) simply reverses the verb-order of the first ( $B$ and $E$ ). G glosses $D-F$ and presents an additional case in a simple declarative sentence.

A-C states that if one wishes to plant a field which is already sown, he first overturns the soil and then plants. The point of $\mathrm{A}-\mathrm{C}$ is that one first overturns the soil and thereby destroys the seeds which are alreddy in the ground, 40 and then plants without being liable for planting diverse-kinds (as in M. 2:3). M. then implies that one may not both plant and sow in the same field. Now $M$. is not clear as to what is being planted in this case. While "sowing" ( $\left.2 r y^{c} h\right)$ may be understood to refer to vegetables or grain, "planting" $\left(n t y^{c} h\right)$ may refer to either trees or grapevines. If $M$. refers to the planting of trees, then M. opposes T. 1:15C, which says that one is permitted to sow tree-seeds together with other kinds of seeds. It is perhaps more probable, therefore, that $M$. refers to the planting of grapevines (most commentaries), as scripture prohibits the sowing of other kinds of seeds in a vineyard (Dt. 22:9). We have interpolated into our translation accordingly.

In $\mathrm{D}-\mathrm{F}$, the circumstances of $\mathrm{A}-\mathrm{C}$ are reversed, so that now one wishes to sow a field which is already planted. E-F states that one first uproots the vines and then sows. The law of D-F is then the same as that of $\mathrm{A}-\mathrm{C}$, for in both cases one must remove whatever is already in the soil before adding the new seeds.

$G$ presents an alternative to $E-F$. If one wishes to sow before uprooting the vines, ${ }^{41}$ he must first cut the vines down to a height of less than a handbreadth. He may then sow, for the vines are no longer easily visible, and there is no appearance of 
sowing diverse-kinds (MR). 42 Later, of course, the vines must be uprooted. 43

A. [If his field] was planted [with vines $\left.{ }^{44}\right]$ and he decided to sow it [with vegetables or grain],

he diminishes (mgryc; Erfurt: $m g r^{c}$; First printed ed.: mgbyh ${ }^{45}$, [the vines] until [they are] less than a handbreadth [high], sows, and afterwards uproots [the vines] [= M. 2:4D+G].

c. [If] he diminishes ( $g w r^{c}$; sirillo: $g r^{c 46}$ ) [the vines] until [they are] less than a handbreadth [high],

D. and [later] he came and found its leaves ( ${ }^{c} z y w ;$ First printed ed.: ${ }^{c}(y n)$ [growing] on top of grain,

E. [the benefit of the vines and the grain] is permitted for [vines which have already grown on top of grain in] the past ( $2 \breve{s}^{c} b r$; omitted by Vienna ${ }^{47}$ ), but [such benefit] is prohibited for [vines which will grow on top of grain in] the future $\left(z^{c} t y d z b^{\prime}\right.$; Erfurt: $\left.l^{c} t y d\right)$ [i.e., one may benefit from diverse-kinds which have already grown together, but once one sees the diverse-kinds growing together he may not allow them to continue to grow in this manner];

F. [rather], he uproots whichever of them (mhn; Erfurt: myn ["which-ever kind"] he wishes [to uproot], and sustains whichever of them he wishes [to sustain].

$$
\begin{aligned}
& \text { T. Kil. } 1: 18 \text { (p. 207, 11. 49-52) } \\
& \text { (E: Y. Kil. } 2: 4 \text { (27a)) }
\end{aligned}
$$

T. Kil. $1: 18$ comments on M. 2:4. T. A-B cites M. D+G (differing only in having the verb $\mathrm{mgry}^{c}$ for $g w m m$ ), which T. C-F then supplements with a related case. We note that C-D+F form a simple declarative sentence which is interrupted by $\mathrm{E}$, for the subject of $\mathrm{E}$ (understood as "the benefit of the vines and the grain") is not that of the sentence (the "one who diminishes the vines" in C). It appears, then, that E glosses C-D+F.

$\mathrm{C}-\mathrm{F}$ describes an instance in which diverse-kinds grow between the time that one sows and the time that one uproots the vines in the case of M. 2:4G. In C-D one diminishes the height of the vines to less than a handbreadth and then sows. Later he finds that the leaves of the vines have begun to grow over the plants which were just sown. F states that one uproots whichever kind he wishes to uproot, and sustains what is left. The point of $F$, then, is that one need not uproot the vines, even though his original intention was to do so. Rather, he may 
change his mind and uproot those plants which he has just sown. $E$ then adds that one may benefit from those vines and plants which are growing together as diverse-kinds at the time that he finds them, ${ }^{48}$ but not from any diverse-kinds which may grow afterwards. PM explains that since one does nothing wrong by sowing while the vines are still in the ground, he may benefit from the vines and plants which are growing together when he finds them. Once, however, he notices the diverse-kinds he may not allow them to continue to grow, for then he would be sustaining diverse-kinds (prohibited by T. $1: 15$, M. $8: 1$ ).

\section{$2: 5$}

A. [If] his field was sown with carum lqnbws; Geniza fragment [margin], K [after correction], L, Mn, N, P, V: qnbs; B, C, Cn, Geniza fragment, 49 K [before correction], O, Pr, Maim., Comm.: qrbs), 50 or arum, 51

B. He should not ( $\left.l^{\prime} y h^{\prime}\right)$ sow $\left(z w r^{c} w b^{\prime}\right)$ on top of them,

C. for [B, Cn, Geniza fragments, O, Maim., Comm.: even though] they produce [fruit] only [after] three years

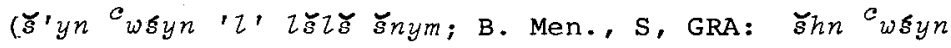

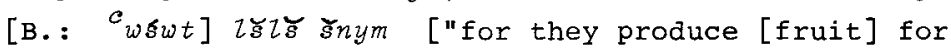
three years"]).

D. (1) Grain among which [Geniza fragment: with which] aftergrowths of woad 52 came up,

(2) and so the threshing-floors [lit.: the place of the threshing-floors] in which many kinds came up,

(3) and so fenugreek ${ }^{53}$ which brought up ( $\breve{s}^{c} \imath_{t}$; Geniza fragment: $\breve{s}^{c} \eta_{t}{ }^{C} m$; B. B. Q.: $\breve{s}^{c} \eta_{t h}{ }^{c}$ ["which came up with"]; Mn and all mss, of B. B. Q.: $\vec{s}^{c}(t)$ [different] kinds of plants (g̣mym; most mss.: cşbym ["grasses"]) --

E. they do not require him to weed ( $2 n k \xi ;$ B. B. $Q . l^{c} q w r["$ to uproot"]).

F. [But] if he weeded or cut down [some of them (Maim.)], they say to him, "Uproot everything, except for one kind."

$$
\begin{aligned}
& \text { M. Kil. } 2: 5 \text { (A-C: B. Men. 15b } \\
& \text { [in printed ed. on } 1 \mathrm{Y}] ; \text { D (3)-E: } \\
& \text { Y. Kil. } 2: 5 \text { (27d), B. B.Q. } 81 \mathrm{a}, \\
& \text { Y. B.B. } 5: 1 \text { (15a)) }
\end{aligned}
$$

M. Kil. 2:5 continues the discussion of M. 2:3-4, presenting another case in which one wishes to sow one kind of seeds in a field which is already sown with another kind. M. 2:5 is divided into two autonomous parts, $\mathrm{A}-\mathrm{C}$ and $\mathrm{D}-\mathrm{F}$. $\mathrm{A}-\mathrm{C}$ discusses the case 
of one who wishes to sow something in a field already sown with carum or arum. D-F concerns the problem of uncultivated plants which come up and, with or without cultivated plants, produce the appearance of diverse-kinds.

A-C forms a simple declarative sentence. The law of A-C states that one may not sow a field which is already sown with carum or arum, for these plants produce fruit only after three years. In other words, carum and arum do not produce fruit for three years, so that if one were to sow on top of them, no appearance of diverse-kinds would result. Even so, the seeds are still in the ground during the three-year period, and therefore one who sows on top of them is liable for sowing diversekinds. Now this reading of $\mathrm{C}$ ("for they produce [fruit] only [after] three years") is difficult, for while it may be the case that arum produces fruit only after three years, 54 carum produces fruit no later than two years after it is sown. 55 we therefore prefer the alternate version of $\mathrm{C}$, which reads "for they produce [fruit] for three years." Accordingly, the point of M. is that both carum and arum produce fruit for several years after they are sown. Therefore, if the plants are not visible at any time within this period, one may not simply assume that they have died. On the contrary, one must assume that they will sprout again, and therefore one may not sow on top of them.

$D-E$, with the order of $D$ and $E$ reversed, forms a declarative sentence. $D-F$ concerns plants which grow wild and produce an appearance of diverse-kinds. D lists three instances in which such plants may come up. In D(I) aftergrowths of woad, growing from seeds or roots which are left behind in the ground, ${ }^{56}$ spring up alongside of grain. In $D(2)$ seeds which are dropped on the threshing-floor sprout by themselves, and $D(3)$ has wild grass coming up together with fenugreek. According to $E$ one does not have to weed out the wild plants. Maimonides (Code, Diverse-Kinds 2:8-9) explains that since these plants are not cultivated, and since it is known that the owner does not want them (and will eventually have to pull them out anyway [Sens]), 57 the owner may allow them to grow and he will not appear to allow diverse-kinds to grow. F states that if one does begin to weed out or cut down the wild plants, he must remove all but one kind. According to Maimonides (Code, Divexse-Kinds 2:10) one who pulls out only some of the surrounding plants implicitly indicates that he wishes the remaining plants to continue to grow. In effect, then, by leaving the plants in the ground, one allows diverse-kinds to grow. If one uproots any plants at all, therefore, he must continue to uproot until there is no longer any appearance of diverse-kinds. 


\begin{abstract}
A. [Concerning] a field in which grasses came up --
B. they do not require him to overturn [the soil before sowing];

C. rather, he plows when he covers over $\left(b \breve{s}^{c} h \Xi_{m} h p h\right.$; Erfurt: $\left.k \breve{s}^{c} t h p k h\right)$ [the seeds], and [thus] overturns [the soil].
\end{abstract}

$$
\text { T. Kil. 1:19a (p. 207, 11. 52-53) }
$$

T. Kil. 1:19a supplements M. 2:5D-E, for both pericopae concern wild plants which come up in a field of crops. A-C, with the order of $A-B$ reversed, forms a declarative sentence.

A-C states that if wild grasses grow in a field, one need not overturn the soil (and so destroy the grasses) before sowing. Rather, one first sows, and then plows the grasses in while covering the seeds, The point of $T$, is then the same as that of M. ${ }^{58}$ since it is known that one who sows does not want the wild grasses and will eventually have to pull them out, one may sow while the grasses still grow without appearing to sow diversekinds, We note that $T$. is a good supplement to M., for the latter speaks of wild plants which come up after sowing, while $T$. concerns grasses which grow before sowing takes place.

D. He removes thorns (mkbkb; Erfurt: mkrkyb) and removes the large [plant ${ }^{59}$ ] from before the workers, and this [action] is not considered "cutting" ( $w^{\prime} y n$ bzh $m \breve{s}^{\prime} m m k s h$; Lieberman 60 prefers the reading of the First printed ed,: mksh) [i.e., even though he removes thorns and large plants, this does not mean that he must remove all of the wild plants].

$$
\text { T. Kil, } 1: 19 b \text { (p. 207, 11. 53-54) }
$$

T. Kil. $1: 19 \mathrm{~b}$ comments on M. 2:5F. M. states that one who begins to remove wild plants from among cultivated ones must pull out every kind of plant but one. For if one were to pull out only some of the plants, it would appear as if he wanted the remaining plants to continue to grow, and so he would appear to be allowing diverse-kinds to grow. T. then comments that one may remove thorns or large plants from before the workers (in order to clear a path for the plow ${ }^{61}$, , and such an action is not considered "cutting." That is, one who removes only some of the thorns or wild plants need not uproot every kind of plant but one. The point of T., then, is that one who clears away some of the plants for a specific purpose, does not appear to be allowing 
diverse-kinds to grow, and so does not have to uproot all but one kind of plant.

\section{$2: 6$}

A. He who wishes to lay out [so Danby for $l^{c} \xi w t$ ] his field [in] narrow beds ( $\left.m \breve{s} r m \breve{s}_{r}\right)$ [Mn omits:] of every kind [i.e., with each bed containing a different kind] --

B. The House of Shammai say, "[He makes the beds as wide as the width of] three furrows of 'opening' ( $\breve{s}$ ptyh) [i.e., furrows plowed for the purpose of "opening" the field in order to collect rainwater ${ }^{62}$ ]."

c. And the House of Hillel say, "[He makes the beds as wide as] the width [so Danby for $m l^{\prime}$ ] of the Sharon yoke."

D. and the words of these [i.e., one House] are near the words of those [i.e., the other House] [i.e., there is little difference between the two measurements].

M. Kil. $2: 6$

M. Kil. 2:6 concerns the planting of different kinds of plants in the same field. A-C presents a Houses-dispute, the opinions of which are neither balanced nor mnemonically formulated ( $\breve{s} \breve{s} h$ tlmym $\breve{s}$ ptyh vs. $m l, h^{c} w l$ h̆swny). D glosses A-C.

A presents the case of one who wishes to lay out his field in narrow beds, ${ }^{63}$ with each bed containing a different kind of seed. In $B-C$ the Houses dispute a measurement which is involved in the case of $A$. We are not told, however, what is being measured. The commentaries offer two explanations. According to several commentaries (Sens [who presents both interpretations], R. Yehosaf Ashkenazi [cited by MS], Sirillo [cited by Feliks $\left.{ }^{64}\right]$, GRA, Lieberman ${ }^{65}$ ) M. presupposes that one may lay out his field in beds containing different kinds only if the beds are of a certain minimum size. In this way, each bed is considered a field unto itself, and the different kinds are easily distinguished from one another. Different kinds may then grow in the same field without producing the appearance of diverse-kinds. The dispute of $\mathrm{M}$. then concerns the minimum width which a bed must have in order to be considered an autonomous field. ${ }^{66}$ Alternatively, most commentaries (e.g., Maim., Comm., TYY, MR) understand M. to assume that the beds of A must be separated from one another in order to prevent the appearance of diverse-kinds. The Houses then dispute concerning the distance by which the beds must be separated. We note, however, that $M$. nowhere states that beds (or similar areas of land) of different 
kinds must be separated from one another. 67 We therefore regard this latter interpretation to be less plausible than the former.

The actual measurements of $\mathrm{B}-\mathrm{C}$ may be explained as follows (following Feliks ${ }^{68}$ ). The House of shammai say that the beds must be as wide as the width of three furrows of "opening." The furrows of "opening" are plowed after the spring harvest in order to loosen the soil and "open" the ground to collect rainwater. These furrows do not lie immediately next to one another, but are separated by a short distance. The House of Hillel say that the width of the beds must equal that of the Sharon yoke. This yoke is made for a single animal (and so is narrower than the average yoke), for it is necessary to use only one animal to plow the soft soil of the Sharon plain. We see, then, that the Houses describe the measure of the width of the beds in completely different terms.

D states that the words of the two Houses are nearly the same. That is, the breadth of the three furrows of "opening" is approximately equal to the width of the sharon yoke. 69 According to $D$, then, the Houses do not dispute at all, but only present the same ruling in different language. 70

A. He who wants to lay out his field [= M. 2:6A] [in] rows of grain and rows of many [different] kinds [of plants] --

B. He makes three open furrows ${ }^{71}$ ( $t \imath_{\text {mym }}$ mpwlsyn) [extending] from the beginning of the field to its ends.

C. R. Leazar b, R. Simeon and Abba Yosé b. Hanan of Vani (w'ny; Erfurt: $y$ 'ny; First printed ed.: ywny) say, "It is sufficient for them (dyn; Erfurt: $d y w$ ) [to measure] fifty amot in length."

D. How much is its width $\left(r h b w\right.$; Lieberman ${ }^{72}$ corrects to $r h b n$, ["their width," $i, e .$, the width of the furrows considered collectively]) [GRA: wrwhb ("and of a width [of]")]?

E. The width (mIw') of the sharon yoke $[=\mathrm{M}, 2: 6 \mathrm{C}]$, which resembles the yoke of the vineyards.

F. Its beginning [i.e., the width at the beginning of the furrows] is of this measure, even though its end [i.e., the width at the end of the furrows] is not of this measure.

T. Kil. 2:la (pp, 207-208, 11. 1-5)

(C: T. Kil. $2: 4, Y, K i l .2: 6$

$(28 a))^{73}$ 
T. Kil. 2:la comments on M, 2:6. We shall consider T.'s relationship to $M$. after our discussion of the substance of $T$. A serves as a topic-sentence for the pericope. B states a law in a declarative sentence, which Leazar $b$. Simeon and Abba Yosé b. Hanan then gloss in $C$. $D-E$ depends on $A-B$ and introduces $a$ secondary issue. F glosses $\mathrm{E}$.

Citing the language of M. 2:6A, A presents the case of one who wishes to plant rows of both grain and different kinds of plants in his field. According to $B$ he must plow, presumably for each kind, three furrows across the entire length of the field. ${ }^{74}$ The point of $T$. is that these rows must extend across the entire length of the field, in order to appear as an autonomous field. ${ }^{75}$ In $C$ Leazar b. Simeon and Abba Yose b. Hanan say that the furrows need extend for only fifty amot. 76 These authorities apparently reason (in this context) that furrows of this length form autonomous fields, so that the furrows need not extend over the entire length of the field. ${ }^{77}$

$D-E$ concerns the width of the furrows described in B. E, apparently referring to the collective width of the three furrows, 78 states that this width must be equal to the width of the sharon yoke [= opinion of House of Hillel, M, 2:6C], which is similar to the yoke of the vineyards. Feliks ${ }^{79}$ points out that both yokes are narrow and made for one animal. The point of $\mathbf{E}$ is that the furrows must be of a specific width. F, however, states that the three furrows must be as wide as the width of the Sharon yoke only at their starting-points. As the furrows traverse the field, though, this breadth may narrow. According to $F$, then, it is necessary for the rows to be of a certain width only at their beginnings in order to prevent the appearance of diverse-kinds.

Let us now compare T. to M. 2:6:

$$
\text { M. Kiz. 2:6 }
$$

1. He who wants to lay out his field [in] narrow beds of every kind --

2. The House of Shammai say, "[He makes the beds as wide as the width of] three furrows of 'opening' ( $\breve{s} l p t y h)$."
T. KiZ. $2: 1 a$

1. He who wants to lay out his field [in] rows of grain and rows of many [different] kinds [of plants]--

2. He makes three open furrows (mpwisym) from the beginning of the field to its end. 
3.

4.

5. And the House of Hillel

say, "[He makes the beds as wide as] the width of the sharon yoke."

6.

7. And the words of these [i.e., one House] are near the words of those [i.e., the other House].
3. R. Leazar b. R. Simeon and Abba Yose b. Hanan of Vani say, "It is sufficient for them [to measure] fifty amot in length."

4. How much is its width?

5. The width of the sharon yoke, which resembles the yoke of the vineyards.

6. Its beginnings [i.e., at their beginnings, the furrows are] of this measure, even though its end Ei.e., at their ends, the furrows are] not of this measure .

7.

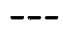

We note that T. explains M.'s protasis in (1), for T.'s phrase "rows of grain and rows of many [different] kinds [of plants]" spells out M.'s "narrow beds of every kind." The more interesting difference between $M$. and T. occurs at (2)-(5). M. contains a Houses-dispute which apparently concerns the width of the rows of different kinds. T. has neither the attributions to the Houses nor a dispute, but it does know the measurements of $M$. While House of Shammai, for example, state that the width of the beds must be that of three furrows, T, rules that each kind must actually be sown in three open furrows (2). Referring to the view of the House of Hillel, T. then states that the combined width of these furrows must be equal to that of a sharon yoke, or the yoke of the vineyards. According to T., then, each kind must be planted in three furrows, the total width of which must be a sharon yoke. By setting the width of three furrows equal to that of the Sharon yoke, $T$. describes an arrangement which illustrates M.'s statement (7) that "the words of these are near to the words of those." 
A. [If] the point of the angle of the field [so Danby for rw "(If) there was a point of an angle of the field of wheat, and it entered"]) into [a field ${ }^{81}$ ] of barley.

B. it is permitted [to grow the wheat in the field of barley];

C. for it [i.e., the point of the angle of the wheat-field] looks like the end of his field (kswp sdhw; B, Geniza fragment, ${ }^{82} \mathrm{~K}$ (before correction), $\mathrm{L}, \mathrm{Mn}, \mathrm{N}$ : bswp sdhw ["for it appears at the end of his field"]) [of wheat].

D. [If] his [field] was [sown with] wheat, and his neighbor's [field] was [sown with] another kind,

E. it is permitted to $f l_{a n k}{ }^{83}$ (lsmwk) it [i.e., his neighbor's field (Maim., Comm.)] [with some] of the same kind [as that of his neighbor's field].

F. [If] his [field] was [sown with] wheat, and his neighbor's [field] was [also sown with] wheat,

G. it is permitted to flank it [i.e., his field] [with] a furrow of flax, but not (wl'; C: 'w ["or"]; cf. MS) [with] a furrow of another kind.

H. R. Simeon says, "It is all the same whether [a furrow of] flax-seeds or [a furrow of] any kind [flanks the field]."

I. R. Yose says, "Even ('p; omitted in $\mathrm{K}^{84}$ ) in the middle of his field it is permitted to test [the suitability of the soil for growing flax] with a furrow ( $2 b d w k b t 2 m ; c$ : $2 s m w k$ tIm ["to flank (the field with) a furrow"] of flax.

M. Kil. 2:7

M. 2:7 concerns the appearances of diverse-kinds which occur when two fields adjoin one another. M. is divided into two large units. A-C discusses a case in which the crops of one field are sown in the other. In $\mathrm{D}-\mathrm{H}$ the two fields are owned by different men, and the issue concerns what may be sown at the common border of the fields. Yose's saying in $I$ is then attached to $\mathrm{F}-\mathrm{H}$ because it deals with a related issue.

$A-B$ is phrased in a declarative sentence (with "if" supplied). C glosses A-B. A describes a case in which a rws twr of wheat enters an adjacent field of barley. rw $t w r$ is a technical term for a triangular or wedge-shaped area, for this is how the expression is commonly understood 85 in the context of $M$. Kel. $18: 2 .{ }^{86}$ A then concerns a triangular area of wheat which enters a field of barley (Maim., Comm., Rosh, ${ }^{87}$ MS; fig. $1^{88}$ ). ${ }^{89}$ 
Alternatively, rw twr may refer to a row of wheat which enters the barley-field diagonally (following the usage of rws twr in B. Suk. $7 \mathrm{a}^{90}$ [as explained by Rashi, ad. Zoc.]; Ribmaș [fig. $2^{91}$ ], Sirkes). ${ }^{92}$ B then rules that one may allow the rws twr to grow in the neighboring field, even though wheat and barley are considered diverse-kinds with one another. C explains that the wheat does not appear to grow in the field of barley at all. Rather, the rws twr appears to mark the end of the field of wheat, 93 and so may be seen as belonging to that field, even though it actually lies in the space of the barley-field (cf. TYT). According to $c$, then, one may permit the wheat to grow in the field of barley because there is no appearance of diverse-kinds.

D-I consists of two cases, D-E and F-I, both of which are presented in declarative sentences (with "if" supplied). The two protases balance one another (wheat + another kind vs. wheat + wheat). In D-E one man's wheat-field adjoins his neighbor's field, which is sown with another kind. According to $E$ the owner of the wheat-field may sow his neighbor's kind at the edge of his own field (fig. 3). The point of D-E is then the sane as that of A-C. Even though the plants of the neighbor's kind actually grow among the wheat, these plants appear to maxk the end of the neighbor's field, so that there is no appearance of diverse-kinds (Maim., Comm., Sens, Bert., TYY). Maimonides (Code, Diverse-Kinds 3:16) explains the law as follows:

\footnotetext{
Under what circumstances does one require distancing (hrhqh) [between plants of diverse-kinds] or something which separates [the diverse-kinds from one another]? When one has sown diverse-kinds in his [own] field, But if his [own] field was sown with wheat, his neighbor is permitted to sow barley next to [the wheat]; for [Scripture] says, You shatl not sow your field [with] diverse-kinds (Lv. 19:19); the prohibition is only that he [not] sow his [own] field with diverse-kinds, for [Scripture] does not say, "You shall not sow the land [with] diverse-kinds." And not only this, but even if he sowed barley in his field next to the wheat, and the barley-grains extended [further] ( $m \widetilde{s} k)$ until they flanked his neighbor's field, which was sown with barley, 1o, this is permitted, for the barley-seeds in his field appeared [to mark] the end of the neighbor's field.
}

F describes a case in which two men own adjacent fields of wheat. The question now becomes what may be sown at the common border of the fields without producing the appearance of diverse- 
kinds. G states that one may sow a furrow of flax at the common edge, and that no other kind may be sown there. A furrow of flax may be placed as a border to the fields because it is known that the owner would not sow a single furrow for the flax itself (for the yield would be too small). Rather, it is assumed that the owner wishes only to test the suitability of the soil for growing flax, and so there is no appearance of diverse-kinds. The same may not be said of other kinds, however, for the owner could sow a furrow of another kind with the intention of growing that kind. In that case, the owner would be liable for sowing diverse-kinds (cf. T. $2: 4 \mathrm{a}$ below).

In $\mathrm{H}$ Simeon disputes with $G$, and so attests it to Usha. Simeon rejects $G^{\prime} s$ distinction between $f l a x$ and other kinds, maintaining that the law is the same in both cases. This statement probably means that one may sow a furrow of any kind at the common border of the wheat-fields (Sens [following Y.], Rosh, TYY, GRA). Simeon apparently reasons that a single furrow will not produce the appearance of diverse-kinds, regardless of what is sown in it, because a single furrow of any kind looks like a border. 94

Yose states in I that one may test the soil by sowing a furrow of flax in the middle of a field. The point of yose's saying is that a single furrow of flax may be sown anywhere without producing an appearance of diverse-kinds, since it is clear that the owner intends only to test the soil. Yose's statement is connected to F-G by ' $p$, which is standard joininglanguage. The statement is autonomous of F-G. Yose speaks of testing the soil for growing flax in the middle of a field, but does not specifically address himself to the case where flax is sown at the common border of the two fields (although he would certainly agree with the ruling of $\mathrm{F}-\mathrm{G}$ ). It is probably that Yose's saying has been attached to $F-G$ because both statements concern sowing flax in a field of another kind.

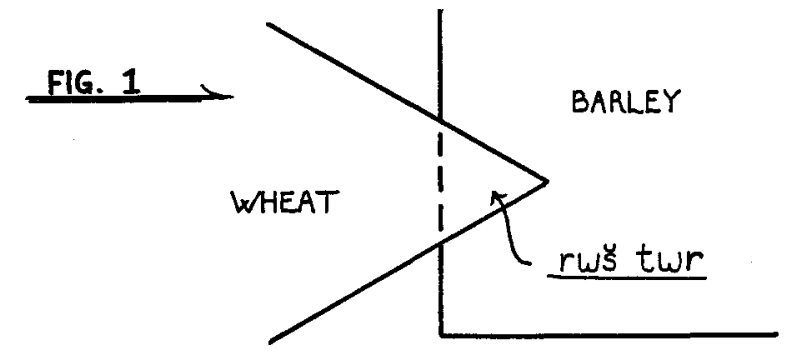



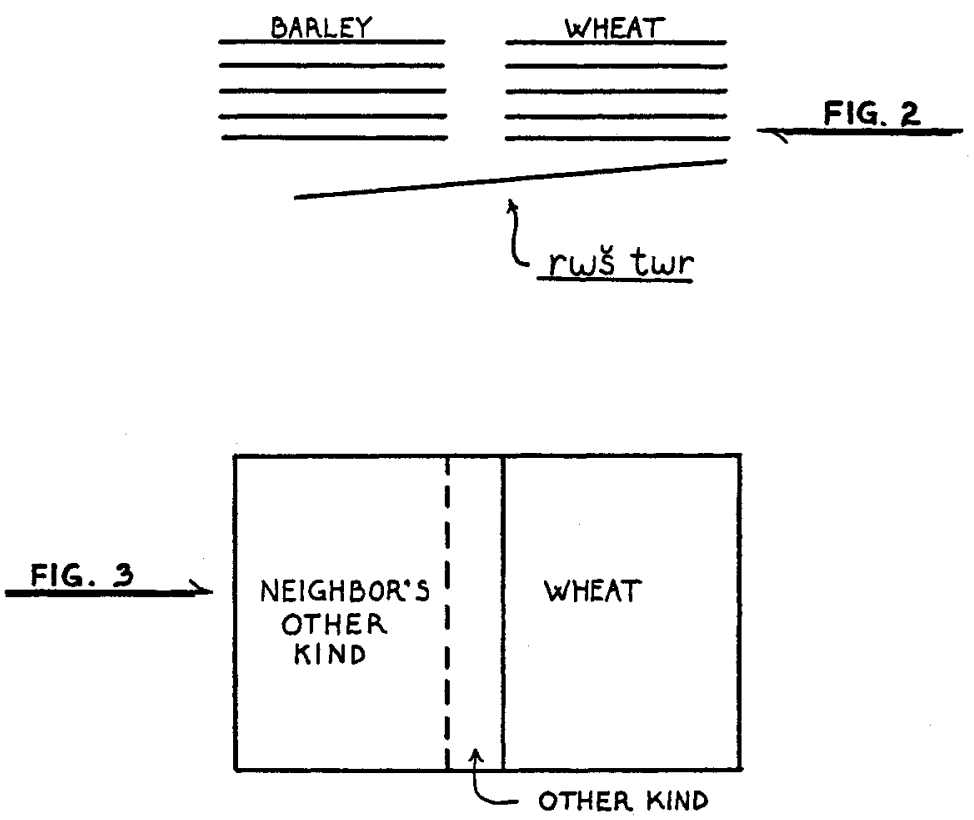

G. [If] one had two fields (sdwt; Erfurt: swrwt ["rows"]), (1) one sown [with] wheat and (2) one sown [with] barley,

H. [and] he would plow and [thereby] bring (1) wheat into a field of barley, or (2) barley into a field of wheat,

I. it is permitted [(1) to grow the wheat in the field of barley, or (2) to grow the barley in the field of wheat];

J. for (1) the wheat appears to be within (btwk; Erfurt: first printed ed.: kswp ["looks like the end of"]) the field of wheat, and (2) the barley appears to be within (btwk; Erfurt: kswp ["looks like the end of"]) the field of barley [first printed ed.: for the wheat looks like the end of the field of barley].

T. Kil. 2:1b (p. 208, 11. 5-8)

K. R. Liezer b. Jacob says, "Also ('py $z w$ ) if (l) one grain of wheat after another ( $h t_{h}$ ' $h r$ hth) enters the field of barley, or (2) [one grain of] barley after another enters the 
field of wheat [i.e., the grains of wheat or barley are sown consecutively in the field of barley or wheat, respectively],

I. it is permitted [(1) to grow the wheat in the field of barley, or (2) to grow the barley in the field of wheat];

M. for (1) the wheat appears to be within [= omitted by Erfurt and first printed ed.] at the end (bswp; Erfurt: kswp ["as the end"]) of the field of wheat, and (2) the barley appears to be within ( $b$ twk; Erfurt: kswp ["as the end of"]; first printed ed.: bswp ["at the end of"]) the field of barley [Y.: for (1) the (one grain of) wheat after another ( $h t h$ ' $h r$ hth) which enters (the field of) barley (is considered the end of the field of ${ }^{95}$ ) wheat, and (2) the (one grain of) barley after another which enters the field of wheat (so GRA; printed text: field of barley) (is considered the end of the field of) barley (following HD, GRA) ] .

$$
\begin{aligned}
& \text { T. Kil. } 2: 2 \text { (p. } 208,11.8-11) \\
& \text { (Y. Kil. } 2: 7 \text { (28a)) }
\end{aligned}
$$

N. [If] one had two [= omitted by Y.] rows (swwwt; Lieberman, following $Y .$, corrects to $s d w t$ ["fields"]), (1) one sown [wịth] wheat, and (2) one sown [with] barley,

o. it is permitted to make a furrow ( $t 2 m$; $L$ : $t b n$ ["straw"]) between them (bynyhn; Erfurt: $m h n$ ["of them"]), and to sow [in it] either wheat or barley [H. adds: (1) for the wheat looks like the end of the field of wheat, and (2) the barley (looks like) the end of the field of barley].

P. (1) [If] [Erfurt, first printed ed. add: one (grain of)] wheat is absorbed $\left(m \omega b l^{c} t\right)$ in the field of barley [i.e., the grains of wheat do not fall consecutively in the field of barley (Lieberman)], or (2) [if]. one [grain of] barley is absorbed in the field of wheat,

Q. it is prohibited [(1) to grow the wheat in the field of barley, or (2) to grow the barley in the field of wheat].

$$
\begin{aligned}
& \text { T. Kil. } 2: 3(\text { p. 208, 1l, 11-14) } \\
& \text { (Y. Kil. } 2: 7(28 a))
\end{aligned}
$$

R. [If] one had two fields (sdwt; Erfurt: $\bar{s} w r w t),(1)$ one sown [with] wheat and (2) one sown [with] barley,

S. it is not permitted ('yn mwtx; Erfurt: 'swr) to make 
a furrow of another kind between them.

T. [first printed ed. adds: And] with [a furrow sown with] flax, it is permitted [to make a furrow between the two fields],

u. because he wishes [only] to test his field [for growing flax];

V. and provided that the furrows be open (mplys; Erfurt, first printed ed.: mprys ["separate"] from one end of the field to the other [lit.: from the head of the field to the other head].

W. R. Leazar b. R. Simeon and Abba Yosah b. Hanan of Vani say, "It is sufficient [For the furrow] to be fifty amot in length."

T. Kil, 2:4a (p. 208, 11. 14-17)

(W: T. Kil, 2:la)

T. Kil. 2:1b-2:4a presents a series of cases which supplement M. 2:7. T. may be divided into five units. G-J describes a case where seeds of one kind enter a field of another kind (= M. 2:7A-C). In K-M Eliezer b. Jacob rules on a similar case in which seeds of one kind fall consecutively in a field of another kind. N-O deals with sowing a furrow of one of two different kinds between two fields containing these kinds (M. 2:7D-E). $P-Q$ reverts to $K-M$ and concerns seeds of one kind which fall haphazardly in a field of a different kind. Finally $R-W$, continuing the theme of $\mathrm{N}-\mathrm{O}$, discusses what may and may not be sown in a furrow located between two fields of different kinds ( $=M$. $2: 7 \mathrm{~F}-\mathrm{G})$.

G-J presents its case in a well-developed declarative sentence. The protasis consists of two parts, $G$ and $H$, each of which is internally balanced (wheat $v s$. barley in $G$; wheat + barley vs. barley + wheat in $\mathrm{H}$ ). J glosses G-I and is also well-balanced (wheat + wheat vs, barley + barley).

In G-H the owner of adjacent fields of wheat and barley plows one of the fields in order to cover the seeds already sown in it. ${ }^{96}$ He accidentally propels some of these seeds into an adjacent field of another kind, with the result that either wheat is sown in a barley-field, or barley grows in a field of wheat. According to I the owner may allow the stray seeds to grow in the field of the other kind. J explains that these errant seeds appear to mark the end of the field of their own kind, so that their growth in the field of the other kind does not 
produce the appearance of diverse-kinds. T.'s point is then the same as that of M. G-I (even though the latter concerns only the case of the rw $t w r)$. Although seeds of one kind may actually grow in a field of a different kind, these seeds appear to belong to the adjacent field of their own kind, so that there is no appearance of diverse-kinds.

Eliezer b. Jacob's saying in $K-M$ depends on $G$, and appears to gloss G-J. However, $\mathrm{K}-\mathrm{M}$ is attached to G-J only by 'py $\mathrm{w}$, which is standard joining-language. In fact, the two sayings are very similar to one another, for they both have the same apodoses ( $I$ and $L$ ) and glosses ( $J$ and $M$ ). They differ only in their protases. H has "[and] he would plow and [thereby] bring (1) wheat into the field of barley, or (2) barley into the field of wheat," while K states "[if] (1) [one grain of] wheat after another enters the field of barley or (2) [one grain of] barley after another enters the field of wheat." While $\mathrm{H}$ and $\mathrm{K}$ do differ in respect to language, they basically state the same law concerning one kind of seed which enters the field of another kind. It appears, then, that Eliezer's saying (originally G+K-L) is autonomous of G-I and that the two sayings were redacted together because of their interest in the same issue. At a redactional stage, therefore, A was dropped from Eliezer's saying, and G-I and K-L were probably glossed by the same hand at $J$ and $M$, giving the pericope its present form.

$\mathrm{N}$ repeats $\mathrm{F}$. I states that one may sow either wheat or barley in a furrow located between the fields of these two kinds (fig. 5). 97 No matter.which kind is sown between the two fields, the furrow of that kind appears to mark the end of the adjacent field of the same kind (following Y.), so that there is no appearance of diverse-kinds. The point of $\mathrm{T}$. is similar to that of M. 2:7D-E. The latter allows one to sow the edge of a field of one kind with seeds of the kind sown in an adjacent field (fig. 6 = fig. 3, p. 97), while T. states that one may sow a furrow of either kind at the common border of the two fields. In both cases one may sow seeds of one kind in an area which lies beyond the border of the field of that kind, for that area appears to mark the end of the field. T. then states the law of 11. 2:7D-E in different language. ${ }^{98}$

$P-Q$ presents another balanced declarative sentence (wheat + barley vs. barley + wheat). $P-Q$ completes the thought of 
$\mathrm{K}-\mathrm{M},{ }^{99}$ for we are now told that it is prohibited to grow seeds of one kind in a field of another $k$ ind, if the stray seeds do not fall consecutively. ${ }^{100}$ The reason is that stray seeds which fall haphazardly in the field do not appear to extend from the adjacent field which contains their own kind, and so produce an appearance of diverse-kinds.

$\mathrm{R}-\mathrm{S}$ forms a simple declarative sentence. $\mathrm{T}-\mathrm{U}$ (with $\mathrm{U}$ glossing $T$ ) depends on R-S, while V-W (with $W$ glossing and opposing $V$ ) glosses $T-U$. We note that $W$ appears verbatim in T. 2:1a, and so may not originally belong in this context. 101 $R$ repeats $G$. S states that one may not sow a furrow of another kind (i.e., a furrow of something other than wheat or barley) between the fields of wheat and barley. Such a furrow would clearly produce an appearance of diverse-kinds. T, however, adds that one may sow a furrow of flax between the two fields $(=$ M. $2: 7 F-G(1))$. U explains that one who sows a single furrow of flax wishes only to test the soil. Therefore, one who sows a furrow of flax does not appear to be sowing diverse-kinds. U thus agrees with Yose (M. 2:7I) that one may test for flax even in the midale of a field.

Maimonides (Code, Diverse-Kinds $3: 17$ ) explains the law as follows:

[If] his field was sown [with] wheat, and his neighbor's field, which was adjacent to it, was sown with wheat, it is permitted for him to sow one furrow of flax beside his wheat, next to his neighbor's field [i.e., between his wheat and his neighbor's field]. For one who sees [the furrow of flax] knows that it is not the common practice $\left(d r k h^{c} m\right)$ to sow one furrow of flax, and that he intended only to test whether or not his field is suitable for sowing flax; and he is [thus] discovered to be like one who sows [only] for [the sake of] destruction. Therefore it is prohibited to sow another kind between these two rows, which are of one kind, until he distances [the other kind from the row which is] in his [field].

According to $\mathrm{V}$ the furrow of flax must extend for the length of the field (i.e., it must be as long as the furrows of wheat or barley). That is, the flax must be sown in a furrow of sufficient length to be considered an area unto itself (cf. M. $2: 6$, T. 2:la), and so distinct from the fields of wheat and barley. The flax then does not appear to be sown among the wheat and barley, and there is no appearance of diverse-kinds. In $W$, Eleazar b. Simeon and Abba Yosah b. Hanan of Vani say that the furrow need only be fifty amot in length, for a furrow of this 
length is already considered an area unto itself (cf. T. 2:1C) 102 We note, then, that $T \cdot R-W$ both restates (R-T) and supplements (U-W) M. $2: 7 \mathrm{~F}-\mathrm{G}$.

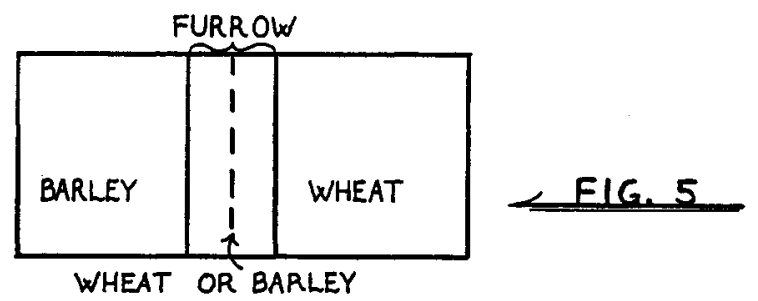

\section{FIG.6}

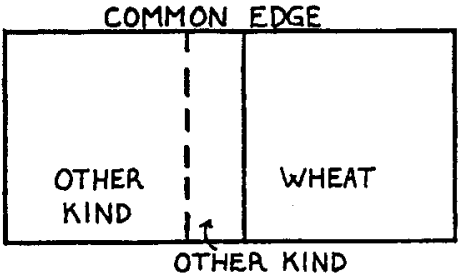

\section{$2: 8$}

A. They do not flank a field of grain [with] mustard or safflower, 103

B. but they flank [Geniza fragments, $104 \mathrm{O}$ : he flanks] a field of vegetabies [with] mustard or safflower.

c. And he flanks [with diverse-kinds (Maim,, Code, Diverse-kinds 3:15) ]

(1) uncultivated land (bwr),

(2) or newly-broken land [so Danby for nyr, ${ }^{105}$ ]

(3) or a loose [most comm. ${ }^{106}$ ] stone wall (gpph),

(4) or a road,

(5) or a fence $(g d r)$ [most mss. add: which is] ten handbreadths high,

(6) or a ditch which is ten [handbreadths] deep and [Geniza fragment omits:] four [handbreadths] wide,

(7) or a tree which shades the ground,

(8) or a rock [most mss, add: which is] ten [handbreadths] high and four [handbreadths] wide. 
M. Kil. 2:8 concerns flanking one kind of seeds with seeds of another kind, and so continues the discussion of flanking begun in M. 2:7D-G. M. consists of two units, $A-B$ and $C$, which differ from one another both formally and thematically. A-B is phrased in a declarative sentence using plural present participles, and concerns flanking fields of grain and vegetables with mustard or safflower. $C$, on the other hand, uses the singular present participle, and presents a list of objects which may be flanked.

$A-B$ states that one may not flank a field of grain, but only a field of vegetables, with mustard or safflower. Feliks ${ }^{107}$ explains that mustard and safflower were usually sown in small plots (e.g., patches; Cf. M. 2:9) so that it was apparently customary to sow them at the edges of fields. ${ }^{108}$ A prohibits the sowing of mustard or safflower next to grain, says Feliks, 109 because the former resembles the latter. ${ }^{110}$ Mustard and safflower both have tall plants with yellow flowers, and so look like ripened stalks of grain. If the two kinds of plants were to be sown next to one another, it would become difficult to distinguish between them, and the field would appear to be sown with diversekinds. In addition, mustard and safflower tend to grow wild once they are sown, 111 and so could actually enter the field of grain, making it even more difficult to distinguish between the two kinds of plants. $B$, on the other hand, says that one may sow mustard or safflower next to a field of vegetables. In this instance the two kinds of plants do not resemble one another, so that an appearance of diverse-kinds does not result from one kind being sown next to the other. 112

$C$ is autonomous of $A-B$, and the two units have been redacted togethex only because both concern the problem of flanking. C lists eight objects which may be flanked with diverse-kinds (Maim., Code, Diverse-Kinds 3:15), that is, eight objects which serve to separate diverse-kinds from one another. In each instance the diverse-kinds are to be sown on opposite sides of the object itself, except in the case of the tree, where one kind is to be sown under the tree's foliage, and the other is to be sown outside of its shade (following T. 2:5b). We note that seven of the eight objects ${ }^{113}$ are mentioned as dividers in some other context in M. -T. Some serve to divide a field for the setting aside of $p e^{\prime a h^{14}}$ or for the giving of bikkurim, ${ }^{115}$ while others divide a vineyard (in respect to the laws of diverse-kinds of a vineyard) ${ }^{116}$ or divide an area into autonomous domains (in respect to the laws of carrying on the sabbath). 117 Finally, the tree which shades the ground is also said to form a Tent. ${ }^{18}$ our 
list, then, consists of objects which are commonly considered dividers for various purposes.

X. Rabbi [Erfurt adds: Yose] says, "A man [= omitted by Erfurt] is permitted to make a row [Erfurt: rows] of mustard [or] [first printed ed. omits:] safflower in his field."

Y. How much is the length of the row [Erfurt: the field]?

z. Ten and one-half amot.

$$
\begin{aligned}
& \text { T. Kil. } 2: 4 \text { b (p. 209, 11. 17-19) } \\
& \text { (Y. Kil. } 2: 8 \text { (28a) } 119 \text { ) }
\end{aligned}
$$

T. Kil. 2:4b presents a saying of Rabbi which opposes the law of M. 2:8A. Rabbi states in $x$ that one may sow a row of mustard or safflower in a field of another kind. He apparently reasons that because mustard and safflower are usually sown in small plots, a single row of either is considered a field unto itself (HD). Therefore a row of mustard or safflower which grows in a field sown with another kind does not produce the appearance of diverse-kinds. We note that Rabbi agrees with simeon in $T$. 2:5a (see below), who says that one may flank any kind with mustard or safflower. Rabbi will then clearly disagree with the law of M. 2:8A, which says that mustard or safflower may not flank a field of grain.

$\mathrm{Y}-\mathrm{Z}$ glosses $\mathrm{X}$, and concerns the minimum length which a row must have in order to be considered an autonomous field. Z states that the row must be ten-and-a-half amot long. This means that the row must be as long as one side of a bet rova (T. Kil. $2: 6)$, which is the minimum size of an area within a field which may be sown with a kind other than that sown in the field itself (cf. M. 2:9-10). According to $z$, then, the row of mustard or safflower must be as long (though not as wide) as an area within a field which is usually considered autonomous.

A. "They edge (mqypyn) 120 only [a field of ] geophytes ${ }^{121}$ (hysyt) alone [with] mustard [or] safflower," the words of R. Meir.

B. R. Judah says, "They edge [a field of] any [kind with] mustard [or] safflower, except for [a field of] grain."

C. [Lieberman, following Erfurt, Y., and Sens ${ }^{122}$ adds: R. Simeon says, "They edge [a field of] any [kind with] mustard [or] safflower."]

D. Rabbi Simeon b. Gamaliel says, "They surround small beds ( ${ }^{c}$ rwgywt; Erfurt: ${ }^{c}$ rwgwt ["beds"]; ${ }^{c}$ rwgwt qtnwt ["small 
beds"]) of vegetables [= omitted by Erfurt] with mustard [or] safflower."

$$
\begin{aligned}
& \text { T. Kil. 2:5a (p. 209, 11. 19-22) } \\
& \text { (Y. Kil. 2:8 (28a)) }
\end{aligned}
$$

T. Kil. $2: 5 \mathrm{a}$ comments on M. 2:8A-B, for it presents an Ushan dispute concerning the flanking of a field with mustard or safflower (and so assigns M. to Judah). The dispute consists of four sayings, with those of Judah and Simeon balancing one another in B-C (both sayings being identical except for the phrase hws $m n h t b w ' h$ in B). It is possible, then, that Judah and simeon were originally in dispute, and the sayings of Meir and Simeon b. Gamaliel later added to form the present dispute.

Meir says in A that one may flank only a field of geophytes with mustard or safflower. According to Feliks ${ }^{123}$ Meir apparently reasons that since geophytes are not visible aboveground, mustard or safflower may flank them without causing an appearance of diverse-kinds. Meir maintains, however, that mustard or safflower may not be sown next to any crops which grow aboveground, for then an appearance of diverse-kinds would result. Meir thus opposes the law of M. 2:8B, which states that one may flank a field of vegetables with mustard or safflower.

In B-C, Judah and Simeon dispute as to whether or not one may flank grain with mustard or safflower. Both men agree (against Meir) that one may sow these kinds next to anything else, so that Meir clearly stands outside of their dispute. Judah maintains that one may not flank grain with mustard or safflower (= M. 2:8A), apparently because an appearance of diverse-kinds would result. Simeon, on the other hand, permits one to sow mustard or safflower next to grain. According to his view mustard or safflower does not produce the appearance of diversekinds even when it flanks grain (Feliks ${ }^{124}$ ).

Simeon b. Gamaliel's saying in $\mathrm{D}$ is autonomous of the foregoing. Simeon b. Gamaliel says that one may surround small vegetable-beds with mustard or safflower. The beds do not appear to be sown with diverse-kinds, for at a distance only the tall mustard or safflower plants are visible, while upon a closer look, the vegetables may be easily distinguished from the other plants (Feliks ${ }^{125}$ ). Simeon b. Gamaliel then agrees with M. 2:8B that one may flank vegetables with mustard or safflower.

E. He flanks [with diverse-kinds] tree-roots which have dried up, [and] [Y. omits:] which are ten handbreadths high. 
F. [Concerning] a tree whose foliage is not [i.e., is less than] three [handbreadths off the ground]--

G. he sows seed under [the tree], and flanks it [with] another kind outside [of the foliage].

$$
\begin{aligned}
& \text { T. Kil. 2:5b (p. 209, 11.22-24) } \\
& \text { (E: Y. Kil. 2:8 (28a)) }
\end{aligned}
$$

T. Kil. $2: 5 \mathrm{~b}$ comments on M. $2: 8 \mathrm{C}(7)$, which says that one may flank with diverse-kinds a tree which shades the ground. T. is divided into two parts, $E$ and $F-G$. E concerns flanking the roots of a tree with diverse-kinds, while F-G deals with the foliage of a tree as a divider of diverse-kinds.

E states its law in a simple declarative sentence (using, as M. does, the singular present participle). According to $\mathbf{E}$ one may flank with diverse-kinds dry tree-roots which are ten handbreadths high. Feliks ${ }^{126}$ explains that only dry roots adequately separate diverse-kinds, for moist roots are green and may be easily confused with the plants growing near them. Feliks ${ }^{127}$ also points out that trees which live long (such as olive or fig trees) commonly have roots which are ten handbreadths off the ground, for eventually the soil surrounding the trees erodes and the roots are exposed. $E$ then supplements M. $2: 8 \mathrm{C}(7)$, for it adds another way in which a tree may be flanked with diverse-kinds.

$F$ describes the case of a tree whose foliage is less than three handbreadths above the ground. 128 G then explains how the tree separates diverse-kinds. One kind is sown under the tree, while the other is sown outside of the tree's foliage, so that the foliage itself divides the two kinds (following Lieberman ${ }^{129}$ ). We note that in this case the two kinds are not actually sown on two sides of a divider. Rather, one kind is sown in the autonomous domain created by the tree's shade, while the other is sown outside of the tree's foliage. F-G then explains how M.'s "tree which shades the ground" may be flanked with diverse-kinds, both by stating how low the foliage must be and by explaining how the foliage itself separates the diversekinds .

A. [If diverse-kinds, separated by a fence (= M. 2:8C (5))] extended ( $m \breve{s} \omega k \omega t$; Erfurt: $m \breve{s} \omega k y n$; first printed ed.: $m w \Im k w t$ ) three handbreadths beyond the fence,

B. he shall not make [the area of each kind] less than [the area of] three open furrows [= T. 2:1a], 
c. so that [the diverse-kinds] appear [to be sown] in rows (kङ̌sh; lit.: "in a row").

$$
\text { T. Kil. 2:6a (p. 209, 11. 24-25) }
$$

T. Kil. 2:6a supplements M. 2:8C(5), which says that one may flank a fence with diverse-kinds. A describes a case in which diverse-kinds extend three handbreadths beyond the fence which separates them (following Lieberman ${ }^{130}$ ). According to $B$ each kind must cover an area no less than that of three open furrows. That is, the plot of each kind must have a width equal to that of three furrows, and each kind must be sown over the entire length of the field (Feliks ${ }^{131}$ ). C glosses B, explaining that each kind then appears to be sown in a row, for the area of a row is defined as that of three open furrows (T. 2:1a). Now according to M. 2:6 rows of diverse-kinds may be sown next to one another, for each row is considered a field unto itself. The diverse-kinds which extend beyond the fence may therefore grow in adjacent rows without producing an appearance of diversekinds.

$$
2: 9
$$

A. He who wishes to lay out his field [in] patches [so Danby for qxht; lit.: bald-spots (cf.M. 4:1)] of every kind [i.e., with each patch containing a different kind] --

B. (1) he lays out twenty-four patches to a bet se'ah, (2) a patch to a bet rovac,

C. and sows in [each patch (Albeck)] any kind that he wishes.

D. "If there were one or two patches [in a field of grain (Sens)], he sows them with mustard;

E. "[but if there were] three [patches], he shall not sow [most mss. ${ }^{132}$ add: them] [with] mustard,

F. "for [then the field as a whole] looks like a field of mustard,"

G. the words of R. Meir.

H. And the sages say, "Nine patches are permitted, [but] ten are prohibited [i.e., it is permitted to lay out no more than nine patches of mustard in a field of grain.]"

I. R. Eliezer b. Jacob says, "Even ('py $l w)$ [if] his entire field is [the size of] a bet kor, he shall lay out only one patch in it."

M. Kil. $2: 9$ 
M. Kil. 2:9 concerns dividing a field into patches of different kinds, and so continues the discussion of M. 2:6, which deals with a field laid out in rows of different kinds. $M$. consists of three units, $\mathrm{A}-\mathrm{C}, \mathrm{D}-\mathrm{H}$, and $\mathrm{I}$. $\mathrm{A}-\mathrm{C}$ discusses the number of patches which may be laid out in a bet se'ah. In D-H Meir and the sages dispute concerning the number of patches of mustard which may be sown in a single field (an alternative interpretation of the sages' views will be presented below). Finally Eliezer $b$. Jacob glosses $A-C$ in $I$, and discusses how many patches may be laid out in a bet kor.

A describes the case of one who wishes to divide his field into patches and sow a different kind in every patch. According to $B(1)$ one may make twenty-four patches in a bet $s e^{\prime} a h$, while $B(2)$ adds that each patch must have the area of a bet rovac (= one twenty-fourth of a bet se'ah). B(2)'s gloss is important, for it establishes that each patch must have a minimum area. 133 These patches are considered fields unto themselves, so that each may contain a different kind (C). The point of $\mathrm{A}-\mathrm{C}$, then, is that each patch must be of a minimum area, for otherwise the different kinds would appear to be growing haphazardly and in confusion, and the field would appear to be sown with diverse-kinds.

Eliezer b. Jacob's saying in I refers to $A-C$, for the language of $I$, bet kor, corresponds to the language of $\mathrm{A}-\mathrm{C}$, bet $s e^{\prime} a h$. Eliezer $b$. Jacob opposes the law of A-C, for he states that even if the field is the size of a bet kor (= thirty times the size of a bet $s e^{\prime} a h$ ), only one patch may be laid out in it. That is, one may sow in a field only one kind other than that which is sown in the greater part of the field, no matter how large the field may be. Eliezer b. Jacob's point is that no more than two kinds may grow in a single field, for the presence of even three kinds in a field produces the appearance of diversekinds.

D-H presents a dispute between Meir and the sages. The dispute is not balanced, for the operative language of $\mathrm{D}-\mathrm{E}$ $\left(z w r^{c} / l^{\prime} y z r^{c}\right)$ differs from that of $\mathrm{H}$ (mwtr/'swr). Both opinions, however, contain similar number-sequences, as D-E has two/three and $\mathrm{H}$ has nine/ten $(\mathrm{X} / \mathrm{X}+1)$. The dispute concerns the number of mustard patches which may be laid out in a field of grain (Sens). Meir says in D-E that two, but not three, patches of mustard may be sown in a single field. Glossing D-E, F explains that three patches of mustard are enough to determine a mustard-field. That is, since mustard is usually sown in small quantities (cf. our discussion of M. 2:8), a field containing even as few as three patches of it is already considered a field of mustard. 
Meir therefore permits only two patches to be laid out, for otherwise the grain growing in the same field would seem to be growing in a mustard field, and the appearance of diverse-kinds would result. The sages, on the other hand, maintain in $\mathrm{H}$ that ten patches of mustard determine a mustard-field, so that one may lay out as many as nine patches without producing the appearance of diverse-kinds. 134

\section{$2: 10$}

A. Everything which is within [an area the size of] a bet rovac counts within the measure of the bet rovac.

B. (1) The ground required for a vine [so Danby for 'kylt hgpn; most mss.: 'klt hgpn; B, Geniza fragment, ${ }^{135} \mathrm{O}, \mathrm{Ox}, \mathrm{Pr}$ : 'wklt hgpn],

(2) or the grave,

(3) or the rock, counts within the measure of the bet rova ${ }^{c}$ [even though these areas may not be sown].

c. (1) Grain [of one kind which is to be sown in a field containing mostly] grain [of another kind] ( $t b w^{\prime} h b t b w^{\prime} h$ ) [must itself cover an area of] a bet rovac.

D. (2) Vegetables [of one kind which are to be sown in a field containing mostly] vegetables [of another kind] (yrq byrq) [must themselves cover an area of] six handbreadths [square].

E. (3) Grain [which is to be sown in a field containing mostly] vegetables ( $t b w$ 'h byrq), or

(4) vegetables [which are to be sown in a field containing mostly] grain (yrq $\left.b t b w^{\prime} h\right)$ [must themselves cover an area of] a bet rova ${ }^{c}$.

F. R. Eliezer $\left[\mathrm{N}, \mathrm{Sn}, \mathrm{V}:\right.$ Eleazar $^{136}$ ] says: "Vegetables [which are to be sown in a field containing mostly] grain (yrq $b t b w(h)$ [must themselves cover an area of] six handbreadths [square]."

$$
\text { M. Kil. } 2: 10
$$

M. Kil. 2:10 concerns the dimensions of an area which is to be considered an autonomous field. M. is divided into two units, $A-B$, and $C-F$. $A-B$ considers whether or not areas which cannot be sown are included in the measuring of a bet rovac. $\mathrm{C}-\mathrm{F}$ concerns the minimum area which one kind of seed must cover when it is sown in a field of another kind (GRA). $A-B$ presupposes that the bet rova ${ }^{c}$ is an autonomous field, 
and so is probably redacted as a comment on M. 2:9 (Albeck). A states that everything within an area the size of a bet rovac is included in measuring the bet rovac. B illustrates A with a list of three areas which may not be sown but which are nevertheless counted as part of a bet rova ${ }^{c}$. The area surrounding a vine (six handbreadths [in each direction (TYY)]; cf. M. Kil. $3: 7,6: 1)$ may not be sown, for the presence of other plants in this area produces the appearance of diverse-kinds of the vineyard. It is prohibited to derive benefit from a grave (TYY; cf. M. Oh. 18:2), and a rock is clearly not suitable for sowing. According to $B$, then, the point of $A$ is that even areas which cannot actually be sown count as part of the bet rova. This means that the bet rova ${ }^{c}$ need not be completely covered with crops of the secondary kind in order to be considered an autonomous field.

C-F defines the minimum area which a plot with a larger field must cover in order to be considered an autonomous field, and so to be sown with a different kind. The two fields may contain either different kinds of the same type of crops (i.e., both have either grain or vegetables) or different types of crops (i.e., one has grain while the other has vegetables). C-F then simply consists of the four possible combinations of the words tow'h and yrq, with each combination having as an apodosis either byt $r w b^{c}$ or $\breve{s} \breve{s}$ tphym. C states that if the two fields contain different types of grain, the smaller, autonomous field must measure a bet rova ${ }^{c}$ in area. $D$, on the other hand, says that if the two fields are sown with different kinds of vegetables, then the smaller field need measure only six handbreadths square. According to $\mathrm{E}$ if one field is sown with grain and the other contains vegetables, the smaller field (regardless of which type of crop it contains) must measure a bet rova ${ }^{c}$. In F, Eliezer (or Eleazar) disagrees with E(4), saying that if the smaller field contains vegetables and the larger one is sown with grain, then the former need measure only six handbreadths square. According to Eliezer, then, a smaller, autonomous field of grain always requires the area of a bet rova while a smaller field of vegetables must always be six handbreadths square, regardless of what the larger field contains.

D. (1) A private road,

(2) or a public road,

(3) or a fence which is ten handbreadths high, does not count within the measure of the [bet] rovac. 
E. [A fence which is] lower than ten handbreadths counts within the measure of the bet rova ${ }^{c}$ [Erfurt: The private road, or the public road, or the fence which is nearly $(s m \omega k)$ ten handbreadths high, counts within the measure of the bet rovac. But the fence which is higher than ten (handbreadths) does not count in the measure of the bet rovac; first printed ed.: The private road, or the public road, or the fence which is lower than ten handbreadths, counts within the measure of the bet rovac. But (the fence) which is higher than ten handbreadths does not count within the measure of the bet rovac].

F. [Erfurt adds: And] what (kmh; lit.: how much) is the measure of a bet rovac?

G. Ten-and-one-half amot by ten-and-one-half amot, squared [Erfurt: Ten-and-one-half amot squared].

H. R. Yosah [Erfurt, first printed ed.: Yose] says, "[An area may be considered a bet rovac] even ('pylw) [if] its length is about twice its width."

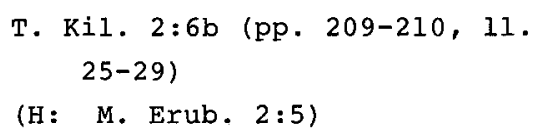

T. Kil. 2:6b is divided into two parts, D-E and F-G. D-E discusses areas which either are or are not counted as part of a bet rova ${ }^{c}$, and so comments on M. $2: 10 \mathrm{~A}-\mathrm{B}$. F-H deals with the dimension of a bet rova $a^{c}$, and so comments on either T. 2:6D-E, M. 2:9 or M. 2:10, all of which concern an area of that size. D-E distinguishes between the private road, the public road, ${ }^{137}$ and the fence which is ten handbreadths high, on the one hand, and the fence which is lower than ten handbreadths, on the other. A similar distinction is drawn by M. 4:7, which rules that the two kinds of road and the fence which is lower than ten handbreadths do not constitute valid dividers of diverse-kinds, while the fence which is higher than ten handbreadths does form a valid divider. It appears, then, that our reading of $D-E$ is difficult, for it groups the two kinds of roads together with the higher fence, and implies that each of the two roads forms an autonomous domain within the field in which it lies. According to M. 4:7, however, the roads do not serve to separate two kinds from one another, and so cannot be considered as being separate from the rest of the field. It is likely, therefore, that $\mathrm{D}(3)$ and the apodosis of $\mathrm{D}$ should be reversed with $\mathrm{E}$ (as in the first printed ed.) ${ }^{138}$, so that $\mathrm{T}$. rules 
that the two roads, ${ }^{139}$ and the lower fence, do not count within the measure of bet rovac. The point of $\mathrm{D}-\mathrm{E}$, then, is that those areas which do not form domains unto themselves are counted in the bet rova ${ }^{c}$, since they are regarded as part of the same field, while those which do constitute a separate domain do not form part of a bet rovac. T. thus qualifies M. 2:10A, which states that everything within a bet rova $a^{c}$ is counted as part of the latter.

F-G defines a bet rovac as an area which measures ten-andone-half by ten-and-one-half amot. In $\mathrm{H}$ Yose says that a bet rova ${ }^{c}$ need not be a square, for he maintains that its length may equal even twice its width. Yosé's saying, however, may not refer to a bet rova ${ }^{c}$ at all. The identical saying appears in a different and more appropriate context in M. Erub. 2:5, so that $\mathrm{H}$ is probably not original to the context of T. Kil. 140

A. The area required for the tillage of vegetables ( ${ }^{c} b w d t$ yrq) [of one kind sown] among vegetables of another [kind] is six handbreadths [square] [Erfurt, sens add: whether (the secondary kind is sown) in the middle (of the field of the primary kind), or whether (it is sown) at the sides (of the field of the primary kind)].

B. [Erfurt adds: And] they consider $\left(r w^{\prime} y n\right)$ it [i.e., the area sown with the secondary kind] as if it were a square tablet [even if it is not perfectly square].

c. Even ('py $2 w$ ) if there is only one stalk there [i.e., in the area sown with the secondary kind], they [Erfurt: he] allow it the area required for its tillage, six handbreadths [square],

D. [Erfurt, Sens omit:] whether [the stalk is sown] in the middle [of the square], or whether [the stalk is sown] at the sides [of the square].

E. If the stalks leaned [over adjacent plants of another kind] in four directions [from the square], 10, this is permitted,

F. for it looks like the end of the field.

T.Kil. $2: 7$ (p. $210,11.29-32$ )

(A-B: B. Shab. $85 b-86 a)$

T. Kil. $2: 7$ is divided into three parts, $A+C-D, B$, and $E-F$. $A+C-D$ concerns sowing vegetables of one kind among another kind of vegetables, and so comments on M. 2:10D. B interrupts $A+C-D$ with a discussion of an area which is not perfectly 
square. E-F, commenting on M. 2:11, deals with vegetables which lean over vegetables of another kind.

A states that if one kind of vegetable is sown in a field consisting of vegetables of another kind, the former requires an area measuring six handbreadths square (following the readings of Vienna Ms. and first printed ed. ${ }^{141}$ ). A thus simply restates M. 2:10D. According to $C$ even if only one stalk of the secondary kind is to be sown in the field, it must still be given the full area of six handbreadths square. D adds that the single stalk must be given the full square even if it is sown at the edge of the primary kind, ${ }^{142}$ that is, in a place where the single stalk would not by itself appear to form a separate and autonomous field. The point of $C-D$ is that any quantity of a secondary kind which is sown among a primary kind must be sown in a field unto itself, for otherwise the larger field would appear to be sown with diverse-kinds.

B states that one regards a certain area as if it were a square tablet. B presumably refers to a plot sown with a secondary kind, and its point is that such a plot need not be in a regular shape. That is, if the plants of the secondary kind extend from an irregularly-shaped area into the field of the primary kind, so that the plants which extend from it are regarded as part of $i t$, the plot of the secondary kind is considered a square (Lieberman ${ }^{143}$ ). Now $B$ does not refer specifically to the case of $A$, and so may be out of place in our pericope. B perhaps belongs in $T .2: 6 \mathrm{~B}$, which concerns the size and shape of a bet rovac.

E states that stalks of a secondary kind, which are sown in a square, may be allowed to lean over the plants outside of the square. E then restates M. 2:11 (plants of one kind may lean over another kind of plant) in the context of M. 2:10 (a secondary kind is sown in a square among a primary kind) and its purpose is to link the two rules. According to $F$ the plants of the secondary kind are allowed to lean over the other plants for, although they extend beyond the square, they appear to mark the end of the square (cf. M. 2:7), and there is thus no appearance of diverse-kinds.

\section{$2: 11$}

A. (1) [If] grain leans [so Danby for nwth] over grain [of another kind],

(2) or vegetables [lean] over vegetables [of another kind],

(3) [if] grain [leans] over vegetables,

(4) [or if] vegetables [lean] over grain -- 
B. everything is permitted,

C. except for the Greek gourd [i.e, any plant may be allowed to lean over any other plant, while the Greek gourd may not be allowed to lean over any plant].

D. R. Meir [C, Geniza fragments, ${ }^{144} \mathrm{~K}, \mathrm{~L}, \mathrm{Mn}, \mathrm{Ox}, \mathrm{P}, \mathrm{S}$ read: Rabbi] says, "Even ('p) the chate melon and the cowpea [lit.: Egyptian bean] [may not be allowed to lean over any plant];

E. "but I prefer $\left(i w^{\prime} h\right)$ their words to my own."

\section{Kil. 2:11}

M. Kil. 2:1l discusses allowing plants of one kind to lean over another kind of plants. A lists all of the ways in which grain and vegetables may lean over plants, presenting all four possible combinations of the words $t b w^{\prime} h$ and $y r q$. According to $B$ any plant may be allowed to lean over a plant of another kind. C glosses B and gives one exception to this rule, the Greek gourd, which is not permitted to hang over plants of other kinds. The reason behind $B$ is apparently that most plants do not spread out very far, so that even if they lean over plants of other kinds they do not become entangled with them and so do not cause the appearance of diverse-kinds. The Greek gourd, on the other hand, spreads out 10-15m.,145 and tends to become entangled with the adjacent plants. Since the Greek gourd, then, could easily produce the appearance of diverse-kinds, ${ }^{146}$ it may not be allowed to hang over nearby plants. ${ }^{147}$

In D Meir (or Rabbi) glosses $C$ and says that the chate melon and the cowpea also may not be allowed to lean over plants of other kinds. ${ }^{148}$ Both the chate melon and the cowpea are climbing plants, 149 so that if they were to spread over other plants, they would become entangled with the latter and cause the appearance of diverse-kinds. In $E$, however, Meir states that he prefers the ruling of $\mathrm{C}$ to his own. He apparently reasons that the Greek groud spreads out farther than do the chate melon and the cowpea. If the Greek gourd were allowed to lean over other plants, it would become entangled to a greater extent than would the other two plants under similar circumstances. Therefore Meir reasons that the chate melon and the cowpea are not in the same category as the Greek gourd with respect to causing the appearance of diverse-kinds. 
Chapter Three, which is concerned with planting vegetables and trailing plants, presents a series of rules defining the minimum area which a secondary kind must cover in order to avoid the appearance of diverse-kinds. The chapter consists of two major units, M. $3: 1-2$, discussing the garden-bed, and M. 3:3D-G + M. 3:6 + M. 3:7C-E, dealing with rows in a field. The intervening pericopae, M. 3:3A-C, M. 3:4-5, M. 3:7A-B, F-H and J-K, are all brief units attached to the larger formal structure. As we shall see, however, the redactor has largely ignored these formal units and has organized the chapter along thematic lines.

M. 3:1-2 determines the number of different kinds of vegetables which may be sown in a garden-bed measuring six handbreadths square. An area of this size is considered an autonomous field (M. 2:10), and so may be sown with one kind and flanked with different kinds along its sides. Judah maintains that an autonomous field need be much smaller, and therefore allows six kinds to be sown in the bed itself.

The pericopae of the second major unit exhibit a distinctive formulary pattern in their protases: hyh $\delta d h w a r w^{c} h \mathrm{x}, w^{h} w^{\prime}$ (or w) $m b q \breve{s}$ (or $b q \breve{s}$ ) $l t^{c} b$ (or (1)) twkh šwrh šl Y. This unit deals with the minimum dimensions of rows of one kind which are sown in a field containing a different kind. M. 3:3D-G concerns sowing a row of vegetables in a vegetable field of another kind, while M. 3:6 discusses planting a row of gourds in a field of onions, and $M .3: 7 \mathrm{C}-\mathrm{E}$ rules on planting a row of gourds among grain. Both M. 3:3D-G and M. 3:6 present disputes between Ishmael and Aqiva, and so were probably formulated together. The redactor of the chapter then separated the two pericopae by means of $M .3: 4+5$, which concern planting different kinds of trailing plants in rows and individually. ${ }^{1}$ we may understand why the redactor chose to place M. $3: 4+5$ where he did if we consider the alternatives which lay before him. He could not insert the two pericopae before M. 3:1-2, for then he would have a unit on the garden-bed (M. $3: 1-2$ ) interrupting a discussion of planting rows in a field (M. $3: 4$ and $M .3: 3$ ). Nor could the redactor place M. 3:4+5 after $M .3: 1-2$, for then rulings concerning trailing plants would separate pericopae dealing with vegetables (M. 3:1-3). Similarly, M. 3:4+5 could not be appropriately set 
between M. 3:6 and M. 3:7, for both of these pericopae deal with planting rows of trailing plants together with vegetables. Finally, M. 3:4+5 could not conclude the chapter, for then the chapter's sequence of themes would not be logical, as a discussion of planting different kinds of trailing plants with one another would follow the rules for planting trailing plants with vegetables. That is, the discussion of planting trailing plants together with vegetables would then not follow units dealing with the planting of vegetables and trailing plants separately. The redactor thus had to insert $M .3: 4+5$ into the unit of $M .3: 3 D-G+M \cdot 3: 6+$ M. 3:7C-E, because he wanted the chapter to have the thematic sequence of vegetables (M. 3:1-3) -- trailing plants (M. 3:4-5) -trailing plants + vegetables (M. 3:6-7). The chapter is thus organized around thematic considerations rather than formal ones.

\section{$3: 1$}

A. A garden-bed which is six handbreadths by six handbreadths --

B. (1) they sow in it five [kinds of] seeds,

(2) four [along] the four sides (rwhwt) of the garden-bed and one in the middle.

C. If it [i.e., the garden-bed] had a border [measuring] a handbreadth [B, Geniza fragment, ${ }^{2}$ L, O, T, Tm omit:] high,

D. (1) they sow in it thirteen [kinds],

(2) three on each and every border and one in the middle.

E. He shall not plant the head of a turnip in the border,

F. because it fills [i.e., spreads throughout] [the border].

G. R. Judah says, "Six [kinds may be sown] in the middle [of a garden-bed]."
M. Kil. $3: 1$ (A-B: M. Shab. 9:2b,
B. Pes. 39b; B(2): B. Qid. 39b)

M. Kil. $3: 1$ concerns the ways in which different kinds may be sown around a garden-bed. M. is divided into two parts, $A-B+G$ and $C-F$. $A-B$ concerns the number of different kinds which may be sown in and around a single garden-bed. In G, Judah glosses and opposes $A-B$. C-F, which has been inserted between $A-B$ and $G$, discusses the number of different kinds which may be sown around a garden-bed surrounded by a border.

According to A-B five different kinds may be sown in a garden-bed which measures six handbreadths square. One kind is to be sown in the garden-bed itself, while each of the other four 
kinds is sown along the outer edge of one side of the square (GRA; cf. fig. $9^{3}$ ). 4 since an area measuring six handbreadths square is considered an autonomous field (cf. M. 2:10 ${ }^{5}$ ), the garden-bed is comparable to a field of one kind which is flanked by different kinds on all four sides. In G., Judah says that six kinds, rather than one, may be sown in the gardenbed itself (fig. $13^{6}$ ). Accordingly, each of these six kinds covers an area measuring six by one handbreadths. Judah's saying here is then consistent with his ruling in $\mathrm{M.} 3: 3$, which states that a row of vegetables of one kind which is sown in a field of another kind of vegetables need measure about six by one handbreadths (Bert., GRA). 7

$C-D$ states that thirteen kinds may be sown in and around a bed which has a border measuring one handbreadth high. One kind is to be sown in the bed itself, as in A-B, but now three kinds may be sown on each side. One kind is sown along the inner edge of the side, a second kind is sown on the border itself, and a third kind is sown just outside of the border (GRA; cf. fig. 158). The border serves to separate the three kinds from one another, so that there is no appearance of diverse-kinds. The garden-bed is again comparable to a field which is flanked by different kinds, only now it is flanked by three kinds, rather than one, on each side.

$\mathrm{E}-\mathrm{F}$ depends on $\mathrm{C}$. According to $\mathrm{E}-\mathrm{F}$ one should not plant the heads (i.e., the hypocotyls ${ }^{9}$ ) of turnips in the border of the garden-bed because they would fill up the border. That is, turnips may not be planted in the border because their leaves would spread out beyond the border and become entangled with the adjacent plants, and so cause the appearance of diverse-kinds.

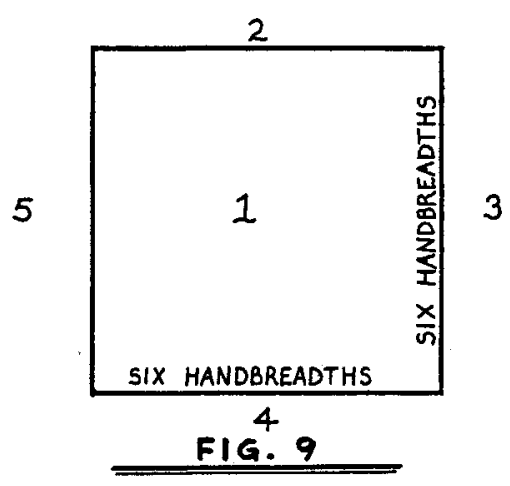




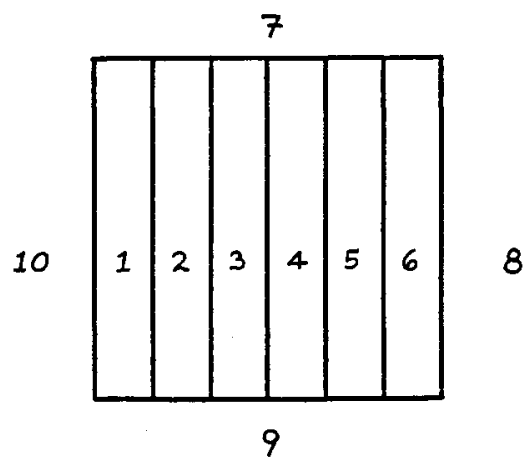

\section{F|G. 13}

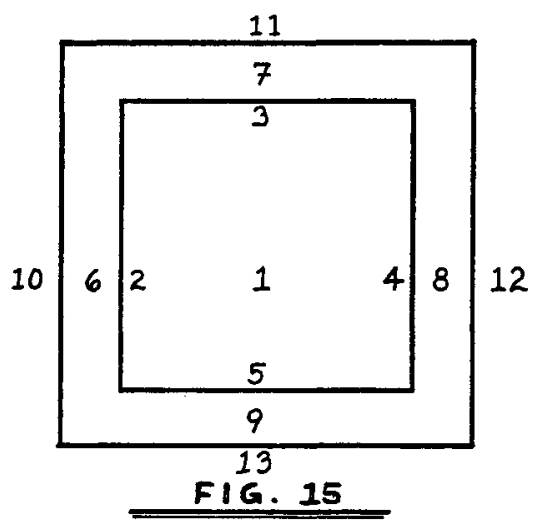

$3: 2$

A. No kind of seeds do they sow in a [B. adds: single] gardenbed,

B. but [= omitted by most mss. ${ }^{10}$ ] all kinds of vegetables do they sow in a [B. adds: single] garden-bed.

C. Mustard and smooth chick-peas ('pwnym hšwpyn; alt. trans.: small chick-peas $\left.{ }^{11}\right)^{12}$ [are considered] kind[s] of seeds,

D. [while] large chick-peas ('pwnym hgmlnym; most mss. ${ }^{13} \mathrm{read}$ hgm(wnym) [are considered] a kind of vegetable. 
E. A border which was [originally] a handbreadth high and became diminished [in height],

F. is fit $(k \bar{s} r)$,

G. for it was fit from [i.e., at] its inception.

H. The furrow and the [dry] water-channel which are a handbreadth deep --

I. (1) they sow in them three [kinds of] seeds,

(2) one on one [side], one on the other [side], and one in the middle.

$$
\begin{aligned}
& \text { M. Kil. } 3: 2(A-B ; \text { B. Pes. } 39 b ; G-H: \\
& \text { Y. Kil. } 3: 1(28 \mathrm{C}))
\end{aligned}
$$

M. 3:2 concerns sowing vegetables in a garden-bed and its borders, and so supplements M. $3: 1$. M. is divided into three parts, $A-D, E-G$, and $E-I$. A-D lists the kinds of plants which may and may not be sown in a garden-bed. E-G presents the case of the border which becomes diminished in height, so that it no longer separates the different kinds along the sides of the garden-bed. H-I concerns the number of different kinds which may be sown in a water-channel or furrow, which, as we shall see, are analogous in this respect to the border.

A-D consists of two sets of balanced declarative sentences, $A-B$ and $C-D$. A and $B$ differ only in that the former reads $z r^{c} y m+$ 'yn $z w r^{c} y m$, while the latter has $y r q w t+z w r^{c} y m . C$ and $D$ also balance one another.

$$
\begin{array}{rr}
\text { C: } & h h r d l w^{\prime p w n y m} \text { hšwpyn myn } z r^{c} y m \\
\text { D: } & \text { 'pwnym hgm Inym myn yrqwt. }
\end{array}
$$

Except for the presence of hhrdl in $C$, the two sentences would be in almost perfect balance ( $\widetilde{s} w p y n+z r^{c} y m v s$. gm Inym + yrqwt). hrdl breaks the tightly disciplined structure of $C-D$ and so appears to be a gloss.

$\mathrm{A}-\mathrm{B}$ refers to the garden-bed of $\mathrm{M}$. 3:1A-B (all commentaries), which contains one kind in its center and a different kind along each of its four sides. According to A-B this garden-bed may be sown with vegetables (i.e., plants which are sown for the sake of their leaves or green [i.e., fresh] seeds [cf. T. Kil. 2:8]), but not with seeds (i.e., plants which are sown for the sake of their dried seeds ${ }^{14}$ ). The reasoning behind $A-B$ is that a garden-bed is considered an autonomous field only when it is sown with vegetables (M. 2:10D). Therefore only a garden-bed 
containing vegetables may be flanked with a different kind on each edge (GRA ${ }^{15}$ ). Different kinds of seeds, however, may not be sown in a garden-bed, for then the latter would not be considered a field unto itself. The different kinds of seeds would simply appear to be sown in confusion, and the appearance of diverse-kinds would result.

C-D states that mustard and smooth chick-peas are considered kinds of seeds, while large chick-peas are a kind of vegetable. C-D clearly intends to contrast the two varieties of chick-peas, and therefore mustard does not belong in $\mathrm{C}$ (even though it is grown for the sake of its seeds). Feliks ${ }^{16}$ explains that the smooth chick-pea is considered a kind of seed because it is eaten either cooked or roasted, while large chick-peas are eaten while still green and so are considered vegetables. 17

$\mathrm{E}-\mathrm{F}$ forms a declarative sentence, with $\mathrm{G}$ glossing $\mathrm{F}$. The language of the apodosis (F-G), ǩsr ("fit"), appears nowhere else in M.-T. Kil. E refers to the garden-bed which is surrounded by a border measuring one handbreadth in height (M. $3: 1 \mathrm{C}-\mathrm{D}$; all commentaries). One kind is sown in the center of the bed, and a different kind is sown on each of the bed's four sides, on the inner edge of the border, on the border itself, and on the outer edge of the border. E describes a case in which the height of the border is dininished, so that the border no longer separates the three different kinds on each side of the bed. According to $F$ the border is still fit, and the plants already sown in and around it are allowed to continue to grow (most commentaries). G explains that since the border was fit (i.e., of sufficient height to separate the different kinds) at its inception, the plants in the garden-bed need not be uprooted, even though they may produce the appearance of diverse-kinds. According to $\mathrm{H}-\mathrm{I}$ a furrow ${ }^{18}$ or water-channel which is one handbreadth deep may be sown with three different kinds. ${ }^{19}$ one kind is sown in the center of the furrow or channel, while a different kind is sown at each of the sides. The furrow or channel is then analogous to the border of M. 3:lC-D, which may be sown in a similar manner. The analogy, in fact, is appropriate, for the furrow or water-channel, being one handbreadth deep, is the mirror-image of the border, which is one handbreadth high.

A. The mustard and the smooth [Lieberman, ${ }^{20}$ following $\mathrm{Y} .$, reads క̋pyn for šypwn; alt. trans.: small ${ }^{2 l}$ ] beans (pwiyn; 
Y.: 'pwnyn ["chick-peas"]) [Y. adds: are a kind of seeds] [= M. 3:2C] --

B. even though [omitted by Y.] he [first printed ed. reads: they] sowed them for [the sake of their] greens (Iyrq),

C. they sow [Lieberman, ${ }^{22}$ following $y$. and first printed ed., corrects to: they do not sow] them in a garden-bed [ $\mathrm{Y}$. throughout reads: they do not place them on a garden-bed].

D. [Erfurt omits D-K] [Concerning] the large beans (pwiyn; Y.: 'wpnyn ["chick-peas"]) [= M. 3:2D] and the cowpea [1it.: Egyptian bean] --

E. when [Y.: which] they sowed them for [the sake of their] seeds $\left(z z r^{c}\right)$,

F. they sow [Lieberman corrects to: they do not sow] them in a garden-bed;

G. [when they sowed them for the sake of their] greens (zyrq),

$H$. they do not sow [Lieberman corrects to: they sow] them in a single [= omitted by first printed ed.] garden-bed.

I. And [concerning] the rest of the field-vegetables and garden-vegetables [Y.: And (concerning) the rest of the garden-seeds which are not eaten] --

$J$. even though he sowed them for [the sake of their] seeds $\left(2 z r^{c}\right)$,

K. they do not sow [Lieberman corrects to: they sow] them in a single [= omitted by first printed ed.] garden-bed.

$$
\begin{aligned}
& \text { T. Kil, } 2: 8 \text { (p, 210, 11. 32-35) } \\
& \text { (Y. Kil. } 3: 2 \text { (28c)) }
\end{aligned}
$$

T. Kil. $2: 8$ comments on M. 3:2A-D, which concerns what may and may not be sown in a garden-bed. T. is divided into three units, $\mathrm{A}-\mathrm{C}, \mathrm{D}-\mathrm{H}$, and $\mathrm{I}-\mathrm{K}$. $\mathrm{A}-\mathrm{C}$ concerns sowing mustard and the smooth bean in a garden-bed (M. $3: 2 C$ ), while $D-H$ deals with the large bean (M. 3:2D) and the cowpea. I-K then presents the rule for sowing a garden-bed with all other kinds of vegetables. The pericope is well-balanced, for each unit consists of a protasis naming the plants under discussion ( $A, D, I)$, a subordinate clause ("even though/when they sown them [for the sake of their] seeds/greens;" $B, E, G, J$ ), and an apodosis (they sow/do not sow; $\mathrm{C}, \mathrm{F}, \mathrm{H}, \mathrm{K})$. D-H is internally well-balanced as well, for it consists of a protasis (D) which is followed by balanced sets of subordinate clauses and apodoses (E-F [seeds + they do not sow] Vs. G-H [greens + they sow]).

According to $M .3: 2$ plants sown for the sake of their seeds 
may not be placed in a garden-bed, while those sown for their greens may be placed there. T. now considers cases in which a plant usually sown for the sake of one item is actually sown for the sake of another. T. A-C rules that mustard and the smooth bean (= smooth chick-pea), both of which are classified by $M$. as kinds of seeds, may not be sown in a garden-bed even if they are sown for their greens (i.e., the plant itself or green seeds). The point of $T .$, then, is that a plant is considered a kind of seed or vegetable according to the purpose for which it is usually sown, regardless of the owner's actual intention in sowing it.

$\mathrm{D}-\mathrm{H}$ concerns the large bean (= large chick-pea), which $\mathrm{M}$. considers a kind of vegetable, and the cowpea. ${ }^{23} \mathrm{~T}$. states that these plants may be sown in a garden-bed if they are sown for the sake of their greens, but not if they are sown for their seeds. In this case we do take account of the owner's intention in sowing the plants, for they are apparently not generally sown for the sake of one item rather than the other. Therefore they may not be classified as either seeds or vegetables without determining the owner's purpose in sowing them. The large bean apparently may be eaten aried as well as green, and both the dried cowpea and its green pod are edible. ${ }^{24}$

$I-K$ states that all other kinds of vegetables may be sown in a garden-bed even if they are sown for the sake of their seeds. The point of $I-K$ is then the same as that of $A-C$. In determining whether a plant is a kind of seed or vegetable, we consider only the usual purpose for which the plant is sown, and not the owner's intention in sowing them.

$3: 3$

A. [If] the point of the angle of a field (rw $\breve{s} t w$ ) of vegetables entered a field of another [kind of] vegetables,

B. it is permitted [to grow one kind of vegetables in the field of the other kind];

c. for it [i.e., the point of the angle of the vegetable-field] looks like the end of his field (kswp $\delta d h w ;$ Geniza fragment, 25 $\mathrm{N}$ : bswp sdhw "for it appears at the end of his field").

D. [If] his field was sown with [one kind of] vegetables, and

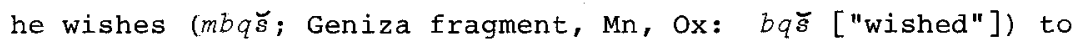
plant in it a row of another [kind of] vegetables --

E. R. Ishmael says, "[He may not do so] unless the furrow is open [i.e., extends] from one end of the field to the other." 
F. R. CAqiva says, "[The row must measure] six handbreadths [in] length and fully as wide [so Danby for $r w h b \quad m l w ' w$ ]."

G. R. Judah says, "The width [of the row] must be as wide as the width of the sole of a foot [so Danby for rwhb hprsh]."

$$
\begin{aligned}
& \text { M. Kil. } 3: 3(A-C: \text { B. Shab. } 85 b ; \\
& \text { G: B. Shab. } 85 a)
\end{aligned}
$$

M. Kil. 3:3 concerns sowing different kinds of vegetables among one another. M. consists of two parts, A-C and D-G. A-C deals with a triangular area of one kind of vegetables which grows in a field of vegetables of another kind. D-G concerns sowing a row of one kind of vegetables in a vegetable-field of a different kind.

A-C is identical to $M .2: 7 \mathrm{~A}-\mathrm{C}$, except that here M. concerns two kinds of vegetables instead of wheat and barley. According to $\mathrm{A}-\mathrm{C}$, the point of the angle of a field containing one kind of vegetables may be allowed to grow in a field of another kind, since that point appears to mark the end of its own field. There is therefore no appearance of diverse-kinds, even though vegetables of one kind actually grow in a field of another kind.

$\mathrm{D}$ describes the case of one who wishes to sow a row of one kind of vegetables in a field already sown with vegetables of another kind. In E-F Ishmael and CAqiva dispute concerning the minimum area which such a row must cover in order to be considered an autonomous field. Judah glosses CAqiva's opinion in G and so provides it with an Ushan attestation. Now this dispute poses linguistic, formal, and substantive difficulties. First, the language of the superscription (D) does not correspond to that of Ishmael's ruling (E), for the former concerns a row ( $\breve{s} w h$ ), while the latter discusses a furrow $(t / m)$. Second, the two opinions of the dispute (E-F) are not balanced, and they are phrased in entirely different terms. Ishmael presents his ruling in terms relative to the field, while $C_{\text {Aqiva }}$ provides a Iinear measure. It is clear, then, that the dispute of $\mathrm{D}-\mathrm{F}$ has been artificially constructed from two autonomous sayings.

In $\mathrm{E}$ Ishmael states that, in a field of one kind of vegetables, only an open furrow may be sown with a secondary kind. Since such a furrow extends across the entire length of the field, it is considered to be marked off from the rest of the field and so autonomous of it. ${ }^{26} \mathrm{C}_{\text {Aqiva }}$ says in $\mathrm{F}$ that the area covered by the secondary kind must measure six handbreadths long and fully 
as wide, or six handbreadths square. CAgiva's rule is identical to the anonymous law of M. 2:10D, which states that a secondary kind of vegetables sown in a vegetable-field of another kind must cover an area measuring six handbreadths square. Such an area, however, is not a row but a garden-bed (cf. M. 3:1). CAgiva then does not rule concerning a row of one kind in a field containing a different kind, but only concerning a garden-bed which is autonomous of the surrounding field.

In $G$ Judah glosses CAqiva's ruling, for the language of his saying ( $\left.r h b \mathrm{~km} l^{\prime}\right)$ corresponds to that of CAqiva's $(r h b \quad m l w ' w) .^{27}$ According to Judah the width of the area containing the secondary kind need measure only the width of the sole of a foot. B. (B. Shab. 85b) and Y. (Y. Kil. $3: 3$ (28b)) explain that this width equals a handbreadth. Judah maintains that a row measuring six by one handbreadths is considered a field unto itself (cf. M. 3:IG). An autonomous row need be only as long, but not as wide, as a garden-bed. Judah thus reads the concerns of the dispute (i.e., the row of another kind) into CAgiva's opinion, and revises that opinion accordingly. Now CAqiva and Ishmael both speak of rows, differing only with respect to the minimum length of the latter (open furrow vs. six handbreadths). Judah thus attests the entire dispute of $D-F$ to Usha.

\section{$3: 4$}

A. He who plants two rows of chate melons, two rows of gourds, [and] two rows of cowpeas -- it is permitted.

B. [He who plants] a row of chate melons, a row of gourds, [and] a row of cowpeas -- it is prohibited.

c. [He who plants] a row of chate melons, a row of gourds, a row of cowpeas and a row of chate melons --

D. R. Eliezer 28 permits,

E. and sages prohibit.

M. Kil. 3:4 (A-B: B. Shab. 85b)

M. Kil. $3: 4$ concerns planting rows of different kinds of vegetables next to one another, and so continues the discussion of M. 3:3D-6, which dealt with sowing a row of one kind of vegetable in a field of another kind. M. consists of two mildly apocopated sentences at $A$ and $B$ (in the "he-who. . . it-is" formulary pattern), and a dispute between Eliezer and sages at $\mathrm{C}-\mathrm{E}$. The pericope is tightly constructed, for the protases are identical to one another except for the shift of a single variable from $A$ to $B$ and again from $B$ to $C$. A has two rows of each kind 


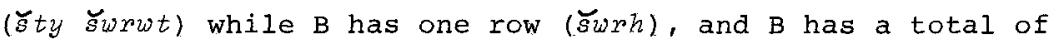
three rows while $C$ has four. In addition, the apodoses use the same language throughout the pericope $(m w t r /$ 'sw $x)$.

M. discusses different ways in which rows of chate melons, gourds, and cowpeas may and may not be planted together. All of these plants are climbing plants, so that the point of $M$. is to define when such plants, which may easily become entangled with each other, may be planted next to one another without producing the appearance of diverse-kinds. According to $A$ one may plant two rows of each kind next to one another. Each set of two rows is considered a field unto itself (Maim,, Comm, and other commentaries), and there is therefore no appearance of diversekinds. B states that individual rows of each kind may not be planted next to each other. A single row of climbing plants is not considered an autonomous field, and, since the plants in each row would become entangled with the plants of the next row, a planting of individual rows next to one another would cause the appearance of diverse-kinds.

$\mathrm{C}$ describes a case in which individual rows of chate melons, gourds, cowpeas and chate melons adjoin one another. In D Eliezer permits such an arrangement, for he maintains that the two rows of chate melons combine to form an autonomous field, which then contains single rows of gourds and cowpeas (as in M. 3:3D; Y., Maim., Comm, , and other commentaries). ${ }^{29}$ Sages disagree with Eliezer in $E$, for they say that the two separated rows of chate melons do not combine to form a field unto itself. Accordingly, the case of $C$ (four individual rows) is no different from that of $B$ (three individual rows), and the planting described in $\mathrm{C}$ is prohibited.

A. One who plants two rows of chate melons, two rows of gourds, two rows of watermelons, and two rows of musk melons, and two rows of cowpeas -- even his entire field is permitted [Erfurt, Sirillo read: One who plants two rows of chate melons, two rows of gourds, and two rows of cowpeas [= M. 3:4A] -- even his entire field is permitted].

$$
\text { T. Kil. 2:11 (p. 211, 11. 44-46) }
$$

T. Kil. 2:11 comments on M, 3:4A, and follows the apocopated sentence-structure of $\mathrm{M}$. T. cites $\mathrm{M}, 3: 4 \mathrm{~A}$, adding watermelons and musk melons ${ }^{30}$ to $\mathrm{M}$.'s list of climbing plants (the variant readings cite $M$. verbatim). T. states that an entire field may be laid out in sets of two rows of climbing plants. T. then 
carries forward the rule of M. 3:4A that one may plant such sets next to one another. The point of $T$. is that each set is considered an autonomous field, so that even if many such sets are planted in a single field there is no appearance of diverse-kinds.

\section{$3: 5$}

A. A man plants a chate melon and a gourd in a single hollow,

B. provided that one leans to one side, and the other leans to the other side;

C. [most mss. ${ }^{31}$ omit C-D] and the foliage [so Danby for $s^{c} r$; 1it.: hair] of one leans to this side, and the foliage of the other leans to the other side;

D. for whatever the sages prohibited, they [so] decreed only on account of appearances $\left(m r^{\prime} y t^{c} y n\right)$.

M. Kil. $3: 5$

M. Kil. 3:5 concerns planting chate melons together with gourds, and so continues the discussion of M. 3:4, which deals with planting rows of such plants next to one another. M. consists of a simple declarative sentence (A) followed by a subordinate clause (B). C then repeats $B$, and D glosses $A-C$. $C-D$ does not appear in most manuscripts, however, and it probably forms a commentary to $A-B$ which has been mistakenly inserted into the text (zachs $\left.{ }^{32}\right)$.

A-B states that one may plant a chate melon and a gourd in the same hollow as long as the two plants lean in different directions. In this way the two climbing plants do not become entangled with one another, and so do not produce the appearance of diverse-kinds (Maim., Comm.). According to $D$ the point of $A-B$ is that two plants may be planted even in the same location, provided that they do not produce the appearance of diverse-kinds. That is, only the appearance of diverse-kinds, but not their actual planting, is prohibited.

A. (1) A man is permitted to make in his field small furrows, [each measuring] a handbreadth [by a] handbreadth, and to place in them three [Erfurt omits:] three kinds,

(2) one on one side, one on the other side and one in the miadre $[=\mathrm{M} .3: 2 \mathrm{H}-\mathrm{I}] ;^{33}$

B. [Erfurt omits:]

(1) A man is permitted to make in his field small garden-beds [each measuring] six [by] six handbreadths, and to place in them five kinds, 

(2) four along the four sides of the garden-bed, and one in the middle [= M. $3: 1 \mathrm{~A}-\mathrm{B}]$;

c. And a man is permitted to make in his field a small hollow which is a handbreadth deep, and to place in it four kinds [Y.: seeds];

D. and he turns them [Y.: and to turn them] to its four sides [i.e., he turns each plant so that it faces a different direction].

$$
\begin{aligned}
& \text { T. Kil. } 2: 9 \text { (pp. 210-2ll, 1l. 36-4l) } \\
& \text { (C-D: Y. Kil. 3:4 (28d)) }
\end{aligned}
$$

E. And a man is permitted to make in his field a furrow in order to plant [in it] chate melons and gourds, watermelons and musk melons [Lieberman ${ }^{34}$ deletes:] and cowpeas;

F. and he turns some to one side, and others to the other side;

G. provided that there be [following Lieberman ${ }^{35}$ ] six handbreadths between one [plant] and its neighbor.

$$
\text { T. Kil. } 2: 10 \text { (p. 211, 11. 41-43) }
$$

T. 2:9-10 forms a commentary to M. $3: 1,3: 2$ and $3: 5$, as it presents a series of rules concerning the number of different kinds which may be sown in given areas. The pericope is formally a unitary composition, for each rule opens with the phrase "A man is permitted to make in his field. . ." T. is divided into five parts, four rules (A [sowing in small furrows], B [small garden-beds], C-D [small hollows], and E-F [furrows]) and G, which glosses all of the foregoing rules.

A restates $M .3: 2 \mathrm{H}-\mathrm{I}$ (citing $I(2)$ verbatim), which says that one may sow three different kinds in a furrow or water-channel. $T$. differs from M. only in reading "small furrows" in place of "furrow or water-channel." T. then either clarifies M.'s "furrows" or supplements the list of $M$. with a third type of area which may be sown with three different kinds.

B similarly rephrases M. 3:1A-B (citing B(2) verbatim), which states that one may sow five different kinds in a garden-bed measuring six handbreadths square. T. reads "small garden-beds" in place of M.'s "garden-bed," but since both types of beds are equal in area, this difference in language is of little consequence.

C-D supplements the rule of M. 3:5A-B. The latter states that one may plant a chate melon and a gourd in a single hollow, provided that the plants lean in different directions. C-D has the same rule (in different language), but speaks of planting four different kinds instead of a chate melon and a gourd. T. then presents a different version of the rule of M., one which deals 
with four kinds instead of two.

$E-F$ supplements $C-D$. According to $E$ one may plant chate melons, gourds, watermelons, and musk melons in a single furrow. $\mathrm{E}$ concerns four kinds, as $\mathrm{C}$ does, only now these kinds are planted in a furrow instead of a hollow. $F$ then repeats $D$.

T. A-F thus links three rules of $M .{ }^{36}$ and supplements them, so that the point of $T$. is to join together the laws of $M .3: 2 \mathrm{H}-\mathrm{I}$, M. 3:1A-B, and M. 3:5A-B. G, however, glosses A-F, adding that in each case the plants sown together must be separated from one another by a distance of six handbreadths. Now this condition is immediately satisfied in the case of $B$ (where the plants are sown along an area measuring six handbreadths square), but it cannot be met in the other three cases, the areas of which (small furrows, small hollows, and a furrow) are too small to allow for the plants to be separated by such a distance. In fact, the point of all four rules is that the different kinds may be sown next to one another without producing the appearance of diversekinds. By introducing a condition which requires the plants to be separated from one another, $G$ effectively contradicts the point of the entire pericope.

$3: 6$

A. [If] his field was sown [with] onions, and he wishes

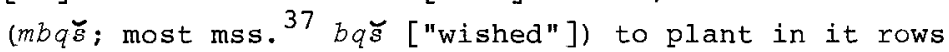
(šwrwt; B, C, Geniza fragment, 38 o, ox: swrh ["a row"]) of gourds --

B. R. Ishmael says, "He uproots two rows [of onions] and plants one row [of gourds],

c. "and leaves the standing crop of onions over a space of two rows [so Danby for wmnyh qmt bṣlym bmqwm šty šwrwt],

D. "and [again] uproots two rows [of onions] and plants one row [of gourds]."

E. R. CAqiva says, "He uproots two rows [of onions] and plants two rows [of gourds],

F. "and leaves the standing crop of onions over a space of two rows,

G. "and [again] uproots two rows [of onions] and plants two rows [of gourds]."

H. And sages say, "If there are not twelve amot between one row [of gourds] and the next, he shall not allow the seed [sown] between [the rows] to grow." 39 
M. Kil. $3: 6$ continues the discussion, begun in M. 3:4-5, of planting gourds with other kinds. M. is divided into three parts, a superscription (A), a dispute between Ishmael and $C_{\text {Aqiva }}(B-G)$, and a saying of sages (H). The dispute of $B-G$ is well-balanced, with each opinion consisting of three clauses (B-D vs. E-G). The first and third clauses balance each other (twotone/twotone vs, twottwo/two+two), and the two middie clauses ( $C$ and $F$ ) are identical. The two rulings are internally balanced as well, for the first and third clauses of each opinion are identical. B-D then has the number-sequence twotone/two/ twotone, while E-G has two+two/two/twottwo.

A describes a case in which one wishes to plant gourds in a field already sown with onions. ${ }^{40}$ The planting of gourds among onions creates a problem in that the former may spread out and cover most of the latter, and so produce the appearance of diverse-kinds. Ishmael and ${ }^{C_{A q}}$ iva then dispute whether the planting of gourds need be restricted in order to avoid the appearance of diverse-kinds, or whether only the actual planting of diverse-kinds is prohibited. While both authorities agree that the gourds are to be planted in the space of two rows, 41 or the area of an autonomous field (cf. M. 3:4), they differ as to whether or not the two rows are to be fully planted. ${ }^{42}$ Ishmael maintains that only one row of gourds may replace the two rows of onions (Maim,, Comm., and others; cf. fig. 1743). ${ }^{44}$ He apparently reasons that if two rows of gourds were to be planted they would spread out to such an extent that they would cover the majority of the onions. There would then not appear to be a full two rows of onions between the rows of gourds, and the appearance of diverse-kinds would result. According to CAqiva, however, one may plant the two rows of gourds in place of the two uprooted rows of onions (fig. 18). Even if these two rows of gourds were to spread out and obscure the remaining onions, the latter would still cover the area of two rows and so continue to form an autonomous domain. The planting of two rows of gourds is then permitted because it does not cause the actual growth of diverse-kinds, regardless of the subsequent appearance of the field. 45

The opinion of sages in $\mathrm{H}$ depends on $\mathrm{A}$. $\mathrm{H}$ is connected to $\mathrm{B}-\mathrm{G}$ only by the conjunction $w$, which is standard joininglanguage, and sages' saying is, in fact, autonomous of the foregoing dispute. According to sages one may allow the onions to 
remain between the rows of gourds only if the latter are separated by twelve amot. Sages are then concerned not with the number of rows of gourds which may be planted together, but with the distance which must be maintained between the rows. They apparently reason that the row of gourds must be separated by a fixed distance, so that the gourds do not cover most of the onions between them and so produce the appearance of diverse-kinds. The point of sages' saying is then similar to that of Ishmael's (i.e., the avoidance of the appearance of diverse-kinds), even though the two opinions are phrased in entirely different terms. ${ }^{46}$

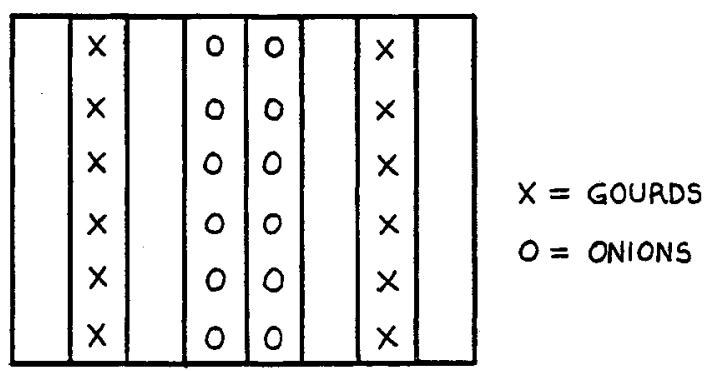

FIG. 17

FIG. 18

$X=$ GOURDS $\quad$\begin{tabular}{c|c|c|c|c|c|}
$x$ & $x$ & 0 & 0 & $x$ & $x$ \\
$x$ & $x$ & 0 & 0 & $x$ & $x$ \\
$x$ & $x$ & 0 & 0 & $x$ & $x$ \\
$x$ & $x$ & 0 & 0 & $x$ & $x$ \\
$x$ & $x$ & 0 & 0 & $x$ & $x$ \\
$x$ & $x$ & 0 & 0 & $x$ & $x$ \\
\hline
\end{tabular}

A. A summary [alt, trans: the essential point ${ }^{47}$ ] of the opinions of both [authorities] $\left(q g_{r}\right.$ dbry క̆nyhm; Erfurt: hqwṣr šnyhm; first printed ed.: hqwṣx dbry צnyhm; Y.: hqwşb dbry šnym; Sirillo ${ }^{48}$ : qṣb labry šnyhm):

B. $\left[\mathrm{I}\right.$ omits $\left.\mathrm{B}-\mathrm{C}^{49}\right] \mathrm{R}$. Ishmael says, "Ten [Y.: Twelve] amot [need separate the rows of gourds from one another]." 
C. R. CAqiva says, "Eight amot [need separate the rows of gourds from one another]."

D. $m^{\breve{c}} \xi h$ hyh in Kefar Pegai and R. Nehemiah ruled [Lieberman, 50 following Erfurt, reads $h w r h$ for $h w d h]$ according to the opinion of $R$. Ishmael.

$$
\begin{aligned}
& \text { T. Kil. } 2: 12 \text { (p. } 211,11.46-48) \\
& \text { (A-C: Y. Kil. } 3: 6 \text { (28d)) }
\end{aligned}
$$

T. Kil. $2: 12$ comments on M. 3:6. T. is divided into two parts, $A-C$ and D. A-C restates the dispute between Ishmael and

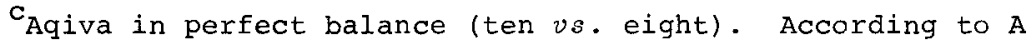
B-C summarizes the dispute of M. 3:6.51 The dispute, which in M. 3:6B-G concerns the number of rows of gourds which may be planted together among the onions, is now phrased in terms of the sages' opinions in M. 3:6H. All three opinions (M. H, T. B-C) may be summarized in the number-sequence twelve/ten/eight.

Let us now consider how T.'s version of the two opinions is related to that of $\mathrm{M}$. According to $\mathrm{M}$. Ishmael maintains that one plants a single row of gourds for every two uprooted rows of onions, allows the next two rows of onions to stand, and repeats the process. T. has Ishmael state that ten amot must separate the rows of gourds from one another. If we assume (following the supposition of $\mathrm{Y}$. ) that a row measures four amot in width, then T.'s restatement of M. may be explained as follows. one uproots two rows of onions (total width = eight amot) and replaces them with a single row of gourds (width = four amot), which is planted down the center of the two uprooted rows. Two amot, which are left uncultivated, then flank the row of gourds on each side. The next two rows of onions (total width = eight amot) are left standing, and a row of gourds is then planted adjacent to them. The two rows of gourds are then separated by ten amot (cf. fig. 21). We note, however, that this distance will not exclusively separate rows of gourds which are planted serially in a field of onions (as the succeeding rows will be alternately separated by fourteen and ten amot; cf. fig. 22). It is therefore possible that $Y$. and samuel (cited by $Y_{.}$)., who read "twelve amot," have the better reading, for intervals measuring twelve amot do repeatedly separate rows of gourds which are planted throughout a field (cf. fig. 23). 52 Alternatively, however, Y. may simply correct the reading of $T$. to agree with the ruling of sages in M. 3:6H (Porton ${ }^{53}$ ). 
In M. 3:6 C Aqiva states that two rows of gourds may replace the two uprooted rows of onions. According to T. 2:12C $\mathrm{C}_{\text {Aqiva }}$ maintains that eight amot must separate the rows of gourds from one another. If we again assume that a row measures four amot in width, then T.'s version of CAqiva's opinion clearly follows from that of $M$. Since the areas which are no longer covered by onions are now fully planted with gourds, only the two rows of onions remaining between the gourds, the total width of which is eight amot, separate the paired rows of gourds from one another (cf. fig. 25).

$\mathrm{D}$ is phrased in the form of a $\mathrm{m}^{\mathrm{c}} \xi \mathrm{h}$. D states that in Kefar Pegai ${ }^{54}$ Nehemiah once ruled according to Ishmael's opinion. In its present context $D$ supports Ishmael's ruling in $M .3: 6$. $D$ itself, however, describes neither the details of the case in Kefar Pegai nor the particular ruling of Nehemiah, and so need not refer to the case of M. 3:6 at all. Rather, D could support

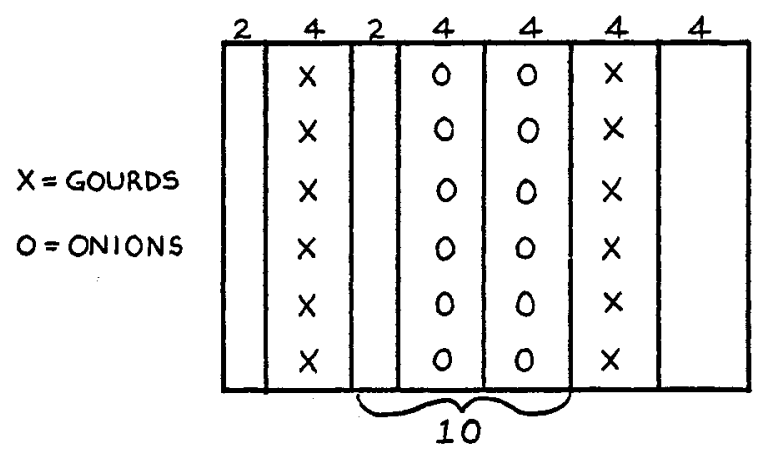

FIG. 21

FIG. 22

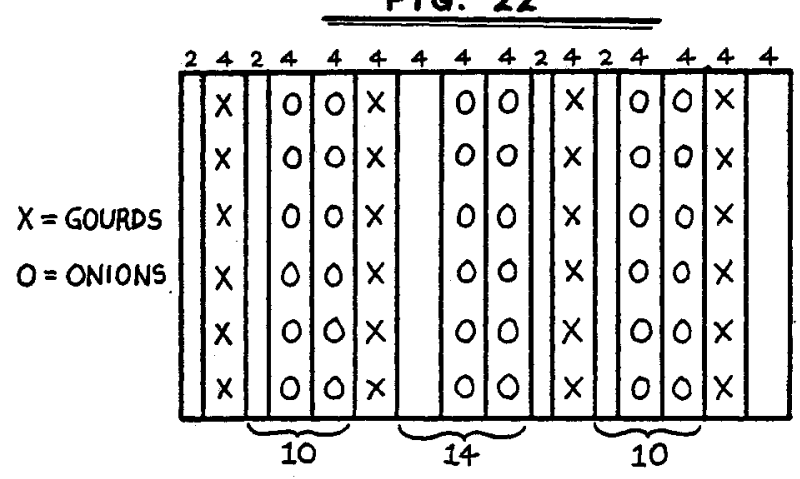


any ruling of Ishmael equally well. D. then does not provide a good attestation for Ishmael's views in M. 3:6.

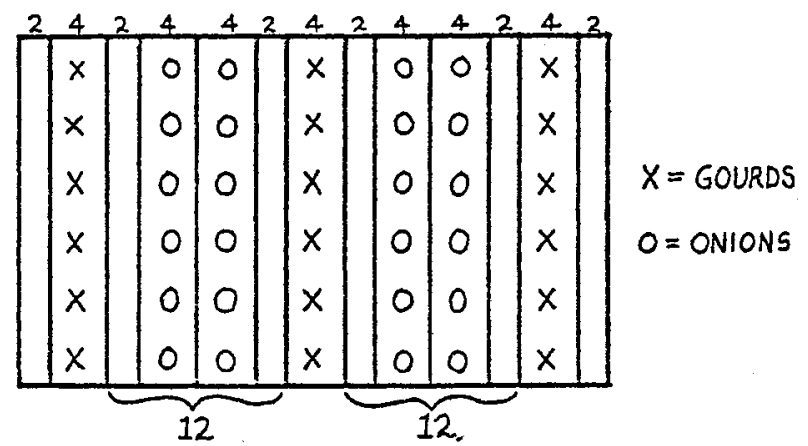

FIG. 23

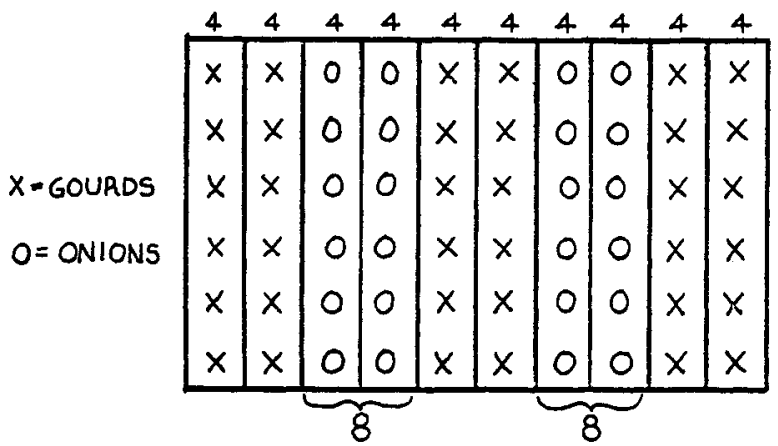

FIG. 25

$3: 7$

A. Gourds [which are to be planted in a field containing mostly] vegetables [are considered] as vegetables [of one kind which are to be sown among another kind of vegetables] [i.e., the gourds require a space measuring six handbreadths square $(=$ M. $2: 10 \mathrm{D})]$.

B. And [concerning gourds which are to be planted in a field containing mostly] grain -- they allow it [i.e., them] a bet rovac.

c. [If] his field was sown with grain, and he wished to plant in it a row of gourds,

D. they allow it [i.e., the row of gourds], as ( $l$; omitted by $\mathrm{B}, \mathrm{C}$, Geniza fragments, ${ }^{55} \mathrm{~K}, \mathrm{Mn}, \mathrm{O}, \mathrm{Ox}, \mathrm{Pr}$ ) the area required for its tillage $\left([l]^{c} b d t h\right)$ six handbreadths; 
E. and if [the gourd(s)] grew larger [i.e., the gourds extended beyond the area allotted for its tillage], he shall uproot ( $y^{c} q r ;$ most mss. $\left.{ }^{56}: y^{c} q w r\right)$ [the grain (Maim.) ${ }^{57}$ ] from before it.

F. R. Yose says, "They allow it [i.e., the row of gourds] as the area required for its tillage, four amot."

G. They said to him, "Will this [i.e., the rule in the case of the gourd] be more stringent than [the rule in the case of ] the vine?"

H. He said to them, "We have found that this [i.e., the rule in the case of the gourd] is more stringent than [the rule in the case of] the vine,

I. "for to a single vine they allow [L, S, sn add: as] its area for tillage, six handbreadths, but $(w)$ to a single gourd they allow a bet rovac."

J. R. Meir says in the name of R. Ishmael, "Wherever $(k \imath)^{58}$ [there are three gourds per bet se'ah, he shall not bring seed [of another kind] into the bet $s e^{\prime} a h$.

K. R. Yose b. HaḤotef (hhwtp; K (before correction), MS, S: $h^{c} w t p$; Geniza fragments: $h^{c} t w p$ or $\left.h^{c} y t w p\right)$ the Ephrathi said [B, Mn, S: says] in the name of $R$. Ishmael, "Wherever $(k l)$ [there are] three gourds per bet kor, he shall not bring seed [of another kind] into the bet kor."

M. Kil. 3:7

M. Kil. $3: 7$ concludes the subunit concerning the planting of gourds with other kinds. M. is divided into three parts, $A-B$, $\mathrm{C}-\mathrm{I}$, and $\mathrm{J}-\mathrm{K}$. A-B concerns planting an autonomous field of gourds in a field sown mostly with vegetables or grain and so continues the interest of M. 3:6 in planting gourds in a field of another kind. C-I deals with planting a row of gourds in a field already sown with grain. $J-K$ then discusses sowing another kind in a field already planted with gourds.

A states its law in a declarative sentence. B depends on A for its subject ("gourds"), and a reversal of its word-order would yield a declarative sentence ("They allow gourds [which are to be planted in a field containing mostly] vegetables a bet rovac"). The protases of $\mathrm{A}-\mathrm{B}$ (gourds + vegetables, gourds + grain) are similar to those of M. 2:l0C-F (e.g., grain + grain, vegetables + vegetables, etc.) and the apodosis of $B$, without the phrase nwtnyn ih ("they allow it") is identical to the apodoses of M. 2:10C+E (bet rova $a^{c}$ ). 59 According to A gourds which are to be planted among vegetables are considered as vegetables of 
one kind which are to be sown in a field of another kind of vegetables. A then apparently presupposes the law of M. 2:10D, which says that in the latter case the secondary kind of vegetable must be sown in an area measuring six handbreadths square. B states that gourds which are to be planted in a field of grain must be allowed a bet rovac. Gourds are then treated as vegetables in this instance as well, for M. 2:10D-E gives the same rule in the case of vegetables which are to be sown among grain. $A-B$ thus follow Aqiva's reasoning in $M$. 3:6 that gourds are treated as vegetables.

C-I consists of two parts, a dispute at C-F and a debate at G-I. C-D presents a law in a declarative sentence which is then glossed by E. In F Yose glosses and opposes C-D (and so attests it to Usha). The dispute is well-balanced, for $D$ and $F$ differ only in that one has క̌sh țphym while the other reads $' r b^{c}$ 'mwt. In G-I Yose debates anonymous authorities (presumably those behind the ruling of $(-D)$ concerning his opinion in F. Yose has the last say in $\mathrm{H}-\mathrm{I}$ and so wins the debate.

$C$ describes a case in which one wishes to plant a row of gourds in a field already sown with grain. According to $D$ the gourds must be planted in an area measuring six handbreadths square ( ${ }^{C}$ Aqiva's ruling in $M, 3: 3 \mathrm{~F}$ concerning a row of vegetables sown in a vegetable-field of another kind). C-D then also follows Aqiva's view in M. 3:6 that gouras are no different from other vegetables. E adds that if the leaves of the goüds extend beyond this space, the adjacent grain is to be uprooted. The two kinds will then not become entangled with one another and produce the appearance of diverse-kinds (Maim., Code, DiverseKinds 3:13). ${ }^{60}$ In $F$ Yose disagrees with $D$, saying that the area of tillage for a row of gourds is four amot (presumably) square. Now the distinction between these two measures of an area of tillage is made with reference to grapevine or the vineyard (defined either as five grapevines or two rows [M. 4:5]) (cf. the debate at $\mathrm{G}-\mathrm{I}$ ). The area of tillage of the former is $\mathrm{six}$ handbreadths square, while that of the latter is four amot square (M. 6:1, following Maim., Comm.; cf. also Maim., Comm. to M. 4:1, and Maim., Code, Diverse-Kinds 7:1). The dispute of $D+F$ then concerns whether a row of gourds is analogous to a grapevine (or a single row of vines) or a vineyard. The reasoning behind $D$ is that there is no difference between a row of gourds and a row of vines, so that the former requires an area of only six handbreadths square. Yose, on the other hand, apparently reasons that gourds tend to spread out to such an extent that a single row of them must be allowed the area usually allotted to 
a vineyard. The dispute of $D+F$ thus concerns the area of tillage of a row of gourds, but it has little to do with C's particular problem of planting a row of gourds in a field of grain. The opinions of the dispute do not relate closely to the issue of the superscription.

In $G$ anonymous authorities oppose Yose's ruling, asking why the law in the case of a row of gourds should be more stringent than that in the case of a row of vines. That is, they ask why, according to Yosé, a row of gourds should require an area measuring four amot square, while a row of vines requires an area of only six handbreadths square. In asking about the difference between gourds and vines, the authorities of $G$ focus upon the point of Yose's ruling, i.e., that a row of gourds is considered as a vineyard rather than as a row of vines. In H-I Yosé answers, in language identical to that of the question, that it is indeed true that the law is more stringent in regard to gourds than it is inrespect to vines. The area of tillage of a single gourd need measure a bet $\operatorname{rova}^{c}(\mathrm{~B})^{61}$ while that of a single vine need measure only six handbreadths square. Similarly, therefore, the area of tillage of a row of gourds should be larger than that of a row of vines. Now while the argument of $\mathrm{H}-\mathrm{I}$ supports Yose's point that the law for gourds is more stringent than that for vines, at the same time it seems to undermine his position at $F$. For if the area of tillage of a single gourd is a bet rovac, it follows that the area of tillage of a row of gourds should measure at least a bet rova $a^{c}$, and not merely four amot square. ${ }^{62}$ Yosé's opinion in $F$ is therefore not supported by the argument of $\mathrm{H}-\mathrm{I}$.

$\mathrm{J}-\mathrm{K}$ is autonomous of the rest of the pericope, but it is related to the foregoing in that it concerns sowing seeds of another kind in a field already planted with gourds. This unit then reverses the circumstances of $A-B$ and $C-D$, in which gourds are planted in a field already sown with another kind. In $\mathrm{J}-\mathrm{K}$ Meir and Yose b. HaHotef present two versions of an Ishmaeltradition which differ from one another in only one word (se'ah vs. kor). According to both authorities Ishmael states that one may not introduce a different kind of seed in a field of a specified size which already contains three gourds. Meir maintains that the saying gives the area of the field as a bet se'ah, while Yose b. HaHotef says that the saying concerns a bet kor, which is thirty times larger. In either case the point of Ishmael's saying is that once three gourds have been planted in a given area they tend to spread over that area, so that if one were to sow another kind anywhere in the field he would 
appear to be sowing diverse-kinds. As in M. 3:6, Ishmael again takes account of the special properties of gourds and distinguishes them from vegetables, just as (in M. 3:6) he restricts the planting of gourds for the same reason.

A. A row of gourds [which is to be planted in a field containing mostly] vegetables [is considered] [Erfurt, first printed ed., Sens omit:] as [a row of] vegetables [of one kind which is to be sown among another kind of vegetables] [= M. 3:7A] --

B. [i.e., the row must measure] six handbreadths [in] length and fuzzy as wide [= M. 3:3F].

c. It is all the same whether a row of chate melons [Erfurt, Sens, Sirillo, (cited by Lieberman: gourds)] or a row of vegetables of another [kind] [Lieberman, 63 following Sens, sirillo, and PM, reads 'hr for 'hd] [is to be sown in a field containing mostly] grain --

D. [the row must measure] ten-and-one-half amot [in] length by a width [of] six handbreadths [Y.: One who wishes to make a row of vegetables in a field of grain, 10, this one makes (a row) ten-and-one-half amot (in length) by width (of) six (handbreadths)].

E. And a row of vegetables [which is to be sown in a field containing mostly] vegetables [of another kind] --

F. [the row must measure] six handbreadths [in] length and fuzly as wide [Lieberman, 64 following Erfurt, Sens, and Sirillo, reads rwhb for rhbw] [= M. 3:3F].

G. [Erfurt and Sens reverse $\dot{G}-I$ and $J-O$ ] [Erfurt and Sens add: A row (swrh); Sirillo: ${ }^{65}$ A field (sdh)] of gourds [which is to be planted in a field containing mostly] vegetables --

H. between one row ( wwh; Erfurt, Sens: $\xi d h[" f i e l d "])$ and the next [there must be] twe zve amot $[=\mathrm{M}, 3: 6 \mathrm{H}]$;

I. and so [the same rule applies] in [the case of a row of gourds which is to be planted in a field containing mostly] grain [following Iieberman ${ }^{66}$ ].

J. [A row] of grain [which is to be sown in a field containing mostly] vegetables [Lieberman ${ }^{67}$ deletes:] of another kind --

K. [the row must measure] from one end of the field to the other [Erfurt, first printed ed, omit:] [in] length, by a width [of] three open furrows $[=T, 2: 1 B]$.

L. [first printed ed. omits L-O] [A row] of vegetables [which is to be sown in a field containing mostly] vegetables of another [kind] -- 
M. between one row and the next [there must be] six handbreadths;

N. [Sens omits:] and a row of grain [which is to be sown in a field containing mostly grain of another kind (Lieber$\left.\left.\operatorname{man}^{68}\right)\right]$--

o. [the row must measure] three open furrows in width $[=\mathrm{M}, 2: 6 \mathrm{~B}]$.

T. Kil. 2:13 (pp. 211-212, 11. 48-54)

(B: Y. Kil. 2:10 (28b))

T. Kil. 2:13 comments upon and supplements M. 3:7, which concerns planting gourds among vegetables and grain. T. is divided into three parts, $A-F, G-I+L-M$, and $J-K+N-O$, which differ from one another both in their subjects and in the concerns of their apodoses. A-F deals with sowing a single row of gourds or vegetables in a field of another kind, and its apodoses concern the linear dimensions of the minimum area which must be covered by that row. G-I+L-M concern sowing rows of gourds or vegetables in a field containing a different kind, and its apodoses are interested in the distance which must separate the rows from one another. $J-K+N-O$ discuss sowing a single row of grain in a field of a different kind, and its apodoses deal with the minimum dimensions of such a row in terms of the measure of the field and its furrows.

A-F consists of three well-balanced declarative sentences. The protases $(A, C, E)$ all follow the pattern of $\breve{s w h} \xi \mathcal{I} \mathrm{X}$ bY (with $A$ adding kyrq from $M .3: 7 \mathrm{~A}$ and $C$ presenting the pattern twice). The apodoses ( $B, D, F)$ also follow a single pattern, reading rek X w/ ${ }^{C} Z$ rwhb Y. $B$ and $D$ are identical, for both are vebatim citations of M. 3:3F.

A-F comments on $M .3: 7 \mathrm{~A}-\mathrm{C}$. A states that a row of gourds which is to be planted among vegetables is considered as a row of vegetables which is to be sown among vegetables of a different kind. B explains that the row of gourds requires an area of six handbreadths square, as does a row of vegetables according to the ruling of CAgiva in M. 3:3F. T. then supplements M. 3:7A, which concerns planting an area of gourds among vegetables, with a discussion of planting a row of gourds in a vegetable-field. T. thus links M. $3: 7 \mathrm{~A}$ to M. 3:6 (planting a row of gourds among vegetables) and M. 3:3 (sowing of a row of vegetables among vegetables of another kind). According to $C-D$ a row of either gourds (this reading better fits the context than that of "chate melons") or vegetables which is to be sown in a field of grain must measure ten-and-one-half amot by six handbreadths. Now 
ten-and-one-half amot is the measure of one side of a bet rovac (T. 2:6B), so that the length of the row must equal that of a side of a bet rovac, while its width must measure six handbreadths. It appears, then, that in combining these two measures, T. attempts to harmonize M. 3:7.B, which says that an area of gourds planted among grain must measure a bet rovac (taking $B$ to refer to a row), and $M .3: 7 C-D$, which rules that a row of gourds planted in a field of grain must cover an area measuring six handbreadths square. In speaking of rows of vegetables as well, T. may at the same time attempt to harmonize M. 2:IOE(4), which says that vegetables sown among grain must be given a bet rova ${ }^{c}$, and M. 2:l0F, where Eliezer/Eleazar says that in such an instance the vegetables require an area measuring only six handbreadths square (again interpreting both rules as referring to rows). In presenting the same rule (i.e., that a row must measure ten-and-one-half amot) for both gourds and vegetables, T. follows CAqiva's view (M. 3:6) that gourds are to be treated as vegetables. Finally, E-F clarifies A by presenting the rule for vegetables sown among vegetables of another kind, which, of course, is identical to that of $A-B(=M .3: 3 F)$.

G-I+L-M are also composed of declarative sentences. $G$ and I balance one another ( $\breve{l} d Z^{c}$ wyn byrq vs. $\breve{s} z$ yrq byrq 'hr) as do $\mathrm{H}$ and $\mathrm{M}\left(\check{s} t y m{ }^{c} \xi r h{ }^{\prime} m h\right.$ vs. $\left.\breve{s} h t p h y m\right)$. I glosses $\mathrm{G}-\mathrm{H}$ and depends on it for both its subject ("A row of gourds") and its apodosis. According to G-H a row or field (i.e., several rows ${ }^{69}$ ) of gourds planted in a field of vegetables must be separated by a distance of twelve amot. $\mathrm{G}-\mathrm{H}$ then simply restates the ruling of sages in $M .3: 6 \mathrm{H}$ in terms of $A-B$ (a row of gourds planted among vegetables). I adds that the same rule holds in the case of rows of gourds which are planted in a field of grain (following Lieberman; we have interpolated accordingly). I then applies the rule of $M .3: 6 \mathrm{H}$ to the case of $\mathrm{C}-\mathrm{D}$ (a row of gourds planted in a field of grain). I-M states that rows of vegetables of one kind sown in a vegetable field of another kind must be separated from one another by six handbreadths. This rule follows from $E-F$, for if the vegetables between the rows must be allowed an area measuring six handbreadths square, then the rows will be separated by six handbreadths. L-M restates $E-F$ in terms of the consideration of the distance between rows. G-I+L-M then goes over the cases of $A-F$ and reads into them the question of the distance required to separate the rows, which is introduced by sages in $M, 3: 6 \mathrm{H}$. Since $A-F$ comments on $M .3: 7 A-C, T, 2: 13 \mathrm{G}-\mathrm{I}+$ L-M effectively link M. $3: 6 \mathrm{H}$ to $\mathrm{M} .3: 7 \mathrm{~A}-\mathrm{C}$. 
$J-K+N-O$ deal with sowing a row of grain in a field of a different kind, and so supplement the foregoing two units, which concern sowing rows of gourds and vegetables. According to $\mathrm{J}-\mathrm{K}$ a row of grain sown among vegetables must extend for the entire length of the field, and its width must equal that of three open furrows. J-K then applies the rule of $T .2: 1 B$, which concerns the minimum size of rows of different kinds sown adjacent to one another, to the case of a row of grain sown in a field of vegetables. $\mathrm{N}-\mathrm{O}$ states that a row of grain sown among a different kind of grain (so Lieberman; we have interpolated accordingly) must be as wide as the width of three open furrows. $\mathrm{N}-\mathrm{O}$ thus assigns the rule of House of Shammai in $M .2: 6 \mathrm{~B}$, which concerns the minimum size of adjacent rows of different kinds, to the case of a row of grain sown among grain of a different kind. $\mathrm{N}-\mathrm{O}$, however, basically repeats $\mathrm{J}-\mathrm{K}$, and it is therefore probable that, following Sens, we should omit it.

A. All the same are [Lieberman, 70 following Erfurt, corrects 'ht to 'hd] a row of chate melons, and a row of gourds, and a row of watermelons, and a row of musk melons, and a row of cowpeas --

B. [Erfurt adds: and he who; GRA ${ }^{71}$ adds: and one who $\left.\left(w^{\prime} h d\right)\right]$ allows a single stalk [= omitted by Erfurt] [of any of these kinds] to grow [for the sake of its] seed [besides a row of the same kind (HD)],

c. [GRA adds: he must allow the stalk a space measuring a bet rova $\left.{ }^{c}\right]$ and [= omitted by Erfurt; GRA: or] he must make [between the row and the stalk] a partition ten handbreadths high and [with] its width [measuring] four handbreadths.

$$
\begin{aligned}
& \text { T. Kil. } 2: 14 \text { (p. } 212,11,55-57) \\
& \text { (B-C: Y. Kil. } \left.3: 6(29 a)^{72}\right)
\end{aligned}
$$

T. Kil. 2:14 supplements $M .3: 7 \mathrm{~J}-\mathrm{K}$, for both pericopae concern the sowing of seed near trailing plants. $A-C$, with the order of $\mathrm{A}-\mathrm{B}$ reversed, forms a declarative sentence. According to $A-C$ one who, for the sake of its seed, allows a single stalk of any kind of trailing plant to grow beside a row of the same kind (HD). must erect a partition between them. ${ }^{73}$ The point of $T$. is that even if the plants adjoining one another are of the same kind, and even if only a single stalk adjoins the row, that single stalk is considered diverse-kinds with the plants in the row, if the former is planted for its seed while the latter are 
planted for their greens. T. thus supplements in two ways Ishmael's saying in $\mathrm{M}$. 3:7J-K, which states that one may not bring seed into an area already containing three gourds. First, T. rules concerning all kinds of trailing plants and not only gourds, and $T$. concerns rows rather than individual plants. T. may then intend to Iink M. 3:7J-K with $M$. 3:4, for the latter deals with rows of the same kinds of trailing plants as those mentioned in T. ${ }^{74}$ second, T. interprets "seed" $\left(z r^{c}\right)$ to mean not merely anything which is sown (as we have interpreted $z r^{c}$ to mean in the context of M. $3: 7 \mathrm{~J}-\mathrm{K})^{75}$ but specifically that which is sown for the sake of its seed (as in M. 3:2). ${ }^{76}$ With this interpretation of "seed," T. effectively contradicts the point of Ishmael's saying. Ishmael presumably reasons that no seed may be introduced into a field planted with three gourds because the latter could spread out over the newly-sown plants and so produce the appearance of diverse-kinds. The point of $T$. , on the other hand, is that the purpose for which the plants are sown determines whether or not they are considered diverse-kinds with one another, regardless of whether or not there is an appearance of diverse-kinds. 77

A. A gentile who grafted a peach [bud] onto a quince [tree] (cwbs; Erfurt: cwgs ["pear"]) [Y.: (Concerning) a gentile who grafted (the bud of) a nut (tree) onto a peach (tree)] --

B. even though he [first printed ed., Y. add: an Israelite; Lieberman ${ }^{78}$ comments: the gentile] is not [himself] permitted to do so [i.e., to perform such a graft],

c. he [i.e., the Israelite] takes a shoot [= omitted by Erfurt and first printed ed.] from it and [Y. adds: goes and] plants it [Erfurt, first printed ed. add: again] in another place.

D. [If a gentile]grafted a spinach-beet onto an amaranth (yrbwz; first printed ed.: yrbh; Y. drkwn or drbwn (PM) $[=\mathrm{T} \cdot 1: 11 \mathrm{~B}]$--

E. even though the Israelite [= omitted by Erfurt] is not [himself] permitted to do so [i.e., to perform such a graft],

F. he [i.e., the Israelite] takes a seed from it and sows it in another place.

$$
\begin{aligned}
& \text { T. Kil. } 2: 15 \text { (p. } 212,11,56-60) \\
& \text { (Y. Kil. } 1: 4 \text { (27a)) }
\end{aligned}
$$

T. Kil. 2:15, together with T. 2:16 (which follows), form an autonomous subunit dealing with the secondary problem of 
benefitting from diverse-kinds grown by others. These pericopae thus provide a fitting conclusion to T.'s discussion of diverse-kinds of seeds in Chapters one and Two. T. 2:15 is a unitary pericope composed of two parts, $A-C$ and $D-F$. A-C concerns the grafting of a tree bud onto a different tree, while D-F deals with grafting a vegetable onto a plant of a different kind (following the sequence of $\mathrm{M}$. 1:7). The two sections are well-balanced, for each of the three clauses of A-C is almost identical with each of the corresponding clauses of D-F .

A describes the case of a gentile who performed a graft of a peach-bud onto a quince tree, a graft which is presumably prohibited on account of diverse-kinds. According to $B-D$ an Israelite may plant a shoot from the hybrid tree, even though he may not perform the graft itself. ${ }^{79}$ similarly, D-F states that an Israelite may sown the seeds of an amaranth which a gentile has hybridized with a spinach-beet, even though again the Israelite is prohibited from performing such a graft (T. $1: 11 B$ ). The point of $T .$, then, is that one may reproduce a hybrid which results from a graft performed by a gentile (who is presumably not prohibited from grafting diverse-kinds), even though one may not initially produce the hybrid on account of diverse-kinds.

A. An Israelite who allowed diverse-kinds to grow in his field --

B. his brothers [= omitted by Erfurt] the priests do not enter it,

c. but rather consider it [i.e., the diverse-kinds] as a sign [Lieberman 80 following Erfurt and oz, reads kgywn for bsywn] [indicating] a graveyard:

D. They do not produce diverse-kinds with an Israelite [i.e., in the field of an Israelite (Lieberman ${ }^{81}$ )] [first printed ed.: with a gentile ${ }^{82}$ ] [B. A.z. 63b: They do not hoe ('yn $\left.{ }^{c} w d r y n\right)$ diverse-kinds with a gentile],

E. but they uproot diverse-kinds with him [i.e., they uproot diverse-kinds in his field without his permission (Lieber$\operatorname{man}^{83}$ )],

F. because he diminishes the impropriety (tplh; Erfurt, Y.: cbph ["transgression"]).

G. They do not produce diverse-kinds with a gentile [i.e., in the fields of a gentile (Lieberman ${ }^{84}$ )] [Y. adds: either diverse-kinds of the vineyard or diverse-kinds of seeds]. 
H. And in the towns surrounded [Y, adds: by the land

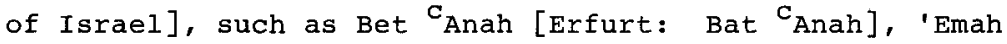
[Erfurt, first printed ed.: 'Umah], and its neighbors,

I. they produce diverse-kinds with a gentile.

$\mathrm{J}$. Just as diverse-kinds [are prohibited] in the Land [of Israel], so are diverse-kinds [prohibited] outside of the Land [of Israel].

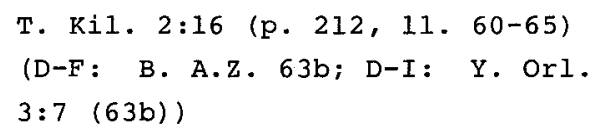

T. Kil. 2:16 continues the discussion of T. 2:15 concerning secondary issues of diverse-kinds. T. is divided into two autonomous parts, $\mathrm{A}-\mathrm{C}$ and $\mathrm{D}-\mathrm{J}$. A-C discusses the significance of the growth of diverse-kinds in an Israelite's field. D-J, perhaps continuing T. 2:15's interest in the issue of deriving benefit from diverse-kinds, concerns the question of sowing diverse-kinds for an Israelite or a gentile.

A-C states its law in an apocopated sentence, for the subject shifts from "the Israelite" in A to "his brothers the priests" in B. According to A-C priests may not enter a field containing diverse-kinds. The assumption behind this rule is that an Israelite will always uproot diverse-kinds, unless the circumstances are such that he cannot use them. Since he has in fact allowed the diverse-kinds to grow, it follows that he did so only because he could not otherwise derive benefit from them, and it is therefore presumed that the area is a graveyard (cf. M. Oh. 18:2-3). The growth of diverse-kinds in an Israelite field is thus taken to be a sign of a graveyard, and priests may not enter the field.

D-J is divided into two parts, D-F and G-J. D and G balance one another, for they differ only in that D has "Israelite" while G has "gentile." E-F glosses D (with the subject changing from plural to singular in $F$ ), while $\mathrm{H}-\mathrm{I}$ qualifies $\mathrm{G}$, with $\mathrm{I}$ balancing and opposing the latter. J then supplements H-I. According to $D$ one may not grow diverse-kinds (presumably for pay) with an Israelite, i.e., in the field of an Israelite (Lieberman). The point of T., then, is that one may not profit from growing diverse-kinds, even if they are grown in the field of another. 85 $E-F$ adds that one may uproot diverse-kinds in the field of an Israelite without his permission (Lieberman), 86 for in this way one lessens the wrong done by the owner of the field. ${ }^{87}$

$G$ expands the ruling of $D$, stating that one may not grow diverse-kinds in the field of a gentile. Qualifying G, H-I 
maintains that one may grow diverse-kinds in a gentile's field which is located in a gentile city surrounded by the land of Israel, such as Bet ${ }^{\mathrm{C}} \mathrm{Anah}$ and 'Emah. ${ }^{88}$ These cities are not considered part of the land of Israel (Lieberman; ${ }^{89}$ cf. T. Ah. 18:4), so that one may help a gentile grow diverse-kinds in them. If we now interpret $G$ in the light of $\mathrm{H}-\mathrm{I}$, then the point of $\mathrm{G}$ is that one may not grow diverse-kinds with a gentile in the land of Israel, for diverse-kinds may not be grown by an Israelite in the Land, regardless of who owns the field in question. ${ }^{90} \mathrm{~J}$, which is autonomous of the foregoing, reverses the rule of $\mathrm{H}-\mathrm{I}$ by stating that the law of diverse-kinds apply both inside and outside of the land of Israel. J then agrees with M. Qid. 1:9, which states that all commandments which depend on the land of Israel are not observed outside of it, except for the laws orzah and diverse-kinds. 91 
Chapter Four opens M.'s discussion of diverse-kinds of the vineyard. The chapter consists of two large formal units, M. 4:1-3 (with M. 4:4 appended to it) and M. 4:5-9. At the head of each unit stands a pair of Houses-disputes which generates the law of the chapter. The chapter accordingly concerns two major themes. M. 4:1-3Q deals with sowing seed in a cleared space within or at the edge of a vineyard, while M. 4:5-7 defines a vineyard in terms of the number of vines and rows it must contain. M. 4:8-9 both supplements M. 4:5-6 and returns to the concerns of M. 4:1-3Q with a discussion of sowing seed between rows of vines. In addition, M. 4:3R-U + M. $4: 4$ form a small subunit dealing with rules pertaining to partitions. Now we might have expected the chapter to begin with its most fundamental rule, the definition of a vineyard (M. 4:5-7), and then to proceed with a discussion of sowing seed between rows of vines (M. 4:8-9, following $M .4: 5-7$ both formally [opening with hnwtc] and thematically [dealing with rows]) and cleared areas (M. 4:1-3Q). The redactor, however, chose to open the chapter with $\mathrm{M} .4: 1-3 Q$, presumably in order to consider, in a logical sequence, the planting of seeds and vines in separate areas (M. 4:1-3Q) and the planting of seeds among vines (M. 4:8-9). The definition of a vineyard in terms of vines and rows thus serves to introduce the latter section.

M. 4:1-3 consists of a pair of Houses-disputes followed by a tightly constructed series of glosses in a question-and-answer pattern. In $M .4: 1$ the Houses-dispute concerning the minimum area which a bald spot or an outer space of a vineyard must have in order to be sown with another kind. The rest of the unit (M. 4:1G-4:3Q) defines these areas and clarifies the law for each according to the viewpoint of the House of Hillel. M. 4:3R-U + M. 4:4 then present several rules concerning partitions.

M. 4:3R-U, following the question-and-answer pattern of M. 4:1-3Q, offers the minimum measurements which a fence or a ditch must have in order to be considered a valid partition, while M. 4:4 discusses partitions which contain gaps. The redactor has apparently appended this subunit to $M .4: 1-3 Q$ only because the fence is mentioned in connection with the definition of an outer space (as the area between the fence and the vineyard). 
The substance of the subunit, however, is not related to that of $M .4: 1-3 Q$, and, in fact, does not specifically discuss issues of diverse-kinds, for it deals simply with rules concerning partitions.

M. 4:5-9 constitutes a distinct formal unit in that each of its pericopae begins with the present participle hnwte. M. 4:5 opens with a Houses-dispute concerning the definition of a vineyard. House of Shammai say that a row of five vines is considered a vineyard, while House of Hillel disagree, maintaining (according to a gloss) that a vineyard consists of two rows. A second Houses-dispute, which discusses the same issue in another context (the sanctification of a vineyard by the sowing of another kind), follows. M. 4:6 and M. 4:7 then carry forward the view of House of Hillel. M. 4:6 discusses how the five vines of M. 4:5 are arranged in the two rows, and M. 4:7 deals with the secondary question of combining two separated rows of vines to form a vineyard.

Continuing the discussion of rows of vines and returning to the concerns of M. 4:1-3Q, M. 4:8-9 deals with sowing seeds between rows of vines. M. 4:8 discusses sowing seed between individual rows arranged in sets of two or three. According to $M$. three rows must be set apart by more space than is necessary to separate two rows, presumably because there is a greater tendency for the appearance of diverse-kinds to develop in the former case. M. 4:9 then concerns sowing seeds between rows of a vineyard. An anonymous opinion maintains that the rule of M. 4:8, which applies to the spacing of three rows, also obtains in the case of a vineyard, while Meir and Simeon disagree, saying that the rows of a vineyard are to be separated according to the rule which applies to two rows.

$$
4: 1-3
$$

A. [The] bald spot (qrht) of the vineyard --

B. House of Shammai say, "[It need measure] twenty-four amot [square (following Sens, Bert.)]."

c. House of Hillel say, "[It need measure only] sixteen amah [P: amot (throughout)] [square]."

D. [The] outer space [so Danby for mhwl] of the vineyard --

E. House of Shammai say, "[It need measure] sixteen amah."

F. House of Hillel say, "[It need measure only] twelve amah."

G. And what is [the] bald spot of the vineyard?

H. [Danby: The part of] a vineyard which is bare [so Danby for hrb] in its midale $\left(m^{\prime} m \varrho^{c} w\right.$; Sn: $\left.b^{\prime} m s^{c} w\right)$. 
I. If there are not there [i.e., in the bald spot] sixteen amah [square of space], [then] he shall not put seed into it.

J. [If] there were there [i.e., in the bald spot] sixteen amah [square of space], [then] they allow it [i.e., the vineyard] its area of tillage and he sows the rest.

M. Kil. $4: 1$ (B. Erub. 3b, 93a)

K. What is [the] outer space of the vineyard?

L. [The area] between the vineyard and the fence.

M. If there are not there [i.e., in the outer space] twelve amah [of space], [then] he shall not put seed into it.

N. [If] there were there [i.e., in the outer space] twelve amah [of space], [then] they allow it [i.e., the vineyard] its area of tillage and he sows the rest.

$$
\text { M. Kil. } 4: 2 \text { (B. Erub. 3b, 93a) }
$$

o. R. Judah says, "This [i.e., the space between the vineyard and the fence] is only [the area of] the fence of the vineyard.

P. "And what is the outer space of the vineyard?

Q. "[The area] between two vineyards."

R. What is [considered] a fence?

S. [A fence] which is ten handbreadths high.

T. And [what is considered] a ditch?

U. [A ditch] which is ten [handbreadths] deep and four wide.

$$
\text { M. Kil, } 4: 3
$$

M. Kil. 4:1-3 concerns the minimum size which an area in a vineyard must have in order to be sown with another kind (e.g., grain or vegetables). The forms of the unit are highly disciplined. $A-C$ and D-F present two parallel, balanced Houses-disputes, the numbers of which, taken together, occur in descending order according to the sequence $a-b-b-c$ (twenty-four $v s$. sixteen, sixteen vs. twelve). G-J and $\mathrm{K}-\mathrm{N}$ then balance one another in respectively glossing $\mathrm{A}-\mathrm{C}$ and $\mathrm{D}-\mathrm{F}$. $\mathrm{G}-\mathrm{H}$ and $\mathrm{K}-\mathrm{L}$ both appear in a question-and-answer pattern, while $I-J$ and $M-N$ form nearly identical sets of conditional sentences (differing only in that the former has sixteen while the latter has twelve), with the protases within each set balancing one another ('yn $\check{s} m$ vs. hyw $\overline{s m})$. The apodoses of the sentences in each set, however, do not all correspond to one another, and differ in that the verbs of I 
and $M$ appear in the imperfect tense, while those of $\mathrm{J}$ and $\mathrm{N}$ are phrased in present participles ( $l^{\prime} y b y^{\prime} z p c l \breve{s m} v s$. nwtnyn $l_{w}$ $c_{b w d t w} w \boldsymbol{z} \omega \mathrm{r}^{c}$ 't $h m \omega t \mathrm{r}^{l}$ ). In $\mathrm{O}-\mathrm{Q}$ Judah glosses and opposes $\mathrm{K}-\mathrm{L}$, following in $\mathrm{P}-\mathrm{Q}$ the question-and-answer pattern of $\mathrm{G}-\mathrm{H}$ and $\mathrm{K}-\mathrm{L}$. $R-S$, repeating the same pattern, glosses $O$, and $T-U$ similarly supplements $\mathrm{R}-\mathrm{S}$.

In $\mathrm{A}-\mathrm{C}$ and $\mathrm{D}-\mathrm{F}$ the Houses dispute concerning the minimum size which areas in and around a vineyard must have in order to be sown with a different kind. These areas must cover a certain amount of space so that the crops sown within them appear to grow in fields unto themselves and therefore do not produce the appearance of diverse-kinds with the vines. A-C concerns the bald spot (qrht ${ }^{2}$ ) of the vineyard, or (according to the gloss at G-H) its bare inner area, while D-F deals with the vineyard's outer space $\left(m h w \tau^{3}\right)$, or (according to the gloss at $K-L$ ) the area between the vineyard and the fence. I and $M$ then restate the views of House of Hillel ( $C$ and $F$ ) in a negative way ("If there are not there $\mathrm{X}$ amah"), while $\mathrm{J}$ and $\mathrm{N}$ rephrase the same rule in an affirmative manner ("[If] thereare there $\mathrm{X}$ amah"). $J$ and $N$, however, do not simply repeat $I$ and $M$, for, instead of balancing the latter with the apodosis "he shall put seed into it," J and $\mathrm{N}$ have a more complex apodosis, "they allow it its area of tillage and he sows the rest." $J$ and $N$ thus introduce a new consideration into the pericope, the area of tillage, saying that this area must separate the vines and the crops sown in the bald spot or outer space. 4 The reasoning behind the rule appears to be that the vines must have sufficient space to spread out without becoming entangled with the crops. Alternatively, the point of the rule may be that the vines and crops must be separated from one another in order to avoid the appearance of diverse-kinds. We note that $I$ and $M$ do not relate anything new, and so appear to be necessary only to introduce, respectively, $J$ and $N$.

In $\mathrm{O}-\mathrm{Q}$ Judah disagrees with the gloss at $\mathrm{L}$, saying that the area between the vineyard and the fence is not the outer space of the vineyard, but merely the area adjacent to the fence. The outer space, rather, is the area between two vineyards. ${ }^{5}$ Judah thus apparently agrees with $L$ that the mhwl discussed by the Houses signifies a border of the vineyard, but he maintains that this border lies outside of the vineyard and not within its fences. R-U then glosses o, describing the minimum dimensions which a fence or ditch must have in order (according to context, since R-U itself makes no mention of diverse-kinds) to separate a vineyard from another kind. $R-U$ is thus only indirectly relevant to $O$, for, although both discuss the fence of the 
vineyard, the latter concerns the area between the fence and the vines while the former deals with the dimensions of the fence (or the ditch) itself.

A. What is [the] bald spot of the vineyard?

B. A vineyard the midale of which is bare [= M. 4:1G-H],

C. and there remained in it [i.e., the vineyard] five [following Lieberman ${ }^{6}$ ], five vines [i.e., sets of five vines] [Y.: and there remained in it enough (vines to constitute) a vineyard],

D. whether [they are found] on [each of] four [Erfurt omits:] sides, or [each of] three sides, or [each of] two sides,

E. one [set of vines] opposite the other.

F. What is the outer space (mhwl) of the vineyard?

$\mathrm{G}$. "[The area] between two vineyards [= M. 4:3P-Q]," the words of R. Judah.

H. And sages say, "If there are not there [i.e., in the outer space]. twelve amot, he shall not put seed into it.

I. "[If] there were there [i.e., in the outer space] twelve amot, they allow it [i.e., the vineyard] its area of tillage and he sows the rest $[=\mathrm{M} .4: 2 \mathrm{M}-\mathrm{N}] . "$

$$
\begin{aligned}
& \text { T. Kil. } 3: 1 \text { (p. } 213,11.1-5) \\
& \text { (A-d: Y. Kil. } 4: 1 \text { (29c)) }
\end{aligned}
$$

T. Kil. $3: 1$ comments on M. 4:1-3, with A-E discussing the bald spot of the vineyard and F-I dealing with the vineyard's outer space. A-E complements M.'s concern with the minimum size of a bald spot with a discussion of the minimum amount of vines which a vineyard with a bald spot must have in order to continue to be considered a vineyard. A-B cites M. 4:1G-H, which $C+E$ then augment, with $D$ apparently interpolated between $\mathrm{C}$ and $\mathrm{E}$. According to $\mathrm{C}$ a vineyard containing a bald spot must have sets of five vines on opposite sides (G) in order to continue to be regarded as a vineyard. D clarifies C+E by stating that the sets of five vines need remain on only two sides of the vineyard, and need not be found on all four sides.

F-I presents an apparent dispute concerning the outer space of the vineyard between Judah, cited at M. 4:3P-Q, and sages, who are assigned the anonymous opinion of M. 4:2M-N. Judah and sages, however, do not actually dispute, for Judah discusses the location of the outer space while sages define its minimum size. Rather, in juxtaposing the two views $T$. applies the rule of M. $4: 2 \mathrm{M}-\mathrm{N}$ (which in $\mathrm{M}$. is attached to $M .4: 2 \mathrm{~K}-\mathrm{L}^{\prime} \mathrm{s}$ view of 
the location of the outer space) to Judah's definition of an outer space at M. 4:3P-Q. The same law now applies to both of M.'s descriptions of an outer space. ${ }^{7}$

A. There is in respect to (b) [the law of] the partition of the vineyard [a side which enables one] to rule more Ieniently, and [a side which enables one] to rule more stringently [than he would in the absence of a partition].

B. How so?

C. [If the] partition is near the vines, he sows outside of it [i.e., the partition] until he reaches the base ( ${ }^{c}$ yqp) of the partition.

D. [In this case one thus rules more leniently,] for were there no partition, they [Erfurt: he] would allow the vineyard four amot [Lieberman, 8 following Erfurt and first printed ed., omits $m \breve{s w k h ~ h e r e] ~[E r f u r t ~ o m i t s:] ~ a n d ~ h e ~ w o u l d ~}$ sow the rest [B. Erub. adds: And this is the partition of the vineyard (which enables one) to rule more leniently].

E. [If the partition] extended [around the vineyard] at a distance of eleven amot [from it], he shall not put seed into it [i.e., the area between the partition and the vineyard].

F. [In this case one thus rules more stringentIy,] for were there no partition, he would allow the vineyard four amot and sow the rest [B. Erub. adds: And this is the partition of the vineyard (which enables one) to rule more stringently].

$$
\begin{aligned}
& \text { T. Kil. } 3: 2 \text { (p. 213, 11. 5-10) } \\
& \text { (B. Erub. 93a) }
\end{aligned}
$$

T. Kil, $3: 2$ supplements M. 4:3R-U, which discusses the partition separating grain or vegetables from a vineyard. A serves as the superscription of the pericope. B introduces $C-F$, which consists of two declarative sentences ( $C$ and $E$ ), each followed by the identical conditional sentence ( $D$ and $F$ ) , C-D and E-F illustrate $A$. In $C-D$ the partition allows one to rule leniently, for one may sow another kind even up to the base of a partition standing within the vineyard's area of tillage, which normally may not be sown. In E-F the partition stands eleven amot away from the vines and creates an outer space (M. 4:2K-L). Following the rule of $M .4: 2 M-N, E$ says that one may not put seed into the outer space, for it measures less than twelve amot wide. The presence of the partition now causes one to rule more stringently, for were the partition absent one could sow another kind up to a 
point just four amot away from the vineyard. The point of T., then, is that the location of the partition determines whether the distance between the vineyard and the other kind must be greater or less than four amot, the vineyard's area of tillage.

A. The partition of reeds --

B. if there are not between [one] reed and the next three handbreadths,

c. [i.e.,] sufficient $(k d y)$ [space] so that a kid may enter (ykns; S, MS read $y z d q r$ ["leap through"]),

D. 1o, this is [considered] as a [valid (Danby)] partition.

E. And a fence which was breached --

F. [if the breach measures] up to ten amot [wide],

G. Io, this is [considered] as an opening [and the fence is still considered a valid divider];

H. [if the breach measures] more than this [i.e, ten amot],

I. opposite the breach it is prohibited [to sow a kind different from that on the other side of the fence].

J. [If] many breaches were breached in it [i.e., the fence] --

K. If the [combined measure (Maim., Comm., TYY) of the parts of the fence which remain] standing exceeds the [combined measure of those parts which were] breached,

L. it is permitted [to sow diverse-kinds on opposite sides of the fence];

M. and if the [combined measure of those parts which were] breached exceeds the [combined measure of the parts which remain] standing,

N. opposite the breach it is prohibited [to sow a kind different from that sown on the other side of the fence].

M. Kil. $4: 4$

(E-N: T. Erub 6(9):13-149)

M. Kil. $4: 4$ continues the interest of $M .4: 3 R-U$ in the divider which separates diverse-kinds. Like M. 4:3R-U, M. 4:4 deals in a general way with rules concerning partitions and has no particular reference to issues of diverse-kinds (cf. the parallels to E-N at T. Erub.). M. is composed of two autonomous parts, A-D and E-N, both of which concern dividers containing gaps. A-D deals with a partition of reeds, while E-N discusses a fence which has been breached.

A-D forms a declarative sentence, with $A$ serving as a protasis, $B+D$ constituting a conditional clause, and $C$ glossing $B$. According 
to $A-B+D$ a partition made of reeds may not have gaps which measure three or more handbreadths wide, for then the reeds would not be regarded as forming a continuous divider. A space smaller than three handbreadths, though, is not seen as affecting the compactness of the partition (Maim., Comm., Sens, following B. and Y. 10), so that a partition containing such gaps is considered valid. $C$ adds that a gap in the partition must be small enough so as not to allow a kid to break through it. ${ }^{l l} \mathrm{C}$ thus defines the validity of the partition in terms of its function, stating that a partition is considered valid only if it serves to set apart the enclosed area, e.g., by keeping out animals.

$\mathrm{E}-\mathrm{N}$ is a unitary composition consisting of two large constructions of declarative sentences, E-I (concerning the fence with one breach) and $\mathrm{J}-\mathrm{N}$ (discussing the fence with many breaches). The two units balance one another, for each is composed of a protasis ( $E$ and $J$ [with $J$ dependent on $E]$ ) and a pair of conditional clauses ( $F-G+H-I, K-L+M-I J)$. In addition both units end with the same apodosis ( $I$ and $N$ ). E-I and $J-N$ are also internally balanced, for within each pair of conditional clauses the protases (though not the apodoses) correspond to one another ( $F$ vs, H $\left[r^{c} d f^{c} s r\right.$ 'mwt vs. ytr mkn] and $\mathrm{K} v s$. M (cwmd + prws vs. prws +

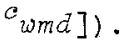

F-G describes a case in which a fence contains a gap measuring up to ten amot wide. Such a breach is regarded as an opening in the fence rather than as an interruption of it, so that the fence is still considered a valid partition. ${ }^{12}$ In $\mathrm{HI}-\mathrm{I}$, on the other hand, the breach is wider than ten amot, and so is seen as breaking the continuity of the fence. Now we might expect that a large breach would invalidate the entire fence as a partition (with the apodosis reading simply ' $s w r$ ), since the fence no longer sets apart the entire area. I, however, states that it is prohibited to sow diverse-kinds only on opposite sides of the breach itself. I thus implies that it is permitted to sow diversekinds on opposite sides of a breached fence where the fence remains standing, for in these places the fence still functions as a divider (Sens, GRA). ${ }^{13}$ I therefore takes an intermediate position (with the apodosis, kngd hprs 'swr, a development of the simple apodosis ( $s w r)$, for it neither completely prohibits nor completely permits the sowing of different kinds on opposite sides of the fence.

In $\mathrm{J}-\mathrm{N}$ the fence has been breached in many places. ${ }^{14}$ According to $\mathrm{K}-\mathrm{N}$ one must determine whether or not the greater part of the fence remains standing (Maim, Comm, TYY). If most of the fence still stands, the fence is considered a valid divider ( $K-L$ ) 
and diverse-kinds may be sown even opposite the breaches (Sens, GRA). If, on the other hand, most of the fence has been breached, one may not sow diverse-kinds opposite the breaches (M-N). Like $I, N$ implies that one may still sow different kinds where the fence remains standing (Sens, GRA), and so again takes an intermediate position (with the same apodosis ${ }^{15}$ ).

We now turn to consider the relationship between the rules of $A-D$ and $E-N$. A-D concerns the partition of reeds, which is, in effect, an example of the partition with many breaches described in $\mathrm{J}-\mathrm{N}$. A-D and $\mathrm{J}-\mathrm{I}$, however, do not present the same criteria for determining the validity of such a partition. A-D states that the gaps between the reeds may not be greater than three handbreadths, while $\mathrm{J}-\mathrm{N}$ rules that the combined measure of the breaches may not exceed that of the standing parts of the partition. $A-D$ and $J-N$ thus differ in that $A-D$ is concerned with the width of the individual breaches, while $\mathrm{J}-\mathrm{N}$ is interested in the combined measure of the breaches relative to that of the standing parts of the partition. 16

A. The partition of a vineyard which was breached --

B. they say to him [i.e., the owner of the vineyard], "Repair $(g d w r)$ [it]."

C. [If] he repaired it [= omitted by B. B.Q.] and it was breached [B. B.B. adds: again (hzrh wnprsh)],

D. they say to him, "Repair [it]."

E. If [= omitted by Erfurt] he became lax [so Lieberman ${ }^{17}$ for $\left.n t y^{\prime} \breve{s}\right]$ as to [repairing] it [i.e., the breached partition] [B. B.Q. adds: and did not repair it (again)],

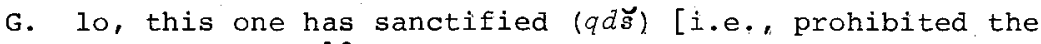
use (so Bokser ${ }^{18}$ for $q d \breve{s}$ ) of the grain or vegetables which adjoin the vineyard] and is answerable for it [so Danby 19 for hyyb b'hrywth] [i.e., he is liable for the loss of the other kinds which adjoin the vineyard (MB)].

$$
\begin{aligned}
& \text { T. Kil. 3:3a (P. } 213,11,9-11) \\
& \text { (B. B.Q. } 100 a-100 b, \text { B. B.B. } 2 a-2 b)
\end{aligned}
$$

T. Kil. 3:3a supplements M. 4:4 with a discussion of the liability for damages resulting from the breaching of a partition, an issue which $M$. does not raise in its consideration of the breached partition. T. consists of three declarative sentences, $A-B$ (with subject and object in inverted order), C-D, and E-F, with two apodoses, $B$ and $D$, identical to one another. T. describes a case in which one person's vineyard is surrounded by a partition 
and is adjoined by another person's field of grain or vegetables (cf. B. B.Q. 100a-100b, B. B.B. 2a-2b, and Lieberman, TZ, P. 210, on 1. 10). According to $A-D$ the owner of the vineyard is responsible for repairing the partition regardless of how many times it may be breached. E-F then states that if at some time the owner of the vineyard fails to repair the breach he is liable for the grains or vegetables which become sanctified by the vineyard $^{20}$ and which therefore may not be used by their owner (MB; cf. Maim., Comm. to M. 4:5). The point of $T$. thus is that the owner of the vineyard is responsible for maintaining the partition which separates the vines from other kinds, for if the partition is breached his vineyard causes a loss to the owner of the adjacent field.

\section{$4: 5$}

A. He who plants a row of five vines --

B. House of Shammai say, "[It is considered] a vineyard."

C. House of Hillel, say, "[It is] not [considered] a vineyard,

D. "unless there are two rows."

E. Therefore,

F. he who sows [within the] four amot which are [allotted as the area of tillage] in the vineyard--

G. House of Shammai say, "He has sanctified [i.e., prohibited the use of (Bokser; ${ }^{21} \mathrm{cf}$. also Maim., Comm.)] one row [of vines]."

H. House of Hillel say, "He has sanctified [i.e., prohibited the use of] two rows [of vines]."

$$
\begin{aligned}
& \text { M. Kil. } 4: 5(\mathrm{E}-\mathrm{H}: \text { Y. Kil. } 4: 1 \text { (29b) ; } \\
& \text { F-H: M. Ed. } \left.5: 2^{22}\right)
\end{aligned}
$$

11. Kil. 4:5 concerns the definition of a vineyard. M. consists of two Houses-disputes, $A-D$ and $F-H$, joined by $E$. The superscriptions of the two disputes are somewhat balanced, for both open with a present participle ( $h n w t^{c} v s . h z w r^{c}$ ) and both contain four words. Each dispute is internally well-balanced, for A-D has krm vs. 'ynw krm, while F-If reads šwrh 'ht vs. $\breve{t y} \breve{s} w r w t$. In $A-D$ the Houses-dispute concerning the way in which vines must be arranged in order to constitute a vineyard, and so to require four amot, (= twenty-four handbreadths) rather than six handbreadths, as an area of tillage (Maim., Comm., Ribmaș, and others; cf. M. $3: 7,6: 1)$. House of Shammai say that a vineyard consists of only a single row of five vines, while House of Hillel maintain in $\mathrm{C}$ that such an arrangement of vines is not considered a vineyard. 
It is not clear from $c$, however, whether House of Hillel hold that a vineyard must consist of more rows, more vines, or more of each. D, glossing $C$, explains that House of Hillel require a vineyard to contain two rows, apparently with a total of five vines between them (cf. M. 4:6).

$\mathrm{F}-\mathrm{H}$ is joined to A-D by lpykk ("therefore") which functions as a conjunction, and so may be either autonomous of $A-D$ and appended to it, or, as we shall see, actually generated by that dispute. F-H concerns the interpretation of the word "vineyard" in Dt. 22:9: You shall not sow your vineyard with two kinds of seed, lest the whole yiezd be sanctified, the crop which you have sown and the yield of the vineyard. The Houses apparently dispute concerning the number of rows of vines which constitute a "vineyard," i.e., the area to be sanctified when another kind is sown near an (actual) vineyard. House of Shammai say that one row forms a "vineyard" and therefore is sanctified, while House of Hillel maintain that the "vineyard" which is sanctified consists of two rows (Maim., Comm., Bert., GRA, MR). The opinions of the flouses thus appear to presuppose a prior definition of a "vineyard," so that $\mathrm{F}-\mathrm{H}$ may depend on $\mathrm{A}-\mathrm{C}$. Alternatively, the two disputes are separate from one another and simply phrase the same issue in different terms. In any event, we note that $D$ may have been added to $A-C$ together with $F-H$, for $D$ allows House of Hillel in $C$ to agree with the corresponding view in $\mathrm{H}$.

\section{$4: 6$}

A. He who plants two [vines] opposite two [others] and one extending out [like a] tail [so Bokser ${ }^{23}$ for w'ht yws'h znb] --

B. 10, this is considered a vineyard.

C. [If there are] two [vines planted] opposite two [others] and one is between [two of the opposing vines],

D. or [if there are] two [vines planted] opposite two [others] and one is in the middle [i.e., equidistant from all four vines] --

E, this [i.e., the vines in these patterns] is not [considered] a vineyard,

F. unless there are two [vines planted] opposite two [others] and one extending out [like a] tail.

$$
\begin{aligned}
& \text { M. Kil. } 4: 6 \\
& \text { (A: B, Sot. } 43 b, B, B . B, 14 a \text { ) }
\end{aligned}
$$


M. Kil. 4:6 presupposes the opinion of House of Hillel in M. 4:5 (MR), for it concerns the manner in which five vines are to be arranged in two rows in order to form a vineyard. M. $4: 6$ is a unitary pericope composed of two parts, $\mathrm{A}-\mathrm{B}$ and $\mathrm{C}-\mathrm{F}$, with the latter glossing the former. A-B is slightly apocopated, following the he-who formulary pattern, while $\mathrm{C}-\mathrm{F}$ forms a conditional sentence 24 consisting of a double protasis (C+D), an apodosis (E), and a gloss (F). A-B and $C-E$ balance one another, for $A, C$ and $D$ all contain the same number sequence (2-2-1), differing only in their final clauses (yws 'h anb vs. bntym vs. $\left.b^{\prime} m s^{c}\right)$. The apodoses, $B$ and $E$, are fixed and so also balance one another. $F$ then repeats $A$.

According to $\mathrm{A}-\mathrm{B}$ the five vines mentioned in $\mathrm{M}, 4: 5 \mathrm{C}-\mathrm{D}$ must be arranged in such a way that two pairs of vines are set opposite each other and the fifth vine extends outward from them. $A-B$ may be taken to mean either that the fifth vine is attached to one of the rows (Sens, Ribmaș, Bert., TYY, TYT, GRA, PM; cf. T. $3: 3 \mathrm{a}$; fig. $32^{25}$, or that it is located opposite the space between the rows (Rashi to B. Sot. 43a, Maim., Comm., KM to Maim., Code, Diverse-Kinds 7:7, TYY [gives both interpretations], TYT [gives both interpretations], MR; fig. 33). ${ }^{26}$ The point of $A-B$ apparently is that five vines must be planted exclusively in two rows. According to the first interpretation, then, the fifth vine belongs to one of the two rows, while according to the second explanation this vine, located outside of the set of four vines but between the two rows, may be regarded as belonging to either of the rows. C-F then rephrases the law of $A-B$ in a negative manner. C states that the fifth vine may not be planted between two opposing vines, meaning either that this vine may not be located between the vines themselves (Ribmaș, Maim., Comm., KM to Maim., Code, Kil. $7: 8$, TYY, TYT; fig. $34^{27}$ ), or that it may not be planted opposite the space between the two vines (Bert. [according to TYT], TYY [gives both interpretations]; fig. $35^{28}$ ), According to $D$ the fifth vine may also not be planted in the middle of the four vines, or equidistant from all of them (figs. $36,2937^{30},{ }^{31}$ In all of these instances the fifth vine is located in the midst of the other four vines, and so does not belong to either of the two rows. ${ }^{32}$ since the five vines are not arranged in two rows alone, they are not regarded as constituting a vineyard. 


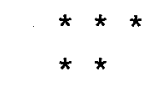

FIGURE 32

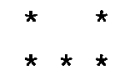

FIGURE 34

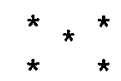

FIGURE 36

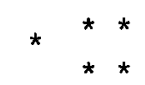

FIGURE 33

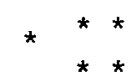

FIGURE 35

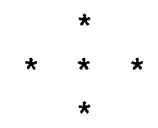

FIGURE 37

\section{$4: 7$}

A. He who plants one row [of vines] in his own [field],

B. and one row [of vines also grows] in his neighbor's [field]--

C. and [even though (Maim., Code, Diverse-Kinds 7:5, TYY)] a private road or a public road are in the middle [i.e., between the two rows of vines] --

D. or a fence lower than ten handbreadths [separates the two rows of vines] --

E. 10, these [two rows] combine [to form a vineyard].

F. [If the fence] is higher than ten handbreadths,

G. they do not combine [to form a vineyard].

H. R. Judah says, "If [= omitted by B] he trained [so Danby for $c_{r s n]}$ [the vines] over [the fence],

I. "lo, [the two rows of vines] combine [to form a vineyard]." M. Kil, $4: 7$

M. Kil. 4:7, again presupposing House of Hillel's. view (M. $4: 5 C-D)$ that two rows constitute a vineyard, discusses the question of combining two separated rows to form a vineyard. $\mathrm{A}-\mathrm{E}$ is an apocopated sentence (with $\mathrm{A}$ in the he-who formulary pattern) consisting of a double protasis, $A-B$ (with $A$ and $B$ balanced) and $C+D$, with $A-B$ serving the two separate protases, 
$C$ and $D$. E functions as an apodosis for both sets of protases $(A-B+C, A-B+D)$. E-G then glosses and balances $D-E$ (nmwk vs. gbwh; mṣtrpyn vs. 'yn mṣtrpyn), and is itself glossed by Judah in $\mathrm{H}-\mathrm{I}$ (with $I$ balancing $G$ ).

In A-D two adjacent rows of vines which are owned by different people are separated by either a public or private road on the one hand, or a low fence on the other. These two rows combine to form a vineyard, for separate ownership does not prevent the vines from combining $(A-B)$, while (taking $C$ and $D$ separately) apparently neither a road nor a low fence is considered a valid divider with regard to a vineyard. ${ }^{33}$ F-G then states that if the fence ishigher than ten handbreadths, the two rows do not combine to form a vineyard, for such a fence is considered a valid divider. ${ }^{34}$ In H-I Judah glosses F-G, saying that if the vines are trained over the high fence the rows do combine to form a vineyard, for the fence no longer serves to separate them. ${ }^{35}$ we note that $F-G$ does not relate anything new, and so apparently serves only to introduce $\mathrm{H}-\mathrm{I}$ :

$4: 8$

$A$, He who plants two rows [of vines] --

$B$, if [Geniza fragment, ${ }^{36} \mathrm{~K}$, Ox; and] there are not between them eight amot, he shall not put seed into it.

C. [If] there were three rows [of vines] --

D. if [C: and] there are not between one row and the next sixteen amot, he shall not put seed into it.

E. R. Eliezer b. Jacob says in the name of Hananiah b. Hakinai, "Even if the middle [row] was laid waste, and [Geniza fragments: if] there are not between one row and the next sixteen amot, he shall not put seed into it,

F, "though if [so Danby for $\breve{s}^{\prime} y z w$ ] from the outset he had planted [two rows], 10, this [i.e., sowing seed between the rows] is permitted with eight amot [between the rows]."

M. Kil. $4: 8$

M. Kil. 4:8 discusses sowing seeds between rows of vines, and so returns to the interest of $M .4: 1-3 Q$ in sowing seeds in a vineyard. M. consists of two balanced (two vs. three; eight vs. sixteen) sentences, $A-B$, a slightly apocopated sentence following the he-who formulary pattern, and $C-D$, which forms a conditional sentence. ${ }^{37}$ Eliezer $b$. Jacob in the name of Hananiah b. Hakinai then glosses $A-D$ and E-F. According to A-B seed may be sown between two rows of vines only if the rows are separated by eight 
amot. The seed then grows in an area unto itself and does not produce the appearance of diverse-kinds with the nearby vines. C-D states that three rows must be set apart by sixteen amot, or twice as much space as must separate two rows, for since there are more vines, the seeds must be allowed twice as much area in order to avoid the appearance of diverse-kinds.

Alternatively, the commentaries interpret $M .4: 8$ in the light of $M .4: 5-7$, and regard $M$. as concerning the problem of the combining of rows to form a vineyard. Two rows which are separated by eight amot do not combine to form a vineyard, so that seed may be sown between them (with the allowance of six handbreadths per row as the area of tillage). Three rows, however, at first sight resemble a vineyard, and therefore must be separated by sixteen amot if they are not to combine and actually form a vineyard (Sens, Ribmas, Bert., MS, GRA; cf. also T. $3: 3 \mathrm{~b}, 3: 5 \mathrm{c}) .{ }^{38}$ This interpretation, however, does not follow the plain sense of $M$. 4:8, for $M$. deals with sowing seed between rows of vines, and does not discuss the issue of the combining of rows to form a vineyard. We therefore favor the first interpretation given above.

In E-F Eliezer b. Jacob, in the name of Hananiah b. Hakinai, describes a case which lies in a gray area between the cases of $A-B$ and C-D. Three rows of vines are planted, but the middle one is laid waste, so that two rows remain. The problem deals with the distance which must separate these rows if seed is to be sown between them. Are these rows still to be separated by sixteen amot, since they originally formed part of a set of three rows, or need they be set apart by only eight amot, since they are now only two in number? Eliezer b. Jacob rules that the two remaining rows must be separated by sixteen amot, for only if they were planted as two rows at the outset could one separate them by eight amot alone (F). The point of Eliezer $b$. Jacob is that the actual planting of diverse-kinds determines the spacing of the rows, regardless of the appearance of diverse-kinds. While the remaining rows may be separated by only eight amot without producing the appearance of diverse-kinds, the same amount of the different kind as was originally sown between the three rows remains between the two rows, so that they must still be separated by sixteen amot.

A. He who plants his vineyard by [intervals of] sixteen amah [most mss. ${ }^{39}$ omit amah], sixteen amah [i.e., in rows sixteen 
amot apart (so Danby and all commentaries)] -- it is permitted to put seed into it [i.e., the area between the rows].

B. Said R. Judah, " $m^{c} \xi h b$ : In Salmon one planted his vineyard by [intervals of] sixteen [B, S, Sn add: amah], sixteen $a m a h$,

c. "and he would turn the foliage [so Danby for $\xi^{c} r$ ] of two rows to one side and sow the cleared land [so Danby for $n y r^{40}$ ].

D. "And in the next year he would turn the foliage to another place [i.e., to the area which he had sown in the previous year] and sow the uncultivated land [so Danby for $b w r^{41}$ ].

E. "And the case came before sages and they permitted [his actions ]."

F. R. Meir and R. Simeon say, "Even ('p) he who plants his vineyard by [intervals of] eight [B, $S$, and B. B.B. add: amot], eight amot $\left[\mathrm{Cn}\right.$, Geniza fragment, ${ }^{42} \mathrm{~L}, \mathrm{O}, \mathrm{Sn}$, and $\mathrm{V}$ read only: eight amot] -- it is permitted [to put seed into the area between the rows]."

M. Kil. $4: 9$

(A-B: B. B.B. $82 \mathrm{~b} ; \mathrm{C}:$ B. B.B. 83a)

Continuing the discussion of $M .4: 8, M .4: 9$ turns to the question of sowing seed between rows of a vineyard. A is a sightly apocopated sentence in the he-who formulary pattern. Judah glosses $A$ in $B-E$ (with $C$ and $D$ roughly balanced) with a precedent introduced by the formula $m^{c} \xi h b$, while in $F$ (joined to the foregoing by ' $p$ ) Meir and simeon gloss A with a saying which almost perfectly balances and opposes it. It appears, then, that B-E has been inserted into the balanced dispute $A+F$.

The dispute of A-B apparently concerns the application of the rules of M. 4:8, which deal with sowing between individual rows to the case of sowing between rows of a vineyard. According to $A$ the rows of a vineyard must be separated by sixteen amot (all commentaries), or the distance which must separate three individual rows (M. $4: 8 \mathrm{C}-\mathrm{D})$. The point of $\mathrm{A}$ is that a vineyard, like a set of three rows, contains many vines which spread over a large area, so that the seed must be sown in a large field unto itself if it is not to produce the appearance of diverse-kinds. In $F$ Meir and Simeon disagree, maintaining that the rows of a vineyard need to be set apart by only eight amot, or the distance required to set apart two rows (M. $4: 8 \mathrm{~A}-\mathrm{B}$ ). Meir and simeon perhaps reason that the rows of a vineyard are separated by 
regular intervals, so that seeds sown even in smaller spaces clearly grow in areas unto themselves and do not produce the appearance of diverse-kinds. 43

In B-E Judah cites a precedent in support of A. A man in Salmon ${ }^{44}$ would separate the rows of his vineyard by sixteen amot in order to sow seed between them (B). He would also turn the foliage of every two rows of vines to the space between the rows (alternating this space with the next one every other year), so that alternate intervals would be completely free of vines and could be sown (C-D). In this manner he would both allow the seed more space to grow (Maim., Comm.) and prevent the seed and the vines from becoming entangled and producing the appearance of diverse-kinds. The point of $B-E$, then, is that one must turn the foliage of the vines away from the seeds in order to avoid the appearance of diverse-kinds. B-E thus only indirectly supports A, for it presupposes the rule of A but does not primarily concern it. 


\section{CHAPTER FIVE}

\section{KILAYIM CHAPTER FIVE}

Chapter Five consists of two subunits, M. $5: 1-3 A-F+5: 4 N-P$ (with M. 5:4G-M+5:4Q-R appended) and $M$. 5:5-6+5:7C-8 (with $M$. 5:7A-B attached). The first unit discusses two themes, the arrangement of vines in a vineyard (a continuation of the interests of Chapter Four; M. 5:1-2) and the sowing of different areas within a vineyard (M. 5:3-4). The second subunit discusses the prohibited acts of sowing and allowing another kind to grow in a vineyard.

All of the protases of the first subunit (M. 5:1A, 5:1E, $5: 2 \mathrm{~A}, 5: 3 \mathrm{~A}, 5: 4 \mathrm{~N}$, five in all) follow the formulary pattern $\mathrm{X} \breve{s} h w^{\prime}+$ participle (while M. 5:lA omits hw'), with those of M. 5:1-2 opening with $\mathrm{krm}$. M. 5:1A-D discusses the number (and, according to a gloss, the arrangement) of vines that a vineyard which lay waste must have in order to remain in the status of a vineyard. M. 5:1E-K+M. 5:2 then deals with the irregularlyplanted vineyard and with the vineyard containing rows separated by less than four amot. M. discusses in each instance whether the internal arrangement of the group of vines or its overall appearance determines its status as a vineyard. Meir (M. 5:1K) favors the latter view (along with sages, M. 5:2C), while simeon (M. $5: 2 B$ ) appears to stand behind the former (along with the anonymous law of $\mathrm{M}$. $5: 1 \mathrm{E}-\mathrm{J})$.

M. 5:3-4 consists of Eliezer b. Jacob's saying at M. 5:3A-F, followed by a brief unit at $M .5: 3 G-M+5: 4 Q-R$, and an interpolated unit at M. $5: 4 \mathrm{~N}-\mathrm{P}$. The protases of $M$. $5: 3 G-M+5: 4 Q-R$ (M. $5: 3 G$, 5:3J, and 5:4Q, three in all) all follow the pattern $\mathrm{X} \breve{s} b k r m$, while the apodoses all read $z \omega r^{c} m b t w k h$. In M. 5:3A-F Eliezer b. Jacob rules that one may sow a ditch of a specified size only if it extends across the entire length of the vineyard, for then it appears to divide the vineyard and so forms an autonomous domain. If the ditch is not open, however, it is considered like a winepress, i.e., a depression in the ground, which may not be sown. The redactor here attaches Eliezer's rule (M. 5:3G-H) that one may sow a winepress in a vineyard, assigning to sages (M. 5:3I) Eliezer b. Jacob's opposing view concerning the winepress (which has been dropped from his saying in order to introduce Eliezer's opinion). The rest of the appended unit (M. 5:3J-M+5:4Q-R) concerns sowing other areas of the vineyard 
(e.g., the watchman's hut or mound, or the house). M. 5:4N-P then complements $M$. 5:3G-I by discussing the sowing of another kind with a vine in a winepress or hollow.

The protases of the second subunit (M. 5:5-6+5:7C-8) all open with the third-person singular present participle (M. 5:5A [hnwt'], M. 5:6A [hrw'h], M. 5:7C [hzwrc], and M. 5:8A [hmqym], four in all). M. 5:5A-B presents a basic rule concerning the number of vines which are sanctified by vegetables planted or allowed to grow in a vineyard. M. 5:5C-G then qualifies this rule, maintaining that it applies only when the vines are planted close together. When, however, the vines are spaced farther apart, the vegetables sanctify an area of the vineyard rather than a quantity of the vines. As we shall see, the commentaries offer various explanations to account for M.'s distinction between the different arrangements of vines.

M. 5:6-8 complements the discussion of M. 5:5 concerning sowing and allowing another kind to grow in a vineyard by defining those actions. According to M. 5:6 one may allow diverse-kinds to grow until he reaches them in the course of his work. Once he comes upon the diverse-kinds, however, he may not leave without uprooting them, for by leaving he would appear to indicate that he wished them to grow. M. 5:7 distinguishes between one who accidentally and unknowingly sows another kind in a vineyard (e.g., the wind scatters the seeds behind him into the vineyard), who does not sanctify the vines, and one who accidentally and knowingly sows in a vineyard (e.g., the wind scatters the seeds before him into the vineyard), who is liable. In M. 5:8A-D Eliezer and sages dispute concerning whether or not one who allows thorns to grow in a vineyard sanctifies the vines. Eliezer maintains that thorns, like other plants, sanctify the vines, while sages disagree, maintaining that one who allows the useless thorns to grow does not thereby appear to desire that they grow. M. 5:8E-K, which in part illustrates the view of sages, then discusses whether or not certain plants are considered diversekinds in a vineyard.

A. A vineyard which lay waste--

B. if there are in it (' $m y \breve{s} b w$; Mn adds: $k d y)$. [enough vines to enable one] to gather ten vines per bet $s e^{\prime} a h$,

c. and [= omitted by a Geniza fragment $\left.{ }^{l}\right]$ they are planted according to the rule [pertaining to] them (khlktn), 
D. 10, this is called a "lean"2 vineyard (krm dz [Danby: "poor vineyard"]; $\mathrm{Cn}, \mathrm{N}, \mathrm{Sn}$ : krm ["a vineyard"]).

E. A vineyard which is planted in an irregular manner [so Blackman for $\left.{ }^{c} r b w b y^{3}\right]$--

F. if there are in it [vines which are so arranged that is able] to align (2kwyn) two [vines] opposite three [others],

G. 1o, this is [considered] a vineyard.

H. And if not [i.e., if two vines may not be aligned opposite three others],

I. it is not [considered] a vineyard.

J. R. Meir says, "Since it [i.e., the irregularly-planted vineyard] looks [in form] like the pattern (ktbnyt) of the vineyards [in general],

K. "1o, this is [considered] a vineyard."

M. Kil. $5: 1$

M. Kil. 5:1 continues the discussion of M. 4:5-7 concerning the manner in which vines must be arranged in order to form a vineyard. M. 5:1 is a unitary pericope composed of two parts, $A-D$, discussing the vineyard which lay waste, and $E-K$, dealing with the irregularly-planted vineyard. The two sections are similar to one another in that both contain conditional sentences $(A-D$ and $E-G)$ following the same formulary pattern ('m $y \breve{s} b w$ ). $A-D$ and $E-G$ somewhat balance one another, for their protases differ only to a small degree (krm šhrb vs. krm šsw' nțwe; cf. M. 5:2), while the apodosis of $A-D$ is slightly more complex than that of E-G (hry $z h$ nqp' $k r m$ dL vs. hry $z h k r m$ ).

A-D consists of a declarative sentence, A-B+D (with subject and object in inverted order), which is glossed by $C$. According to $A-B+D$ a vineyard which lay waste and which still contains ten vines per bet selah is called a "lean" vineyard, and so apparently remains in the status of a vineyard (cf. other mss. readings at $D)$. $C$ adds that the ten must be planted according to the rule applying to them, i.e., the law of M. 4:6 (all commentaries; cf. T. $3: 3 \mathrm{~b}) .{ }^{4}$ The latter states that five vines constitute a vineyard if they are so arranged that two pair of vines face one another, and the fifth vine extends outward from them. C thus rules that the ten vines discussed in B must form two sets ${ }^{5}$ of five vines, ordered in the pattern described in M. 4:6. The point of $\mathrm{C}$ is that the arrangement of the remaining vines, as well as their number, determines whether or not a vineyard which lay waste continues to be considered a vineyard. 
$E-K$ is composed of a declarative sentence, E-G (with subject and object again in inverted order), a gloss at $H-I$, and Meir's gloss of $\mathrm{H}-\mathrm{I}$ at $\mathrm{J}-\mathrm{K}$ (with the fixed apodoses of $\mathrm{G}, \mathrm{I}$, and $K$ balancing one another). E-G describes a case in which the vines of a vineyard are planted irregularly, that is, without being arranged in rows (Maim., Comm., Code, Diverse-Kinds 7:9, Sens, and others). According to F-G such an area may be considered a vineyard only if a row within it containing two vines may be aligned opposite a row of three vines. In other words, five vines in the vineyard must be so arranged that two pair of vines stand opposite one another, and the fifth extends outwards. The five vines are thus laid out in the pattern described in M. 4:6, and so form a vineyard, which is extended to include the entire irregularly-planted area. H-I then restates the rule of E-G in a negative manner. In $J-K$ Meir opposes $H-I$ (and E-G as well), maintaining that an irregularly-planted area is considered a vineyard even if it does not contain two vines aligned opposite three others, for the area has the overall appearance of a vineyard. According to Meir, then, the appearance of an area planted with vines determines its status as a vineyard, regardless of the actual arrangement of the vines. We note that H-I relates nothing new, and so apparently serves only to introduce Meir's statement at $\mathrm{J}-\mathrm{K}$.

T. Kil. 3:3b-3:9 forms a sustained commentary to M. 5:I. The following chart shows the relationship of $M$. to $T$.:
T. $3: 3 b$
$\frac{\text { M. }}{\text { M. } 5: 1 \mathrm{~A}-\mathrm{D}}$
Issue
Distance allowed between vines of a vineyard which lay waste
T. 3:4 M. 5:1E-I The parts of the vine which must be aligned in order for the vines to be considered to be lined up
T. 3:5a M. 5:1A-D The circular espalier which is not considered an espalier
T. 3:5b M. 5:1E-I The alignment of vines in an irregularly- planted vineyard
(T. $3: 5 \mathrm{C}$ M. $5: 2$ )
T. 3:6 M. 5:1E-I The odd row in the regularly-planted vineyard
T. 3:7- autonomous The status of the slope of the terrace in $8+9$ respect to adjacent fields

T. thus groups together and presents first those pericopae which comment on M., closing with a set of autonomous materials. T. $3: 3 b-3: 6$ is well-organized. Except for $T .3: 5 \mathrm{c}$, which 
comments on M. 5:2, and T. 3:4, which appears to be out of place, T. comments on M. $5: 1 \mathrm{~A}-\mathrm{D}$ and M. $5: 1 \mathrm{E}-\mathrm{I}$ in sequence. T. $3: 3 \mathrm{~b}$ and T. 3:5a both interpret M. 5:1C, which states that the ten vines of a vineyard which lay waste must be "planted according to the law [pertaining to] them." T. $3: 3 \mathrm{~b}$ explains that this rule deals with the distance which may separate the remaining vines. T. 3:5a presents a counter-example to M. 5:1C, describing the case of a circular espalier, which is not regarded as an espalier even though it is properly planted. T. 3:4, 3:5b, and $3: 6$ then comment on M. 5:lE-I, which states that five vines of an irregularly-planted vineyard may combine (if correctly aligned) to form a vineyard. T. 3:4 discusses the part of the vines which must be aligned in order for the vines to form a vineyard. T. $3: 5 \mathrm{~b}$ cites the rule of $\mathrm{M}$. and presents it in the context of a macaseh, while T. 3:6 presents the contrasting case of a properly-planted vineyard containing a row which is out of place.

T. 3:7-8+9 concerns the relationship of the slope of a terrace to adjacent fields. T. 3:7-8 rules that an individual vine or plant of another kind which is planted on a slope is not considered to be attached to the vineyard or field below. T. 3:9 similarly rules that a slope separates a vineyard on one terrace from a field of another kind on the other. The point of T. 3:7$8+9$ thus is that the slope is considered to be autonomous of the terraces which it joins.

A. How much [i.e., how many vines] shall its [i.e., a vineyard's] planting be?

B. Three [vines] opposite three [others].

C. [If] one of the outer [vines] is removed, how much [space] may there be between them [i.e., the remaining five vines]?

D. Two [vines which are] opposite two [others may be separated from the latter by a distance measuring] from four amot to eight [amot],

E. and the [one extending out like a] tail [may be separated from each pair of vines by a distance measuring] from four amot to eight [amot].

F. [If the] two [vines which are] opposite [the] two [others] were [separated from the latter by a distance measuring] [Erfurt, first printed ed. omit: less than] from four amot to eight [amot],

G. and the [one extending out like a] tail [Erfurt adds through $\mathrm{H}$ [to "tail"] (Vienna omitting ${ }^{6}$ ):] [is separated from each 
pair of vines by a distance measuring] less than four amot or more than eight [amot];

H. or [if the] two [vines which are] opposite [the] two [others] were [separated from the latter by a distance measuring] less than [= omitted by first printed ed.] four amot or more than eight [amot],

I. and [the one extending out like a] tail [was separated from each pair of vines by a distance measuring] from four [amot] to eight [amot],

J. [Erfurt omits:] 10, this is not [considered] a vineyard, K. unless [the] two vines [which are] opposite [the] two [others are separated from the latter by a distance measuring] from four amot to eight [amot] [= Efurt omits],

I. and the [one extending out like a] tail [is separated from each pair of vines by a distance measuring] from four amot to eight [amot].

$$
\text { T. Kil. 3:3b (pp. 213-214, 11. 11-17) }
$$

T. Kil. $3: 3 \mathrm{~b}$ comments on M. 5:lA-D, explaining M.'s phrase "planted according to the rule [pertaining to] them" as referring to the distance which may separate the vines of a "lean" vineyard from one another. T. is a unitary pericope composed of two parts, $A-E$ and $F-L$, with the latter glossing the former. $A-B$ and C-E follow a question-and-answer pattern, with $D$ and $E$ somewhat balancing one another (both ending with the phrase "from four [amot] to eight [amot]"). F-L consists of two balanced conditional clauses, F-G and H-I (which balance D-E as well), an apodosis at $\mathrm{J}$, and $\mathrm{K}-\mathrm{L}$, which glosses $\mathrm{F}-\mathrm{J}$ by repeating $\mathrm{D}-\mathrm{E}$. We note that F-I forms an apocopated sentence, for the subject of F-I, the individual sets of vines, is not that of J, which concerns the vineyard as a whole.

A-B describes a vineyard which contains two opposing rows of three vines each. ${ }^{7}$ In $C$ an outer vine is removed, so that the vineyard now lies waste, with its five remaining vines arranged in the pattern described in M. 4:6. C then asks how much space may separate the vines if they are to form a "lean" vineyard. Following the language of M. 4:6 ("Two [vines] opposite two [others], and one extending out [like a] tail"), $D-E$ states that the rows may be separated from one another and from the fifth vine by a distance covering from four to eight amot. F-L then simply restates $\mathrm{D}-\mathrm{E}$ in a negative manner (i.e., the distance may not be less than four or more than eight amot), perhaps following the pattern of M. 4:6 (rule + two rejected 
alternatives + repetition of rule). In addition to reading M. 4:6 into M. 5:1A-D (as we have already noted), T. reads two other rules into $M$. The law of $T$. also includes Meir and Simeon's view (M. 4:9) that one may not sow another kind between two rows of vines separated by less than eight amot, 8 and simeon's rule (M. 5:2) that the rows of a vineyard must be separated by more than four amot (cf. also T. 3:5c). T. effectively links these four pericopae of M. (M. 4:6, 4:9, 5:1, and 5:2) together.

A. [If] the stem[s] (so. Lieberman ${ }^{9}$ for kwwrt) [of the vines are] aligned and the foliage [of the vines] is not aligned --

B. 10, this is [considered] a vineyard.

C. [If] the foliage [of the vines] is aligned, and the stem[s of the vines are] not aligned --

D. 10, this is not [considered] a vineyard.

E. [Erfurt reverses $E-G$ and $\left.H-M^{10}\right]$ [If the stems (MB)] were thin and were not aligned,

F. [and then] became thick and became aligned --

G. 1o, this is [considered] a vineyard.

H. How does he know if [the stems] were aligned or not?

I. He stretches a thread to the base of the vines [ ${ }^{c}$ yqr hgpnym; Erfurt: $c_{2}$ gby hgpnym ("over the vines")] --

J. if they [i.e., the vines] all touch the thread [bhwt; Erfurt: $k^{\prime h t}$ ("if they all touch as one")] [on the same side] --

K. 10, this is [considered] a vineyard;

I. if one [vine] stands inside (nknst) and the other stands outside (ywg't) [of the thread] --

M. 10, this is not [considered] a vineyard.

$$
\begin{aligned}
& \text { T. Kil. } 3: 4 \text { (p. } 214,11,17-22) \\
& \text { (A-I: Y. Kil. } 5: 1 \text { (29d)) }
\end{aligned}
$$

T. Kil. $3: 4$ comments on M. 5:1E-G, ${ }^{11}$ which states that vines which are irregularly planted form a vineyard only if two of the vines are aligned opposite three others. T. consists of two subunits, $A-G$, concerning the parts of the vines which must be aligned with one another, and H-M, glossing the foregoing with a discussion of the method of determining whether or not the vines are aligned. $A-G$ is composed of three declarative sentences, $A-B, C-D$, and $E-G$. A and $C$ balance one another $(k w w r t+n w p$ vs. nwp $+k w w r t)$, while E-F is internally bälanced $\left(d q+\tau^{\prime} m k w w n\right.$ vs. $\left.h^{c} b w+m k w w n\right)$. All three apodoses (B, D, and $\mathrm{G}$ ) are fixed ( $\mathrm{krm} v \mathrm{~s}$. ' $y n w \mathrm{krm})$, and so balance one another 
as well. H-M consists of a question, $\mathrm{H}$, and an answer, I-M, with the latter forming an apocopated sentence composed of a protasis, $I$, and a pair of conditional clauses, J-K and $\mathrm{L}-\mathrm{M}$ (with fixed apodoses at $K$ and $M$ ).

According to A-D the vines are considered to be aligned with one another if their stems, presumably their principal parts, oppose each other, regardless of whether or not their foliage, a secondary feature, is also lined up. E-G adds that if stems which are not aligned at the outset grow thicker and become aligned, then at that point the vines form a vineyard. Explaining the rule of $A-D, H-M$ describes the manner in which one determines whether or not the vines are aligned. One stretches a thread between the two rows at the base of the vines. If the vines all touch one side of the thread they are considered to be aligned, but if they make contact with the thread on different sides ("inside" and "outside") they clearly are not lined up with one another.

A. R. Simeon says, "An espalier [so Lieberman ${ }^{12}$ for hrys; Erfurt: ${ }^{c}$ rys] which [was] planted according to the rule [pertaining to] it,

B. "or [Lieberman ${ }^{13}$ suggests instead: but ('2!)] which was circular (mwqp; Erfurt: mkwwn ["aligned"]) like that dovecote [which is] round ( $\left.k \breve{s w b k} h z h{ }^{\circ} g w l\right)$,

c. "10, this is [= omitted by Erfurt] not [considered] an espalier."

$$
\text { T. Kil. 3:5a (p. 214, 11. 22-23) }
$$

T. Kil. 3:5a comments on M. 5:1A-D. While M. states that ten vines which are planted according to the rule pertaining to them constitute a "lean" vineyard, T. presents a contrasting case in which vines planted according to the law applying to them do not combine to form a single group. Simeon maintains that trained vines which are properly planted, or properly spaced (Lieberman ${ }^{14}$ ), do not constitute an espalier if they are arranged in a circle. Simeon apparently reasons that the vines of an espalier must be planted in a straight line (cf. M. 6:1).

A. A vineyard which is planted in an irregular manner--

B. If there are in it [vines which are so arranged that one is able] to align (lkwyn) two [vines] opposite [Lieberman, 15 following first printed ed., omits: two] three [= omitted by Erfurt] [others], 
C. 2o, this is [considered] a vineyard.

D. And if not [i.e., if two vines may not be aligned opposite three others],

E. it is not [considered] a vineyard [= M. 5:1E-I].

F. [Erfurt omits F-L] zh hyh $m^{c} s h w$ : They came and asked Rabban Gamaliel [concerning the irregularly-planted vineyard].

G. And he said to them, "(1) Go and ask Yosah b. Geali [first printed ed.: Gulai], (2) who is excellent ${ }^{16}$ and expert $(b r w b q y)$ in the rules [pertaining to] the vineyard."

H. They went and asked him [concerning the irregularly-planted vineyard].

I. He said to them, "If there are in it [vines which are so arranged that one is able] to align (lkwyn) two [vines] opposite three [others],

J. "Zo, this is [considered] a vineyard.

K. "And if not [i.e., if two vines may not be aligned opposite three others],

L. "it is not [considered] a vineyard [= M. 5:1F-I]."

$$
\text { T. Ki1. } 3: 5 b \text { (p. } 214,11.23-27 \text { ) }
$$

T. Kil. 3:5b comments on M. 5:1E-I. A-E cites M., which F-K then supplements with a precedent introduced by the formula mesh $w$. F-L is attached to A-E by the phrase $a h h y h, 17$ and depends on $A-E$ for its context. The point of $F-L$ is to support the rule of $\mathrm{M}$. 5:1E-I, perhaps in response to the opposing view of Meir at M. 5:1J-K (HD). In F-G Gamaliel, who was asked concerning the irregularly-planted vineyard, refers the question to Yosé b. Geali, whom he considers (according to $G(2)$, perhaps a gloss) to be an expert in the laws of the vineyard. Yose then presents what we have in M. 5:1F-I. T. thus attributes M. to this Yavnean Yosé.

A. A vineyard which is planted according to the rule [pertaining to] it --

B. and one row extends from it [i.e., one row is longer than the others ] --

C. when he measures [the area of tillage] of the vines,

D. he allows the vineyard four amot and the [extended] row four [GRA and Lieberman ${ }^{18}$ (following Erfurt) correct to: six] handbreadths.

E. [Erfurt omits E-H ${ }^{19}$ ] [If the vineyard] was planted according to the rule [pertaining to] it -- 
F. and the outer vines [i.e., the vines of the outer row] are visible through [the spaces] between [the vines of the other rows] --

G. When he measures [the area of tillage] from within [i.e., between the outer row and the rest of the vineyard],

$\mathrm{H}$. he allows the vineyard four amot and the [outer] row six handbreadths.

$$
\text { T. Kil. 3:6 (p. 214-215, 11. 28-33) }
$$

T. Kil. 3:6 supplements M. 5:1E-G. While M. discusses the irregularly-planted vineyard which contains five vines aligned to form a vineyard, T. presents the reverse case of the regularlyplanted vineyard which has one row out of place. T. is not directiy relevant to $M$., however, for $T$. is concerned not with the status of the vines as a vineyard but with the areas of tillage of the vineyard and the odd row (although, as we shall see, the latter issue presupposes the former). T. is a unitary pericope composed of two parts, A-D, concerning the row which extends beyond the vineyard, and $\mathrm{E}-\mathrm{H}$, discussing a row the vines of which are out of phase with the other vines of the vineyard. $A-D$ appears in apocopation, while $\mathrm{E}-\mathrm{H}$ forms a conditional sentence. 20 The two units somewhat balance one another, for A differs only slightly from $E$ (which depends on it for its meaning), while C-D is virtually identical to G-H (differing only in that $G$ adds the phrase "from within").

$A-B$ describes the case of a properly-planted vineyard containing one row which extends further than the others. According to C-D this row is granted its own area of tillage of six handbreadths (= the area of tillage of a single vine [M, 6:1]), while the vineyard is allowed its four amot. In other words, the extended row is not considered part of the vineyard. In $E-H$ a vineyard which is properly planted contains an outer row which is so arranged that its vines stand opposite the spaces of the vines in the other rows. G-H again rules that the vineyard and the outer row are allowed separate areas of tillage. The gloss "from within" in $G$, interpreting $H$ to apply to a single area, explains that both areas of tillage are granted in the area between the vineyard and the outer row, 21 The point of $\mathrm{T}$. once more is that the odd row of vines does not belong to the vineyard. T. thus would probably not agree with the rule of M. 5:lE-H. While M. rules that the irregularly-planted vines belong to the vineyard formed by the five regularly-planted vines, T. maintains that vines which are planted irregularly in respect to a vineyard are not considered part of the vineyard. 
A. A vine which is planted on [the slope of (HD)] a terrace [above a vineyard (Lieberman ${ }^{22}$ )] --

B. he [Erfurt, first printed ed.: they] allows it its [owr] area of tillage [apart from that of the vineyard].

$$
\text { T. Kil. } 3: 7 \text { (p. 215, 11. 31-32) }
$$

C. Seeds or vegetables which are planted on [the slope of] a terrace [above a field of the same kind (Lieberman)] --

D. he [Erfurt, first printed ed.: they] allows them their [own] area of tillage [apart from that of the field].

$$
\text { T. Kil. } 3: 8 \text { (p. 215, 11. 32-33) }
$$

T. Kil. 3:7-8, together with T. 3:9 (which immediately follows), form an autonomous subunit concerning the relationship of the slope of a terrace to adjacent fields. T. 3:7-8 consists of two balanced, apocopated sentences, A-B and C-D, which differ only in that $\mathrm{A}-\mathrm{B}$ has gpn while $\mathrm{C}-\mathrm{D}$ reads $z r^{c} y m$ wyrqut. $\mathrm{A}-\mathrm{B}$ describes the case of a vine which is planted on a slope above a vineyard (Lieberman). A-B rules that this vine is considered to be planted in an autonomous area, and so is allowed its own area of tillage. C-D similarly states that seeds or vegetables planted on a slope above a field of the same kind are not regarded as belonging to the field, and therefore are allowed their own area of tillage. The point of T., then, is that the slope of a terrace is not considered to be connected to the fields adjoining it, but rather forms an autonomous domain.

A. [If] he had two fields, one above another --

B. [if] the lower one is planted [with] a vineyard, and the upper one is not planted [with] a vineyard,

C. he sows [first printed ed. adds through "he sows" in $\mathrm{E}$ (Vienna omitting):] the upper [field] until he reaches the base of the lower [field];

D. [if] the upper one is planted [with] a vineyard, and the lower one is not planted [with] a vineyard,

E. he sows the lower [field] and the [slope of the (HD)] terrace until he reaches the base of the vines [in the upper field].

$$
\begin{aligned}
& \text { T. Kil. } 3: 9 \text { (p. } 215,11.33-36) \\
& \text { (D-E: Y. Kil. } 6: 2(30 a))
\end{aligned}
$$


T. Kil. 3:9 continues the discussion of T. 3:7-8 concerning the status of the slope of the terrace. T. consists of a protasis, $A$, and a pair of conditional clauses, $B-C$ and $D-E$. These clauses almost perfectly balance one another, differing only in that $\mathrm{E}$ adds "the [slope of the] terrace," which may be a gloss. T. concerns the case of two neighboring terraces which are planted with different kinds. In B-C a vineyard is planted in the upper field and another kind is sown in the lower terrace, while in $\mathrm{D}-\mathrm{E}$ the circumstances are reversed. In both instances $\mathrm{T}$. rules that one may sow the other kind on the slope right up to the beginning of the vineyard, presumably even within the latter's area of tillage. The point of $T$. is that the slope of the terrace is considered to be autonomous of the fields which it joins, so that the crops sown in it are not regarded as being connected to either of the adjoining terraces. We note that T.'s rule, in allowing the other kind to be sown right up to the vineyard itself, is concerned only that there be no actual planting of diverse-kinds, regardless of whether or not the appearance of diverse-kinds may result.

$5: 2$

A. A vineyard which is planted by [intervals of] less than four amot--

B. R. Simeon says, "[It] is not [considered] a vineyard [B. B.B. 83a reads: the words of $R$. Simeon]."

C. And sages say, "[P, B. B.B. $37 \mathrm{~b}$ add: Lo, this is (considered)] a vineyard."

D. And they [i.e., sages] regard the middle [rows] as if they are not [there].

M. Kil. 5:2 (B. Erub. 37b, 83a, 102b,

Y. Shev. $1: 3$ (32b), Y. Naz. $9: 3(57 d))$

M. Kil. 5:2 discusses the minimum distance which must separate rows of a vineyard, and so continues the interest of $M$. $5: 1 \mathrm{E}-\mathrm{K}$ in the arrangement of a vineyard. M. presents a dispute consisting of a protasis at A (following the formulary pattern

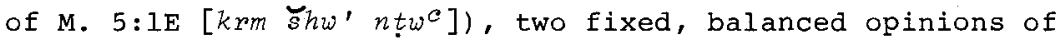
Simeon and sages at $B-C$, and a gloss of C at D. The dispute concerns whether or not the rows of a vineyard must be set apart by a fixed distance, so that they may be differentiated from one another and the vineyard may appear to be planted in an orderly manner. ${ }^{23}$ simeon maintains that the rows must be separated by four amot, the area of tillage of a vineyard, for then the rows will surely appear to be distinct from each other. 
Sages, on the other hand, maintain that rows may form a vineyard even if they are separated by less than four amot. Sages therefore will agree with Meir (M. $5: 1 J-K$ ) that the vines of a vineyard need only produce the overall appearance of a vineyard, but need not actually be planted in a regular arrangement. D explains that sages, ignoring the actual planting of the vineyard, maintain that the middle rows, or the rows which (individually) lie between any two rows separated by four amot, are regarded as if they do not exist, so that all vineyards are considered to be arranged by intervals of four amot. D thus brings the opinion of sages in line with that of simeon, for now all agree that the rows of a vineyard must be separated by four amot.

A. R. Simeon says, "A vineyard which is planted by [intervals of] less than four amot [= M. 5:2A] or more than eight amot,

B. "lo, this is [= omitted by Erfurt] not [considered] a vineyard $[=$ M. $5: 2 \mathrm{~B}]$."

T. Kil. 3:5c (p. 214, 11. 27-28)

T. Kil. 3:5C restates M. 5:2A-B, incorporating M.'s protasis (M. 5:2A) into simeon's saying and adding the rule that a vineyard's rows must be separated by less than eight amot. T. derives this rule from M. 4:9F, where Meir and Simeon state that one may sow another kind between rows of a vineyard which are set apart by eight amot. T. interprets this saying to mean that rows which are separated by eight amot do not combine to form a vineyard, and therefore another kind may be sown between them without producing a planting of diverse-kinds of the vineyard. T. thus combines the rules of $M .4: 9 F$ and $M .5: 2 \mathrm{~B}$, and so has simeon presenting both the minimum and maximum distances which may separate the rows of a vineyard.

$$
5: 3-4
$$

A. A ditch which passes through a vineyard [and measures] ten [handbreadths] deep and four wide --

B. R. Eliezer b. Jacob says, "If [= omitted in sn] [the ditch] was open [= omitted in $M$ ] [i.e., extending] from the beginning of the vineyard to its end (swpw; most mss., MS: $\quad r^{\prime} \vec{s} w$ ["from one end of the vineyard to the other"]), C. "lo, this appears as [if it extends] between two vineyards,

D. "and they sow [another kind] in it.

E. "And if not [i.e., if the ditch is not open], 
F. "Io, this is [considered] like the winepress."

G. And [= omitted by most mss.] the winepress which is in the vineyard [and measures] ten [handbreadths] deep and four wide --

H. R. Eliezer says, "They sow [another kind] in it."

I. And sages prohibit [sowing another kind in it].

J. The watchman's booth [so Danby for Ěwmrh; alternatively, a mound or hill upon which a watchman stands (most commentaries)] which is in the vineyard [and measures] ten [handbreadths] high and four wide --

K. they sow [another kind] in it [i.e., on top of it (Maim., Code, Diverse-Kinds 7:22)].

L. And if it is overhung by interlaced foliage [so Danby for $\left.\xi^{0} r k t \check{s}\right]$,

M. it is prohibited [to sow another kind in it].

$$
\text { M. Ki1. } 5: 3
$$

N. A vine which is planted in the winepress or in the hollow $\left(n q^{c}\right)^{24}--$

o. they allow it its area of tillage and he sows the rest.

P. R. Yose says, "If there are not there four amot [of space], he shall not put seed into it."

Q. And the house which is in the vineyard --

R. they sow [another kind] in it.

M. Kil. $5: 4$

M. Kil. 5:3-4 discusses sowing another kind in different areas of the vineyard. A-F concerns sowing a ditch, while G-M+Q-R deals with seeding a winepress (G-I), a watchman's booth or mound $(J-M)$, and a house $(Q-R)$. As we shall show, N-P is an interpolated unit which concerns sowing another kind together with a vine in a winepress or hollow, and so complements G-I.

$A-F$ consists of a protasis, $A$, following the formulary pattern of M. 5:IE and M. 5:2A (X $\breve{s} h w^{\prime}+$ participle), and Eliezer b. Jacob's saying at $B-F$. The latter is composed of a pair of conditional sentences, B-D (forming, with A, a mildly apocopated sentence) and E-F. These two sentences are not well-balanced, as we see from the following chart: 
B. R. Eliezer b. Jacob says,

"If the ditch was open [i.e., extending] from the beginning of the vineyard to its end,

c. "lo, this appears as [if it extends]' between two vineyards,

D. "and they sow [another kind] in it."
E.

"And if not,

F. "lo, this is [considered]

like the winepress."

While E-F corresponds to B-C, we would expect the phrase "they do not sow [another kind] in it" to follow $F$ and balance $D$. This phrase has been dropped so that F, which by itself simply compares the "closed" ditch to the winepress, may introduce Eliezer's opposing view (G-H) that one may not sow in a winepress. The ruling of Eliezer b. Jacob is not obscured, however, for the redactors both preserved it and increased its prominence by assigning it to sages (I), thus giving it the status of a majority opinion.

The three parts of $G-M+Q-R$ (G-I, J-M, and $Q-R$ ) all open with protases in the formulary pattern $\mathrm{X} \breve{s k k r m}$. Two of the protases ( $G$ and $S$ ) also give the dimensions of the area discussed with nearly identical phrases ("ten [handbreadths] deep (or high) and four wide"), while $Q$ lacks such a specification of size because of the substance of its rule. ${ }^{25}$ The apodoses of the unit $\left(\mathrm{H}, \mathrm{K}\right.$, and $\mathrm{R}$ ) all read $z \omega r^{c} y m$ btwkh (with $\mathrm{L}-\mathrm{M}$ glossing $\mathrm{K}$ ). The protasis of N-P follows the formulary pattern of M. 5:1E, 5:2A, and 5:3A. Since $\mathrm{N}$ follows a distinctive formulary pattern, but not that of the protases of $\mathrm{G}-\mathrm{M}+\mathrm{Q}-\mathrm{R}$, it appears that $\mathrm{N}-\mathrm{P}$ is separate from the foregoing. Furthermore, the apodosis of the unit, $O$ (= the apodoses of M. 4:1J, 4:2N), differs from the apodoses of $G-M+Q-R$ in introducing the consideration of the area of tillage. $\mathrm{N}-\mathrm{P}$ is therefore an autonomous unit which has been inserted into $\mathrm{G}-\mathrm{M}+\mathrm{Q}-\mathrm{R}$ to complement the discussion of the winepress in G-I.

Eliezer b. Jacob rules in A-F that a ditch measuring ten handbreadths deep and four wide may be sown only if it extends across the length of the vineyard. The ditch then forms an autonomous domain, both because of its size and because it appears to divide two separate vineyards. If the ditch is not open, however, it is regarded as a winepress, which may not be sown (regardless of its size) because it lies entirely within the vineyard and is not adequately set apart from it (as it would be, 
for example, by partitions). In G-H Eliezer 26 disagrees with Eliezer b. Jacob, maintaining that, because of its size, the winepress measuring ten handbreadths deep by four wide does constitute an area unto itself in the vineyard.

According to $\mathrm{J}-\mathrm{K}$ one may sow on top of a $̌ w m r h, i . e .$, a watchman's booth or mound, which measures ten handbreadths high and four wide, for a mound of such dimensions forms an autonomous domain within the vineyard. 27 L-M then qualifies J-K by saying that a swmrh covered by an overhang of interwoven vines may not be sown, 28 for now the booth or mound clearly belongs in the domain of the vineyard. ${ }^{29}$ Q-R states that one may sow in the house of a vineyard (presumably under a partially-open roof), for the house is separated from the vineyard by its walls and roof, and so constitutes an area unto itself.

The point of $\mathrm{N}-\mathrm{O}$ is that a vine and another kind may be sown even in a small, bounded area, as long as they are separated by the vine's area of tillage (Maim., Comm.). Yosé then qualifies $\mathrm{N}-\mathrm{O}$ by saying that the winepress may be sown only if it contains four amot of space, or (presumably) enough space to allow both the vine and a substantial amount of the other kind to grow. Albeck apparently understands "four amot" to mean "four square amot (rather than four amot in one direction or four amot square)," so that yose refers to the vine's area of tillage (= one amah in each direction). Yose then makes the obvious point that the winepress or hollow may not be sown unless it is large enough to contain the vine and its area of tillage.
A. A vine which is planted in a hollow [measuring] ten [hand- breadths] deep and four wide --
B. they alzow it its area of tizlage [i.e., the area between the vine and another kind] below [i.e., within the hollow itself (HD) ].
C. [If the hollow measures] less than this,
D. they alzow it its area of tizlage [i.e., the area between the vine and another kind] above [i.e., outside of the hollow (HD) ].

$$
\text { T. Kil. 3:10a (p. 215, 11. 36-38) }
$$

T. Kil. 3:10a cites and glosses M. 5:4N-O. T. consists of a declarative sentence, $A-B$, followed by a conditional sentence, $C-D$, which depends on $A-B$ for its context. The two apodoses are glossed citations of M. 5:40, and so perfectly balance one another ( $m$ th $v s . m^{e}(h)$. M. $5: 4 \mathrm{~N}-0$ states that one may sow another kind near a vine planted in a winepress or hollow, 
provided that he allows the vine its area of tillage, which here refers simply to the distance which must separate a vine from another kind. $T$. now assumes that a vine planted in a hollow will eventually climb out of it, and therefore asks whether in this case the area of tillage is to be allowed within the hollow or outside of it. According to $T$, the answer depends on the size of the hollow. If the hollow measures ten handbreadths deep and four wide, then the vine is considered to grow in a distinct, autonomous area ( $\mathrm{CF}$. M. 5:3A-F+G-I), so that the area of tillage is to be allowed within the hollow itself $(A-B)$. If, however, the hollow is smaller than the specified size, the vine is not considered to grow in a separate area unto itself, and the area of tillage is to be allowed aboveground (C-D). In the latter case $T$. takes the middle position between permitting the area of tillage to be allowed within the hollow (as in $\mathrm{A}-\mathrm{B}$ ), and not permitting the area of tillage to be allowed at all (i.e., prohibiting another kind from being sown near the vine). T. thus introduces the consideration of the hollow's size within the framework of M.'s rule that a vine in a hollow is allowed its area of tillage. T. therefore concerns not whether or not the area of tillage is to be allowed, but where it is to be granted.

A. A ditch which passes through a vineyard and measures ten handbreadths deep and four wide [= M. 5:3A] --

B. R. Liezer [Erfurt, first printed ed.: Eliezer] says, "They sow in it three seeds ( $z r^{c}$ wnyn; Erfurt: mynyn ["kinds"]),

c. "one on one [side], one on the other [side], and one in the middle."

D. Said R. Liezer [Erfurt, first printed ed.: Eliezer] b. Jacob [first printed ed.: R, Eliezer b. Jacob says], "The words of R. Eliezer [Lieberman, ${ }^{30}$ following Erfurt, first printed ed., omits: b. Jacob] appear [correct (Neusner $\left.{ }^{31}\right)$ ] with [regard to] a breached ditch [so Neusner for hrys mbwrs]."

$$
\begin{aligned}
& \text { T. Kil. 3:10b (p. 215, 11. 38-40) } \\
& \text { (C: M. Kil. 3:2) }
\end{aligned}
$$


T. Kil. 3:10b cites and glosses M. 5:3A. A's citation of M. is glossed by Eliezer in $B-C$, whose opinion is then glossed in turn by Eliezer b. Jacob in D. In B-C Eliezer applies the rule of M. $3: 2 \mathrm{H}-\mathrm{I}$ to $\mathrm{M}$. $5: 3 \mathrm{~A}$ (Lieberman ${ }^{32}$ ), saying that one may sow the ditch described in $A$ with three kinds of seeds, one on either side and a third in the middle. Eliezer thus presupposes that one may sow a ditch of the specified size which passes through a vineyard, and so is consistent with his rule (M. 5:3H) that one may sow a winepress of the same size in a vineyard (for both areas are simply depressions in the ground). Eliezer b. Jacob in D qualifies Eliezer's ruling, saying that it applies only in the case of a breached, or open (Lieberman ${ }^{33}$ ), ditch. Eliezer b. Jacob then brings Eliezer into accord with the view attributed to Eliezer b. Jacob at M. 5:3A-D. T. thus links the rules of Eliezer and Eliezer $b$. Jacob, which appear in different contexts in M. (concerning the winepress and the ditch, respectively), so that both authorities now discuss a single issue, the sowing of a ditch in a vineyard.

\section{$5: 5$}

A. He who plants vegetables in the vineyard or allows them to grow,

B. lo, this one sanctifies [i.e., prohibits the use of] fortyfive vines.

C. When [is this the case]?

D. When [the vines] were planted by [intervals of] four, four [amot, i.e., the vines were separated from one another by four amot in four directions (most commentaries)], or by [intervals of] five, five [amot, i.e., the vines were separated from one another by five amot in four directions].

E. [If the vines] were planted by [intervals of] six, six [amot, i.e., the vines were separated by six amot in four directions], or by [intervals of] seven, seven [amot, i.e., the vines were separated from one another by seven amot in four directions],

F. 1o, this one sanctifies [i.e., prohibits the use of the vines planted within] sixteen amah in each direction,

G. [measured] in circles and not in squares [following Danby for 'gwiwt wl' mrwbcwt; Danby adds (p. 34, n. 1): The vines are forfeit that lie within a circle of sixteen cubit radius, not within the square that contains the circle]. 
M. Kil. 5:5 continues the discussion of M. 5:3-4 concerning the sowing of another kind in a vineyard, turning from the instances of permitted sowing to the case of prohibited sowing. 1. consists of A-B, a declarative sentence which is glossed by C-G. The latter is a unitary construction composed of C-D, which appears in a question-and-answer pattern, followed by a conditional sentence at E-F (with $\mathrm{E}$ balancing $\mathrm{D}$ [four + five vs. six + seven]), and an internal gloss at $G$.

A-B describes the case of one who plants vegetables or allows them to grow among vines (i.e., within a vineyard), ruling that the sower thereby sanctifies forty-five vines. Now we have already seen that one who sows another kind within the vineyard's area of tillage, i.e., at the edge of the vineyard, sanctifies either one (House of Shammai) or two (House of Hillel) rows of vines (M. 4:5F-H). This rule follows from the Houses' respective definitions of a vineyard as consisting of either one or two rows (M. 4:5A-D), and Dt. 22:9, which states that, by sowing another kind, one sanctifies a vineyard: You shall not sow your vineyard with two kinds of seeds, lest the whole yield be sanctified, the crop which you have sown and the yield of the vineyard. $A-B$ then complements M. 4:5F-H. While the latter defines the "vineyard" which is sanctified when one sows another kind at the edge of the vineyard, A-B determines this "vineyard" when one sows the other kind among the vines. It is not clear, however, why $A-B$ should define the "vineyard" to consist of exactly forty-five vines. In order to understand $A-B$, therefore, we must first turn to the explanation presented in $C-G$.

$C-D$ states that the rule of $A-B$ applies only when the vines of the vineyard are set apart by four or five amot in each direction. When the vines are separated by six or seven amot, however, all of the vines which lie within a radius of sixteen amot from the vegetables are sanctified (E-G). Maimonides (Comm.) explains the significance of the spacing of the vines as follows. The rule of $A-B$, as interpreted by $C-D$, is a particular instance of $E-G$, for the latter, although referring to vines separated by six or seven amot, actually presents a general rule applying to all arrangements of vines. $A-B$ thus gives the number of vines which happen to lie within the specified radius when the vines 
are separated by four or five amot. Now while forty-five vines do lie in a circle of radius sixteen amot when four amot separate the vines (fig. 38), ${ }^{34}$ only thirty-seven vines are actually contained in such a circle when the vines are set apart by five amot (fig. 39). Maimonides here explains that the circle is considered to be wholly planted with vegetables, so that the row immediately outside of the circle but within four amot of it is also sanctified, since this row lies within the sanctified vineyard's area of tillage. In this case as well, then, the number of sanctified vines totals forty-five (fig. 40).

$A-B$ is thus shown to be an example of the rule of $E-G$. Maimonides summarizes his view as follows (Code, Diverse-Kinds 6:1-2):

[6:1] He who sows vegetables or grain in the vineyard, or he who allows them to grow until they have increased by one two-hundredth [cf, M. 5:6], 10, this one sanctifies [i.e., prohibits the use of] vines which [lie] around it [i.e., the vegetables or grain] sixteen amot in each direction, [measured] in circles and not in squares $[=M .5: 5 \mathrm{~F}-\mathrm{G}]$. And they regard the entire circle, the width [i.e., the diameter] of which is thirty-two amah, as if it is full of vegetables throughout. And every vine which is within this circle is sanctified with the vegetables, and all vines which are outside of the circle are not sanctified.

[6:2] Under what circumstances? When there were between the circumference of this circle and the row of vines which [lies] outside of it more than four amot. But if there were between them exactly (msumsmwt) four amot or less, they regard the circle as $i \dot{f}$ it reaches the [outside] row nearest to it, and as if the circle's width [i.e., diameter] is forty amah. And as to [lit.: they regard $\left.\left(r w^{\prime} y n\right)\right]$ every vine which falls within this circle of [diameter] forty amot, lo, this one is sanctified.

Maimonides' reading of $A-B$ as an instance of $E-G$ is somewhat difficult, though, for he must maintain that, when the vines are separated by five amot, vines outside of the circle of sixteen amot are also sanctified. M., however, nowhere states that vines lying outside of a radius of sixteen amot are sanctified (Rabad to Code, Diverse-Kinds $6: 2$ ). 35 we therefore turn to the alternative interpretation based on TAS.

According to TAS both $A-B$ (as explained by $C-D$ ) and $E-G$ describe cases in which vegetables are sown or allowed to grow around the vine which is located at the very center of the vineyard (Samuel in Y. Kil. 5:5 (30a)). ${ }^{36}$ A-B+C-D states that when the vines are separated by four or five amot, forty-five vines 
are sanctified, while E-G rules that when the vines are six or seven amot away from each other, all vines within a radius of sixteen amot from the vine in the center are sanctified. Now TAS agrees with Maimonides that E-G states a general rule applying to all arrangements of vines. We maintain, however, that such a position raises the same problems mentioned above with reference to Maimonides' opinion (i.e., only thirty-seven vines are contained in a radius of sixteen amot when the vines are set apart by five amot). ${ }^{37}$ We shall therefore modify the view of TAS and not read $\mathrm{A}-\mathrm{B}$ as an instance of $\mathrm{E}-\mathrm{G}$. The two rules then disagree because of the difference in the spacing of the vines. In the case of $A-B$ the vines are separated by four or five amot (C-D), so that the vegetables lie within the area of tillage ( = four amot) of both the vine at the center and the eight surrounding vines (cf. fig. 41), and are regarded as being sown near each of these nine vines. We have already seen that, according to House of Hillel (M. $4: 5 \mathrm{H}$ ), vegetables which lie within the area of tillage of a vineyard sanctify a "vineyard" consisting of two rows of vines. ${ }^{38}$ This rule is here applied to each of the nine vines, so that every vine which may combine with one or more of these vines to form a vineyard (consisting of two rows of vines, with two vines aligned opposite three others [M. 4:6]) is sanctified. The number of vines which are sanctified when the vines are separated by four or five amot thus turns out to be fortyfive (fig. 42).

At E-G, on the other hand, the vines are set apart by six or seven amot, and the vegetables sown around the vine in the center lie within the area of tillage of that vine alone. In this instance, then, only those vines are sanctified which may combine with the central vine to form a vineyard. Now we may support the interpretation of TAS by showing that all of these sanctified vines, and these vines alone, lie within a radius of sixteen amot from the vine in the center. We may demonstrate that all of the sanctified vines are contained in the circle of radius sixteen amot by showing that the sanctified vine which lies furthest from the center is less than sixteen amot away from it. We may similarly show that only the sanctified vines are contained in the circle by determining that the vine which is closest to the center and yet not sanctified lies more than sixteen amot away from the center. In each case the distance between the vine in the center and the outer vine may be measured 
by constructing a right triangle with the hypotenuse drawn between the two vines. The measure of the hypotenuse is then equal to the square root of the sum of the squares of the measures of the triangle's other two sides (Pythagorean Theorem).

The proof proceeds as follows. First, the perpendicular sides of a right triangle with a hypotenuse drawn from the center to the furthest sanctified vine respectively measure either 6 and 12 amot (with the vines spaced at intervals of six amot) or 7 and 14 amot (with the vines spaced at intervals of seven amot) (fig. 43). The distance between the furthest sanctified vine and the center is then either

$$
13.41=\sqrt{6^{2}+12^{12}} \text { or } 15.65=\sqrt{7^{2}+14^{2}} \text { amot, }
$$

so that this vine lies within the circle of radius sixteen amot. Since the sanctified vine furthest from the center lies within the circle, all other sanctified vines are contained in the circle as well. Second, the perpendicular sides of a right triangle with a hypotenuse drawn from the vine in the center to the nearest vine which is not sanctified respectively measure either 12 and 12 amot (with the vines spaced at intervals of six amot) or 14 and 14 amot (with the vines spaced at intervals of seven amot) (fig. 43). The vine which is closest to the center and yet not sanctified is either

$$
16.97=\sqrt{12^{2}+12^{2}} \quad \text { or } \quad 19.79=\sqrt{14^{2}+14^{2}} \text { amot }
$$

away from the center, and thus lies outside of the circle of radius sixteen amot. Since the nearest vine to the center which is not sanctified is not contained in the circle, no vine which is not sanctified lies within the circle. We have thus accounted for the rule of $E-G$ by first determining which vines are sanctified, and then showing that the circle of radius sixteen amot exclusively contains all of these vines. 

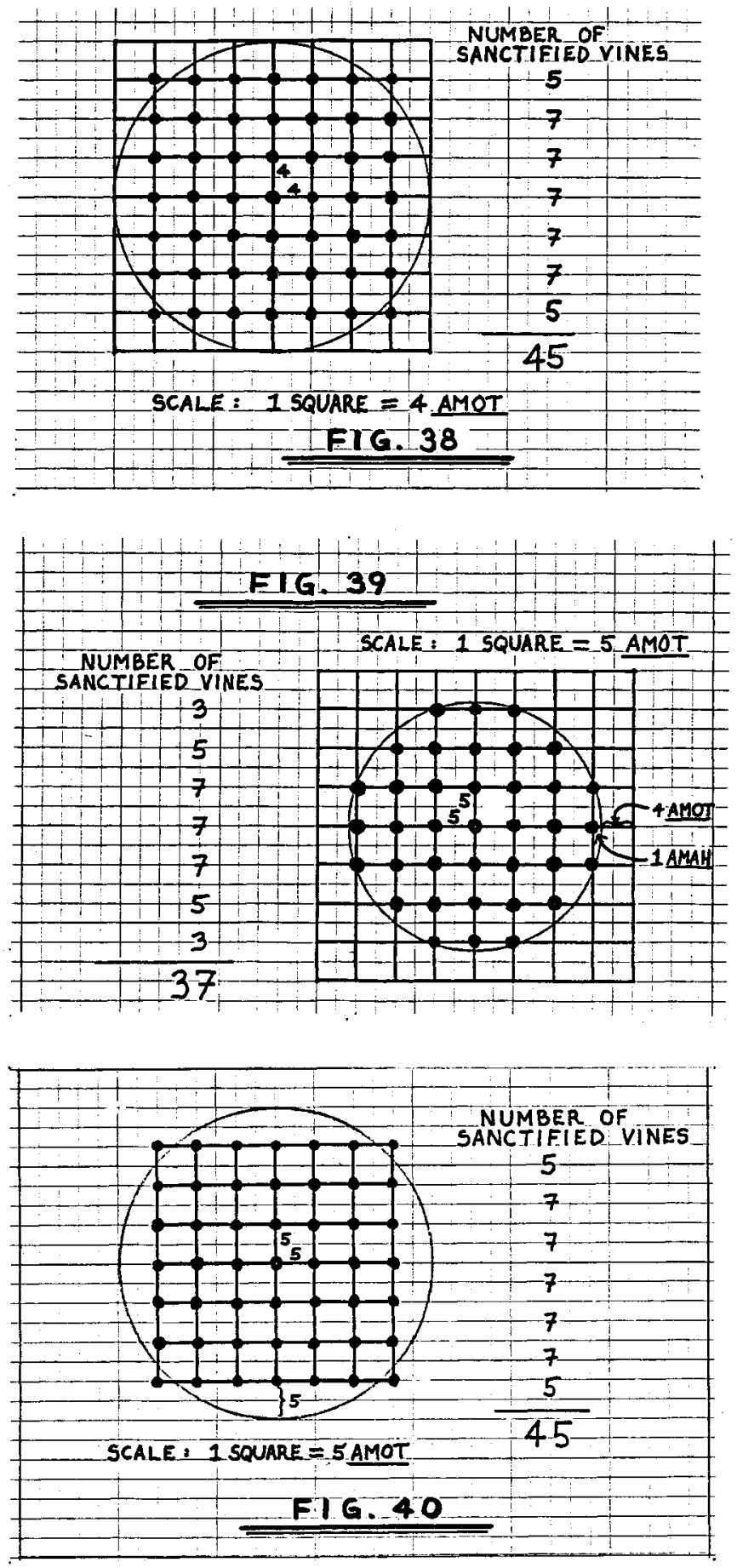

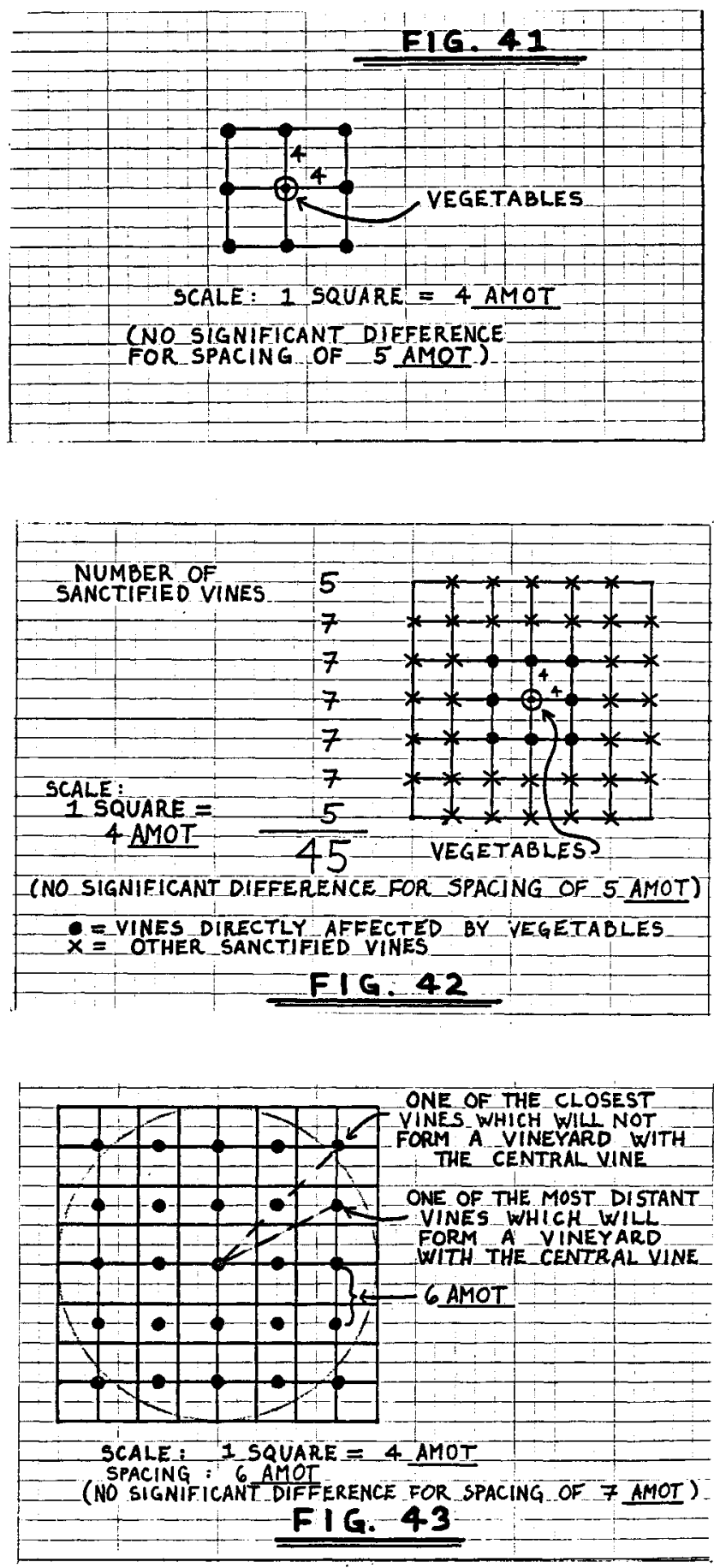
A. He who plants vegetables in the vineyard or allows them to grow,

B. Zo, this one sanctifies [i.e., prohibits the use of] fortyfive vines.

C. When [is this the case]?

D. When [the vines] were planted by [intervals of] four, four [amot, i.e., the vines were separated from one another by four amot in each direction], or by [intervals of] five, five [amot, i.e., the vines were separated from one another by five amot in each direction].

E. [If the vines] were planted by [intervals of] six, six [amot, i.e., the vines were separated from one another by $s i x$ amot in each direction], or by [intervals of] seven, seven [amot, i.e., the vines were separated by seven amot in each direction],

F. Lo, this one sanctifies [i.e., prohibits the use of the vines planted within] sixteen amah in [Erfurt omits the following through I] each direction,

G. [measured] in circles and not in squares [= M. 5:5A-G].

H. R. Simeon b. Eleazar says, "He drives [GRA ${ }^{39}$ adds: a stake $(y t d)]$ into the ground [at the spot at which the vegetables grow], and measures from it sixteen amah in each direction,

I. "[measuring] in circles and not in squares [HD: (measuring) in squares and not in circles],

J. "because they [i.e., the vines in the corners of the square] appear [as if they are] in [Erfurt, first printed ed.: like] the corner[s] of a tablet [i.e., they are considered to be part of the whole] [Erfurt: it (i.e., the vineyard) is regarded (to be) like a curved horn (kqrn ${ }^{c}$ gw $\left.2 h\right)^{40}$ ]."

$$
\text { T. Kil. 3:11 (pp. 215-216, 11. 41-45) }
$$

T. Kil. 3:11 cites M. 5:5 at A-G, with Simeon glossing and opposing $\mathrm{G}$ at $\mathrm{H}-\mathrm{J}$. The reading of $\mathrm{H}-\mathrm{J}$ is somewhat difficult. According to our present text simeon b. Eleazar agrees with $G$ and $H-I$, saying that $F$ refers to a circle and not to the square in which it is inscribed. At $J$, however, he states that the vines in the corners of the square are regarded as being in corners of a tablet, or as part of a whole (cf. T. Ah. 15:2 [Neusner, HMLP, IV, pp. 292-293] for a similar use of the phrase qrn tbl'). 
These vines would not be contained in a circle, so that simeon b. Eleazar here appears to oppose H-I. We therefore follow HD and emend I to read "[measuring] in squares and not in circles." Simeon b. Eleazar then opposes G, maintaining that $F$ describes the square rather than the circle inscribed within it, for the corner-vines are to be sanctified along with the other vines.

\section{$5: 6$}

A. He who sees vegetables [growing] in the vineyard and said [Mn, N: says], "When I shall reach it [i.e., the vegetables] I shall pluck it [so Danby for 'Zqtnw]" --

B. it is permitted [i.e., the vegetables and surrounding vines are not sanctified].

C. [If he said,] "When I shall return I shall pluck it"--

D. if [in the meantime] it [i.e., the vegetables] increased [in size] by [one] two-hundred[th] [all commentaries],

E. it is prohibited [i.e., the vegetables and the surrounding vines are sanctified].

M. Kil. $5: 6$

M. Kil. 5:6 defines the act of allowing diverse-kinds to grow in a vineyard, and so complements the discussion of $M .5: 5$ concerning, "He who plants vegetables in the vineyard or allows them to grow." $M$. is a unitary pericope consisting of $A-B$, a declarative sentence and $C+E$, a conditional sentence dependent on $A$ for its context. D glosses $\mathrm{C}+\mathrm{E}$. C balances the latter part of $\mathrm{A}\left(k \breve{s}^{\prime} g y^{e} z_{w} v s, k \breve{s}^{\prime} h z r\right)$, while the apodoses at $\mathrm{B}$ and $E$ are fixed. We note that $A$ opens with a participle and then uses the perfect tense, a shift which may indicate that $A$ has been revised to follow the formulary pattern of $M .5: 5$.

According to $A-B$ one who spots vegetables growing in his vineyard need not immediately remove them, but may allow them to grow until he reaches them in the course of his work. Since he has not overtly indicated that he wishes the vegetables to grow in the vineyard, it does not appear as if he allows diverse-kinds to grow, and he therefore need not make a special effort to uproot them. $\mathrm{C}+\mathrm{E}$, on the other hand, states that, having reached the vegetables, one may not leave the area with the intent of returning to remove them. By leaving one makes it appear as if he wishes the vegetables to continue to grow, and he is thus regarded as one who allows diverse-kinds to grow in the vine- 
yard. D adds that one may not leave and allow the vegetables to remain if, in the meantime, they grow by one two-hundredth.

A. The owner $\left(b^{c} l\right.$ hbyt) [of a vineyard] who allowed wild vegetables (yrqut $s d h$ ) to grow in the vineyard--

B. it [i.e., the use of the vegetables or vines] is prohibited for him and prohibited for everyone [else] [Y.: whether for him or for anyone else].

c. Another [person] from any place [Y.: a worker] who allowed wild vegetables to grow in [someone else's] vineyard--

D. it [i.e., the use of the vegetables or vines] is prohibited for him and permitted for everyone [else].

$$
\begin{aligned}
& \text { T. Kil. } 3: 12 \mathrm{~b} \text { (p. } 216,11.47-49) \\
& \text { (Y. Kil. } 5: 5(30 \mathrm{a}) \text { ) }
\end{aligned}
$$

T. Kil. 3:12b comments on M. 5:6, introducing a distinction between the owner and the passerby who allow diverse-kinds to grow in the vineyard. T. is composed of two well-balanced declarative sentences, $A-B$ and $C-D$. T. concerns the case of wild vegetables which grow in a vineyard, and thus underlines the fact that the vegetables involved are not sown. 41 According to $A-B$ the owner who allows the vegetables to grow in his vineyard renders them prohibited, or sanctifies them (along with the surrounding vines), for everyone. C-D then states that one who sees vegetables growing in another's vineyard but fails to remove them, as he is allowed to do (cf. T. 2:16 [cited by TZ, P. 216, on 1. 48]), renders them prohibited for himself but not for others. In this instance one may not himself use diverse-kinds which he has allowed to grow, but he does not render them prohibited for others, presumably because one cannot sanctify that which is not his (cf. M. 7:4-5). T. thus effectively understands sanctification in a relative sense, for in the latter case the vegetables and vines do not become absolutely prohibited, but are forbidden only to certain individuals.

\section{$5: 7$}

A. [If] he was passing through the vineyard, and seeds fell from him [i.e., from those which he was carrying]--

B. or [if seeds] went out [into the vineyard] with the dung [used in manuring the vineyard] or with the water [which irrigated the vineyard]-- 
C. he who sows [in a field of grain (Y.)] and the wind blew $\left(s^{c} r t w\right)$ [the seeds] behind him [into the nearby vineyard]--

D. it is permitted.

E. [If] the wind blew (scrtw; most mss.: syy ${ }^{c} t w$ ["aided him (in spreading)"]) [the seeds] before him [Bert. (according to MS), $\mathrm{KP}^{42}$ add: --it is prohibited]--

F. R. CAqiva says, "If [he allowed the seeds to grow until they yielded] blades [so Danby for ${ }^{c} s b y m$ ], he shall overturn [them].

G. "If [he allowed the seeds to grow until they reached] an early stage of ripening [so Primus 43 for 'byb], he shall break [the ears] off [following Danby for ynps].

H. "And if [he allowed the seeds to grow until they] yielded [Primus adds: ripened] grain--it shall be burnt."

M. Kil. $5: 7$

M. Kil. 5:7 discusses the act of sowing diverse-kinds in a vineyard, and so further complements M. 5:5. M. is composed of $A-D$, consisting of three protases $(A-C)$ with a single, fixed apodosis (D), and $E-H$, containing a protasis $(E)$ which balances $C$ and a saying of Aqiva $(F-H)$. Since $E$ responds only to $C$, and since $C$ (rather than $A-B$ ) follows the formulary pattern of M. 5:5A and M. 5:6A, it appears that C originally opened the pericope, and that $A-B$ was later attached to it. The balance of $C$ and $E$ leads us to expect $D$ to be balanced by the fixed apodosis 'swr, which has apparently been dropped in favor of CAqiva's saying at $\mathrm{F}-\mathrm{H}$. The latter is then not primary to the pericope, and we shall see, in fact, that it does not deal with the issue of M. 5:5E at all. T. 3:12a, furthermore, assigns to simeon,

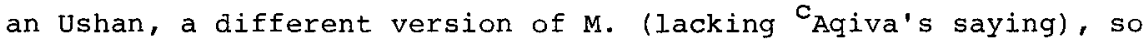
that it is unlikely that the pericope is of Yavnean origin. $M$. then appears to have originally consisted of C-E + the apodosis 'swr.

A-B describes cases in which seeds accidentally enter a vineyard without being sown. $C$ and $E$ then contrast two cases of accidental sowing in a vineyard, distinguishing between the appearances of intentional and unintentional sowing. In both instances the wind blows into an adjacent vineyard seeds which are sown in a field of grain (Eleazar in Y. Kil. 5:7). If the wind blows the seeds behind the sower into the vineyard (C) the sowing is considered to be unintentional. Since the sower clearly does not want the wind to blow the seeds away from the 
spot of sowing, it does not appear as if he wishes the seeds to go into the vineyard. This sowing is therefore permitted (D), 44 i.e., it does not sanctify the vines. ${ }^{45}$ It is now clear that $A$ and $B$ have been added in order to illustrate the case of $C$. If, on the other hand, the wind blows the seeds before the sower (E), the sowing is considered to be intentional. Since the sower desires the wind to blow from behind him and scatter the seeds, he thus appears to wish that the seeds be blown into the vineyard. In this instance, then, the sowing is presumably prohibited.

In F-H CAqiva describes that method of destroying seeds which is appropriate to each stage of the seeds' development. 'Aqiva's saying is then not relevant to the case of $\mathrm{E}$. While the latter concerns only the sowing of seeds in a vineyard, CAqiva's saying presupposes that the seeds have been allowed to grow as well. F-H perhaps better fits the context of M. 5:6, which specifically discusses the question of allowing diverse-kinds to grow in a vineyard. M. 5:6 would then read as follows:

A. He who sees vegetables [growing] in the vineyard and said, "When I shall reach it [i.e., the vegetables] I shall pluck it"--

B. it is permitted [i.e., the vegetables and surrounding vines are not sanctified].

C. [If he said,] "When I shall return I shall pluck it"--

D. if [in the meantime] it [i.e., the vegetables] increased [in size] by [one] two-hundred[th]--

E. R. CAqiva says, "If [the seeds yielded] blades, he shall overturn [them].

F. "If [they reached] an early stage of ripening, he shall break [the ears] off.

G. "And if [they] yielded [ripened] grain--it shall be burnt."

CAqiva's methods of destroying the seeds may be described as follows. If one allows the seeds to sprout only blades, he may destroy them by simply overturning them (F). If, however, the plants have reached an early stage of ripening ('byb), in which they already have ears containing partially-ripened grains, 46 then they are not to be overturned. Although the ears, by being overturned, would be detached from the ground, they would still continue to provide nourishment to the grains within them. One must therefore break off the ears $(G)$, and thereby dislodge the 
grains, which will then dry up. 47 Finally, grains which are fully ripened are able to survive even outside of the ears, so that these grains can only be destroyed by being burnt (H).

A. R. Simeon b. Judah says in the name of R. Simeon, "He who sows [in a field of grain] and the wind blew (sycrtw) [the seeds] behind him [into the nearby vineyard]--

B. "it is permitted [= M. 5:7C-D],

C. "for it is [a case of] an unavoidable accident [so Danby 48 for 'wns].

D. "[If] the wind aided him [in spreading] (syyctw; first printed ed.: sycrtw ["blew"]) [the seeds] before him $[=\mathrm{M}, 5: 7 \mathrm{E}]$,

E. [Erfurt, first printed ed., add:] "it is prohibited."

$$
\begin{aligned}
& \text { T. Kil. } 3: 12 \mathrm{a}(\mathrm{p}, 216,11.45-47) \\
& \text { (A-C: Y. Kil. } 5: 7(30 \mathrm{a}))
\end{aligned}
$$

T. Kil. 3:12a attributes M. 5:7C-E, with slight differences, to simeon $b$. Judah in the name of simeon. T.'s version of the pericope differs from that of $M$. in two places. C glosses $A-B$, explaining that the sowing described in the latter is considered to be an unavoidable accident, since the wind scatters the seeds in the direction opposite to that in which the sower intends them to fall. At E T. presents the apodosis 'swr, which the presence of mwtr in M. 5:7D (=T. 3:12a/B) had led us to expect.

R. [You shall not sow your vineyard with diverse-kinds lest the whole yield be sanctified,] the seed [which you have sown and the yield of the vineyard (Dt. 22:9)]--

s. excluding [the cases of] seed which went out [into the vineyard] with the dung [used in manuring the vineyard] or with the water [which irrigated the vineyard],

T. [or the case of] he who sows in a white field and the wind blew (the seeds) behind him (into the nearby vineyard) $[=$ M. $5: 7 \mathrm{~B}-\mathrm{C}]$.

U. Might one say that I should exclude [as well the case of] he who sows and the wind aided him [in spreading] (msyy ${ }^{c}$ tw; London, Hiliel, GRA: $m s^{\mathrm{c} t \omega}[$ "blew"]) [(the seed) before him $[=$ M. 5:7E]?

v. Scripture says, which you have sown. 
Sifre Dt. 230e supplies proof-texts from Dt. 22:9 to M. 5:7B$\mathrm{C}+\mathrm{E}$. R-T takes the phrase the seed to exclude all but the seed which the owner desires to be sown, and so to exclude the cases of S-T. At U-V the relative clause which you have sown is understood to include all cases of intentional sowing, and thus to include the case of $\mathrm{E}$.

$$
5: 8
$$

A. He who allows thorns to grow in the vineyard--

B. R. Eliezer [B. B.B. 156b: Eleazar] says, "He has sanctified [the surrounding vines of the vineyard]."

c. And sages say, "He does not sanctify [the surrounding vines of the vineyard],

D. "except [when he allows to grow] something the like of which they [Danby: ordinarily] allow to grow."

E. (1) Iris, ${ }^{49}$ and (2) ivy, ${ }^{50}$ and (3) a white lily, 51

F. and all kinds of [plants grown for the sake of their] seeds [Geniza fragments, ${ }^{52} \mathrm{P}, \operatorname{Pr}$ (cf. also T. 3:12c, MS, and Lieberman ${ }^{53}$ ): are kinds of seeds and],

G. are not [GRA: are] [considered] diverse-kinds in the vineyard.

H. (4) Hemp $54--$

I. R. Tarfon says, "It is not [considered] diverse-kinds [in the vineyard]."

J. And sages say, "[It is considered] diverse-kinds [in the vineyard] ."

K. (5) And the globe artichoke ${ }^{55}$ is [considered] diverse-kinds [in the vineyard].

\author{
M. Kil. 5:8 (A-D: B. Shab. 144 b, B. B.B. \\ 156b, Y. Kil. $1: 1$ (26d))
}

M. Kil. 5:8 consists of two parts, $A-D$ and $E-K$, which may be distinguished from one another by the language of their apodoses. A-D concerns the sanctification of vines by the growing of another kind in the vineyard, and its operative language is

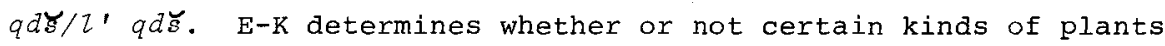
are considered diverse-kinds in a vineyard, and its apodoses read $k l^{\prime} y m /$ 'ynn kl'ym ( $t b k r m$ ).

$A-D$ is composed of a well-balanced dispute at $A-C$ (with $A$ in the formulary pattern of $M .5: 5 \mathrm{~A}, 5: 6 \mathrm{~A}, 5: 7 \mathrm{C}$ ), with $\mathrm{D}$ glossing C. According to $D$ the dispute concerns whether or not one who allows useless plants, such as thorns, to grow in a vineyard thereby sanctifies the vines. Eliezer says that he does sanctify 
the vines, for any kind which he allows to grow is considered to be diverse-kinds in the vineyard. Sages, on the other hand, maintain that the vines are sanctified only by a kind which is usually allowed to grow, i.e., a kind which is beneficial to the owner (D), for only then does it appear as if the owner wishes the other kind to grow in the vineyard. According to Eliezer, then, the actual growth of diverse-kinds determines the status of the vines, while sages say that one sanctifies the vines only when one desires the diverse-kinds to grow, and thus one may allow certain kinds to grow without sanctifying the vines.

$E-K$ consists of a list of three plants at E+G ( $g$ lossed by F), a balanced dispute concerning another plant at $\mathrm{H}-\mathrm{J}$, and a declarative sentence dealing with a fifth plant at $\mathrm{K}$. According to $E+G$ iris, ivy, and the white lily are not considered diversekinds in a vineyard, apparently because they serve no useful purpose for the owner (following Rabad, Maim., Code, Diverse-kinds $5: 19$ ). E+G then illustrates the position of sages in $C-D$ (and $E-K$ is related to $A-D)$. F states that plants grown for the sake of their seeds are also not considered diverse-kinds in the vineyard. The reasoning behind this rule is difficult, for presumably any kind of plant is considered diverse-kinds in a vineyard (cf. the emendation of GRA). The point of $F$ is perhaps analogous to that of $D$, maintaining that since the owner desires the seeds but not the plants themselves, the latter are not considered diverse-kinds in a vineyard. Alternatively, some manuscripts (perhaps following $T$.) read $F$ as referring to $E$. $F$ then states that even though the three plants of $\mathrm{E}$ are grown for the sake of their seeds, they are not considered diverse-kinds in the vineyard because they are not usually allowed to grow (Rabad). ${ }^{56}$

The dispute of H-J apparently concerns whether or not hemp is grown primarily for the sake of its seeds or for its plant. Tarfon maintains that hemp is grown mainly for its seeds, which produce an oil, and therefore is not considered diverse-kinds in a vineyard (F). Sages, however, say that hemp is grown primarily for its fibers, which are used in the manufacture of rope and clothing, 57 and thus is considered diverse-kinds in the vineyard. ${ }^{58} \mathrm{~K}$ concerns the globe artichoke, of which both the leaves and flowers may be eaten. 59 The point of $\mathrm{K}$ apparently is that the plant is grown primarily for the sake of its leaves, and therefore is considered diverse-kinds in a vineyard.
A. (1) Chrozophorae, 60 and
(2) spurges, 61
1 and (3) cudweed $($ brkwyy $r), 62$ and (4) muscari, 63 and (5) dyer's reseda, 64 and (6) saffron, 65 
B. and (7) a globe artichoke [= M. 5:8K] and (8) ammi,66 and (9) mallow, 67

C. and (10) savory, 68 and (11) hyssop, ${ }^{69}$ and (12) thyme, 70

D. and (13) chate melons, and (14) gourds, and (15) watermelons, and (16) musk melons, and (17) a cowpea,

E. [even though they are] kinds of [plants grown for the sake of their] seeds,

F. 1o, they are [considered] diverse-kinds in the vineyard.

T. Kil. 3:12c (p. 216, 11. 49-53)

G. (18) Iris, and (19) ivy, and (20) a white lizy

$\mathrm{H}$. are kinds of [plants grown for the sake of their] seeds,

I. and are not [considered] diverse-kinds in the vineyard [= M. Kil. $5: 8 \mathrm{E}-\mathrm{G}]$.

J. R. Dosethai b. Judah says, "Kinds of grasses [are considered] diverse-kinds in a vineyard."

T. Kil. $3: 13$ (p. 216, 11. 52-53)

K. (21) A cat-tail flag, 71 and (22) a juncus, ${ }^{72}$ and (23) a papyrus plant, 73

L. and everything which grows in the dirt [i.e., in meadow-grass (Lieberman) ],

M. are kinds of grasses,

N. [and] 10, they are [Erfurt: are not] [considered] diversekinds in the vineyard.

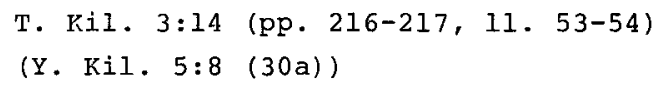

o. (24) Reeds, 74 and (25) alhagi, 75 and (26) the hawthorns, 76 and (27) buckthorns, 77

P. are kinds of trees,

Q. and are not [considered] diverse-kinds in the vineyard.

R. This is the general rule: Every [plant] which sends out its leaves from its base, 10, this is [considered] an herb $(y r q)$.

s. And every [plant] which does not send out its leaves from its base, 10, this is considered a tree.

$$
\begin{aligned}
& \text { T. Kil. } 3: 15 \text { (p. } 217,11.55-57) \\
& \text { (O-Q: B. Erub. 34b, Y. Kil. 5:8 (30a)) }
\end{aligned}
$$

T. (28) Squill ${ }^{78}=$ 
U. R. Ishmael [Erfurt: Simeon] says, "It is [considered] diverse-kinds in the vineyard."

v. And sages say, "It is not [considered] diverse-kinds in the vineyard."

W. (29) Dodder 79

X. R. Tarfon says, "It is not [considered] diverse-kinds [in the vineyard]."

Y. And sages say, "It is [considered] diverse-kinds [in the vineyard]."

z. Said R. Tarfon, "If [it is considered] diverse-kinds in the vineyard, let [it be considered] diverse-kinds [when planted] with seeds.

AA. "And if it is not [considered] diverse-kinds [when planted] with seeds, let it not be [considered] diverse-kinds in the vineyard."

$$
\begin{aligned}
& \text { T. Kil. } 3: 16 \text { (p. 217, 11. 57-60) (W-Y: } \\
& \text { B. Shab. 139a) }
\end{aligned}
$$

BB. (3) Caper $^{80}--$

CC. House of Shamai say, "It is [considered] diverse-kinds [Erfurt, first printed ed. omit:] in the vineyard."

DD. House of Hillel says, "It is not [considered] diverse-kinds."

$E E$. And both agree that [the caper] is liable in [respect to the laws of] ${ }^{\text {orlah. }}$.

$$
\begin{aligned}
& \text { T. Kil. } 3: 17 \text { (p. } 217,11.60-61 \text { ) (B. Ber. } \\
& \text { 36a, Y. Kil. } 5: 8(30 a))
\end{aligned}
$$

T. Kil. 3:12c-17 complements M. 5:8E-K with a large construction concerning whether or not certain plants are considered to be diverse-kinds in a vineyard. T. consists of three major subunits, $A-I, J-N$, and $0-E E$. A-I lists twenty kinds of seeds which either are or are not considered diverse-kinds in a vineyard. $\mathrm{J}-\mathrm{N}$ then discusses the status of three kinds of grasses which grow in a vineyard, and O-EE concerns whether or not seven kinds of plants are treated as trees and are thus not considered diversekinds in a vineyard. T. therefore discusses thirty plants in all.

A-I complements $M .5: 8 F$ by contrasting those kinds of seeds which are considered diverse-kinds in a vineyard (A-F) with those that are not so considered (G-I) (Lieberman ${ }^{81}$ ). A-F lists seventeen plants, which may be arranged in sublists of six (A), three (B), three (C), and five (D). The five trailing-plants of $D,{ }^{82}$ however, are clearly not grown for the sake of their seeds, and so apparently do not belong on the list. The remaining 
twelve plants are all presumably grown for their seeds. Four of the six plants of $A(1-2,5-6)$ are grown for their dyes. ${ }^{83}$ The identification of brkwyyr (3) as cudweed, an herb, is tentative. Muscari (4) is grown for its edible bulbs. It is possible, then, that plants 3 and 4 do not belong on the list of $A$, so that A should contain four plants and A-D should list ten in all. The three plants of $B$ are all grown for use as food. The globe artichoke, the leaves and flowers of which are edible, is mentioned in $\mathrm{M}$. 5:8K as being considered diverse-kinds in a vineyard. $T$. then perhaps contrasts the globe artichoke with the plants of $G$, so relating M. $5: 8 \mathrm{~K}$ to M. 5:3E-G. Ammi (8) is used as flavoring, ${ }^{84}$ while mallow is similar to the globe artichoke in that both its leaves and its flowers may be eaten. 85 All of the plants of $\mathrm{C}$ belong to the mint family (Labiateae), and so are grown for use as spices. G-I then cites M. 5:8E-G (reading $M .5: 8 F$ as referring to $M .5: 8 \mathrm{E}$ ), saying that iris, ivy, and white lily are kinds of seeds, and are not considered diversekinds in the vineyard. A-I may read $M$. 5:8A-D into $M .5: 8 F^{86}$ in order to qualify the latter. T's point then is that although the plants of both $A-D$ and $G$ are kinds of seeds, the former are beneficial to the owner and are considered diverse-kinds in the vineyard, while the latter are not usually allowed to grow and thus are not so considered.

$\mathrm{J}-\mathrm{N}$ consists of Dosethai b. Judah's ruling at $\mathrm{J}$, followed by a list at $K+M-N$, which is perhaps glossed by $L$. Dosethai $b$. Judah rules that kinds of grasses are considered diverse-kinds in a vineyard. $\mathrm{K}+\mathrm{M}-\mathrm{N}$ then either illustrates his rule, or, according to the reading of Erfurt $\mathrm{Ms}$, , presents exceptions to it, following the pattern of A-I (Lieberman ${ }^{37}$ ). All of the plants of $K$ grow in or near water, so that $I$ simply generalizes the rule of $\mathrm{K}$.

$O-E E$ is composed of $O-Q$, a list of trees, R-S, a we11balanced general rule for distinguishing between trees and herbs, and $T-E E$, a series of three disputes ( $T-V, W-A A$, and $B B-E E$ ) concerning whether certain plants are considered trees or herbs. o lists four plants which are regarded as trees and so are not considered diverse-kinds in a vineyard. ${ }^{38}$ These plants are treated as trees either because their leaves do not come out of their roots (R-S), or because they have hard stems (Iieber$\operatorname{man}^{89}$ ). R-S then differentiates between herbs and trees, ruling that plants with leaves coming directly out of their bases or roots are considered herbs, while those with leaves coming out of other parts (e.g., branches) are regarded as trees. 90 
In T-V Ishmael and sages dispute concerning whether squill is considered an herb or a tree. Squill is a bulbous plant with a two-part growth-cycle. In late summer it sprouts a stem containing many flowers. When the fruits of the plant ripen and its seeds scatter, the stem withers and dies, and all that remains of the plant is the underground bulb. In the fall leaves then sprout up directly from the bulb. 91 Ishmael apparently maintains that squill is an herb because its leaves grow out of its base in the fall, while sages say that because of its summer stem squill is considered a tree. 92

$W-A A$ consists of a dispute between Tarfon and sages at $W-Y$, followed by an argument of Tarfon at Z-AA which appears to be the beginning of a debate. Sages, however, are not assigned a response to the argument, so that the redactor of $W-A A$ appears to favor Tarfon's position. ${ }^{93}$ The dispute of $W-Y$ deals with dodder, a parasitic plant which abandons its own roots upon latching onto a host plant. ${ }^{94}$ Tarfon perhaps reasons that dodder is considered a tree because once it becomes attached to the host its leaves do not appear to come out of its base. Sages, though, maintain that dodder is considered an herb, ${ }^{95}$ presumably because its leaves originally grow out of its roots. Tarfon then determines the status of the plant on the basis of its appearance, while sages take account of its actual process of growth. In $z-A A$ Tarfon argues that sages' views are inconsistent, for while they do not regard dodder as being diverse-kinds among seeds (thus considering dodder to be a tree), they do regard it as being diverse-kinds in a vineyard (thus treating it as an herb). The view attributed by Tarfon to sages, which states that dodder is considered to be diverse-kinds among seeds, is not found anywhere else in M. - T. 96

The Houses-disputes at BB-DD (which is glossed by EE) concerns caper, which, like squill, has a two-part growth cycle. During the summer its leaves and flowers grow on branches. The latter then dry up and disappear, 97 and a new stem sprouts from the roots in spring. 98 House of shammai apparently consider caper to be an herb because its leaves and flowers grow directly from the base of the plant in spring. House of Hillel, on the other hand, maintain that because the plant grows branches in the summer it is regarded as a tree. ${ }^{99}$ According to $\mathrm{EE}$ both sides agree that caper is considered a tree in respect to the laws of corlah, so that EE effectively brings House of Shammai over to the position of House of Hillel. 
W. He who allows thorns to grow in the vineyard--

X. R. Eliezer says, "He has sanctified [the surrounding vines of the vineyard $[=\mathrm{M} .5: 8 \mathrm{~A}-\mathrm{B}]$,

Y. [GRA, Nesiv $100^{\circ}$ reverse $C$ and $E$ ] "as it is written, [The seed] which you have sown (Dt. 22:9)."

Z. And sages say, "The seed (Dt. 22:9),

AA. excluding He who allows thorns to grow in the vineyard."

Sifre Dt. $230 f$ (ed. Finkelstein, p. 263, 11. 6-3)

Sifré Dt. 230f, citing M. 5:8A-B, provides proof-texts from Dt. 22:9 for both sides of M.'s dispute. In X-Y Eliezer's view that thorns which are allowed to grow in a vineyard sanctify the vines is supported by the phrase which you have sown. Since this phrase on the surface adds nothing to the preceding phrase, The seed, it is taken to include every plant which is allowed to grow among the plants which sanctify the vines (Hillel). Sages' view that the thorns do not sanctify the vines is supported in $\mathrm{z}-\mathrm{AA}$ by the phrase The seed, which is understood to include as plants which sanctify the vines only those plants which one usually allows to grow. According to the alternate reading of GRA and Nesiv, Eliezer's view is supported by the phrase The seed, which is taken to include all plants, while sages' opinion is supported by the phrase which you have sown, which is understood to exclude everything which one would not normally allow to grow. 



\section{CHAPTER SIX}

\section{RILAYIM CHAPTER SIX}

Chapter six presents an essay dealing with the relationship between a trained vine and its supporting structure. M. discusses this question in a logical sequence, considering first the structure which actually supports the vine (M. $6: 1+2 \mathrm{~A}-\mathrm{C}$ [with M. 6:2D-F appended]), then that part of the structure which is not covered by the vine (M. $6: 3-5+6+7$ ), and finally those parts of either the vine or structure which project beyond the whole (M. 6:8-9). The chapter opens (M. 6:1-2A-C) and closes (M. $6: 6+7+8+9$ ) with a discussion of the espalier, or row of trained vines, and treats at its center the single trained vine (M. $6: 3-5$ ).

The chapter logically begins with the definition of an espalier as a row of five vines trained on a fence (M. 6:1). Like a vineyard, an espalier is allowed four amot as its area of tillage. The Houses then dispute whether these four amot are measured from the vines or from the fence, i.e., whether the former or the latter constitutes the principal part of the espalier. This dispute is based on the Houses-dispute of M. 4:5, which concerns whether one (House of Shammai) or two (House of Hillel) rows of vines form a vineyard. House of Shammai reason here that the vines are regarded as being primary to the espalier, for they maintain that the row of vines itself forms a vineyard and would thus be allowed four amot even without a fence. House of Hillel, on the other hand, maintain that the espalier's chief component is the fence, without which, in their view, the row of vines would be allowed the area of tillage of a single vine, six handbreadths. M. $6: 2 \mathrm{~A}-\mathrm{C}$ then augments $M$. $6: 1$ with a discussion concerning the area of tillage which is allowed to an espalier planted on a terrace, and is itself complemented by M. 6:2D-F, which discusses another problem related to planting vines on a terrace.

The attention of $M$. now turns to that part of the structure which does not support the vine. The discussion of this part of the structure is opened by M. 6:3-5, a subunit characterized by its distinctive formulary pattern (hmdlh, at M. $6: 3 \mathrm{~A}, \mathrm{D}, 6: 4 \mathrm{~A}$ ), and by its subject, the single trained vine. The issue of $M$. 6:3-5 concerns whether the entire supporting structure is considered to be merely an extension of the vine (as in the case of the 
espalier), so that one may not sow even under that part which is not covered by the vine, or whether the structure retains its own aspect, and one may sow under the part which does not serve the vine. M. at first distinguishes between an inanimate structure (e.g., a latticework of laths), which is considered to be entirely "taken over" by the vine trained upon it, and an animate structure (e.g., a fruit tree), which keeps its own aspect. A glossator, however, redraws this distinction, contrasting instead a non-fruit-bearing structure (e.g., a barren tree), which is regarded as an extension of the vine, and a fruit-bearing structure (e.g., a fruit tree), which is not so regarded.

M. $6: 6+7$ then raises the question of M. $6: 3-5$, i.e., whether one may sow under that part of the structure which does not support the vine, with respect to uncovered areas in the middle (M. 6:6) or at the end (M. 6:7) of an espalier's wall. M. rules that one may sow at such spots along the wall after allowing the vines their area of tillage, and so disagrees with the rule of $M .6: 3-5$, according to which one would not be able to sow at all along any part of the wall (since the latter is neither animate nor fruitbearing). M. $6: 6+7$ therefore appears to be interested not in the issue of the status of the supporting structure, but in the entirely different question of separating the vines from the other kind in order to prevent the appearance of diverse-kinds. We note that M. $6: 7$ follows the formulary pattern of $\mathrm{M}$. $6: 2 \mathrm{~A}$ (crys hyws ' $m n \mathrm{X}$ ), so that the two pericopae were originally redacted together. A redactor then separated the two pericopae, which are not related to each other in substance, by inserting between them M. $6: 2 \mathrm{D}-\mathrm{F}$, which augments $M$. $6: 2 \mathrm{~A}-\mathrm{C}$, and $M$. $6: 3-5+6$, which (as we have just seen) discusses the same issue as does M. $6: 7$.

Reversing the formulary pattern of M. $6: 7$ ('roys hyws' $m n \mathrm{X}$ [M. 6:7] vs. X hyws' $m n h^{c}$ rys [M. 6:8A,6:9E]), M. 6:8-9 concludes the chapter with a sub-unit dealing with the projections of an espalier. The issue of the sub-unit concerns whether part of the espalier which projects beyond it may nevertheless be regarded as belonging to an espalier, so that one may not sow under such a projection. Reeds projecting from the supporting structure, on the one hand, do not at all serve the vines and so are considered to be separate from the espalier. A projecting vine-blossom, on the other hand, will eventually produce grapes, and therefore is regarded as part of the espalier. 
$6: 1$

A. What is an espalier ( ${ }^{c}$ rys)?

B. He who plants a row of five vines beside a fence which is ten handbreadths high, or beside a ditch which is ten handbreadths deep and four wide--

C. they allow it its area of tillage of four amot.

D. House of Shammai say, "They measure four amot from the base of the vines to the field."

E. House of Hillel say, "From the fence to the field."

F. Said R. Yohanan b. Nuri, "All err who say so [tr. Danby].

G. "Rather, [the four amot are measured as follows:] If there are four amot from the base of the vines to the fence, they allow it its area of tillage and he sows the rest."

$\mathrm{H}$. And how much is the area of tillage of a [single] vine?

I. Six handbreadths in all directions.

J. R. CAqiva says, "Three [handbreadths]."

$$
\begin{aligned}
& \text { M. Kil. } 6: 1 \text { (A-B [until "vines"]: } \\
& \text { Y. Kil. } 4: 1 \text { (29b); J: Y. Kil. 7:1 (30d)) }
\end{aligned}
$$

M. Kil. 6:l opens the chapter's discussion of the espalier by dealing with the distance which must separate the vines from another kind. M. begins with a question at $A$, followed by a mildly apocopated sentence (in the he-who-formulary pattern) at B-C. The latter, however, does not respond to $A$, for it concerns not the definition of an espalier but the extent of its area of tillage. Furthermore, B-C contains both a protasis and an apodosis, and so can stand without $A$. It is possible that A was originally answered by a phrase such as "A row of five vines beside a fence, etc.," which was then absorbed by B-C when the latter was attached to $A$. We note that $B$ follows the formulary pattern of M. 4:5A ("He who plants a row of five vines"). Since M. $6: 1 \mathrm{~B}-\mathrm{C}$ and M. 4:5A are both followed by Houses-disputes, it is possible that the two pericopae were redacted together. At D-E a Houses-dispute glosses $B-C$, with the superscription of the dispute included in the opinion of House of Shammai. In its primary, balanced formulation, the dispute probably read cyqr vs. gdr. ${ }^{l}$ Yohanan b. Nuri glosses $B-E$ at $F-G$, and so attests it to Usha (or late Yavneh). H-J then glosses F-G with a balanced (six vs. three) Yavnean dispute concerning a secondary issue.

$B-C$ states that a row consisting of five vines trained $\mathrm{c} n$ a fence or in a ditch of a specified size (i.e., according tc $A$, an espalier) must be separated from another kind by an area of tillage of four amot, or the area of tillage of a vineyard. Now 
we have already seen that, while House of Shammi consider a row of five vines to be a vineyard, House of Hillel require a vineyard to contain two rows of vines ( $M, 4: 5 \mathrm{~A}-\mathrm{D}$ ). House of Hillel would presumably agree here that a row of trained vines is to be treated as a vineyard, reasoning that the structure upon which the vines are trained, which forms an autonomous domain, joins the individual vines together to constitute a single group of vines (HD to T. 4:1). At $\mathrm{D}-\mathrm{E}$ the Houses dispute concerning the secondary problem of where to allow the four amot of the espalier. According to Maimonides (Comm.) and GRA the dispute concerns which part of the espalier is considered to be primary to it. House of Shamai rule that one measures the four amot from the base of the vines to the field (both of which lie on the same side of the fence or $\mathrm{ditch}^{2}$ ). Since the vines themselves are considered to be a vineyard, they, rather than the fence (or ditch), are considered to be primary to the espalier. House of Hillel, on the other hand, maintain that, since the vines are considered to be a vineyard only when they are trained on a fence, the latter is considered to be the primary part of the espalier, and the four amot are measured from the fence to the field.

In F-G Yohanan b. Nuri revises $B-E$ so that the position of House of Hillel in $E$ does not conflict with House of Hillel's view (M. 4:5C-D) that a single row of vines does not form a vineyard. According to Yohanan $b$. Nuri the four amot mentioned in connection with the row of vines refer not to its area of tillage (c), but to the area between the vines and the fence. If this area measures four amot, then the row is allowed its area of tillage (= six handbreadths $[\mathrm{J}]$ ), and the rest of the space may be sown. An area measuring less than four amot may not be sown, presumably because the other kind would then not cover enough area and so would produce the appearance of diverse-kinds. Yohanan b. Nuri thus does not discuss an espalier at all (since it is not likely that he would permit sowing under trained vines), but rather refers to the outer space of a row of vines, 3 which has been defined as the space between the vineyard and the fence (M. 4:2L). He thus supplements House of Hillel's view (M. $4: l F$ ) that the outer space of a vineyard must contain twelve amot in order to be sown, ruling that the outer space of a row may be sown if it contains four amot. Although Yohanan b. Nuri does not present House of Shammai's opinion, it is clear that, since they regard a row of five vines as a vineyard, they would require an outer space of a row to contain sixteen amot in order to be sown (M. 4:lE). Yohanan b. Nuri thus resolves the conflict 
between the two views of House of Hillel by revising $B-F$ so that it deals with the outer space, rather than the area of tillage, of such a row.

$\mathrm{H}-\mathrm{J}$ glosses $\mathrm{F}-\mathrm{G}$ with a dispute concerning the secondary issue of the area of tillage of a single vine. While the anonymous opinion in I holds that this area of tillage measures six handbreadths in each direction (= two amot square), CAqiva maintains that it measures only half as much, or three handbreadths (= one amah square). CAqiva's rule is consistent with his view that trailing plants are allowed no more space than are vegetables (M. 3:6E-G), for according to his opinion, the vine's area of tillage is equal in size to a vegetable's autonomous domain (when sown with vegetables of another kind) (= one amah square; M. 3:3F). CAqiva apparently maintains that a vine is allowed no more space for its area of tillage than is required to constitute an autonomous domain for vegetables.

T. Kil. 4:1-7a consists of two parts, T. 4:1-2, which comments on M. $6: 1$, and T. 4:3-7a, an autonomous subunit dealing with rules concerning the construction of partitions. T. 4:la comments on M.'s discussion of the area of tillage of an espalier. T. $4: 1 \mathrm{~b}-2$ (repeated by T. $4: 9 \mathrm{~b}$ ) then continues this interest in the area of tillage, asking whether vines need be allowed their area of tillage if they are already separated from another kind by a partition. T. 4:3-7a supplements the foregoing by presenting a separate set of rules which, although formally diverse, all pertain to the construction of partitions. The point of $T$. is that a partition must be so constructed that it clearly appears to separate different parts of a field. T. 4:3 lists the types of materials from which a partition must be built. T. 4:4-5 then supplements T. 4:3 with sayings of Eleazar and Yose, who discuss whether, because of the nature of their materials, certain kinds of supporting structures of an espalier may serve as partitions, and so separate the vines of the espalier from another kind on the other side. We note that although both T. 4:4 and M. 6:1 deal with an espalier, the former does not appear to serve as a comment on the latter, for T. $4: 4$ is interested in the materials of the espalier's supporting structure, and not in the vines of the espalier. T. 4:6, discussing a partition composed of sections, concerns how large a breach may separate the sections without invalidating the partition. Finally, T. 4:7a, returning to the concerns of T. 4:3, presents a dispute between an anonymous opinion and Yose $b$. Judah as to whether a partition is considered to be adequate if its materials extend in only one direction (i.e., 
either perpendicular or horizontal to the ground; e.g., a partition of reeds [anonymous opinion]), or whether a valid partition must be constructed out of materials extending in both directions (e.g., a partition of mats [Yosé b. Judah]).

A. Rabban Gamaliel and his court ordained (htqynw) that they shall allow a distance [of] four amot from the base of the vines to the fence.

$$
\text { T. Kil. } 4: 1 \mathrm{a} \text { (p. 217, 11. 1-2) }
$$

According to T. Gamaliel and his court ordained that one must separate vines from a nearby fence by four amot, presumably in order to sow another kind between them. ${ }^{4} \mathrm{~T}$. thus attributes to Gamaliel and his court the rule of Yohanan b. Nuri in M. $6: 1 \mathrm{~F}-\mathrm{G}$ (Lieberman $\left.{ }^{5}\right)$.

B. He who makes a partition for the vineyard [measuring] ten [handbreadths] high and four wide, has annulled $(b t \tau)$ the [requirement of allowing] four amot [as the area of tillage] of the vineyard.

$$
\text { T. Kil. } 4: 1 b \text { (p. } 217,11.2-3 \text { ) }
$$

C. He who makes a partition for the vine [measuring] ten [handbreadths] deep [Eirfurt, GRA, and Lieberman ${ }^{6}$ read: high] and four wide, has annulled $(b t l)$ the [requirement of allowing six] handbreadths [as the area of tillage] of the vine.

$$
\begin{aligned}
& \text { T. Kil. } 4: 2 \text { (p. } 217,11.3-4) \text { (B-C: } \\
& \text { T. Kil. } 4: 9 \mathrm{~b} \text { ) }
\end{aligned}
$$

T. 4:1b consists of a pair of well-balanced declarative sentences. According to $T$. the area of tillage, or the area which separates a vine from another kind, need not be allowed to a vine (B) or a vineyard (C) which is already set apart from the other kind by a partition, since the partition is regarded as adequately separating the two kinds. T. complements M. 6:1's rule concerning the separation of two kinds growing on the same side of the fence with a discussion of separating the two kinds which grew on opposite sides of a partition.

A. He who makes a partition for the vineyard [measuring] ten handbreadths high and [with] its width not [measuring] four [handbreadths], has not annulled [Vienna omits the following 
until "six handbreadths"; first printed ed:] the [requirement of allowing] four amot [as the area of tillage] of the vineyard.

B. He who makes a partition for the vine [measuring] ten handbreadths high and [with] its width not [measuring] four [handbreadths], has not annulled the [requirement of allowing] six handbreadths [as the area of tillage] of the vine.

T. Kil. $4: 9 b$ (p. $219,11.33-34$ )

T. 4:9b simply restates the rules of $T .4: 1 b-2$ in a negative manner. I cannot account. for the location of $T .4: 9 \mathrm{~b}$ in T. Chapter Four, for this pericope is not at all related to the pericopae surrounding it (e.g., T. 4:8-9a, which discusses sowing in the gaps of an espalier ${ }^{7}$ ).

A. With all [kinds of materials] they make a partition [T. Sheb.: enclosures (shryn)]:

B. with (1) stones, and (2) mats, (3) straw, and (4) reeds, and (5) stalks,

C. even [with] three ropes [strung] one above another,

D. provided that there not be between one reed [T. Sheb.: rope] and the next three handbreadths,

E. [i.e.,] sufficient [space] so that a kid may enter.

T. Kil. $4: 3$ (pp. 217-218, 11. 4-6)

(T. Shev. $2: 19 ; A-B(1)-(3)$ :

Y. Shev. $3: 3 ; B(3)-(5)+C-D$ :

T. Erub. $2: 1 ; 8$ C: Y. Kil. $4: 4$

(29b) ; C-D: M. Erub. $1: 9 a i^{9}$

D: M. Erub. $1: 10 a ; 10$ D-E:

M. Kil. $4: 4 \mathrm{~B}-\mathrm{C}$, T. Kil. $4: 6 \mathrm{C}-\mathrm{D}$ )

T. Kil. 4:3 consists of a superscription at $A$, a list of five items at $B$ which is augmented by a sixth at $C$ (joined to the foregoing by ' $p y(w)$ ), and $D-E$, which qualifies $B(4)$ (or, according to $T$. Shev., $C$ ). The point of $\mathbf{T}$. apparently is that the items listed in $B$ are suitable for use in the construction of partitions (in this context) between diverse-kinds, for such materials clearly appear to divide a field. Three ropes strung above one another similarly form a valid partition (C). D-E, which also appears (in the same context) in $M .4: 4 \mathrm{~B}-\mathrm{C}$ and T. $4: 6 C-D$, then comments on $B(4)$, ruling that a partition of reeds must be sufficiently compact, so that it does not contain 
breaches measuring three or more handbreadths wide, or spaces large enough to allow a kid to enter.

A. [Erfurt reverses the order of $A-C$ and $D-G$ ] R. Leazar [Erfurt: Eliezer; first printed ed.: Eleazar] says, "An espalier [so Lieberman ${ }^{11}$ for hrysg; Erfurt: ${ }^{c}$ rys] [i.e., trained vines] which he passed over lattice-work (rypyn), 12

B. "and [= omitted by Erfurt] 10, the lattice-work is [considered] as a [valid] partition,

c. "provided that there not be between it [i.e., one slat of the lattice-work] and the next [an area] fully as wide [as the slat itself (HD)]."

$$
\text { T. Kil. } 4: 4 \text { (p. 218, 11. 6-8) }
$$

D. R. Judah says, "An espalier (hrys; ; Erfurt: $c_{\text {rys }}$ [i.e., trained vines] which he passed over reeds,

E. "and [= omitted by Erfurt] 10, [Erfurt adds: the] reeds are [considered] as a [valid] partition,

F. "[but] it is necessary that there not be between one reed and the next three handbreadths,

G. "[i.e.,] sufficient [space] so that a kid may enter."

H. R. Yosah [Erfurt, first printed ed.: Yosé] says, "If the reeds were pronged (mawqrnyn) [i.e., split at the top] and he made for them ( $2 h m$; Erfurt: 'wtn ["(of) them"]) a plait $\left(p y^{\prime} h\right)$ at the top [by running a string through them (Lieber$\left.\operatorname{man}^{13}\right)$, it is permitted [i.e., the plaited reeds form a valid partition]."

$$
\begin{aligned}
& \text { T. Kil. } 4: 5 \text { (p. } 218,11.8-11 \text { ) } \\
& \text { (F: M. Erub. 1:9a; F-G: M. Kil. } \\
& 4: 4 \text { B-C, T. Kil. 4:3D-E; H: T. Kil. } \\
& 4: 6 \mathrm{~S}+\mathrm{U} \text { ) }
\end{aligned}
$$

T. concerns an espalier, which, because it is constructed out of certain kinds of materials, may also serve as a partition. T. is composed of two sayings, A-C (attributed to Eleazar) and D-G (attributed to Judah), with the latter glossed by Yose at $\mathrm{H}$. $A-C$ and $D-G$ balance one another, for both consist of nearly identical sentences in mild apocopation ( $A-B$ and $D-E ;$ rypyn vs. qnym) followed by similar qualifying clauses (C and F-G $[=$ M. 4:4 B-C, T. 4:3D-E]: km[w'w vs. šlsh tphym). It appears, then, that both sayings were formulated together. We note that $H$ also appears anonymously at T. 4:6S+U. H is apparently primary to T. 4:4-5, however, since T. 4:6 does not deal specifically with 
the partition of reeds. We also note, though, that $\mathrm{H}$ is not particularly concerned with the espalier of reeds of $T \cdot 4: 4-5$, and could fit equally well in the context of $M .4: 4 \mathrm{~A}-\mathrm{C}$ (with M. $4: 4 \mathrm{~B}-\mathrm{C}=\mathrm{T} .4: 5 \mathrm{~F}-\mathrm{G})$, which deals simply with the partition of reeds.

According to Eleazar and Judah an espalier constructed out of lattices or reeds may serve as a partition and separate the vines on the espalier from another kind on the other side of the structure (Lieberman ${ }^{14}$ ). The point of $T$. is that the materials of the espalier appear to separate the vines from another kind, so that the structure may serve as a partition as well. $C$ and $F-G$ then qualify their respective preceding rules, stating that the espalier must have a certain degree of solidity in order to serve as a partition. An espalier constructed from lattices must not contain gaps wider than the width of the lattice itself (C), while an espalier of reeds may not contain breaches measuring three or more handbreadths wide, or enough space to allow a kid to enter, again so that the partition may appear to separate the different kinds. In $H$ Yosé qualifies $D-G$, saying that if the reeds are tied together at the top they form a satisfactory partition, even if the reeds are separated by gaps measuring three or more handbreadths wide. The reeds which are tied together in this fashion are not easily breached, so that the partition is valid regardless of the size of the gaps within it. ${ }^{15}$

A. The result is $\left(n m s^{\prime} t\right.$ ' $\left.^{\prime}[r]\right)$ [that there are] three measures of the partition:

B. (1) All [sections of a partition] which [measure] less than three [handbreadths wide]--

c. it is necessary that there not be between it [i.e., one section of the partition] and the next three handbreadths,

D. [i.e.,] sufficient [space] so that a kid may enter [B. Erub.: may leap headlong $\left(y z d q r\right.$ hgdy bbt $\left.\left.r^{\prime} \breve{s}\right)\right]$.

E. (2) And all [sections of a partition] which [measure] three [Erfurt adds: or $(w)$ ] three to four [handbreadths wide]--

$F$. it is necessary that there not be between it [i.e., one section of the partition] and the next [a space] fully as wide [as one section of the partition],

G. so that $(k d y)$ [the measure] of the breaches may not equal [that of] the structure itself (bnyn; E. Erub.: 'wmd ["that which stands"] [throughout]).

H. [Erfurt, B. Erub. add: If (the measure) of the breaches] exceeded [that of] the structure, 
I. even opposite the structure it is prohibited [to sow diverse-kinds].

J. (3) All [sections of a partition] which [measure] four [Erfurt adds: or $(\omega)$ ] from four [handbreadths] upwards [other versions: ${ }^{16}$ from four (handbreadths) to four amot, and from four amot to ten (amot)]--

k. it is necessary that there not be between it [i.e., one section of the partition] and the next [a space] fully as wide [as one section of the partition],

L. so that [the measure of] the breach[es] may not equal [that of] that which stands.

M. If [the measure of] that which stands is [equal to that of] the breach[es],

N opposite that which stands it is permitted [to sow diversekinds],

o. but opposite the breach[es] it is prohibited [to sow diversekinds].

P. If [the measure of] that which stands exceeded [that of] the breach[es],

Q. even opposite the breach[es] it is permitted [to sow diverse-kinds],

R. provided that the breach[es] do not exceed ten amot [in width] [B. Erub. reads instead of $\mathrm{R}$ : (If the partition) was breached by (a breach) greater than ten amot, it is prohibited].

s. If the reeds were pronged (mawarnyn) [i.e., split at the top], and he made for them a plait $\left(p y^{\prime} h\right)$ at the top [by running a string through them (Lieberman ${ }^{17}$ )],

T. even [if the breaches] exceed ten amot,

U. it is permitted [to sow diverse-kinds opposite the breaches].

T. Kil. $4: 6$ (pp. 218-219, 11. 11-19)

(B. Erub. 16a; A-R: Y. Kil. $4: 4$

$(29 b), Y$. Erub. $1: 8(9 b), Y$. Suk.

$1: 1(52 b) ;^{18} \mathrm{E}-\mathrm{K}:$ T. Erub. $2(3)$ :

$2 a ;{ }^{19} \mathrm{~S}+\mathrm{U}:$ T. Kil. $4: 5 \mathrm{H} ; \mathrm{S}-\mathrm{U}$ :

B. Erub. 11a)

T. Kil. 4:6 A-R is a unitary pericope consisting of a superscription, A, and three parts, B-D, E-I, and J-R, with the latter glossed by $S-U$. Each part is composed of a protasis in the pattern $k l$ shn $\mathrm{X}(\mathrm{B}, \mathrm{E}$, and $\mathrm{J})$, and an apodosis following the pattern sryk. . . kdy (C-D, F-G, and $\mathrm{K}-\mathrm{L}$ ). In addition, the rules of $\mathrm{E}-\mathrm{G}$ and $\mathrm{J}-\mathrm{L}$ are supplemented by one or more conditional 
sentences $(H-I, M-O$, and $P-R$, with $N$ balancing $O$, and $P-Q$ corresponding to $M+O)$, the apodoses of which all follow the same formulary pattern, knga $h^{e} w m d / h p r w s+' s w r / m w t r$.

$B-D, E-I$, and $J-R$ concern a partition which is composed of sections. Each rule discusses how large a gap may separate sections of a particular size if the partition is to be considered valid. B-D states that sections measuring three handbreadths or less in width may not be separated by gaps measuring the same width (i.e., three handbreadths), or by a space large enough to allow a kid to enter (cf. M. $4: 4 \mathrm{~A}-\mathrm{C}, \mathrm{T} .4: 3 \mathrm{D}-\mathrm{E}$, for the same rule applied to a partition of reeds). A partition containing gaps of such size would not appear to separate the diverse kinds. E-F then similarly rules that sections measuring from three to four handbreadths wide may not be set apart by breaches equal in width to the sections themselves. G, glossing E-F, explains that the rule of $E-F$ does not allow the measures of the breaches to equal those of the sections of the standing structure of the partition. If, on the other hand, the breaches measure more than do the sections of the standing structure, it is prohibited to sow diverse-kinds on different sides of the entire partition (H-I), for now the partition as a whole does not seem to divide the diverse-kinds, and so is not considered valid. We note that $I$, in stating that "even opposite the structure it is prohibited," perhaps follows the language of $L-R$, which distinguishes between sowing opposite the structure and opposite the breaches. The language, however, while appropriate to the context of $L-R$, has little significance at E-I, which does not make such a distinction. I then could have read simply "it is prohibited." $J-L$ applies the rule of E-G (with a slight variation in language from prwșt to prws and from bnyn to ${ }^{c} w m d$ ) to the partition made up of sections measuring four or more handbreadths wide. M-O then discusses the case in which the width of the breaches equals that of the sections, with N-O taking an intermediate position between prohibiting and permitting the sowing of different kinds on opposite sides of the partition. One may sow diverse-kinds on opposite sides of the standing structure, which itself serves as a partition, but not opposite the breaches, which do not set the diverse-kinds apart. If the width of the sections exceeds that of the breaches, then one may sow diversekinds even opposite the breaches $(P-Q)$, for the partition as a whole is considered as serving to separate the different kinds. $R$ glosses the foregoing, stating that the rule of $P-Q$ applies only when the breaches measure less than ten amot in width, presumably because a partition containing a gap of that size no 
longer appears to serve as a partition (although it is not clear whether one may still sow opposite the standing structure ${ }^{20}$ ). The following chart summarizes the rules of $\mathrm{B}-\mathrm{R}$ :

\begin{tabular}{|c|c|c|c|}
\hline $\mathrm{T}$. & Measure of Sections & Measure of Breaches & Rule \\
\hline$B-D$ & $\begin{array}{l}\text { less than three } \\
\text { handbreadths }\end{array}$ & $\begin{array}{l}\text { three or more hand- } \\
\text { breadths }\end{array}$ & prohibited \\
\hline \multirow[t]{2}{*}{$E-I$} & $\begin{array}{l}\text { three to four } \\
\text { handbreadths }\end{array}$ & $\begin{array}{l}\text { less than that of } \\
\text { sections }\end{array}$ & permitted \\
\hline & & $\begin{array}{l}\text { greater than that } \\
\text { of sections }\end{array}$ & $\begin{array}{l}\text { prohibited, } \\
\text { even oppo- } \\
\text { site sections }\end{array}$ \\
\hline \multirow[t]{3}{*}{$J-R$} & $\begin{array}{l}\text { four or more } \\
\text { handbreadths }\end{array}$ & $\begin{array}{l}\text { less than that of } \\
\text { sections }\end{array}$ & permitted \\
\hline & & $\begin{array}{l}\text { equal to that of } \\
\text { sections }\end{array}$ & $\begin{array}{l}\text { permitted } \\
\text { opposite } \\
\text { sections } \\
\text { prohibited } \\
\text { opposite } \\
\text { breaches }\end{array}$ \\
\hline & & $\begin{array}{l}\text { less than that of } \\
\text { sections }\end{array}$ & $\begin{array}{l}\text { permitted, } \\
\text { even oppo- } \\
\text { site breaches } \\
\text { (measuring } \\
\text { less than } \\
\text { ten amot) }\end{array}$ \\
\hline
\end{tabular}

$\mathrm{S}-\mathrm{U}$, supplementing $\mathrm{R}$, consists of $\mathrm{S}+\mathrm{U}$, an anonymous version of Yosé's saying concerning the partition of reeds (T. $4: 5 \mathrm{H}$ ), and $\mathrm{T}$, which has apparently been interpolated into the pericope in order to relate $S+U$ to $R$. In its present context the point of $\mathrm{S}-\mathrm{U}$ is that a breach measuring more than ten amot does not invalidate a partition of reeds, provided that the reeds are tied together at the top and so serve to close the breach and to separate the different kinds from one another.

A. Every partition which is made [of materials extending] perpendicularly [so Danby ${ }^{21}$ for sty; lit.: "warp"] and is not made [of materials extending] horizontally [so Danby for ${ }^{c} r b$; lit.: "woof"],

B. [or which is made of material extending] horizontally and is not made [of materials extending] perpendicularly,

C. 1o, this is [considered a valid] partition.

D. R. Yosah [Erfurt, first printed ed.: Yosé] b. R. Judah says, "It is not [considered a valid] partition unless it is made [of materials extending both] perpendicularly and horizontally ."

$$
\text { T. Kil. 4:7a (p. 219, 11. 19-21) }
$$


A. "Every partition which is not [made of materials extending both] perpendicularly and horizontally is not [considered a valid] partition," the words of $R$. Yose $b$. Judah.

B. And sages say, "[A partition need have only] one of the two things [i.e., characteristics; the partition need only be made of materials extending either perpendicularly or horizontally]."

M. Erub. 1:10b (Y. Erub. 1:S (19b))

T. consists of $\mathrm{A}-\mathrm{C}$, a declarative sentence with a duplicated

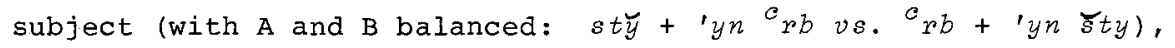
and Yose $\mathrm{b}$. Judah's saying at $\mathrm{D}$, which glosses and opposes the foregoing (balancing $A+B$ with $\Im t y+{ }^{c} b$ ). M. Erub. 1:l0b presents the same dispute in a different variation of the dispute form, as we see from the following chart:

$$
\text { T. Kiz. } 4: 7 a
$$

1. Every partition which is made

[of material extending]

perpendicularly and is not

made [of materials extending]

horizontally,

2. [or which is made of materials extending] horizontally and

is not made [of materials extending] perpendicularly,

3. 10, this is [considered a valid] partition.

4. R. Yosah b. Judah says,

"It is not considered a valid partition unless it is made [of materials extending both] perpendicularly and horizontally."

5. (see 1-3)
M. Erub. $1: 10 b$

1. (see 5)

2. (see 5)

3. (see 5)

4 .

"Every partition which is not [made of materials extending both] perpendicularly and horizontally is not [considered a valid] partition," the words of R. Yose b. Judah.

5. And sages say, "[A partition need have only] one of the two things [i.e., characteristics]."

M. Erub. 1:10b differs from T. Kil. 4:7a in presenting the opinions of the dispute in reverse order, for sages gloss Yosé b. Judah's view with the anonymous opinion of T. 4:7a/A-C. M. Erub. 1:10b 
also makes no attempt to balance the opposing views. The two versions of the dispute, however, do not differ in substance. The dispute apparently concerns whether a partition appears to separate diverse-kinds if it is composed of materials extending in only one direction. According to $\mathrm{A}-\mathrm{C}$ the materials of a partition may extend either horizontally (e.g., a partition of three ropes [T. 4:3]; Cf. TYY to M. Erub. $1: 10 ;$ MB) or vertically (e.g., a partition of reeds [M. 4:4, T. 4:3]). Yosé b. Judah, on the other hand, maintains that a partition is valid only if it is constructed out of materials extending in both directions (e.g., a partition of mats [T. 4:3]), for only then does it have enough surface area to divide the diverse-kinds. Yose b. Judah would then disagree with T. 4:3, which allows a partition to be made out of materials extending in only one direction. We note that $\mathrm{A}-\mathrm{C}$ has apparently been generated by $\mathrm{D}$, for it is necessary to state that the materials of a partition may extend either horizontally or vertically only in response to the view that they must extend in both directions.

$$
6: 2
$$

A. An espalier which projects from [so Danby for yws' $m n$ ] a terrace--

B. R. Eliezer b. Jacob says, "If he [can] stand on the ground and harvest all of it [i.e., harvest all of the grapes of the espalier's vines], 10, this [espalier] prohibits four amot in the field [below].

c. "And if not [i.e., if he cannot harvest all of the grapes of the espalier's vines while standing on the ground], [the espalier] prohibits only that [part of the field which lies] opposite [i.e., under] it."

D. R. Eliezer [OX, P, Rosh, 22 MS: Eleazar: L: Leazar] says, "Even (' $p$ ) [= omitted by $\mathrm{Pr}$ ] he who plants one [row of vines (Maim., Comm., Code, Diverse-Kinds 7:6, others)] on the ground and one on the terrace--

E. "if [the row on the terrace] is ten handbreadths higher [C, Geniza fragment, ${ }^{23} \mathrm{~K}, \mathrm{~L}, \mathrm{Mn}, \mathrm{Ox}, \mathrm{P}$, and $\mathrm{s}$ omit:] than the ground, it does not combine with it [i.e., with the row on the ground] [to form a vineyard].

F. [Mn omits:] "And if not [i.e., if the row on the terrace is not ten handbreadths higher than the ground], 10, this [row on the terrace] combines with it [i.e., the row on the ground] [to form a vineyard]." 
M. consists of two rules, Eliezer b. Jacob's saying concerning the espalier planted on a terrace $(A-C)$, and Eliezer/ Eleazar's statement dealing with planting one row of vines on a terrace and another on the ground ( $D-F$, joined to the foregoing by ' $p$ ). Both sayings consist of a protasis $(A, D)$ followed by a pair of conditional sentences (B-C, E-F). The two rules appear to be autonomous, however, for they open with different formulary patterns ( ${ }^{c}$ rys $\zeta h w^{\prime}[A]$ vs. hnwt ${ }^{C}[D]$ ) and concern different arrangements of vines (espalier [i.e., one row] [A-C] vs. two rows $[D-F])$. We note that, since the question of terraces is discussed by Eliezer b. Jacob, an Ushan, at A-C, the Eliezer/ Eleazar of $D-F$ is probably an Ushan as well.

A-C continues the interest of M. $6: 1$ in the area of tillage of an espalier, asking whether the same area of tillage, four amot, is required for an espalier which is planted on a terrace but hangs over the field below. The issue of $A-C$ concerns whether the espalier, because it is planted on a terrace, is considered separate from the field and so does not require four amot in the field below, or whether, because it hangs over the field, the espalier is regarded as belonging to the latter and so requires its full area of tillage. Eliezer b. Jacob rules in B-C that the criterion for deciding this question is the proximity of the overhanging vines to the field, which is measured in terms of one's ability to harvest the grapes of the espalier. If the vines hang so low that one may harvest all of their grapes while standing in the field, then for all practical purposes these vines may be regarded as if they were planted in the field itself (Maim., Comm., Code, Diverse-Kinds, 8:8). That is, the vines of the espalier may produce the appearance of diverse-kinds with the other kind in the field equally as well as if the vines were actually planted in the field itself, and they therefore must be allowed four amot in the field (presumably measured either from the terrace [Maim., Code, Diverse-Kinds 8:8, $\mathrm{MS}^{24}$ ] or from the spot where the vines meet the field ${ }^{25}$ ). If, on the other hand, the vines of the espalier hang so far above the field that one cannot pick all of their grapes while standing in the field, then the espalier is not regarded as if it were planted in the field. One then need allow as its area of tillage only that part of the field which lies directly below the espalier, for only in that area could the vines of the espalier produce the appearance of diverse-kinds with the kind sown in the field.

In D-F Eliezer/Eleazar discusses whether or not two rows of vines, one planted on a terrace and the other planted in the field below, combine to form a vineyard (following the definition 
of a vineyard as two rows, given by House of Hillel, M. 4:5C-D). The issue of D-F concerns whether or not the terrace is considered part of the field. Eliezer-Eleazar rules that if the terrace measures ten handbreadths higher than the field, it forms a domain unto itself (R. Mena in Y. Kil. $6: 2$; Cf. M. $2: 8,5: 3$; cf. also T. $3: 7-8^{26}$, and the two rows do not combine. If, on the other hand, the terrace measures less than the specified height above the ground, then it is considered part of the field and the two rows do combine to form a vineyard. Eliezer/Eleazar thus simply goes over the anonymous law of $M .4: 7 \mathrm{C}-\mathrm{G}$, concerning two rows of vines which are separated by a fence, and presents it in terms of the question of the terxace.

Let us now turn to consider the redactor's view of the relationship between the sayings of Eliezer b. Jacob and Eliezer/ Eleazar. If, as we have already shown, the two rulings are autonomous of one another, why did the redactor decide to join them together? We may explain this decision by showing that the pericope may have actually undergone two stages in its history. At first a redactor may have simply juxtaposed the rulings, viewing them as two separate answers to the same question, i.e., whether or not a terrace is considered to be part of the field below it. Eliezer b. Jacob presents one criterion, concerning one's ability to work from the field on the terrace's vines, and Eliezer/ Eleazar offers another rule, dealing with the height of the terrace. At some later point a (presumably different) glossator then added ' $p$ ("even") to Eliezer/Eleazar's saying in D, making the latter appear to be a restatement of Eliezer b. Jacob's rule of $B-C$. When read together with ' $p$, Eliezer/Eleazar's saying may be taken to mean that a terrace ten handbreadths higher than the field is considered to be separate from the latter because one standing in the field cannot reach vines which are planted on a terrace of that height. The two sayings may thus have been viewed differently at separate stages in their history, being regarded first as autonomous opinions and then as statements of the same rule.

$$
6: 3-5
$$

A. He who trains [so Danby for hmdlh] a vine over some of the laths [of a latticework] shall not put seed under the remaining [laths].

B. If he did put [seed there], he has not sanctified [the seeds underneath]. 
c. And if the new growth (hhdš; Danby: tendrils) [of the vine] spread [over the rest of the laths], it is prohibited [i.e., the seeds underneath are sanctified].

D. And so [is the rule for] he who trains [a vine] over part of a barren tree ('yln srq).

M. Kil. $6: 3$

E. He who trains a vine over part of a fruit tree ('y $2 n m^{\prime} k l$ )-it is permitted to put seed under the remainder [of the tree].

F. And if the new growth [Danby: tendrils] [of the vine] spread [over the rest of the tree], he shall turn it [i.e., the new growth] back (yhzyrnw).

G. $m^{e} \xi h \breve{s}:$ R. Joshua went to R. Ishmael at Kefar Aziz, 27 and he showed him a vine which was trained over part of a fig tree.

H. He [i.e., R. Joshua] said to him, "May I put seed under the remainder [of the tree]?"

I. He [i.e., R. Ishmael] said to him, "It is permitted."

$\mathrm{J}$. And he brought him up from there to Bet Hamaganyah, ${ }^{28}$ and he showed him a vine which was trained over part of a branch [so Porton ${ }^{29}$ for qwrh] and [ $\mathrm{K}$ (after correction), $\mathrm{Mn}, \operatorname{sirillo:}:^{30}$ in $\left.(b t \omega k)\right]$ a trunk of a sycamore tree, in which there were many branches.

K. He [i.e., R. Ishmael] said to him, "Under this branch it is prohibited [to put seed], and under the rest [of the branches] it is permitted."

M. Kil. $6: 4$

L. What is [considered] abarren tree ('yln srq)?

M. Every [tree] which does not produce fruit.

N. R. Meir says, "Every tree is [considered] a barren tree, except for the olive tree and the fig tree."

o. R. Yose says, "Every [tree] the like of which they do not plant as whole groves, 10, this is [considered] a barren tree."

$$
\text { M. Kil. } 6: 5 \text { (N: Y. Orl, } 1: 1(60 \mathrm{C}))
$$

M. 6:3-5 forms a new subunit dealing with single trained vines. M. opens with three rules, A-C (vine trained on a latticework of laths), D (vine trained on a barren tree), and E-F (vine trained on a fruit tree), all of which begin with the formulary pattern $h m d i h . A$ and $E$ somewhat balance one another ('ppywrwt vs. 'yln m'kl, $l^{\prime} y b y$ ' vs. mwtr $\left.2 h b y '\right)$, although $\mathrm{C}$ and 
F do not closely correspond to each other (mwtr vs. yhzyrnw, as we shall see below). B's language differs from that of $\mathrm{C}$ (qyď vs. ' $s w r), 31$ and $B$ has no corresponding clause in $E-F$, so that $B$ appears to be secondary to the construction. D (joined to $\mathrm{A}-\mathrm{C}$ by $w k n)$ and the protasis of $\mathrm{E}$ are almost perfectly paired ('y $\mathrm{ln}$ srqus. ' $y(n) \cdot k l$ ). D, however, lacks an apodosis, and states no new rule of its own. It appears, therefore, that $D$ has been added to the pericope in order to present a contrast for $\mathbf{E}$ (barren tree $v s$. fruit tree). D thus serves the redactional function of linking $A+C$ to $E+F$. $G-K$ then augments $E-F$ with a $m^{c} \xi h$. L-O glosses $D$, and thus is also secondary to the original construction, which may now be seen to have consisted of $A+C+E-F$. L-O was probably placed after $G-K$ and not immediately after $D$ so that it would not interfere with the contrast between $D$ and $E$. $A$ and $E$ describe cases in which a vine is trained over part of some structure. The question discussed in both instances is whether one may sow another kind under that part of the structure which remains uncovered by the vine. The issue of $\mathrm{A}$ and $\mathrm{E}$ concerns whether or not the uncovered part of the structure is considered to be "taken over" by the trained vine, so that the vine and the entire structure are deemed to form a single entity (as in the case of the espalier [M. 6:1]), under which one may not sow. M. here distinguishes between a latticework of laths (A), which is regarded as an extension of the vine (cf. MR, Albeck), and a fruit tree (E), which is not so considered. The reasoning behind $M$. appears to be that the laths are inanimate, and therefore lose their aspect to the animate vines, while the animate fruit tree retains its own aspect in supporting the vine. The glossator responsible for $D$, though, apparently sees the issue differently, for he compares the barren tree, which is animate, to the latticework of laths, which is not. According to $D$, therefore, M. distinguishes between the non-fruit-bearing structure (latticwork of laths, barren tree), which is "taken over" by the fruit-bearing vine, and the fruit tree, which, because it bears fruit itself, keeps its own aspect while supporting the vine.

$B$ then weakens the force of $A$, saying that one who actually does sow under the uncovered part of a latticework of laths does not thereby sanctify the seeds. We may understand the function of $B$ in the pericope only after turning to $C$. The latter states that if one sows under the remaining part of the structure, and the vine subsequently spreads out over that part, the seeds are prohibited, or sanctified, for the vine now hangs directly over seeds which should not have been sown at that spot in the 
first place. A has already told us, however, that one may not sow under the remaining part, and it should follow from $A$ that any seeds which are sown there are sanctified. The rule of $\mathrm{C}$ thus appears to be unnecessary. $C$, however, is already part of the original construction, for it balances $\mathrm{F}$ (kngdw mwtr $v s$. kngdw yhzyrnw). B therefore has apparently been added to the pericope in order to clarify $A+C$. B explains that, although $\mathbb{A}$ does not allow sowing under the remaining part of the latticework of laths, such an action does not sanctify the seeds, presumably because they do not lie directly under the vine. The rule of $\mathrm{C}$ then logically follows that of $B$.

Like $C, F$ rules concerning the vine which spreads over seeds previously sown under the uncovered part of the fruit tree. Now we might expect $F$ to read mwtr in order to balance C's 'swr. F, however, reads yhzyrnw ("he shall turn it back") and so takes an intermediate position, in which the seeds are neither entirely permitted or prohibited. The seeds are not prohibited, or sanctified, for it was originally permitted to sow them under the fruit tree. At the same time, though, the seeds and the vine may not continue to grow in their respective positions, for they would then produce the appearance of diverse-kinds. The vines must therefore be turned back, so that they do not cover the seeds. G-K presents a $m^{c} \xi h$ in which Joshua asks Ishmael (or vice versa ${ }^{32}$ ) concerning two cases of sowing under a tree which supports a vine. In G-I Ishmael permits Joshua to sow under that part of a fig tree which is not covered by the vine. In $\mathrm{J}-\mathrm{K}$ Ishmael prohibits sowing under a sycamore branch upon which a vine is trained, but he permits sowing under the other branches which grow out of the same trunk. G-I and $J-K$ thus both illustrate $E$, for in both instances Ishmael permits one to sow under the uncovered part of the fruit tree (for the sycamore bears a figlike fruit ${ }^{33}, 34$. Alternatively, Maimonides (Comm.) ${ }^{35}$ notes that, although $\mathrm{J}$ states that the vine is trained over only part of the sycamore branch, Ishmael in $K$ prohibits sowing under the entire branch. Maimonides therefore reasons that the sycamore, which yields fruit but is grown primarily for its lumber, 36 is considered partly like a barren tree, so that one may not sow under any part of the branch supporting the vine (a rule analogous to that of $\mathrm{A}$ ), and partly like a fruit tree, so that one may sow under the uncovered part of the tree (as in E). According to this interpretation the point of $\mathrm{G}-\mathrm{K}$ may be to contrast the status of the fig tree with that of the sycamore, for both trees are members of the same botanical genus (Ficus, of the nettle family [Urticaceae] ${ }^{37}$, and both yield similar fruits. It is not clear, 
however, that one may read $\mathrm{J}-\mathrm{K}$ to imply that a sycamore is considered a barren tree. $J-K$ may not intend to place any emphasis at all on the fact that, although the vine is trained on only part of the branch, Ishmael prohibits sowing under the whole branch. We therefore prefer the first interpretation given above.

L-O glosses D with a dispute concerning the definition of a barren tree. The dispute consists of three opinions, an anonymous saying $(M)$, and the views of Meir and Yose $(\mathbb{N}-0)$, all of which respond to the question at $L$. $M$ and $N-O$, however, deal with entirely separate issues. While $M$ presents the obvious 38 definition of an ' $y$ In srq as a tree which does not produce fruit, Meir and Yose define the 'y In srq not in terms of a tree's ability to bear fruit but in terms of the economic importance of its fruit. Meir maintains that all but fig and olive trees are considered "barren," or economically insignificant, for these two trees, together with the vine, alone produce the most important fruits of the Mediterranean area. 39 Yose, on the other hand, states that any tree with which one would not plant an entire grove is considered a "barren" tree, for only those trees for which one would invest a whole grove are regarded as important. Yose thus encompasses and relativizes Meir's definition of a "barren" tree, making it dependent on the value of the tree's fruit. In defining a "barren" tree in terms of a tree's economic importance, Meir and Yose effectively revise the criterion for determining whether a tree supporting a vine is "taken over" by the vine or whether it retains its own aspect. The barren tree of $\mathrm{D}$, which is considered an extension of the vine trained upon it, now refers to all economically unimportant trees, and the fruit tree of $E$, which keeps its own aspect, now describes either the fig or olive tree (Meir), or any frlit-bearing tree of significance (Yose). We note that it is possible that L-M, which merely states the obvious and is not interested in the concerns of $\mathrm{N}-\mathrm{O}$, serves only to introduce $\mathrm{N}-\mathrm{O}$ and to underline the latter's divergence from the standard definition of an 'yln srq.

A. $m^{c} \xi h \breve{s}: R$. Joshua went to R. Ishmael at Kefar Azin [Erfurt: Aziz], and he showed him a vine which was trained on part of a fig tree.

B. He [i.e., R. Joshua] said to him, "May I put seed under the remainder [of the tree]?"

C. He [i.e., R. Ishmael] said to him, "It is permitted [= M. 6: $4 \mathrm{G}-\mathrm{I}]$,

D. "for a man does not set his fig tree at nought ( $m b t z)$ before his vine." 
E. He brought him up from there to Bet Hameganin, 40 and he showed him there a vine which was trained on part of a branch, and with it was a trunk of a sycamore tree, and in it [i.e., the trunk] were many branches.

F. He [i.e., R. Ishmael] said to him, "Under this branch it is prohibited to [to put seed], and [under] the rest [of the branches] it is permitted [= M. $6: 4 \mathrm{~J}-\mathrm{K}]$,

G. "for I regard each and every branch [Erfurt omits: "in the tree"] in the tree as a tree unto itself."

H. R. Simeon b. Leazar [first printed ed.: Ishmael] says, "If [the vine] was climbing (mpsy ; Erfurt: mpsy ${ }^{c}$ ) from one branch to another, [the branches are all considered] as [belonging to] a single tree."

$$
\begin{aligned}
& \text { T. Kil. 4:7b (p. 219, 11. 21-25) } \\
& \text { (H: Y. Kil. } 4: 3(30 \mathrm{c})^{41} \text { ) }
\end{aligned}
$$

T. cites and glosses M. $6: 4 \mathrm{G}-\mathrm{K}$, presenting reasons at $\mathrm{D}$ and $G$ for the two rulings of the $m^{c} s h(A-C, F-H)$. D has Ishmael explain that one may sow under the uncovered part of a fig tree which supports a vine because he is not assumed to set his fig tree at nought for the vine, i.e., to regard the fig tree as losing its own aspect and taking on that of the vine (= M. 6:4E). $G$ has Ishmael state that one may sow under the uncovered branches of a sycamore tree if a vine is trained on one branch, because each branch is considered a tree unto itself. In making the point that each branch is considered a separate tree, $T$. apparently presupposes that the sycamore is considered as a barren tree. T. thus explains that one may not sow under the entire tree upon which the vine is trained, but that the tree in question refers only to the supporting branch and not to the whole sycamore.

At $\mathrm{H}$ Simeon $\mathrm{b}$. Eleazar glosses $E-G$, saying that if the vine begins to climb from one branch to another, all of the branches are considered part of one tree, for now the branches are all regarded as serving the vine and thus are no longer considered as separate trees. In this instance, therefore, one may not sow under any part of the sycamore. 42

$$
6: 6
$$

A. Gaps [so Danby for $p s q y$ ] of an espalier [must measure] eight amot and a little more [so Danby for $w^{c} w d$ ] [in order to be sown with another kind].

B. And all of the dimensions of which sages spoke in [reference to] the vineyard--there is no [mention of] "and a little more" in them, except for [the dimensions of] the gaps of an espalier. 
C. What are [considered] the gaps of an espalier?

D. An espalier which lies waste at its center [following Danby for $\left.h r b m^{\prime} m s^{c} w\right]$, and there remained in it five vines on one side [of the center] and five vines on the other--

$E$. if there are there [i.e., between the two groups of vines] eight amot, he shall not put seed there.

F. [If there are there (i.e., between the two groups of vines)] eight amot and a little more, they allow it [i.e., each group of vines] enough [space] for its area of tillage, and he sows the rest.

M. Kil. $6: 6$

Returning to the subject of the espalier, M. consists of a statement at $A$, which is then glossed separately by $B$ and $C-F$. Apparently referring to the issue of sowing, A states that the gaps of an espalier must measure "eight amot and a little more." $B$ points out that similar rules concerning the minimum area which may be sown among vines (e.g., M. 4:1-2, 8-9 [Albeck], M. 5:4) do not include the phrase "and a little more," giving instead an exact measurement of the area. C-F explains that $A$ concerns an espalier which contains more than ten vines. The middle of the espalier is destroyed, and two groups of five vines each, or two espaliers (cf. M. 6:1B), remain on either side of the gap. E-F (following the formulary pattern of M. 4:II-J, $4: 2 \mathrm{M}-\mathrm{N}$ ) then spells out the rule of $\mathrm{A}$. One may not sow in the gap if it measures only eight amot (E), for then there would be enough space only for the areas of tillage of the two espaliers (four amot each [M. 6:1A-C]), but not for the other kind. If, on the other hand, there is more than eight amot of space in the gap, one allows each espalier its area of tillage and sows the rest (F), for then there is enough space for both the areas of tillage and the other kind (the latter being sown in the space referred to by the phrase "and a little more" in A). By interpreting $A$ to refer to two espaliers which are separated by a gap, C-F thus explains why the gap must contain "eight amot and little more" in order to be sown. 43

A. What are [considered] the gaps of an espalier (hrys)? 44

B. An espazier which lies waste at its center and there remained in it five vines on one side [of the center] and five vines on the other--

c. if there are not there [i.e., between the two groups of vines] [Lieberman: ${ }^{45}$ if there are there onzy] eight amot, he shazl not put seed there. 
D. [If there are there (i.e., between the two groups of vines)] eight amot and a little more, they allow it its area of tizrage and he sows the rest [=M. 6:6C-F].

$$
\text { T. Kil. } 4: 8 \text { (p. 219, 11. 28-30) }
$$

E. How much is "and a little more?"

F. One of six handbreadths of an amah [Sens, Ribmas: one-sixth of an amah; Maim., Comm., Code, Diverse-Kinds 5:5, others: ${ }^{46}$ one-sixtieth of an amah].

$$
\text { T. Kil. 4:9a (p. 219, 11, 30-31) }
$$

T. cites and glosses M. 6:6C-F, specifying at $E-F$ the measure meant by the phrase "and a little more (D)." T. states that this phrase refers to one of the six handbreadths of an amah, or simply one handbreadth. In phrasing its answer in this manner, T. disagrees with Meir's view that the amah mentioned in reference to the gaps of an espalier measures five handbreadths (T. Kel. B.H. 6:13). We note that the reading of Sens and Ribmas avoids the question of the number of handbreadths in an amah by stating simply "one-sixth of an amah." 47

\section{$6: 7$}

A. An espalier which projects [so Danby for yws'] along [so Danby for $m n ; \mathrm{B}, \mathrm{Cn}$, Geniza fragment, $\left.{ }^{48} \mathrm{O}, \mathrm{Ox}, \mathrm{P}: c_{m}\right]$ a wall from (mtwk) the corner [formed by two walls] and stops $(\omega k l h)$ [in the middle of the wall]--they allow it its area of tillage and he sows the rest.

B. R. Yose says, "If there are not there four amot, he shall not put seed there."

$$
\text { M. Kil. } 6: 7 \text { (B: Y. Kil. } 6: 1 \text { (30b)) }
$$

M. consists of $A$, a declarative sentence in the formulary pattern of M. 6:2A ('crys hyws' $m n \mathrm{X}$ ), followed by Yosé's gloss at $B$. The language of $A$, "An espalier which projects along a wall from the corner and stops," describes a case in which an espalier, located in a walled area, begins in one corner, goes along a wall, and stops before reaching the next corner (cf. fig. 44). The issue which A discusses concerns whether one may sow another kind between the end of the espalier and the next corner without producing the appearance of diverse-kinds. ${ }^{49} \mathrm{~A}$ rules that one may sow in this space after allowing the espalier its area of tillage, for then the two kinds are adequately 
separated (or, alternatively, they grow in separate domains) and do not appear to grow as diverse-kinds. ${ }^{50}$ yose states in $B$ that the area between the end of the espalier and the far corner must cover four amot in order to be sown, for only then will there be enough space to allow the espalier its area of tillage of four amot (M. 6:1C).

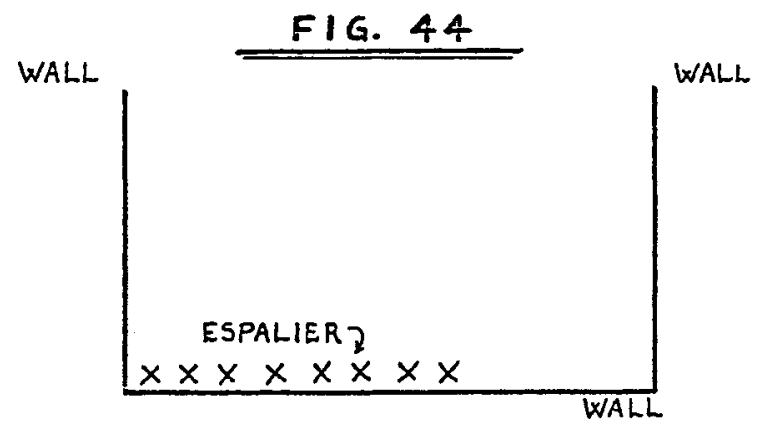

$6: 8-9$

A. The reeds which project beyond the espalier--

B. and [ $=$ omitted by most mss. $\left.{ }^{51}\right]$ he refrains from cutting them short [so Danby for hs ${ }^{C}$ yhm $\left.2 p s q n\right]$--

C. opposite [i.e., under] them, it is permitted [to sow another kind].

D. [If] he prepared them [following Danby for ${ }^{c} \xi{ }^{\prime} n$ ] so that the new growth [of the vines] would spread over them, it is prohibited [to sow another kind under them].

M. Kil. $6: 8$

E. The blossom [of the vine] which projects beyond the espalier--

$F$. they regard it as if a plummet [so Danby for mtwt tt; $B, C$, Mn: mțltzt] were suspended from it--

G. opposite [i.e., under] it, it is prohibited [to sow another kind].

H. And so $(w k n)$ [is the rule] for [a blossom which projects beyond] a trained vine (dlyt).

I. He who extends (hmwth) a vine-shoot from tree to tree--

$\mathrm{J}$. under it, it is prohibited [to sow another kind].

K. [If] he attached to it [so Jastrow ${ }^{52}$ for spkh] rope or reed-grass (gmy), 
L. [the space] under that which is attached (spwk), it is permitted [to sow another kind].

M. [If] he prepared it so that the new growth [of the vines] would spread over it, it is prohibited [to sow another kind under it].

$$
\text { M. Kil. } 6: 9
$$

M. opens with two apparently apocopated sentences, A-C and $E-G$, both of which follow the same formulary pattern ( $X$ hyws'/hyws'm $m n h^{c}$ rys). The two sentences partially balance each other in that $\mathrm{A}$ corresponds to $\mathrm{E}$ (with a shift from singular to plural; qnym hyws'm vs. prh hyws') and C balances G (mwtr vs. 'swr). B and F, however, the clauses which actually produce the apocopation, are not at all balanced, and so appear to be secondary to the original construction of the declarative sentences $A+C+E+G$. H then glosses $E-G$. I-L augments $A-G$ with a separate rule following its own formulary pattern (he-who. . . it-is apocopation [hmwth]). D and $M$ are identical glosses of $A-C$ and $I-L$, respectively, and thus were added to the pericope after the insertion of I-L. The addition of identical glosses to $\mathrm{A}-\mathrm{C}$ and $\mathrm{I}-\mathrm{I}$ supports our claim that I-I is to be regarded as related to that which precedes it.

$A-C$ and $E-G$ both describe cases in which some part of the espalier projects outwards. Both ask whether one may sow under the projection. The issue of $A-C$ and $E-G$ concerns whether the projection is considered part of the espalier. ${ }^{53} \mathrm{~A}-\mathrm{C}$ concerns sowing under projecting reeds, which, B explains, one did not wish to cut for fear of destroying the espalier (Maim., Comm.; cf. also Maim., Code, Diverse-Kinds 6:14), These reeds do not serve the vine and thus are not regarded as belonging to the espalier, so that one may sow under them (C). D adds, however, that if one arranges the extended reeds in such a way that the vines will eventually spread over them, he may not sow under them, for, since the reeds will ultimately support the vines, they are considered part of the espalier. In contrast to A-C, E-G rules that one may not sow under a vine-blossom which projects from an espalier, for, since the blossom will eventually yield grapes, it is considered an integral part of the espalier. F notes that one determines the extent of the prohibited area underneath the vine-blossom by imagining that a plummet is dropped from the blossom to the ground. All of the space between the imaginary plummet and the espalier is then considered the area under the vine-blossom. H adds that the rule of $E-G$ applies also 
in the case of a blossom which extends not from an espalier, but from an individual trained vine.

I-I complements $A-G$ with another case concerning sowing under something which is connected to a vine. I-L consists of two declarative sentences, $\mathrm{I}-J$ and $\mathrm{K}-\mathrm{L}$, with the latter dependent on the former for its context. I-J describes the case of a vineshoot which is extended from one tree to another, ruling that one may not sow under the shoot, for one would then produce the appearance of diverse-kinds. In $\mathrm{K}-\mathrm{L}$ the shoot is attached to one of the trees by rope or reed-grass. Now we might expect $\mathrm{I}$ to read thtyh mwtr in order to balance J's thtyh 'swr. L, however, reads tht hspwk mwtr, emphasizing that it is permitted to sow only under the attached rope or grass, and implying that one may not sow under the vine. The reasoning behind $I-L$ appears to be that, since the vine does not actually grow on the attached connector, the latter is not considered merely as an extension of the vine, and one is permitted to sow under the rope or reedgrass. The point of the glossator who inserted I-L into the pericope is apparently that the rope or reed-grass "projects" from the vine rather than supports it, so that the case of I-L is analogous to that of $A-C$. M then repeats $D$. We note that the rule of I-J makes a rather obvious point, and so may serve only to introduce the case of $\mathrm{K}-\mathrm{L}$ (Ridbaz to Maim., Code, DiverseKinds $6: 15$ ).
A. A vine-shoot which was trained over grain,
B. even if it is a hundred amah [in length]--
C. the entire vine is prohibited [i.e., sanctified],
D. [i.e.], it [i.e., the vine] and its fruit.

T. Kil. $4: 10 \mathrm{a}$ (p. $220,11,34-35)$

T. complements M. 6:9I-J, turning from the latter's discussion of sowing under a vine-shoot to deal with a vine-shoot which is trained over grain. T. consists of an apocopated sentence, $A+C$, with $B$ and $D$ respectively glossing $A$ and $C$. According to $\mathrm{A}+\mathrm{C}$ a vine-shoot which is trained over grain prohibits, or sanctifies, the entire vine, including the main stem and the fruit (D). T. takes M.'s case and extends it, maintaining that if any part of a vine, even a shoot, overshadows grain, the entire vine is sanctified. B presents an extreme case, maintaining that the whole vine is sanctified even if the shoot is a hundred amot long and the grain which it overshadows is distant from the main stem of the vine (Lieberman ${ }^{54}$ ). 
oO. [Some mss. ${ }^{55}$ omit OO-PP+QQ-SS] [Hillel ${ }^{56}$ reads OO-PP here:] Another matter [= omitted by R. Hillel]: Lest the whole yiezd be sanctified (Dt. 22:9)--

PP. "Lest the whole yield be prohibited," according to the words of R. Josiah [other mss.: 57 Judah].

$$
\begin{aligned}
& \text { Sifré Dt. } 230 \mathrm{~m} \text { (ed. Finkelstein, } \\
& \text { p. 264, 11. 2-3) }
\end{aligned}
$$

QQ. He who extends (hmwth) a vine-shoot over seeds--

RR. even [if it is] a hundred amah [in length]=-

ss. the vine is prohibited [GRA omits:] and its fruit [as well] $[=\mathrm{T} .4:[10 \mathrm{a}]$.

$$
\begin{aligned}
& \text { Sifré Dt. } 230 j \text { (ed. Finkelstein, } \\
& \text { p. } 263,11.11-12 \text { ) }
\end{aligned}
$$

In OO-PP Josiah defines the term sanctified to mean "prohibited," or forbidden for use. QQ-SS then cites T. 4:10a with mostly minor variations. The one major difference occurs at QQ, which opens with the language of $M$. (hmwth) rather than that of $T$. ( $h m w d i h)$, and so links $M$. and $T$. by reading the former into the latter. Hillel's reading 58 juxtaposes oO-PP and QQ-SS, and thus implicitly connects QQ-SS to Dt. 22:9. The rule that a shoot extending over grain sanctifies the entire vine is then deduced from the phrase the whole yield, which is taken to refer to the entire vine. 



\title{
CHAPTER SEVEN
}

\author{
KILAYIM CHAPTER SEVEN
}

Chapter seven consists of two separate parts, M. 7:1-2C, discussing rules pertaining to the sunken vine-shoot, and $\mathrm{M}$. $7: 2 \mathrm{D}-8$, dealing with cases in which a vine and another kind grow together but no sanctification takes place. This second section is composed of two subunits, M. 7:2D-F+3 (augmented by M. $7: 8$ ), concerning one who produces the appearance, but not the actual growth of diverse-kinds, and M. 7:4-5+6-7, describing instances in which different kinds actually do grow together, but against the wishes of the owner.

M. 7:1-2C forms a subunit characterized both by the distinctive formulary pattern of its opening protases (hmbryk [M. 7:1A,7:2A]) and by its interest in the sunken vine-shoot. The subunit consists of two rules concerning such a shoot, which is sunk into the ground so that it may grow new roots and produce a new vine. M. 7:1 asks whether one may sow the seeds of another kind above the sunken shoot without allowing the roots of the seeds to penetrate into the vine. Under these circumstances the other kind would not grow as diverse-kinds with the latter. M. differentiates between the shoot sunk into the ordinary earth, above which one may sow if the shoot is covered with three handbreadths of soil, and the shoot sunk into rocky ground, which need be covered only by the smallest amount of soil in order to be protected from the roots of the seeds. M. 7:2A-C then discusses whether a row of vines which develops from the shoots of a row of parent vines (and appears to be separate from the parent vines) combines with the latter to form a vineyard. The issue of $M$. concerns whether the arrangement of the two rows resembles that of a vineyard. Eleazar b. Sadoq rules that, like any two rows of a vineyard, the two rows must be far enough apart to be distinguishable from one another, but sufficiently close together to appear to form a single unit.

M. 7:2D-F presents three cases in which sowing another kind near a vine is prohibited but does not sanctify the vine. In each instance the sowing of the other kind is prohibited because it produces the appearance of diverse-kinds, but the vine itself is not sanctified because the two kinds do not actually grow together. The last of the three cases, M. 7:2F, shares with M. 7:1-2C both an attribution to Eleazar b. Sadoq (M. 7:2A-C) 
and an interest in the question of sowing above a sunken vineshoot (M. 7:1), and thus serves to relate its own subunit (M. 7:2D-F+3) to M. 7:1-2C. Eleazar b. Șadoq (M. 7:2F), however, differs with M. 7:1's view of the problem of sowing above a sunken shoot. He takes the issue of such a case to concern not whether the seeds which are sown actually grow together with the vine as diverse-kinds (as in $M .7: 1$ ), but whether the seeds and the vine produce the appearance of diverse-kinds. M. 7:3 complements M. 7:2D-F with two contrasting lists. One describes cases in which seeds sown near a vine produce only the appearance of diversekinds and so do not sanctify the vine, while the other presents instances in which such seeds do grow as diverse-kinds with the vine and thus sanctify the latter.

M. 7:4-5+6-7 discusses cases in which the growth of diversekinds actually takes place, but against the desire of the owner. M. 7:4 presents a dispute between an anonymous opinion, on the one hand, and Yose and simeon (augmented by a $\mathrm{m}^{c} \xi h$ involving CAqiva [M. 7:5]), on the other, concerning one who trains a vine over his neighbor's grain. The issue of the dispute concerns whether sanctification occurs automatically with the growth of diverse-kinds, so that the neighbor's grain is sanctified (anonymous opinion), or whether the process of sanctification is relative to the intention of the owner, in which instance the grain is not sanctified, for one cannot sanctify that which does not belong to him (Yose and Simeon). M. 7:6-7, a subunit characterized by its apocopated sentences (M. 7:6A, 7:7A,D), then complements the view of Yose and Simeon. M. 7:6 illustrates the position of these authorities, ruling that one who usurps and sows a vineyard does not sanctify the latter. The rightful owner need only cut down the other kind, lest he appear to allow diverse-kinds to grow. A gloss adds that he must do so immediately upon regaining his property. M. 7:7 turns from the above cases, which concern a person who sows diverse-kinds against the owner's wishes, to one in which the owner himself separately sows the two kinds, which accidentally (e.g., by being blown together by the wind) grow together as diverse-kinds. M. 7:7 follows Yose and simeon's principle that sanctification is relative to the intent of the owner, ruling that, since the owner clearly does not wish the different kinds to grow together, no sanctification takes place, and the owner need only remove the appearance of diverse-kinds.

Returning to the interests of $\mathrm{M} .7: 2 \mathrm{D}-\mathrm{F}+3, \mathrm{M} .7: 8$ presents a dispute between an anonymous opinion and simeon concerning whether, when placed in a vineyard, a perforated pot containing another kind produces the actual growth, or only the appearance, 
of diverse-kinds. According to the anonymous opinion the roots of the seeds in the pot can penetrate to the vineyard's soil and be nourished from it, so that the seeds actually grow as diversekinds with the vines and therefore sanctify the latter. Simeon, on the other hand, maintains that the seeds in a perforated pot are not regarded as being attached to the vineyard's soil, so that, like seeds in an unperforated pot, they produce only the appearance of diverse-kinds when placed in a vineyard. According to Simeon, then, it is prohibited to place either a perforated or unperforated pot containing another kind in a vineyard, and the seeds in the former, like those in the latter, do not sanctify the vines.

\section{$7: 1$}

A. He who sinks (hmbryk) a vine-shoot into the ground--

B. if the soil on top of it does not [measure] three handbreadths [high],

c. he shall not put seed on top of it [i.e., the underground vine],

D. even if he sank it in a [Maimonides, Comm.: dried] gourd or pipe $(s y l w n)$.

E. [If] he sank it in stony ground [so Danby for $s l^{c}$; Maim., Comm.: hard ground]--

F. even though the soil on top of it [measures] only three fingerbreadths [high]--

G. it is permitted to put seed on top of it [i.e., the underground vine].

H. The "knee" (h'rkwbh; B. B.B.: hrkbh) of the vine-shoot [i.e., the part of the vine that is bent under the ground]-they measure for it [most mss.: ${ }^{1}$ they measure] [its area of tillage] only from the second root (cyqr) [i.e., from the spot at which the vine grows new roots].
M. Kil. $7: 1$ (A-C;
B. B.B. $19 \mathrm{~b} ; \mathrm{H}$ :
B. B.B. $83 a$ )

M. is composed of two declarative sentences, A-C (glossed by $D)$ and $E-G$, with the latter dependent on the former for its content. The two sentences somewhat balance one another ( $h$ 'rs

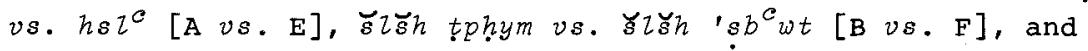
$l^{\prime} y b y^{\prime}$ vs. mutr $2 h b y^{\prime}$ [C vs. G]). H complements A-G with a separate rule.

M. concerns the method of plant propagation known as layering, ${ }^{2}$ which consists (in the case of vines) of sinking a 
vine-shoot into the ground so that it may develop new roots. The shoot (also called the layer) is then separated from the parent vine and grows from its own roots. M. asks whether one may sow another kind above the sunken shoot without sowing diversekinds. M. here distinguishes between the types of soil in which the vine-shoot may be sunk. A-C rules that one may sow over a vine-shoot which has been sunk into the ground only if three handbreadths of soil cover the vine. This amount of soil prevents the roots of the seeds from penetrating into the vine and gaining nourishment from it, for then the seeds would be considered to be grafted onto the vine (Sens, Ribmaș; cf. M. 1:7-8; cf. also Lieberman, $T K$, II, p. 644, on 1. 40). D adds that when the shoot is sunk into a dried gourd or a pipe, presumably in order to hold it in place, ${ }^{3}$ three handbreadths of soil must nonetheless cover the vine, for the roots of the seeds may perforate the casing and penetrate into the vine. In $E-G$ the vine-shoot is sunk into rocky or hard ground, in which the roots of the seeds cannot penetrate as deeply as they can in ordinary soil. In contrast to the rule of $\mathrm{A}-\mathrm{C}$, therefore, one may sow on top of the vine even if it is covered by only three fingerbreadths ( = three-quarters of a handbreadth). This contrast is underlined by the language of F-G, which balances that of $B-C$ :

\section{B. if the soil on top of it does not [measure] three hand- breadths [high],}

c. he shall not put seed on it.
F. even though the soil on top of it [measured] only three fingerbreadths [high],

G. it is permitted to put seed on it.

F's "three fingerbreadths" is clearly meant to contrast with B's "three handbreadths," and so to emphasize the difference between the two rulings.

$\mathrm{H}$ augments the interest of $\mathrm{A}-\mathrm{C}$, sowing above a sunken shoot, with a discussion of measuring the area of tillage of the new vine which rises aboveground. The new vine is here referred to as the "knee" of the vine-shoot, or that part of the shoot which is bent and which produces roots as the shoot turns upwards. ${ }^{4}$ The "knee" may then be said to represent the point at which the new vine begins. H deals with the question concerning whether one measures the area of tillage of the new vine from the parent vine, to which the former is still attached, or from the roots of the new vine itself. H rules that, although the new vine is still connected to the parent vine, once it has its own roots it is 
considered a separate plant and its area of tillage is measured from the new roots.

A. He who sinks a vine-shoot into the ground [ = M. 7:1A]--

B. if there is on top of it soil [in] only the least amount ( $\left.k \imath \breve{s} h w^{\prime}\right)$, it is permitted to sow on either side (mykn wmykn), but it is prohibited to sow [Vienna omits following to "it is permitted to sow"; first printed ed.:] on top of it.

C. "If he sunk it into stony ground $\left(s l^{c}\right)$ [ $=$ M. $\left.7: 1 \mathrm{E}\right]--$

D. "even though the soil on top of it measures only two fingerbreadths [high]--

E. "it is permitted to sow on top of it," the words of R. Meir.

F. R. Yosah says, "[The soil must measure] three fingerbreadths [high]."

G. R. Simeon b. Gamaliel says, "(1) House of Shammai say, 'Ten [Erfurt omits:] amot [GRA: Ten handbreadths], " and (2) House of Hillel say, 'Six [Erfurt: ten] handbreadths.'"

$$
\text { T. Kil. } 4: 11 \text { (p. 22a, I.1. 39-43) }
$$

T. comments on $M .7: 1$, with $A-B$ citing and glossing $M .7: 1 A$, $\mathrm{C}-\mathrm{F}$ relating to $\mathrm{M}$. $7: 1 \mathrm{E}-\mathrm{G}$, and $\mathrm{H}$ complementing $\mathrm{M}$. $7: 1 \mathrm{~A}-\mathrm{C}$. $\mathrm{A}-\mathrm{B}$ turns from M.'s interest in the problem of sowing on top of a sunken shoot to the related question of sowing beside such a shoot. B somewhat follows the formulary pattern of $\mathrm{M}$. $7: 1 \mathrm{~B}$

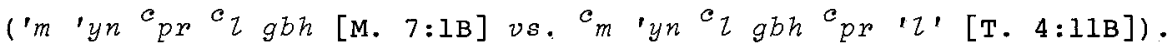
$B$ rules that one may not sow upon a sunken vine-shoot which is covered by only a little soil (thus agreeing with M. 7:1A-C), but one is permitted to sow on either side of the vine-shoot, for one does not assume that the roots of the seed will penetrate the vine from the side (Lieberman ${ }^{5}$ ).

At C-F Meir and Yosé dispute concerning how much soil must cover a vine-shoot which is sunk into rocky soil. T. attributes the language, though not the rule, of M. 7:IE-G to Meir at C-E, who maintains that two fingerbreadths must cover the shoot, while assigning to Yosé at $\mathrm{E} M$. 's view that three fingerbreadths of soil are required.

At $G$ Simeon $b$. Gamaliel presents a balanced Houses-dispute concerning the amount of soil which must cover a sunken shoot. Both Houses disagree with the rule of $\mathrm{M}$. $7: 1 \mathrm{~A}-\mathrm{C}$ that only three handbreadths of soil need cover the vine (Lieberman ${ }^{6}$ ). They both maintain that the issue of sowing above a sunken vine-shout concerns not the prevention of the roots of the seeds from penetrating into the vine, but the separation of the other kind from the vine 
by some fixed distance. House of Shammai maintain that ten handbreadths (according to the readings of Erfurt, GRA, and Lieberman ${ }^{7}$ ) must cover the vine. House of shammai apparently reason that, because the other kind is to be sown above the sunken shoot (and not, for example, beside it), it must be sown in a domain unto itself, or in a space ten handbreadths ${ }^{8}$ above the vine-shoot. House of Hillel, on the other hand, do not distinguish between the space above the vine and the space beside it, ruling that in all cases one separates the other kind from the vine by the latter's area of tillage, six handbreadths. ${ }^{9}$

$7: 2$

A. (1) He who sinks three vine-shoots (2) and their roots [i.e., the roots of the layers (new vines)] are visible--

B. R. Eleazar b. Sadoq says, "If there are between them [i.e., between the layers and the parent vines] from four to eight amot, 1o, these [i.e., the layers and the parent vines] combine [to form a vineyard].

C. "And if not, they do not combine [to form a vineyard]."

D. A vine which withered [so Danby for $y b s h$ ] is prohibited [i.e., it is prohibited to sow near it], but does not sanctify [the seeds sown near it].

E. R. Meir says, "Also ('p) [the] cotton (smr gpn) [tree $\left.{ }^{10}\right]$ is prohibited, [i.e., it is prohibited to sow near it], but it does not sanctify [the seeds sown near it]."

F. R. Eleazar b. Sadoq says in his name, "Also (' $p$ ) on top of the vine-shoot it is prohibited [to sow], but it [i.e., the vine-shoot] does not sanctify [the seeds sown above it]."

$$
\begin{aligned}
& \text { M. Kil. } 7: 2(A-C: \text { B. B.B. } 83 a \text {; } \\
& \text { D: Y. Kil. } 2: 3(27 d), \\
& \text { Y. Bes. } \left.5: 2(63 a)^{11}\right)
\end{aligned}
$$

M. consists of Eleazar b. Sadoq's saying at A-C (in the formulary pattern of M. 7:1A [hmbryk]), followed by a rule at D, which is augmented by both Meir and Eleazar b. Sadoq in Meir's name at $E-F$ (both joined to $D$ by $' p$ ). $A-C$ and $D-F$ are autonomous of one another, for the former deals with an issue concerning sunken vine-shoots, while the latter discusses the entirely separate question of whether the act of sowing near certain vines sanctifies the seeds. $\mathrm{A}-\mathrm{C}$ and $\mathrm{D}-\mathrm{F}$ were probably joined together because of $F$, which, like A-C, is attributed to Eleazar b. Sadoq, and which concerns whether sowing over a sunken shoot sanctifies the seeds, thus serving to link together the interests of both parts of the pericope. 
A(1) describes a case in which one sinks three vine-shoots (from three different vines) into the ground in order to produce a set of new vines, or layers, alongside the standing vines. $A(2)$, which perhaps glosses $A(1)$, states that the roots of the layers are exposed, so that the layers appear to be vines unto themselves, even though they may still be attached to the parent vines. In B-C Eleazar b. Șadoq discusses whether the layers may combine with the parent vines to form a vineyard consisting of two rows (following House of Hillel, M. 4:5C-D). The issue of $B-C$ concerns whether or not the layers and the parent vines appear to be aligned in two separate rows. Following Simeon's view concerning the spacing of rows in a vineyard (M. 4:9F [with Meir]+ $5: 2 \mathrm{~B} ;$ T. $3: 5$ ), Eleazar b. Sadoq rules that the layers and the parent vines combine to form a vineyard only if they are separated by a distance measuring between four and eight amot. The reasoning behind the rule is that rows which are separated by less than four amot do not appear to be distinct from one another, and rows which are set apart by more than eight amot do not appear to constitute a single entity.

$D-F$ presents three instances of an act of sowing which is prohibited but does not sanctify the seeds of the other kind. In each case the point of $M$. is that the sowing is prohibited because it creates the appearance of diverse-kinds, but, since no actual sowing of diverse-kinds takes place, the seeds are not sanctified. In the case of $\mathrm{D}$ sowing near a withered vine produces only the appearance of diverse-kinds, for, since the vine no longer bears fruit, two kinds do not actually grow at the spot which is sown. Similarly, Meir maintains in $\mathrm{E}$ that one may not sow near a cotton tree without producing the appearance of diverse-kinds, for the cotton tree resembles a vine (Rosh ${ }^{12}$ ). The seeds are not sanctified, of course, for they and the cotton tree do not grow as diverse-kinds of the vineyard. ${ }^{13}$ According to Eleazar b. Sadoq (in the name of Meir) at $F$ sowing above a sunken vine-shoot produces the appearance of diverse-kinds, presumably because such a sowing takes place between the parent vine and the layer. Eleazar b. Sadoq apparently holds that sowing above a vine-shoot is not considered an actual sowing of diverse-kinds, perhaps because he believes sowing above a vine to differ from sowing beside it (an act which does sanctify the seeds [c]). In prohibiting the sowing of another kind above a sunken shoot, Eleazar $b$. Sadog disagrees with the rule of M. 7:1A-C, which permits one to sow above a sunken shoot as long as the latter is covered by soil measuring three handbreadths deep. Eleazar b. Sadoq sees the issue to concern not whether the roots of the seeds will penetrate 
into the vine (as in M. $7: 1 \mathrm{~A}-\mathrm{C}$ ), but whether the seeds produce the appearance of diverse-kinds. 14

GG. [(Lest the whole yield be sanctified, the crop which you have sown and) the yield of the vineyard (Dt. 22:9)--]

HH. I know only [concerning] a vineyard which bears fruit [i.e., that one may not sow in $i t]$.

II. Whence [do I know concerning] a vineyard which does not produce fruit [i.e., that one may sow in it]?

JJ. Scripture says, [You shall not sow your] vineyard [with diverse-kinds (Dt. 22:9)]--in every instance (mkI mqwm).

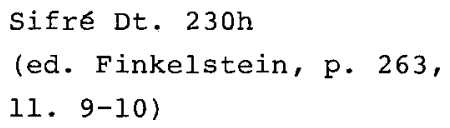

GG-JJ discusses whether the prohibition of sowing another kind in a vineyard (Dt. 22:9) applies in the case of a vineyard which does not bear fruit. GG-HH deduces that this prohibition applies to the fruit-bearing vineyard from the phrase yiezd of the vineyard (Dt. 22:9), which implies that the vineyard discussed in the verse does bear fruit. II-JJ then states that the phrase [your] vineyard in the opening of the same verse may be taken to include all vineyards. In maintaining that the rule (i.e., that sowing sanctifies the seeds) is the same for both fruit-bearing and barren vineyards, sifre disagrees with M. 7:2D, which distinguishes between sowing near a fruit-bearing vine, which does sanctify the seeds, and sowing next to a withered vine, which is prohibited but does not sanctify the seeds.

\section{$7: 3$}

A. These prohibit but $(w)$ do not sanctify [the seeds sown in them]:

B. (1) The remainder of the waste-state [so Neusner ${ }^{15}$ for hron; Danby: patch] of the vineyard, (2) the remainder of the outer space (mhwl) of the vineyard, (3) the remainder of the gaps of an espalier, (4) the remainder of the [latticework of] laths.

c. But (1) [the area] under the vine, and (2) the area of tillage of the vine, and (3) the four amot of the vineyard, 10, these sanctify [the seeds sown in them].

$$
\begin{aligned}
& \text { M. Kil. } 7: 3 \text { (B: T. Kel. } \\
& \text { B.M. } 6: 13^{16} \text { ) }
\end{aligned}
$$


M. augments M. 7:2D-F's discussion of acts of sowing near a vine which do not sanctify the seeds, presenting both further instances and contrasting cases of the same rule. M. consists of a superscription at $A$, a list of four items (all beginning with the word $m w t r$ ) at $B$, and a list of three at $C$ (joined to B by 'bl), thus enumerating seven items in all.

$B$ discusses four instances in which one who sows near a vine does not sanctify the seeds. $B(1)-(3)$ refers to cases in which one is permitted to sow the "remainder" of an area of a specified size, or that space which remains after the nearby vines are allowed their respective areas of tillage. M. rules that if the area is of insufficient size, and one nevertheless sows in its "remainder," the seeds are not sanctified. In the cases of the vineyard's waste-state or bald spot $(B(1)), 17$ and the outer space of the vineyard $(B(2)), 18$ the reasoning behind $M$. is that one who sows in the "remainder" of an area which is too small appears to sow diverse-kinds, for the other kind does not appear to be sown in an area unto itself. Like M. 7:2D-F, therefore, M.'s point is that one who produces only the appearance of diverse-kinds does not sanctify the seeds.

The rule of $\mathrm{B}(3)$, which concerns sowing the "remainder" of an espalier's gap, is difficult. According to M. 6:6A the gap must measure eight amot and "a little more" in order to be sown, and M. 6:6D-F explains that an area of this size is required because the gap lies between two espaliers, each of which is allowed an area of tillage of four amot. If, therefore, the gap measures less than the specified size, the area to be sown actually lies within one of the areas of tillage of the vines. $c(2)-(3)$, however, explicitly states that one who sows within a vine's (or vineyard's) area of tillage does sanctify the seeds. B(3) may therefore follow Yohanan b. Nuri's view (M. 6:1F-G) that the area of tillage of an espalier is only six handbreadths. Alternatively, $B$ (3) may reject $M$. 6:6D-F's explanation that the gap mentioned in M. 6:6A lies between two espaliers, maintaining that it lies simply between two parts of the destroyed espalier. In any event $B(3)$ apparently holds that the vines on either side of the gap are allowed only six handbreadths as their respective areas of tillage, and that the "remainder" refers to the rest of the eight amot and "a little more." If the gap then initially measures less than the specified measure, one who sows in the "remainder" produces the appearance of diverse-kinds, for again the other kind does not lie in an autonomous area. As in the case of $B(1)-(2)$, therefore, the seeds sown in the "remainder" are not sanctified. 
B (4) rules that sowing under the "remainder" of a latticework of laths does not sanctify the seeds. In this instance the term "remainder" refers not to the area remaining after the vines are allowed their areas of tillage (as in $B(1)-(3)$ ), but to that part of the latticework which remains uncovered by the vine trained on the laths. According to M. 6:3A one may not sow under the "remainder" of the latticework, for the entire latticework is regarded as an extension of the vine. M. 6:3B then rules that one who does sow under the "remainder" does not sanctify the vines, presumably because the seeds are not sown directly under the vine. ${ }^{19}$ Like $B(1)-(3)$, therefore, the point of $B(4)$ is that the seeds are not sanctified because no actual sowing of diverse-kinds takes place. 20

$C$ augments $B$ with three instances in which sowing near a vine does sanctify the seeds. One who sows either under a vine (C(1); e.g., by trellising his vines over grain [M. 7:4], or by sowing under a vine-shoot extended between trees [M. 6:9I-J (Ribmaș, Bert., MS, TYY)]) or within the area of tillage of a vine $(C(2))$ or a vineyard $(C(3))$ sanctifies the seeds, for in these cases he sows within the domain of the vine and thus actually sows diverse-kinds. By ruling that the seeds are sanctified by the actual sowing of diverse-kinds, $C$ thus complements $B^{\prime}$ 's principle that the appearance of diverse-kinds does not sanctify the seeds.

F. [You shall now sow your vineyard with diverse-kinds (Dt. $\left.22: 9)^{--}\right]$

G. I know only [that the prohibition against sowing a vineyard with diverse-kinds applies to] a full vineyard.

H. Whence [do I know that the prohibition applies] even [to] a single vine which bears fruit?

I. Scripture says, [Lest the whole yiezd be sanctified, the crop which you have sown and the yield of] the vineyard (Dt. 22:9) [So Nesiv]--under all circumstances.

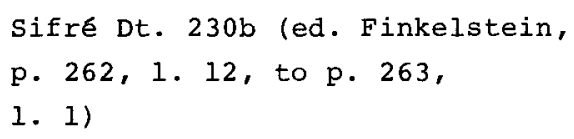

G understands the word vineyard (Dt. 22:9) to mean that it is prohibited to sow diverse-kinds only in a full vineyard. H-I then takes the second mention of vineyard in the verse to include in the prohibition the act of sowing near an individual vine which bears fruit (Neșiv; cf. also Ish-Shalom ${ }^{21}$ ). Sifré thus agrees 
both with M. 7:3C's rule that a single vine sanctifies another kind sown near it, and with $M .7: 2 D^{\prime}$ s statement that a withered vine does not sanctify diverse-kinds which are sown nearby.

$$
7: 4-5
$$

A. He who trellises [so Bokser ${ }^{22}$ for $m s k k$ ] his vine over the grain of his neighbor, lo, this one has sanctified [the grain underneath the vines] and is liable [B. B.Q. omits:] to replace it [so Bokser for hyyb b'hrywth].

B. R. Yose and R. Simeon say, "A man does not sanctify (mqd̆,; Y. Kil. 2:5, 4:5, 5:5: mqdy $\breve{s}$ ) something which is not his own."

$$
\begin{aligned}
& \text { M. Kil. } 7: 4 \text { (B. Yev. } 83 a, \\
& \text { B. B.Q. } 100 a ; \text { B: Y. Kil. } 2: 5 \\
& \text { (28a), } 4: 5(28 c), 5: 5(30 a) \text { ) }
\end{aligned}
$$

C. Said R. Yosé, " $m^{c} \xi h b$ : One sowed his own vineyard in the Seventh Year, and the case came before R. CAqiva, and he said, 'A man does not sanctify something which is not his own." "

$$
\text { M. Kil. } 7: 5
$$

M. consists of a declarative sentence at $A$, which Yosé and Simeon gloss and oppose at $B$. Yosé then augments $B$ with a $m^{c} \xi h$ at $C$. A discusses whether one who trellises a vine over his neighbor's grain sanctifies the latter, even though it does not belong to him. The issue of $A$ is whether sanctification always takes place whenever another kind grows near a vine, or whether other considerations, such as the ownership of the different kinds, must be taken into account as well. A rules that the owner of the vine does sanctify his neighbor's crop and must compensate his neighbor for them (for the crops must now be burnt along with the vine). A thus maintains that sanctification occurs automatically with the sowing of diverse-kinds of the vineyard, regardless of the circumstances of the sowing. Yose and simeon disagree at $B$, saying that one may not sanctify that which is not his. These authorities thus regard sanctification to be relative to other factors, such as (in this instance) the ownership of the two kinds which grow together. We note that $B$ does not respond directly to the case of $A$, and need not even refer to a problem concerning diverse-kinds. ${ }^{23} \mathrm{~A}$ and $\mathrm{B}$ are therefore autonomous sayings which have been juxtaposed in order to create the semblance of a dispute. 
Unlike $B$, the $m^{c} \xi h$ cited by Yose relates specifically to the question of $A$ (i.e., diverse-kinds of the vineyard), and thus was probably added to $B$ when the latter was joined to $A$. The

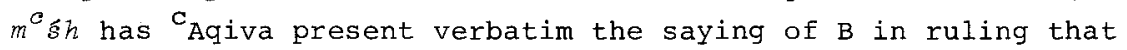
one who sows his vineyard in the seventh year does not sanctify it. C presupposes that one's fields are considered ownerless in the Seventh Year (Maim., Comm.; Cf. Ex. 23:10-11, Lv. 25:7), so that, since one may not sanctify that which is not his own, he who sows his vineyard cannot sanctify it. The $m^{c} s h$ thus illustrates B. C is curious, however, for it assigns to CAgiva, a Yavnean, a saying which is attributed at $B$ to the Ushans Yosé and Simeon. Now it is unlikely that Ushans would be assigned a saying which had originally been attributed to a Yavnean. It is therefore more probable that the $m^{c} s h$, which perhaps originally read "and he permitted it," was revised to include $B$ and thus to serve more clearly as a precedent for the rule of $B$.

[KK. (You shall not sow) your vineyard (with diverse-kinds) (Dt. $22: 9$ )--]

LL. I know only [concerning] your [own] vineyard [i.e., that you may not sow in it].

MM. Whence do I know [concerning] a vineyard belonging to others [i.e., that you may not sow in it]?

NN. Scripture says, you shalz not sow your vineyard with diverse-kinds --in every instance (mkl mqwm).

$$
\begin{aligned}
& \text { Sifré Dt. } 230 i \text { (ed. Finkelstein, } \\
& \text { p. 263, 11. 10-11) (Y. Kil. } 7: 3 \\
& (30 d)^{24} \text { ) }
\end{aligned}
$$

Sifré discusses whether one may sow a vineyard which belongs to someone else. KK deduces from the phrase your vineyard that the prohibition of sowing a vineyard refers to one's own vineyard. NN then extends the prohibition to apply to all vineyards by taking the phrase you shall not sow to refer to all cases of sowing in a vineyard. Sifré would thus agree with M. 7:4A's rule that one does sanctify that which does not belong to him.

$$
7: 6
$$

A. The usurper [following Danby for $h$ 'ns] who sowed a vineyard--

B. and it left his possession (wyg 'mzpnyw) [Danby: and it was recovered from him]--

c. he [i.e., the rightful owner] cuts down [the other kind], 
D. even ('py $2 w$ ) on [the intermediate days (Maim., Comm., Code, Diverse-Kinds $5: 12$ ) of] a festival.

E. How much more does he pay the workers [for cutting down the other kind on the intermediate days of a festival]?

F. Up to a third [more than their usual wages].

G. [If they demand] more than this,

H. he continues to cut [it] down in his [usual] manner,

I. even [if he does not finish cutting it down until] after the festival.

$J$. At what point is [the vineyard] called [that of the] usurper?

K. At the point that [the vineyard] settles $\left(m \widetilde{s}_{y} \breve{s}_{q}^{c}\right)$ [firmly into the usurper's possession and the rightful owner may no longer recover it from him (Albeck)].

M. Kil. $7: 6$

M. opens with an apocopated sentence, A-D, dealing with a vineyard which has been sown by a usurper. E-I and $J-K$ then separately gloss A-D. Now E-I responds only to D (with I somewhat balancing $\mathrm{D}\left[{ }^{\prime} p y z w b m w^{c} d v s\right.$. 'pylw $Z$ ' $\left.h r m w^{c} d\right]$ ), for $\mathrm{D}$ alone shares E-I's interest in the issue of cutting down the other kind during a festival. Along with E-I, then, D actually glosses A-C, which presents a perfectly intelligible rule by itself. It therefore appears that the gloss D-I, introducing the issue of work which may be done during a festival, has been inserted into the unit $A-C+J-K$, which concerns simply the problem of the usurper who has sown a vineyard.

A-C complements $M$. 7:4B with another instance of Yose's and Simeon's rule that one cannot sanctify that which is not his own. A-C describes a case in which one recovers his vineyard from one who had illegally seized it and had sown it with another kind. The issue of $\mathrm{A}-\mathrm{C}$ concerns whether the usurper sanctified the vineyard by sowing it, so that the rightful owner must burn the other kind together with the vines. According to $\mathrm{A}-\mathrm{C}$ the owner must cut down the other kind, lest he appear to allow diverse-kinds to grow. A-C does not rule, however, that the two kinds must be burnt, and thus implies that the vineyard was not sanctified by the usurper, presumably because he could not sanctify that which did not belong to him. J then asks concerning the point at which the usurper is regarded as the owner of the vineyard, so that he does sanctify it by sowing it (Bert., TYY). ${ }^{25} \mathrm{~K}$ answers that the usurper is considered the vineyard's owner once the property rests firmly in his possession, for he then has control over the vineyard and so effectively functions as its owner. 
$D$ introduces the consideration of the haste with which the owner must clear the vineyard of the other kind. According to $D$ the owner must immediately cut down the other kind, even if he must do so during the intermediate days of a festival, when such work is usually prohibited. The point of $\mathrm{D}$ is that one must act as soon as possible to destroy the appearance of diverse-kinds. E-I then augments $D$ with a discussion of the maximum amount which the owner is required to pay the workers in order to induce them to work during the festival. E-F states that the owner must pay the laborers up to a third more than their regular wages. He need not offer more than this amount, however, even if these wages will not attract workers and the vineyard thus will not be entirely cleared of the other kind until after the festival (G-I). According to G-I, then, one need not suffer a great economic loss in order to remove the other kind, which after all produces only the appearance of diverse-kinds. G-I thus qualifies D, for it rules that, under certain circumstances, one may allow the other kind to remain in the vineyard until after the festival.

$7: 7$

A. Wind which hurled [so Danby for ${ }^{c}{ }_{2}{ } / h$ ] vines on top of grain--

B. he should cut them [i.e., the vines] down at once (ygdwr; $V$, Sens: ygrwr; ${ }^{26} \mathrm{~B}, \mathrm{Cn}, \mathrm{O}, \mathrm{P}$, Maim., Comm., Code, Diverse-Kinds $5: 11$ [some mss. ${ }^{27}$ ]: ygrwd ["he shall remove them (Maim., Comm.)"]; Geniza fragment, ${ }^{28} \mathrm{~s}$, other commentaries: ${ }^{29}$ ygdwd).

c. If an unavoidable accident ('wns) befell him [and he could not immediately cut down the vines], it is permitted [i.e., the grain is not sanctified].

D. Grain which sways [so Danby for nwth] under the vine,

E. and so [is the rule] in [the case of] vegetables [which sway under the vine]--

$F$. he returns [the grain or the vegetables to their origina] positions] and does not sanctify [i.e., forfeit the vines].

$G$. At what point does grain become sanctified?

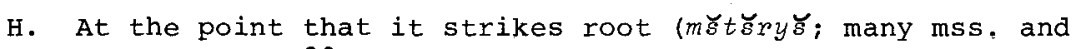

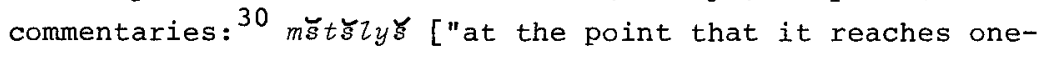
third of its growth"]).

I. And [at what point do] grapes [become sanctified]?

J. At the point that they become like [i.e., the size of] a hyacinth bean.

K. Grain which has become fully aried or (w) grapes which have fully ripened do not become sanctified. 
M. continues its discussion of diverse-kinds of the vineyard which grow against the wishes of the owner, turning from the case of the usurper who sows a vineyard (M. 7:6) to instances in which vines accidentally hang over another kind. M. 7:7 opens with an apocopated sentence, A-B ( $g$ lossed by $C$ ), concerning vines which are blown on top of grain by the wind. D+F (glossed by $E)$, which is also in apocopation, then presents a separate rule characterized by a differed apodosis, dealing with grain which sways under a vine. $D+F$ has been joined to $A-B$ because it reverses the circumstances of the latter, discussing grain which extends under the vine, rather than the vine which hangs over grain. G-J then augments $A-F$, and is itself complemented by $K$. A describes a case in which the wind blows vines on top of some nearby grain. The issue of A concerns whether sanctification occurs automatically with the growth of diverse-kinds, even though the owner could not have prevented such a growth. B rules that the owner must cut down the overhanging vines at once so that he not appear to allow diverse-kinds to grow. B does not state, however, that the two kinds must be destroyed, and so implicitly rules that the grain is not sanctified by the vine. $A-B$ thus agrees with $M .7: 6 \mathrm{~A}-C^{\prime}$ 's principle that sanctification takes place only when diverse-kinds are sown intentionally. $C$ then makes this point clear, stating that the grain is not sanctified even if one is unable immediately to cut down the vines, for in any case the owner did not wish the diverse-kinds to grow.

$D$ presents a similar case, in which grain (or, according to E, vegetables) sways under a vine. Like A, D concerns whether sanctification takes place regardless of the intentions of the owner. According to $F$ the vines are not sanctified if the owner returns the grain to its original position, for he then does not appear to allow diverse-kinds to grow. $D+F$ then agrees with the principle of A-B, i.e., that sanctification occurs only when diverse-kinds are sown intentionally, but differs from the actual rule of $A-B$, maintaining that the kind which has moved from its original position need only be returned to its proper place, but need not be cut down.

G-J augments A-F with a discussion of the points in their respective growth processes at which grain and grapes can become sanctified. According to one reading of $\mathrm{H}$ ( $m \breve{s} t \breve{s} r y \breve{s}$ ) grain can become sanctified once it has struck root, presumably because at that point it visibly begins its process of growth. Alternatively, $\mathrm{H}$ (when $m \breve{s} t \breve{s} z y \breve{s}$ is read) maintains that grain cannot become sanctified until it reaches a third of its projected size, ${ }^{31}$ presumably because only then does it begin to acquire 
distinctive characteristics of grain. I-J then rules that grapes can become sanctified as soon as they reach the size of hyacinth beans, for only at that point may they be properly called grapes. $K$ then augments G-J by defining the points at which grain and grapes can no longer be sanctified. According to $k$ one cannot sanctify grain which has fully dried or grapes which are fully ripe, for in either case the crop has ceased to grow. The point of $\mathrm{K}$ thus is that diverse-kinds are sanctified only if they actually grow together, so that a kind which has stopped growing can no longer be sanctified.

A. Grain which sways under the vine--

B. he returns it [to its original position] and does not sanetify $[=\mathrm{M} .7: 7 \mathrm{D}+\mathrm{F}]$ the vines.

C. And vegetables [= M. 7:7E] which sway into (ltwk; Erfurt: tht ["under"]) the vine [Erfurt, first printed ed. omit: grain]--

D. Abba Saul says [= omitted by Y. Kil. 7:5], "(1) R. CAqiva says, 'He shall return [them to their original positions],'

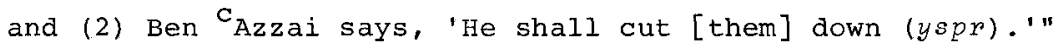

E. If their [i.e., the vegetables'] roots extended [from outside of the vineyard's area of tillage] into the four amot [Erfurt, first printed ed. add:] of the vineyard, all agree [Erfurt, first printed ed, add:] that he shall uproot them [first printed ed.: $y^{c} q w r ;$ Erfurt: $\left.c_{w q r}\right]$.

F. Roots of madder [so Lieberman, ${ }^{32}$ reading $p w^{\prime} h$ for $p y^{\prime} h$ ] which extended [from outside of the vineyard's area of tillage] into the four amot of the vineyard [even (= omitted by Y. Kil. $\left.1: 8,5: 3,6: 2 ; \mathrm{GRA}^{33}\right)$ ] more than three handbreadths below [the surface]--it is permitted [i.e., the madder does not sanctify the vine].

$$
\begin{aligned}
& \text { T. Kil. } 4: 10 \mathrm{~b}(\mathrm{p} .220,11.35-39) \\
& \text { (D: Y. Kil. } 7: 5(31 \mathrm{a}) ; \mathrm{F}: \mathrm{Y}, \mathrm{Kil} \\
& 1: 8(27 \mathrm{~b}), 5: 3(29 \mathrm{~d}), 6: 2(30 \mathrm{c}))
\end{aligned}
$$

T. cites M. $7: 7 \mathrm{D}+\mathrm{F}$ at $\mathrm{A}-\mathrm{B}$, adding "the vines," an obvious gloss, at B. C-D cites and glosses M. 7:7E, filling out its protasis and augmenting it with a dispute between $\mathrm{C}_{\text {Aqiva }}$ and Ben CAzzai (cited by Abba Saul). The dispute concerns how one removes the appearance of diverse-kinds which is produced when vegetables sway under vines. The issue of the dispute is whether one need deal only with the current appearance of diverse-kinds, or whether one must also ensure that the appearance of diverse-kind will not reoccur in the future. According to Aqiva one has only 
to return the vegetables to their original positions, for one need be concerned only with the present appearance of diversekinds and not with the possibility that the vegetables might again sway under the vines. CAqiva is thus assigned the view of M. $7: 7 \mathrm{E}(=\mathrm{M}$. $7: 7 \mathrm{D}+\mathrm{F})$. Ben $\mathrm{C}_{\mathrm{Azzai}}$, on the other hand, maintains that one must cut down the vegetables in order to prevent them from again producing the appearance of diverse-kinds. Ben CAzzai's view is similar to M. 7:7A-B's rule that one must cut down vines which the wind has blown on top of grain. $T$. thus perhaps links M. 7:7A-B to M. 7:7D-F by placing the two rules in dispute with one another in the context of $\mathrm{M}$. 7:7E.

$E$ then augments $C-D$ with a case in which vegetables are sown outside of a vineyard's area of tillage, but their roots then extend into the four amot of space surrounding the vines. ${ }^{34}$ The vegetables thus actually grow with the vines as diverse-kinds, although, of course, they do not sanctify the vines, since they were originally sown outside of the vineyard's area of tillage. In this instance all of the parties to the dispute of $\mathrm{D}$ agree that the vegetables must be uprooted, for only in this way can the growth of diverse-kinds be stopped. $F^{35}$ complements $E$ with an exception to its rule. If the roots of madder ${ }^{36}$ extend from outside of the vineyard's area of tillage into the four amot at a depth of three handbreadths below the surface, they do not sanctify the vines, since the two sets of roots do not touch one another.

A. Grain which has struck root, lo, (1) this is prohibited [i.e., it is prohibited to plant vines near it], and (2) it sanctifies [vines growing near it], and (3) it is sanctified [by vines growing near it].

B. Vines which have struck root, 10, (1) these are prohibited [i.e., it is prohibited to sow grain near them] ('swryn; GRA: 37 'wsryn ["prohibit"]), and (2) they sanctify [grain growing near them], but (3) they are not sanctified [by grain growing near them].

c. until they [i.e., their grapes] shall become like [i.e., the size of] a hyacinth bean [= M. 7:7J].

D. (1) If some of the vines produced [grapes] like [i.e., the size of] a hyacinth bean, and (2) others did not produce [grapes like (i.e., the size of) a hyacinth bean].

E. (1) those [vines] which produced [grapes] like [i.e., the size of] a hyacinth bean are prohibited [i.e., sanctified], and (2) those [vines] which did not produce [grapes] like [i.e., the size of] a hyacinth bean are permitted [i.e., not sanctified].

T. Kil. $4: 12$ (p. 221 ,

11. $44-47)$ 
T. complements M. 7:7G-J's interest in the points at which grain and vines can become sanctified, presenting additional rules concerning the instants at which each of these two kinds may not be sown with each other and can sanctify one another. A-B forms a well balanced pair of declarative sentences, with $A$ and $B$ differing only at their respective openings ( $t b w^{\prime} h$ vs. gpn) and at $A(3)$

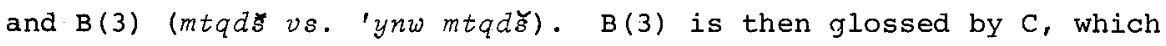
cites $11.7: 7 \mathrm{~J}$. D-E augments the latter with a conditional sentence, the protasis and apodosis of which are each internally balanced (D(1) vs. $\mathrm{D}(2), \mathrm{E}(1)$ vs. $\mathrm{E}(2))$.

A restates and expands the rule of $\mathrm{M}$. $7: 7 \mathrm{G}-\mathrm{H}$, saying that once grain has struck root it not only can become sanctified $(A(3))$, but it can also sanctify vines growing around it $(A(2))$, and one may not plant vines near it $(A(1))$. This last rule appears to be unnecessary, for it appears to follow clearly from $A(2)$ and $A(3)$ that one is not permitted to plant vines near grain. T. perhaps follows the language of $M .7: 3 \mathrm{~A}$ (' $\mathrm{l} w$ 'wsryn

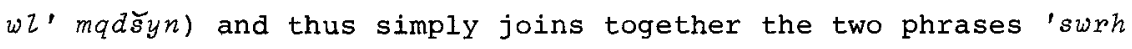
and mqdst, even though the latter (+A(3)) makes the former redundant. $B$ extends the rule of $A$ to the case of vines, maintaining that, like grain, vines which have struck root can sanctify, and it is prohibited to sow near them. The rule for vines differs from that for grain, however, for vines cannot become sanctified until their grapes grow to the size of hyacinth beans (= M. 7:7J[C]). $D-E$ then augments $C$ with an intermediate case in which only some of the vines of a sanctified vineyard have produced grapes as large as hyacinth beans. The issue of D-E concerns whether sanctification ${ }^{38}$ takes place with respect to the vineyard as a whole, even though some of the vines do not contain grapes of the specified size, or whether sanctification affects each vine separately. According to $\mathrm{E}$ only those vines which have produced grapes of the size of hyacinth beans are sanctified, so that sanctification may be said to take effect only in respect to single vines, and not in regard to the entire vineyard.

M. Lest be sanctified the fullness of seed (hmI'h harc) [which you have sown and the yield of the vineyard (Dt. 22:9)]

[Alternatively: Lest the whole yield be sanotified ( $h m l ' h$ ) (, the seed which you have sown and the yield of the vineyard) ].

N. At what point does the fullness of seed (hml'h $h z p^{c}$ ) [some mss.: $39^{\circ}$ the whole yield $\left.(h m l ' h)\right]$ become sanctified?

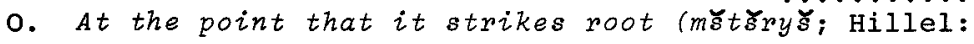
$m$ tszly ["At the point that it reaches one-third of its growth"]) 
P. And [at what point do] grapes [become sanctified]?

Q. At the point that they become like i.e. the size of a hyacinth bean $[=\mathrm{M}$. $7: 7 \mathrm{G}-\mathrm{J}]$.

Sifré Dt. 230 d (ed. Finkelstein, p. $263,11.4-5)$

Sifre cites M. $7: 7 \mathrm{G}-\mathrm{J}$ at $\mathrm{N}-\mathrm{Q}$ and links it to Dt. $22: 9$ (M). According to one reading of $B$ Sifre connects $M$. to the words $h m l ' h h z r^{c}$ (substituting them for tbw'h in its citation of M. 7:7G), which are read as a single phrase meaning the fullness of seed. Sifre takes this phrase to indicate that grain cannot be sanctified until it reaches a certain "fullness," and thus cites M. at 0 to define when this instant occurs. Alternatively, Sifre links $M$. at $\mathrm{N}$ to the word $h m l \cdot h$ (substituting it for tbw'h in citing $M .7: 7 \mathrm{G}$ ), which, read by itself, is taken to mean the whole yiezd and to refer to grain (Neșiv). According to this reading of $B$ Sifre understands scripture to say that grain cannot be sanctified until it is regarded as producing a "yield," and so cites M. at o to describe the point in the growthprocess of the grain at which this development takes place. We note that although sifre cites $M .7: 7 \mathrm{G}-\mathrm{J}$, it is relevant only to $M .7: 7 \mathrm{G}-\mathrm{H}$.

BB. [The seed which you have sown and] the yiezd of the vineyard (Dt. 22:9).

CC. At what point does grain become sanctified?

DD. At the point that it strikes root.

EE. And [at what point do] grapes [become sanctified]?

FF. At the point that they become like [i.e., the size of]

a hyacinth bean $[=\mathrm{M}$. $7: 7 \mathrm{G}-\mathrm{J}]$.

Sifré Dt. $230 \mathrm{~g}$ (ed. Finkelstein, p. 263, 11. 8-9) (EE-FF: CF. Y. Kil. $7: 5^{40}$ )

Sifré cites M. 7:7G-J (CC-FF), linking M. 7:7I-J to Dt. 22:9. Sifre thus complements Sifre Dt. 230d, which connects M. 7:7G-H to the same verse. Sifre here specifically links M. to the phrase the yield of the vineyard (tbw't hkrm), taking this phrase to indicate that the vines cannot be sanctified until they produce a "yield." Sifre then cites M. 7:7I-J at EE-FF to specify the point at which such a "yield" is produced.

\section{$7: 8$}

A. A perforated pot [containing another kind] sanctifies [the vines when located] in the vineyard. 
B. And that [pot containing another kind] which is unperforated does not sanctify [the vines when located in the vineyard].

c. And [= omitted by most mss. $\left.{ }^{41}\right] \mathrm{R}$. Simeon says, "Both [perforated and unperforated pots containing another kind] prohibit ('wsryn; some mss.: ${ }^{42}$ 'swryn ["are prohibited"]) [i.e., it is prohibited to place them in a vineyard] but $(w)$ do not sanctify [the vines when located in the vineyard]."

D. He who carries a perforated pot [containing another kind] through the vineyard--

E. if [while he carried the pot through the vineyard] it [i.e., the seeds of the other kind] increased in size by [one] two-hundredth--

F. it is prohibited [i.e., it sanctifies the vines]. M. Kil. $7: 8$ (A-B: Y. Dem, $5: 8(25 a)$, Y. Shab. $10: 6$ (12d); D-F; B. Pes. 25a, B. Hul. 116a)

M. opens with a pair of well-balanced declarative sentences,

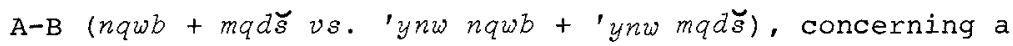
perforated pot containing seeds which is located in a vineyard. Simeon glosses and opposes $A-B$ at $C$. Following its own formulary pattern (he-who... it-is apocopation $\left.\left[h m^{c} b y r\right]\right), D+F$ (glossed by $E$ ) then complements $A-C$ with a separate rule dealing with the perforated pot which is carried through a vineyard.

A-B discusses whether seeds which grow in a pot located in a vineyard are regarded as growing in the vineyard itself, and so sanctify the surrounding vines. The issue of $A-B$ concerns whether or not the seeds contained in the pot derive nourishment from the soil of the vineyard. M. here distinguishes between those seeds which are planted in a perforated pot and those which grow in a pot without any holes. In the first instance the roots of the seeds can penetrate through the holes in the pot to the vineyard's soil, from which they may be nourished. The seeds are thus regarded as growing in the vineyard itself and so sanctify the vines. ${ }^{43}$ If the pot has no holes, on the other hand, the seeds within it do not sanctify the vines. Since in this case their roots cannot come into contact with the soil of the vineyard, the seeds are not considered to grow in the vineyard itself.

At $C$ simeon disagrees with the view of $A-B$, maintaining that the rule is the same whether or not the pot containing the seeds is perforated. 44 In either case it is prohibited to place the pot in the vineyard, but the seeds within the pot do not sanctify the vines. One may not place the pot in the vineyard lest the seeds within it appear to grow as diverse-kinds with the vines (e.g., if the pot should be hidden from view). According to this interpretation, then, simeon follows the principle of $M .7: 2 \mathrm{D}-\mathrm{F}+3$, 
i.e., that the appearance of diverse-kinds does not sanctify the seeds or the vine. In ruling that seeds in either type of pot do not sanctify the vines, simeon implies that the seeds contained in a perforated pot, like those which grow in a pot without holes, are not regarded as growing in the vineyard itself. Simeon may reason here that the seeds in the perforated pot may be sustained from the soil of the pot alone. One therefore need not assume that the seeds are actually nourished by the vineyard's soil, even if their roots can penetrate into that soil. The seeds contained in the perforated pot are thus considered to grow in the pot, 45 and not in the vineyard, so that they do not sanctify the vines.

According to $D+F$ it is prohibited for one to carry a perforated pot containing another kind through a vineyard, for it would then seem as if he intended to place the pot in the vineyard, and he would thus appear to sow diverse-kinds. This rule is separate from that of $\mathrm{A}-\mathrm{C}$, for in this instance the perforated pot is only carried through the vineyard, while in the case of $\mathrm{A}-\mathrm{C}$ the pot is actually set down there. Both Simeon and the anonymous authority behind $A-B$, who disagree concerning whether or not the pot sanctifies the vines of the vineyard, would presumably be in accord with the rule of $D+F$. Both authorities would agree that carrying a perforated pot through a vineyard produces only the appearance of diverse-kinds, and thus does not sanctify the vines. Glossing $D+F, E$ states that the rule of the latter applies only when the seeds in the pot grow by one two-hundredth while being carried through the vineyard. The significance of the figure "one twohundredth" may be explained as follows (cf. also M. 5:7). Only that part of a plant which actually grows while the pot is in the vineyard is considered to be prohibited. This additional, prohibited part of the plant is regarded as if it were in a mixture with other, permitted parts of the plant. Now one prohibited part may be neutralized in a mixture containing two hundred permitted parts (M. Orl. 2:1). If, therefore, the prohibited part of the plant measures less than one two-hundredth of the whole, that prohibited part is neutralized by the rest of the plant. If the plant grows one two-hundredth or more, however, the prohibited part is not neutralized by the remainder of the plant (for the ratio of permitted to prohibited parts is less than 200:1), and the entire plant is prohibited. The point of $E$ is that the issue of $D+F$ concerns not the appearance of diverse-kinds, but their actual growth in the vineyard. Accordingly, E may take 'swr (F) to mean "it [i.e., the plant in the pot] is sanctified" rather than simply "it is prohibited," and thus follows the view of A-B (i.e., that a perforated pot can sanctify [and be sanctified by] the vines of a vineyard). 
A. He who carries a perforated pot [containing another kind] through the vineyard --

B. If [while he carried the pot through the vineyard] it [i.e., the seeds of the other kind] increased in size by [one] two-hundredth--

C. it is prohibited [= M. 7:8D-F],

D. but (1) it does not become sanctified (2) until he places it under the vine.

E. R. Simeon says [= omitted by Y. Kil. $]$, "The perforated pot differs from that which is not perforated only in [respect to] rendering seeds susceptible."

T. Kil. $4: 13$ (p. 22, 11. 47-49)

(E: Y. Kil. 7:6 (3la), B. Shab. 95a)

T. cites and glosses $M .7: 8 \mathrm{D}-\mathrm{F}$ at $\mathrm{A}-\mathrm{D}$, complementing $\mathrm{M}$.' $\mathrm{S}$ case of one who carries a perforated pot through a vineyard with the instance of one who actually sets down such a pot in a vineyard. T. understands 'swr in $\mathrm{M} .7: 8 \mathrm{~F}$ to mean simply that it is prohibited to carry a perforated pot through a vineyard, and thus adds in $D(1)$ that such an act does not sanctify the seeds in the pot. $D(2)$, which may gloss $D(1)$, then states that the pot does become sanctified when it is actually set down in the vineyard, as in the case of M. 7:8A ("A perforated pot [containing another kind] sanctifies [the vines when located] in the vineyard"). T. thus links $M .7: 8 \mathrm{~A}-\mathrm{C}$ to $\mathrm{M}$. $7: 8 \mathrm{D}-\mathrm{F}$ by reading the former into the latter.

At $\mathrm{E}$ T. augments Simeon's saying of M. 7:8C, having Simeon extend to every case but one his principle that one does not distinguish between perforated and unperforated pots. The one instance in which simeon does make such a distinction concerns rendering seeds susceptible to uncleanness. Simeon here refers to M. Uqs. 2:10, which states that seeds planted in a perforated pot may not be rendered susceptible to uncleanness (by being wet down), for the seeds are considered to be attached to the ground. Seeds contained in an unperforated pot, on the other hand, are regarded as being detached from the ground, and thus may be rendered susceptible to uncleanness, when wet down. Simeon thus reasons that the tenuous connection (through the seeds' roots) between the seeds in a perforated pot and the ground is considered to be significant only in regard to the issue of rendering seeds susceptible to uncleanness, perhaps because in this instance even the slightest connection is considered to attach the plant to the ground (M. Uqs. $3: 8 \mathrm{H}$ [Lieberman] ${ }^{46}$ ). ${ }^{47}$ 


\section{KILAYIM CHAPTER EIGHT}

Chapter Eight is divided into two parts, M. 8:1, which introduces the chapter with a series of rules concerning various types of diverse-kinds, and M. 8:2-6, which discusses prohibitions dealing specifically with diverse-kinds of animals. M. 8:1 serves to link M. 8:2-6 to Chapter Seven, for it opens with a rule concerning diverse-kinds of the vineyard, the subject of the previous chapter, and closes with the prohibition against breeding animals of diverse-kinds, a concern of M. 8:2-6. M. 8:1 thus serves a clear redactional purpose. This last rule is glossed by the statement, "Diverse-kinds of animals are prohibited with the another (M. 8:1J)." This statement apparently means that diverse-kinds of animals, i.e., animals born of the union of different kinds, may not be mated with one another, for such a union would surely be a pairing of different kinds. We shall immediately see, however, that at least one redactor apparently understood M. 8:1J differently, and that his understanding of this rule had a direct bearing on the redaction of the chapter.

M. 8:2-6 consists of three parts, M. $8: 2-4 B$, concerning the prohibition of yoking animals of different kinds to do work, M. 8:4C-E+5A-B, discussing the mating of mules with one another, and $M .8: 5 C-G$, dealing with animals of doubtful status (e.g., animals which may be regarded as either wild or domesticated). Now it is not clear why $M$. $8: 2-4 B$, which concerns the yoking of animals to do work, separates $M .8: 1 \mathrm{~J}$ and M. $8: 4 C-E+5 A-B$, both of which discuss the mating of animals of diverse-kinds. If M. $8: 1 \mathrm{~J}$ were immediately to be followed by $M .8: 4 C-E+5 A-B$, then the former's prohibition against the mating of animals of diverse-kinds would be augmented with the latter's discussion of the mating of mules, i.e., particular animals of diverse-kinds. M. $8: 1 \mathrm{~J}$ and M. 8:4C-E+5A-B would thus together form a coherent subunit. It is therefore likely that $M .8: 1 \mathrm{~J}$ and $M, 8: 4 \mathrm{C}-\mathrm{E}+5 \mathrm{~A}-\mathrm{B}$ were at one point juxtaposed with one another, and that M. 8:2-4B was later inserted between them. The redactor responsible for this insertion apparently understood M. 8:1J to have a meaning different from that presented above. It is likely that he took the phrase "diverse-kinds of animals" in M. 8:1J to refer not to animals born of the union of different kinds, but simply to 
different kinds of animals. He could not, however, understand M. 8:1J to refer to the mating of such animals with one another, for that act is already prohibited by the rule which $M$. 8:1 J glosses. The redactor therefore took M. 8:1J to concern the yoking together of different kinds of animals to do work, and so attached to it $M .8: 2-4 B$.

M. $3: 2-4 B$ opens with the prohibition against joining together animals of different kinds to do work (M. 3:2), and then turns to two secondary problems. M. 8:3A-C presents a dispute between an anonymous opinion and Meir concerning whether or not one is liable for being passively pulled by animals of different kinds. M. $8: 3 D+4 A-B$ then rules that an animal of one kind may not be attached to any part of a wagon drawn by another kind of animal, for, although the two animals are not actually yoked together, they are still considered to be joined to one another.

M. 3:4C-E+5A-B presents Judah's view that mules born of dams of the same kind may be mated with another. Judah maintains that animals of diverse-kinds themselves form different "kinds" and so may be mated with other members of their own kind. Judah thus opposes M. 8:1J's rule that animals of diverse-kinds may not be mated with each other.

M. $3: 5 C-G$ and M. 8:6 present two lists (respectively containing two and five items, or seven in all) of animals of doubtful status. Although neither list explicitly raises concerns of diverse-kinds, and each is relevant to such other considerations as uncleanness (as indicated by glosses), the context of the lists allows us to interpret them as referring to matters of diverse-kinds. M. 8:5C-G thus concerns whether certain creatures are regarded as wild animals and not as either men (in one case) or creeping things (in the other), and so subject to the rules of diverse-kinds. M. 8:6A-G then considers whether certain animals are regarded as wild or domesticated, i.e., whether certain animals are considered to be diverse-kinds with similar kinds living in a different environment (e.g., the ox and the wild ox). M. 8:6H glosses the list with the rule that man may join together with animals to do work, for the rules of diverse-kinds do not apply to man. Following the language of M. $8: 2$, M. $8: 6 \mathrm{H}$ serves to relate M. 8:6A-G, which implicitly concerns the mating of animals of different kinds, to $M .8: 2$, which discusses the joining together of different kinds to do work, and so ties together the subunit of M. 3:2-6, a good piece of secondary redaction. 
$8: 1$

A. Diverse-kinds of the vineyard [i.e., another kind growing in a vineyard] are prohibited from being sown and being allowed to grow,

B. and are prohibited in respect to benefit [i.e., one may not profit from them in any way.

c. Diverse-kinds of seeds [i.e., two kinds of seeds growing together] are prohibited from being sown and being allowed to grow,

D. but $(w)$ are permitted in respect to eating [i.e., one may eat the produce of the seeds],

E. [most mss. ${ }^{1}$ omit:] and all the more so in respect to benefit [i.e., one may profit from them].

F. Diverse-kinds of garments [i.e., garments composed of a mixture of wool and linen] are permitted in every respect [e.g., one may manufacture them],

G. and are prohibited only from being worn.

H. Diverse-kinds of animals [i.e., the offspring of the mating of two kinds of animals] are permitted to be reared and maintained,

I. and are prohibited only from being bred [following Danby for $\left.m i h r b y^{c}\right]$ [i.e., one may not breed one kind of animal with another].

J. Diverse-kinds of animals [i.e., the offspring of the mating of two kinds of animals] are prohibited [i.e., may not be mated] with one another [zh $b z h ;$ many mss.: $\left.{ }^{2} z h c_{m} z h\right]$.

M. Kil. $8: 1$

M. is a unitary pericope consisting of four rules, $A-B$, C-D (glossed by E), F-G, and H-I (glossed by J). All of the rules open with the formulary pattern $k l^{\prime} y \mathrm{x}$, and all contain a double apodosis composed of one or both of the contrastive predicates 'swr and mwtr. The four rules may be divided into two pairs, for the apodoses of $A-B$ and $C-D$ open with 'swryn, while those of F-G and H-I begin with mwtryn. The rules of each pair also balance one another. $A$ and $C$ are almost identical to each other ( $h k r m v s . z r c y m)$, and B balances D ('swryn bhn'h vs. mwtryn $b^{\prime} k(z h)$. Now $\mathrm{F}$ and $\mathrm{H}$ only roughly correspond to one another (kl'y $\mathrm{x}+$ mwtryn in each), but G closely balances I (mIZbws vs. mIhrbyc), so that these two rules may be considered a pair as well.

M. presents fundamental rules concerning the creation and use of the four different types of diverse-kinds. A-B and C-D 
compare and contrast the case of diverse-kinds of the vineyard with that of diverse-kinds of seeds. According to $\mathrm{A}$ and $\mathrm{C}$ the two cases are similar in that one may neither sow nor maintain either type of diverse-kinds. $B$ and $D$, on the other hand, distinguish between these two instances, maintaining that one may not derive any benefit from diverse-kinds of the vineyard, which are sanctified and must be burnt, while one is permitted to eat the produce of diverse-kinds of seeds, to which the law of sanctification does not apply. We should expect $D$ to balance $B$ and so read mwtryn bhn'h. D, however, reads mwtryn b'kylh, thus making the further point that one may not only derive benefit from diverse-kinds of seeds, e.g., sell them, but one may even eat their produce, and thus use them for the purpose for which they were sown. $E$, which is omitted in most manuscripts, then supplies the expected phrase $b h n ' h$.

F-G states that one is prohibited only from wearing garments of diverse-kinds, and thus follows scripture, which prohibits only the wearing of such garments: Nor shall there come upon you a garment of cloth made up of two kinds of stuff (Lv. 19:19); you shall not wear a mingled stuff, wool and linen together (Dt. 22:11). H-I similarly follows scripture in prohibiting only the breeding of animals of diverse-kinds, for scripture refers only to breeding such animals: You shazl not let your cattle breed with a different kind (Lv. 19:19). H-I thus rules that one may rear and maintain animals of diverse-kinds. Glossing $\mathrm{H}-\mathrm{I}$, $J$ adds that one may not breed animals of diverse-kinds with one another, for such breeding would certainly represent a mating of different kinds.

A. Diverse-kinds of the vineyard are permitted with regard to [the law of] robbery [i.e., one may steal diverse-kinds from another's vineyard] and are exempt from tithes.

$$
\begin{aligned}
& \text { T. Kil. } 5: 1 \text { (p. 221, 1. 1) } \\
& \text { (T. Sheq. } 1: 3 \text { ) }
\end{aligned}
$$

B. Diverse-kinds of seeds are prohibited with regard to [the law of] robbery [i.e., one may not steal diverse-kinds from another's field] and are liable for tithes.

T. Kil. $5: 2$ (p. 221, 11. 1-2)

(T. Sheq. $1: 3^{3}$ )

T. augments $M, 8: 1 A-F$, extending the latter's comparison of diverse-kinds of the vineyard with diverse-kinds of seeds to 
include the considerations of liability for robbery and for tithes. Like M., T consists of well-balanced declarative sentences. The issue of $\mathrm{T}$. concerns whether or not diverse-kinds are regarded as ownerless, so that a robber is not liable for stealing them, and the owner is not obligated to tithe them (as to the latter, cf. M. Hal. 1:3). Diverse-kinds of the vineyard, on the other hand, are sanctified and cannot be used by their owner (M. 8:1B), who is therefore assumed to renounce his rights of ownership over them. 4 Diverse-kinds of seeds, on the other hand, may be eaten by their owner (M. 8:1D). The latter is therefore assumed to want the diverse-kinds for himself, so that they may not be stolen without penalty and are liable for tithes. ${ }^{5}$

A. [Erfurt, Ribmas, sens, and $O Z^{6}$ reverse $A-B$ and $\left.C-D\right] A$ horse which brought forth [a foal of] a kind [resembling] [following Ribmas, sens, and $\mathrm{MB}^{7}$ who read $m y n$ for $m n$; Oz: ${ }^{8}$ kmyn ("[a foal] like") (throughout)] an ass--[the foal] is permitted [to be mated] with its dam [i.e., with a horse].

B. And if its sire was an ass, [the foal] is prohibited [from being mated] with its dam.

c. An ass which brought forth [a foal of] a kind [resembling] a horse--[the foal] is permitted [to be mated] with its dam [i.e., with an ass].

D. And if its sire was a horse, [the foal] is prohibited [from being mated] with its dam.

E. [Erfurt, Ribmas, Sens, and $O \mathrm{Z}^{9}$ reverse $\mathrm{E}-\mathrm{F}$ and $\mathrm{G}-\mathrm{H}$ ] A fattailed sheep which brought forth [a foal of] [Vienna omits, Erfurt and first printed ed. read:] a kind [resembling] a member-goat--[the foal] is pernitted [to be mated] with its dam [i.e., with a fat-tailed sheep].

F. If its sire was a member-goat, [the foal] is prohibited from being mated with its dam.

G. A member-goat which brought forth [a foal of] a kind [resembling] a fat-tailed sheep--[the foal] is permitted [to be mated] with its dam [i.e., with a member-goat].

H. If its sire was a fat-tailed sheep, [the foal] is prohibited [from being mated] with its dam.

I. And [whether a fat-tailed sheep or member-goat only appears to be of a kind different from that of its dam or whether it actually is the offspring of diverse-kinds (Sens, $10 \mathrm{HD}$ )], it is not sacrificed upon the altar.

$$
\text { T. Kil. } 5: 3 \text { (pp. 221-222, 11, 2-7) }
$$


T. complements M. 8:1J, which concerns the mating of one animal of diverse-kinds with another, with a discussion of the mating of such an animal with an animal similar in kind to the former's dam. T. consists of four perfectly balanced sets of rules, $A-B, C-D, E-F$, and $G-H$, each composed of one rule presented in that-which. . . it-is apocopation, and a second stated in a conditional sentence. The four groups form two internallybalanced pairs $(A-B+C-D, E-F+G-H)$, with the second set of each pair reversing the order of animals of the first (horse + ass [A] vs. ass + horse [C], fat-tailed sheep + member-goat [E] vs . member-goat + fat-tailed sheep [G]). I clearly stands outside of the well-balanced construction of $\mathrm{A}-\mathrm{H}$ and thus apparently glosses the entire unit. Since, however, I discusses only those animals which are fit for sacrifices, it relates only to $E-F+G-H$, which alone refers to such animals. Alternatively, I may be read as glossing $\mathrm{H}$ alone.

Each set of rules discusses the -case of an anjmal which, although produced from the union of two animals of the same kind, actually resembles an animal of a kind different from that of its dam. In each instance the issue of $T$. concerns whether such an animal is regarded as being of its dam's kind or as an animal of diverse-kinds. A, for example, states that if a horse gives birth to a foal resembling an ass, the foal may be mated with its dam, i.e., with any horse, for it is considered to be a horse in spite of its appearance. If, however, the foal was sired by an ass, it may not be mated with a horse (B), for now the foal is the offspring of a nating of different kinds. The point of T., then, is that an animal is regarded as being of diverse-kinds only if it is actually produced by the union of different kinds, regardless of its appearance. $C-D$ repeats the rule of $A-B$ but reverses the order of the animals, so that now an ass brings forth a foal resembling a horse. $E-F$ and $G-I I$ then repeat the sequence of $A-B$ and $C-D$, with the fat-tailed sheep and the member-goat, respectively, replacing the horse and the ass.

As we have already mentioned, I apparently glosses the completed unit $E-F+G-H$, and so refers to the member-goat or fattailed sheep which either only appears to be of diverse-kinds or actually is the product of a mating of different kinds (Sens, HD). I thus applies to both apparent and actual instances of diversekinds the rule that animals of diverse-kinds are not fit to be sacrificed (cf. M. Zeb. 9:3, 14:2, M. Tem. 6:1). In not differentiating between those animals which only appear to be of diverse-kinds and those which actually are of diverse-kinds, I 
opposes the principle behind $\mathrm{A}-\mathrm{H}$, which does draw such a distinction. Alternatively, if $I$ is taken to gloss $\mathrm{H}$ alone, then it applies the rule concerning the sacrifice of animals of diverse-kinds to a fat-tailed sheep which actually is of diversekinds, and thus does not oppose the principle of $\mathrm{A}-\mathrm{H}$. If $I$ is to be read in this way, though, it is not clear why I was not also attached to $\mathrm{F}$, for the member-goat does not differ from the fattailed sheep in its fitness for sacrifice. It is more probably that $I$ is to be understood as glossing $\mathrm{E}-\mathrm{H}$, and we therefore prefer the first interpretation given above.

A. When a bulz or ('w) sheep [Vatican Codices 31,66 add: or goat] [is born, it shall remain seven days with its mother; and from the eighth day on it shall be acceptable as an offering by fire to the Lord] (Lv. 22:26)--

B. excluding [an animal of] diverse-kinds.

C. [Vatican codices 31,66 omit C-D] or ('w) goat--

D. excluding [the animal] which appears [to be of diverse-kinds].

Sifra Emor VIII:3a

(ed. Weiss, 99a)

(B. B. $Q .77 \mathrm{~b}$,

B. Hul. 38a, B. Nid. 4la,

B. Bek. 12a, 57a)

Sifra comments on Lv. 22:26, which mentions several different kinds of animals in its discussion of the age at which animals are fit to be sacrificed. A-B considers the word "or" ('w) in the opening of Lv. 22:26 to add nothing to the meaning of the verse, and so takes it to exclude animals of diverse-kinds from among the animals mentioned in the verse, i,e., those animals which are fit to be sacrificed. C-D similarly understands the second "or" in the verse to exclude from the same category those animals which only appear to be of diverse-kinds. Sifra thus agrees with $T$. 5:3I's rule that neither animals which only appear to be of diverse-kinds nor animals which actually are of diversekinds are fit to be sacrificed. Alternatively, the vatican codices read the phrase or goat as part of $A$, and thus take both instances of "or" to exclude the animal of diverse-kinds. According to this reading, then, Sifra discusses only the animal which actually is of diverse-kinds.

A. Koy--they place upon it two stringencies. T. Kil. $5: 4 \mathrm{a}$ (p. 222, 1. 7) 
T. complements M. 8:1I, turning from the latter's general prohibition against breeding animals of diverse-kinds to the special case of the koy. The koy is an animal which is not clearly defined to be either wild (i.e., a hyh) or domesticated (i.e., a bhmh; cf. M. Bik. 2:8). T. relates to M. Bik. 2:11, which states that a koy is considered to be diverse-kinds with both wild and domesticated animals. The two stringencies mentioned in $T$. therefore refer to the dual prohibition against mating a koy with either wild or domesticated animals.

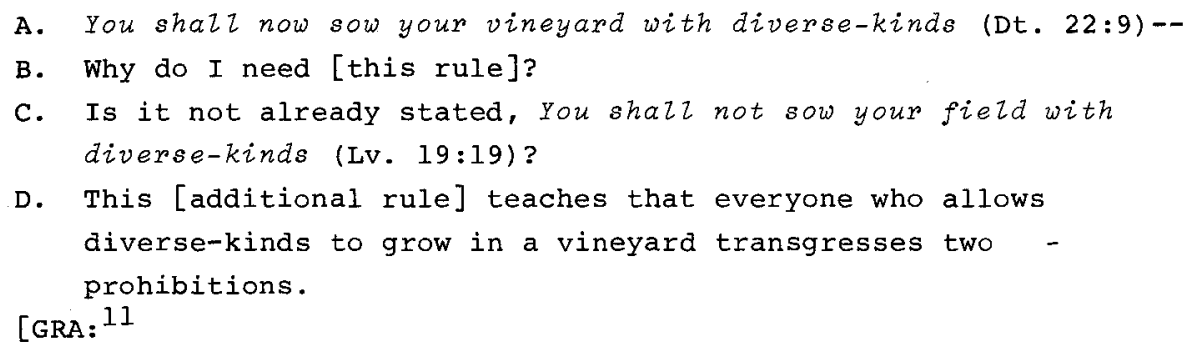

A. Another matter: [You shalz not sow your vineyard with] diverse-kinds (Dt. 22:9).

B. Why is this [rule] stated?

C. Is it not already stated, you shall not sow your field with diverse-kinds (Lv. 19:19)?

D. This [additional rule] is to render [the sower of diversekinds of the vineyard]'liable both an account of [the prohibition of sowing diverse-kinds in] a field and on account of [the prohibition of sowing diverse-kinds in] a vineyard.

E. This teaches that everyone who sows diverse-kinds in a vineyard transgresses two prohibitions.]

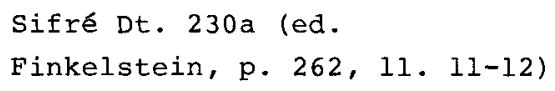

A-C regards as unnecessary Dt. 22:9's prohibition against sowing diverse-kinds in a vineyard, for this rule is considered to be implicit in Lv. 19:19, which prohibits sowing diverse-kinds in a field (which is taken to include a vineyard). D therefore understands Dt. 22:9 to state that one who allows diverse-kinds to grow in a vineyard transgresses two prohibitions, that of having diverse-kinds in a field (Lv. 19:19), and that of maintaining them in a vineyard (Dt. 22:9). D is difficult, for it apparently combines two separate answers to the question of $\mathrm{A}-\mathrm{C}$, viz., that the verse refers to one who allows diverse-kinds to grow, and that the sower of diverse-kinds in a vineyard transgresses 
two prohibitions. Alternatively, GRA presents a less problematic reading of sifre, ${ }^{12}$ in which the verse is taken to state that the sower of diverse-kinds transgresses two prohibitions.

YY. Another matter: [You shall not sow your vineyard with] diverse-kinds (Dt. 22:9)--

$\mathrm{zz}$. This [phrase] is to render. [the sower of diverse-kinds in the vineyard] liable both on account of [the prohibition of sowing diverse-kinds in] a vineyard and on account of [the prohibition of sowing diverse-kinds in] a field.

Sifre Dt. 2301

(ed. Finkelstein, p. 264,

1. 2)

Sifré considers the phrase diverse-kinds in Dt. 22:9 to be unnecessary, for one who sows a vineyard clearly sows diverse kinds. Diverse-kinds is therefore understood to refer to the prohibition of sowing diverse-kinds in a field (which is taken to include a vineyard; Lv, 19:19), so that one who sows a vineyard is liable on account of this rule as well as the prohibition of sowing diverse-kinds in a vineyard. The pericope is similar in substance to sifré Dt. 230a, differing only in basing its exegesis on the phrase diverse-kinds, rather than on the entire verse, and in reading the verse to refer to the sower of diverse-kinds, rather than to one who allows them to grow. 13

AAA. [You shall not sow your vineyard with diverse-kinds, lest the whole yield be sanctified, the cropl which you have sown [and the yiezd of the vineyard] (Dt. 22:9)--

BBB. I know [that he is liable] only [in the case] that he [himself] sowed.

ccc. Whence [do I know that one is liable if] his neighbor sowed [another kind in the former's vineyard] and he [i.e., the owner] wanted to allow it to grow?

DDD. Scripture says, You have sown (tzre; GRA: hzre ["the crop"])--under all circumstances.

Sifré Dt. 230 n (ed. Finkelstein, ${ }^{14}$ p. $264,11.3-4$ )

AAA-BBB understands the phrase which you have sown (Dt. 22:9) to mean that one is prohibited only from actually sowing diversekinds in a vineyard. CCC-DDD then takes the phrase you have sown to prohibit one from maintaining diverse-kinds sown in his 
vineyard by someone else. It is not clear, however, how sifré can read the same phrase, you have sown, to yield two opposing rulings at $A A A-B B B$ and $C C C-D D D$. GRA therefore reads the crop $\left(h z r^{c}\right)$ for you have sown $\left(t z r^{c}\right)$ at DDD. ${ }^{15}$ According to this reading $C C C-D D D$ understands the phrase the crop to include all crops which are sown in the vineyard, whether or not they are sown by the owner of the vineyard himself. Sifre thus agrees with M. 8:1A that one may not allow diverse-kinds to grow in a vineyard.

$\mathrm{J}$. Whence [do we know that] diverse-kinds of the vineyard are prohibited in respect to benefit?

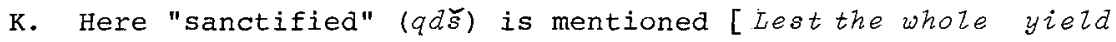
be sanctified (Dt. 22:9)] and there "sanctified" (qd $\bar{s}$ ) is mentioned [If any one commits a breach of faith and sins unwittingly in any of the holy things (qday) of the Lord (Lv. 5:15) (Hillel)].

L. Just as [the phrase] "sanctified" mentioned there [refers to that which] is prohibited in respect to benefit, so [the phrase] "sanctified" mentioned here [refers to that which] is prohibited in respect to benefit.

$$
\begin{aligned}
& \text { Sifré Dt. } 230 \mathrm{c} \text { (ed. Finkelstein, } \\
& \text { p. } 263,11.1-3 \text { ) (Y. Kil. } \\
& 8: 1(31 \mathrm{~b})^{16} \text { ) }
\end{aligned}
$$

Sifre bases the rule that one may not benefit from diversekinds of the vineyard on an analogy (gezerah shavah) between the use of the root $q d \breve{s}$ in Lv. 5:15 (Hillel) and the use of the same root in Dt. 22:9. Just as one may not use those items which are dedicated to God and thus regarded as sanctified, so one may not derive benefit from diverse-kinds of the vineyard, which are also said to be sanctified. Sifre thus agrees with M. 8:IA's rule that one is prohibited from deriving benefit from diverse-kinds of the vineyard.

\footnotetext{
A. Your field you shall not sow [with diverse-kinds] (Lv. 19:19) --

B. I know only that he should not sow [diverse-kinds].

C. Whence [do I know that] he should not allow [diverse-kinds] to grow?

D. Scripture says, Not.. . diverse-kinds.
} 
E. [B, M.Q., B. Mak., B. A.Z., GRA omit:] I have said [this] only on account of [the law of] diverse-kinds.

Sifra Qedoshim 4:16

(ed. Weiss, 89a)

(B. M.Q, 2b, B. Mak, $21 \mathrm{~b}, 17$

B. A.Z, 74a; cf. Y, Kil $8: 1$

(31b))

Sifra deduces the prohibition of allowing diverse-kinds to grow in a field from the word-order of LV. 19:19. Since not precedes diverse-kinds as well as sow, it is taken to be read with the former as well as with the latter (D). The verse is thus understood to state not only that one may not sow diverse-kinds (as it explicitly rules $[A-B]$ ), but also that one may not have diverse-kinds in his field, i.e., allow diverse-kinds to grow $\left(Q^{18}\right)$. E explains that the point of the verse is to prohibit the growing of diverse-kinds rather than the particular act of sowing them $(Q A)$. Sifra thus agrees with M. $8: 1 C^{\prime} s$ rule that one may not allow diverse-kinds of seeds to grow.

A. Were it stated [only], You shall not let your cattie breed [Vatican Codices 31,66, B. B, M, , Hillel, GRA omit: with a different kind] (2' trbyc bhmtk) (Lv. 19:19), one might think that he should not take hold of the [female] domesticated animal and make it stand before the male [domesticated animal so that they may mate] [B. B.M.: I might say that a man should not hold [down] the [female] domesticated animal when the male [domesticated animal] mounts her].

B. Scripture says, With a different kind--

C. I have said [this] to you only on account of [the law of] diverse-kinds.

\author{
Sifra Qedoshim $4: 13$ \\ (ed. Weiss, 89a) \\ (B. B.M. 9la; cf: Y. Kil. 8:2)
}

According to $A^{19}$ the phrase you shall not let your cattze breed could be understood to mean that one may make a female animal stand before a male animal so that they may mate. B-C thus explains that the phrase with a different kind was included to prohibit not the holding of the female animal during mating, but the mating of animals of diverse-kinds. 
[A. You shall not let your cattle breed with a different kind (Lv. 19:19).]

B. I know only [that you may not make] your [own] domesticated animal [mount] on your [own] domesticated animal.

c. Whence [do I know that you may not make] your [own] domesticated animal [mount] on a domesticated animal of others, [nor make] a domesticated animal of others [mount] on your [own] domesticated animal?

[GRA omits "whence," and so reads: [nor] your [own] domesticated animal on a domesticated animal of others, nor a domesticated animal of others on your [own] domesticated animal.]

D. Whence [do I know that you may not make] a domesticated animal of others [mount] on a domesticated animal of others?

E. Scripture says, You shall keep my statutes (Lv. 19:19).

Sifra Qedoshim $4: 14$

(ed. Weiss, 89a)

B understands the phrase your cattle in Lv. 19:19 to mean that one is prohibited from mating animals of different kinds with one another only when both animals are one's own. C-E then takes the clause you shall keep all my statutes to imply that the prohibition covers all matings of animals of different kinds, including those instances in which either only one of the animals is one's own or both animals belong to someone else. 20

Alternatively, according to GRA's reading your cattle is taken to include all cases in which at least one of the animals is one's own. The clause you shall keep my statutes is then understood to include the mating of another's animals of different kinds.

$3: 2$

A. (1) A domesticated animal with a domesticated animal,

(2) and a wild animal with a wild animal,

(3) a domesticated animal with a wild animal,

(4) and a wild animal with a domesticated animal,

B. (1) an unclean [animal] with an unclean [animal],

(2) and a clean [animal] with a clean [animal],

(3) an unclean [animal] with a clean [animal],

(4) and a clean [animal] with an unclean [animal],

c. are [each] prohibited [from being joined together] to plow, draw ( $(m \bar{s} w k)$ [e.g., a wagon], or be led (2hnhyg).21

M. Kil. $8: 2$ (C: Gn. R. $7: 4$ ) 
M. $8: 2$ continues M. $8: 1 \mathrm{H}-\mathrm{J}^{\prime} \mathrm{s}$ discussion of the pairing of animals of different kinds, turning from the issue of the mating of such animals to the question of joining them together to do work. M. consists of a two-part protasis, A-B, served by the apodosis at $C$. A and $B$ balance one another and are internally balanced as well, for each lists four pairs of animals in the sequence $a+a / b+b / a+b / b+a$.

M. presupposes the rule of Dt. 22:10, You shall not plow with an ox and an ass together. According to A-B this prohibition includes all possible pairings of wild and domesticated or clean and unclean animals. ${ }^{22} \mathrm{C}$ rules that one is prohibited not only from plowing with such pairs of animals, but also from having them draw objects and from leading them together, that is, from having them do any work at all.

[A. You shall not let your cattle (bhmh) breed with a different kind (Lv. 19:19).]

B. I know only that [one may not let] a domesticated animal $(b h m h)$ [mount] on a domesticated animal $[=M .8: 2 A(i)]$.

c. Whence $[$ do $I$ know that one may not let $]$ a domesticated animal [mount] on a wild animal nor a wild animal [mount] on a domesticated animal? [GRA omits "whence" and so reads: (nor) a domesticated animal on a wild animal nor a wild animal on a domesticated animal $][=M \cdot 8: 2 A(3)-(4)]$

D. Whence $[$ do $\mathrm{I}$ know that one may not let] an unclean [animal mount] on a clean [animal] n nor a clean [animal] on an unclean [one $][=\mathrm{M}$. $8: 2 \mathrm{~B}(3)-(4)]$ ?

E. Scripture says, you shall keep my statutes (LV. 19:19).

Sifra Qedoshim 4:15

(ed. Weiss, 89a)

Sifra cites M. $8: 2 A(1)$ at B, M. $8: 2 A(3)-(4)$ at $C$, and M. $8: 2 B(3)-(4)$ at D. Unlike M., however, Sifra concerns not the joining of animals of different kinds to do work, but the mating of such animals with one another. A-B takes LV. 19:19, which refers to the $b h m h$, to prohibit the mating of different kinds of domesticated animals alone. C-E then understands the clause you shall keep my statutes to include in the prohibition the mating of all animals of different kinds, and thus to prohibit the mating of both domesticated with wild animals and clean with unclean animals. Alternatively, according to GRA's reading A-C understands Lv. 19:19 to refer to all matings which involve at least one domesticated animal. The clause you shall keep my 
statutes is then understood to include in the prohibition the matings of clean with unclean animals alone.

[TT. You shall not plow with an ox and an ass (Dt. 22:10).]

UU. One might think that [the prohibition] "he shall not plow" refers to [plowing with] this [animal] by itself and that [animal] by itself.

vV. Scriptures says, Together--

ww. But [plowing with] this [animal] by itself and that [animal] by itself is permitted.

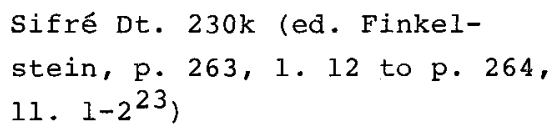

TT-UU states that if Scripture were to read simply You shall not plow with an ox and an ass, one could understand it to mean that it is prohibited to plow at all with either animal. Scripture therefore adds together, and thus prohibits plowing only with both animals together, but not with each animal separately (VV-WW).

A. You shazl not plow with an ox and an ass [Hillel omits:] together (Dt. 22:10)--

B. One might think [that the prohibition of plowing with an ox and (i.e., or) an ass applies] under all circumstances $\left(2^{c} w \tau_{m}\right)$.

c. Since $(k)$ it [i.e., Scripture] states, [Six days you shatl do your work, but on the seventh day you shall rest;] that your ox and your ass may have rest (Ex. 23:12), [we] already [know that] an ox and [i.e., or] an ass do work [during the rest of the week (Hillel)].

D. If so, why is it stated, you shall not plow with an ox and an ass?

E. [To prohibit working the animals] with one another.

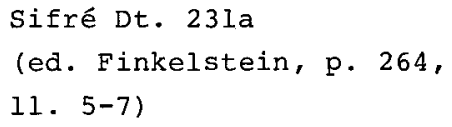

A-B states that the clause You shall not plow with an ox and an ass could be understood to mean that it is prohibited to plow with either animal under any circumstances (cf. Sifre Dt. 230k, above). According to $C$, however, Ex. 23:12, which rules that one must rest his ox and ass on the sabbath, implies that one is 
permitted to do work with these animals during the rest of the week (Hillel). D-E therefore states that the clause cited in $\mathrm{A}$ can mean only that it is prohibited to plow with both animals together, as the last word in the verse, together, in fact indicates (Hillel).

\section{$8: 3$}

A. He who leads [a pair of animals of different kinds] incurs [so Danby for swpg; 1it.: absorbs] the forty lashes.

B. And he who sits in a wagon [drawn by a pair of animals of different kinds] incurs the forty [lashes].

C. R. Meir exempts [one sitting in the wagon from the forty lashes ].

D. And a third [anima]] which is tied to the harness [so Danby for $\left.r s w^{c} w t\right]$ of a wagon drawn by a pair of animals of another kind] is prohibited.

M. Kil. $8: 3$

$(A-C: B \cdot B \cdot M \cdot 8 b)$

M. $8: 3$ continues M. $8: 2$ 's interest in the question of pairing animals of different kinds to do work. The opening word of M. 8:3, in fact (hmnhyg), has the same root (nhg) as the closing word of M. 8:2. M. opens with A-B, a pair of nearly identical declarative sentences (differing only in their respective subjects) hmnhyg vs. hywšb bqrwn. Meir then glosses and opposes $B$ at $C$. D, which depends on $B$ for its context (the drawing of a wagon by animals), augments the latter with a separate rule following a different formulary pattern (that-which + 'swrh). According to $A-B$ one who leads a pair of animals of different kinds and one who merely sits in a wagon drawn by such a team are both liable for forty lashes. The point of $A-B$ is that one may not make any use of a pair of animals of different kinds, whether one actually leads the animals and thus forces them to work together, or whether one merely sits as a passenger in a wagon drawn by such animals. Meir disagrees at $C$, maintaining that, since the passenger in the wagon does not overtly act to lead or direct the animals together, he is not liable for the forty lashes.

D supplements $B$, which concerns a wagon drawn by animals of different kinds, with a case in which a wagon is drawn by animals of a single kind, but a different kind of animal is attached to the harness, presumably so that it will not stray. D rules that one may not tie the third animal to the other two in this manner. 
Although the third animal does not actually pull the wagon together with the team (since it is not harnessed to the wagon itself), it nevertheless moves along with the animals of the other kind and so is considered to be joined with the latter. The point of $D$, then, is that animals which are attached to one another are considered to be joined together, whether or not the animals actually function as a team and work together.

L. You shall not plow [with an ox and an ass together] (Dt. $22: 10)--$

M. I know only [that this rule applies to] one who plows.

$\mathrm{N}$. Whence [do I know] to include one who (1) threshes, (2) sits [in a wagon], or (3) leads [a pair of animals]?

o. Scripture says, Together--under all circumstances.

P. R. Meir exempts [from liability] one who sits [in a wagon drawn by a pair of animals of different kinds $][=$ M. $8: 3 \mathrm{C}]$.

Sifré Dt. $231 \mathrm{c}$ (ed.

Finkelstein, p. 264, 11. 11-12)

According to I-M Dt. 22:10 prohibits the pairing of animals of different kinds only for the purpose of plowing, for this is the sole activity explicitly mentioned in the verse. N-O then deduces from the word "together" that one may not join animals of different kinds for any purpose, so that one may neither thresh with them, sit in a wagon drawn by them, nor lead them. N $(2)-(3)$ thus agrees with M. 8:3A-B, which states that one who leads a pair of animals of different kinds or sits in a wagon drawn by such a pair is liable for forty lashes. P cites Meir's opposing view (M. 8:3C), which maintains that a passenger in a wagon drawn by such a pair of animals is not liable, since the passenger himself does not lead or direct the animals.

$8: 4$

A. They do not tie a horse either to the sides of a wagon or to the rear of a wagon [drawn by a pair of animals of another kind],

B. nor [do they tie] a Libyan ass [so Jastrow, Danby, for lwbdqs$\left.s^{24}\right]$ to camels.

C. R. Judah says, "All offspring of a [female] horse, even though their sires are ass[es], are permitted with one another.

D. "And so ( $w k n$; most mss.: ${ }^{25}$ wkz ["All"]) offspring of a [female] ass, even though their sires are horse[s], are permitted with one another. 
E. "But the offspring of a [female] horse with [i.e., and] the offspring of a [female] ass are prohibited with one another."

M. Kil. $8: 4$ (C+E: B. Hul. 79a)

M. consists of two autonomous parts, A (glossed by B) and $C-E$. The two sayings discuss entirely separate issues, for $A-B$ continues M. 8:3D's discussion of an animal tied to a wagon drawn by another kind, while C-E presents a saying of Judah concerning the pairing of different kinds of mules. $A-B$ and $C-E$, in fact, need not relate to the same prohibitions at all. Unlike $A-B$, $C-E$ does not explicitly refer to the joining of animals to do work, and thus probably concerns the mating of animals with one another. There are two possible views concerning the relationship of C-E to A-B. As we shall see, Judah's saying apparently belongs after M. 8:lJ ( $\mathrm{CF}$. MR), which prohibits the mating of animals of diverse-kinds (i.e., animals born of a union of different kinds) with each other. On the other hand, by juxtaposing $A-B$ and $\mathrm{C}-\mathrm{E}$ the redactor perhaps indicates that he understands $\mathrm{C}-\mathrm{E}$ to refer to the joining of mules (i.e., the product of the union of horses and another kind) to do work, and thus to complement $A-B$, which concerns the joining of a horse to animals of another kind.

A concerns a case in which one wishes to tie a horse to the side or rear of a wagon, presumably so that the horse will not stray. According to A one may not attach the horse to the wagon in this manner if the wagon is drawn by an animal (or animals) of another kind. The point of A, like that of $M .8: 3 D$, is that, although the horse does not actually help draw the wagon, it is still attached to the latter and moves with it, and so is considered to be joined with the animal of the other kind. $B$ adds that one may not tie a Libyan ass to camels in order to lead them or have them pull a load (Lieberman ${ }^{26}$ ), even though these animals do not work together well. B thus complements A with another case in which animals are considered to be joined with one another even though they do not actually work together as a team.

At C-E Judah discusses the pairing of mules with one another. According to Judah two mules which were born of dams of a single kind (and, of course, of sires of a single kind as well) may be paired with one another (C-D), for these animals themselves form a single "kind." If, on the other hand, the mules were born of dams of different kinds, they do not share a similar parentage and are not regarded as belonging to a single 
"kind." In this instance, therefore, the pairing of mules would be a pairing of different kinds, and thus would be prohibited (E). If Judah here refers to the mating of mules, he may be regarded as qualifying $M$. 8:1J, which states that animals of diverse-kinds may not be mated with another. Judah maintains that animals of diverse-kinds themselves form "kinds" according to parentage, so that animals of diverse-kinds belonging to the same "kind" may be mated with one another.

A. They do not tie a horse either to the sides of a wagon or to the rear of a wagon [drawn by a pair of animals of another kind],

B. nor [do they tie] a Libyan ass to camels [= M. 8:4A-B].

C. R. Meir permits [Y.: exempts (from liability)].

D. If they [i.e., the horse or the Libyan ass] aided (msycyn; Erfurt, first printed ed.: $m s y y^{c} y n$ ) [the other animals] in descending and ascending, all agree that it [i.e., tying the horse to the wagon or the Libyan ass to camels] is prohibited.

$$
\begin{aligned}
& \text { T. Kil. } 5: 4 \mathrm{~b}(\mathrm{p}, 222,11.7-9) \\
& \text { (Y. Kil. } 8: 3 \text { (3lc)) }
\end{aligned}
$$

$A-B$ cites M. 8:4A-B, which Meir then glosses and opposes at C. The issue of the dispute concerns whether one is prohibited from joining together animals of different kinds even if they do not work together as a team. As we have already seen, A-B rules that one may not tie either a horse to a wagon or a Libyan ass to camels, even though in each case the two kinds do not work together. Meir, on the other hand, permits one to join together the different kinds mentioned in $A-B$, maintaining that one is prohibited only from having animals of different kinds actually work together. D then glosses $A-C$, saying that, if the animals aid each other in ascending or descending (e.g., the horse pushes the wagon uphill or slows its descent [PM], or the Libyan ass and the camels pull each other along [following Lieberman ${ }^{27}$ ]), then Meir agrees that they may not be joined, for now they do function as a team. D thus serves to underline the fact that the issue of the dispute deals with animals of different kinds which are attached to one another but do not actually work together.

A. One should not tie (1) a horse to a mule, nor (2) a mule to an ass, nor (3) an ass to an Arabian onager $[=\mathrm{M} .1: 6 \mathrm{~A}(5)-(7)]$,

B. because they lead one another along.

C. If he did so-- 
D. R. Meir declares [him] liable,

E. and sages exempt.

F. R. Judah says, "The [mule-]offspring of a female horse and the [mule-]offspring of a female ass, [GRA ${ }^{28}$ omits:] [when used] as one [i.e., together (Lieberman ${ }^{29}$ )], prohibit [Erfurt: are prohibited with] one another."

G. And sages say, "All mules are [regarded as belonging to] a single kind."

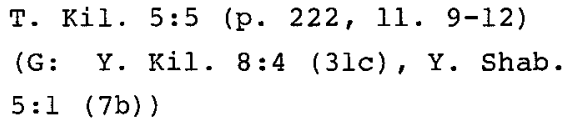

T. complements $M$. $8: 4$, with $A-E$ referring to $M .8: 4 A-B$ and $F-G$ augmenting $M .8: 4 C-F$. $A-B$ cites and glosses $M .1: 6 A(5)-(7)$, a sublist consisting of three pairs of animals. According to M. 1:6 the members of each pair are considered to be diverse-kinds with one another even though they resemble each other. A rules that one may not tie one member of a pair to another, and thus has the sublist, which in the context of $M .1: 6$ refers to the mating of animals of different kinds, deal with M. 3:3's issue of joining together different kinds of animals. B, which perhaps glosses $A$, then explains that in each case the two members of the pair tend to lead each other along, so that the animals of different kinds actually work together. B therefore follows Meir's view (T. $5: 4 \mathrm{~b} / \mathrm{C}$ ) that one is prohibited from joining together animals of different kinds only if they actually function as a team. A-B thus complements $M .8: 4 \mathrm{~A}-\mathrm{B}$, which prohibits one from joining together animals of different kinds under all circumstances, by illustrating Meir's opposing position.

C-E supplements A-B with a balanced (hyyb vs. $p t w r$ ) dispute between Meir and sages. The dispute deals with the liability of one who actually joins together two members of one of A's pairs. The issue of the dispute is not clear, but it may concern whether the actual joining of animals of different kinds or only the appearance of such a joining ultimately determines liability. Meir maintains that, since the members of each pair are actually considered to be diverse-kinds with one another, one is liable for joining them together. Sages, on the other hand, say that since the animals belong to the same family (Equus) and resemble one another (M. 1:6), one who ties one to the other does not appear to join together animals of different kinds. Sages therefore rule that, although one may not join together such a pair of animals at the outset, one is not liable for actually doing so. 
F-G complements Judah's saying of M. 8:4C-E with a dispute between Judah and sages concerning whether or not mules may be divided into different kinds according to parentage. In $F$ Judah restates his view of $M .8: 4 C-E$, this time with reference to the question of joining animals together. T. thus links M. 8:4C-E to $M$. 8:4A-B, which also discusses the issue of joining animals together to do work. Alternatively, according to GRA's reading (omitting "as one") F, like M. 8:4C-E, refers to no particular prohibition of diverse-kinds. In any event, Judah states that mules may be classified into two categories, those mules born of a female horse and those born of a female ass, with each kind of mule considered to be diverse-kinds with the other. At G sages disagree, maintaining that one does not take account of differences in the parentage of mules, so that all mules are considered to belong to a single kind, defined as consisting of all animals born of the union of a horse and an ass.

A. Isi the Babylonian says, "It is prohibited to ride on the back of a mule,

B. "[as we learn] from an argument a fortiori: If, in a case in which it is permitted to wear two garments [i.e., one of wool and one of linen] as one [i.e., together], lo, he [Erfurt: it] is prohibited in respect to [wearing a garment composed of] their mixture [i.e., a mixture of the two materials], in a case in which it is prohibited to lead two animals [of different kinds] as one [i.e., together], is it not logical that it should be prohibited in respect to [using an animal composed of] their mixture [i.e., a mixture of the two kinds of animals]?"

c. They said to him, "Lo, it [i.e., Scripture] says, [Take with you the servants of your lord,] and cause solomon my son to ride on my own mule, and bring him down to Gihon (I Kings $1: 33)$."

D. He said to them, "They do not respond from Tekoa [i.e., they do not rule on the basis of the practices of townspeople (e.g., David, who was not a legal authority)]."

E. They said to him, "Lo, it [i.e., Scripture] says, And David did what was right in the eyes of the Lord, and did not turn aside from anything that he commanded him alz the days of his life, except in the matter of Uriah the Hittite (I Kings 15:5)."

T. Kil. 5:6 (pp, 222-223, 11 .

12-19) (Y. Kil. $8: 2(31 c)^{30}$ ) 
T. augments T. 5:5's interest in the joining of mules to other kinds with a discussion of the permissibility of riding on a mule. T. consists of a saying of Isi the Babylonian at A, followed by a debate between Isi and anonymous authorities at $B-E$. The anonymous authorities are given the last word at $E$ and thus are allowed to win the debate.

At A Isi states that one may not ride on the back of a mule. He thus opposes M. 8:IH-I, which rules that one is prohibited only from breeding animals of diverse-kinds. Isi then supports his position at $B$ with an argument a fortiopi in which he compares the prohibition of diverse-kinds of animals to that of diversekinds of garments. Isi reasons that if, in the case of diversekinds of garments, where one is permitted to wear garments of different kinds together (i.e., one on top of the other), one is prohibited from wearing a garment composed of a mixture of two kinds, in the case of diverse-kinds of animals, where one may not join together animals of different kinds, one should surely be prohibited from using an animal born of the union of two kinds. The anonymous authorities reply at $c$, not by responding to the argument at $B$, but by citing a scriptural verse (I Kings 1:33) which tells that David ordered Solomon to be taken to Gihon on his (i.e., David's) mule. Isi answers at D with the curious expression, "They do not respond from Tekoa." Referring to the small town southeast of Jerusalem, this saying apparently means that the actions of people of a small town are not considered to be authoritative. In this case, then, the point of Isi is that the actions of David, who was not a legal authority, cannot be cited as precedent. ${ }^{31}$ At E Isi's opponents cite I Kings 15:5, which states that David's only transgression occurred in the case of Uriah the Hittite. The verse thus implies that all of David's other actions, including his order to have solomon ride on a mule, were correct. David's actions thus do establish an authoritative precedent, and the anonymous authorities win the debate.

\footnotetext{
S. [You shall not plow with an ox and an ass] together (Dt. $22: 10)--$

T. Excluding one who ties a horse to the sides of the wagon or to the rear of the wagon,

U. and [one who ties] a Libyan ass to camels [= M. $8: 4 \mathrm{~A}-\mathrm{B}]$.

Sifré Dt. 23le (ed. Finkelstein, p. $264,11.12-13$ )
} 
Sifré cites M. $8: 4 \mathrm{~A}-\mathrm{B}$ at T-U, linking it to Dt. $22: 10$ (=S). The phrase together in Dt. 22:10 is taken to indicate that the verse's prohibition of joining together animals of different kinds applies only if the animals actually work together as a team. This phrase thus excludes from the prohibition the cases of $M$., for neither the horse and the animal pulling the wagon nor the Libyan ass and the carnels work together and function as a team. Sifré thus disagrees

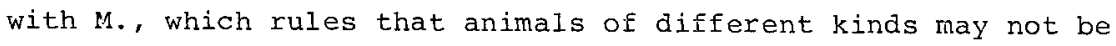
joined together even if they do not work well as a teara.

\section{$8: 5$}

A. Mules of unknown parentage [following Sens for prwtywt; alternatively: mules (Maim., Comm.)] are prohibited [from being mated with one another].

B. But $(w)$ a mule foaled by a horse [so Danby (following Bert.) for rmk; alternatively: a wild horse (Maim., Comm.; cf. also Code, Diverse-Kinds 9:5)] is permitted [to be mated with a like animal].

c. (1) And "wild men" [so Danby for 'dny $h \xi d h$ ] are [considered a kind of] wild animal.

D. R. Yose says, "[When dead] they convey uncleanness in a tent like a man."

E. (2) A hedgehog ( $q p d$ ) and (3) a weasel ${ }^{32}$ (hwldt hsnyym) are [each considered a kind of] wild animal.

F. The weasel--

G. R. Yose says, "House of Shammai say, '[When dead] it conveys uncleanness in an olive's bulk by being carried, and in a lentil's bulk by contact [to the person touching it].'"

M. Kil. $8: 5$

M. consists of two autonomous parts, $A-B$ and $C-G$. The former continues $M .8: 4 C-E$ 's discussion of the mating of mules with one another, while the latter opens a new subunit, continued at $M .8: 6$, concerning whether or not certain creatures are regarded as wild animals.

A-B is composed of two declarative sentences with contrasting apodoses ('swr vs. mwtr [Cf. M. 8:4C-E]). The two sentences differ, however, in that the subject of $\mathrm{A}$ appears in the plural while that of $B$ is presented in the singular. A and $B$ do not appear originally to have been formulated together as a unit. A states that one may not pair prwtywt together, with $B$ adding that one may mate a rmk with an animal of the same kind. Now the identification of these two animals is not clear. According to one interpretation the term prwtywt refers to mules of unknown parentage, and a rmk is a mule born of a female horse (Bert. [following sens ${ }^{33}$ in first instance; cf. also TYY]). The point of $A$, therefore, is that mules of unknown parentage may not be mated with one another, lest a mule born of a female horse 
be paired with one born of a female ass. B then complements A with the rule that mules born of dams of the same kind may be mated with each other. A-B thus illustrates Judah's view (M. $8: 4 C-E$ ) that only mules of similar parentage may be mated with one another. Alternatively, llaimonides (Comm.) explains that prwtywt refers to mules of any parentage, and that a rmk is a kind of wild horse. According to this interpretation $A$ maintains that mules may not be mated with each other at all, with $B$ adding that pairings of wild horses are permitted. ${ }^{34}$ A thus follows M. 8:1J's rule that diverse-kinds of animals may not be mated with one another, and $B$ then adds the obvious rule that animals of the same kind may be mated with each other (PM). A-B then augments Judah's view of M. $8: 4 \mathrm{C}-\mathrm{E}$ by presenting the opposing view of M. $8: 1 \mathrm{~J}$.

C-G concerns certain animals of doubtful status. The pericope consists of a three-item list composed of $C$, discussing a creature which may be regarded as either a man or a wild animal, and $E$, concerning whether two different animals are considered either creeping things or wild animals. Yosé then respectively glosses each part of the list at $D$ and $F-G$, introducing in each instance the consideration of uncleanness. We note that C+E itself need not concern issues of diverse-kinds, for the determination of an animal's status is relevant to other issues as well, as Yosé's glosses indicate. In placing $C-G$ in the context of a discussion of diverse-kinds, however, the redactor implies that he understands the pericope to concern whether or not the specified animals are considered to be wild animals, and thus, unlike men or creeping things, to be subject to the laws of diverse-kinds.

C discusses the "wild man," which is apparently an ape-like creature resembling a human being. ${ }^{35}$ According to $\mathrm{C}$ the "wild man" is regarded as a wild animal, so that (in this context) the laws of diverse-kinds apply to it. At D Yosé qualifies C, maintaining that, like a man, the "wild man" conveys uncleanness in a tent (cf. M. Kel. 1:4). According to Yose, then, the "wild man" is not treated simply as a wild animal, for, at least in regard to matters of uncleanness it is regarded as a man.

E states that the hedgehog and the weasel are regarded as wild animals. The point of $\mathrm{E}$ apparently is that even though these animals crawl on the ground and thus could be considered creeping things, they are actually considered to be wild animals, perhaps because both are animals of prey. ${ }^{36}$ yosé then glosses $E$ with F-G, which consists of a superscription and a saying of House of Shammi, and so appears to be a defective Houses-dispute. House of Shammai maintain that, like a wild animal, a dead weasel conveys uncleanness in an olive's bulk by being carried (cf. $M$. Kel. 1:2, M. Oh. 1:7). In this regard a weasel is not considered 
a creeping thing, which, when dead, does not convey uncleanness in this manner at all (M. Kel. $1: 1$ ). The weasel is regarded as a creeping thing, however, in that its carrion conveys uncleanness in a lentil's bulk by contact (i.e., when a person touches it; cf. M. Kel. 1:1, M. Oh. 1:7). The weasel differs in this respect from the wild animals, the carrion of which does not convey uncleanness by contact (M. Kel. 1:2). House of Shammai thus hold that, since the weasel is of doubtful status and may be regarded either as a creeping thing or a wild animal, it is subject to the stringencies of both categories. By citing House of Shammai's opinion Yosê qualifies $E$, maintaining that, as in the case of $C$, the specified animals are not regarded simply as wild animals, but are actually considered to belong to two separate classes.

Q. [You shall not plow with an ox and an ass] together (Dt. 22:10)--

R. Excluding the mule foaled by a horse ( $r m k$; alternatively: the wild horse; GRA: prd ["the mule"]).

Sifré Dt. 23ld (ed. Finkelstein, p. 264, 1. 12)

Sifre takes the word together in Dt. 22:10 to exclude from the verse's prohibition the rmk, or the mule born of a female horse, presumably because this animal will not work together with animals of other kinds. Sifre thus agrees with Meir (T. 5:4b) that it is prohibited to join together animals of different kind only when the animals actually function as a team. It is not clear, however, why sifre should exclude from the prohibition only a specific kind of mule, and GRA therefore reads prd, which refers to any kind of mule, in place of $r m k$ at $R$. Alternatively, if rmk refers to a kind of wild horse, then sifre's point again is that such an animal will not work well with other animals and so may be joined with them. Sifre thus agrees with M. 3:5B that the rmk may be paired with a second animal. Sifre, however, relates M., which concerns the mating of animals, to the prohibition of joining together animals of different kinds to do work. sifre thus refers to pairing the rmk not with another animal of the same kind (as in M.), but with a different kind of animal.

\section{$8: 6$}

A. (1) A wild ox is [considered] a kind of domesticated animal.

B. And R. Yose says, "[It is considered] a kind of wild animal."

C. (2) A dog is [considered] a kind of wild animal.

D. R. Meir says, "[It is considered] a kind of domesticated animal."

E. (3) A swine is [considered] a kind of domesticated animal.

F. (4) An Arabian onager is [considered] a kind of wild animal. 
G. (5) An elephant and a monkey are [considered] kind[s] of wild animal[s].

H. And a man is permitted [to be joined] with all of them [i.e., with either a wild or domesticated animal] to pull [e.g., a wagon], plow, [some mss., 37 B. Shab., B. B.Q., TYT, and MS reverse the order of the preceding verbs and omit:] or be led.

$$
\begin{aligned}
& \text { M. Kil. } 8: 6 \text { (A-B: B. Sanh. } \\
& \text { 25b, B. Hul. } 80 a ; \text { H: B. Shab. } \\
& 54 a, \text { B. B.Q. } 54 b \text { ) }
\end{aligned}
$$

M. continues M. 8:5C-G's discussion of animals of doubtful status. While M. $8: 5 C-G$ concerns whether certain animals are regarded as either men or creeping things, on the one hand, or wild animals, on the other, M. 8:6 turns to discuss those creatures which may be considered either wild or domesticated animals. M. consists of a list of five items at $A+C+E-G$, with $A$ and $C$ respectively glossed and opposed by Yosé and Meir at $B$ and $D$. H glosses the entire list with a rule concerning man. The list of six animals (presented as five items) may be divided into two sublists, $A+C+E-F$, a catalogue of four items which repeats the formulary pattern $\mathrm{x}+b h m h / \mathrm{y}+h y h$, and $\mathrm{G}, \mathrm{a}$ sentence consisting of a compound subject. In addition, the apodoses of the first sublist, together with those of the glosses of Yosé and Meir, follow the pattern ab/ba/ab. Like M. 8:5, M. 8:6A-G need not specifically concern questions of diverse-. kinds. ${ }^{38}$ In this context, however, M. concerns whether certain animals, which are found in both domesticated and wild states, may be distinguished either from wild animals of the same kind (in the first instance) or from their domesticated counterparts (in the second). Repeating the language of $M, 8: 2 \mathrm{C}$ (as we shall see), $H$ then serves to relate the list to the issue of joining together animals of different kinds to do work.

$A t A-B$ an anonymous opinion and Yose dispute concerning the status of the wild ox. According to the anonymous opinion of A the wild ox may be successfully domesticated, so that it is considered a domesticated animal, and thus (in this context) is not considered to be diverse-kinds with the domesticated ox. Yose, on the other hand, maintains that, regardless of the possibility of domesticating the animal, the wild ox retains its status of a wild animal, and so may not be mated with the ox. $C-D$ then presents a dispute between an anonymous opinion and Meir concerning the dog. C maintains that even domesticated breeds of dogs are regarded as wild animals, while Meir argues that such 
dogs are considered domesticated animals and thus may not be paired with wild dogs ( $Y$. Kil. 1:6 (27a)). According to $E$ the swine is regarded as a domesticated animal, and so is considered to be diverse-kinds with the wild boar (cf. T. 1:8b). F then states that although it may be domesticated, ${ }^{39}$ the Arabian onager is still regarded as a wild animal and may not be mated with the domesticated ass (cf. M. $1: 6^{40}$ [MR]). Finally, G rules that even though elephants and monkeys may survive in captivity and so be domesticated, they are still regarded as wild animals (GRA), and may be mated with wild members of their respective kinds.

$H$ states that one may join a man together with any animal, whether the latter is wild or domesticated, to pull a load, to plow, or to be led. The point of $\mathrm{H}$ is that the prohibition against joining together different kinds refers only to animals, and thus does not bar man, who is not considered an animal, from being joined to an animal to do work. This point is underlined by the fact that the language of $H$ is identical to that of M. $8: 2 \mathrm{C}$ (with a slight change in word-order), which states the prohibition against joining together different kinds of animals. The phrase "to be led," however, is not appropriate to $H$, for it is not likely that one would lead a man carrying a load together with a burdened animal. It appears, then, that the phrase was mistakenly inserted into $\mathrm{H}$ because of $\mathrm{M} .8: 2 \mathrm{C}$, and it is therefore omitted by some manuscripts and commentaries.
A. A dog is [considered] a kind of wild animal.
B. R. Meir says, "[It is considered] a kind of domesticated animaz [M. $8: 6 \mathrm{C}-\mathrm{D}] . "$
C. What is the difference between [the views of] R. Meir and sages?

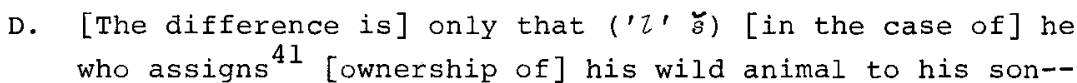
E. R. Meir says, "He has not assigned him [ownership of his] dog."
$F$. And sages say, "He has assigned him [ownership of his] dog."
G. [Erfurt, sens, $\mathrm{KP}^{42}$ omit G-I] He who assigns [ownership of] his domesticated animal to his son--
H. R. Meir says, "He has assigned him [ownership of his] dog."
I. And sages say, "He has not assigned him [ownership of his] [Vienna omits, first printed ed. reads:] dog."

$$
\text { T. Kil. } 5: 7 \text { (p. 223, 11. 19-22) }
$$


T. cites $M, 8: 6 C-D$ at $A-B$ and augments it with $C-I$, which consists of a question at $C$ and a pair of disputes at D-F and G-I (joined to $\mathrm{C}$ by ' 2 ' $\breve{s}$ ). The two disputes balance one another ( hyh vs. bhmh) and are balanced as well ( $l+k t b v s, k t b)$.

$A-B$ cites the dispute between the anonymous opinion of M. 8:6C and Meir concerning the status of the dog. C then asks concerning the practical significance of this dispute and thus introduces $D-F$, which spells out the dispute between Meir and sages (= anonymous opinion of M. $8: 6 \mathrm{C}$ ). This dispute concerns whether one who, in a document, assigns the ownership of his wild animal to his son intends to give the latter the rights to his dog. Maintaining that the dog is regarded as a domesticated animal, Meir rules that the father does not intend to give his son ownership of the dog. Sages, on the other hand, consider the dog to be a wild animal, and therefore argue that the document written by the father does give the son the rights to the dog. G-I, which is omitted in some versions, then reverses the circumstances of D-F. The dispute now concerns one who assigns his domesticated animal to his son, and the positions of Meir and sages are therefore reversed as well. T. thus complements M. by illustrating the dispute of $M .8: 6 C-D$ with a concrete case.

A. A wild dog is [considered] a kind of wild animal.

B. A yerodin (yrwdyn; Lieberman ${ }^{43}$ [following Erfurt]: yrwryn) and an ostrich ${ }^{44}\left(n^{c} m y t ;\right.$ Erfurt: $n^{c}$ mywt; first printed ed.: $\left.n^{c} m \omega t\right), 10$, they are [considered] as birds [Erfurt omits:] in every respect.

$$
\begin{aligned}
& \text { T. Kil. } 5: 8 a \text { (p. 223,11, 22-23) } \\
& \text { (B: Y. Kil. } 8: 5 \text { (3lc)) }
\end{aligned}
$$

T. consists of two autonomous declarative sentences, $A$ and $B$, each of which complements $M$. 8:6's list of animals of doubtful status. A augments M. 8:6C-D's dispute concerning the status of the dog with the rule that the wild dog is regarded as a wild animal. It follows that the anonymous opinion of $\mathrm{M}$. $8: 6 \mathrm{C}$, which views the dog as a wild animal, would not consider the dog to be diverse-kinds with the wild dog, while Meir, regarding the dog as a domesticated animal, would prohibit the pairing of the two dogs. Like T. 5:7, then, T. 5:8a apparently serves to illustrate the significance of the dispute of M. $3: 6 \mathrm{C}-\mathrm{D}$.

$B$ adds two animals to $M . ' s$ list of animals of doubtful status. Unlike M., however, B concerns not whether the specified animals are considered to be wild or domesticated, but whether they are 
regarded as birds or as (presumably) wild animals. According to $B$ the yerodin and the ostrich are considered to be birds in every respect. The identity of the first creature is not clear, as it is apparently either some legendary bird or a member of the ostrich family (Lieberman ${ }^{45}$ ). If the yerodin is similar to the ostrich, then the point of $B$ is that these two creatures are regarded as birds, even though they cannot fly. The phrase "in every respect" perhaps refers to matters of uncleanness, in regards to which birds are distinguished from other animals. ${ }^{46}$

A. For [= omitted by Lieberman ${ }^{47}$ ] an unclean animal does not bear [offspring] [B. Bek.: become pregnant] from (myn; 43 Erfurt, first printed ed.: $m n$ ) [mating with] a clean [animal],

B. nor does a clean [animal bear offspring] from [mating with] an unclean [animal].

c. And a large [animal] does not [bear offspring] from [mating with] a small [animal],

D. nor does a small [animal bear offspring] from [mating with] a large [animal].

E. And a man does not [bear offspring] from [mating with] any of them [i.e., any animal],

F. nor do any of them [bear offspring] from [mating with] a man.

$$
\begin{aligned}
& \text { T. Kil. } 5: 8 b \text { (p. } 223,11,23-25) \\
& \left(T . \text { Bek. } 1: 9 ;^{49}\right. \text { A-D: B. Bek. } \\
& \left.7 a^{50}\right)
\end{aligned}
$$

T. is composed of three pairs of balanced declarative sentences, $A-B, C-D$, and $E-F$. According to $T$. the matings of clean and unclean animals, large and small animals, and men with all animals do not produce offspring, presumably because each union involves two entirely different types of creatures. In noting that the union of a man and an animal cannot produce offspring, $E-F$ serves to complement M. 8:6H. While the latter rules that a man may be joined together with any animal to do work, E-F discusses another type of pairing of man and animal. Because of E-F, therefore, the entire pericope was redacted as a comment on M. $8: 6$.

A. Every [animal] which is [found] in inhabited places (byy šwb) is [found] in the desert;

B. many [animals] are [found] in the desert which are not [found] in inhabited places. 

c. Every [animal] which is [found] on dry land is [found] in the sea;
D. many [animals] are [found] in the sea which are not [found] on dry land.
E. There is no kind of weasel in the sea.

$$
\begin{aligned}
& \text { T. Kil. 5:10 (p. 223, 11. 26-27) } \\
& \text { (C-E: Y. Shab. } 14: 1 \text { (14c); } \\
& \text { C+E: B. Hul. 127a) }
\end{aligned}
$$

T. consists of two declarative sentences, $A-B$ and $C-D$, which both balance one another (inhabited places + desert vs. dry land + sea) and are internally bảlanced as well (inhabited places + desert vs. desert + inhabited places [A vs. B], dry land + sea vs. sea + dry land [C vs. D]). E glosses $C$. A-B and $C-E$ discuss the correspondence between kinds of animals belonging to one setting and similar kinds living in a different environment. According to $A-B$ every kind of animal found in inhabited places, i.e., every kind of domesticated animal, has a counterpart in the desert, or among the wild animals. ${ }^{51}$ The converse of this statement, however, is not true, for not every kind of wildanimal corresponds to a kind of domesticated animal. Similarly, C-D states that all land-animals have counterparts in the sea, but not all sea-animals correspond to similar land-animals. E then presents an exception to $C$, stating that no animal of the sea is similar to the weasel. In discussing the correspondence between kinds of wild and domesticated animals, $A-B$ serves to complement M. 8:6, which discusses whether certain animals are considered to be wild or domesticated, i.e., whether certain animals are considered to be diverse-kinds with similar animals of a different environment. We note that C-E is not relevant to $M .8: 6$, so that the pericope as a whole was redacted as a comment on $\mathrm{M}$. 8:6 on account of A-B alone.

A. (1) He who muzzles a cow, and (2) he who pairs [i.e., joins together] diverse-kinds [of animals] is [i.e., are] exempt [from liability].

B. You find that one is liable only [in the case of] the one who leads or drives [diverse-kinds of animals].

$$
\begin{aligned}
& \text { T. Kil. } 5: 11 \text { (p. } 223,11.27-28 \text { ) } \\
& \text { (T. B.M. } 8: 12 \text {, T. Mak. } 5(4): 1, \\
& \text { B. B.M. } 90 b^{52} \text { ) }
\end{aligned}
$$


T. consists of $A$, a declarative sentence with a double protasis, and $B$, which glosses $A(2)$ (but cf. B. B.M., which has $B$ gloss $A(1)$ as well). According to $A(1)$ one who merely muzzles a cow but does not himself thresh with it is exempt from liability, for scripture prohibits one not from muzzling an ox but only from actually threshing with a muzzled ox: You shall not muzzle an ox when it treads out the grain (Dt. 25:4) (Rashi, B. B.M. 90b, s.v. hhwsm 't $h p h^{53}$ ). A(2) similarly states that one is not liable for merely joining together a pair of animals of different kinds, for scripture prohibits one only from working such a pair: You shall not plow with an ox and an ass together (Dt. 22:10) (Rashi, B. B.M. 90b, s.v. wkn hmzwg swr whmwr). B then illustrates this last point, saying that one is liable only for leading or driving the animals, i.e., for using them to do work. B thus serves to complement M. 8:6H, which rules that man may be joined with animals to do work, with the prohibition against joining different kinds of animals. B perhaps also serves to link M. $8: 6 \mathrm{H}$ to M. $8: 2$, which presents the same prohibition. We note that $A$ is not relevant to $M .8: 6 \mathrm{H}$, so that the entire pericope was redacted as a comment on the latter because of $B$ alone.

F. [You sharz not plow with] an ox and an ass [together] (Dt. $22: 10)--$

G. I know only [that one is prohibited from plowing with] an ox and an ass.

H. Whence [do I know] to make ( $2^{c} \xi w t ;$ some mss. : ${ }^{54} \mathrm{zrbwt}$ ["to include"]) other pairs of domesticated animals, wild animals, or fowl [of different kinds] like an ox and an ass [in respect to the rule against joining together animals of different kinds]?

I. Scripture says, You shall not plow--under all circumstances.

J. If so, why is it stated, with an ox and an ass?

K. With an ox and an ass [together] you may now plow, but you may plow with a man and an ass [together] [Y.: With an ox and an ass (together) you may not plow, but you may plow with an ox and a man together or with an ass and a man (together) ].

$$
\begin{aligned}
& \text { Sifré Dt. } 231 \mathrm{~b} \text { (ed. Finkelstein, } \\
& \text { p. 264, 11. 7-10) (J-K: Y. Kil. } \\
& 8: 6 \text { (3ld)) }
\end{aligned}
$$

F-G understands the phrase $a n o x$ and an ass (Dt. 22:10) to include in the verse's prohibition only the two specified animals. 
H-I therefore takes the phrase you shall not plow to include in the prohibition all other animals which one may join together, or all domesticated animals, wild animals, and birds. J then asks why, if the prohibition includes all animals, the verse explicitly names two in particular. $K$ answers that the phrase an $o x$ and an ass serves to exclude man, for man is not subject to the laws of diverse-kinds and so may be paired with an animal. $\mathrm{J}-\mathrm{K}$ thus agrees with M. 8:6H's rule that a man may be joined together with animals to do work. 



\section{CHAPTER NINE}

\section{KILAYIM CHAPTER NINE}

The closing chapter of our tractate discusses diverse-kinds of garments. The chapter is divided into three parts, M. 9:1-2B, which concerns the mixing of wool and flax, M. 9:2C-7, which deals with the definition of a garment, and M. 9:8-10, which returns to the concerns of the opening of the chapter and discusses ways of combining and connecting wool and flax together.

M. 9:1A-C opens the chapter by presenting a unitary set of three general rules concerning wool and flax, with the first stating that wool and flax alone combine to produce diverse-kinds. M. then turns to two secondary cases, one discussing the status of wool or flax which is mixed with another kind (M. 9:1D-H), and the other dealing with fibers which resemble wool and flax and thus produce the appearance of diverse-kinds in a mixture (M. 9:2A-B). M. 9:2A establishes the formulary pattern which is followed by $M .9: 2 \mathrm{C}-7$, and so has been formulated to provide a smooth transition to the succeeding subunit.

M. $9: 2 \mathrm{C}-7$ presents an essay exploring some of the criteria of the definition of a garment. The subunit is constructed around four rules, all of which follow the same formulary pattern ('yn bhm/bw mswm kl'ym [M. 9:2C, 9:3A, 9:4A, 9:7E]). Each rule discusses items which are not regarded as garments and thus not subject to the laws of diverse-kinds. These four rules are arranged in a series in such a way that each successive group of items satisfies an additional criterion of the definition of the garment. M. 9:2C opens the series with the rule that items which are neither designed to serve as garments nor actually worn (e.g., mattresses and cushions) are not regarded as garments. According to $M .9: 3 \mathrm{~A}$ the same rule applies to items which, although not made to be worn, may actually function as garments (e.g., towels). (Eliezer glosses and opposes this rule, maintaining that items which secondarily serve as clothing are regarded as garments.) M. 9:4A then turns to items which are made to be worn, but not by man (e.g., pack-saddles). Such items are not subject to the laws of diverse-kinds, for they are not used as garments by those who are prohibited from wearing diverse-kinds. Finally, M. 9:7E discusses an item which is designed to be worn by man, but which, because it does not stay securely on the body, is not regarded as a garment (e.g., a heelless cloth slipper). In 
addition, an interpolated unit (M. 9:5-6) introduces the consideration of intention, discussing whether one's purpose in using an article of clothing affects its status as a garment (cf. also M. $9: 2 \mathrm{G}, 9: 4 \mathrm{C})$.

Opening with a rule $(M .9: 8 \mathrm{~A})$ in the formulary pattern of M. 9:1A, M. 9:8-10 returns to the interests of M. 9:1-2B with a discussion of the ways in which wool and flax may combine to form diverse-kinds. The subunit is divided into two parts, M. 9:8-9D and M. 9:9E-10. The former discusses methods of combining wool and flax during the process of manufacturing garments (e.g., hackling, spinning, and weaving), while the latter concerns different ways of attaching finished items (e.g., garments) of wool and linen to one another. The two parts are joined smoothly at Yosé's saying of M. 9:9E-F, which follows the formulary pattern of M. 9:9A-D but concerns the problem of attaching a woolen cord to a linen garment.

$9: 1$

A. Nothing is prohibited on account of [the laws of] diversekinds except [a garment composed of a mixture of] wool and linen.

B. Nor is anything susceptible to uncleanness through plagues except [a garment composed of either] wool or linen.

c. Nor do priests wear anything to serve in the Temple except [garments composed of either] wool or linen.

D. Camel's hair and sheep's wool which one hackled [so Danby for trpn] [i.e., combed] together--

E. if the greater part is from the camels, it is permitted [to mix the fibers with flax (Maim., Comm.)].

F. But if the greater part is from the sheep, it is prohibited [to mix the fibers with flax].

G. [If the quantity of camel's hair and sheep's wool is divided] half and half--it is prohibited [to mix the fibers with flax].

$\mathrm{H}$. And so [is the rule for] flax and hemp which one hackled together [i.e., if at least half of the hackled fibers are of flax, it is prohibited to mix them with wool].

M. Kil. $9: 1$ (D-H: M. Neg. $11: 2^{l}$ )

M. consists of $\mathrm{A}-\mathrm{C}$, a series of three rules concerning wool and linen, and an autonomous pericope concerning the status of wool or linen which is mixed with another kind. A-C is composed of three declarative sentences, all of which follow the same formulary pattern ('yn + present participle + ' $l$ ' + smr wp $\breve{s t y m}$ ). 
We note that the phrase smr wprtym in A concerns a mixture of wool and linen, while the same phrase in $B$ and $C$ refers to garments composed of either wool or linen (although, as we shall see, $C$ concerns the mixture of the two kinds as well). According to $A$ the prohibition of diverse-kinds of garments applies to mixtures of wool and linen alone, for only such mixtures are specifically mentioned by Scripture: You shall not wear a mingled stuff, wool and linen together (Dt. 22:11). ${ }^{2}$ B then states that only garments composed of either wool or linen are susceptible to uncleanness through plagues, for again scripture explicitly mentions these two fibers alone: When there is a leprous plague in a garment, whether a woolen or a linen garment (Lv. 13:47). Finally, C states that, when serving in the Temple, priests wore only garments composed of either wool or linen or a mixture of both (Maim., Comm.), for scripture states (with reference to the materials used in fashioning Aaron's garment ${ }^{3}$ ): They shall receive gold, blue and purple and scarlet stuff, and fine twined linen (Ex. 28:5). All of the priest's garments were thus made of either blue and purple and scarlet stuff, or dyed wool (Maim., Comm.) (e.g., the robe of the ephod [Ex, 28:31-35]), linen (e.g., the coat and turban [Ex. 28:39]), or a mixture of dyed wool and linen (e.g., the ephod [Ex. 28:6ff.]). We note that, when serving in the Temple, the priest is permitted to wear garments of diversekinds. It follows, then, that the laws of diverse-kinds paradoxically do not apply to priests engaged in the performance of cultic duties.

D-H discusses the status of wool or flax which is mixed with another kind of fiber. $D-H$ consists of a protasis at $D$ and $a$ pair of balanced conditional sentences at E-F (gmlyn + mwtr vs. rhizm + 'swr), followed by G. H then glosses D-G. D describes a case in which camel's hair and sheep's wool are hackled, ${ }^{4}$ or combed, together, so that the two kinds are indistinguishable from one another (MR; Cf. T. 5:12). E-G discusses whether or not the wool is considered to be annulled by the camel's hair, so that the hackled fibers may be accorded the status of the latter and may be mixed with flax (Maim., Comm.). According to E-F the status of the hackled fibers follows that of the majority of fibers in the mixture. G adds that if equal amounts of both kinds have been hackled together, we rule stringently and regard the hackled fibers as wool, so that they may not be mixed with flax. H then states that the same rule applies to flax and hemp which have been hackled together, so that the combined fibers may be mixed with wool only if the greater part of them derives from hemp. 
A. (1) A poultice ('stplnyt; Lieberman, 5 following Erfurt and commentaries, reads 'ysplnyt),

(2) a plaster (mlwgm'),

(3) and a compress (rtyyh)

are not subject to [the laws of] diverse-kinds.

T. Kil. 5:25 (p. 225, 1. 52)

B. (1) A corpse,

(2) and an animal,

(3) and tents,

(4) and a comb ('ksylwn),

(5) and [first printed ed. omits:] a grgs,

(6) and a wreath ('stm'),

(7) and a hanging of a curtain [i.e., a cloth upon which a curtain is hung (Lieberman, ${ }^{6}$ reading $w q z^{\circ}$ wyzwn for $w q z^{c}$ w'y $z w n$; alternatively: a sail and a curtain (HD))],

(8) and the garments of priests,

(9) and the garments of the high priest are not subject to [the laws of] diverse-kinds.

$$
\text { T. Kil. 5:26 (pp. 225-226, 11. 53-54) }
$$

T. is composed of two lists (consisting respectively of three [A] and nine [B] members) of items which are not subject to the laws of diverse-kinds. According to $A$ three kinds of dressings which may be made with cloth, a poultice (containing grease and wax $^{7}$ ), a plaster, ${ }^{8}$ and a compress (containing medication $^{9}$ ), do not come under the laws of diverse-kinds. ${ }^{10}$ The reasoning behind $A$ is that all of these dressings are simply placed on the wound but apparently are not tied securely to the body, and thus are not worn as garments (cf. T. 5:23). 11

The list of nine items at $B$ is divided into three parts, $(1)-(2)$, concerning items which are permitted to bear diversekinds, (3)-(7), dealing with items which are not designed to serve as garments, and (8)-(9), discussing items which function as garments but which nevertheless are not subject to the laws of diverse-kinds. According to $B(1)-(2)$ one is permitted to place diverse-kinds upon a corpse or animal, for the prohibition against wearing diverse-kinds applies only to living people (cf. M. 9:4A). We note that in this instance the language "are not subject to [the laws of] diverse-kinds" refers to something which bears diverse-kinds, and not to something which may be worn.

$B(3)$ rules that a tent does not come under the laws of diverse-kinds, for, although it serves to protect man, it is not 
designed to be worn as a garment. B(4) concerns the 'ksylwn, which Lieberman ${ }^{12}$ identifies as the sdivlv or sdiviov, a, type of comb used as a head-ornament. According to Lieberman such a comb was attached to a piece of cloth (which protected the head) and then set in the hair. The point of $B(4)$, then, is that the comb and the cloth are regarded as forming an ornament, and not a garment, and thus are not subject to the laws of diverse-kinds. The meaning of grgs $(B(5))$ is not known (Lieberman ${ }^{13}$ ). B(6) rules that, like a comb, a wreath is regarded as an ornament, 14 and thus does not come under the laws of diverse-kinds. We note that, since $B(4)$ and $B(6)$ refer to types of ornaments, it is possible that $B(5)$ concerns a kind of ornament as well. $B(7)$ refers to the term $q l^{c}$ wwy $z$, which may be interpreted in one of two ways. According to Lieberman ${ }^{15} q z^{c}$ wwy $z w n$ refers to a single item, the hangings of curtains, i.e., cloths upon which curtains were suspended. These hangings are not subject to the laws of diverse-kinds, for they cannot be worn as garments. Alternatively, the first $w$ of wwy $w$ wn may be taken as a conjunction, so that $q \tau^{c}$ wwy $z w n$ may refer to two separate items, a sail $\left(q z^{c}\right.$ ) and a curtain (wytwn) (HD), neither of which is designed to serve as a garment.

$B(8)-(9)$ rules that the garments of priests and of the high priest are not subject to the laws of diverse-kinds, for priests were required to wear diverse-kinds while serving in the Temple. T. thus augments M. 9:1C's rule that priests wear only garments of wool and linen in the Temple (cf. also T. 5:27).

A. Garments of the high priest--

B. he who goes out [while dressed] in them to the provinces [i.e., outside the Temple] is liable.

c. But [following Lieberman, 16 who reads $w$ for $\breve{s}$ ("for")] [he who wears them] in the Temple,

D. whether [he does so] to serve [i.e., to participate in the Temple service] or not to serve [i.e., while he does not participate in the Temple service],

E. is exempt [from liability],

F. because they [i.e., the garments] are fit (r'wyyn) for the Temple service.

T. Kil. 5:27 (p. 226, 11. 54-56)

(B. Yoma $69 a$, Tamid $27 b^{17}$ )

T. augments the rule of T. 5:26B(8)-(9) concerning the status of priestly garments. T. consists of declarative sentences at $A-B$ and $C+E$, with the latter glossed by $D$ and $F$. According 
to $A-C+E$ the high priest may not wear priestly garments, which include garments of diverse-kinds (cf. our discussion of M. 9:1C, above), outside of the Temple, for, as F explains, he is required to wear such garments while participating in the Temple service. $D$ then appears to gloss C+E-F, explaining that, although the high priest wears the garments oniy because he must perform certain cultic actions, he may keep the clothes on even when he does not actually take part in the service. We note that the separate glosses of $D$ and $F$ create a difficulty in the final version of the pericope, for these two statements, when read together, imply that the high priest may wear his garments even when he does not serve because the garments are fit for the Temple service.

A. Camel's hair and sheep's wool [GRA adds: which one hackled together] [= M. $9: 1 \mathrm{D}]$

[B. (GRA adds:) if the greater part is from the camel, it is permitted (to mix the fibers with fiax) ${ }^{18}$ (= M. 9:IE).]

C. Under what circumstances?

D. When he [first] hackled them [i.e., the camel's hair and the sheep's wool] together, and [then] introduced flax into the mixture and hackled [it together with them] [Erfurt, Sens: ${ }^{19}$ When he (first) brought flax and hackled (it) together with them (i.e., with the camel's hair ${ }^{20}$ ) and (then) hackled them (i.e., the camel's hair combined with the flax, and the sheep's wool) together].

E. But he who makes a shirt $(h(w q)$ wholly of camel's hair or (w) wholly of hare's hair [so Lieberman, following Erfurt ${ }^{21}$ ], and wove into it one thread of [sheep's] wool on one side, and another ('hr; Erfurt, first printed ed.: "hd ["one"]) thread of flax [first printed ed. and commentaries ${ }^{22}$ add: on the other side ${ }^{23}$ ]--it is prohibited [i,e., the shirt is considered a garment of diverse-kinds].

$$
\text { T. Kil. 5:12 (pp. 223-224, 11. 28-31) }
$$

T. cites M. 9:1D at A (with GRA completing the citation at $A$ and adding $M .9: I E$ at $B$ ), which is then augmented by $C-E$. According to C-D M. 9:ID-E's rule that wool mixed with a greater quantity of camel's hair may be combined with flax applies only when the wool is hackled together with the camel's hair. ${ }^{24}$ In this case the wool becomes indistinguishable from the camel's hair, so that the latter annuls the former (Lieberman ${ }^{25}$ ), and the combined fibers may be mixed with flax. One may not, however, weave separate threads of flax and wool into a garment composed 
wholly of camel's or hare's hair (E). In this instance the flax and wool remain recognizable when mixed with the third kind, and so are not annulled even when woven into a garment composed entirely of that third kind. The shirt is therefore regarded as containing a mixture of flax and wool, and thus is prohibited as a garment of diverse-kinds.

\section{$9: 2$}

A. Silk and bast-silk [so Danby for šryym wklk] are not subject to [the laws of] diverse-kinds,

B. but are prohibited for appearance's sake.

C. Mattresses [so Danby for krym; alternatively: pillows (Maim., Comm. ${ }^{26}$ )] and cushions [so Danby, following Maim., Comm. 27 for kstwt] [composed of a mixture of wool and linen] are not subject to [the laws of] diverse-kinds,

D. provided that one's flesh not be touching them [while one sits or lies on them].

E. There is no [rule permitting] temporary use $\left({ }^{c} p{ }^{\prime} y\right)$ in respect to diverse-kinds [of garments].

$F$. And one shall not wear [a garment of] diverse-kinds even [= omitted by B. B.Q. $113 a$ and most mss. ${ }^{28}$ ] on top of ten [garments],

G. even ('pylw) to avoid (Zgnwb; B. B.Q. 113a: Zhbryh) [paying] customs-dues [so Danby for lgnwb 't hmks].

$$
\begin{aligned}
& \text { M. Kil. } 9: 2 \text { (E: B. Men. 4la; } \\
& \text { F-G: B. B.Q. 113a) }
\end{aligned}
$$

M. opens a large subunit (extending through M. 9:7) dealing with a series of issues related to the problem of defining a garment. $M$. begins with two autonomous rules, $A-B$ and $C-D$. Although $A$ and $C$ contain identical apodoses ('yn $b h m m s ̌ w m ~ k l ' y m$ [continued at $M .9: 3-4,7])$, the two rules are clearly not related to one another in substance. While A-B concerns whether certain kinds of fibers produce mixtures of diverse-kinds, C-D discusses the entirely separate question of whether the laws of diversekinds apply to certain types of objects. C-D is then augmented by the autonomous rules of $E$ and $F-G$.

$A-B$ concerns šyrym, a kind of silk resembling flax, ${ }^{29}$ and klk, i.e., bast-silk, which apparently is similar to wool (Maim., Comm.). A may be understood in one of two ways. According to one interpretation (Maim., Code, Diverse-Kinds 10:1, Bert., TYY) A rules that it is permitted to mix syryym with wool or $k$ lk with flax, for, although appearing to consist of diverse-kinds, 
such mixtures are not actually composed of wool and flax. Alternatively, A may be taken to mean that one is permitted to mix šyryym and klk with one another, for again such a mixture would only appear to contain wool and flax (Maim., Code, Diverse-Kinds $10: 1$, MS, TYY ${ }^{30}$ ). According to either interpretation, then, the point of $\mathrm{A}$ is that a mixture of fibers is prohibited only if it actually contains diverse-kinds, regardless of its appearance. Glossing A, B then reverses the latter's rule. B maintains that the mixtures (or mixture) described in $A$ are prohibited because they appear to consist of wool and flax. $B$ thus holds that a mixture is prohibited even if it produces only the appearance of diverse-kinds, regardless of the actual presence or absence of diverse-kinds within it.

According to $C$ one is permitted to use mattresses (or pillows [Maim., Comm.]) or cushions composed of diverse-kinds, for scripture prohibits one from using only garments (i.e., items which are usually worn) of diverse-kinds: Nor shall there come upon you a garment of cloth composed of two kinds of stuff (LV. 19:19), and You shalz not wear a mingled stuff, wool and iinen together (Dt. 22:11). D then qualifies $C$, ruling that one may not allow his flesh to touch the articles of diverse-kinds while he sits or lies upon them. The reasoning behind $D$ apparently is that diverse-kinds which come into direct contact with the flesh serve to warm the latter, and thus function as articles of clothing. One who allows his flesh to touch the mattresses or cushions of diverse-kinds is therefore considered to be wearing a garment of diverse-kinds. 31

E states that one is not permitted to wear diverse-kinds even temporarily. In this context $\mathrm{E}$ serves to contrast items which are not designed to function as garments (e.g., mattresses and cushions) (C-D) with items which are so designed. While the former may be used as long as they do not function as clothing (D), the latter may not be used even momentarily, i.e., under any circumstances. F-G then makes a similar point with a separate rule. According to $F-G$ one may not wear a garment of diversekinds on top of ten other garments, even if he thereby wishes only to avoid paying customs-dues (which were not levied on one's personal apparel), and thus does not intend to use the garments as clothing at all (Sens). By itself, F-G states simply that one may not wear diverse-kinds even when they lie upon many layers of clothing and thus do not serve the functions of garments. In this context, however, the point of $F-G$, like that of $E$, is to contrast items which are not designed to function as clothing (C-D) with articles which are so designed. The former may be 
used as long as they are not directly touched (D), while the latter may not be worn even if they lie upon ten layers of clothing and thus cannot touch the flesh of their bearer.

A. Linen which one dyed with blacking [so Jastrow for hrt]--

B. he shall not sell it to a gentile,

C. and he shall not make it into a recognizable border [Y. Kil. $9: 2$ omits:] of linen.

D. [If he made it into a border] for mattresses and cushions, Io, this is permitted.

\author{
T. Kil. 5:24 (p. 225, 11. 50-52) \\ $(A+C-D: Y$. Kil. $9: 2(32 a))$
}

T. is composed of a mildiy-apocopated sentence $(A-C)$ with a compound apodosis (B-C; Cf. T. 5:19). D then glosses C. A concerns linen which is dyed with blacking, a substance usually applied only to wool (Sens to M. 9:2). According to B one may not sell such a dyed piece of linen to a gentile, lest the latter in turn sell it to an Israelite. Thinking the fabric to be wool, the Israelite might then attach it to a garment of wool, and so unknowingly produce a garment of diverse-kinds (as in T. 5:19; Lieberman ${ }^{32}$ ). C then rules that one may not make the dyed piece of linen into a recognizable border of a garment composed of undyed linen. The point of $\mathrm{C}$ is that, although the two pieces of linen do not actually form a garment of diverse-kinds, they appear to constitute a garment of linen which is bordered with wool, and they therefore may not be joined together. According to $\mathrm{C}$, then, one is liable for producing the appearance of diverse-kinds whether or not the wool and linen are actually mixed together ( $\mathrm{CF}$. M, 9:2B). D adds that one may make the dyed pieces of linen into a border of a mattress of cushion (Lieberman ${ }^{33}$ ) which is presumably also composed of linen. ${ }^{34}$ The point of $D$ is that a mattress or a cushion is not subject to the laws of diversekinds (M. 9:2C), and we are therefore not concerned if it appears to contain diverse-kinds. T. thus augments M. 9:2C-D's rule concerning the status of mattresses and cushions.

A. A garment which contains diverse-kinds at one end--

B. he shall not cover himself with the other side [i.e., with the other end of the garment],

c. even though the [end containing the] diverse-kinds [thus] rests on the ground.

$$
\text { T. Kil. } 5: 13 \text { (p. 224, 11. 32-34) (Y. Kil. 9:1 (31d) }{ }^{35} \text { ) }
$$


T. consists of an apocopated sentence, $A-B$, which is glossed by $C$. T. presupposes the scriptural rule, Nor shazl there come upon you a garment of cloth made up of two kinds of stuff (Lv. 19:19), taking it to prohibit one from covering himself with diverse-kinds. A describes a garment which contains diversekinds at only one end. B states that one may not cover himself with the other end of the garment, even if the end containing the diverse-kinds would then rest on the ground and thus not cover the person at all (C). T. thus augments $M .9: 2 F-G$, which prohibits one from wearing diverse-kinds on top of ten layers of clothing, even though he receives no benefit from the diversekinds, with the rule that one is prohibited from covering himself with garments of diverse-kinds, even if the mixed fibers themselves do not serve to cover him.

A. A shirt of wool which was torn (צnyprs), and which one fastened [Rosh ${ }^{36}$ omits "and," reading: he wraps (kwrkw $\left.{ }^{37}\right)$ ] [together] with a thread of flax--

B. or (w) a shirt of linen which was torn, and which one fastened it [together] with a thread of wool--

c. if he sewed them [i.e., the torn ends of the shirt] together, they [i.e., the shirt and the thread] are prohibited on account of [the laws of] diverse-kinds.

D. And they go out [from one domain to another] with them [i.e., the shirt and the thread] on the sabbath.

$$
\text { T. Kil. 5:14 (p. 224, 11. 33-35) }
$$

\section{T. 5:14 and 5:15 (which immediately follows) form an} autonomous subunit concerning whether certain ways of joining together wool and flax produce a garment of diverse-kinds. T. consists of a balanced double-protasis at $A-B$ (wool + flax vs. flax + wool), followed by a conditional sentence at $C$, which is augmented by D. A-B describes a case in which a shirt of wool or linen is torn, and the torn ends are tied together, or fastened, with a thread of either flax (in the first case) or wool (in the second). C then rules that if one sews up the tear with the thread, the latter is considered to be connected to the shirt, which thus becomes prohibited as a garment of diverse-kinds. D adds that one may wear the shirt ${ }^{38}$ from one domain to another on the Sabbath, for he is not regarded as carrying the thread, which is considered to be part of the shirt. ${ }^{39}$ Now the rule of C-D, concerning a thread which is sewn onto a shirt, implies that if the thread is only fastened onto the shirt, as in the case of $A-B$, 
it is not considered to be connected to the shirt. In this instance, then, the shirt is not considered a garment of diversekinds, and one is not permitted to wear it from one domain to the other on the Sabbath. The version of Rosh renders explicit this understanding of T., for Rosh omits "and" and replaces the perfect verb in $A$ with a present participle, thus reading $A$ and $C$ as two separate rules. Maimonides ${ }^{40}$ similarly explains $A+C{ }^{4}$ as follows (Code, Diverse-Kinds 10:10):

A garment of wool which was torn--it is permitted to fasten it together with threads of flax. And he ties [the garment together], but he shall not sew [it together]. 42

A. A man wears two shirts, [one of wool and one of linen (Maim., Code, Diverse-Kinds 10:11)] one on top of the other,

B. even though his belt (pwndtw) is tied on [i.e., around] him on the outside,

C. provided that he does [not (following Lieberman ${ }^{43}$ )] take (ytn; Rosh and Maim., Code, Diverse-Kinds 10:11: ${ }^{44}$ ytrwp ["wind" ${ }^{45}$ ]) the cord (hmsyhh) [i.e., the cords of the two shirts (Lieberman ${ }^{46}$ )] and tie [the two shirts together] between the shoulders.

$$
\text { T. Kil. 5:15 (p. 224, 11. 35-36) }
$$

T. continues T. 5:14's discussion concerning whether various ways of joining together wool and linen yield a mixture of diverse-kinds. T. opens with a declarative sentence at $A$, which is then separately glossed by $B$ and $C$. According to $A$ one is permitted to wear two shirts, one of wool and one of linen (Maim., Code, Diverse-Kinds 10:11), on top of one another, for the two garments are not connected to each other (e.g., they may be removed separately [Rosh; cf. also Lieberman ${ }^{47}$ ]) and thus are not considered to constitute a single garment of diverse-kinds. B adds that one may even tie a belt around the two shirts, for once the belt is unfastened the shirts are no longer connected (e.g., they may be removed separately). The belt thus represents only an extrinsic connection, and does not alter the status of the shirts as distinct garments. C, however, rules that one may not tie the cords belonging to each shirt (Lieberman) together at the shoulders, for then the shirts are intrinsically connected to one another (e.g., they cannot be removed individually), and so are considered to form a single garment of diverse-kinds. The point of $T .$, then, is that one is permitted to wear separate garments of wool and linen on top of one another, provided that he does not so connect them that they are considered a single garment. 
I. Since it [i.e., scripture] says, Nor shall there come upon you [a garment of cloth made up of two kinds of stuff] (Lv. 19:19), might I think that he shall not tie [a garment of diverse-kinds] in a bundle [and throw it] behind him [i.e., over his shoulder]?

J. Scripture says, you shall not wear [a mingled stuff, wool and linen together] (Dt. 22:11).

K. You shazl not wear--

I. I know only that he shall not wear [a garment of diversekinds].

M. Whence [do I know] that he shall not cover himself [with such a garment]?

N. Scripture says, Nor shazl there come upon you.

o. [It follows that] you are permitted to spread it ( $\left.\operatorname{lh} s y^{c} w\right)$ [i.e., a garment of diverse-kinds] under you.

P. But sages said, "You shall not do so, lest a single fringe (nym') [of the garment of diverse-kinds] come upon (thyh $c_{w}$ th; B. Yoma, Bes., and Tamid: tkrk ["wind itself around"]) his [i.e., your] flesh."

Sifra Qedoshim 4:18b (ed. Weiss, $89 b)$ (N-P: B. Yoma 69a, B. Bes. 14b, B. Tamid 27b)

I-N discusses why Scripture presents two prohibitions concerning diverse-kinds of garments ( $L v .19: 19$ and Dt. 22:11). According to I the phrase Nor shatl there come upon you (Lv. 19:19) by itself implies that one may not bear diverse-kinds on his body in any way, so that one may not even tie his garments of diversekinds in a bundle and throw them over his shoulder. J therefore cites the phrase you shall not wear (Dt. 22:11), which serves to limit the prohibition of garments of diverse-kinds to concern only the act of wearing such garments. I-J thus agrees with M. $9: 5 \mathrm{C}$, which states that the more scrupulous clothes-sellers would carry diverse-kinds in a bunde over their shoulders in order to avoid carrying them on their backs. $k$ then states that the phrase you shalz not wear by itself indicates that one is prohibited only from wearing garments of diverse-kinds. L-M therefore maintains that the rule of Nor shall there come upon you is necessary in order to include in the prohibition the act of covering oneself with diverse-kinds as well. The point of sifra, then, is that the prohibitions of Lv. 19:19 and Dt. 22:11 serve to qualify one another. 
o then takes the phrase Nor shall there come upon you to imply that, while one is not permitted to cover himself with diverse-kinds, he is permitted to sit or lie on them. Sages, however, reverse this ruling in $P$, maintaining that one may not sit or lie on garments of diverse-kinds, for a fringe of one of the garments might come to rest upon him, and he would then be liable for covering himself with diverse-kinds. $P$ thus presents a more stringent view than M. 9:2C-D, which permits one to sit or lie on mattresses or cushions of diverse-kinds, provided that he does not allow his flesh to come into contact with them.

E. You shall not wear [a mingled stuff, wool and linen together] (Dt. 22:11)--

F. I know only that he shall not wear [a garment of diversekinds].

G. Whence [do I know] that he shall not cover himself [with such a garment]?

H. Scripture says, Nor shall there come upon you [a garment of croth made up of two kinds of stuff] (Lv. 19:19).

I. I might think that [according to this verse (Hillel)] he shall not tie it [i.e., a garment of diverse-kinds] in a bundle [and throw it] behind him [i.e., over his shoulder].

J. Scripture says, You shall not wear.

K. [The act of] wearing was [included] in the general principle [i.e., Nor shall there come upon you a garment of cloth made up of two kinds of stuff].

L. And why was it [i.e., the act of wearing] specified (ys 't)?

M. To compare [the general principle] to it [i.e., the prohibition against wearing garments of diverse-kinds], and to tell you that just as [the act of] wearing is distinctive (mywhdt) because it [involves] the comfort of the body (hnyt $h(w p)$, so too every [act of placing diverse-kinds upon oneself] which [involves] the comfort of the body [is prohibited].

Sifré Dt. 232b (ed. Finkelstein, p. 265, 11. 4-7) (A-B+D-F+I: Y. Kil. $9: I$ (3ld))

E-H = Sifra Qedoshim 4:18K-M, and $(H+) I-J=$ Sifra gedoshim $4: 18 \mathrm{I}-\mathrm{J}$, so that sifré simply restates sifra dedoshim $4: 18 \mathrm{I}-\mathrm{M}$ in reverse order. $\mathrm{K}-\mathrm{L}$ then asks why the act of wearing diversekinds, which is presumably included in Lv. 19:19's prohibition against having diverse-kinds upon oneself, is specifically prohibited at Dt. 22:11. M answers that this particular prohibition 
is mentioned so that it may qualify the general prohibition against having diverse-kinds upon one's body. Just as the act of wearing concerns the pleasure or comfort of the body, so the act of placing diverse-kinds upon oneself in any way is prohibited only when it benefits the body. We note that sifré disagrees with $M .9: 2 \mathrm{~F}$ as interpreted by Maimonides (Code, Diverse-Kinds 10:18), for according to Maimonides the point of $\mathrm{M}$. is to prohibit the wearing of diverse-kinds even when such an act does not add to the body's pleasure at all.

N. [you shall not wear a mingled stuff, wool and linen] together (Dt. $22: 11$ )--

o. I might think that he shall not wear a shirt of wool on top of a shirt of linen, nor $(w)$ a shirt of linen on top of a shirt of wool.

P. Scripture says, Together.

Sifre Dt. 232c (ed. Finkelstein, p. 265, 11. 7-8)

According to $\mathrm{N}-0$, were Dt. 22:11 to omit the word together and to read simply you shall not wear a mingled stuff, wool and linen, one might conclude that it is prohibited to wear separate garments of wool or linen on top of one another (i.e., at the same time). P therefore cites the word together, which implies that one is prohibited from wearing only garments composed of a mixture of wool and linen. Sifré thus agrees with T. 5:15, which rules that one may wear separated garments of wool and linen on top of one another, provided that he does not connect them to form a single garment.

U. [you shall not wear a mingled stuff,] wool and linen together (Dt. 22:11)--

V. but [wearing] this one [i.e., a garment composed of one fiber] by itself and that one [i.e., a garment composed of the other fiber] by itself is permitted.

Sifré Dt. $232 e$ (ed. Finkelstein, 48

p. 265, 1. 11)

$\mathrm{U}-\mathrm{V}$ takes the word together in Dt. 22:11 to prohibit one from wearing only garments composed of a mixture of wool and linen, and so implicitly to permit one to wear garments consisting of either wool or linen alone. 49 
$9: 3$

A. (1) Hand-towels (mtphwt hydym), (2) scroll-wrappers (mtphwt sprym), and (3) bath-towels [so Danby for mtphwt hspg] are not subject to [the laws of] diverse-kinds.

B. R. Eliezer prohibits [i.e., they are subject to the laws of diverse-kinds].

c. And barbers' towels (mtphwt hsprym) are prohibited on account of [the laws of] diverse-kinds.

M. Kil. $9: 3$

A consists of a list of three items which are not subject to the laws of diverse-kinds, with each member of the list presented in the formulary pattern mtphwt $\mathrm{x}$. Eliezer then glosses and opposes A at B. C augments A with a contrary case, presenting an article which, although similar to those listed in $A$ (and presented in the same formulary pattern), does come under the laws of diverse-kinds.

A-B turns from M. 9:2C-D's discussion of items which are not designed to serve as garments and deals with items which, although not designed to be worn, may still serve as clothing. The issue of A-B concerns whether one takes account of the secondary functions of such items in determining whether or not they are regarded as garments. According to A hand-towels, scroll-wrappers, and bath-towels do not come under the laws of diverse-kinds, for, like the mattresses and cushions of M. 9:2C-D, these articles are not designed to be worn as garments. A thus holds that an item's status is determined by its primary function alone. Eliezer disagrees at $B$, maintaining that, although the items of $A$ are not made to be worn, they may still function as garments, for one may use a hand-towel or scroll-wrapper to warm one"s hands, 50 and one may cover his body with a bath-towel (cf. Y. Kil, 9:3). According to Eliezer, then, the items of $A$ do come under the laws of diverse-kinds. Eliezer thus argues that one does take account of the secondary function of an item in determining whether or not it is regarded as a garment.

$C$ states that one may not put on a barber's towel which is composed of diverse-kinds, for such a towel is designed to protect a person and his clothing fromcut hair, and so is intended to function as a garment. C thus serves to contrast the barber's towel, which is designed to serve as a garment, and does come under the laws of diverse-kinds, with the three cloths of $A$, which are not made for such a purpose and so are not subject to the laws of diverse-kinds, C therefore serves to underline A's 
view that an article's primary function alone determines whether or not it is subject to the laws of diverse-kinds.

A. Women's bath-towels [following Lieberman ${ }^{51}$ for bl'py ņym] are not subiect to [the laws of] diverse-kinds.

B. And if he sewed them [i.e., if he sewed two ends of the towel together],

c. they receive uncleanness, and

D. they are prohibited on account of [the laws of] diverse-kinds.

$$
\begin{aligned}
& \text { T. Kil. } 5: 16 \text { (p. 224, } 11.36-38) \\
& \text { (Y. Kil. } \left.9: 3(32 a)^{52}\right)
\end{aligned}
$$

T. augments M. 9:3A(3), which states that a bath-towel is not subject to the laws of diverse-kinds, with a discussion of a similar item, the women's bath-towel. According to $A$ a women's bath-towel does not come under the laws of diverse-kinds, for, like the bath-towel of M.9:3A(3), it is intended to be used only to dry off the body, and it is not designed to be worn as a garment (Lieberman ${ }^{53}$ ). If, however, one sews together two ends of a women's bath-towel, it is regarded as a garment, for it is now made to stay securely on the body and to be worn like an article of clothing. In this case, therefore, the women's bathtowel, which formerly was not used for lying or sitting and thus was not susceptible to midras-uncleanness, is now treated as a garment and thus is susceptible to this type of uncleanness (Lieberman ${ }^{54}$ ) (C). Similarly, like any garment, the women's bath-towel is now subject to the laws of diverse-kinds (D). 55 By distinguishing between the different ways in which the women's bath-towel may be designed, T. illustrates M. 9:3A's view that an item's primary purpose alone determines whether or not it comes under the laws of diverse-kinds.
A. Wrappers of cases (mtphwt tybh) [of scrolls (Lieberman 56 )] are not subject to [the laws of] diverse-kinds.
B. "Hand-towels, and seroll-wrappers, and bath-towels are not subject to [the laws of] diverse-kinds [ = M. 9:3A].
C. "And R. Liezer prohibits [ = M, 9:3B]," the words of R. Meir.
D. R. Judah says, "R. Liezer permits,
E. "and sages prohibit."

$$
\text { T. Kil. } 5: 17 \text { (p, 224, 11, 33-40) }
$$

A augments M. 9:3A(2)'s discussion of scroll-wrappers with a rule concerning another type of cloth which is used to protect 
scrolls, the wrapper of a case of scrolls. Such a cloth was used either to cover the case itself (Lieberman ${ }^{57}$ ) or to line the case and thus protect the scrolls placed within it $\left(\mathrm{Oz}^{58}\right)$. According to $A$ the wrappers of cases do not come under the laws of diverse-kinds, for like wrappers of scrolls, they are not designed to be worn as garments.

B-E presents a dispute between Meir and Judah concerning the correct version of $M$. 9:3A-B's dispute between an anonymous opinion and Eliezer. B-C attributes M.'s version of the dispute to Meir. Judah then glosses B-C, reversing the opinions assigned by $M$. to the two parties of the dispute. ${ }^{59}$

\section{$9: 4$}

A. (1) Shrouds and (2) a pack-saddle $\left(m r d^{c} t\right)$ of an ass are not subject to [the laws of] diverse-kinds.

B. One shall not place a pack-saddle [of diverse-kinds] on his shoulder,

c. even to carry out dung upon it.

M. Kil. $9: 4$

M. turns from the discussion of items which are not designed to serve as garments (M. 9:2C-D, 9:3A) to a consideration of articles which are made to be worn, but not by man. M. opens with $A$, a sentence containing a compound subject, and glosses A with the autonomous rule of $\mathrm{B}-\mathrm{C}$. According to $\mathrm{A}$ shrouds and asses' pack-saddles do not come under the laws of diverse-kinds, for, although these items are designed to be worn, they are made to be used respectively on corpses and animals, to which the prohibition against wearing diverse-kinds does not apply. The point of $A$, then, is that the only items which are subject to the laws of diverse-kinds are those designed to serve as garments for man, the only one who is prohibited from wearing diverse-kinds. $B-C$ then serves to qualify $A$, ruling that one may not place a pack-saddle of diverse-kinds on his shoulder, for the pack-saddle would then cover and protect the shoulder and so function as a garment (MR). 60 Like M. $9: 2 \mathrm{C}-\mathrm{D}$, B thus rules that one may use an item which is not subject to the laws of diverse-kinds only as long as it does not serve as a garment. We shall see that $T$. takes $A$ and $B$ to be in dispute with one another, for $T$. understands A to imply that the shroud and the pack-saddle may be used in any way at all, even as a garment. Glossing $B, C$ adds that one may not place a pack-saddle of diverse-kinds on his shoulder even if he wishes only to carry out dung upon it, and thus does not intend to use it as a garment at all (as in M. 9:2G). 


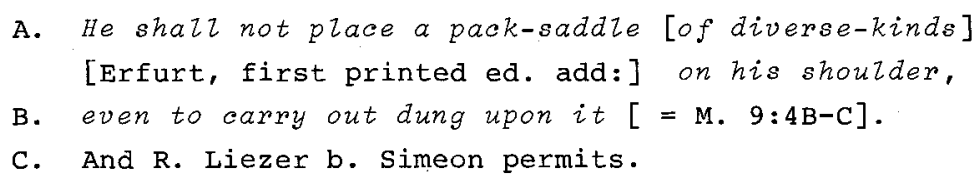

A-B cites M. 9:4B-C, which Eliezer b. Simeon glosses and opposes at $C$. Eliezer $b$. Simeon maintains that one is permitted to place a pack-saddle of diverse-kinds on one's shoulder, even though the pack-saddle then serves as a garment. Eliezer $b$. Simeon thus takes up the position of M. 9:4A, which states that a pack-saddle is not subject to the laws of diverse-kinds, and therefore implies that such an item may be used in any manner, even to serve as a garment. T. thus presents the views of M. 9:4A and $9: 4 \mathrm{~B}-\mathrm{C}$ in the form of a dispute, and so renders explicit the disagreement between the two rules which is only implicit in $M$.

A. A garment in which diverse-kinds were lost [some commentaries: ${ }^{61}$ A garment in which one wove $\left(\breve{s}^{\prime} r g\right)$ diversekinds]--

B. he shall not sell it to a gentile,

C. and he shall not make it into a pack-saddle of an ass.

D. R. Simeon b. Leazar says, "He shall not make it into a recognizable border ('ymp' hmpwrsmt) [of another garment],

E. "but he may make [Erfurt: makes] it into a shroud."

T. Kil. 5:19 (pp. 224-225, 11. 42-44)

$(A-C+E:$ B. Pes. 40b, A.Z, 65b,

Nid. 6lb)

T. consists of a mildly-apocopated sentence at $A-C$, which is glossed and continued by Simeon b. Eleazar at D-E. A describes a case in which threads of flax are woven into a garment of wool (or vice versa) in such a way that the flax becomes "lost" in the garment and cannot be distinguished from the wool (Lieberman [citing commentaries] ${ }^{62}$ ). According to $B$ one may not sell such a garment to a gentile, lest the latter in turn sell it to an Israelite. Being unable to spot the flax among the wool, the Israelite would then put on the garment, and so unknowingly wear an item of diverse-kinds. C then states that one may not make the garment of $A$ into an ass' pack-saddle, for one might pick up such a pack-saddle and place it on one's shoulder, and so unknowingly have an item of diverse-kinds serve as a garment 
(as in M. 9:4B-C). Simeon b. Eleazar adds at $D$ that one may not make the garment of $A$ into a recognizable border, i.e., a border of a garment which is composed of a different kind. The point of simeon b. Eleazar here is that one may not make a woolen garment containing threads of flax into a border of a garment of flax, even though the two garments together now clearly combine to form a garment of diverse-kinds, which one should be permitted to sell to a gentile. Simeon b. Eleazar apparently reasons that if one were to make such a garment of diverse-kinds and sell it to a gentile, the latter might remove the border and sell it separately to an Israelite, who again would unknowingly wear diverse-kinds (Lieberman ${ }^{63}$ ). Simeon b. Eleazar also rules that one may make the garment of $A$ into a shroud (E), for the latter does not come under the laws of diverse-kinds, and we thus need not be concerned lest someone using it transgress the prohibition against wearing diverse-kinds. By ruling that one may make the garment of $A$ into a shroud, but not into a pack-saddle, $T$. serves to make explicit a distinction between these two items which is implicit in $\mathrm{M}$. In juxtaposing the rule of M. 9:4A (i.e., pack-saddles and shrouds are not subject to the laws of diverse-kinds) with that of M. 9:4B-C (i.e., one may not place a pack-saddle of diverse-kinds on one's shoulder), M. has been understood by $T$. to imply that the latter rule applies specifically to the packsaddle, and not to the shroud, so that one is not liable for wearing a shroud of diverse-kinds.

$$
9: 5-6
$$

A. Clothes-dealers sell [garments of diverse-kinds] in their usual manner [i.e., while carrying them on their backs (Maim., Comm.)],

B. provided that they do not intend, in a hot sun, [for the garments to protect them] from the hot sun, or $(w)$, in the rain, [for the garments to protect them] from the rain.

c. And the more scrupulous ones [so Danby for $\$ n w^{\circ} y m$ ] tie [the garments of diverse-kinds] on a stick [B. Shab. 29b, $46 \mathrm{~b}$, B. Pes. 26b, explain: (and throw the garments) behind them (i.e., over their shoulders)].

$$
\begin{aligned}
& \text { M, Kil. } 9: 5 \text { (B. Shab. 29b, 46b, } \\
& \text { B. Pes. 26b; B: Y. Kil. 9:2 (32a)) }
\end{aligned}
$$

D. Tailors sew [garments of diverse-kinds] in their usual manner [i.e., with the garments resting on their laps (Bert.)],

E. provided that they do not intend, in a hot sun, [for the 
garments to protect them] from the hot sun, or $(w)$, in the rain, [for the garments to protect them] from the rain.

F. And the more scrupulous ones sew [while sitting] on the ground [i.e., with the garments resting on the ground as well].

M. Kil. $9: 6$

M. consists of two perfectly-matched subunits, $A-C$ and D-F. The two subunits balance one another at $A$ and $D$ (mwkry vs. twpry) and at $C$ and $F$ (mpsylyn bmq 2 vs. twpryn b'rs [plural present participle $+b$ - in each]), and are glossed by the same clause at $B$ and $E$. Since $B$ and $E$ are identical to one another, it is probable that they were respectively added together to the completed subunits $\mathrm{A}+\mathrm{C}$ and $\mathrm{D}+\mathrm{F}$.

Reverting to the concerns of $\mathrm{M} .9: 2 \mathrm{G}$ (and M. 9:4C), $\mathrm{M}$. discusses whether one is liable for wearing diverse-kinds even if he does not intend for them to serve as garments. According to $A$ and $D$ clothes-dealers, who usually carry their merchandise around on their backs, and tailors, who tend to rest clothes on their laps while they work on them, may bear diverse-kinds upon themselves just as they would bear any garment, for they do not intend for the diverse-kinds to function as their own clothing. $B$ and $E$ then underline this point, ruling that clothes-dealers and tailors may not intend to use the diverse-kinds to protect themselves from heat or rain, for then the diverse-kinds would surely serve as their personal garments. According to M., then, one's intention determines whether or not he is liable for wearing diverse-kinds. M. thus disagrees with M. 9:2G (Sens and others), which states that one may not wear a garment of diverse-kinds even if he wishes only to avoid paying customs-dues for it, and thus does not intend for it to function as clothing (cf. also $M .9: 4 C)$. $C$ and $F$ then augment respectively $A$ and $D$, adding that the more scrupulous clothes-dealers and tailors do not bear diverse-kinds upon themselves at all. Such clothes-dealers tie the diverse-kinds onto a stick and thus carry them over their shoulders, and not on their backs, and such tailors sew while sitting on the ground, and so allow the diverse-kinds to rest on the latter, and not on their laps.

A. (1) A birrus (hbrsyn ${ }^{64}$ ), and (2) a bardaicus [so Windfuhr 65 for hbrdsyn], and (3) a dalmatic (hdlmtqywn), and (4) shoes of coarse wool (mncly hpynwn; ${ }^{66}$ alternative translation: shoes of pinna)-- 
B. he shall not put them on until he shall examine [them for diverse-kinds].

C. R. Yose says, "Those [of the above items] which come from the seacoast or from distant lands (mmdynt hym) do not require examination [for diverse-kinds],

D. "for the presumption concerning them is [that they are composed] of hemp [and not flax]."

E. A cloth shoe [following Maim., Code, Diverse-Kinds 10:15 for $m n^{c} \imath \breve{s}_{z r} d^{67}$ (some mss.: ${ }^{68} m n^{c} \breve{s}_{z} \approx r b$ ); alternative translation: a cloth-lined shoe (Y. Kil. 9:5)] is not subject to the laws of diverse-kinds.

M. Kil. $9: 7$

M. consists of two autonomous parts, $A-D$, which discusses whether certain types of garments are likely to contain diversekinds, and $\mathrm{E}$, which returns to the issues of $\mathrm{M}$. 9:2-4 and concerns whether a certain kind of shoe is subject to the laws of diverse-kinds. A-D is composed of a mildly-apocopated sentence, $A-B$, which is grossed by Yosé at C-D. A-B lists four types of garments, the birrus, the bardaicus, the dalmatic, and shoes of coarse wool, ${ }^{69}$ all of which must be examined for diverse-kinds before being worn. The birrus and the bardaicus are types of heavy, ${ }^{70}$ hooded cloaks ${ }^{71}$ which were apparentiy made of wool, 72 and the dalmatic is a robe or tunic which could be made of either wool or linen. ${ }^{73}$ In the case of the birrus, bardaicus, and the shoe's of coarse wool, then, the point of $A-B$ is that the heavy or coarse wool of these garments may contain flax beneath its surface, so that the garments must be thoroughly inspected before they can be worn. The point of $A(3)$ is not clear, for $A(3)$ may be interpreted in one of two ways. If $M$, refers specifically to a dalmatic made of wool, then such a garment, like the other three items of A, may contain hidden flax and so must be carefully inspected. Alternatively, if $M$. refers to a dalmatic made of any kind of material, then $A(3)$ 's point is that one must examine the garment to be certain that it consists of wool or Iinen alone, and not of a mixture of diverse-kinds.

Yose qualifies $A-B$ and $C-D$, maintaining that any of the garments of $A$ which come from the seacoast or from distant lands are presumed to be free of diverse-kinds. These garments, which are composed mainly of wool, 74 are assumed to contain hemp rather than flax (e.g., in their stitching [Sens]) (D). Yose here apparently assumes that on the seacoast and in distant lands hemp, a coarse fiber used mainly for rope or sacking, is cheaper 
or more readily available than flax, and thus is substituted for the latter in the manufacture of clothing. 75

E consists of a simple declarative sentence following the formulary pattern 'yn bhm $m s$ wm $k l^{\prime} y m$ (M. 9:2-4) and thus serving to close the subunit begun at M. 9:2. E concerns the $m n^{c} l$ šzrd (or $\breve{s} z r b)$, which apparently refers to a kind of heelless cloth shoe or slipper (Maim., Code, Diverse-Kinds 10:15). According to $E$ such a slipper is not subject to the laws of diverse-kinds, for, although it is clearly designed to be worn, it does not completely enclose the foot. ${ }^{76}$ Unlike a garment, then, such a shoe is not made to stay securely on the body. 77 E thus complements M. 9:2-4's discussion of items which are not regarded as garments because they are not designed to be worn (or to be worn by man [M. 9:4]), turning to deal with an item which is made to be worn, but, because of the way it is worn, is not regarded as a garment. ${ }^{78}$

$9: 8$

A. Nothing is prohibited on account of [the laws of] diversekinds except [wool and flax which are] spun (twwy) or (w) woven ('rwg) [together],

B. as it is written, You shall not wear shacatnez (Dt, 22:11)-something which is hackled $\left(\breve{s}^{c}\right)$, spun $(t w w y)$, or $(w)$ woven $(n w z)$.

C. R. Simeon b. Eleazar says, "It [i.e., a fabric of diversekinds (Albeck)] is turned away $(n / w z)$, and turns $(m / y z)$ his Father in Heaven against him."

$$
\begin{aligned}
& \text { M. Kil. 9:8 (A: Y. Kil. } 9: 5 \\
& \text { (32d); B: B. Yev. 5b, Nid. 61b) }
\end{aligned}
$$

M. opens with a declarative sentence, $A$, which is augmented by $\mathrm{B}-\mathrm{C}$, an autonomous unit consisting of an exegesis of scripture at $B$ and Simeon $b$. Eleazar's gloss of $B$ at $C$. Reverting to the formulary pattern of M. 9:1A ('yn 'swr mšm kl'ym 'Z' X), A begins a new subunit dealing with the ways in which wool and flax may be combined or connected with one another. According to $A$ a union of wool and flax is prohibited only if the two fibers have been spun or woven together, for only through being combined in these ways are the fibers regarded as forming a mixture of diverse-kinds. B then augments $A$ with an exegesis of the word shacatnez $\left(\xi^{c} t n z\right)$ of Dt. 22:1l. Using the exegetical method of noţarikon, B divides $\breve{s}^{c}$ tnz into three parts, $\breve{s}^{c}, t$, and $n z$, and takes these parts to represent respectively the words $\breve{s}^{c}$ (i.e., hackled), twwy (i.e., spun), and nwz (i.e., woven). According 
to $B$, then, a union of wool and flax is prohibited if the fabrics have been either hackled, spun, or woven together. ${ }^{79}$ B has thus been juxtaposed with $A$ because it agrees with the latter's rule that wool and flax which are spun or woven together are prohibited. B disagrees with $A$, however, in maintaining that wool and flax which are hackled together are also prohibited. $B$ is thus not an entirely appropriate gloss of A.

At C Simeon b. Eleazar glosses $B$ with another interpretation of the word nwz ("woven"). Apparently taking the letters $n$ and $l$ to be interchangeable, ${ }^{30}$ simeon b. Eleazar reads $n w z$ as iwz, a verb meaning "to turn or bend." He then interprets shacatnez to refer to the notion of "turning" in two ways. First, a mixture of diverse-kinds is called $n z w z, 81$ i.e., turned awry, for it represents a deviation from the natural order, which is based on a system of distinct kinds (Albeck). Second, such a mixture is called mlyz, i.e., that which turns (something else), for it serves to turn or estrange God from its bearer.

A. Wool which one put into flax [i.e., to which one attached flax] in order to weave upon it [i.e., wool]--1o, this [i.e., the act of combining wool and flax] is prohibited, B. for at the same time that he would comb [following Lieberman, ${ }^{82}$ who reads $2 w g y z$ for $\left.2 y g w z\right]$ [the wool] it would become spun [with the flax].

$$
\text { T. Kil. 5:21a (p. 225, 1. 45) }
$$

T. serves to illustrate M. 9:8A's rule prohibiting wool and flax from being spun together. A describes a case in which one wishes to weave a fabric upon a warp of woolen threads. He therefore attaches pieces of flax to the ends of groups of woolen threads, presumably so that the threads would be weighted down ${ }^{83}$ and kept in place. 84 According to $A$ one may not join wool and flax in this manner, for in combing the wool (to separate the threads) and attaching the flax to it, one twists the threads of the fabrics together, and so, in effect, spins them together (following the commentary attributed to sens, Sifra qedoshim $\left.4: 18^{85}\right) .86$

A. Said R. Simeon b. Leazar, "Why is it called shacatnez?

B. "Because it turns (mylyz) his Father in Heaven against him [= M. 9:8B]." 
T. restates simeon b. Eleazar's gloss of M. 9:8B as an autonomous saying in a question-and-answer pattern. T. clarifies M. $9: 8 \mathrm{C}$ by explicitly stating that the subject of the saying is the diverse-kinds, and not the person wearing them. T. also omits nlwz ("turned awry") at B, perhaps because the term more appropriately describes a person than the subject of the sentence, a fabric.

A. You shall not wear shacațez (Dt. 22:11)--

B. Might I think that he shall not wear pieces of shorn wool (gyzy smr) and bundles of flax-stalks ('nysy p štn) together?

c. Scripture says, shacatnez--something which is hackled $\left(s w^{c}\right)$, spun (twwy) , or woven (nwz).

D. $\quad$ R. Simeon b teazar says "It [i.e. a fabric of diversekinds]. is turned awry (ntwz) and turns (mlyz) his Father in Heaven against him $[=\mathrm{M} .9: 8 \mathrm{~B}-\mathrm{C}]$

Sifre Dt. 232a (ed. Finkelstein, p. $265,11.1-3)$

A-B cites the clause you sharl not wear shacatnez (Dt. 22:11), taking it to mean that one may not wear anything made of diversekinds, even pieces of shorn wool which are joined to bundles of flax-stalks. C-D therefore presents the exegesis of shac atnez $\left(=\right.$ M. $9: 8 \mathrm{~B}-\mathrm{C}^{87}$ ), which prohibits one from wearing only wool and linen which have been hackled, spun, or woven together, but not pieces of wool and flax which have been simply fastened together. ${ }^{88}$

A. Felted stuffs [composed of wool and linen] are prohibited,

B. because they are hackled [i.e., their fibers are hackled together].

c. A fringe (pyw; most mss: ${ }^{89}$ pyp) of wool [fastened] onto [a garment of] flax is prohibited,

D. because they [i.e., the threads of the fringe] interlace the web [of the garment] [so Danby for hwaryn b'ryg; some readings: ${ }^{90} z^{\prime} r y g$; printed ed.: k'ryg ("they come up as if woven [together with the flax ${ }^{91 ")}$ ].

E. R. Yose says, "Cords [composed] of purple [wool] are prohibited [to be worn on a garment of flax],

F. "because one bastes (mwIZ) [the cord to the garment] before tying [the ends of the cord together]." 
G. One shall not tie a strip (srt) of wool to one of linen in order to gird his loins,

H. even though a [leather (most comm.)] strap is between them.

M. Kil. $9: 9$ (A-B: Y. Kil. $9: 5$

(32d); E: Y. Kil. $\left.9: 5(32 d)^{92}\right)$

M. consists of four rules, A-B, C-D, E-F and G-H. The first three rules all follow the same formulary pattern ( $X+$ 'swrym/'swr + mpny $\zeta$ ) and thus were formulated together. These rules, however, differ with one another in substance, for A-B and C-D augment M. 9:8's discussion of mixing together wool and flax, while Yose at E-F deals with the separate question of attaching discrete items of wool and linen with one another. G-H then continues the discussion of this issue with an autonomous rule (following its own formulary pattern $\left[l^{\prime}+\right.$ imperfect + $\left.{ }^{\prime} p c_{2} \mathrm{c}_{\mathrm{s}} \mathrm{s}\right)$. It appears, then, that a redactor has so formulated $E-F$ that it presents the issue of $\mathrm{G}-\mathrm{H}$ in the formulary pattern of $A-B$ and $C-D$, and thus serves to link the pericope (and the subunit of M. 9:8-10) together.

A-B concerns felt, a fabric consisting of fibers which have simply been compressed together. ${ }^{93}$ According to A felted stuffs composed of wool and linen are prohibited as fabrics of diversekinds, for, although the fibers of such cloths are not spun or woven together, they are hackled with one another (B). A-B thus illustrates the rule of M. 9:8B, which, unlike M. 9:8A, prohibits one from wearing wool and linen which are hackled together. $C$ then rules that one may not attach a fringe or border of wool to a garment of linen, for the woolen threads would then become entangled with the web of the garment (D) and so appear to be woven together with the linen. C-D thus augments M. 9:8A-B's prohibition against wearing wool and linen which are woven together, maintaining that the wool and linen may not even appear to be woven with one another, regardless of whether or not they actually form a mixture of diverse-kinds.

At $\mathrm{E}$ Yose states that one may not wear cords composed of purple wool on a garment of flax (Ribmas, Sens, Rosh), for such cords would be temporarily stitched to the garment under them and thus held in place before being tied (F). In this case, then, the cords would be attached to the garment of flax, and so would combine with the latter to form a garment of diverse-kinds. 94 $G$ then rules that one may not tie a strip of wool and flax to one another and thus make a belt, for the two strips would then be connected to one another and so combine to form a single garment 
of diverse-kinds. Glossing $\mathrm{G}, \mathrm{H}$ adds that the strips of wool and flax are considered to be connected to each other even if they are attached to opposite ends of a leather strap, and thus do not touch one another at all. 95

A. R. Hananiah b. Gamaliel says, "One shazr not tie a strip (srq) of wool and [a strip] of linen [together] in order to gird his loins,

B. "even though a [Zeather] strap is between them [= M. 9:9G-H]." T. Kil. $5: 22$ (p. 225, 11. 47-49)

A-B cites M. 9:9G-H with only minor differences (e.g., reading $s r q$ for $s r t^{96}$, , attributing the anonymous rule of $M$. to Hananiah b. Gamaliel.

W. Felted stuffs [composed of wool and linen] are prohibited $[=\mathrm{M} .9: 9 \mathrm{~A}]$ on account of $[$ the laws of $]$ diverse-kinds,

$x$. [for] even though they do not come under [the category of] woven [fibers], they do come under [the category of] hackled [fibers].

Sifre Dt. $231 f$ (ed. Finkelstein, 97

p. $265,11.11-12)$

W cites and glosses M. 9:9A. Presupposing the prohibition against wearing wool and linen which are hackled, spun, or woven together, $\mathrm{X}$ then simply restates and slightly expands $\mathrm{M}$. 9:9B.

A. Nor [shall] a garment of cloth made up of two kinds [of stuff come upon you $]^{98}$ (Lv. 19:19)--

B. Why does Scripture say so?

C. Since Scripture says, you shall not wear a mingled stuff, wool and linen together (Dt. 22:11), might I [not] think that one shall not wear pieces of shorn wool (gyzy șmr) and bundles of flax-stalks ('nyṣy prtn) together?

D. Scripture says, A garment.

E. I know [from this phrase] only [that the laws of diverse-kinds apply to] a garment.

F. Whence [do I know] to include felted stuffs [in the prohibition]?

G. Scripture says, [A garment of cloth made up of two kinds] of stuff $\left(s h a^{c} a t n e z\right)-$ something which is hackled $\left(\breve{s}^{c}\right)$. spun $($ twwy) $)$ or woven (nwz). 
H. R. Simeon b. Eleazar says, "It [i.e. ! a fabric of diversekinds]. is turned awry (nlwz) ! and turns (mlyz) his Father in Heaven against him $[=$ M. $9: 8 \mathrm{~B}-\mathrm{C}]$. Sifra Qedoshim 4:18a (ed. Weiss, 89a)

A-B cites Lv. 19:19, asking why it is necessary for scripture to state this verse, since Dt. $22: 11$ also prohibits one from wearing diverse-kinds (Hillel). C-D answers that Dt. 22:11, which states simply you shall not wear a mingled stuff, may be taken to mean that one may not wear anything which is composed of diverse-kinds, even pieces of shorn wool and stalks of flax which have been joined together. Lv. 19:19 therefore specifically mentions the word garment, and so includes in the prohibition only garments, and not other items composed of vegetable or animal fibers. 99

E-F then takes the word garment to refer only to items which are woven, and thus asks whether the prohibition of Lv. 19:19 applies also to felted stuffs which are composed of wool and linen. G-H answers by citing ${ }^{100}$ the exegesis of shacatnez (= M. 9:8B-C), which rules that hackled fibers of wool and linen are also prohibited as fabrics of diverse-kinds. E-H thus agrees with the rule of $M$. 9:9A-B, and directly links this rule to the exegesis of shacatnez at 9:8B-C.

\section{$9: 10$}

A. Marks of weavers [so Danby for hgrdyn] and marks of washermen [which are composed of wool or linen and sewn respectively onto garments of linen or wool] are prohibited on account of [the laws of] diverse-kinds.

B. He who fastens [wool and linen together] with a single fastening [of thread] [following I. Epstein ${ }^{101}$ for htwkp tkyph 'ht] [i.e., with an incomplete stitch]--

c. it [i.e., the fastening] is not considered a connector [for uncleanness],

D. and it [i.e., the fabrics joined by the fastening] is not subject to [the laws of] diverse-kinds,

E. and he who undoes it [i.e., the fastening] on the Sabbath is exempt [from liability for tearing a stitch in order to sew another].

F. [If] he brought both ends [of the thread] to one side [i.e., if he completed the stitch]--

G. it [i.e., the stitch] is considered a connector [for uncleanness], 
H. and it [i.e., the fabrics joined by the stitch] is subject to [the laws of] diverse-kinds,

I. and he who undoes it [i.e., the stitch] on the Sabbath is liable.

J. R. Judah says, "[The above rules do not apply] unless he makes three [fastenings] [i.e., one complete and one incomplete stitch]."

K. A sack and a basket [that are patched, one with wool and the other with linen, and then bound together,] combine to produce diverse-kinds.

$$
\begin{aligned}
& \text { M. Kil. 9:10 (B-C: B. Shab. 54a, } \\
& \text { Men. 39a; F: Y. Kil. 9:6 (32d), } \\
& \text { Y. Shab. 7:2 (10c); J: Y. Kil. 9:6 } \\
& \text { (32d); K: Y. Shab. 13:1 (14a)) }
\end{aligned}
$$

M. consists of three autonomous rules, A, B-I (glossed by $J)$, and $K$, all of which deal with the problem of attaching wool and linen to one another. A concerns threads which weavers and washermen would sew into garments in order to mark them for identification. According to $\mathrm{A}$ one may not for this purpose sew a woolen thread into a linen garment (or vice versa), for the garment would then contain diverse-kinds. The point of A is that, although the thread is actually extrinsic to the garment (i.e., it is added after the garment is completed) and serves no function for the owner (cf. Maim., Code, Diverse-Kinds 10:23), it is nevertheless connected to the garment, which thus is regarded as containing diverse-kinds.

B-I presents a series of rules related to the question of the connection of fabrics. The pericope has been redacted here because it is relevant to the issue of diverse-kinds at $\mathrm{D}$ and $\mathrm{H}$. B-I is a unitary construction consisting of a mildly-apocopated sentence, $B-E$, and a conditional sentence, $F-I$, the apodoses of which balance one another (C-E vs. G-I). Judah then glosses F-I at J. According to B-E a thread which is inserted through two fabrics (taken, in this context, to be wool and linen) only once does not serve to connect them together. The thread thus is not considered a connector (C), presumably for uncleanness (most commentaries), the fabrics of wool and linen do not combine to form a garment of diverse-kinds (D), and one is permitted to undo the fastening on the sabbath $(E)$. In this instance one is not liable for tearing a stitch in order to sew it again, since the stitch has not been completed (Sens, Bert,). ${ }^{102}$ If, on the other hand, one brings the thread through the fabrics 
again (F), and thus completes a full stitch, the thread is regarded as connecting the two fabrics together and the rules of C-E are reversed. ${ }^{103}$ Judah then opposes F-I at J, maintaining that the fabrics are not considered to be connected unless the thread is inserted through them an additional time, or three times in all.

$K$ describes a case in which a sack and a basket are patched, one with wool and one with linen, and then joined together. According to $\mathrm{K}$ these two items combine to produce diverse-kinds and so, for example, may not be carried on one's back (Maim., Comm.; cf. M. 9:4B-C). The point of $\mathrm{K}$ is that, although the wool and linen patches are not directly attached to each other, they are fastened to items which are joined together, and which thus serve to connect them with one another. $K$ thus carries forward the rule of $\mathrm{M}$. 9:9G-H, turning from a case in which wool and linen are fastened to the same item (the leather strap) to an instance in which the two fabrics are attached to separate items which are joined together.

A. A woolen fringe [so Jastrow for ${ }^{c} y t$; alternatively: a wrapper (Lieberman $\left.\left.{ }^{104}\right)\right]$ which one put into flax [i.e., which one attached to $f l a x]$ is permitted.

B. [If] he brought both ends. [of the fringe] to one side [= M. $9: 10 \mathrm{~F}]$, it is prohibited.

$$
\text { T. Kil. 5:20 (p. 225, 11. 44-45) }
$$

T. describes a case in which an ${ }^{c} y t$ of wool is attached to a linen garment. The meaning of ${ }^{c} y t$ is not clear, and the term has been taken to refer either to a fringe or a kind of wrapper. According to $A$ one is permitted to attach a woolen ${ }^{c} y t$ to a linen garment by inserting it into the latter, for a simple fastening is not considered to connect the two fabrics together. If, on the other hand, one inserts the wool into the linen and brings it out again, so that both ends of the ${ }^{c} y t$ lie on the same side of the garment, the two fabrics are considered to be connected with one another, and they thus combine to form a garment of diverse-kinds (B). T. thus complements M. 9:10B-I (citing M. 9:10F at B). While the latter discusses whether a thread inserted into two garments serves to connect one to the other, T. concerns whether an item which is itself inserted into a garment is considered to be connected to the latter. We note that if the cyt does refer to a fringe, then $T$. apparently reads the rule of $M .9: 10 B-I$ into the case of $M$. 9:9C-D, which concerns 
one who attaches a woolen fringe to a linen garment. According to this interpretation, then, T. serves to link M. 9:10B-I to M. 9:9C-D.105 If $T$. does concern a woolen fringe, though, it does not deal with the issue of M. 9:9C-D, for the latter prohibits one from attaching a woolen fringe to a linen garment, lest the two fabrics appear to be woven together.

Q. R. Hananiah b. Gamaliel says, "Whence [do I know that] one shall not tie a strip (srt) of wool to one of linen in order to gird his loins,

R. "even though a [leather] strap is between them [= T. 5:22]?

S. "Scripture says, [You shail not wear a mingied stuff, wool and linen] together (Dt. 22:11)--under all circumstances."

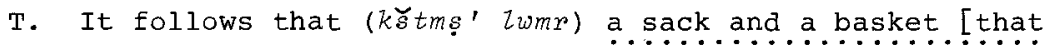
are patched, one with wool and the other with linen, and then bound together, $]$ combine to produce diverse-kinds $[=\ddot{M} \cdot 9: 10 \mathrm{~K}]$.

Sifré Dt. 232d (ed. Finkelstein, p. $265,11.8-10)$

Q-R cites T. 5:22 ( = the anonymous rule of $M .9: 9 \mathrm{G}-\mathrm{H}$ ), adding the word "whence" to the saying and so rephrasing it as a question. S then presents an exegetical basis for the rule of Q-R, taking the word together of Dt. 22:11 to indicate that wool and linen may not be joined together under any circumstances, even if the two fabrics are separated by a leather strap and thus not directly attached to one another. T then cites M. 9:10K and links it to $\mathrm{S}$. According to $\mathrm{T}$, then, the reasoning behind M. 9:10K is that wool and linen may not be joined together in any manner, even if they are attached to separate items (i.e., the sack and the basket) which have been joined together. Sifre thus links M. 9:10K to M. 9:9G-H by showing that both cases illustrate the same principle.

A. A tuft [of wool] (hpwqryt) and a strip [of wool] (eyph) are not subject to [the laws of] diverse-kinds.

B. And if he sewed them [i.e., if he sewed the ends together in each case],

C. they receive uncleanness,

D. and are prohibited on account of [the laws of] diverse-kinds.

$$
\text { T. Kil. 5:23 (p. 225, 11. 49-50) }
$$


T. is an autonomous pericope concerning whether or not pieces of wool used as dressings for wounds are subject to the laws of diverse-kinds. T. exactly follows the language of T. 5:16's rule concerning the status of women's bath-towels. According to A tufts or strips of wool, ${ }^{106}$ which were usually placed on wounds (Lieberman ${ }^{107}$ ), do not come under the laws of diverse-kinds. The point of $A$ is that these pieces of wool are simply put on the wound, but are not bound securely to it, so that, unlike a garment, they are not made to stay on the body. If, however, one ties the ends of the tufts or strips together (B), then the pieces of wool are designed to stay on the body, and therefore are regarded as garments. ${ }^{108}$ Like garments, therefore, they receive midras-uncleanness (C), 109 and are subject to the laws of diverse-kinds. 110 



\section{INTRODUCTION}

$1_{\text {The tractates which discuss man's role in ordering the }}$ sacred deal with his ability to bring objects into (or, in some cases, remove them from) a process of sanctification and uncleanness. In the Division of Agriculture the tractates Terumot and Macaserot in particular state that man is able to designate heave-offering and tithes. For an analysis of Mishnah's conception of agricultural offerings, see R.S. Sarason, "Mishnah and Scripture: Preliminary observations in the Law of Tithes," now published in W.S. Green, ed., Approaches to the Study of Ancient Judaism, II (Missoula: Scholars Press, 1980). The tractates Zebahim and Menahot in the Division of Holy Things deal with the effect of man's intention upon the designation of sacrifices and meal-offerings; see the analysis of J. Neusner, $A$ History of the Mishnaic Law of Holy Things (Leiden: E.J. Brill, 1978-80), VI, Chapters 2-3. Finally, in the Division of Purities the tractates Kelim and Makhshirin in particular claim that man is able to render objects susceptible to uncleanness, while the tractates Parah and Miqvaot deal with man's role in the process of purification; see the analysis of J. Neusner, A History of the Mishnaic Law of Purities (Leiden: E.J. Brill, 1974-77), XXII, pp. 269-303.

${ }^{2} \mathrm{BDB}$ (p. 476) explains $k L^{\prime} y m$ as meaning "two", and as having cognates in Arabic and Ethiopic. M. Noth (Leviticus: $A$ Commentary, trans. J.S. Anderson, The old Testament Library [Philadelphia: Westminster Press, 1965], p. 142) notes that the term perhaps originally meant "double," but here has the sense of "of two different kinds."

$3_{\mathrm{BDB}}$ (p. 1043) notes that A. Knobel derived the word $\mathfrak{s}^{c}$ thz from the Coptic saht (woven) and nudj (false). Lv. 19:19 appends to $\xi^{c} t n z$ the term $k l^{\prime} y m$, "of two kinds, " and so takes $s^{c} t n z$ to refer to a garment composed of any mingled stuff. Dt. $22: 11$, on the other hand, explains $\widetilde{s}^{c} t n z$ with the phrase smr wpstym yhdyw, "wool and linen together," and so defines the term as referring to the mingling of these two kinds alone.

${ }^{4}$ Cf. J. Soler, "The Dietary Prohibitions of the Hebrews," New York Review of Books, June 14, $1979(26: 10)$, p. 29.

${ }^{5}$ For a detailed study of this phenomenon in the Division of Purities, cf. J. Neusner, A History of the Mishnaic Law of Purities, XXI, Chapter Two.

6 Tosefta Ki-fshutah. A Comprehensive Commentary on the Tosefta. I. Order Zeracim (New York: Jewish Theological Seminary, 1951).

${ }^{7}$ The Six Orders of Mishnah. I. The order of Zeracim [Heb.] (Jerusalem and Tel Aviv: Bialik Institute and Devir, 1957), pp. 95-129.

${ }^{8} M$. Zeracim (Jerusalem: Makhon HaTalmud HaYisraeli HaShalem, 1972-75), I, pp. 219-305.

pp. 28-39.

${ }^{9}$ The Mishnah (London: Oxford University Press, 1933), 
10 Mishnayot. I. Order Zeraim (2nd ed.; New York: Judaica Press, 1964), pp. 273-299.

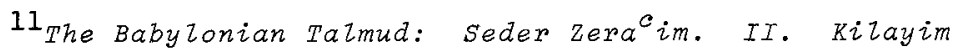
(London: Soncino Press, 1948), pp. 130-144.

12 The Tosefta. I. Order Zeracim (New York: Jewish Theological Seminary, 1955), pp. 203-226.

${ }^{13}$ Sifra debe Rab (1862; rpt. New York: Om, 1946).

14 Sifré on Deuteronomy (Berlin, 1939; rpt, New York; Jewish Theological Seminary, 1969).

\section{CHAPTER ONE}

$1_{\text {Either Triticum durum ("hard" wheat) or Triticum aestivum }}$ (vulgare, turgidum) ("soft" wheat). For all Latin names, see Yehuda Feliks, Mixed Sowing, Breeding and Grafting [Heb.] (Tel Aviv: Devir, 1967), p. 17 .

2 Tare is also called bearded darnel (both names are given by Danby). Its Latin name is Lolium temulentum.

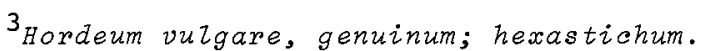

${ }^{4}$ Hordeum distichum.

$5_{\text {Triticum diococcum. }}$

6 Triticum spelta.

${ }^{7}$ Vicia faba.

${ }^{8}$ Vicia narbonensis. This is apparently the only place this bean appears in rabbinic literature (Feliks, Mixed Sowing, p. 35). The identification was first made by Immanual Löw, Die Flora der Juden (Vienna: R. Löwit, 1926), II, p. 503.

${ }^{9}$ Lathyrus cicera.

${ }^{10}$ Lathyrus sativus.

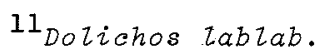

12 vigna nizotica.

13 Although Maimonides presents this interpretation only with reference to $C(3)$, we assume that it applies to the entire pericope.

${ }^{14}$ This is true, of course, only if we assume that our identifications (which follow those of Feliks, Mixed Sowing) are correct. We admit that the method of identification may sometimes be circular in nature, for one member of a pair may be identified on the basis of its resemblance to the second. It is possible, however, to identify members of pairs by other methods (e.g., the endives and wild endives of $M .1: 2$ ) and to infer from these cases that the members of each pair resemble one another, thus avoiding the circularity. 
${ }^{15}$ Feliks, Mixed Sowing, p. 22.

${ }^{16} \mathrm{Cf}$. the parable of the wheat and tares, Mt. 13:24-30.

17 Jonah in Y. 1:I (26d) presents the view that tares constitute an inferior variety of wheat, comparing the name zwnyn to the root $Z N H$, "to go astray."

${ }^{18}$ S. G. Harrison, G. B. Masefield, and Michael Wallis, The oxford Book of Food Plants (London: Oxford University Press, 1969), pp. 4-5.

${ }^{19}$ Feliks, Mixed Sowing, p. 29.

$20_{\text {Ibid., p. } 35 .}$

${ }^{21}$ Cucumis meto var. Chate. For all Latin names, see Feliks, Mixed Sowing, p. 44.

${ }^{22}$ Cucumis mezo $L$.

${ }^{23}$ Lactuca sativa, Zongifolis.

${ }^{24}$ Lactuca scariola.

25 This reading is given by several Geniza fragments and the commentary of R. Nathan, the Head of the Academy. See Zachs, pp. 220, on 1.4. Cf. also Erfurt's reading of $T .1: 1 \mathrm{C}$.

${ }^{26}$ Cicorium intybus.

${ }^{27}$ Cicorium pumilum.

28 azzium porrum.

29 Allium ampeloprasum.

${ }^{30}$ Coriandrum sativum.

$31_{B i f o r a}$ testieulata.

32 Brassica nigra.

${ }^{33}$ Sinapsis alba.

${ }^{34}$ Lagenaria vulgaris forma Asiatica.

${ }^{35}$ This gourd probably has the same name as that given in the previous note.

${ }^{36}$ Vigna sinensis Savi.

${ }^{37}$ Vigna sesquipedalis. This is also called the yard-long bean (Feliks, Mixed Sowing, p. 73, n. 77).

${ }^{38} \mathrm{Cf}$. also Maimonides, Code, Diverse-Kinds $3: 3$.

${ }^{39} \mathrm{Y}$. Kil. $1: 2$ (27a) reads as follows:

A. (1) Chate melons, and (2) watermelons, and (3) musk melons

B. are not [considered] diverse-kinds with one another.

C. R. Judah says, "[They are considered] diverse-kinds."

$Y$. thus differs from M. in adding watermelons at A (perhaps 
from $T$. $1: 1 \mathrm{H}$; see above $\mathrm{P}, 30$ ) and thus has $A$ contain three melons rather than two.

${ }^{40}$ Pair (8) presents a problem, fcr its seems to make the same distinction that (9)-(11) make. Its language, however, is slightly different, and it thus does not appear originally to have belonged with the group of three pairs. (8), therefore, either stands alone or is part of a group of five $((8)-(12))$, depending on how we read (12).

${ }^{41} 1_{\text {Feliks, Mixed Sowing, p. } 52 .}$

42 Ibid., p. 63 .

${ }^{43}$ Cf. George E. Post, Flora of syria, Palestine and sinai. Second edition. Ed. by J. E. Dinsmore (1896; Beirut: American Press, 1932-3), I, p. 123.

${ }^{44}$ Feliks, Mixed Sowing, p. 65.

45 Ibid., p. 70. For Amoraic interpretations of the name rmwgh, see B. Bokser, Samuel's Commentary on the Mishnah (Leiden: E.J: Brill, 1975), I, pp. 34-38.

${ }^{46}$ Lageneria vurgaris.

${ }^{47}$ Citrullus vulgaris. This identification follows Feliks in Mar'ot HaMishnah (Jerusalem: Midrash Bnei Siyon, 1967), p. 2. In Mixed Sowing, p. 52, Feliks identifies 'btyh as citruzzus colocynthis, the colocynth.

${ }^{48}$ Concerning the different attributions, see Lieberman, $T K$, II, p. 597 on 1.5 .

${ }^{49}$ But cf, Tos., B. Shab. 85b, s.v. 'ytybyh, which rules the opposite, and MR to M. Kil. $3: 4$.

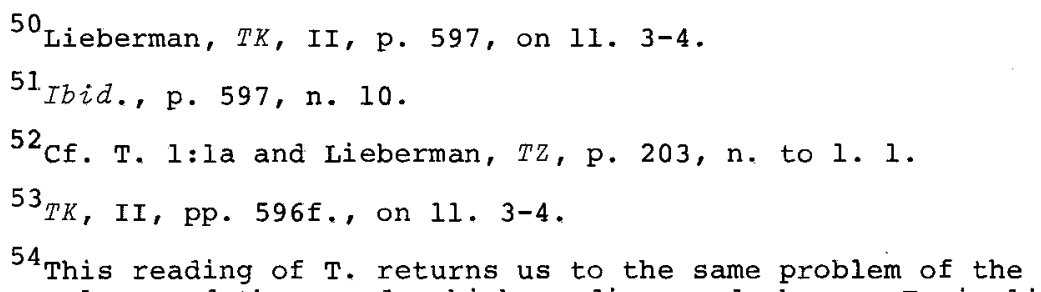
chate melons and the gourds which we discussed above. T. implies that since neither the chate melon nor the gourd is considered diverse-kinds with the musk melon, the chate melon and the gourd are also not considered diverse-kinds with each other. As we have already mentioned, M. Kil. 3:4-5 implies that the chate melon and the gourd are considered diverse-kinds. Again we may offer two explanations. We may simply say that $\mathrm{T}$. disagrees with $\mathrm{M}$. Alternatively, Iieberman argues (TK, II, Pp. 596-597, on 11. 3-4) that one may not infer from $T$, that the chate melon and the gourd are not considered diverse kinds. Although the chate melon is not considered aiverse-kinds with the musk melon, it still may be considered diverse-kinds with the gourd (or the watermelon). T. then does not oppose $M, 3: 4-5$.

In order to justify this way of reading $T . " s$ list, Lieberman analyzes the treatment of the baraita given in $Y$. 1:2 (27a), which adds "watermelons" to M. $1: 2 \mathrm{~A}-\mathrm{C}$ (cf. above n. 39). Y. begins by asking what Judah would say concerning the chate melon and the watermelon, since he offers no explicit opinion as to 
whether or not they are considered diverse-kinds. $Y$, then cites the baraita and asks whether Judah's opinion may be deduced from it. The conclusion is that Judah's opinion refers to two pairs, the first and third melons on the one hand, and the second and third on the other. However, his opinion concerning the first two melons themselves (the chate melon and the watermelon) cannot be deduced (following PM, GRA). Lieberman interprets the conclusion of $Y$. as referring to the anonymous opinion of the baraita as well, so that no ruling at all concerning the first and second melons is deducible, Lieberman thus reads $T$. in the same way, and concludes that chate melons and gourds need not be considered diverse-kinds with one another. p. 74 .

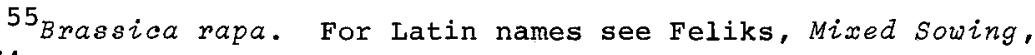

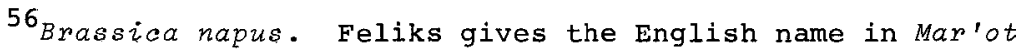
HaMishnah, p. 89. In Mixed Sowing, p, $78 \mathrm{n}$. 13, he called the plant a turnip. For mss. reading npws see Zachs, I, p. 221, on 1.7 .

57 Brassica oleracea var. acephala.

${ }^{58}$ Possibly Brassica oleracea var. Capitata (Feliks, Mixed Sowing, p. 81, n. 28).

${ }^{59}$ Beta vulgaris var. cicla.

60 Rumex acetosa. Feliks, p. $85, \mathrm{n} .38$, credits Löw, I, p. 358, with the identification. The English name is given by Feliks in Mar'ot HaMishnah, p. 82.

${ }^{61_{\text {For a }}}$ full list see Zachs, I, p. 222 , on 1.8 .

${ }^{62}$ Allium sativum.

${ }^{63}$ Alzium schoenoprasum.

64 Aliium cepa.

${ }^{65}$ Alzium ascalonicum.

${ }^{66}$ Lupinus termis.

${ }^{67}$ Lupinus luteus.

${ }^{68}$ Although M. 1:4 lists two pairs which also seem to belong on the list, these pairs are actually part of a separate list of fruits of M. $1: 4$.

${ }^{69} \mathrm{Y}$. N. Epstein, Introduction to Amoraitic Literature [Heb.] (Jerusalem: Magnes Press, 1962), p. 401, n. 3 .

${ }^{70}$ Feliks, Mixed Sowing, p. 79. Cf, also Y. $1: 5$ and Maimonides, Code, Diverse-Kinds $3: 6$.

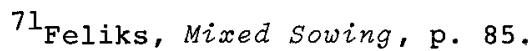

72 Ibid., pp. 88-89.

${ }^{73}$ This explanation may also account for the lack of a subscription following $T$. I:2A (for Simeon's comment would make little sense after $M .1: 3 \mathrm{D}$ as we have already seen).

${ }^{74}$ Cf. Feliks, Mixed Sowing, pp. 77-78. 
p. 90 .

75 Pirus communis. For Latin names, see Feliks, Mixed Sowing,

$76_{\text {pira crustamina. }}$

${ }^{77}$ Cydonia obzonga (= C. vuzgaris).

${ }^{78}$ Crataegus azarolus.

${ }^{79}$ Malus sylvestris (=Pyrus malus = Malus communis).

80 Pirus syriaca.

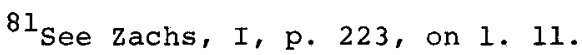

${ }^{82}$ Persica vulgaris (= Prunus persica).

${ }^{83}$ Amygdalus communis (= Prunus amygdalus).

${ }^{84}$ zizyphus jujuba (=z. vulgaris).

${ }^{85}$ Zizyphus spina-Christi. The English name is given by Feliks, Mar'ot HaMishnah, p. 138 .

${ }^{86}$ We note that, although we assume that B lists two pairs, $Y$. presents a dispute concerning this very point. In $Y$. Kil. $1: 4$ (27a) Rav and Joshua $b$. Levi argue as to whether $B$ contains two pairs or a single group of four. Y. apparently concludes that $B$ speaks of two pairs. The four fruits do appear as a single group, however, in other contexts in M.-T. Zera im (M. Macas. 1:3, T. Shev. 7:16), so that it is possible that they should be so considered here as well.

87Feliks, Mixed Sowing, pp. 93-96.

${ }^{88}$ Löw, III, p, 245.

${ }^{89}$ Feliks, Mixed Sowing, pp. 93-96.

90 Ibid., p. 96. Cf. M. Dem. 1:1, where cwarr is considered one of the qlyn $\breve{s} b d m ' y$.

91 Feliks, Mixed Sowing, pp. 99-101.

92 Ibia.

${ }^{93}$ As we have noted above (p. 27) it was probably his interpretation of $M$. $1: 4$ (and $M .1: 5-6$ as well) which is based on $M$. $1: 4 \mathrm{E}$, that led Maimonides to his interpretation of M. $1: 1-3$.

$94 \mathrm{M}$. Avi-Yonah places Ariah on the shores of the sea of Galilee, southwest of Tiberias: Cf. Carta's Atias of the Period of the Second Temple, the Mishnah and the Talmud [Heb.] (Jerusalem: Carta, 1966), map 131. Elsewhere, Avi-Yonah mentions the accepted identification of Bet Yerah as Philoteria, but expresses doubts about this identification. Cf. Historical Geography of Palestine from the End of the Babylonian Exile up to the Arab Conquest [Heb.] Second edition (Jerusalem: Bialik Institute, 1951), p. 139, n, 2 .

95 Raphanus sativus. Feliks, Mixed Sowing, p. 79. The English name is given by Feliks in Mar'ot HaMishnah, p. 120 .

96 Brassica napus. 
${ }^{97}$ For a full list see Zachs, I, p. 224 , on 1.13.

${ }^{98}$ Brassica nigra (M. $1: 2$ above (p. 317, n. 32)).

${ }^{99}$ Sinapsis arvensis. Feliks, Mixed Sowing, p. 63. In Mar'ot HaMishnah Feliks translates it (more literally than we have) as "field mustard."

100 An African variety of Lagenaria vulgaris. Feliks, Mixed Sowing, p. 70 .

${ }^{101}$ Lagenaria vulgaris forma Asiatica (M. 1:2, above (p. 28 and n. 34$))$.

102 For a full list see Zachs, I, p.224, on 1.14.

${ }^{103}$ see n. 101 above.

104 Maimonides, Code, Diverse-Kinds 3:5-6, interprets taste as a major criterion for determining diverse-kinds (the other criterion being similarity in appearance) only in the case of two plants which are not of the same kind $(m y n)$. If they are of the same kind, they are not considered diverse-kinds even if they are not similar in appearance or taste. MR (to M. 1:1), however, takes taste as a significant criterion (along with appearance) for all determinations of diverse-kinds and interprets $M$. accordingly. The plants listed in M. $1: 1$ are thus not considered diverse-kinds, for, while they differ slightly in taste (and therefore might be considered diverse-kinds), they are similar in appearance. If, however, two plants differ greatly in taste (or slightly in taste but greatly in appearance) they are considered diverse-kinds. And if the two plants do not differ at all in respect to taste, even if they differ greatly in appearance, they are not considered diverse-kinds.

${ }^{105}$ Feliks, Mixed Sowing, p. 66.

${ }^{106}$ Ibia.

107 Ibid., p. 70 .

108 We assume this because they are both varieties of the same species of gourds.

${ }^{109} \mathrm{Cf}$. Feliks, Mixed Sowing, p. 70.

110 It does not appear likely that a third list, relating the plants which are common to both $M .1: 1-3$ and $M .1: 5$, (e.g., Egyptian mustard and wild mustard) may be generated from the two lists before us. We cannot determine the status of plants B and $C$, even knowing that $A$ and $B$ are not considered diverse-kinds, and that $A$ and $C$ are so considered. While we may assume that $B$ and $C$ resemble each other, we cannot know whether or not they might form a pair which would be considered diverse-kinds in spite of a similarity of appearance. Therefore, I do not believe that we can logically derive a third list. Y. 1:2 does not discuss one pair which would be on such a list, the turnip and the radish, but its conclusion is unclear (see Maimonides, Code, Diverse-Kinds 3:5-6, Rabad's comments there and MR to M. 1:2).

${ }^{111}$ Anethum graveolens. For all Latin names see Lieberman, $T K$, II, p. 596, notes 1, 2, 4, 5, and Harrison, Mansfield and Wallis, The oxford Book of Food Plants, p. 148. 
112 Foeniculum vulgare.

113 Apium graveolens.

114 Lieberman, $T K, I I$, p. 596, on 1.2 , says that the four plants belong to Umbellaceae. Post, pp. $327 \mathrm{ff}$, lists them under Umbelliferae, as does Michael Zohary, A New Analytical Flora of Israel (Tel Aviv: Am Oved, 1976), pp. 270, 273.

${ }^{115}$ Harrison, Mansfield and Wallis, op.cit., p. 138.

${ }^{116}$ Feliks, Mixed Sowing, p. 63.

$117_{T Z}$, p. 204 , note to 1.14 .

118 Bokser, pp. $35 \mathrm{f}$.

${ }^{119} \mathrm{Y}$.'s version differs from that of $\mathrm{T}$. in that the order of its items is $1,4,2,3,5$.

120 Feliks, Mixed Sowing, p. 308 , n. to 1.3 .

$121_{Y} .2: 11$ (28b) explains that T. refers only to actual contact between the Greek gourd and the other plants, but the Greek gourd may be allowed to overshadow them.

$122_{T K}$, II, p. 599, on 1. 15. Cf. also Bert. to M. Uqs. 1:6.

${ }^{123}$ That is, one does not take account of the volume of the stalk in calculating the volume of the gourd. An item of food becomes unclean only when it has the volume of an egg (cf. Bert. to M. Uqs. $1: 1$ ).

$124 \mathrm{M}$. comments at the end of the list that the prohibition involved is either orlah (fruit of the first three years after planting) or diverse-kinds of the vineyard. Since orlah applies only to the fruit of the tree (Maim., Comm., ad. Zoc.), the Greek gourd can become prohibited only because of the diverse-kinds of the vineyard.

${ }^{125} \mathrm{Cf}$. Dt. $22: 9, \mathrm{M}$. Kil. 5:5, 8:1, and Maim., Code, DiverseKinds, $5: 7$.

126 A History of the Mishnaic Laws of Purities (Leiden: E. J. Brill, 1974-1977), IV, p. 190.

127 Presumably because an item possessing one property need not possess the other. Cf. M. Oh. $8: 3-4$.

128 According to Lieberman (TK, II, P. 599, on 1.16$)$ there is some question as to whether this law belongs on the list of five rulings. Erfurt and sens omit "and" before the law, which may imply that it is not connected to the list, and Erfurt even has a space between (4) and (5). HD points out that (5) states the only law of the list which is not found in M. In addition, Bar Qappara does not include this law on his list. If (5) does not belong on the list, then it is possible that (4) may be considered as two laws (conveying the uncleanness and interposing before it), so that the list would still contain five items.

${ }^{129} \mathrm{Cf}$. Feliks, Mixed Sowing, p. 65, n. to 1. 84 .

${ }^{130}$ Canis lupus. For Latin and English names, see Feliks, Mixed Sowing, pp. $117 \mathrm{ff.}$, and Feliks, The Animal World of the Bible, 
trans. Pinhas Irsai (Tel Aviv: Sinai, 1962), and HaHai

BaMishnah (Jerusalem: Institute for Mishnah Research, 1972).

${ }^{131}$ Canis famiziaris putiatini.

132 Same as in note 131. The translation of "wild dog" is given by Danby and Israelstam.

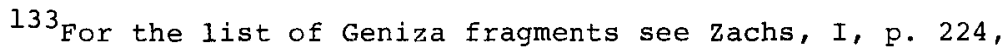
on 1.15 .

${ }^{134}$ Canis aureus.

${ }^{135}$ Capra hircus mambrica.

136 Gazella subguttorosa (yellow) or Gazella gazella (red).

137 Capra nubiana.

${ }^{138}$ ovis vignei platyura.

${ }^{139}$ Equus caballus orientalis.

$140_{\text {Equus asinus muzus. }}$

${ }^{141}$ Equus asinus.

142 Equus hemionus.

143 Feliks, Mixed Sowing, p. 122.

144 Ibid., pp. 126-127.

${ }^{145}$ Ibid., pp. 127-128.

${ }^{146}$ Ibid., p. 128 .

${ }^{147}$ The fact that it is the mating of animals of diverse-kinds which is important, and not the possible product of such a union, is further illustrated by M. $3: 1$, which states that it is permitted to raise the offspring of animals of diverse-kinds.

${ }^{148}$ Cf. Feliks, Mixed Sowing, p. 128.

149 Gallus gallus domesticus. For Latin names, see Feliks, Mixed Sowing, p. 132 .

150 pavo eristatus.

${ }^{151}$ phasianus colchicus.

152 The cock, or the hen, always stands as a separate bird throughout M. -T. Neither word (trngwl or trengwlt) is used to simply denote the gender of any bird, as cock and hen are used in English.

153 We assume that, according to Erfurt and B., the cock and the peacock are still considered diverse-kinds. But see our discussion of T. 1:lc for Lieberman's way of reading a list of three items. Lieberman claims that one cannot deduce anything concerning the first two items from such a list.

${ }^{154}$ Mixed Sowing, p. 132.

$155_{\text {Ibid., p. } 134 .}$ 
${ }^{156}$ Cf. M. 8:4, where Judah distinguishes between the mule (the dam of which is a mare) and a hinny (the dam of which is a she-ass), and does not allow one to be mated with the other. T. (which makes no such distinction) and M. thus represent two different traditions of Judah concerning the same issue.

157 Bos taurus. For all English and Latin names see Feliks, The Animal World of the Bible.

${ }^{158_{B o s}}$ primogenius (so Feliks, ibid., says s.v. šwr hbr; but in HaHai BaMishnah, p. 156, Feliks identifies the "wild ox" as the European bison, Bison bonasus.

$159_{\text {Equus asinus hemionus. }}$

$160_{\text {Sus }}$ domestica.

$1^{16 \mathrm{i}_{\text {Sus }}}$ scropha.

${ }^{162} \mathrm{Y}$. Kil. 8:6 (3lc) attributes T. C(1) to Yosé, based on the dispute in M. Kil. 8:6 between Yose and an anonymous opinion. The latter states that the wild ox is adomesticated animal ( $(h \mathrm{hm} h)$, while Yosé claims that it is considered to be a wild animal $(h y h)$. Y. reasons that the ox and the wild ox could be considered diverse-kinds only according to Yosé's opinion (since one would be a $b h m h$, and one a $h y h$ ), and assigns T.'s ruling to him. While one may not actually wish to attribute to Yosé, it is certainly true that Yosé would agree with the ruling of $T$.

We may note further, that $M .8: 6$ also mentions members of two other pairs of T., the hog and the Arabian onager (see note 163 below). M. calls the hog a bhmh and the onager a hyh. If we follow $Y$. and assume that a $b h \mathrm{mh}$ and a hyh are considered diverse-kinds with each other, then T. agrees with M.'s classification. The hog (a bhmh) is paired with the wild boar (presumably a hyh), while the ass (presumably a $b h m h$ ) is grouped. with the wild ass (= Arabian onager, a hyh). It is possible, therefore, that the list of $T$. is related to that of $M .3: 6$.

${ }^{163}$ The wild ass of $A(2)$ may be identical to the Arabian onager of M. 1:6A(7) (Lieberman, $T K$, II, p. 600, on 1. 19). If so, then $T$. simply has the same law as $M$, in a different tradition.

${ }^{164}$ Following Blackman's translation of M. M.S. $1: 3-4$.

${ }^{165}$ Cf. Sifré Dt. 100 (ed. Finkelstein, p. 160): "And the t' $w$ (Dt. 14:5), R. Yose says, "The $t^{\prime} w--$ this is the wild ox."

166 Although we have stated that $T$. 1:9 was meant to supplement T. $1: 8 \mathrm{~b}$, we also note that $T .1: 9 \mathrm{~A}-\mathrm{B}$ actually opposes the law of $T$. $1: 8 \mathrm{~b}$. It is possible that the redactor also meant for $T .1: 9$ to comment upon and oppose T. 1:8b. This is probably not the case, though, since T. 1:9D-E does agree with T. 1:8b. Rather, it is more likely that $T$. $1: 9$ was placed after $T$. $1: 8 \mathrm{~b}$ because both pericopae deal with similar issues.

${ }^{167}$ We understand the sages in $F$ as saying that the $t^{\prime} w$ is one creature and the wild ox is another. The phrase "a creature unto itself" simply means that each animal is to be distinguished from the other. A less likely interpretation of the sages' statement is that the $t^{\prime} w$ and the wild ox are each a species unto itself, being neither a hyh or a bhmh. While it is true that the 
phrase bryh bpny ${ }^{\mathrm{g} m h}$ (not $2^{c} \mathrm{gmh}$ ) may indicate that the subject belongs to its own, unique species (cf. B. Shab. 28b [concerning the tḩ], B. Yoma $74 \mathrm{~b}$, and B. Hul. $80 \mathrm{a}$ [concerning the kwy]), the phrase is used in different ways as well. It may, for example, mean simply that the animal is an independent creature, and not considered merely a part of its mother (B. Nid. 22b). Therefore $b r y^{\prime} z^{\circ} s m h$, as used here, need not mean that the $t$ ' $w$ and the wild ox are each a unique kind of animal. In addition, as we shall see, M. Kil. 3:6 records a dispute in which an anonymous opinion says that the wild ox is a $b h m h$, and Yosé maintains that it is a hyh. Although it is possible that the sages in $F$ would take the middle position that the wild ox is neither a $b h m h$ nor a hyh, it does not seem likely that they would dispute with both of the positions given in $M$. We therefore maintain that our interpretation is the more plausible of the two.

${ }^{168}$ This dispute parallels the dispute of M. Kil. 3:6, which we have described in note 167 above. See also our discussion below of the second dispute of the pericope.

${ }^{169} \mathrm{Cf}$. Sifra Emor VIII:8 (ed. Weiss, p. 99a), where the word "ox" is taken to exclude the wild animal.

170 Cf. Sifra Sav x:2 (ed. Weiss, p. 38b), where the animals listed in the verse are taken to exclude the unclean animal (bhmh $\left.t m^{\prime} h\right)$, the wild animal, and birds.

${ }^{171} \mathrm{Cf}$. Sifra Wayiqra II:6, (ed. Weiss, p. 4b), where the animals 1 isted in LV. 1:2 are taken to exclude wild animals.

172 For English names (and alternates) see Feliks, the Animat World of the Bible.

173 Feliks, $i b i d ., p .21$, states that the $t$ ' $w$ is to be identified with either the bison (Bison bonasus) or the bubalis antelope (Bubazis bosezaphus).

174. Cf. also B. Hul. 80a, where the dispute of Yosé and the anonymous opinion in $\mathrm{M}$. Kil. 8:6 is related to the issue of the meaning of t'w in Dt. 14:5.

${ }^{175} \mathrm{~B}$ has this as a corrected reading. See Zachs, I, p. 225, on 1.17 .

${ }^{176}$ Feliks, Mixed Sowing, p. 139.

177 As a matter of convenience, however, we shall continue to use "graft" to designate any method of uniting two plants.

${ }^{178}$ Lieberman ( $T K, I I, \mathrm{p} .601$, on 1. 27) points out that B only prohibits any union by which two trees are nourished by the same roots. One is, however, permitted to plant tree-seeds of diverse-kinds near each other (separated by a space of three handbreadths), for this is not considered a planting of diversekinds (whereas it would be so considered in the case of vegetables or grains in a field). See also T. Kil. 1:10D.

179 According to Rosh and sens (Bert. and MR also give this interpretation) the prohibition of $B$ concerns only cases in which at least one of the trees involved produces edible fruit. Two barren trees, however, are considered to be of a single kind and may be grafted onto one another. This interpretation is apparently inferred from Y. 1:7 (27b), which specifically prohibits grafts involving one tree which bears edible fruit, but says 
nothing concerning two barren trees. See Feliks, Mixed Sowing, pp. $139-140$.

${ }^{180}$ Feliks, Mixed Sowing, p. 147, n. to 1. 84.

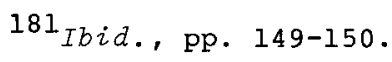

$182 \mathrm{Cf}$., however, Sirillo's version of $\mathrm{Y}$. and Sens' alternate version (both cited by Feliks, Mixed Sowing, p. 139), which prohibits grafts involving two barren trees as well.

${ }^{183}$ See Zachs, I, p. 225 , n. to 1.19.

184 Ficus sycomorus, or the mulberry family (Moraceae; so Post, p. 514. But cf. also zohary, p. 78, who places the genus Ficus in Ulmaceae, the elm family). For Latin names, see Feliks, Mixed Sowing, p. 151 .

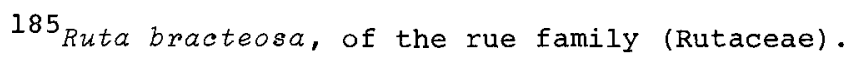

136 Poncirus trifoliata, of the rue family (Rutaceae). See Feliks, Mar'ot HaMishnah, p. 122. Feliks, Mixed Sowing, p. 159, n. 26, gives Citrus trifoliata as a synonym.

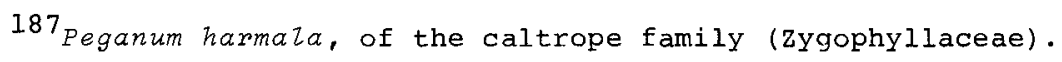

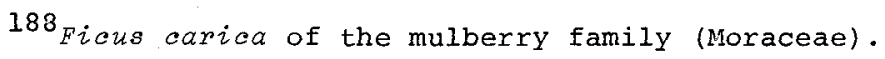

${ }^{189}$ Urginea maritima, of the lily family (Liliaceae). The English name is given by Feliks, Mar'ot HaMishnah, p. 55.

${ }^{190}$ Vitis vinifera, of the vine family (Malvaceae).

${ }^{191}$ Malva silvestris, of the mallow family (Malvaceae).

${ }^{192}$ See M. 1:4D-F for examples of forbidden grafts of a tree onto a tree. The presence of the examples in $M .1: 4$ does not account for their absence in $M$. 1:8, for the context of the former is entirely different. See also T. Kil. 1:10.

193 Feliks, Mixed Sowing, p. 153.

${ }^{194}$ CE. T. Kil. 1:10.

${ }^{195}$ Feliks, Mixed Sowing, p. 153.

196 That is, in a feather-like arrangement.

${ }^{197}$ Feliks, Mixed Sowing, p. 157. Feliks also notes (p. 158) that Josephus ( $B J$ 7. 178f) mentions the rue as being larger than a fig-tree. Feliks suggests that Josephus may be describing a rue grafted onto a tree.

${ }^{198}$ Feliks (ibid., p. 153) rejects Löw's identification (Die Flora der Juden, II, p. Ils) of qydh $2 b n h$ as calycotome (Calycotome viliosa). Feliks claims that the calycotome is not related systematically to rue, and therefore the grafting described in $M$. could not take place. Feliks rejects the identification under the assumption that $M$. deals only with cases which are practically feasible.

199 Feliks, Mixed Sowing; p. 159. Cf. also p. 160, n. 27, where Feliks discusses other plants of $M$. which originated in China. 
200 Feliks, ibid., p. 162, disagrees with this interpretation of $\mathrm{E}$. He maintains that mqrr should be understood in the sense of "flow" (nwbe), and that $E$ means that the plant will "flow forth," or spread rapidly.

${ }^{201}$ Ibid., pp. 161-162.

202 Ibid., p. 162 .

203 Apparently, this is what $\mathrm{E}$ means in saying that squill will keep the fig-shoot cool.

204 Cf. also Theophrastus, Bistoria PZantarum 2.5.5., (cited by Feliks, Mixed Sowing, p. 162, n. 35), where he says that the fig grows faster if placed in a squill bulb, and 7.13.4, where he describes how cuttings strike root faster if placed in squill.

${ }^{205}$ Feliks, Mixed Sowing, p. 162, bases this assumption on $Y .$, although he does not explain his inference. Y. 1:8 (27b) discusses why it is necessary to state F-G, which appears to describe a simple case of diverse-kinds of the vineyard, rather than a type of graft. Yose answers that F-G speaks of a case where the two plants unite at a depth of three handbreadths (for the earth below this depth is not considered part of the vineyard; cf. Feliks, ibid., p. 152, n. to 1. 26), and where the plants are six handbreadths apart. Feliks apparently assumes that since the plants are united at that depth, one is not speaking of a vine-shoot which is cut off (which could not be grafted under ground), but one which is still attached to the vine.

206Feliks, Mixed Sowing, pp. 163-164. See especially the illustrations on p. 163.

207 See n. 205 above. Sens differs from sirillo in requiring that the vine and the watermelon plant also be separated by three handbreadths above ground (reading three for six in Y. 1:8). Sirillo's edition of $Y$. apparently lacked this additional requirement (Feliks, Mixed Sowing, p. 166).

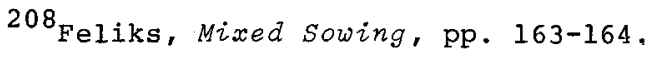

210 This interpretation forces Feliks to re-interpret Yose's saying in $\mathrm{Y}$. that one deepens the roots below three handbreadths. According to Feliks, Yose refers to digging around the vine or the watermelon and cutting all roots which are above three handbreadths deep. This is done so that the other roots will grow deeper. According to this view, then, Yose says that if its shorter roots are cut, the watermelon is not actually planted in a vineyard (as the vineyard does not extend below three handbreadths) and does not fall under the prohibition of diverse-kinds of the vineyard.

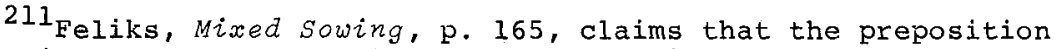
$2 t w k w$ in $G$ must refer to the watermelon, since it has a masculine antecedent, and a vine (gpn or zmwrh) is always referred to in the feminine. Several mss. however, do read $2 t w k h$, which has a feminine antecedent (cf. Mss. B, Cn, O).

212 Mixed Sowing, p. 167.

${ }^{213}$ Punica granatum, of the loosestrife family (Lytharieae).

${ }^{214}$ Following Lieberman, TK, II, p. 601, on 11. 28-29. 
${ }^{215}$ phoenix dactyfera, of the palm family (Palmae).

216 orea europea, of the olive family (Oleaceae).

217 Feliks, Mixed Sowing, p. 154.

218 Ibid.

${ }^{219}$ Feliks, ibid., p. 151, n. to 1.10 , notes that $B$ refers to a vine-shoot which is either attached to the vine or cut off from it. He does not, however, give any reasons for his comment.

220 That is, the difference between tibla (qal imperfect) and tibzia (niphcal imperfect).

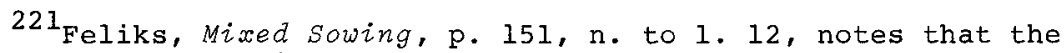
tube is made from either a reed or clay.

$$
\begin{aligned}
& 222_{T K}, I I, \text { p. } 601 \text {, on } 11.28-29 . \\
& 223 \text { Ibid., p. } 601 \text {, on 1. } 29 . \\
& 224 \text { Immanuel Löw, Die Flora der Juden, II, p. } 324 \text { (not } 234
\end{aligned}
$$
as cited in Feliks, p. 155, n. 11). We follow the interpretation of Feliks, p. 155. Löw maintains that $\mathrm{T}$. cannot refer to a Block of the palm tree which has taken root, for the graft of an olive-shoot onto it would not be successful. Rather, he says that $r k b$ refers to a trunk of a palm tree which lies on the ground. Löw cites Pliny (Historia Naturalis, 13.8.36), who records that in Assyria they used to lay a palm tree on the ground so that its shoots would strike root in the ground (a1though shrubs, rather than trees, would result, so that the cuttings of the new plants would have to be transplanted). Löw's interpretation presents difficulties, however, for it is not clear why the olive graft should succeed in this case and not in the previous one, where the palm tree is rooted in the ground.

$$
\begin{aligned}
& 225_{\text {Mixed Sowing, p. } 156 .} \\
& 226_{\text {Ibid., pp. } 156-157 .} \\
& 227_{\text {Cuscuta sp., of the convolvulus family (Convolvulaceae). }}
\end{aligned}
$$
For Latin names, see Feliks, Mixed Sowing, pp. 144-145.

${ }^{228}$ Athagi maurorum, of the pea family (Papilionaceae).

229 Amaranthus retroflexus, of the amaranth family (Amarantaceae).

230 Feliks, Mixed Sowing, pp. 145-146.

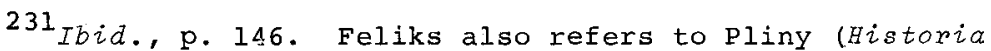
Naturatis, 13.46.129) who says that a species of dodder is used in making spiced wine.

232 Ibid.

233 Ibid, , pp. 108-109.

${ }^{234}$ Calycotome vilzosa, of the pulse family (Leguminosae).

$235 \mathrm{D}-\mathrm{E}$ may attest M. 1:7D to Yavneh, if we assume that Judah b. 'Agra is a Yavnean. In Mekizta de Rabbi Ishmael, Amalek 4 (ed. Lauterbach, II, p. 180, 11. 14-19), Judah of Kefar Akko asks a question of Gamaliel. If the attribution to Gamaliel is 
reliable, then Judah b. 'Agra is a Yavnean. However, it is possible that Gamaliel should be Simeon b. Gamaliel, and in that case Judah b. 'Agra would be an Ushan. The evidence, therefore, that Judah b. 'Agra is a Yavnean is not conclusive, and it is only possible that he attests $\mathrm{M}$. 1:7D to Yavneh.

${ }^{236}$ Lieberman, $T K$, II, p. 602 , on 1.32 , identifies the ' $g$ ' with the hgyn of T. 3:15, which is explicitly called a tree.

237 Feliks, Mixed Sowing, pp. 147-148.

$238_{\text {Ibid., p. } 150 .}$

${ }^{239}$ Cf. Feliks, Mixed Sowing, p. 152, n. to 1. 28.

240 Actually, T. 1:19 differs from the other pericopae in both its opening and its apodosis. T. $1: 13$ opens with a singular participle while the others begin with 'yn + plural participle. T. $1: 13$ then closes with hyyb, which the other pericopae do not need, since they already have'yn in the opening clause. Rather, the other pericopae close with mpny $\breve{s}+$ the appropriate category of M. 1:7. T. 1:13 is then similar to the other pericopae only in its structural outlines, but otherwise it differs significantly.

$241_{\text {Mixed Sowing, p. } 167 .}$

242 Cf. Theophrastus, Historia Plantarum, 1.7 .3 and 8.11 .8 (cited by Lieberman, TK, II, p. 602, on 1. 34, and Feliks, Mixed Sowing, p. 167, n. 58). Cf. also Pliny, Historia Naturalis, 18.36.133-136 (cited by Lieberman, TK, II, p. 602, on 1. 33).

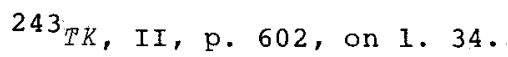

${ }^{244}$ For a list of Geniza fragments of the pericope, cf. Zachs, I, p. $227 \mathrm{f}$.

245 Ibid., p. 227, n. 61. Cf. also MS.

246 Even according to the alternate reading of $D$ (nwtzyn for nytlyn) the subject of $D$ is still not that of $A$, for the verb of $D$ is in the plural rather than in the singular.

247 Most of the commentaries take the $w$ in A to mean "or." The one exception is Bert., who takes $w$ to mean "and," maintaining that $A$ concerns turnips and radishes which are buried together. It is not clear, however, what the point of $\mathrm{M}$. would be in such a case (it is not even clear whether turnips and radishes are considered diverse-kinds with one another, although one might argue from $M .1: 3 \mathrm{~A}$ and $M$. $1: 5 \mathrm{~A}$ that they are). We therefore follow the view of the majority of commentaries and read $w$ as "or."

248 single turnip or radish under a vine (Rabad to Maim. Code. Diverse-Kinds $2: 11$; cf. the reading of $\mathrm{B}$. Erub. $77 \mathrm{a}-\mathrm{b}$; "a turnip or a radish"). Several commentaries, however, following Y. Kil. $1: 9(27 \mathrm{~b})$, maintain that the turnips or radishes must be buried in bunches (Sens, Maim., Code, Diverse-Kinds 2:11, TYY), for in this way the owner indicates that he intends only to bury the vegetables, and not to plant them. Sens and TYY, in fact, maintain that $B$ applies only to $D$, so that growing the vegetables in bunches is the only means of avoiding the appearance of diversekinds. This interpretation, then, agrees with Rabad that the owner must avoid even the appearance of transgressing the laws of C, but disagrees as to how this goal is to be achieved. Compare the views of GRA and MR, though, who maintain that all vegetables 
(or at least turnips and radishes) are planted in bunches, so that $Y$. does not wish to make a particular point in mentioning this fact.

$$
\begin{aligned}
& { }^{249} \text { Mixed Sowing, p. } 169 . \\
& 250 \text { Cited by Feliks, ibid., p. 170. Cf. B. M. Lewin, ed.' } \\
& \text { Otzar HaGeonim (Haifa: 1930), II, part 2, p. 22. }
\end{aligned}
$$

$$
251_{\text {Mixed Sowing, p. } 170 .}
$$

252 Cf. also the explanation of TYY, which relates $C(1)$ to T. Kil. 1:15's rule that one may plant seeds of vegetables or grains near tree-seeds, but not near a vine.

$$
\begin{aligned}
& 253 \text { On B. Erub. } 77 \mathrm{~b} \text {, s.v. 'ynw hws̆. } \\
& 254 \text { Beth HaBehirah on the Talmudical Treatise Shabbath, ed. } \\
& \text { by Isaak S. Lange (Jerusalem: } 1971 \text { ), p. } 185 \text { (on B. Shab. 50b). } \\
& 255_{\text {We note, of course, that the radishes or turnips must }}
\end{aligned}
$$
presumably still be tithed after they are first harvested and before they are buried.

256 Maimoniaes derives this ruling from an exegesis of $\mathrm{LV}$. $27: 30$, which reads: All the tithe of the land, whether of the seed of the land or of the fruit of the trees, is the Lord's; $i t$ is holy to the Lord. The phrase of the seed of the land is taken to include only those things which are planted, and to exclude those which are not.

257 The commentaries actually give three different cases in which the after-growth could be obligated for tithes. Rashi

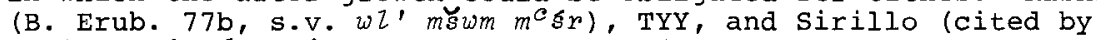
Feliks, Mixed Sowing, p. 173), all say that the case concerns an after-growth which may be liable for first tithe. Sens constructs the case differently, stating the vegetables are planted in the second year of the seven-year cycle, and therefore are liable for second tithe. They are then buried in the third year, during which time they produce after-growths. According to sens the point of $\mathrm{C}(3)$ is that while one is obligated to give second tithe, one need not give poorman's tithe (which would be given in the third year) for the after-growths. Similarly, R. Tam (cited by Feliks, Mixed Sowing, p. 173) maintains that vegetables are planted in the third year, and therefore are liable for poorman's tithe. They are then buried in the fourth year and produce after-growths, The point of $\mathrm{C}(3)$, accordingly, is that the after-growths need not be redeemed in the fourth year as second tithe.

${ }^{258} \mathrm{Cf}$. also the explanation of Hai Gaon (B. M. Lewin, ed., otzar HaGeonim, v. II, part 2, p. 22), who says that what B means is that the top of the actual plant is exposed, as this is not the way in which vegetables are usually planted. Cf. also the explanation of the reading holywn given by MS.

259 We note that Maimonides requires one to bury the vegetables in bunches in addition to exposing the leaves, while Rabad believes that it is sufficient to expose the leaves in order to avoid the appearance of diverse-kinds.

260 Mixed Sowing, p. 170. See also Sens, who rejects a similar interpretation.

${ }^{26 I}$ On B. Erub. $77 \mathrm{~b}, \mathrm{s.v}$. mqst $c_{\text {lyw mgwlyn. }}$ 
262

T. Shab. $16(17): 10$ (cited in Y. Kil. 1:9 (27b)), which presents a similar case of one who is permitted to remove a fig from straw or cake from coals, provided that the fig or the cake is partially exposed. The point again is that the straw or the coals may be moved indirectly. Maimonides (Code, Sabbath 24:14-15) explains this law as follows:

If two articles are situated side by side, or one on top of the other, or one inside the other, in such a way that whenever one is moved the other is moved also, and one of these articles may not be moved while the other may, the rule is as follows: If one needs the article which may be moved, he may move it, even though the forbidden article is moved together with it. But if one needs the forbidden article, he may not move it by moving the permitted article.

Thus one may insert a spindle or a whorl into a fig stored in straw, or into a cake baked over coals, and lift it out, even though the straw or the coals will be stirred up on the Sabbath at the moment of lifting. Similarly, if turnips or radishes are stored in soil with some of the leaves showing, they may be lifted out by the leaves on the Sabbath, even though the soil will be shaken off in the process.

(Trans. S. Gandz and H. Klein)

263 This interpretation reads $\mathrm{E}-\mathrm{F}$ in the light of $\mathrm{G}$. $\mathrm{E}-\mathrm{F}$ could be taken to mean simply that one who sows wheat and barley together is liable on account of diverse-kinds. Such a statement, however, would be trivial. We therefore understand E-F as it appears in context.

264 The commentaries compare Judah's understanding of $s d h$ with the exegesis of $\mathrm{krm}$ which lies behind Josiah's statement ( $\mathrm{Y}$. Kil. $8: 1$ ) that "One is not liable [for sowing diverse-kinds in a vineyard] until he sows two kinds in the vineyard." The relevant verse, Dt. 22:9, states you shall not sow your vineyard with diverse-kinds. Just as Josiah understands "vineyard" to refer to a vineyard which has already been planted (i.e., already in existence), so does Judah take "field" to mean a field which has already been sown.

${ }^{265}$ Following $T K$, II, p. 603 , on 1.36 .

${ }^{266}$ See Abraham Eben-Shoshan, HaMiIon HaHadash (Jerusalem: Kiryat-Sefer, 1969), v. 2, p. 757, s.v. hyzt. Eben-Shoshan cites B. Sot. $49 \mathrm{~b}$ as his source for understanding hylt to mean "rushes."

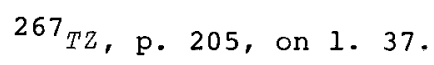

${ }^{268}$ Cf. Hudson T. Hartmann and Dale E, Kester, Plant Propagation: Principles and Practices, Second ed. (Englewood Cliffs: Prentice-Ha11, 1968), p. 135.

${ }^{269}$ We differ from the view of HD only in understanding hylt to refer to rushes, not, as HD says, to sandy soil (as derived from hol).

$270 \mathrm{Cf}$. Y. Kil. 1:9 (27b), where it is said that Resh Lagish, who holds a stringent position with regard to areas which may be sown, would agree that there is no liability for sowing diverse-kinds 
over water or rocks, among other places.

271 In $T K$, II, pp. 602-603, on 11. 35-36, Lieberman offers a completely different interpretation of $T$. According to Lieberman the point of $T$. is that one is liable for sowing diverse-kinds only if the act of sowing immediately results in the growth of the seeds. In $A-C$ seeds which readily germinate are sown over swamps or rushes. These areas contain a great deal of water, so that upon being sown, the seeds promptly stick together and begin to grow. The sower is therefore liable. In $D-E$, on the other hand, the same seeds are sown over a rock or a water-channel. Now the seeds cannot stick together until either rain falls (in the case of the rock) or water starts to flow through the waterchannel. Since growth does not occur instantly after sowing, there is no liability. Finally, F-G describes a case where the seeds are dormant. Even though they are sown over swamps or rushes where they immediately become attached to one another, these seeds do not germinate at all. Therefore, in this case as well, the sower is not liable (Lieberman's reference to seeds sticking together is apparently based on a passage in $B$. Zeb. $94 \mathrm{~b}$, which speaks of flax-seeds sticking to each other in water [following Rashi]).

According to Feliks (Plant world of the Bible [Heb.] [Tel Aviv: Masada, 1957], p. 281), they used to sow flax above the ground, and then the seeds would become attached to the ground by rain. However, Lieberman speaks of the seeds sticking to each other, and not to the ground. Furthermore, it is not clear whether other grains besides flax grow in the same way (although $\mathrm{B}$. Zeb. 94 a does imply that both wheat and barley may also be sown in water). A study has shown that some seeds can actually germinate in water, but only under special conditions (e.g., where additional oxygen is provided). Cf. Toshitaro Morinaga, "Germination of Seeds under Water," American Journal of Botany, 13 (1926), pp. $126-140$.

$$
272_{T Z}, \text { p. } 205 \text {, on } 1.37 \text {. }
$$

${ }^{273}$ Lieberman (TK, II, p. 604, on 11. 38-39) cites this source as $\mathrm{Y}$. $1: 5$.

$274 \mathrm{Cf}$. C. Primus, ${ }^{A}$ Aqiva's Contribution to the Law, I, Zeracim (Leiden: E. J. Brill, 1977), p. 35. Primus also notes that this position is consistent with that taken by $C_{\text {Aqiva at }} \mathrm{M} .5: 7$, where he states that one must actually destroy diverse-kinds growing in his field.

275 According to T. Mak. 5(4):10, however, each apodosis has a different legal significance. T. states that one who sustains diverse-kinds of the vineyard (Vienna, first printed ed. omit "vineyard") transgresses a negative commandment, but does not receive stripes. T. then states a general rule that one receives stripes only when he actually performs an act. For attempts to harmonize T. Mak., T. Kil., and B., see Lieberman, TK, II, p. 603, on 1. 38. Cf. also Sifré Dt. 230a (ed. Finkelstein, p. 263; see below p. 258) where mss. also give the same two different apodoses (cited by Lieberman, TK, II, pp. 603, n. 41).

276 Primus, p. 36, notes that T. and B. Mak. $21 \mathrm{~b}$ are interested in different aspects of the rule: "The baraita-editor shifts the focus of the pericope away from the issue of intention. Instead he emphasizes the punishment for the violation of biblical law, a separate issue." Primus goes on to say that this shift is made clear by the changing of the apodoses in the pericope. 
277 The reason for this exemption may be that trees generally are clearly recognizable when planted next to grain or vegetables, so that they would not appear to grow as diverse-kinds when sown with the latter. Similarly, trees which are planted together need room in which to grow, so that different kinds of trees appear to be distinct from one another even when planted in the same field. It is necessary to point out, however, that a tree may not always be distinct from other types of plants (as in the case of the vine), so that the validity of the above explanation rests on the question of such a definition. Cf. S. Lieberman, "The Natural Science of the Rabbis," in HeZlenism in Jewish Palestine (New York: The Jewish Theological Seminary of America, 1950), pp. $180 \mathrm{ff}$.

${ }^{278}$ Cited by Lieberman, TK, II, pp. 603ff, on 11. 38-39.

\section{CHAPTER TWO}

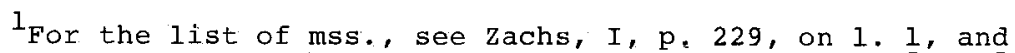
Y. N. Epstein, Introduction to the Text of the Mishnah [Heb.]. Second edition (1948; Jerusalem: Magnes Press, 1964), p. 78.

${ }^{2}$ For the particular Geniza fragments, see zachs, ibid.

${ }^{3}$ According to zachs, I, p, $229, \mathrm{n}, 4$, this reading is due to a copyist's error.

"Lieberman (TK, II, p. 6a5, n. 49) notes that the verb "falls" has the sense of "sown in a known area." Cf, also Feliks, Agriculture in Palestine in the Period of the Mishna and Talmud [Heb.] (Jerusalem: Magnes Press, 1963), p. 157.

${ }^{5}$ Linum usitatissimum, of the flax family (Linae). See Feliks, Mixed Sowing, p. 198.

${ }^{6} \mathrm{~A} s e^{\mathrm{t} a h}(=0.5651$. ) consists of $\operatorname{six} q a b s$ (one $q a b=1.427$ 1,2 , so that a quarter $-q a b \quad(=356.896 \mathrm{cc}$.$) is one twenty-fourth$ of a $s e^{\prime} a h$.

7Feliks, Mixed Sowing, pp. 194-195. Feliks adds that rice, sorghum and millet were also considered grains, except that they were sown at a rate lower than that of the others. For this reason, Feliks suggests that $M$. does not refer to these three grains when it speaks of a mixture of grain and pulse (for then the rate of the former would not correspond to that of the latter).

${ }^{8}$ Ibid.

${ }^{9} \mathrm{~A}$ bet se'ah is an area of fifty by fifty amot, or 784 square metres (Feliks, p, 186). MR reasons as follows: One twentyfourth of the volume sown in a bet $s e^{r a h}$ prohibits the sowing of a se'ah (see M. 2:2H+J). According to A a quarter-qab prohibits the sowing of a selah. Therefore one twenty-fourth of the volume sown in a bet se' $a h$ equals a quarter-qab and the volume sown in a bet $z e^{r} a h$ then equals one se'ah.

10 TK, II, p. 605, on 1. 41 .

${ }^{11}$ Cf. M. Ter. $2: 1$, M. Shab, $1: 3,10: 4$, M. Naz, $7: 3$, M, B.M. $4: 11$, and M. B.B. $2: 3$. 
12 While this interpretation gives an unusual sense to the word "combine" we shall see below that, in the case of J, it is the only possible interpretation of the word. J says that flax combines at a certain measure, and since flax only refers to one kind of seeds, "combines" must have the sense of "prohibits." The word may then have the same meaning here.

${ }^{13}$ If $\mathrm{F}-\mathrm{H}$ is read as a unitary text, then, according to this interpretation of $\mathrm{H}, \mathrm{F}-\mathrm{G}$ may be read as glossing $\mathrm{E}$, and not $A-B$.

${ }^{14} \mathrm{Y}$. cites a baraita which says that garden-seeds are sown at the rate of one or $1 \frac{1}{2} q a b s$ per $b$ et $s e^{\prime} a h$. Garden-seeds would then prohibit the sowing of a se'ah at one twenty-fourth or one-sixteenth of a $q a b$.

${ }^{15}$ Feliks, Mixed Sowing, p. 197, on 1. 31. Cf. also TYY.

16 According to $Y$. $f l a x$ is sown at three times the rate of wheat, so that its rate is presumably three se'ahs per bet se'ah (cf. also Bert.). Flax then prohibits the sowing of a $s e$ 'ah at three-quarters of a $q a b$. Following T. Kil. 1:16a, though, Feliks (Mixed Sowing, p. 201) points out that wheat may have been sown at three or four qabs per bet $s e^{\prime} a h$, and that it may have prohibited the sowing of a se'ah at three-eighths or one-half of $a$ qab. Either way, though, it takes more than a quarter-qab of flax-seeds to prohibit the sowing of a se'ah.

17 Alternatively, Lieberman (TK, II, P. 605, on 1. 41), following $Y .$, understands $T$. as extending the law of $M$. $2: 1 \mathrm{~A}$ to apply to smaller seeds of pulse which are sown at relatively low rates (three or four qabs per bet $s e^{\prime} \alpha h$ as opposed to a $s e^{\prime} a h$ per bet $\left.s e^{\prime} a h\right)$. T. then says that a quarter-qab of seeds which are sown at three or four qabs per bet se'ah also prohibits the sowing of a $s e^{\prime a h}$. This is so even though in this case a quarter-qab is one-twelfth of the volume sown in a bet $s e^{\prime} a h$, and not one twenty-fourth (cf. M. 2:2H). That is, the law of M. 2:lA applies to these seeds, even though this means that it takes double the usual volume to prohibit the sowing of a se'ah.

$$
\begin{aligned}
& { }^{18} \text { Mixed Sowing, p. 196, on 1. } 22 \text {. } \\
& \left.{ }^{19} \text { Alternatively, Lieberman (TK, II, p. 605, on } 1.42\right)
\end{aligned}
$$
understands bnwpl lmynw in the sense of bnwpl bmynw ("that which falls in its own kind"). He therefore says that $D$ describes the case of garden-seeds which are mixed with another kind of seeds "of the same family," i.e., seeds which are sown at the same rate.

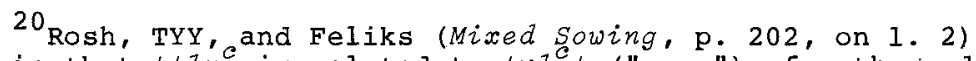
explain that $t$ t $y_{y} e^{\text {is }}$ related to $t w l^{c} t$ ("worm"), for the radicles resemble small worms.

$$
\begin{aligned}
& { }^{21} \text { Following Feliks, ibid., p. } 202 \text { on } 1.3 . \\
& 22 \text { See Zachs, I, p. 231, on 1. 11. } \\
& 23 \text { Following Sens, Bert., TYY, and Feliks, Mixed Sowing, }
\end{aligned}
$$
p. 202, on 1. 5. Alternatively, Maim., Comm. and MS maintain that the furrows are dug before the rainfall.

${ }^{24}$ It is clear that one may not sow the barley with the intention of later destroying the wheat. For in that case one would be sowing the barley without having performed any act to indicate this intention. He thus would actually be sowing diverse-kinds (cf. Feliks, Mixed Sowing, p. 206). 
${ }^{25}$ We may compare M. to Pliny's description of the method of "plowing in" (Historia Naturalis, 18.49.182-183):

We will not omit one additional method of ploughing that has been devised in Italy north of the Po owing to damage caused by war. When the Salussi were devastating the farms lying below the Alps they made an attempt to destroy the crops of panic and millet that were just appearing above the ground: but after Nature proved contemptuous of their efforts, they ploughed in the crops: these however came up in multiplied abundance, and thus taught us the practice of ploughing in -- artrare as it is now called, that as I believe being the form at that time in use of the word aratrare. This is done either when the stem is beginning to grow or when it has already shot up as far as the second or third set of leaves. Nor will be withheld a recent instance that was ascertained two years ago in Trier country: the crops having been nipped by an extremely cold winter, in March they actually sowed the fields again, and had a very bounteous harvest (trans. H. Rackham, Loeb ed., V, pp. 303-305).

In the first case which he presents, Pliny clearly states that the crops which were plowed in came back up again. It appears, then, that Pliny disagrees with M.'s presupposition that a seed (or a plant, as in $\mathrm{D}-\mathrm{F}$ ) is destroyed by plowing in.

26Feliks, Mixed Sowing, pp. 204-206.

27 Ibid., pp. 209-210.

${ }^{28}$ Ibid., p. 210, adds that the opinion of $\mathrm{H}$ assumes that the field will be plowed up again later, when the barley is covered. Therefore even the wheat in the unplowed areas will eventually be destroyed, and the entire field will be free of diverse-kinds.

${ }^{29}$ Sens points out that Abba Saul may be understood in two different ways. I means either that one may not leave unplowed a continuous area the size of one twenty-fourth of a bet se'ah, or that the sum of all the unplowed areas in the field may not total one twenty-fourth of a bet se'ah.

${ }^{30}$ According to GRA and Lieberman (TK, II, p. 606, on 1. 44) $Y$.'s reading is an error.

${ }^{31}$ So Reuben Alcalay, The Complete Hebrew-English Dictionary (Tel Aviv: Massadah, 1965), p. 374, s.v. hrys̆gs.

32 Alternatively, T. may mean that one plows the seeds deeper into the soil, so that they cannot grow under any circumstances.

$33_{T K}$, II, p. 606, on 11. 45-46.

${ }^{34}$ Cf. John Percival, The wheat Plant: A Monograph (London: Duckworth \& Co., 1921), p. 24: "A normally ripened wheat grain, sown an inch or an inch and a half deep in good soil, early in September, begins to germinate in two or three days, the coleoptile [i.e., the plumule-sheath] and first leaf appearing above ground in about two days." Percival goes on to say that the first part to emerge from the seed when it bursts is the coleorhiza, 
or root-sheath, which contains several of the radicles (see also p. 14).

35Hartmann and Kester, Plant Propagation: Principles and Practices, p. 118 .

${ }^{36}$ Cf. n. 34 above and Feliks, Agriculture, pp. 169-170.

${ }^{37} \mathrm{Cf}$. Lieberman, $T K$, II, p. 606, on $11.48-49$, and Feliks, Mixed Sowing, p. 203 on 1. ll.

${ }^{38}$ Feliks (p. 207) points out that $K$ allows one to sow barley after bringing the animal into the field, even though the animal will not pull the wheat out by its roots. According to Feliks T. assumes that the wheat will be uprooted anyway when the barley is covered, and the purpose of bringing the animal into the field is only to show that one does not want the wheat.

${ }^{39}$ Following most commentaries. See our discussion below.

${ }^{40}$ Feliks (Mixed Sowing, p. 211 on 1. 2) points out that in order to destroy the seeds one must wait for them to sprout radicles before overturning the soil (cf. M. 2:3B). Feliks accordingly maintains that this condition is understood by M. 2:4 even though it is not specifically stated. Cf. also TYT.

${ }^{41} \mathrm{HD}$ explains that by sowing first, one is able to test the soil for grain or vegetables without necessarily losing his vines. If the grains or vegetables grow well, he uproots the vines. If the grains or vegetables do not grow well, then he uproots them and allows the vines to grow.

42 MR also cites M. Shev, $1: 8$ and states that when the vine is less than a handbreadth it is as if it does not exist (i.e., it is no longer in the category of a tree).

43 Ridbaz (to Maim., Code, Diverse-Kinds 6:6) points out that one who sows before uprooting does not perform extra work (by cutting and then uprooting), for one may uproot when he covers the newly-sown seeds.

${ }^{44}$ Following Lieberman, $T K, I I$, p. 607, on 11. 49-50.

$45_{\text {According to } L i e b e r m a n}(T K$, II, p. 607 , on 1,50$)$ this reading is a mistake.

${ }^{46}$ Cited by Lieberman, TZ, p. 207 , on 1.50 , and $T K, I I$, p. 607 , on 1.50 .

${ }^{47}$ Lieberman (TK, II, p. 607, on 1. 51) states that this omission is a mistake.

48 The law that one may benefit from diverse-kinds is understandable if one maintains that $T$. refers to trees (and not vines), for $M .8: 1$ states that one may benefit from diverse-kinds of seeds (and $M$. perhaps may be interpreted to include tree-seeds). The same M., however, also states that one may not benefit from diverse-kinds of the vineyard. If $T$, refers to grapevines, as we have assumed, then T. apparently opposes M. 8:1. Alternatively, we must assume that vines which are less than a handbreadth high do not sanctify seeds which are sown in a vineyard (B. Sot. $43 \mathrm{~b}$, Maim., Code, Diverse-Kinds 6:4). Both sources are cited by Lieberman, TK, II, p. 607, on 11. 49-50. 
${ }^{49}$ For Geniza fragments, see Zachs, I, p. 232, on 11. 16ff.

${ }^{50}$ Carum carvi, of the parsley family (Umbelliferae). Carum is commonly known as caraway. We follow Feliks (Mixed sowing, pp. 220-221), who says that the correct reading is qrbs (cf. also Albeck, p. 105). For the different readings of the commentaries, see Feliks, ibid., and zachs, I, pp. 232-233, n. 27. For all Latin names, see Feliks, ibid., p. 220, and M. Zohary, A New Analytical Flora of Israel, passim.

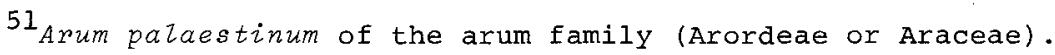

52 Isatis tinctoria, of the mustard family (Cruciferae).

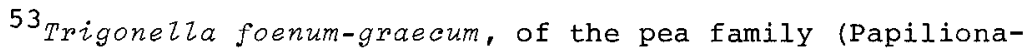
ceae).

${ }^{54}$ According to Feliks (Mixed Sowing, pp. 221-222), arum may be propagated by means of its tubers (underground stem-like structures). The tubers separate from the main plant and grow on their own. They are able to produce fruit only after three or four years. However, it is possible that they produce fruit earlier (cf. T. Shev. 4:3, cited by Feliks, ibid., p. 220) a fact which will support the alternate reading below.

${ }^{55}$ Carum is either biennial (S. G. Harrison, et. al., The Oxford Book of Food Plants, p. 138) or perennial (Albert F. Hill, Economic Botany: A Textbook of Useful Plants and Plant Products, 2nd ed. (1937; rpt. New York: McGraw-Hill, 1952), pp. 455-456), so that it produces fruit within at least two years after it is sown.

56 Feliks, Mixed Sowing, p. 226.

57 In the case of $\mathrm{D}(2)$, the owner does not want the wild plants on the threshing-floor because the floor must be kept smooth (Feliks, Mixed Sowing, p. 218, on 1.4). In the cases of $D(1)$ and $D(3)$, one does not want the wild plants because they harm the growth of the cultivated ones. If this interpretation of $M$. is sound, however, then M. opposes the view of Pliny in regard to fenugreek. Pliny (cited by Feliks, Mixed Sowing, p. 232) writes (Historia Naturalis, 18.39.40 [trans. H. Rackham, Loeb ed., v. 5, p. 279]): ". . the worse it [i.e., fenugreek] is treated the better it comes on -- a singular proposition that there is something which is benefitted by neglect." According to Pliny, then, wild plants do not appear to harm the growth of fenugreek, and may, in fact, even help it.

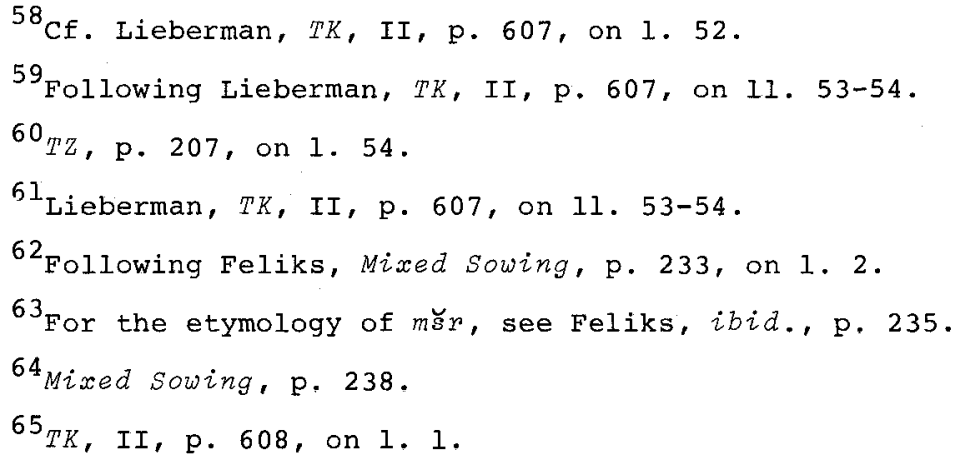


$66_{\text {The reasoning and evidence for this view are presented }}$ by GRA (long commentary) as follows:

The rule in this [matter is] that it is not necessary [to have] any distancing at all with [regard to] seeds [of diverse-kinds]. Only because of [the possibility of the appearance of] confusion is it necessary for every kind [to be sown in an area of] a size like that of a field. For example, with [regard to] grain [sown among grain of a diferent kind, each area must measure] a bet rova , and with [regard to] vegetables [sown among vegetables of a different kind, each area must measure] six handbreadths [M. 2:10], And each according to its measure is considered a field unto itself, and then there is no [appearance of] confusion. And [this follows the law] as it is explicitly stated in M. 3:4, that "two rows of chate-melons, etc., it is permitted" [i.e., it is permitted to sow two rows of one kind next to two rows of another kind], but "one row, it is still prohibited" [i.e., it is prohibited to sow one row of one kind next to one row of another kind, for one row is not considered a field unto itself]. But [concerning] one who wishes to make a narrow bed (my $\breve{s} w$ ) -- that is, not [an area the size of ] a bet rova, which is ten-and-a-half [amot squared], but he wishes only to make furrows and to sow a different kind in each furrow -he is permitted to do so.

${ }^{67} \mathrm{M}$. does know the notion that diverse-kinds must be separated from one another (Cf. M. 2:8, which says that one may flank certain objects with diverse-kinds, and $M .3: 4,6$, which state that one may now sow a single row of one kind next to another row of a different kind). M. does not, however, discuss the separation of diverse-kinds when the different kinds are sown in plots of land of significant size (e.g., two rows, beds, or patches [M. $2: 6,9,3: 4,6])$. It appears that the commentaries derive such a notion from an exegesis of M. 2:9. According to the commentaries M. 2:9 presents a dispute between Meir and the sages concerning how many patches may be laid out in a bet se'ah. Meir says that twenty-four patches may be laid out (with each the size of a bet rovac, or one twenty-fourth of a bet $s e^{\prime} a h$ ), while the sages allow only nine patches to be arranged. The commentaries (following $Y_{.}$) then maintain that the dispute concerns the separation of diverse-kinds, with Meir requiring no separation and the sages limiting the number of patches in a field in order to separate one from the next with uncultivated land. The issue of the dispute, however, may not concern the separation of diversekinds at all. GRA maintains that the sages only say that more than nine patches in a single field produce the appearance of diverse-kinds. It is then not likely that the requirement of separating diverse-kinds originates in $M$. itself.

68 Feliks, Mixed Sowing, p. 236.

${ }^{69}$ Feliks, ibia., maintains that both measures equal about two amot.

${ }^{70} \mathrm{Cf}$. Jacob Neusrer, The Rabbinic Traditions about the Pharisees before 70 (Leiden: E. J. Brill, 1971), II, p. 167.

$7^{1}$ So Reuben Alcalay, The Complete Hebrew-English Dictionary,

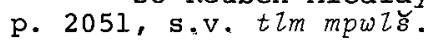


$72_{T Z, \text { p. } 207 \text {, on } 1.3 .}$

${ }^{73} \mathrm{Y}$.'s version reads as follows:

R. Leazar b. R. Simeon [and] Abba Yosé b. Yohanan of Yavneh said, "In a large [field the furrows are] fifty amot [in length], and in a small

[field the furrows run] according to [i.e., for] the greater part ( $m w b h)$ of the field [GRA: according to the entire (field)]."

${ }^{74}$ Alternatively, three furrows are to be placed between the rows, so that the latter are then separated from one another and the field does not appear to be sown with diverse-kinds (HD, MB; following the alternate interpretation of M. 2:6 [above, p. 90]).

${ }^{75} \mathrm{Cf}$. Lieberman, TK, II, p. 608 , on 1. 1, and Feliks, Mixed Sowing, p. 233, on 1. 6 .

76 According to $Y$.'s version above (n. 73), the rule of fifty amot applies only to large fields. In small fields, however, the furrows must extend across either most of the field or all of it (depending on the reading of $Y$. ).

${ }^{77}$ Feliks (Mixed Sowing, p. 233, on 1. 8), follcwing the alternative interpretation, explains that a furrow which is fifty amot long and two amot wide (see our discussion of M. 2:6) covers about the area of a bet rova (= one hundred square amot $=$ one twenty-fourth of a bet $\left.s e^{\prime} a h\right)$. Feliks then relates $T$. to M. Kil. 2:10 which says that a bet rova of one kind of grain may be sown next to a bet rova of a grain of another kind.

${ }^{78}$ According to our interpretation of the pericope $T$. should be interested in the width of all three furrows taken together, rather than in the width of each individual furrow. We assume that this is how Lieberman understands T., for he prefers the reading of rhbr: ("their width") to rhbw ("its width"). It is of course still possible that $T$. refers to the width of each

individual furrow. According to the alternative interpretation of T., D-F does refer to individual width (cf. Feliks, Mixed Sowing, F. 233, on 1. 10).

${ }^{79}$ Mixed Sowing, p. 236.

${ }^{80}$ Cf. Epstein, ITM, p. 1093; cited by Zachs, I, p. 235, n. $49 *$.

${ }^{81}$ Following Albeck, I, p. 106.

82 For Geniza fragments, see Zachs, I, p. 235, on 1. 25.

${ }^{83}$ So Danby for $2 s m w k$.

${ }^{84}$ Cf. Epstein, ITM, p. 1008 ; cited by zachs, I, p. $236, \mathrm{n} .56$.

${ }^{85} \mathrm{Cf}$. most commentaries to $\mathrm{M}, \mathrm{Kel}, 18: 2$ and Neusner, HMLP, II, p. 125 .

${ }^{86}$ The relevant part of $M$. concerns measuring the volume of the space covered by an arch (qmrwn) attached to a chest ( $\breve{s} y d h$ ). $M$. says that this volume is measured by a rws twr, which is understood to involve the description of a triangle with its apex at the highest point of the arch (cf. Danby's comment, cited by Neusner, ibid.). 
${ }^{87}$ Rosh differs from the other commentaries who explain rws twr as a triangle in that he maintains that such a triangle is created at the end of each furrow (as the farmer turns his plow around). Accordingly, more than one rws twr enters the field of barley (cf. Feliks, Mixed Sowing, p. 243, fig. 118, no. 1).

${ }^{88}$ Figure 1 is given by Joseph Qappah, Mishnah with the Commentary of $R$. Moses b. Maimon (Jerusalem: Mossad HaRav Kook, 1963), I, p. 108. Cf. Feliks, Mixed Sowing, p. 243, for an alternate interpretation of the view of Maimonides.

${ }^{89}$ The commentaries who maintain that a pws̆ twr is a triangle offer two etymologies for the term. Maimonides (Comm.), citing Cant. 1:11, identifies twr as a triangular earring. A more widely-held explanation says that rw twr is equivalent to rws $\breve{s} w$, or "ox-head" (Rosh, MS). MS explains that the head of an ox is broad at its horns and becomes progressively narrower until it reaches a point. The ox-head is then shaped like a triangle (cf. G. Dalman, Arbeit und Sitte in Palästina [1928-42; rpt. Hildesheim: George Olms, 1964], II, p. 114 [cited by Feliks, p. 243]), who identifies twr as the turtle-dove, whose head may similarly come to a point). I am not certain as to how much weight should be given to any of these etymologies.

${ }^{90}$ Cited by Albeck, p. 360 . B. Suk. 7 a presents a discussion concerning the third wall of a sukkah (of three walls). Kahane and Assi suggest to Rav that the third wall should be placed opposite the other two, krw $\breve{s}$ twr, or as a diagonal.

$91_{\text {Figure }} 2$ is presented by Ribmas himself in the Romm ed.

${ }^{92}$ It is also possible that the expression rws twr is equivalent to rw $\breve{s}$ swrh, "the head of a row." The term then refers to a row of wheat which extends beyond the borders of the wheatfield, and enters the field of barley (so sens, following T. 2:2; cf. figure 4 [given by Feliks, Mixed Sowing, p. 243, fig. 118, no. 2]).
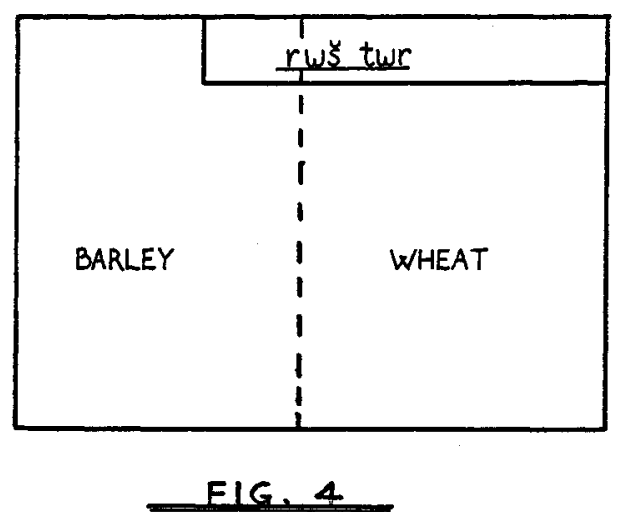
${ }^{93}$ We note that in the alternative explanations of rus twr (in which the term is considered a single row), M. is taken to refer to the last row of the field.

94 Alternatively, simeon may be understood as saying that one may not sow either flax or anything else at the common edge of the two fields (Maim., Comm.). Simeon then differs with G as to whether or not a furrow of flax will produce an appearance of diverse-kinds (MR). We do not regard this understanding of Simeon's saying as probable, for Simeon's statement that there is no difference between flax and other kinds follows G's statement that flax is permitted. If Simeon then says that it is all the same whether flax or another kind, it is reasonable to assume that he means that all kinds should be permitted. We therefore believe that the interpretation presented in the text is the more probable one.

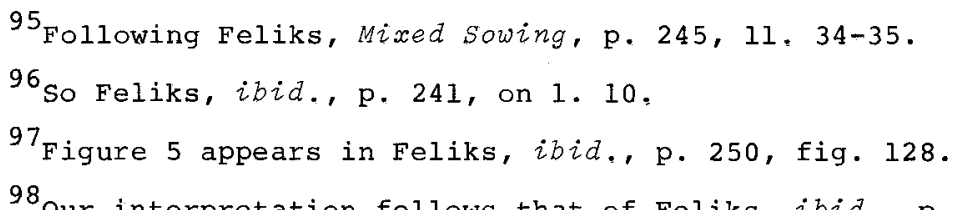
Our interpretation follows that of Feliks, ibia., p. 245 , on 1. 23, and p. 250, fig, 128. Alternatively, Lieberman (TZ, p. 208, on 1. 11) understands iht hyth w'ht sewrh to mean "botr. wheat and barley." That is, both wheat and barley may be sown in a single furrow between the fields of the two kinds. The half of the furrow which is adjacent to the wheat-field may contain wheat, while the half next to the field of barley may be sown with barley (fig. 7). Accordingly, the point of law is that, in the case of adjacent fields containing different kinds, the two kinds may be sown together in a single furrow between the fields without producing the appearance of diverse-kinds, for each kind appears to mark the end of the field adjacent to it. This interpretation, however, does not appear to be very plausible, for it is based on a non-idiomatic translation of the phrase tht. . . $w^{\text {'ht }}$. This phrase usually has the sense of "either. ․ or" (c). C. Y. Kosowsky, Thesaurus Mishnae [Heb.] (Jerusalem, Massadah, 1956), I, pp. 57-58, s.v, 'hd. . ' hd). We therefore favor the interpretation given above in the text.

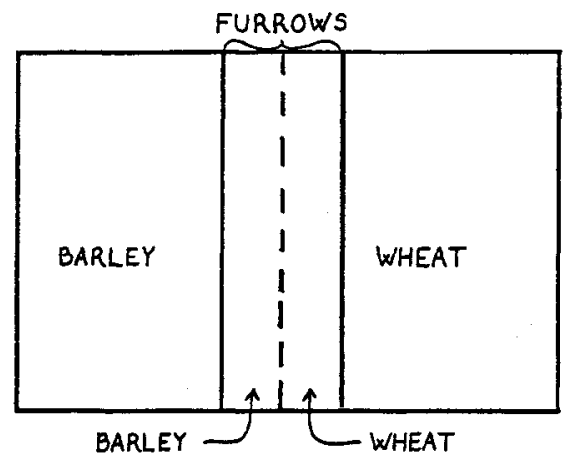

FIG. 7 
${ }^{99} \mathrm{Y}$. apparently attributes $\mathrm{P}-\mathrm{Q}$ as well as $\mathrm{K}-\mathrm{M}$ to Eliezer

b. Jacob (following Feliks, Mixed Sowing, pp. 249-250).

100 Following Lieberman, TK, II, p. 611 on $11.12-13$.

${ }^{101}$ In fact, since the law here apparently follows that of T. 2:la (as explained below), it is probably that T. 2:4a does not provide the original context of the sayings.

${ }^{102}$ We note that if T. $2: 4 a$ is related to T. $2: 1 \mathrm{a}$, then the former must understand the latter according to our alternate interpretation (but cf. Erfurt's reading of $P$ ). That is, T. 2:1a is taken to concern the rows themselves, and not the separation between them. The question in both T. 2:1a and T. 2:4a then becomes how long the rows must be in order to be considered autonomous areas. This appears to be the most plausible way of explaining T. 2:4a (although, of course, both interpretations of $\mathrm{T} .2: 1 \mathrm{a}$ still remain viable).

103 Carthamus tinetorius, of the composite family (Compositae). Cf. Feliks, Mixed Sowing, p. 261, n. 5.

104 For the relevant Geniza fragments for this pericope, see Zachs, I, pp. 236-237, on 11. 29, 31 .

$105_{n y}$ is land which is plowed for more than one year in order to ready it for sowing in the following year (Feliks, Mixed Sowing, p. 269; cf. T. B.M. 9:7, cited by Feliks, ibid., n. 26).

106 Most commentaries maintain that gpph refers to a loose stone wall, and that a $g d r$ is a wall whose stones are plastered. Feliks (Mixed Sowing, p. 270), however, says that a gpph is a plastered wall, and that a gdr is a loose stone wall.

$107_{\text {Mixed sowing, p. } 261 .}$

${ }^{108} \mathrm{Cf}$, P. F. Knowles' statement about the cultivation of safflower in India ("Safflower-Production, Processing and Utilization," in Economic Botany 9 (1955), p. 274): "In these regions [i.e., Bombay, Madhya, Pradesh and Hyderabad] it is often found in association with such crops as wheat, barley, and chick peas, being sown either as a border about the field or as a few rows alternating with a larger number of those of the main crop. Its purpose in such an arrangement seems to be to provide protection from stray cattle, sheep, or goats."

$$
{ }^{109} \text { Mixed Sowing, pp. 261-262. }
$$

110 The only other possible explanation of A-B is given by Maimonides. In fact, Maimonides gives two different and opposing interpretations in his Commentary and Code. In his Commentary Maimonides maintains that mustard and safflower harm the growth of grain, so that one seeing them growing next to grain will assume that the owner himself wants them to grow there (for the owner of the grain-field would certainly not allow his neighbor [who owns the adjacent field (cf. M. 2:7D-G)] to flank the grainfield with a damaging crop). Since it looks as if the owner wishes the mustard or safflower to grow there, the owner appears to be growing diverse-kinds. One may, however, flank a field of vegetables with mustard or safflower, since these plants do not harm vegetables, and those who see them will think that the neighbor has sown them. 
In his Code (Diverse-Kinds 3:18) Maimonides presents a contrary interpretation. Here he says that mustard and safflower are harmful to everything but grain. If mustard or safflower were to be sown next to grain, it would appear as if the owner himself sowed them (since there is no reason why he should not have) and so the owner would appear to be sowing diverse-kinds. One may flank vegetables with mustard or safflower, though, for since the latter are harmful to the former, one may assume that the owner himself did not wish the two crops to be sown next to one another. One seeing them growing together will assume that the neighbor has sown the mustard or safflower, so that the owner of the grain-field does not appear to be sowing diverse-kinds.

In any event, we do not accept either of the interpretations given by Maimonides (and later commentaries). M. nowhere states that mustard or safflower are damaging to crops. Furthermore, there appears to be no botanical evidence which supports the claim that mustard or safflower damages one (grain or vegetables) and not the other. We therefore favor the interpretation of Feliks given above.

${ }^{111}$ Feliks, Mixed Sowing, p. 262, n. 14. Cf. also Pliny, Historia Naturalis, 19.54.170 (trans. H. Rackman, Loeb Classical Library ed., v. 5, p. 529):

It [i.e., mustard] grows entirely wild, though it is improved by being transplanted; but on the other hand when it has been sown once it is scarcely possible to get the place free of it, as the seed when it falls germinates at once.

112 Feliks, Mixed Sowing, p. 262.

${ }^{113}$ The one exception is the loose stone wall (3), which is not mentioned elsewhere in M. -T. as a divider.

114 These are uncultivated land (1), newly broken land (2), and the road (4) (M. Peah 2:10). We note that wherever the road is mentioned as a divider in M. $-\mathrm{T}$. a distinction is usually made between public and private roads, although $\mathrm{M}$. does not make the distinction here.

$115_{\text {This }}$ is the road (4) (M. Bik. I:1).

116 These are the road (4), the fence (5) and the ditch (6) (M. Kil. $4: 3,4: 7,5: 3,6: 1)$.

117 These are the fence (5) (M. Erub. 1:8, 7:2), the ditch (M. Erub. 7:3), the tree which shades the ground (7) (M. Erub. $10: 8$ ), and the rock (8) (M. Shab. 11:2).

$118 \mathrm{M}$. Oh. $8: 2$.

$119 \mathrm{Y}$. reads: "A man is permitted to sow a row of mustard or safflower in his field, provided that he makes the length of the row ten-and-one-half amot and rwhb $m l^{\prime} w^{\prime} w . "$ For the various interpretations of $Y$. (i.e., for an explanation of the phrase whb $m\left(w^{\prime} w\right)$ see Lieberman $T K, I I, p p .611-612$, on 11. 18-19, and Feliks, Mixed Sowing, pp. 263-266. Cf. also our discussion of M. Kil. 3:3, and Primus, p. 31 .

120 our translation of mqypyn as "edge" follows the interpretation of Epstein (ITM, p. 446; cited by Feliks, Mixed Sowing, p. 263, and Lieberman, TK, II, p. 611 on 11. 17-18), who suggests that the word may have the same sense as swmkyn, "they flank." 
The term then does not indicate encirclement, but "bringing near" (cf. Jastrow, II, p. 934, s.v. nqp, I). Cf. Epstein and Lieberman, however, for the distinction made by $Y$. between mqypyn and swmkyn (the former term implies actual contact between the plants, while the latter implies some separation between them). In the case of D, however, simeon b. Gamaliel does refer to the actual encirclement of the small beds (Lieberman, TZ, p. 209 on 11. 21-22, and $T K$, II, P. 612, on 11. 21-22). Feliks (p. 263) points out that the phrase used in $\mathrm{D}$ is mqypyn 'wtn ("they surround them," the phrase having a direct object), and not mqypyn $2 h n$ ("they bring [mustard or safflower]. near to $\mathrm{x}$," the phrase having an indirect object), as in $A-C$.

${ }^{121}$ Geophytes are those plants which grow underground. T: Ter. lists arum, garlic, onions and leek as geophytes. Cf. Löw, II, p. 125 (cited by Lieberman, TK, I, p. 444, on 1. 12), and Feliks, Mixed Sowing, p. 262.

122 Erfurt actually reads as follows:

B. R. Judah says, "They edge [a field of] any

[kind with] mustard. [or] safflower."

C. R. Simeon says, "They edge [a field of] any

[kind with] mustard [or] safflower, except for [a field of] grain."

According to Lieberman, (TK, II, p. 612, on 11. 20-21) however, the last phrase of Simeon's saying actually belongs to Judah's statement (as the other mss. read it).

123 Mixed Sowing, p. 262.

124 Ibia.

125 Ibid.

126 Mixed Sowing, p. 278. Cf. also Sirillo (cited by Lieberman, $T K$, II, p. 612, on 1. 22), who makes a similar comment.

127 Ibid.

${ }^{128} \mathrm{Cf}$. M. Erub. 10:8 (cited by Lieberman, TK, II, p. 612, on 1. 23) and T. Erub. 10:5, which state that a tree whose foliage is less than three handbreadths above the ground forms an autonomous domain, so that one may carry within it on the Sabbath. Cf. also M. Oh. 8:2, where a tree's foliage clearly forms a Tent.

$$
\begin{aligned}
& 129_{T K}, I I, \text { pp. } 612-613 \text {, on } 1.23 . \\
& 130_{T K}, I I, p .613 \text {, on } 1.24 . \\
& 131_{\text {Mixed Sowing, p. } 272 \text {, on } 1.35 .} \\
& 132 \text { Cf. Zachs, I, ad. Zoc. }
\end{aligned}
$$

${ }^{133}$ The commentaries present several different ways in which a bet $s e^{\prime a h}$ may be laid out so as to contain twenty-four patches, with each patch the size of a bet rova. We shall briefly summarize the two major interpretations. Maimonides explains in his Commentary that each patch is a square measuring 10.2 by 10.2 amot. The area of the entire field is then 2,496.96 square amot (compared with the area of a bet se'ah, 2,500 square amot). (Maimonides assumes that the bet se'ah is a square 
measuring 50 by 50 amot.) Feliks (Mixed sowing, p. 282), however, cites TYT as saying that a square bet se'ah cannot be divided into twenty-four square baté rovac ${ }^{\mathcal{C}}$. Feliks then shows how twenty-four square patches may be laid out (in six rows) in a rectangular bet $s e^{\prime a h}$.

Alternatively, Ribmas and Sens (following T. 2:6b; for an explanation as to how they follow T., see Feliks, Mixed sowing, p. 281) maintain that each patch measures 10 amot and 2.5 handbreadths by 10 amot or 10.42 by 10 amot. According to this interpretation the total area of the field is $2,500.8$ square amot.

${ }^{134}$ Alternatively, the dispute between Meir and the sages concerns not the number of mustard-patches which may be sown in a field (D-G vs. H), but the number of patches which may be laid out in a bet se'ah (A-C [also attributed to Meir] vs. H; this approach, taken by most commentaries, follows Y.). Meir says that twenty-four patches, each the size of a bet rovae, may be laid out in a bet se'ah, while the sages allow only nine patches to be sown in a field of that size. According to most commentaries (e.g., Maim. [Comm., Code, Diverse-Kinds 4:7], Sens, etc.), the dispute concerns the necessity of separating diverse-kinds from one another. Meir maintains that the patches need not be separated from each other, even though each patch may contain a different kind. Accordingly, the patches may cover the entire area of the bet se'ah. The sages, on the other hand, require the patches to be separated, and so limit the number of patches to nine.

The commentaries conceive of how the sages separate the diverse-kinds in many different ways. We present here only the explanation of Maimonides (Comm.) which is illustrated in figure 8 (found in Qappah, p. 109; the units are amot). According to Maimonides each patch must be separated from its neighbor by nearly a bet rovac, so that only nine square patches may be sown. For the other interpretations of the commentaries and for diagrams illustrating their positions, see Feliks, Mixed sowing, pp. 287291 .

FIG. 8

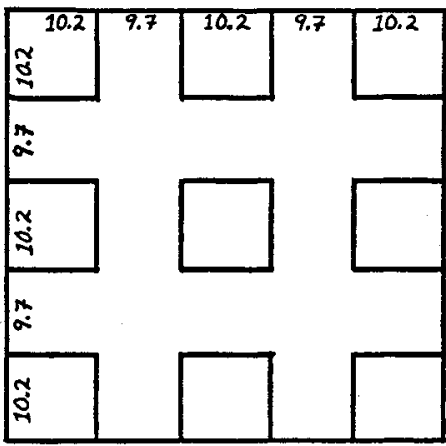


GRA presents yet another alternative interpretation of the dispute, maintaining that the latter concerns simply how many kinds may be sown in one field without producing the appearances of diverse-kinds. Meir says that twenty-four different kinds may be sown, while the sages permit only nine kinds to grow in a single field, for the presence of ten different kinds in one field would already produce the appearance of diverse-kinds.

Albeck ( $I, p, 361$ ), compares the ruling of sages to M, Shev. $1: 4,6$, which says that ten trees determine a field of trees. Albeck argues that the sages similarly maintain that ten patches determine a field, which in turn, because it contains different kinds, appears to be sown with diverse-kinds,

These interpretations of $M$. do not appear to be plausible, for they require a reconstruction of the text. In order to form a dispute between $\mathrm{A}-\mathrm{C}$ and $\mathrm{H}$, this approach must maintain that $D-F$ appears in the wrong place (since it interrupts the dispute) and that $\mathrm{A}-\mathrm{C}$ is to be attributed to Meir. We see no reason to read $M$, in this way, particularly since $M$, makes sense as it stands. $D-H$ is presented in a variation of the dispute form (opinion + words of $X / Y$ says + opinion), so that the dispute simply consists of $D-G$ vs. $H$. We further argue that $D-H$ forms a dispute because both opinions make use of similar numbersequences, as we have shown. We therefore favor the interpretation given earlier.

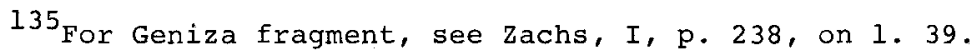

${ }^{136}$ Neusner (Eliezer, I, p. 352) lists F among the traditions which cannot be reliably assigned to Eliezer b. Hyrcanus.

137 A public road clearly cannot be located in a bet rovac, for the former is sixteen amot wide (M. B.B. 6:7), while the latter is only ten-and-one-half amot wide (see T. D below). Therefore Lieberman ( $T K$, II, p. 613, on 1 , 25) maintains that the road narrows as it enters the bet rova and widens as it leaves.

${ }^{138}$ Erfurt's reading agrees with the law of the reading of the first printed ed., but is formulated in order to emphasize the fact that the height of ten handbreadths distinguishes between the two classes of walls.

${ }^{139}$ Although M. Kil. $2: 8$ does not differentiate between public and private roads, M. Peah $2: 1$ does mention both types of roads in reference to dividing a field for the giving of pe'ah.

$140 \mathrm{M}$. Erub. 2:5 concerns whether or not one may carry on the Sabbath within a garden and outer area of a specified size. The garden is said to be square. Eliezer states that one is allowed to carry in the garden only if it is a perfect square. Yose then glosses Eliezer, saying, "Even if its length is twice its width, they carry within it," since Yose's saying is more intelligible as a gloss to Eliezer's saying than as a gloss to T. 2:6F-G (which is not interested specifically in the fact that the bet rova is a square), we maintain that yose's saying belongs primarily in the context of $M$. Erub. 2:5.

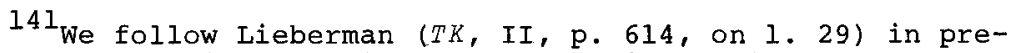
ferring the readings of Vienna Ms. and first printed ed. to those of Erfurt and Sens.

142 Following Lieberman, $T K$, II, pp. 614-615, on 1. 30 . 
$143_{T K}$, II, p. 614, on 1. 29.

144 For Geniza fragment, see zachs, I, p. 239 , on 1. 43.

$145_{\text {Feliks, Mixed Sowing, p. } 70 .}$

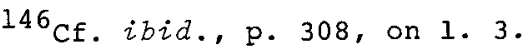

${ }^{147} \mathrm{Cf}$. T. Kil. 1:6: "It is prohibited to train [the Greek gourd] over plants."

148 Although D reads only (without ' $p$, which is standard joining-language), "The chate melon and the cowpea," and could conceivably refer to any law at all, we see no alternative but to follow the redactor and interpret it in this context.

${ }^{149}$ Feliks, Mixed Sowing, p. 310.

\section{CHAPTER THREE}

$1_{M} .3: 4$ and M. 3:5 do not, however, comprise a major unit, for each contains a different formulary pattern in its protasis (hnwte [M. 3:4] vs. nwte $d m$ [M. 3:5]).

2 For the Geniza fragment, see Zachs, I, p. 241 , on 1.3 .

3 Alternatively, other commentaries maintain that all five kinds are to be sown within the bed itself. In addition, all of the kinds are said to be separated from one another by (for the most part) one-and-a-half handbreadths, so that they should not nourish one another (Sens, Maim., Code, Diverse-Kinds 4:9). Maimonides (Comm.), for example, presents two ways in which the five kinds may be sown in the garden-bed (figures 10-11 the

shaded portions are uncultivated]; from Qappah, I, pp. 110-1ll). The main difference between the two figures concerns whether or not the corners of the bed are sown. Sens, following Y., gives yet another figure (fig. 12; from Romm ed. of M. Zeracim, in Babylonian Talmud).

For yet other interpretations of M., cf. Ribmas and MS. We do not accept these interpretations of $M$. because they do not follow from the plain sense of the text. M. nowhere says that the different kinds must be separated from one another, and so does not imply that the beds are to be arranged in such complex patterns. We therefore prefer the more straightforward explanation of GRA.

FIG. 10

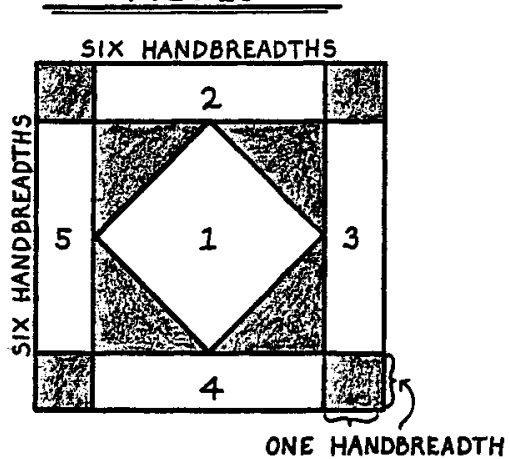




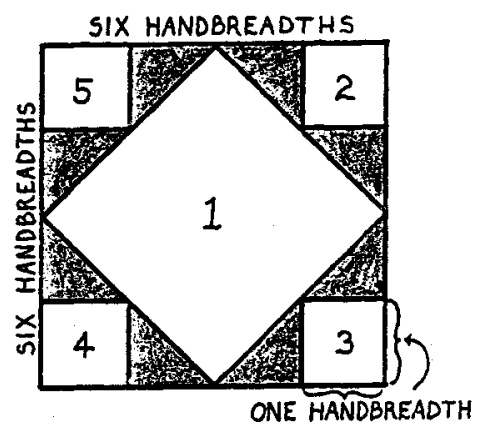

FIG. 11

FIG. 12

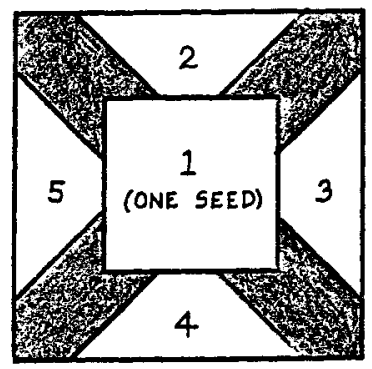

${ }^{4}$ We note that $M$. Shab. $9: 2 b$ cites $M$. A-B and provides it with a Scriptural basis:

Whence, do we know that "[Concerning] a garden-bed which is six by six handbreadths, that they sow in it five [kinds of] seeds, from along the four sides and one in the middle?" As it is written, For as the earth puts forth its blossom and like a garden causes its seeds (zrwcyh) to sprout (Is. 61:11), "Its seed" $\left(z r^{c} h\right)$ is not stated, but its seeds $\left(z p^{c} y h\right)$. 
That is, the plural noun "its seeds" implies that more than one kind of seeds may be sown in a bed (Albeck). Cf. also B. Shab. $84 \mathrm{~b}-85 \mathrm{a}$ for Judah's saying, which has the verse yield exactly five kinds.

$5_{\text {While it is true that an area six handbreadths square is }}$ only mentioned as an autonomous field with reference to vegetables, M. 3:2 states that only vegetables are sown in a garden-bed.

${ }^{6}$ Maimonides (Comm.) gives the following figure to illustrate M. 3:1G (fig. 14; from Qappah, I, p. Ill):

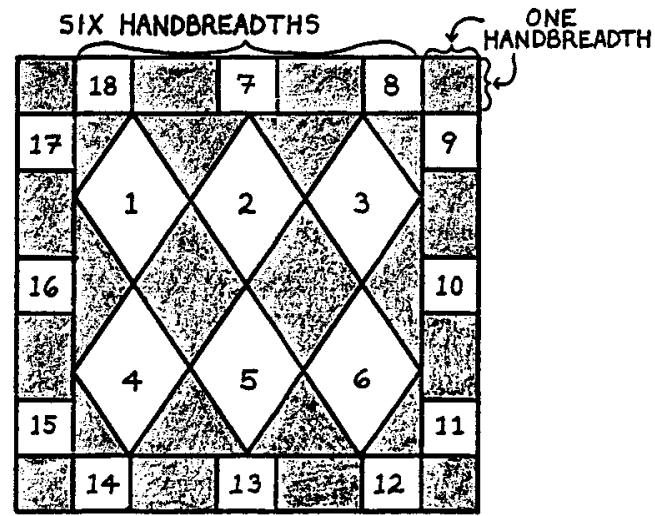

FIG. 14

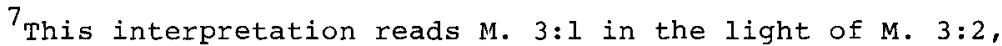
which says that only vegetables are sown in garden-beds.

8 Maimonides (Comm.) gives the following figure to illustrate M. C-D (fig. 16; from Qappah, I, p. 111):

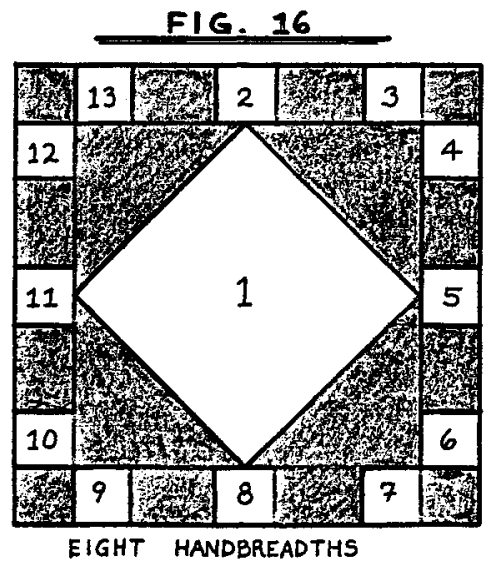


9 The hypocotyl of a turnip is the swollen "root" which lies between the plant's first leaves (cotyledons) and its true root (S. G. Harrison, et al., The Oxford Book of Food Plants, p. 172).

${ }^{10}$ Cf. Zachs, I, p. 243 , on 1. 6 .

$11_{\text {Cicer arietinum, of the pea family (Papilionaceae). For }}$ this identification see Löw, Die Flora der Juden, II, pp. 727ff., and Feliks, Mar'ot HaMishnah, p. 15.

${ }^{12} \mathrm{Cf}$. Lieberman, $T Z$, p. 210 , on 1.32 , and $T K, I I$, p. 615, on 1.32 .

${ }^{13}$ Cf. Zachs, I, pp. $243 \mathrm{f}$, on 1.7.

${ }^{14}$ Feliks, Agriculture, p. 118.

${ }^{15} \mathrm{Cf}$. also Lieberman, TK, II, p. 616, on 1.38.

16 plant world of the Bible, p. 162.

${ }^{17}$ Pliny describes the different types of chick-peas as follows (Historia Naturalis, 18.22.124 [Loeb ed., trans. H. Rackham, v. 5, p. 265]):

There are several varieties differing in size, colour, shape, and flavour. One resembles a ram's head and so is called 'ram's chick-pea;' of this there is a black variety and a white one. There is also the dove-pea, another name for which is venus's pea, bright white, round, smooth and smaller than the ram's chick-pea; it is used by religious ritual in watchnight services. There is also the chickling vetch, uneven in shape and with corners like a pea. But the chick-pea with the sweetest taste is one that closely resembles the bitter vetch; the black and red varieties of this are firmer than the white.

It is possible that M.'s "smooth chick-pea" is identical with Pliny's dove-pea, while the "large chick-pea" may be the "ram's chick-pea." Cf. also Theophrastus, Enquixy into Plants, 8.5.1.

${ }^{18}$ Feliks (Agriculture, p. 323) suggests that the furrow of $\mathrm{H}$ is an irrigation-furrow (i.e., a furrow which leads water from the water-channel to the fields).

19 We note that Y. Kil. $3: 3$ cites a baraita in which Bar Qappara opposes the law of H-I, saying, "He sows only one kind in it [i.e., the furrow or water-channel]." 1. 32 .

${ }^{20} \mathrm{Cf}$. Lieberman, $T Z$, p. 210 , on 1.32 , and $T K, \mathrm{p}, 615$, on

$$
21_{\text {Ibid. }} \text {. }
$$

22 For all of Lieberman's corrections, cf. TZ, p. 210, on 11. $32 \mathrm{ff} .$, and $T K$, II, p. 615, on 11 . $33 \mathrm{ff}$. Lieberman suggests ( $T K$, II, p. 615, on 1.33 ) that Erfurt's omission of D-K may account for the transposition of apodoses. C may have originally followed $J$, but when D-J was dropped, C may have been attached to $\mathrm{A}-\mathrm{B}$. 
${ }^{23}$ On sowing the cowpea for its seeds, cf. M. Shev, $2: 8$. ${ }^{24}$ Feliks, Mixed Sowing, pp. $71 \mathrm{f}$.

${ }^{25}$ Cf. Zachs, I, ad.Zoc., for Geniza fragments.

${ }^{26} \mathrm{Cf}$. also T. Kil. $2: 1 \mathrm{a}, 2: 4 \mathrm{a}$, where an open furrow is also considered a field unto itself.

${ }^{27}$ G. Porton (The Traditions of Rabbi Ishmael [Ieiden: E. J. Brill, 1976] I, p. 34) observes that the dispute of D-G is arranged so that the dimensions discussed in the unit appear in this order: length, length-width, width.

${ }^{28}$ Neusner (Eliezer, I, p. 352) lists M. Kil. $3: 4$ among the traditions which may not be reliably attributed to Eliezer b. Hyrcanus.

${ }^{29}$ Alternatively, Eliezer reasons that since the first kind appears again after the third, the different kinds are planted in a regular sequence $(1-2-3-1)$, and there is therefore no appearance of diverse-kinds (Albeck). This interpretation is interesting, but there is no evidence in $M$. that the sequence of planting has anything to do with the appearance of diversekinds.

${ }^{30}$ The four plants mentioned in $T$. often appear together in T. Kil. (cf. T. $1: 1 \mathrm{c}, 2: 10$ ). For other places in M. - T. where these plants appear as a group, see Lieberman, $T K, I I$, p. 597, n. 10 .

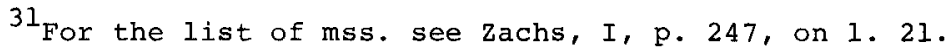

32 Ibid. , p. 247 , n. 34 .

33 Erfurt transposes T. 2:9A with T. 2:9C-D. Cf. Lieberman, $T K$, II, P. 616, on 11. 36-37.

${ }^{34}$ Lieberman $(T Z, p, 211$, on 1.42 , and $T K, I I, p .616$, on 1. 42) maintains that "cowpeas" has been mistakenly inserted here from T. 2:11.

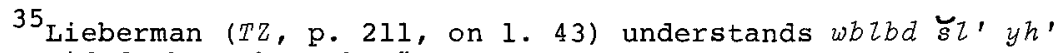
as "provided that there be."

${ }^{36}$ The order in which $T$. joins these three rules is difficult. $T$. clearly does not follow the order of M., nor does it follow any order which takes account of the substance of the rules. The rules are not listed according to the order of the size of the area involved, for a garden-bed is larger than both a furrow and a hollow, and yet it follows the former and precedes the latter. The order of $T$. also does not follow the order of the number of different kinds which may be sown in a given area, for the sequence of numbers in A-D is three/five/four. It is perhaps possible that the original sequence was three/four/five (i.e., $C-D$ preceded $B)$, and $C-D$ was then placed immediately before E-G because of their similarity in substance (e.g., both have four kinds, and $F=D)$. Alternatively, if we follow Erfurt's reading and omit B, T. then follows both the order of $M$. and a three/four number sequence (or the reverse, as Erfurt transposes $A$ and C-D). We see no reason, though, to prefer Erfurt's reading to those readings which do include $B$.

${ }^{37}$ For the list of mss. see Zachs, I, p. 247 , on 1.23 . 
${ }^{38}$ For Geniza fragment, see zachs, ibid.

${ }^{39}$ our translation of $\mathrm{H}$ follows that of Primus, p. 30 .

40 We note that $A$ (and M. 3:7C below) describes a plausible situation, in that the two crops involved (gourds and onions/ grain) are sown in late winter, and so begin to grow before the planting-time of gourds, which is in the spring. Cf. Theophrastus, Enquiry into Plants, 7.1.2 (Loeb, ed., trans., Arthur Hort, v. 2, p. 61), Columella, De Re Rustica, 11.15 (Loeb ed., trans. E. S. Forster and Edward Heffner, v. 3, p. 139), and Pliny, Eistoria Naturalis, 19.24 .69 and 19.32 . 105-107 (Loeb ed., trans. H. Rackham, v. 5, pp. 467, 487f.). Cf. also Feliks, Agriculture, pp. 148, $153 f$.

${ }^{41}$ We assume (following ${ }^{C}$ Aqiva) that a row of onions is equal in width to a row of gourds. Cf. Maimonides (Comm.), who says (following the assumption of $\mathrm{Y}$. ) that both types of rows measure four amot in width.

42 An autonomous field, of course, need not be fully planted. Cf. T. $2: 7$.

$43 \mathrm{Fig} .17$ follows the interpretation of Maimonides (Comm.), who maintains that the row of gourds is planted in the middle of the space formerly occupied by the two rows of onions. Cf. Kahane's statement in Y., though, which gives the various possibilities for planting the row in a space of two rows (discussed below at T. $2: 12$, n. 52).

${ }^{44}$ Alternatively, Sens, Ribmas, and Rosh maintain that the row of gourds is planted beside the space formerly occupied by the onions, which is then left uncultivated (fig. 19). Sirillo (cited by MS) points out that this interpretation is difficult, for presumably other onions adjoin the uprooted rows, and the gourds cannot be planted there. In any event, this interpretation seems to read into the text a concern for the distance between the rows of gourds (perhaps following $\mathrm{H}$ ), and so does not follow the plain sense of the text.

\section{FIG. 19}

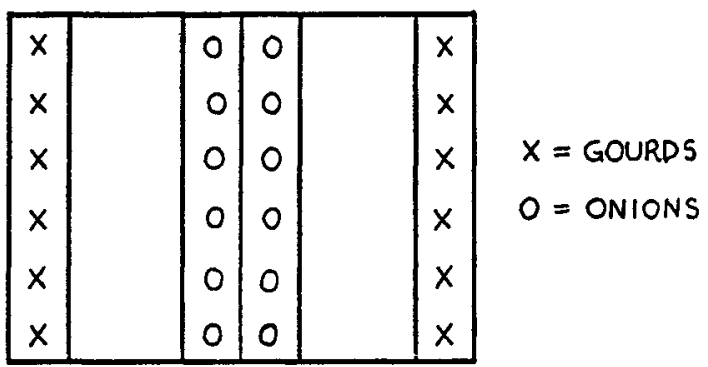


${ }^{45}$ Alternatively, Maimonides (Comm.) and others say that the issue of the dispute concerns the separation of the gourds from the onions. Ishmael maintains that a single row of gourds is planted between the two uprooted rows of onions, so that it is flanked by two amot of uncultivated land on each side (since the row of gourds is four amot wide, and it is planted in the middle of two uprooted rows of onions $[=8$ amot $]$ ). The gourds must then be separated from the onions by two amot. CAqiva, though, requires only a nominal separation (by a single furrow) between the two kinds, and therefore allows two rows of gourds to separate the two rows of onions (cf. figs. 17-18). This interpretation introduces into $\mathrm{H}$. the consideration of separating the different kinds which adjoin one another (a consideration which Maimonides introduces throughout Chapters Two and Three), and perhaps also represents a reading of the dispute in light of sages' opinion on $\mathrm{H}$. This explanation, though, does not follow the plain sense of the text, and we therefore find it less plausible than the one which we have suggested above.

46 According to Maimonides (Comm.) and others the view of sages is identical with that of Ishmael, for in each case the rows of gourds are separated by twelve amot (fig. 20; units are amot). Maimonides (following $\mathrm{Y}$. ), reading $\mathrm{A}-\mathrm{H}$ as a unitary pericope, maintains that sages differ from Ishmael only in that they do not agree that the gourds must be separated from the onions by more than a nominal distance (and in this respect they agree with CAqiva; cf. especially MR for a good summary of this interpretation). We do not agree, of course, that $\mathrm{A}-\mathrm{H}$ forms a unitary pericope, and that sages are therefore in dispute with Ishmael and cAqiva. We therefore do not consider this interpretation to be as plausible as the one which we have presented in the text.

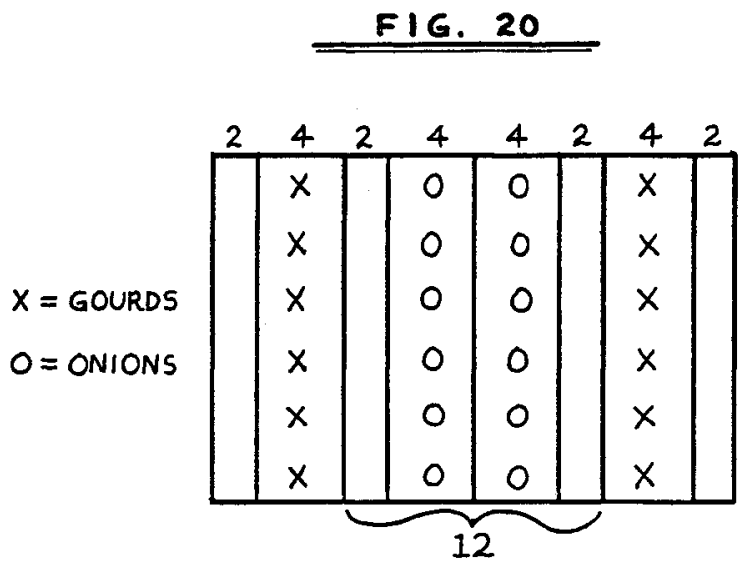

47 Our translation follows Lieberman's understanding of $q s \mathrm{r}^{\circ}$ as tmsyt or swrs (TK, VIII, p. 763, on 11. 52-54; cited by Bokser, I, p. 46, n. 114).

48

Cited by Lieberman, $T Z$, p. 2Il, on 1.46 , and $T K$, II, p. 617, on 1.46. Lieberman originally emended the text on the basis of Sirillo's reading, but he later explicitly changes his mind and follows Vienna's reading. Cf. TK, VIII, p. 763, n. 32 . 
${ }^{49} \mathrm{~L}$ adds $\mathrm{B}-\mathrm{C}$ in the margin. Bokser, I, p. 45, n. 109 explains that $B-C$ may have been omitted because of a homoioteleuton, as "R. Ishmael said, 'Twelve," "appears again in $Y$. after the citation of $T$.

$50_{T Z}$, p. 211 , on 1. 47, and $T K, I I$, p. 617 , on 1.47.

$51_{\text {Alternatively, }} \mathrm{y}$. and sirillo have $q s ̣$ (or $h q w s ̧ b$ ) for $q g r$, so that $A$ reads "The opinions of both of them are fixed," i.e., given in fixed (Iinear) measurements. This reading seems to be particularly appropriate to the context in which $Y$. cites T. Y. presents a "dispute" (cf. Bokser, I, pp. 45f) between Kahane and Samuel concerning the ways in which Ishmael's opinion in M. may be translated into linear measurements. Kahane presents three possibilities, while samuel gives only one. T. is then cited in support of Samuel's view that the rule of Ishmael is fixed and not variable. The reading of $q s b$ thus allows $T$. to fit nicely into $Y$.'s discussion of $M$. , and, since it makes little sense outside of the context of $Y$., it is possible that this reading arises out of the context of the citation.

${ }^{52}$ In Y. Kil. 3:6 (28d) Kahane presents three distances which could separate the rows of gourds planted according to the opinion of Ishmael. This distance may either be sixteen amot (if the row of gourds is planted on the outer side of the area of uprooted rows of onions; cf. fig. 24), twelve amot (if the gourds are planted down the midale of the area; cf. fig. 20 above), or eight amot (if the gourds are planted on the inner side of the area; cf. fig. 25 below) (following PM). We note that the distance of sixteen amot, like that of ten amot, does not occur exclusively in a field planted serially with gourds and onions.

\section{FIG. 24}

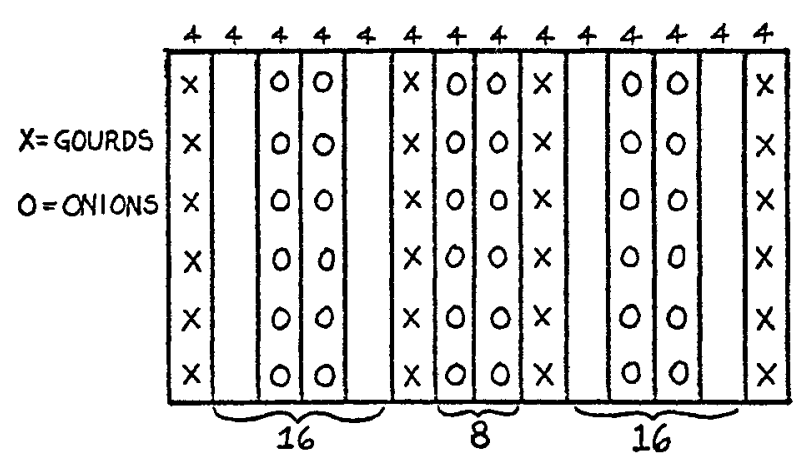

53 Ishmael, I, p. 36.

${ }^{54}$ Kefar Pegai is located about $15 \mathrm{~km}$. north of Lod. It was also known as Antipatris. The location derives its several names (miryal, Rosh Hacayin, and Arethusa) from the fact that it is situated above several springs. Cf. M. Avi-Yonah, Historical Geography, p. 42 (map, 129).

55 For Geniza fragments, see zachs, I, p. 249 , on 1. $31 \mathrm{ff}$. 
${ }^{56}$ For a list of mss., see zachs, I, p. 249 , on 1.31.

57 Maimonides, Code, Diverse-Kinds 3:13. Cf. Maim., Comm. ad. Zoc., where it is stated that the leaves of the gourds are to be cut off (see note 60 below).

${ }^{58}$ Following Danby, who translates $k z$ as "where," and Porton (Ishmael, I, pp. 36ff.), who translates $k l$ as "whenever."

59 If. M. 3:7A-B depends on M. $2: 10$ (as seems to be the case), then the reasons that the apodosis of $B$ does not also read kyrq (and so refer to $M .2: 10 \mathrm{E}$ ) may be due to the fact that $\mathrm{E}$ is opposed by Eliezer/Eleazar in $\mathrm{M}$. 2:10F. If $\mathrm{B}$ were to read kypq, it could refer to either of the two rulings of $M .2: 10$, and the law would be ambiguous. The apodosis of $B$ therefore had to present the ruling of M. 2:l0E.

60 Alternatively, Maimonides says in his Commentary that in this instance one should uproot (i.e.. cut off) the leaves of the gourds from before the grain. It is more likely, however, that the antecedent of mlpnyh is "the gourds" rather than "the grain," so that the explanation given in the code is more plausible.

${ }^{61}$ Although B speaks of an area of gourds (plural), a single gourd requires an area of the same size. Cf. our interpretation of T. $2: 7$ above.

${ }^{62}$ Sens, Rosh, and Bert. explain in another context (that of harmonizing $B$ and $D$ ) that the law concerning a row of gourds is more lenient than the law regarding a single gourd. A row is clearly demarcated as an entity unto itself, and therefore requires less area of tillage than does a single gourd, which, without enough surrounding area, would appear to be planted as diverse-kinds. This line of reasoning, however, has no basis in the text, and there is no reason to assume that it is a consideration in Yose's argument in $\mathrm{H}-\mathrm{I}$.

$$
\begin{aligned}
& 63_{T Z}, \text { p. } 211 \text {, on } 1.49 \text {, and } T K, I I, \text { p. } 617 \text {, on } 1.49 . \\
& 64 T Z, \text { p. } 211 \text { on } 1.51 \text {, and } T K, I I, \text { p. } 618 \text {, on } 1.51 . \\
& { }^{65} \text { Cited by Lieberman, } T K, \text { II, P. } 618 \text {, on } 1.51 . \\
& 66_{T 2}, \text { p. } 211 \text {, on } 1.52 \text {. } \\
& { }^{67} T Z, \text { p. 211, on 1. 52. The word thr is clearly unnecessary }
\end{aligned}
$$
in the context of $\mathrm{J}$ (where grain is sown among vegetables), and Lieberman maintains that it was mistakenly introduced into $J$ from $C$ and $L$.

$$
\begin{aligned}
& { }^{68} T Z, \text { p. } 212 \text {, on } 1.54 \text {, and } T K, I I, p .613 \text {, on } 1.54 \text {. } \\
& { }^{69} \text { Since G clearly refers to several rows of gourds, there }
\end{aligned}
$$
is no significant difference between the two readings of surh and $s d h$.

$$
70_{T Z}, \text { p. } 212 \text {, on } 1.55 \text {, and } T K, \text { II, p. 618, on } 1.55 .
$$

${ }^{71}$ According to GRA's glosses, which are printed in the back of the Romm ed. of the Babylonian Talmud, GRA reads here simply "one who." "And" $(w)$, however, is cited as part of GRA's gloss by MB and Lieberman (TZ, p. 212, on 1.56 , and $T K, I I$, p. 618, on 11. 56-57). 
$72 \mathrm{Y}$. reads as follows:

B. One who allows single moist stalks to grow [for the sake of their] seed,

c. must clear [a space] for them [measuring] a bet rovac, or make for them a partition ten handbreadths high.

${ }^{73} \mathrm{Cf}$. M. 2:8 for the dimension of the partition.

${ }^{74}$ If it is the case that $T$. links $M .3: 7 \mathrm{~J}-\mathrm{K}$ to $M .3: 4$, then the link is only formal (i.e., the two pericopae are similarly formulated) and not substantive. M. 3:4 concerns planting rows of different kinds together, while the point of $T$. is that its law applies to any of the kinds (individually).

${ }^{75} \mathrm{Cf}$. M. $3: 6 \mathrm{H}$, where sages use $z \mathrm{r}^{\mathrm{C}}$ in a general sense to refer to that which is sown between the rows of gourds.

${ }^{76} \mathrm{Cf}$. Albeck's comment on M. $3: 7 \mathrm{~J}-\mathrm{K}$, where he interprets Ishmael's saying to concern sowing grain in a field of gourds. Albeck may follow $T$. in interpreting zre to mean that which is sown for the sake of its seed, i.e. (in many cases), grain.

77 Although it appears that GRA interprets $T$. as we have explained it (CF. MB), we note that Lieberman may understand GRA differently. Lieberman ( $T Z, \mathrm{p}, 212$, on 1.55 , and $T K, I I$, pp. 618f., on 11. 56-57) seems to maintain that GRA, in adding w'id to $B$, sees $B$ as part of the protasis, so that the pericope reads as follows:
A. All the same are a row of chate melons, and a row of gourds and a row of watermelons, and a row of musk melons and a row of cowpeas,
B. [and] one who allows a single stalk [of any of these kinds] to grow for [the sake of their] seed --
c. [he must allow the stalk a space measuring] a bet rovac, or he must make a partition [between one kind and the next] ten handbreadths high and [with] its width [measuring] four handbreadths.

According to this reading the point of $T$. is that whether one plants single stalks or individual rows of trailing plants next to one another, he must separate the different kinds, by either the distance of a bet rovac (following $Y_{\text {.) }}$ or a partition. T. then supplements $M$. 3:4 by saying that individual stalks of different kinds of trailing plants, as well as individual rows, are considered diverse-kinds with one another. This interpretation of $T .$, however, is difficult, for it does not allow any significance to the fact that the single stalk is planted for the sake of its seed. We therefore maintain that the explanation given above in the text is the more plausible one.

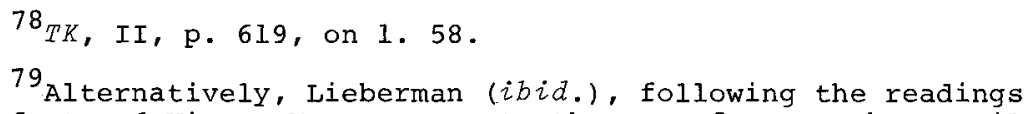
of Erfurt and Vienna Mss., suggests that $B$ refers to the gentile of $\mathrm{A}$, and not to the Israelite. According to this interpretation the gentile is presumed to be liable for the grafting of trees of diverse-kinds (cf, Eliezer's ruling, Y. Kil. 1:7 (27b), B. Sanh. 56b; cf. Lieberman for sources of later discussions of this issue). The point of T., then, is that one may reproduce the product of a gentile's graft, even though the gentile is prohibited from performing such a graft. If this is the point of T., though, it is not clear why the pericope chose to speak of a 
graft performed by a gentile, and not one made by an Israelite. We thus prefer our first interpretation of $T$. , which takes account of the fact that it is the gentile and not the Israelite who performs the graft.

$$
\begin{aligned}
& 80_{T Z}, \text { p. } 212 \text {, on } 1.62 \text {, and } T K, I I, \text { p. } 620 \text {, on } 1.62 . \\
& 81_{T Z,} \text { p. } 212 \text {, on } 1.63 \text {, and } T K, I I, \text { p. } 620 \text {, on } 11.62-63 \text {, }
\end{aligned}
$$
and on 1.63 .

${ }^{82}$ Lieberman (TK, II, p. 620 , on 1. 62) suggests that the first printed ed. has corrected T. on the basis of B. A.Z. $63 \mathrm{~b}$.

$$
\begin{aligned}
& { }^{83} T Z, \text { p. } 212 \text {, on } 1.62 \text {, and } T K, I I, \text { p. } 620 \text {, on } 1.62-63 \text {. } \\
& 84 T Z, \text { p. } 212 \text {, on } 1.63 \text {, and } T K, I I, p .620 \text {, on } 1.63 \text {. } \\
& { }^{85} \text { This point seems to be somewhat obvious, and Lieberman }
\end{aligned}
$$
(TK, II, P. 620, on 1.62 ) suggests that D appears only because of what follows (either $E$ or $G$ [Lieberman is not clear on this point]).

${ }^{86}$ Lieberman (ibid.) notes that E-F contradicts A-C, for the latter implies that diverse-kinds which grow in an Israelite's field should not be uprooted. The opposition between $A-C$ and D-F may account for the juxtaposition of the two pericopae, which present entirely separate rules.

87 Alternatively, B. A.z. $63 \mathrm{~b}$ has D-F refer to a gentile's field. According to this reading the point of $D-F$ is that one may not hoe diverse-kinds with a gentile, but one may uproot them for him (for pay), even though one then wishes the diversekinds to continue growing until he has a chance to uproot them. This reading, however, is less plausible than that given by T., for it is not clear how diverse-kinds become an impropriety $(t p 2 h)$ in the field of a gentile.

${ }^{88}$ According to Lieberman (TK, II, p. 621, on 1,64$)$ these two cities are located to the north, on the eastern side of the Jordan River.

${ }^{89} \mathrm{TZ}$, p. 212 , on 1. 64. T. Ah. states that "surrounded cities" are exempt from the laws of tithes and the seventh-year, but are not considered as part of the "land of the peoples" for purposes of cleanness.

${ }^{90}$ Similarly, Lieberman (TK, II, p. 620, on 1. 63) explains that $G$ follows the principle that "a gentile does not acquire possession of real estate in the land of Israel (attributed to Meir, Y. Kil. 7:3)." That it, it is prohibited to grow diversekinds with a gentile because the latter does not actually own his field. One who would grow diverse-kinds for a gentile, would, in effect grow them for an Israelite (the true owner of the field), and such an act is prohibited (D).

${ }^{91}$ Lieberman (TZ, p. 212, on $11.64-65$, and $T K, I I, p .621$, on 11. 64-65) following $Y$. Orl. $1: 9$ and $B$. Qid. $39 \mathrm{a}$, says that both M. Qid. 1:9 and T. Kil. 2:16J apply only to diverse-kinds of the vineyard but not to diverse-kinds of seeds. Neither M. Qid. 1:9 nor T. Kil. 2:16J, however, offers any support to this interpretation. Cf. also Y. Orl. 1:9, where Samuel says that diversekinds of seeds are permitted outside of the land of Israel, while Yohanan prohibits them. 
${ }^{1}$ We note that the apodosis of the first sentence in each set is phrased in the singular $\left(y b y^{\prime}\right)$, while that of the second opens in the plural (nwtnyn). The second apodosis, however, shifts to the singular (zwre), which suggests that nwtnyn $2 h$ $c$ bwdth may be an idiomatic phrase which always appears in the plural (cf. M. Kil. $3: 7,5: 4,6: 1,6: 2$, and $6: 7$ ).

2 The term "bald spot of the vineyard" is actually a metaphor, for a bald spot (qrht) literally refers to a bare, hairless area of a head.

${ }^{3}$ For various etymologies of mhwl, see Maim., Comm. (from $m h z$ "to leave, abandon"). Sens (from mhwl, "dance" i.e., the area of the vineyard set aside for dancing) and Meiri to B. Erub. $93 \mathrm{a}$ (cited by Iieberman, $T K, \mathrm{II}, \mathrm{p} .622$, on 1.3 ) (from $h z w \tau$, "empty space").

4 If we follow the commentaries (e.g., Maim., Comm., Sens, etc., all following $M .6: 1$ ) and assume the area of tillage of a vineyard to be four amot, then in a bald spot either sixteen (House of Shammai; fig. 26) or eight (House of Hillel; fig. 27) amot square are sown. Similarly, in an outer space either twelve (House of Shammai; fig. 28) or eight (House of Hillel; fig. 29) amot wide may be sown.

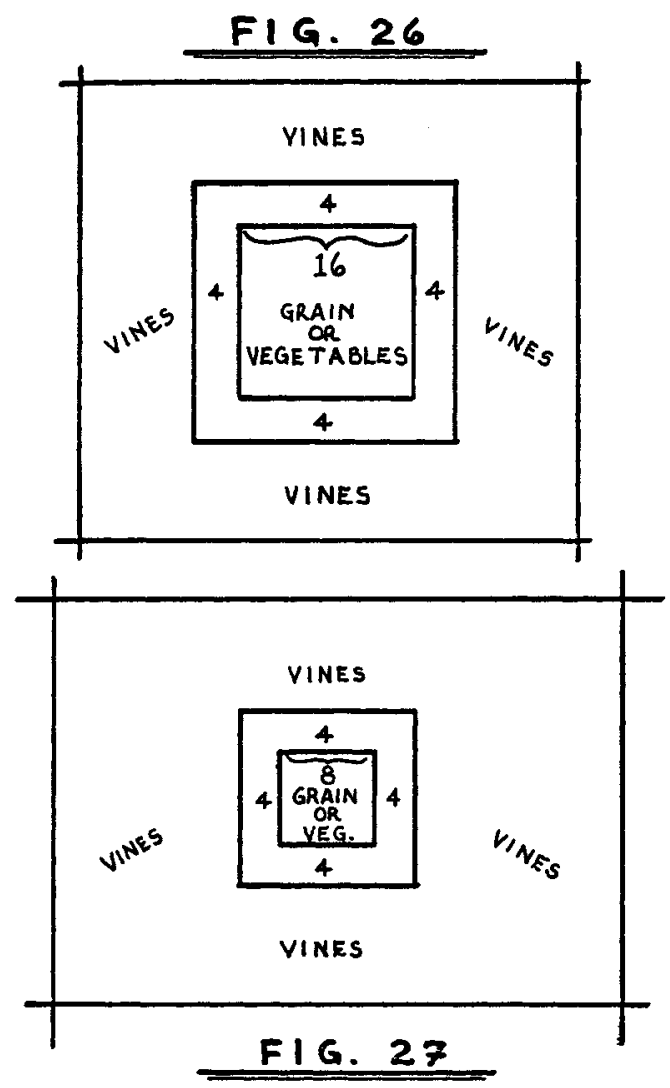




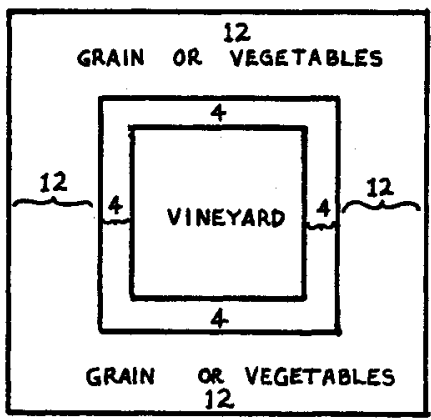

FIG. 28

\section{FIG. 29}

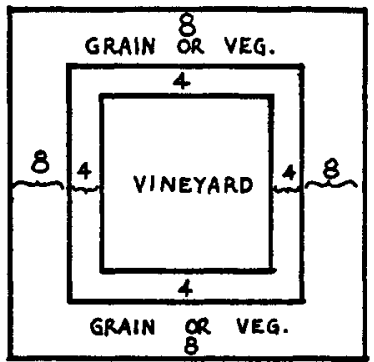

${ }^{5}$ If we apply the measurements of the Houses to Judah's conception of an outer space, we find that an area either ejght (House of Shammai; fig. 30) or four (House of Hillel; fig. 31) amot wide may be sown.

FIG. 30

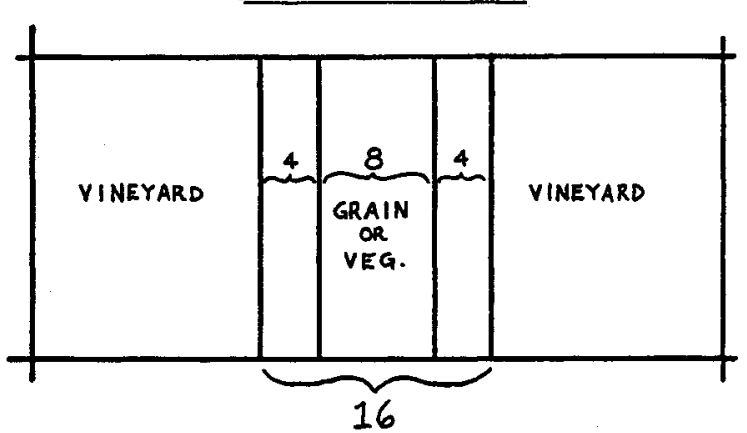




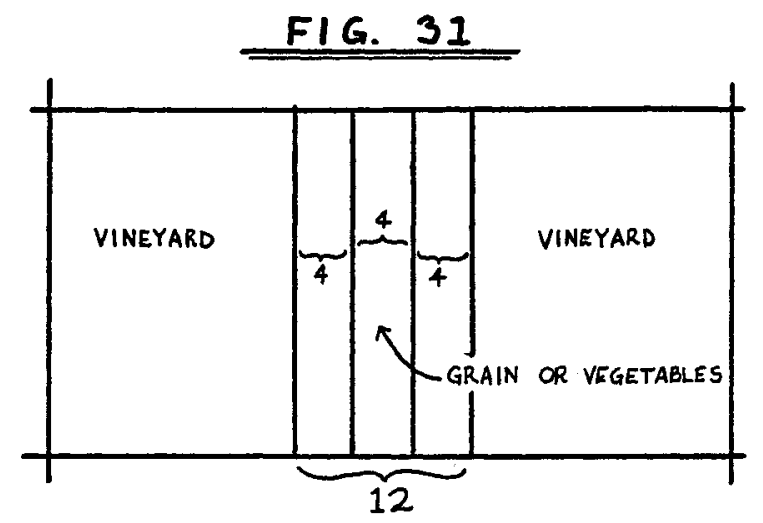

${ }^{6}$ Lieberman, (TK, II, p. 621, on 11. 1-2) maintains that through a scribal error "five," represented by the letter $h$, was incorrectly copied as "four and $(d w)$."

${ }^{7}$ Alternatively, Lieberman $(T Z, p .213$, on $11.3-4$, and $T K$, II, p. 622, on $11.3-4$ ), following $\mathrm{HD}$, maintains that $\mathrm{H}-\mathrm{I}$ abbreviates $M$. and should actually read: "And sages say (The area between the vineyard and the fence. If there are not there twelve amot, etc." "Such a reading would incorporate into the opinion of sages the definition of an outer space of $M .4: 2 \mathrm{~K}-\mathrm{L}$, and so would create an actual dispute between Judah and sages. There is, however, no reason to suppose that the definition of the outer space is implicitly part of sages opinion, and in my view it is more likely that $\underline{T}$. reads one rule in light of another, and does not simply repeat the dispute of $M$.

8 T2, p. 213, critical apparatus to 1.8 .

9T. Erub. 6(9):13-14, compared with M. Kil, 4:4E-N, reads as follows:

$$
\text { M. Kiz. } 4: 4
$$

1. And a fence which was breached --

2. [if the breach measures] up to ten amot [wide],

3.

4. 10, this is considered as an opening.

5. [if the breach measures] more than this [i.e., ten amot].

6. opposite the breach it is prohibited.
T. Erub. 6(9):13-14.

1. The wall of a courtyard which was breached --

2. [if the breach measures] from four handbreadths to ten amot [wide],

3. it is permitted,

4. for it [i.e., the breach] is considered as an opening.

5. [if the breach measures] more than this [i.e., ten amot],

6. opposite the breach it is prohibited [Lieberman (TM, p. 122, on 1. $42, T K$, III, p. 426, on 11. 43-44) maintains that this phrase does not belong in T. Erub. and 
M. KiZ, $4: 4$

7. [If] many breaches were breached in it [i.e., the Eence] --

8. if the [combined measure of the parts of the fence which remain] standing exceeds the [combined measure of those parts which were] breached,

\section{9. it is permitted;}

10. and if the [combined measure of those parts which were] breached exceeds the [combined measure of the parts which remain] standing,

11. opposite the breach it is prohibited.
T. Erub. $6(9): 13-14$

has been mistakenly inserted here from M. Kil. $4: 4]$.

7. [If] many breaches were breached in it [i.e., the wall] --

8. if the [combined measure of the parts of the wall which remain] standing exceeds the [combined measure of those parts which were] breached,

\section{9. it is permitted;}

10. and if the [combined measure of those parts which were] breached exceeds the [combined measure of the parts which remain] standing,

11. opposite ten houses [Lieberman (TM, p. 122, on 1. 44 and $T K$, III, p. 426 , on 1. 44) suggests that $T$. may read: at a height of ten amot] the partition is considered invalid.

We see that, except for the protasis (1) and several apodoses ((6) and (11)), the two pericopae are identical. The unit concerning partitions thus does not appear to be primary to either the problem of diverse-kinds or the issue of the cerub. Rather, the pericope is an autonomous unit which the redactors have inserted (with slight modifications) into various appropriate contexts.

${ }^{10}$ B. Ber. 25b, Y. Kil. 4:4, B. Shab. 97a, B. Erub. 16a, $79 \mathrm{~b}$, Y. Erub. $1: 8$, and B. Suk. $7 \mathrm{a}, 16 \mathrm{~b}$ all state (with minor variations): "Every [space measuring] less than three [handbreadths] is [considered] as a solid (klbwd) [i.e., as nonexistent]."

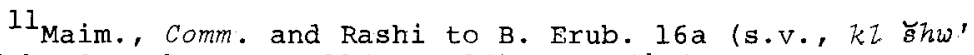
cited by Qappah, I, p. 117, n. 10) note that $C$ concerns a partition which wili keep out a kid under normal conditions, that is, when the kid does not apply an unusual amount of force to the partition.

12 Sens, Bert., and TYY, reading $H-I$ into $F-G$, maintain that in this instance one may sow different kinds even on opposite sides of the breach itself.

13 Maimonides (Code, Diverse-Kinds 7:16; cf. also Ribmas, Sens, and MR) points out that in the case of a vineyard one may still sow another kind opposite the breach, but now he must allow the vineyard four amot as its area of tillage (and he may not sow up to the base of the partition itself).

14 Sens, TYY, and GRA, reading $E-I$ into $J-N$, point out that each gap in the wall must be ten amot or less wide, for otherwise 
it would be prohibited to sow different kinds opposite the breaches $(\mathrm{H}-\mathrm{I})$.

${ }^{15}$ It is clear here that the more developed apodosis (kngd hprws 'swr) has been chosen over the simpler one ('swr), for the latter would have balanced L's mwtr.

${ }^{16} \mathrm{Cf}$. also MR, who harmonizes the two rules by stating that, in the case of $A-D$, the spaces between the reeds which measure less than three handbreadths are considered as if they were actually solid ( $2 b w d)$ (B. Trub. 16a and parallels). The measure of the standing part of a partition of reeds is then greater than that of the breaches, for the latter are not even considered to exist. According to this interpretation the rule of $A-D$ agrees with that of $\mathrm{J}-\mathrm{N}$ that a partition is valid only if the measure of its standing part exceeds that of its breaches.

${ }^{17}$ Lieberman (TZ, p. 213, on 1. 10, and TK, II, p. 623, on 11. 10-11) understands nty'š' to mean htrph wntrst.

${ }^{18} \mathrm{Cf}$. his translation of M. Kil. 5:5a (apparently following Maim., Comm. to M. Kil. 4:4), I, p. 50 .

${ }^{19} \mathrm{Cf}$., for example, his translation of M. Bik. 1:9, 2:4.

${ }^{20}$ The basis for the rule that a vineyard sanctifies adjacent crops (and that crops sanctify a vineyard) is found in Dt. 22:9: You shall not sow your vineyard with two kinds of seed, lest the whole yield be sanctified (tads), the crop which you have sown and the yield of the vineyard.

${ }^{21}$ Cf. Bokser, I, p. 50 .

${ }^{22}$ Yosé cites F-H in M. Ed. 5:2 (and so attests it to Usha).

${ }^{23}$ I, p. 47.

${ }^{24}$ Except for the presumed "if," and with the phrase "He who plants" understood, C-F would also appear in slight apocopation.

$25_{\text {Figure }} 32$ is found in Ribmas, TYY, and TYT.

${ }^{26}$ Figure 33 is found in Maim., Comm., KM to Maim, Code, Diverse-Kinds 7:7, TYY, and TYT.

27 Figure 34 is found in Maim., Comm., KM to Maim., Code, Diverse-Kinds 7:7, Ribmas, TYY, and TYT.

${ }^{23}$ Figure 35 is given by TYY and TYT.

${ }^{29}$ Figure 36 is given by Maim., Comm., KM to Maim., Code, Diverse-Kinds 7:7, Ribmas, TYY and TYT. Sens also presents this interpretation of $\mathrm{D}$. This arrangement of vines was common in Roman viticulture, where it was known as the quincunx (= the form of five spots on dice [D.P. Simpson, Cassell's New Latin Dictionary (New York: Funk and Wagnall's, 1960), p. 496]). Cf. Columella, De Re Rustica, 3.13.3, E.B, White, Roman Farming (Ithaca: Cornell University Press, 1970), p. 237, and Lieberman, $T K$, II, p. 624, on 1.12 (all cited by Bokser, I, p. 49, n. 120).

${ }^{30}$ Figure 37 is given by TYT, TYY (both of whom give both interpretations of $\mathrm{D})$. According to TYT Bert. holds this view as well. 
${ }^{3} I_{\text {For further sources of the different interpretations }}$ of M. 4:6, cf. Lieberman, TK, II, p. 624, on 1. 12,

${ }^{32}$ We note that the commentaries clearly disagree concerning the pattern represented in both figures 33 and 35 , for some maintain that vines planted in such an arrangement do constitute a vineyard, while others say that they do not. According to our interpretation of $M$. the difference of opinion concerns whether the fifth vine, being outside of the set of four, belongs to one of the two rows, or whether this vine, being between the two rows, belongs to neither. We see no reason to favor one interpretation over another.

${ }^{33}$ In connection with C-D Sens refers to M.-Peah $2: 3$, which states in part:

Al1 [of the items mentioned above (M. Peah 2:1-2)] divide [a field for the purpose of giving pe'ah] for [the case of a field sown with] seeds, but only a fence divides [a field for the purpose of giving $p e^{\prime} a h$ ] for [the case of a field planted with] trees.

According to Sens the latter rule applies to the vineyard as well as to trees.

${ }^{34}$ Sens and GRA again refer to $M$. Peah $2: 3$ in explaining F-G.

${ }^{35}$ Sens and GRA regard the substance of the law of $\mathrm{H}-\mathrm{I}$ as similar to that of the latter part of $M$. Peah $2: 3$, which reads as follows:

If the branches of the trees were intertwined (so Danby for $\left.\xi c_{p} k \omega t \breve{s}\right)$ [the fence] does not divide [the field of trees], but ('l') one gives [one] pe'ah for all.

${ }^{36}$ For Geniza fragments referred to in $B$ and $E$ see Zachs, I, p. 256 , on 1.26 , and p. 257 , on 1.29 , respectively.

${ }^{37} \mathrm{C}-\mathrm{D}$ would also appear in apocopation if the phrase "there were" [and the presumed "if"] were dropped, and the phrase "he who plants" were understood.

${ }^{38}$ We also note that Maim., Comm. (and others), reading M. 4:8 in light of $M$. 4:1, see C-D as describing a bald spot of the vineyard, which also (according to House of Hillel) requires sixteen amot. M. 4:1, however, discussed a cleared space within a vineyard, while M. 4:8 concerns the spaces between rows (cf. also Albeck, p. 364). Cf. also MR, who distinguishes between the two cases by noting that in the instance of the bald-spot four amot are allowed the vines as area of tillage, while in the case of the space between the rows only six handbreadths are allowed as the area of tillage.

${ }^{39}$ For the list of mss., see Zachs, I, p. 257, on 1. 31. ${ }^{40} \mathrm{Cf}$. also Danby's translation of nyr in M. $2: 3$ as "newlybroken land."

${ }^{41}$ Danby thus translates $b w r$ in $M_{2} 2: 8$. Cf. also his translation of M. 4:9, where he renders bwr as "fallow land." 
${ }^{42}$ For Geniza fragment, see Zachs, I, p. 258 on 1.36.

43 We note that M. $4: 9$, like M. $4: 3$, is interpreted by many commentaries as concerning the issue of the combining of rows to form a vineyard.

${ }^{44}$ Salmon (or Salamin) may refer to one of two cities. One is located in the south, approximately fifteen $\mathrm{km}$. northeast of Sepphoris (cf. M. Avi-Yonah, Historical Geography, p. 177 [map, p. 173] [for first Salmon], and Carta's Atras, pp. 107-108, 131 [for the second salmon], 145 [for the first]).

\section{CHAPTER FIVE}

${ }^{1}$ See zachs, I, p. 259 , on 1. 1 .

${ }^{2}$ Cf. R. Alcalay, p. 437, s.v. krm dl.

${ }^{3}$ Danby similarly translates 'rbwby' as "in irregular fashion."

${ }^{4}$ Most commentaries maintain that $\mathrm{C}$ also refers to the rule that the vines must be separated by a distance measuring from four to sixteen amot (M. 4:9 and M. 5:2). Since, however, this rule is actually a composite of several (explicit [M. 5:2] or inferred [M. 4:9]) rules of $M$. , we maintain that it is not likely that $C$ makes reference to it. But cf. T. $3: 3 \mathrm{~b}$, where the issue of the distance between the vines is raised in reference to M. 5:1.

${ }^{5} \mathrm{MR}$, on the other hand, states that a vineyard need not be composed of two sets of five vines arranged in the pattern of M. 4:6, for one such set by itself is considered a vineyard. He therefore maintains that only five of the ten vines need be arranged in the pattern of $M .4: 6$, and that on account of these five the entire area is considered a vineyara.

${ }^{6}$ Lieberman (TK, II, p. 624, on 11. 14, 15, and 16) explains that the omissions by Vienna Ms. in E-F, by the first printed ed. in F, and by Erfurt Ms. in $\mathrm{G}-\mathrm{H}$ are all the result of copyist's errors.

${ }^{7}$ Alternatively, Lieberman (TK, II, p. 623, on 11. 11-12) follows Maimonides' reading of $\mathrm{M}$. in the light of $\mathrm{T}$. (Code, Diverse-Kinds $7: 8$ ):

A vineyard which lay waste--if there are in it [enough vines to enable one] to gather ten vines per an entire bet $s e^{\prime} a h$, and they are planted [in rows of] two [vines] opposite two [others], and one extending out [like a] tail; or [if] there are in it [enough vines to enable one] to align three [vines] opposite three [others], lo, this is called a "lean" vineyard, and it is prohibited to sow [another kind] in any [part of] it.

Lieberman accordingly interprets $A-B$, which has three vines opposing three others, as referring (along with C-D) to the "lean" vineyard. C, however, appears to describe how the vineyard is laid waste, so that it is more likely that $A-B$ discusses the vineyard in its original shape. 
${ }^{8}$ T. apparently reasons here that two rows separated by more than eight amot do not constitute a vineyard (cf. our discussion of M. $4: 8$ ).

${ }^{9 Z}$, p. 214 , on 1. 17; cf. also $T K$, II, p. $625, \mathrm{n} .22$.

${ }^{10}$ Lieberman (TK, II, p. 625 , on 1. 19) maintains that Erfurt reverses the order of $\mathrm{E}-\mathrm{G}$ and $\mathrm{H}-\mathrm{M}$ by mistake.

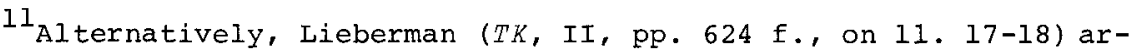
gues that $T$. $3: 4$ precedes $T$.'s citation of $M .5: 1 \mathrm{E}-\mathrm{G}$ at $\mathrm{T} .3: 5 \mathrm{~b}$, and therefore actually comments on M. 5:1A-D, adding another rule pertaining to the "lean" vineyard. M. 5:1A-D, however, does not explicitly require the vines of a "lean" vineyard to be aligned (as does $M$. 5:1E-G, although this is required by the interpretation of $M$. 5:1A-D in the light of $M .4: 6$ ), so that we consider it more likely that T. 3:4 comments on M. 5:1E-G.

$$
\begin{aligned}
& 12_{T Z} \text { p. } 214 \text {, on } 1.22 \text {, and } T K \text {, II, p. } 625 \text {, on } 1.22 \text {. } \\
& 13 \text { Ibid. }
\end{aligned}
$$

${ }^{14}$ Lieberman (TK, II, p. 624 , on 1.22 ) states that the vines of an espalier may be separated by a distance measuring from four to eight amot. Cf. M. 6:6 (and T. $3: 3 \mathrm{~b}$ ).

$$
15_{T Z, P .214,1.24} \text {. }
$$

${ }^{16}$ Following Lieberman (Greek in Jewish Palestine [New York: Jewish Theological Seminary, 1942], p. 51 [cited by Lieberman, $T K$, II, p. 626, n. 25]) who translates $b r$ in various contexts as "select."

${ }^{17}$ It is not clear whether $z h$ hyh has been appended to the formula mesh $w$ or is actually part of the formula itself. We claim only that by its very meaning ("this was") the phrase $z h$ hyh serves to join $\mathrm{F}-\mathrm{K}$ to $\mathrm{A}-\mathrm{E}$, regardless of whether or not zh hyh is part of the formula.

$$
\begin{aligned}
& 18_{T Z,} \text { p. } 215 \text {, on } 1.30 \text {, and } T K, I I, p .626 \text {, on } 1.30 \text {. } \\
& { }^{19} \text { Lieberman }(T K, I I, \text { p. } 626, \mathrm{n} .27) \text { suggests that Erfurt } \\
& \text { mistakenly omits E-H because both D and H end with similar }
\end{aligned}
$$
phrases.

20 We note that, except for the presumed "if" in $E$ and with krm understood, E-H may be considered to appear in apocopation as well.

$21_{\text {Following }} \mathrm{Y} .$, Lieberman (TK, II, p. 626, on $\left.11.30-31\right)$ reasonably assumes that the outer row and the vineyard are separated by more than four amot (and less than eight), for otherwise the two areas of tillage would overlap.

$22 T Z$, p. 215, on 1. 32, and $T K$, II, pp. 626-627, on 11. 31-32, 32. Lieberman further maintains that T. 3:7-8 continues the discussion of T. 3:6 concerning the row which is not considered part of the vineyard and therefore is allowed its own area of tillage. T. 3:7-8, however, appears to introduce a new issue dealing specifically with the slope of a terrace, and does not seem to concern the set of problems involved with the "vineyard which is planted according to the rule [pertaining to] it." We therefore maintain that T. 3:7-9 forms an autonomous subunit concerning the problem of the slope of the terrace. 
23 Alternatively, the commentaries maintain that the dispute concerns whether or not the vines of a vineyard need be allowed sufficient room to grow (Maim., Comm.), or whether or not the rows of a vineyard need be separated by enough space to allow a plough and its animals to pass through (Rosh, Bert., PM; cf. Columella, De Re Rustica 5.5.3 (Loeb ed., II, p. 31), who also cites this reason as a consideration in the spacing of rows of a vineyard). Cf. also B. B.B. 102 b for another interpretation based on $D$. We do not see, however, why any of these considerations should affect the status of the vines as a vineyard.

24 our translation follows Maim., Comm., Rosh, and others, who understand $n q$ c to mean gwm, ("hollow").

${ }^{25}$ Since the area within the house is clearly separated from that of the vineyard by the walls and the roof, a house of any size presumably forms an autonomous domain within the vineyard.

${ }^{26}$ Cf. Neusner, Eliezer, I, pp. 354f., who maintains that this Eliezer is not Eliezer b. Hyrcanus. Since Eliezer here (indirect1y) disputes with Eliezer b. Jacob concerning the winepress, he is probably an Ushan as well.

$27 \mathrm{y}$. explains (cf. also Ribmas, Rosh, Albeck) that the case of the watchman's booth or mound differs from that of the winepress in that the seeds on the booth or mound grow outside of the vineyard's airspace, while those sown in the winepress remain within it. The difference may also be explained with regard to the appearance of diverse-kinds. One may sow on top of a booth or mound because the plants are visible above the surrounding vines. Since, however, plants sown in a winepress would not grow higher than the vines (and so could produce the appearance of diverse-kinds), they may not be sown there.

28 According to Maimonides (Code, Diverse-Kinds 7:22) the overhanging vines will touch the vegetables sown on top of the šmrh, so that sowing on top of the swmrh is clearly prohibited.

${ }^{29} \mathrm{Cf}$. M. Peah $2: 3$ and M. Kil. $4: 7 \mathrm{H}-\mathrm{I}$, which state that a divider covered by interlaced vines is no longer considered a valid divider. $30_{T Z}, \mathrm{p} .215$, critical apparatus to 1.40 , and $T K, \mathrm{II}, \mathrm{p} .628$,
on 1. 40 . $30_{T Z}$, p. 215 , critical apparatus to 1.40 , and $T K, I I, p .628$,
on 1.40.

$$
\begin{aligned}
& 31_{\text {Eliezer, I, p. } 354 .} \\
& 32_{T K}, \mathrm{II}, \mathrm{p} .628 \text {, on } 1.39 . \\
& 33_{T Z}, \mathrm{p} .215 \text {, on } 1.40 \text {, and } T K, \mathrm{II}, \mathrm{p} .628 \text {, on } 1.40 . \\
& 34_{\mathrm{Figures}} 38-40 \text { are found in Qappah, I, pp. 121-122. } \\
& 35_{\mathrm{C} f \text {. also TYT and GRA, who explain the case of vines sepa- }}
\end{aligned}
$$
rated by five amot as follows. One cannot distinguish between the appearance of vines set apart by five amot and that of vines separated by four amot. If, therefore, one were to destroy only thirty-seven vines which are separated by five amot, it would appear as if he were allowing eight sanctified vines to grow in a vineyard with the vines separated by four amot. Therefore forty-five vines are sanctified in both cases.

${ }^{36} \mathrm{Cf}$. also Yose b. Haninah's comment in $\mathrm{y}$. that the vegetables are sown opposite the central vine. For further discussion of Y., see Bokser, I, pp. 50-54. 
${ }^{37}$ TAS solves this problem by maintaining that several circles of radius sixteen amot are drawn, each with its center at either the vine at the center of the vineyard or one of the eight vines surrounding it. Those vines are sanctified which both lie in one of those circles and form a vineyard with one of the nine vines (see interpretation in text). We maintain, however, that this interpretation does not follow the plain sense of M., which nowhere mentions that several circles are drawn. Furthermore, the reading of $A-B$ as an instance of $E-G$ does not appear to be necessary to the interpretation of $A-B$ itself. We therefore omit this point in following the interpretation of TAS.

${ }^{38}$ According to this interpretation there is no difference between sowing at the edge of a vineyard and sowing within it. $A-B$ then does not complement $M .4: 5 H$, but provides an instance of the view of the House of Hillel.

${ }^{39}$ Cited by Lieberman, $T Z$, p. 216 , on 1.44 , and $T K, I I$, p. 629 , on 1.44 .

${ }^{40}$ Lieberman (TK, II, p. 629, on 1. 45) rejects Erfurt's reading (which perhaps follows the present reading of $I$ ) in favor of the reading in Vienna Ms. and the first printed ed.

$41_{T K}$, II, p. 629 , on $11.47-48$.

${ }^{42}$ Cited by Lieberman, TK, II, p. 629 , on 1. 47 ,

43 Primus, p. 33.

${ }^{44}$ We note that Maimonides (Code, Diverse-Kinds 5:17 [see n. 45 below]; cf. also TYY) maintains that although the sowing itself is permitted, one must still uproot the other kind as it grows, lest one allow diverse-kinds to grow in the vineyard. Maimonides here perhaps reads M. 5:6 into M. 5:7, for the pericope itself does not discuss allowing the other kind to grow.

45 According to Maimonides, who perhaps reads $\mathrm{F}-\mathrm{H}$ (which discusses the destruction of seeds) into $A-E$, the sowings of $C$ and $E$ affect only the seeds, and not the vines (Code, DiverseKinds 5:17):

[If] he was passing through the vineyard and seeds fell from him, or [if] the seeds went out [into the vineyard] with the dung or with the water, or [if] he was sowing or scattering [seeds] in a white field, and the wind blew [the seeds] behind him, and the seeds fell into the [nearby] vineyard and sprouted--10, this [i.e., these seeds] have not been sanctified, as it is written [You shall not sow your vineyard with two kinds of seed lest the whole crop be sanctified, the crop] which you have sown [and the yield of the vineyard (Dt. 22:9], and this he did not sow. And he is obligated to uproot it when he sees it [growing]. And if he allowed them to grow, 10, this one has sanctified [them]. If the wind blew [the seeds] before him and he sees the seeds which fell into the vineyard, 10, this one is [considered] as one who sows [diverse-kinds]. And what shall he do if they have sprouted? The blades he shall overturn with a plow, and it is sufficient [i.e., the plants are thereby destroyed]. And if he found that they developed into an early state of ripening ('by), 
he shall break [the ear] off in order to destroy it, for all of it is prohibited in [respect to] deriving benefit from it. And if he found that it developed into grain, 1o, this shall be burnt. And if he saw them [growing] and allowed them to grow, 10, these shall be burnt with the vines which are near them.

Maimonides thus rules that the vines are destroyed only when the seeds are allowed to grow, but not when they are only sown. It appears, then, that Maimonides does not regard the sowing which is aided by the wind as an intentional sowing of diverse-kinds (Ridbaz, ad. Zoc.; Albeck, p. 366). If we read A-E without F-H, however, D (and the missing apodosis 'swr) appear to discuss the status of both the seeds and the vines.

${ }^{46}$ Feliks, Agriculture, p. 171.

47 Ibid.

${ }^{48}$ Cf. his translation of M. B.M. $7: 9$.

${ }^{49}$ Iris pazzida, of the iris family (Iradaceae). For identification of all plants, cf. Feliks, Mar'ot HaMishnah.

${ }^{50}$ Hedera helix, of the aralia family (Araliaceae).

${ }^{51}$ Lizium candidum, of the lily family (Liliaceae).

52 For Geniza fragments, cf. Zachs, I, p. 265, on 1. 26.

$53 T K$, II, p. 631, on 11. 52-53.

${ }^{54}$ Cannabis sativa, of the nettle family (Urticaceae; so Post, s.v. Cannabis). Cf. also Feliks, Maro't HaMishnah, p. 131, who identifies the plant as belonging to Cannabinaceae.

${ }^{55}$ Cynara scolymus, of the composite family (Compositae).

${ }^{56}$ For Rabad's views cf. Lieberman, TK, II, p. 632, on 11 . 52-53. It is not clear to me, however, whether these plants would be grown for the sake of their seeds. For further discussion of the various explanations of $F$ presented by the commentaries, cf. MR and TK, II, pp. 631-633, on 11. 52-53.

${ }^{57}$ For the uses of hemp, cf. Feldman, Simhe HaMishnah, pp. $279 \mathrm{ff}$, , and Feliks, Mar'ot_HaMishnah, p. 131.

${ }^{58}$ Alternatively, the dispute concerns whether hemp is considered a tree or an herb. Tarfon maintains that the plant has the appearance of a tree, and so is not considered diverse-kinds in a vineyard. Sages, on the other hand, say that since the leaves of hemp sprout directly from its roots it is considered an herb (T. $3: 15)$, and thus is considered diverse-kinds in a vineyard. While this explanation of the dispute is plausible, it requires a reading of $M$. in the light of $T$. $3: 15$, while we prefer to attempt to explain $M$. in terms of its own issues.

${ }^{59}$ Feliks, Mar'ot HaMishnah, p. 127.

${ }^{60}$ Chrozophora tinctoria, of the spurge family (Euphorbiaceae). Cf. Löw, I, pp. 595ff., TK, II, p. 549, on 1. 11, and Feldman, pp. $324 \mathrm{ff}$. 


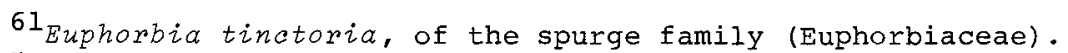
Cf. Löw, I, pp. $597 \mathrm{ff} .$, cited by Lieberman, TK, II, pp. $549 \mathrm{ff} .$, on 1. 12, who gives a full discussion of this identification. Cf. also Feldman, p. 22 .

${ }^{62}$ Gnaphalium luteo-album, of the composite family (Compositae). This is the identification tentatively made by Löw, IV, p. 506. Feldman, pp. 319f. rejects this identification and lists various other possibilities, concluding that the plant has not been identified with any certainty.

${ }^{63}$ Muscari comosum, of the lily family (Liliaceae). Cf. Löw, II, pp. 184f. (cited by Lieberman, TK, II, pp. 548f., on 1.7), and Feldman, pp. 159-160.

${ }^{64}$ Reseda luteola, of the mignonette family (Resedaceae). Cf. Löw, III, p. 130 (cited by Lieberman, TK, II, p. 630, on 1. 50), Feldman, pp. 339f., and Feliks, Mar'ot HaMishnah, p. 139.

${ }^{65}$ Crocus sativus, of the iris family (Iridaceae). Cf. Löw, II, pp. 7ff., Feldman, pp. 322f., and Feliks, Mar'ot HaMishnah, p. 75 .

${ }^{66}{ }_{A m m i}$, of the parsley family (Umbelliferae). Cf. Löw, III, p. 421 (cited by Lieberman, $T K$, II, p. 630, on 1. 50).

${ }^{67}$ Cf. M. $1: 8$.

${ }^{68}$ Satureia thyumbra of the mint family (Labiatae). Cf. Löw, II, p. 103, Feldman, pp. 29lff., and Feliks, Mar'ot HaMishnah, p. 90 .

${ }^{69}$ origanum maru, of the mint family (Labiatae). Cf. Löw, II, pp. $84 \mathrm{ff.,}$ and Feldman, pp. $295 \mathrm{ff}$. For English name see Feliks, Mar'ot HaMishnah, p. 8, who gives the Latin name as Majorana syriaca.

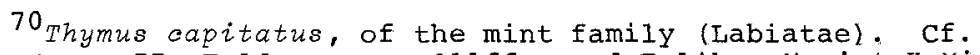
Löw, II, p. 77, Feldman, pp. 31lff., and Feliks, Mar'ot HaMishnah, p. 123.

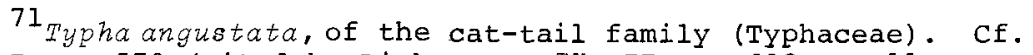
Löw, I, p. 579 (cited by Lieberman, TK, II, p. 633, on 11 . 53-54), and Feldman, pp. 27ff. For English name, cf. Post, p. 314.

72 Juncus, of the rush family (Juncaceae). Cf. Löw, I, p. 572, and Feldman, pp. I7ff.

${ }^{73}$ Cyperus papyrus, of the sedge family (Cyperaceae). Cf. Löw, I, p. 569, Feldman, pp. $320 \mathrm{ff}$., and Feliks, Mar'ot HaMishnah, p. 28 .

${ }^{74}$ Arundo donax, of the grass family (Graminae). Cf. Löw, I, p. 663, Feldman, pp. 28lff., and Feliks, Mar'ot HaMishnah, p. 132 .

$$
\begin{aligned}
& { }^{75} \text { Cf. T. } 1: 12 . \\
& { }^{76} \text { Cf. M. } 1: 4 .
\end{aligned}
$$

${ }^{77}$ Lycium europaeum, of the nightshade family (Solanaceae). Cf. Löw, IV, p. 28, Feldman, pp. 231f., and Feliks, Marlot HaMishnah, p. 11 . 
${ }^{78}$ Cf. M. $1: 8$.

${ }^{79}$ CF. T. $1: 12$.

${ }^{80}$ Capparis spinosa, of the caper family (Capparidaceae). Cf. Löw, I, p. 323, Feldman, pp. 255f., and Feliks, Mar'ot HaMishnah, p. 118 .

$8 I_{T K}$, II, p. 632 , on $11.52-53$.

82 These plants frequently appear together in M.-T. Kil. Cf. M. $3: 4$, T. $2: 10-11$.

${ }^{83}$ For more information concerning these and other plants, refer to the sources given in the notes.

${ }^{84}$ Cf. Pliny (Historia Naturalis, 20.163 [Loeb ed., trans. Jones, v. 6, p. 97]), who states that ammi grains were sprinkled on bread or used as flavoring.

${ }^{85}$ Feliks, Mar'ot HaMishnah, p. 49.

${ }^{86}$ It makes no difference here whether or not $F$ is read as being separate from $E$, for either understanding of $F$ yields the point that all kinds of seeds are considered diverse-kinds in a vineyard.

${ }^{87} T K$, II, p. 632 , on $11.52-53$.

${ }^{88}$ Cf. Maim., Code, Diverse-Kinds 1:6, who rules that trees are considered diverse-kinds only in respect to cases involving grafting .

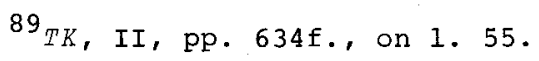

90 Theophrastus (cited by Lieberman, HeZlenism in Jewish Palestine, p. 181 [Gereboff, Tarfon, p. 48, n. 7], and TK, II, p. 636, n. 8I) draws a similar distinction between herbs and plants (Historia Plantarum, 1.3.1 [Loeb ed., trans. Hort, I, pp. 23-25]) :

A tree is a thing which springs from the root with a single stem, having knots and several branches, and it cannot easily be uprooted; for instance olive fig vine. A shrub is a thing which rises from the root with many branches; for instance, bramble Christ's thorn. An under-shrub is a thing which rises from the root with many stems as well as many branches; for instance, savory rue. A herb is a thing which comes up from the root with its leaves and has no main stem, and the seed is borne on the stem; for instance, corn and pot-herbs.

${ }^{91}$ Cf. Feldman, pp. 23f., and Feliks, Mar'ot HaMishnah, p. 54.

$92 \mathrm{Cf}$. M. I:8, where squill is considered a tree in the context of grafting.

${ }^{93} \mathrm{Cf}$. Gereboff, Tarfon, p. 28. Gereboff also notes that B. perhaps drops $\mathrm{Z}-\mathrm{AA}$ in order to improve $\mathrm{T}$.

${ }^{94}$ Cf. T. $1: 11$.

${ }^{95} \mathrm{Cf}$. T. 1:11, where dodder is assumed to be an herb in the context of grafting. 
${ }^{96}$ Cf. Gereboff, Tarfon, p. 29. Gereboff also notes that according to Feldman ( $p .353$; perhaps following Rashi and $R$. Gershom) kswt may alternatively refer to Humulus lupulus, of the nettle family (Urticaceae), or hops. Hops are cones which grow on vines and resemble grape clusters. According to this interpretation the dispute concerns whether hops are considered diverse-kinds in the vineyard because they are similar in appearance to grapes. But cf. Feliks, Mixed Sowing, p. 146, who opposes this identification on the grounds that T. 1:11 clearly refers to a parasitic plant, which a hop is not.

${ }^{97}$ The branches, however, may also harden and remain. Cf. Feliks, Plant World of the Bible, p. 132 .

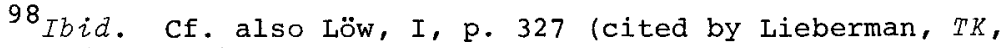
II, p. 636, n. 81 ).

${ }^{99}$ Alternatively, the disputes dealing with dodder and alhagi may concern whether or not they resemble trees. Cf. Lieberman, $T K$, II, pp. $636 \mathrm{ff}$, on 1. 60 . We prefer the interpretation given above, however, for M. - T. offers no criterion besides that of T. 3:15 for distinguishing between trees and herbs.

${ }^{100} \mathrm{Cf}$. also Maim., Comm. to M. Kil. 5:8.

\section{CHAPTER SIX}

$I_{\text {Neusner, Pharisees, II, p. } 70 .}$

${ }^{2}$ Alternatively, Maimonides (Code, Diverse-Kinds $8: 2$; cf. also Sens), following $Y$. , maintains that the fence or ditch lies between the vines and the field. Since, however, the vines are trained on the fence, the latter is not considered a partition, and the area of tillage must still separate the vines from the other kind on the opposite side of the fence. KM supports this interpretation by arguing that, according to our first interpretation, House of Hillel would hold the unlikely opinion that the foliage of the vines would be further removed from the field than would be the base of vines. Cf. also Ridbaz (ad.20c.) for a further argument against our first interpretation, B-C does not, however, indicate that the fence lies between the vines and the field, and we therefore see no reason to interpret it in this manner,

${ }^{3}$ Cf. M. 6:3-4, Maim., Comm. (M. 6:1), R. Yehosaf Ashkenazi (cited by MS, M. 6:1), and Lieberman, TK, II, p. 637, on 1.1 .

${ }^{4}$ Alternatively, the four amot mentioned in $A$ refer to the area of tillage of the vines (Maim., Comm, to M. 4:3 [cited by Lieberman, TK, II, p. 637, on 1, 1], MB). The case discussed in $A$ then concerns vines which are separated from another kind by a fence, and Gamaliel and his court rule that even in this instance one must allow the vines their area of tillage. The reasoning behind $A$ would be that the partition does not annul the requirement of the area of tillage (cf. T. 4:Ib-2), perhaps because a partition is not deemed to separate vines, which are trailing plants, from another kind. T. 4:la would then complement T. 4:lb2, which presents the opposing view. We regard our first interpretation to be the more plausible one, however, both because it places $T$. in an appropriate context (that of $M$ ) and because $T$. nowhere mentions the issue of area of tillage. 
$5_{T Z, p} 217$, on $11.1-2$, and $T K, I I, p \cdot 637$, on 1.1 .

$6 T 2$, p. 217 , on 1.3 .

7 Alternatively, Lieberman (TK, II, p. 642, on 1. 31) maintains that, because of the proximity of T. $4: 9 \mathrm{~b}$ to $T .4: 8-9 \mathrm{a}$, both T. $4: 9 \mathrm{~b}$ and $T .4: 1 \mathrm{~b}-2$ are to be understood in the context of the issue of sowing the gaps of an espalier. It is not at all clear, however, how the two issues (i.e., the issue of the area of tillage with a partition, and that of sowing the gap of an espalier) may be related to one another, and we therefore think that it is more likely that the two questions are to be considered separately.

${ }^{8}$ T. Erub. $2: 1$ reads:

A. A caravan which rested ( $\boldsymbol{s}_{\mathrm{r}} \mathrm{th}$ ) in the valley and they surrounded it with (1) camels, or (2) pack saddles [so Neusner, HMLP, II, p. 215, (M. Kel. 23:2) for obyt], or (3) saddles ('kypwt), or (4) sacks, or (5) reeds, or (6) straw, or (7) stalks,

B. even [with] three ropes [strung] one above another--

C. he carries within it [i.e., the enclosed area],

D. provided that there not be (1) between one camel and the next [an area] fully as wide as a camel, nor (2) between one pack-saddle and the next [an area] fully as wide as a pack-saddle, nor (3) between one saddle and the next [an area] fully as wide as a saddle, nor (4) between one reed and its neighbor three handbreadths, [i.e.,] sufficient [space] so that a kid may enter.

$T$. Erub. thus differs from $T$. Kil. in that it includes additional items which are relevant to its subject-matter and not to that of T. Kil.

${ }^{9}$ M. Erub. 1:9a reads: They surround [an area] with three ropes [strung] one above another, provided that there not be between one rope and the next three handbreadths.

10 M. Erub. 1:10a reads: They surround [an area] with reeds, provided that there not be between one reed and the next three handbreadths.

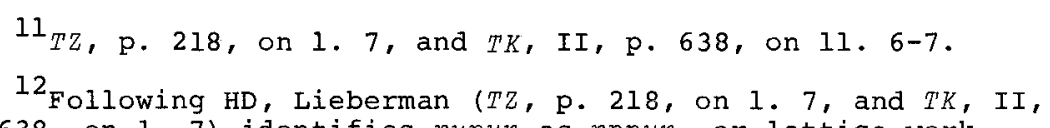
p. 638 , on 1. 7) identifies rypyn as rppyn, or lattice-work constructed of willow branches. He also identifies the term with the Greek oí, píros [mats]. These branches were used because their flexibility allowed them to be shaped to the growth of the trained plants.

$$
\begin{aligned}
& 13_{T Z}, \text { p. } 218 \text {, on } 1.10 \text {. } \\
& 14_{T K}, \text { II, pp. 638-639, on } 1.7 \text {. }
\end{aligned}
$$

15 Alternatively, MB explains that when the reeds are tied together at the top the breaches appear to be openings rather than gaps, so that the partition is considered valid. This interpretation, however, appears to be based on M. 4:4 (which discusses gaps which appear like openings), and does not necessarily follow from the plain sense of $T$. 
11. 14-15.

16 For reading of $\mathrm{J} ., \mathrm{cf}$. Lieberman, $T K, \mathrm{II}, \mathrm{p} .640$, on

${ }^{17}$ TK, II, p. 639, on 11. 10-11.

${ }^{18} \mathrm{Y} . \mathrm{Kil}, 4: 4$ (29b), Y. Erub. $1: 8$ (9b), and Y. Suk. $1: 1$

(52b), with minor variations from $T$. Kil. at many points, all read as follows:

A. The result is $\left(n m \underline{s}^{\prime} t\right.$ ' $\left.w m r\right)$ in [regard to] the issue of diverse-kinds:

B. (1) All [breaches] which [measure] less than three [handbreadths wide] are [considered] as solid (kstwm).

c. (2) And all [sections of a partition] which [measure] [Y. Suk. adds: (from) less than] three to four [handbreadths wide]--

D. if [the measure of] that which stands exceeds [that of] the breach[es] it is permitted [to sow diverse-kinds on opposite sides of the partition].

E. And if [the measure of] the breaches exceeds [that of] that which stands, it is prohibited [to sow diverse-kinds on opposite sides of the partition].

F. (3) [If the sections of the partition measured] from four [handbreadths] to ten [amot]--

G. if [the measure of] that which stands exceeds [that of] the breach[es], it is permitted [to sow diverse kinds on opposite sides of the partition].

H. If [the measure of] the breach[es] exceeds [that of] that which stands,

I. opposite that which stands it is permitted [to sow diverse-kinds],

J. opposite the breach[es] it is prohibited [to sow diverse-kinds].

K. [If the breaches measured] more than ten [amot],

L. even though [the measure of] that which stands exceeds [that of] the breach[es],

M. opposite that which stands it is permitted [to sow diverse-kinds],

N. opposite the breach it is prohibited [to sow diversekinds].

All three passages then present a similar pericope concerning laws pertaining to carrying on the Sabbath in an area enclosed by partitions.

${ }^{19}$ For the possible readings of T. Erub., cf. Lieberman, TK, III, p. 318 , on $11.5-6$.

${ }^{20} \mathrm{Y} . \mathrm{Kil} .4: 4$ (29b), Y. Erub. $1: 8$ (9b), and Y. Suk. 1:1 (52b) state that if the breach measures more than ten amot in width it is prohibited to sow diverse-kinds opposite the breaches (cf. n. 18 above).

${ }^{21}$ Cf. his translation of M. Miq. 6:9.

22 Cited by Zachs, I, p. 269 , n. 9.

${ }^{23}$ Ibid., p. 269, on 1. 12 . 
24 MS explains that since the vines lean over the terrace, the latter is considered as if it were a fence supporting the vines, so that the four amot are measured from it (following the view of House of Hillel, M. 6:1E). This view, however, presupposes that M. $6: 1$ concerns sowing on the side opposite that of the vines of the espalier (cf. our discussion of M. 6:1).

${ }^{25}$ If the spot at which the vines meet the ground is considered the spot at which the vines would be regarded as growing out of the ground (cf. Maim., Comm., Code, Diverse-Kinds 8:8), it follows that the four amot should be measured from that spot.

26 T. Kil. 3:7-8 maintains that a terrace is considered separate from the field below, but does not discuss whether or not the terrace must be a specific distance above the ground.

${ }^{27}$ Kefar Aziz is located about $12 \mathrm{~km}$. south of Hebron. Cf. M. Avi-Yonah, Historical Geography, p. 115, and idem., Carta's Atlas, pp. 87, 116, and 128 .

${ }^{28}$ For variant readings see zachs, I, p. 270 , on 1.19 . Bet Hameganyah was apparently a private estate (Sirillo, cited by Lieberman, $T K$, II, p. 640 , on 1.24 ).

${ }^{29} \mathrm{Cf}$. Porton, Ishmael, I, p. 38.

${ }^{30}$ Cited by zachs, I, p. 271, n. 28.

${ }^{31} \mathrm{Cf}$. Porton, Ishmael, I, p. 38.

${ }^{32}$ We here follow the commentaries in assigning the questions to Joshua and the replies to Ishmael, although there is no reason why these attributions may not be reversed (following william s. Green, The Traditions of Joshua b. Hananiah, I, p. 21).

${ }^{33} \mathrm{Cf}$. Theophrastus, Enquiry into Plants, 4.2 .1 (trans. Arthur Hort, Loeb ed., v. I, p. 293; cited by Feliks, Plant World of the Bible, p. 55), who compares the fruit of the sycamore to the fig as follows:

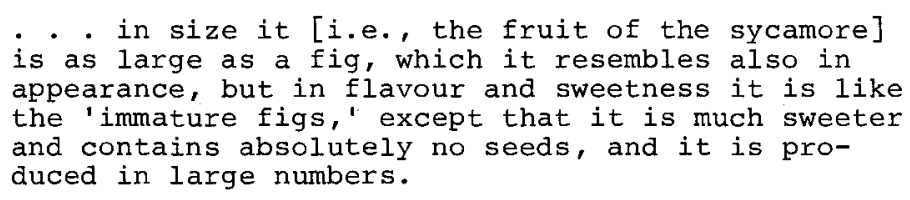

Cf. also Pliny, Historia Naturalis, 14. 56-57 (cited by Hort, p. 291, n. 6).

${ }^{34}$ Porton ( $\mathrm{p}, 38$ ) notes, however, that $\mathrm{E}$ and $\mathrm{J}-\mathrm{K}$ were formulated separately, for the language of $\mathrm{K}, \breve{s}^{\prime} r$ ("the rest [of the braches]"), differs from that of $\mathbf{E}$, mutr ("the remainder [of the tree]").

${ }^{35}$ Cited by Lieberman, TK, II, pp. 640f., on 11. 26-27, who discusses Maimonides' interpretation in the light of T. 4:7b. Cf. our discussion of $T$. below.

${ }^{36} \mathrm{Cf}$. Feliks, Plant World of the Bible, p. 54, and Mixed Sowing, pp. 153-154, and Feldman, Simhe HaMishnah, pp. 135-138. 
37 The sycamore's botanical name is Ficus sycamorus, while that of the fig tree is Ficus caricus (Feliks, Mixed Sowing, pp. 153, 160, and Mar'ot HaMishnah, pp. 152-153). For both trees as members of the nettle family, cf. Post, Flora of Syria, Palestine, and Sinai, s.v. Ficus. Feliks, however, places both trees in Moraceae (mulberry family) (Mar'ot HaMishnah, pp. 152153).

${ }^{38} \mathrm{Cf}$. M. Oh. $18: 3$.

${ }^{39}$ K.D. White, Roman Farming, p. 224. Olives or olive oil were used as food, as a source of illumination, and for anointing. Figs were used mainly as food (e.g., dried figs, bread).

40 For variant readings cf. Lieberman, $T 2, p .219$, critical apparatus on 1. 24, and $T K$, II, p. 640, on 1.24 .

${ }^{41}$ In Y. Kil. $4: 3$ (30c) the saying of simeon b. Eleazar appears in the context of a discussion of a vine trained over laths, and the saying there reads as follows:

R. Simeon b. Leazar says, "If it was its [i.e., the vine's] manner to climb from lath to lath, [all of the laths together are considered] as [belonging to] a single lath."

42 Alternatively, Lieberman $(T Z, p .219$, on 1.27 , and $T K$, II, pp. 640-64I, on 11. 26-27, 27) explains that in $\mathrm{G}$ each branch is considered as separate from the others because the sycamore tree is considered partly as a fruit tree, so that one may sow under the branches which do not support the vine. At $\mathrm{H}$ Simeon $\mathrm{b}$. Eleazar then states that if the vine climbs from one branch to the next, all of the branches are considered to belong to a single tree, for now the entire tree is regarded as serving the vine, and is now treated as a barren tree. This interpretation is difficult, however, for it does not account for $T$.'s specific language at G ("a tree unto itself"), nor does it explain why the status of the sycamore should change so that it should be considered a fruit tree at $G$ but a barren tree at $H$. We therefore prefer the first explanation offered above.

43 Alternatively, one may adopt Yohanan b. Nuri's view (M. 6:1F-G) that the area of tillage of an espalier is six handbreadths, or that of a single vine. The area which is to be sown then measures at least six amot (cf. Maim., Comm.). (Cf. also GRA, who maintains than an espalier is allowed four amot as its area of tillage, but only in respect to the area facing it. At the sides of the espalier, on the other hand, it is allowed only six handbreadths.) Although there is no reason to rule out such an interpretation, we prefer the one given above, for it explains the significance of the phrase "eight amot and a little more." According to the view which maintains that an espalier is allowed six handbreadths as its area of tillage, the measure of "eight amot and a little more" appears to have no particular significance at all.

$4^{44}$ Cf. our translation of T. 4:4-5, above.

$45_{T Z}$, p. 219 , on 1.29 , and $T K$, II, p. 641 , on 1.29.

${ }^{46}$ Cited by Lieberman, $T K$, II, p. 642 , on $11.30-31$.

${ }^{47}$ Lieberman (TK, II, p. 642, on 1. 30) cites the version presented by Nathan, the Head of the Academy, which reads, 
"one-fifth of an amah." This reading agrees with Meir's view in T. Kel. B.M. $6: 13$, and perhaps reads into T. both that view and that of Yohanan (Y. Kil. 6:5 (30C)) that the phrase "and a little more" refers to a handbreadth. Lieberman proposes to conflate the readings of Nathan and the text before us to read, "one-sixth of five handbreadths of an amah" meaning five-sixths of a handbreadth. We see no reason, however, to conflate the two readings. We therefore prefer the reading in the text before us, for there does not appear to be sufficient reason to change it.

$$
{ }^{48} \text { Cf. Zachs, I, p. } 273 \text {, on 1. } 29 .
$$

${ }^{49} \mathrm{Cf}$. MS and Ribmas (second interpretation), who perhaps give interpretations similar to our own (the language of both is unclear).

${ }^{50}$ We shall here present three alternative explanations offered by the commentaries. Ilaimonides (Comm.) explains that A refers to an espalier which extends diagonally from a corner and stops, thus forming an imaginary triangle with one of the walls (cf. fig. 45 [adapted from Qappah, I, p. 127]). The question discussed by $A$ concerns whether one may sow between this triangle (the area of which is regarded as part of the espalier [Qappah]) and the second wall at the point where the espalier stops, even though sowing another kind between the espalier and the wall may produce the appearance of diverse-kinds. A rules that one may sow in the specified space after allowing the espalier its area of tillage (which Maimonides takes to be six handbreadths [following Yohanan b. Nuri, M. 6:1]), for the area of tillage separates the other kind from the vines and so prevents them from appearing to be sown as diverse-kinds. Referring to the distance between the end of the espalier and the second wall, Yose states in B that if this distance does not measure four amot, the area may not be sown, presumably (although Maimonides does not explicitly state this) because sowing in such a small, bounded area would produce the appearance of diverse-kinds. Maimonides states his views in the Code (Diverse-Kinds 8:9) as follows:
Two walls are near one another, and the vines are planted in the angles between them, and the espalier projects along $\left({ }^{c} \mathrm{~m}\right)$ the walls from the corner and stops-he allows a space from the base of the vines according to the [appropriate] measure and sows at the place where the espalier stops, [i.e., the place] upon which there is no espalier. And even though the seed is aligned (mkwwn) between the two walls between which the espalier [lies], since he allowed a space [from the espalier] according to the appro- priate measure, he sows between the two walls.

Maimonides' interpretation is difficult, however, for it is not clear how vines extending diagonally from a corner may continue to be trained on a wall and so remain in the status of an espalier.

Sens and Ribmas both interpret $A$ to concern an espalier which is divided into two parts, with each beginning at an opposite end of the wall and with a gap separating them (cf. fig. 46). $A$ discusses an issue similar to that of $M$. 6:6A, namely whether one may sow in a gap of an espalier without causing the appearance of diverse-kinds. A rules that one may do so after allowing the 
vines their area of tillage of six handbreadths (for the vines do not join together to form an espalier). In B Yose maintains that the area between the two sections of the espalier must cover four amot in length, just as he rules in $M$. 5:4P that one may sow near a vine located in a hollow or winepress only if four amot are present. This explanation is difficult, however, for while it speaks of two rows of vines coming out of two separate corners, M. mentions only one row extending from one corner.

TYY explains that $A$ concerns a group of vines which is planted in a corner, with some vines trained along one wall, and some along the other wall (cf. fig. 47 [Romm ed., ad.20c.]). The issue of $\mathrm{A}$ is whether one may sown between the two groups of vines without appearing to sow diverse-kinds. A rules that one may sow in this space after allowing each group of vines its area of tillage of six handbreadths (since the two groups do not combine to form an espalier). Yosé, however, disagrees with A, maintaining that the vines are joined by the corner to form an espalier, so that four amot must be present between them in order to allow for their area of tillage. We find this interpretation to present problems as well, though, for $M$. does not appear to speak of two rows of vines extending out of a corner in opposite directions. It is therefore not clear how closely the interpretation of TYY is based on the plain sense of $M$.

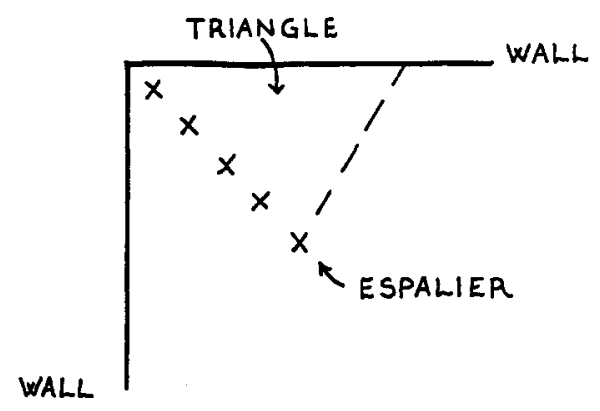

FIG. 45

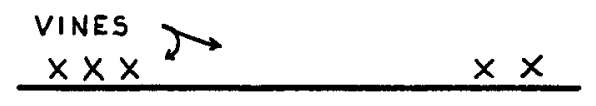

WALL 


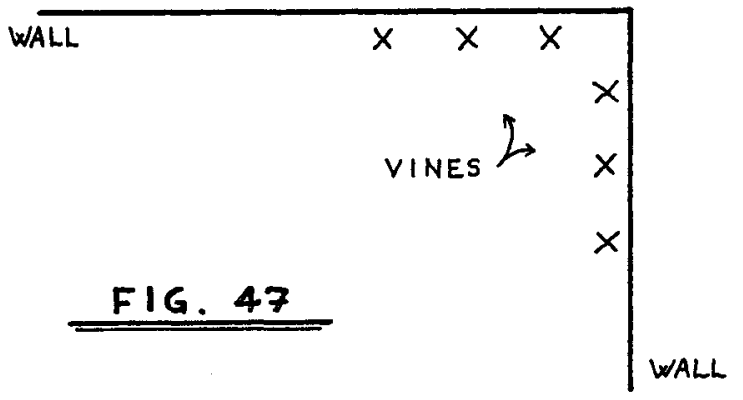

${ }^{51}$ Cf. Zachs, I, p. 273 , on 1. 32 .

52 Jastrow, II, p. 1015, s.v. spk I.

53 We note that M. $6: 8-9$ is not interested in the consideration of the espalier's area of tillage.

$54_{T Z,}$, 220 , on 1. 34, and $T K$, II, pp. $642 \mathrm{ff.}$, on 1.34 .

${ }^{55} \mathrm{Cf}$. Finkelstein, p. 263, on 1. 11. Finkelstein maintains that the section containing OO-PP+QQ-SS (p. 263, 1. 11, to p. 264, 1. 4) is actually a marginal gloss which has been erroneously inserted into the text of sifre. Since this section does appear in some manuscripts, however, we have decided to include it in our discussion of sifré.

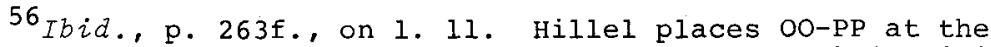
opening of the discussion of the citation Lest the whole yield be sanctified. We note that Neșiv places OO-PP after QQ-SS.

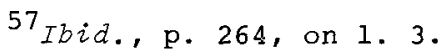

${ }^{58}$ GRA places QQ-SS in the midale of a discussion of the citation you shall not sow your vineyard (Dt. 22:9). It is not clear, however, whether GRA intends to link the rule to the verse, for there is no obvious connection between them.

\section{CHAPTER SEVEN}

${ }^{1}$ Cf. Zachs, I, p. 275 , on 1. 4.

2 Layering may be defined as "the development of roots on a stem while it is still attached to the parent plant" (Hartmann and Kester, Plant Propagation: Principles and Practices, p. 481).

${ }^{3} \mathrm{Cf}$. Hartmann and Kester, p. 487, who indicate that the layer should be held in place underground by such an item as a wooden peg, a bent wire, or a stone placed underground beside the shoot. 
${ }^{4}$ Figure 48 is adapted from Hartmann and Kester, p. 486.

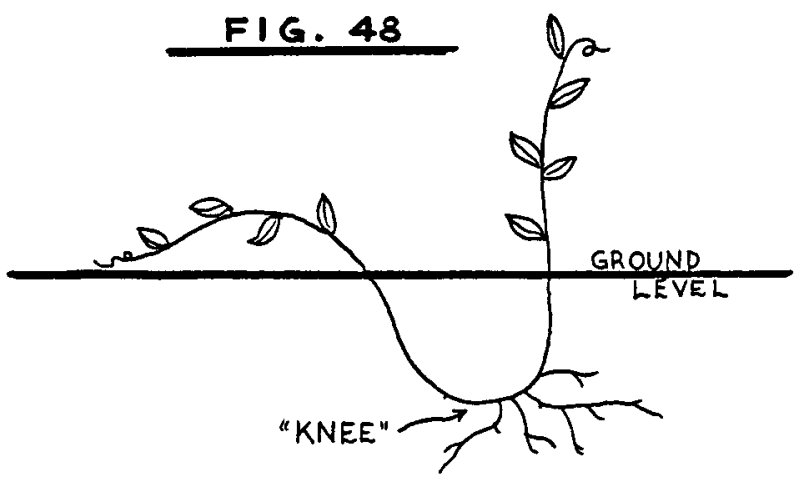

$5_{T K,}$ II, p. 644 , on 1. 40 .

${ }^{6}$ Ibid., p. 644, on 11. 42-43.

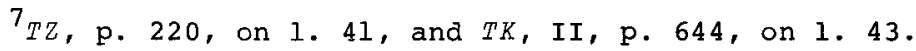

${ }^{8}$ For the height of ten handbreadths as marking a separate domain, cf. M. $2: 8,4: 7,5: 2$, and $6: 2 \mathrm{D}-\mathrm{F}$.

${ }^{9}$ Alternatively, Lieberman (TK, II, p. 644, on 1. 43) maintains that House of Shammai reason that a sunken shoot, like a vine which grows aboveground, must be allowed an airspace of ten handbreadths. House of Hillel, though, argue that, since the "airspace" of a sunken shoot is actually composed of soil, the amount of soil allowed above the vine should not differ from the amount of soil allowed beside it, which is six handbreadths. This interpretation is difficult, however, for the notion that a vine must be allowed ten handbreadths of airspace is found in Y. (e.g., Y. Kil. 6:2, 7:2), but not, as far as I am able to determine, in M.-T. itself. We therefore prefer the first explanation given above.

${ }^{10}$ Gossypium herbaceum or Gossypium arboreum, of the mallow family (Malvaceae). Cf. Feldman, p. 119, and Feliks, Mar'ot HaMishnah, p. 285.

$11_{Y}$. Bes. $5: 2$ attributes $D$ to Meir.

${ }^{12} \mathrm{Cf}$. Theophrastus, Enquiry into Plants, 4.7 .7 (cited by Feliks, Plant World of the Bible, p. 286), and Pliny, Historia Naturalis, 12.21.38, who note that the leaves of the cotton tree resemble those of the vine.

13 Alternatively, Maimonides (Comm., Code, Diverse-Kinds 5:19) understands Meir to refer not to sowing another kind near a cotton tree, but to sowing a cotton tree near a vine. Feliks (Plant World of the Bible, p. 285) explains that, although it is prohibited to plant a cotton tree in a vineyard, such a tree is not actually considered diverse-kinds in a vineyard, for it is regarded as a tree rather than simply as a bush. It is not clear, however, why the cotton tree, if it is a tree, should be prohibited at 
all in a vineyard. Furthermore, this interpretation does not follow the view of the redactor, who, in formulating $D$ and $E$ in a similar manner, and in juxtaposing them, clearly regards the two sayings to be related in substance. We therefore prefer the first interpretation given above, according to which $E$ presents another instance of the rule of $D$.

${ }^{14}$ Alternatively, most of the commentaries read $M .7: 1 \mathrm{~A}-\mathrm{C}$ into M. $7: 2 \mathrm{~F}$. For example, Maimonides (Comm.) and Bert. maintain that Eleazar b. Şadoq refers to a case in which three handbreadths of soil do not cover the sunken shoot. These commentaries, however, do not explain why the seeds are not sanctified in this instance. According to TYB, on the other hand, Eleazar b. Sadog discusses a case in which there are three handbreadths of soil above the shoot. One may not sow even in this instance, however, for it may appear that less than three handbreadths of soil cover the sunken shoot. Since three handbreadths of soil are in fact present, though, the seeds are not sanctified. There is no reason, however, to believe that the rule of Eleazar $b$. sadoq is at all interested in the considerations of $\mathrm{M}$. $7: 1 \mathrm{~A}-\mathrm{C}$.

MR explains that Eleazar b. Sadog and M. 7:1A-C disagree as to whether the sower is liable if the roots of the seeds penetrate into the vine. Eleazar b. Sadoq maintains that the sower does not intend for the seeds to be nourished from the vine, and that the penetration of the roots does not occur immediately after sowing. The sower therefore is not liable and the act of sowing, although prohibited, does not sanctify the seeds. M. 7:1A-C, on the other hand, rules that, since the sower knows that the roots will definitely penetrate into the vine, he is liable and the seeds are sanctified (unless, of course, he separated the two kinds by three handbreadths of soil). Again, however, there is no reason to assume that Eleazar b. Sadoq's saying is related to $\mathrm{M} .7: 1 \mathrm{~A}-\mathrm{C}$, and we therefore prefer our first interpretation to all of the explanations given above.

${ }^{15} \mathrm{Cf}$. Neusner's translation of T. Kel. B.M. $6: 13 \mathrm{~A}, H M L P$, II, p. 102 .

${ }^{16}$ In T. Kel. B.M. 6:13 Meir presents the list of B (omitting mwtr at $B(1)-(3)$ ) in a discussion of the length of an amah used in measuring certain areas.

17 The bald spot (= patch) of a vineyard must measure either twenty-four (House of Shammai) or sixteen (House of Hillel) amot square in order to be sown (M. $4: 1 \mathrm{~A}-\mathrm{C}$ ).

${ }^{18}$ The outer space of a vineyard must be either sixteen (House of Shammai) or twelve (House of Hillel) amot wide in order to be sown (M. $4: 1 D-F)$.

${ }^{19} \mathrm{Cf}$. M. $6: 3 \mathrm{C}$, which rules that the seeds are sanctified if the vine spreads over them, thus implying that the seeds are not sanctified as long as they do not lie under the vine. We also note that, unlike M. $7: 3$, M. $6: 3 \mathrm{C}$ uses 'swr in the sense of "sanctified." Cf. our discussion of M. 6:3-5, above.

${ }^{20} \mathrm{Cf}$. GRA (M. $6: 3$ ), who explains that one who sows under the "remainder" of the latticework does not sanctify the seeds because he produces only the appearance of diverse-kinds (i.e., it appears that the vines will spread over the latticework). According to this interpretation the rule of $B(4)$ follows the principle of $M .7: 2 D-F$ and $M .7: 3 B(1)-(3)$. We have not accepted this interpretation of $M .6: 3-5$, however, for it does not account for the difference between the "remainder" of the latticework of 
laths and the "remainder" of the fruit tree. We fail to see why the appearance of diverse-kinds is not produced in the case of the latter as it is in the instance of the former. We therefore prefer the interpretation presented in our discussion of M. 6:3-5, above.

${ }^{21}$ Cited by Finkelstein, p. 263, on 1.1 .

22 Bokser, I, p. 54 .

23 The term $q d \xi$ is used in several contexts besides that of diverse-kinds, e.g., in reference to the mixture of corlahfruit and permitted fruit (M. Orl. $3: 7$ ).

\section{${ }^{24} \mathrm{Y}$. Kil. $7: 3$ differs from Sifre mainly at NN, where $Y$. reads as follows:}

NN. Scripture says, [your] vineyard (Dt. 22:9)--

and not diverse-kinds [i.e., the prohibition

You shall not sow precedes the phrase [your] vineyard and not the phrase diverse-kinds

(PM); GRA reads: Scripture says, [The produce

of the] vineyard (Dt. 22:9)--and not your

vineyard].

PM explains that, unlike the prohibitions of LV. 19:19, which place the verb after the direct object and before the phrase

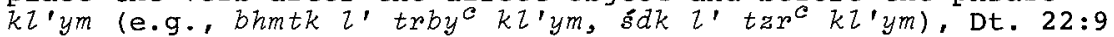
places the verb before the direct object ( $\left.l^{\prime} t a r^{c} k_{r m k} k l ' y m\right)$. $\mathrm{Y}$. takes the proximity of the direct object to the verb in Dt. 22:9 to mean that the prohibition applies to any act of sowing in a vineyard (reading your vineyard as simply vineyard). According to GRA's reading the point of $\mathrm{Y}$. is that the phrase at the end of Dt. 22:9, the produce of the vineyard, refers to all vineyards, rather than only to your vineyard, as the verse states at its beginning.

25 Alternatively, GRA understands J to read, "At what point is he [i.e, , the man who seized the vineyard] called a usurper?" According to this reading $\mathrm{J}-\mathrm{K}$ distinguishes between one who has seized the vineyard but does not yet have full control of it, and the usurper, who does have a firm hold on the land. J-K cannot then gloss only $\mathrm{A}-\mathrm{C}$, for it is difficult to distinguish between the two thieves in respect to the question of the sanctification of the vineyard. If, according to $\mathrm{A}-\mathrm{C}$, a usurper does not sanctify the vineyard which he sows, it does not follow that the thief who does not have control of the property should be able to sanctify it. This reading of $\mathrm{J}-\mathrm{K}$ thus requires a unitary interpretation of the pericope, an interpretation which GRA provides as follows. The usurper is effectively the owner of the vineyard at the time that he sows $i t$, and he therefore renders the vineyard prohibited by his act of sowing. For this reason the rightful owner must cut down the other kind as soon as possible. He need not burn the other kind with the vines, however, for the vineyard has not actually been sanctified. If, on the other hand, a thief who did not have complete control over the property sowed the vineyard, he does not sanctify it even at the time of sowing, since he may not be said to have "owned" the vineyard. The rightful owner, therefore, need not hurry to remove the other kind. This explanation, however, presents several difficulties. First, as I have said, it presupposes a unitary reading of the pericope, which we have rejected for the reasons given above. Second, GRA attempts to distinguish between the usurper, who may be said to "own" the 1and, and the thief, who does not have firm control over the property and thus is not considered its "owner." Ultimately, however, the vineyard is not sanctified 
by either thief, so that it is not clear why the owner should hurry to remove the other kind in one case and not in the other. We can see no relationship between the fact that the usurper actually functions as an owner and the rule that the rightful owner need hurry to remove the other kind which the usurper sowed. We therefore see no reason to distinguish between the two thieves, and so prefer the translation and explanation of $\mathrm{J}-\mathrm{K}$ presented above.

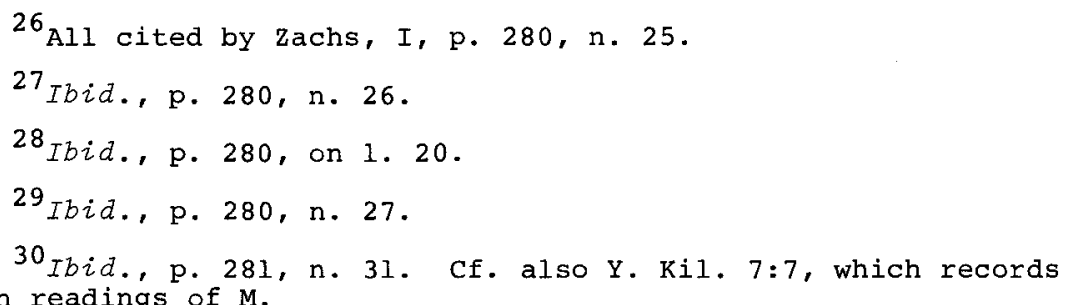
both readings of $M$.

${ }^{31}$ Cf. M. MaCas. $1: 3$ (and M. Hal. 1:3), which states that grain becomes liable for tithes once it has reached one-third of its projected size.

32 Following Sirillo and Elijah Fulda, in $T K$, p. 220, on 1. 31, and $T K$, II, p. 643, on 1. 38. The Latin name of madder is Rubia tinctorum (TK, II, p. $643, \mathrm{n}$. 31), of the madder family (Rubiaceae). Cf. Feliks, Mar'ot HaMishnah, p. 102.

${ }^{33}$ Cited by Lieberman, TK, II, p. 643 , on 1.39.

${ }^{34}$ Alternatively, Lieberman $(T Z, P .220$, on 1.37 , and $T K$, II, p. 643, on 1. 37), following Maimonides (Code, Diverse-Kinds $8: 11$ ), maintains that $E$ refers to the roots of the vines rather than to those of the vegetables. According to this interpretation $E$ states that if the roots of the vines extend from the latter into the four amot of the vineyard, the vegetables must be uprooted, for now the roots of the vegetables (which are apparently presumed to have entered the four amot as well) may gain nourishment from the roots of the vines, and the two kinds thus grow together as diverse-kinds. This interpretation is difficult, however, for the language "[If] their roots extended into the four amot of the vineyard" seems to apply more appropriately to the vegetables, which lie outside of the vineyard's area of tillage, than to the vines, which are already located in the four amot of the vineyard. Furthermore, Maimonides' interpretation of $E$ may have been influenced by his reading of $F$. According to Maimonides (Code, Diverse-Kinds 8:11; cf. Lieberman, $T K$, II, p. 643 , on 1.37$)$ F refers to roots of grain $\left(p y^{\prime} h\right)$ which enter the four amot of the vineyard. Maimonides perhaps reasoned that if $F$ refers to roots of grain, $E$, which gives the opposite rule, must refer to roots of vines. Since, however, we do not accept Maimonides' reading of $F$, we see no reason to interpret $\mathrm{E}$ to refer to the vines. We therefore prefer the interpretation given above.

${ }^{35}$ We follow $Y$. and GRA in omitting "even" ('py $z w$ ) at $F$, for otherwise $F$ would make no sense. When read with "even" $F$ states that the roots of madder do not sanctify the vines even if they are more than three handbreadths below the surface. F thus implies that the roots of madder also do not sanctify the vines if they are less than the specified depth below the surface. Now the point of $F$ can only be that the vines are not sanctified because the madder's roots do not come into contact with those of the vines. The two sets of roots will surely meet, however, if 
the roots of the madder are less than three handbreadths under the ground. F thus cannot be read with "even," and we therefore follow those readings which omit it.

${ }^{36}$ Lieberman ( $T Z$, p. 220, on 1.38 , and $T K$, II, p. 643 , on 1. 38) notes that $F$ specifically mentions madder because its roots have a tendency to spread out.

37 Commentary to $M .7: 7$, cited by Lieberman, $T K, I I, p .645$, on 11. 44-45.

${ }^{38}$ It is clear from B-C, which states that vines can become sanctified once their grapes grow to the size of hyacinth beans, that "prohibited" in $\mathrm{E}(1)$ can mean only "sanctified."

${ }^{39}$ Cf. Finkelstein, p. 263 , on 1.4 .

${ }^{40}$ In Y. Kil. $7: 5$ Hananiah b. Hillel first cites EE-FF and then quotes $B B$.

${ }^{41}$ Cf. Zachs, I, p. 282 , on 1.25 .

42 Ibid.

43 For other instances in which a plant growing in a perforated pot is considered to be attached to the ground, cf. M. Dem. 5:10 and M. Shab. 10:6.

${ }^{44}$ For other instances in which simeon does not distinguish between perforated and unperforated pots, cf. T. Shev. 8:10 (one may write a prozbol for either type of pot [cited by Lieberman, $T K$, II, p. 646, on 11.48-49]), and M. Shab. I0:6 (one may uproot a plant on the Sabbath from either type of pot [cited by Y., MS, and TYT]).

${ }^{45}$ Simeon's view may be related to his rule at M. Uqs. $2: 9$ (cited by TYT), which read as follows (trans. Neusner, HMLP, $\mathrm{XX}, \mathrm{pp} .61-62)$ :

A. A cucumber [which was rendered susceptible to uncleanness] which one planted in a pot and grew, and [the root of which grew and] went outside of the pot is [thereby] insusceptible to uncleanness.

B. Said R. Simeon, "What is its character that it should be insusceptible to uncleanness?"

C. "But that which is susceptible to uncleanness remains on its status of susceptibility to uncleanness, and that which is insusceptible to uncleanness is eaten."

A states that a plant growing in an unperforated pot (Neusner) is rendered insusceptible to uncleanness if a shoot grows into the soil outside of the pot, for the plant is now considered to be attached to the ground. Simeon, however, maintains that the plant in the pot remains susceptible to uncleanness and the shoot alone is rendered insusceptible, for only the latter is actually attached to the ground and clearly derives nourishment from it. In both M. Kil. $7: 8$ and M. Uqs. 2:9, therefore, Simeon apparently reasons that a plant which begins to grow in a pot can be sustained by the soil in that pot alone. The plant thus is not assumed to derive nourishment from a source outside of the pot if a part of the plant becomes attached to the ground around the pot. In 
both cases, then, simeon rules that the plant inside the pot is not considered to be attached to the ground outside of the pot.

$46_{T K}$, II, p. 646, on 1. 49. M. Uqs. 3:8H states (trans. Neusner, HMLP, $\mathrm{xx}, \mathrm{p} .67), "$ "Grain which was uprooted, and is attached even by a small root, is insusceptible to uncleanness."

${ }^{47}$ In B. Shab. 95b (cf. also Y. Kil. 7:6) Rav explains that Simeon's position is based on an interpretation of LV. 11:37, which reads, And if any part of their carcass falls upon any seed for sowing that is to be sown, it is clean. According to Rav the repetition of the root $z r^{c}$ in the phrase any seed for sowing that is to be sown is taken to mean that anything which is in any way connected to the earth cannot be rendered susceptible to uncleanness (Rashi, ad Zoc.).

CHAPTER EIGHT

${ }^{1}$ Cf. Zachs, p. 283 , on 1.2 .

2 Ibia., p. 285 , on 1.5.

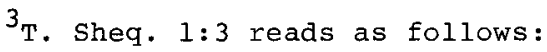

A. On the fifteenth of it [i.e., Adar] the messengers of the court go out and declare the diverse-kinds ownerless,

B. for that which is declared to be ownerless by the court is [considered to be] ownerless,

c. and is exempt from tithes.

D. [If] he found diverse-kinds in the vineyard, it [i.e., the diverse-kinds] is permitted with regard to [the law of] robbery and exempt from tithes.

E. [If he found diverse-kinds] in the field, it [i.e., the diverse-kinds] is prohibited with regard to [the law of] robbery and liable for tithes.

$A-C$ and $D-E$ can each stand by itself, and it appears that they have been joined because of $C$. Since $D-E$ does not depend on $A-C$ for its context, it is probable that D-E is primary to T. Kil. (where it appears by itself), rather than to $T$. Sheq.

${ }^{4}$ HD (to T. Sheq. 1:3; cited by Lieberman, TK, II, p. 646 , on 1. 1) points out that diverse-kinds of the vineyard are considered to be ownerless even if they grow without being sown and have not yet sanctified the vineyard (i.e., the owner is not yet aware of their growth). In this instance it is assumed that the owner, who would have to destroy the diverse-kinds anyway, wishes them to be uprooted by someone else, and so renounces his rights of ownership over them.

${ }^{5}$ Cf., however, T. 2:16, which, without distinguishing between the types of diverse-kinds, rules that one may uproot another's diverse-kinds without permission because he thereby "lessens the impropriety $\left(m^{c} t\right.$ ' $\left.t h t p l h\right) . "$ 
${ }^{6}$ Cited by Lieberman, $T K$, II, p. 647 , on $11.2-3$.

${ }^{7}$ Cited by Lieberman, ibia.

${ }^{8}$ Cited by Lieberman, ibia.

${ }^{9}$ Cited by Lieberman, ibid., on 1I. 4-5.

${ }^{10}$ Cited by Lieberman, ibid., on $11.6-7$.

${ }^{11}$ Cited by Finkelstein, pp. 262-263, on 1.11 .

${ }^{12}$ On D in GRA's reading of Sifre, see sifré Dt. 2301.

${ }^{13} \mathrm{Cf}$. GRA, who reads the present pericope (without its exegesis of diverse-kinds) in the context of sifre Dt. 230a, while taking the latter to refer to one who sows a vineyard. We note that Finkelstein (p. 263, on 1. 11) considers the present pericope to be a marginal gloss of sifre.

${ }^{14}$ We note that Finkelstein ( $p .263$, on 1 . 11) regards this pericope to be part of a long marginal gloss on Sifré.

${ }^{15} \mathrm{Cf}$. also Nesiv, who reads which you have sown at $\mathrm{D}$ and takes the word which to include the act of allowing diverse-kinds to grow.

${ }^{16} \mathrm{Y}$. offers two versions of the pericope. The first is garbled and refers to a non-existent verse (cf. GRA, PM, ad 200.). The second differs from Sifra (according to Hillel's interpretation) in referring to another verse in the gezerah shavah:

A. Here Lest [the whole yield] be sanctified (Dt. 22:9) is said, and there Neither shall there be a cult prostitute (qdas) of the sons of Israel (Dt. 23:18) is said.

B. Just as [the phrase] "sanctified" mentioned there [refers to that which] is prohibited in respect to benefit, so [the phrase "sanctified" mentioned] here [refers to that which] is prohibited in respect to benefit.

Y. thus reasons that just as one may not derive benefit from a cult prostitute, so may one not benefit from diverse-kinds of the vineyard. This reading of the pericope is somewhat less plausible than that of Hillel, for the prohibition against deriving benefit is related more directly to the law of "holy things" (which is concerned with the proper and improper use of such items) than to the law of the cult prostitute (the issue of which is the proper conduct of the cult, not deriving benefit or pleasure from the prostitute). It is thus more likely that sifre would choose to draw an analogy between the sanctified diverse-kinds of the vineyard and the "holy things to the Lord" than between the diverse-kinds and the cult prostitute. We therefore prefer the interpretation of Hillel given above.

17B. M.Q. 2b and B. Mak. $21 \mathrm{~b}$ read $D$ as follows:

D. Scripture says, [Your cattle you shall not let breed with] a different kind; your field [you shall] not [sow with diverse-kinds] (Lv. 19:19).

According to this reading the rule that one may not derive benefit from diverse-kinds is derived from the juxtaposition of a different kind (the last word in the previous clause), your field, and not. These three phrases are read together and taken 
to mean that one may not have diverse-kinds in his field, so that one is prohibited not only from sowing diverse-kinds but from allowing them to grow as well.

${ }^{18} \mathrm{QA}$ also offers an alternative explanation (which he prefers to the one given above), basing upon the phrase your field the rule that one may not allow diverse-kinds to grow. This phrase is regarded as unnecessary, for the prohibition against sowing diverse-kinds may be easily understood from the rest of the verse (You shall not sow with diverse-kinds). Your field is therefore taken to indicate that one is prohibited not only from sowing diverse-kinds, but also from having them in one's field, i.e., allowing them to grow. This explanation of the pericope is difficult, however, for $D$ does not include your field in its citation of LV. 19:19, and there is no reason to assume that this phrase figures in the exegesis of sifra. We therefore prefer the first interpretation given above.

${ }^{19}$ We here follow the reading which omits with a different $k i n d$, for this phrase clearly does not belong in $A$.

20 Rabad understands "others" in $C$ and $D$ to refer to gentiles. We see no basis for this interpretation in the text itself, though, and we therefore prefer to read "others" to refer simply to other people.

${ }^{21}$ Referring to Gn. R. $7: 4$, Albeck (p. 368) maintains that $\mathrm{lm}$ šk refers to leading the animals, and that 2 hnhyg refers to driving them from behind (cf. also Danby, ad zoc.). We here simply follow the view of the majority of the commentators. In any event, though, the difference in translation does not affect our exegesis of the pericope.

22 Alternatively, Maimonides (Comm.; cf. also GRA) takes Dt. 22:10, which specifically mentions an ox and an ass (both of which are domesticated animals), to prohibit the pairing of clean and unclean animals alone. He therefore understands $A$ to continue the discussion of $\mathrm{M}$. $8: 1 \mathrm{~J}$ and thus to refer to the mating of animals of different kinds, so that $C$, which refers to the yoking together of animals, serves B alone. Maimonides' reconstruction of M.'s exegesis of scripture is interesting, but $A$ and $B$ are perfectly matched, and it is difficult to see any good reason to separate them. We therefore prefer our first interpretation given above.

23 We note that Finkelstein (p. 263, on 1. 11) regards this pericope to be a marginal gloss of sifre.

${ }^{24}$ For variant readings of $l w b d q s$, cf. Epstein, ITM, pp. 97ff. (cited by Lieberman, TK, II, p. 648, on 1.8 ). Feliks (Mixed Sowing, p. 130, fig. 74) identifies the Libyan ass as Equus asinus (cf. our discussion of M. 1:6).

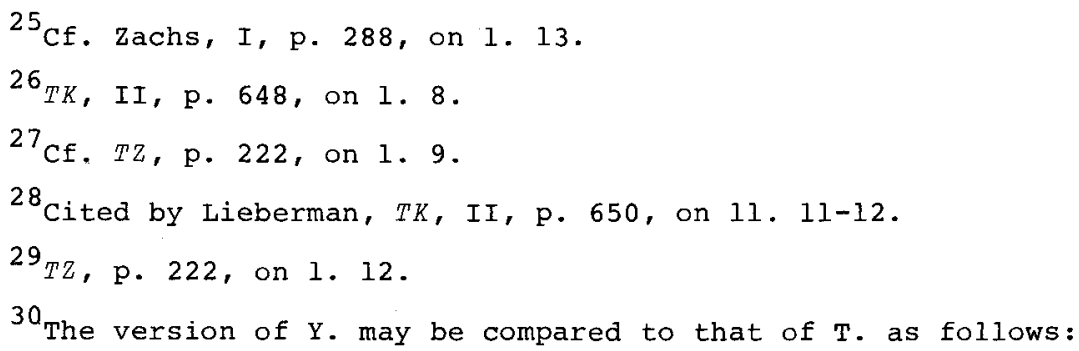


T. Kiz. $5: 6$

1. Isi the Babylonian says, "It is prohibited to ride on the back of a mule,

2. "[as we learn] from an argument a minori: If, in a case in which it is permitted to wear two garments as one, 10, he is prohibited in respect to their mixture, in a case in which it is prohibited to lead two animals as one, is it not logical that it should be prohibited in respect to their mixture?"

3. They said to him, "Io, it [i.e., scripture] says, [Take with you the servants of your zord, ] and cause Solomon my son to ride on my own mule, and bring him down to Gihon (I Kings $1: 33)$."

4. He said to them, "They do not respond from Tekoa."

5. They said to him, "Lo, it [i.e., scripture] says And David did what was right in the eyes of the Lord, and did not turn aside from anything that he commanded him alz the days of his life, except in the matter of Uriah the Hittite (I Kings 15:5)."
I. KiZ. $8: 2$

1. Isi b. CAqavyah says, "It is prohibited to ride on the back of a mule,

2. "[as we learn] from an argument a minori: If, in [the case of] two garments which you are permitted to wear one on top of the other, you are prohibited in respect to their mixture, [in the case of] an animal which you are prohibited to lead [i.e.,] one [kind] with another, all the more so should you be prohibited from riding on it."

3.

And

is it not written,

[Then alz the King's sons arose,] and each mounted his mule and fled (II Sam. 13:29)?

4. do not learn [the law] from royalty.

5.

And

is it not written, [Take with you the servants of your lord, ] and cause solomon my son to ride on my own mule, and bring him down to Gihon (I Kings $1: 33)$ ?

6. This mule was a creature from the six days of creation [i.e., it was created as a mule, and was not born of the union of a horse and an ass (PM)].

Y. significantly differs with T. at (3)-(6). While T. cites David's action (I Kings $1: 33$ ) as precedent at (3) and supports it with I Kings $15: 5$ at (5), Y. cites the action of David's sons (II Sam. 13:29) as precedent at (3) and supports it by citing David's own action (I Kings 1:33) at (5). In Y.'s version, then, David's authority is not questioned (as it is in T.), but in fact is used to support the argument of Isi's opponents (and is not challenged by Isi). We note that Y. clarifies T.'s reading of (4) by replacing "Tekoa" with "royalty." Y. also adds (6), and thus has Isi win the debate. Isi now responds that David's action does not set a precedent, for his mule was created at the creation of the world and, unlike other mules, was not born of the union of a horse and an ass (PM). Y. here presupposes Isi's statement at (2), which specifically states that one is prohibited from using an animal born of the union of two kinds, so that $Y$. perhaps links (2) and (3)-(6).

${ }^{31}$ Alternatively, Sirkes (cited by Lieberman, TK, II, p. 65I, on 1. 17) explains that "Tekoa" refers to Ira the son of Iqqesh of Tekoa, one of David's advisers (II Sam. 23:26). This 
reference, however, is obscure, and thus not likely to provide the basis for the idiomatic saying of D. Following Sens (who reads $h t q w^{c}$ at $D$ ) and Rosh (who reads $h t w q^{c}$ at D), Lieberman interprets $t q w^{c}$ as $h t q w^{c}$, meaning one who establishes ( $h t w q^{c}$ ) the law for himself (cf. B. Yev. 109b). It is not clear, however, why such a description should be applied to David in particular. We therefore prefer the explanation given in the translation as the most probable one.

32 For the identification of the hedgehog and the weasel, cf. Danby, who follows the views of most of the commentaries. to the identification of the weasel, cf. also Feliks, Animal World of the Bible, p. 42, who argues that the hldh is not a weasel but a rat.

${ }^{33}$ Sens maintains that the parentage of prwtywt cannot be ascertained because such mules do not exhibit the characteristics which generally distinguish one kind from another (cf. also TYY, who explains the prwtywt are mules which are too young to display such characteristics). Sens here refers to signs which distinguish a mule born of a female horse from a mule born of a female dam in respect to the sound of the voice and the length ofthe ears and tail (B. Hul. 79a). Cf. Varro, On Agriculture 2.8.6 (trans. W.D. Hooper, rev. Harrison Boyd, Loeb ed., p. 395), who states:

The so called hinny is the offspring of a horse and a jenny; smaller than the mule, usually rather redder, with ears like a horse's, but with mane and tail like those of the ass.

${ }^{34}$ Maimonides actually states with respect to $A-B$ only that "it is prohibited or permitted to allow them to mate ( $2 h r k y b$ )." Since Maimonides presumably takes A to mean that mules may not be permitted to mate with each other, we assume that he understands $B$ to mean that wild horses may be mated with each other. Alternatively, MR takes B to mean that wild horses may be paired with other horses. Neither M. nor Maimonides mentions other horses, however, and we therefore prefer the first interpretation of Maimonides given above.

${ }^{35}$ So Louis Ginzberg, "Beiträge zur Lexikographie des Aramaischen," in Festschrift Adolf Schwartz, ed. Samuel Krauss (Berlin: R. Löwit, 1917), pp. 329ff. (cited by Albeck, p. 379). Cf. also Danby (p. $37, n .4$ ), who suggests that the creature may be identified as a chimpanzee or an ape. TYY identifies the "wild man" as the orangoutang (which, in fact, means "wild man" in Malay), but, since the latter is found only in Borneo and Sumatra, it is probable the TYY actually refers to the ape, to which the name "orangoutang" was often mistakenly applied (cf. Oxford English Dictionary [Oxford: Oxford University Press, 1933], v. 7, p. 172, s.v. orangoutang).

${ }^{36}$ Hedgehogs feed on mice, birds, lizards, and snakes, as well as insects (J[ames Smith] Fi[ndlay], "Insectivora," Encyclopaedia Britannica 15 th ed., Macropedia, 9:623) and weasels prey on rodents, fish, frogs, and birds" eggs ("Weasel," Encyclopaedia Britannica, 15th ed., Micropedia, 10:588).

${ }^{37}$ Cf. Zachs, I, p. 281 , on 1. 20.

${ }^{38}$ Cf. T. Kil, 1:9, M. Bik. 2:8-11 for other issues related to the distinction between wild and domesticated animals.

${ }^{39}$ Cf. Feliks, Animal world of the Bible, p. 30. 
40 The point of M. $1: 6$, though, is that the Arabian onager and the ass are considered to be diverse-kinds with one another even though they resemble each other. Cf. also T. 1:8b, which states that the wild ass, which MR identifies as the Arabian onager, is considered to be diverse-kinds with an ass.

41 our translation of $h k w t b$ follows that of Danby in $M$. Bik. $2: 11$.

42 All cited by Lieberman, TK, II, p. 652, on $11.21-22$.

$43 T Z$, p. 223 , on 1.22 .

${ }^{44}$ For the identification of the ostrich, cf. Feliks, Animal World of the Bible, p. 91 .

$45_{T K}$, II, p. 652 , on $11.22-23$.

${ }^{46}$ Cf. M. Kel. $17: 14$, T. Kel. B.M. $7: 5-6$, and M. Toh. 1:3 (cited by Lieberman, TK, II, p. 652, on 1. 23).

$47_{T Z}$, p. 223 , on 1.22 , and $T K, I I, p .652$, on 1.23. Lieberman maintains that "for" was mistakenly inserted into T. Kil. 5:8b from T. Bek. l:9 (see below, n. 49).

48 Alternatively, A could be translated as "an unclean animal does not bear a kind of clean animal." At E-F, however, mn clearly means "from" and not "a kind of" (for there is only one kind of man), and we therefore prefer to translate it as "from" throughout the pericope.

${ }^{49}$ T. Bek. $1: 9$ reads as follows:

A. R. Simeon says, "Why does Scripture say, came 2 (Lv. 11:24), camel (Dt. 14:7) twice?

B. "To include the camel which is born of a cow as one which is born of a female camel.

c. "And if its head and greater part resemble its dam, it is permitted in [respect to] eating."

D. And sages say, "That which comes from an unclean animal is [considered to be] unclean,

E. "and that which comes from a clean animal is [considered to be] clean;

F. "for an unclean animal does not bear [offspring] from [mating with] a clean [animal],

G. "nor does a clean [animal] bear [offspring] from [mating with] an unclean [animal].

H. "And a large [animal] does not [bear offspring] from [mating with] a small [animal],

I. "nor does a small [animal bear offspring] from [mating with] a large [animal].

$\mathrm{J}$. "And a man does not [bear offspring] from [mating with] any of them [i.e., any animal],

K. "nor does any of them [bear offspring] from [mating with] a man."

T. Bek. 1:9F-K, which corresponds to T. Kil. 5:8b, supports sages' position (T. Bek. 1:9D-E, a citation of M. Bek. $1: 2$ ), which states that any offspring of an unclean animal is considered unclean (and vice vers $\alpha$ ). T. Bek. 1:9F-K is thus presented only 
because of $T$. Bek. 1:9F-G, for only this part of the pericope is relevant to sages' views. In addition, T. Bek. $1: 9 \mathrm{D}-\mathrm{E}$ and F-K can each stand without the other. It appears, then, that T. Bek. $1: 9 \mathrm{~F}-\mathrm{K}$ is an autonomous unit which has been appended to T. Bek. 1:9D-E because of T. Bek. 1:9F-G. At the same time, however, we note that the pericope does not explicitly raise the issue of diverse-kinds, and thus need not be primary to T. Kil. The pericope could thus primarily concern either the issues of M.-T. Bekorot (e.g., the status of a first-born of one kind born to a dam of another kind) or questions of diverse-kinds (e.g., the results of the mating of different kinds of animals with one another).

$50_{B}$. Bek. 7a attributes $\mathrm{C}-\mathrm{H}$ to Joshua b. Levi.

${ }^{51}$ Cf. Pliny, Historia Naturalis 8.79.213f. (trans. H. Rackham, Loeb ed., v. III, p. 149), who states:

- . But not only in pigs but in all animals as well whenever there is any tame variety of a genus there is also found a wild one of the same genus, inasmuch as even in the case of man an equal number of savage races have been predicted to exist.

52 B. B.M. $90 \mathrm{~b}$ reads B as follows:

B. One incurs forty lashes only [in the case of] he who threshes [with a muzzled cow] and he who drives [diverse-kinds of animals].

B. thus replaces T.'s mention of liability with the specific punishment for the act. B. also replaces the verb "leads" with "threshes," so that $B$ refers to $A(1)$ as well as to $A(2)$. Cf. also the version of Sefer HaEshkol (cited by Lieberman, $T K$, II, p. 653, on 1. 28), which adds $h m s k$ ("he who pulls") to $B$.' $s$ version, and so brings $B$. closer to the language of M. 8:2C ("plowing, pulling [e.g., a wagon], and being led").

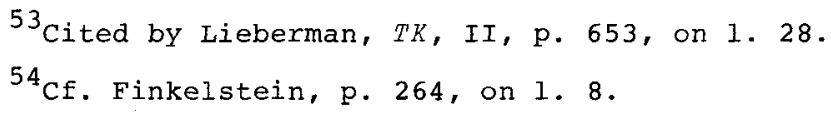

CHAPTER NINE

$1_{M}$. Neg. $11: 2$ reads as follows (trans. Neusner, HMLP, VI, p. 199):

A. Camel's hair [which is not susceptible to plagues] and sheep's wool which one hackled together--

B. if the larger part is from the camels, they are not susceptible to uncleanness through plagues.

c. If the greater part is from the sheep, they are susceptible to uncleanness through plagues.

D. Half and half--they are susceptible touncleanness through plagues.

E. And so the flax and the hemp which one hackled together.

M. Neg. 11:2 differs from M. Kil. 9:1D-H only in its apodoses, reading "are/are not susceptible to uncleanness through plagues" for the latter's "it is permitted/prohibited [tomix the fibers with flax]." The two versions thus use the same case to illustrate 
different rules, with $\mathrm{M}_{\text {. Kil. }}$,:1D-H augmenting M. Kil. 9:1A, and $M$. Neg. $11: 2$ referring to $M$. Kil. 9:1B. The pericope could have originally appeared in either context, and it is thus impossible to tell whether M. Kil. 9:1D-H or M. Neg. 11:2 represents the primary formulation of the pericope.

${ }^{2}$ All scriptural references for $\mathrm{A}-\mathrm{C}$ are cited by Maim, Comm.

${ }^{3}$ Cf. also Ex. 29:27ff. (cited by Sens), which states that the garments of Aaron's sons were also composed of wool or linen.

${ }^{4}$ Hackling, or combing, involves the separation of fiber from unwanted parts of the stem (in the case of vegetable fibers), or the removal of tangles and impurities from the fibers (in the case of animal fibers). This process represents the last stage of the preparation of the fibers for spinning (cf. J.P. Wild, Textize Manufacturing in the Northern Provinces [Cambridge: Cambridge University Press, 1970], pp. 24, 28). For a discussion of Pliny's account of hackling (Historia Naturalis 19.16-18) and a description of the type of hackle mentioned by him, cf. J.P. Wild, "The Roman Flax-Hackle (AENA)," Museum Eelveticum 25 (1968), pp. 139-142 (cited by wild, Textile Manufacture, p. 29, n. 1). CE. also R.J. Forbes, Studies in Ancient Technology, IV, second ed. (Leiden: E.J. Brill, 1964), p. 32. Forbes, however, relates hackling to the Hebrew root srk, and does not mention the root trp (or M. Kil. 9:1) at all.

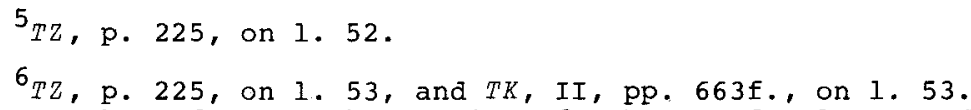
Lieberman here follows the reading of Rabad. Cf. also GRA (cited by Lieberman, $i b i d$.$) , who presents the same reading.$ $133 b)$.

${ }^{7}$ Lieberman, $T K, I I, P .663$, on 1.52 (following B. Shab.

${ }^{8}$ Ibid.
${ }^{9}$ Ibid.

10 These three types of dressings also appear together at T. Kel. B.B. $6: 3$.

${ }^{11}$ Alternatively, cf. Maimonides (Code, Diverse-Kinds 10:19; cited by Lieberman, $i b i d$.$) , who explains that the dressings do not$ serve to warm the body and thus do not function as garments.

$12_{T K}$, II, p. 663 , on 1.53.

$13 T Z$, P. 225, on 1. 53, and TK, II, pp. $663 \mathrm{f}$. , on 1.53.

${ }^{14} \mathrm{Cf}$. T. Shab. 4:5(7), which also states that a wreath is not subject to the laws of diverse-kinds.

$15_{T K}, I I$, p. $663 \mathrm{f}$. , on 1.53.

16 TK, II, p. 664, on 1. 55. Lieberman here follows the readings of Erfurt, first printed ed., B. Yoma and Tamid, and the commentaries.

${ }^{17} \mathrm{~B}$. Yoma $69 \mathrm{a}$ and $\mathrm{B}$. Tamid $27 \mathrm{~b}$ actually read as follows:

A. Garments of the high priest--

B. he who goes out [while dressed] in them to the provinces [i.e., outside of the Temple]--it is prohibited. 
c. And [he who wears them] in the Temple,

D. whether [he does so] at the time of the [Temple] service or not at the time of the [Temple] service--

E. it is permitted,

F. because the priestly garments were intended to be enjoyed [i.e., to be used privately].

B. differs with $T$. mainly at $F$. B. replaces T.'s version of $F$, which, as we shall see, cannot be read together with $D$, with a version which does take account of the rule of $D$. B. thus resolves the difficulty which occurs in $T$. when $D$ and $F$ are read together.

${ }^{18} \mathrm{Cf}$. also Sefer HaEshkol (cited by Lieberman, TK, II, p. 653f., on 1l. 28-29), which reads, "Camel's hair and sheep's wool are permitted."

${ }^{19}$ For other commentaries which follow this reading, cf. Lieberman, TK, II, p. 654, on 11. 29-30.

20 Alternatively, Lieberman (ibid.) maintains that "them" refers to the sheep's wool, and so takes Erfurt's reading of $T$. to say that wool and flax may be hackled together and then combined with camel's hair. It is not likely, however, that one would be permitted to hackle together sheep's wool and flax under any circumstances, and we therefore prefer the interpretation given above in the translation.

${ }^{21}$ Lieberman (TK, II, pp. 654-655, on 1. 30) cites Erfurt's reading as the key to understanding the reading of Vienna. Erfurt reads $k w l w$ smr hgmlyn $w k w l w$ smr 'rnbyym for Vienna's $s m r$ gmlym kwlw wkwiw smr 'rnbyym, and so clarifies the latter's reading by placing the first $k w \tau w$ at the outset of the phrase. For various other readings of $\mathrm{E}, \mathrm{cf}$. Lieberman, ibid.

22 For the commentaries which add the same phrase, cf. Lieberman, TK, II, p. 655 , on 1.31 .

${ }^{23}$ For the secondary question (generated by this reading) of whether $\mathrm{E}$ applies only when the threads touch one another (Sens) or even when the threads are at opposite end of the shirt (Maim., Code, Diverse-Kinds 10:9), cf. Lieberman, TK, II, pp. 655-656, on 1. 31 .

24 According to the reading of Erfurt and sens the flax is first hackled with the camel's hair, and the combined fibers and then mixed with wool. This reading, though, does not differ in substance from that of vienna.

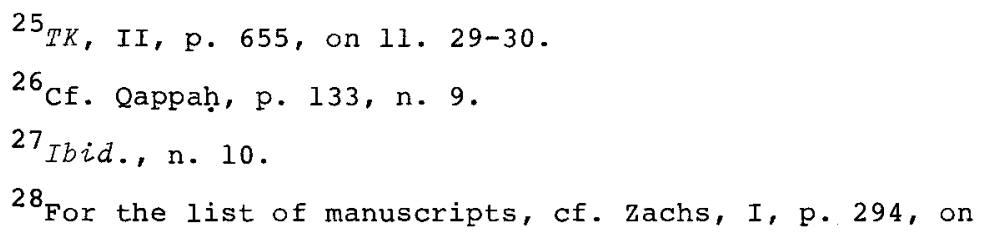
1. 8 .

${ }^{29}$ Classical sources describe a silk, known as amorginon, as being similar to linen. For such sources, cf. Forbes, p. 52. Forbes cites the description of this silk as given in the lexicon Suidas: 
Amorginon is like linen and very dear. .

Amorgis is like unhackled linen, they strip

it and work it. It is much finer than cotton

(byssos) or linen (karpasos).

${ }^{30}$ Maimonides (Code, Diverse-Kinds 10:1) and TYY offer both interpretations, which, of course, do not mutually exclude one another.

${ }^{31}$ Alternatively, the rule of $C-D$ may be based on an exegesis of LV. 19:19 (Sens and others, following Sifra Qedoshim $4: 18 \mathrm{~b}$ and B. Yoma 69a). C takes the phrase Nor shall there come upon you to imply that it is prohibited to place diverse-kinds only upon, but not under, one's body, so that one is permitted to sit or lie on mattresses or cushions of diverse-kinds, D then states that one may not allow his flesh to touch the mattress or cushions, lest a fringe of diverse-kinds wrap itself around the flesh. In that case diverse-kinds would rest upon the body, and one would transgress the prohibition of Nor shall there come upon you. This interpretation is somewhat difficult, however, for it does not explain why one is prohibited specifically from touching diverse-kinds. According to this explanation one should also be liable if a fringe of diverse-kinds were to wrap itself around a covered part of the body, for in this instance as well the fringe would lie upon the body. We therefore prefer the interpretation given above in the text.

$$
\begin{aligned}
& 32_{T K}, I I, \mathrm{p} .662 \text {, on } 1.51 . \\
& 33_{T K}, I I, \mathrm{p} .662 \text {, on } 11.51-52 .
\end{aligned}
$$

${ }^{34}$ We assume that the mattresses and cushions are also composed of linen, for if they were made of wool one could not attach a linen border to them. In such a case one would be concerned lest someone think them to be composed entirely of wool and so unknowingly allow his skin to touch diverse-kinds (Cf. M. 9:2D). If the mattresses and cushions are made of linen, on the other hand, one may use them even if they appear to be bordered with wool, as long as he does not allow his flesh to touch them.

$$
{ }^{35} \mathrm{Y} \text { 's version reads as follows: }
$$

A. R. Neha b. Sabbah, R. Yohanan in the name of R. Zecira [say], "For if there was a large garment--

B. "one end of it contains diverse-kinds and rests on the ground, and the [other] end of it does not contain [diverse-kinds]--

c. "he shall not cover himself with the other side [i.e., with the end which does not contain the diverse-kinds]."

$Y$. thus differs from $T$. mainly in that it describes the garment as being large, and incorporates the gloss of T. $5: 13 \mathrm{C}$ into the description of the case at $B$.

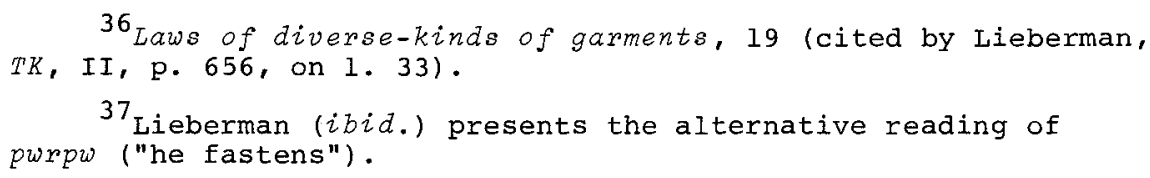


${ }^{39}$ This is apparently the view of HD (for the discussion of this issue in M., of. M. Shab., Chapter Six). Alternatively, Lieberman (TK, II, p. 657, on 11. 34-35) maintains that if the shirt were only fastened together, one would be liable for carrying not the thread, but the torn end, from one domain to the other on the Sabbath. According to his interpretation, then, the point of $D$ concerns not whether or not the thread is considered to be connected to the shirt, but whether or not the torn end of the shirt is considered to be attached to the rest of the shirt. While this explanation is possible, we consider it to be more likely that the issue of $\mathrm{D}$ is identical to that of $\mathrm{C}$, so that both rules concern whether or not the thread is regarded as part of the shirt. We therefore prefer the first interpretation given above.

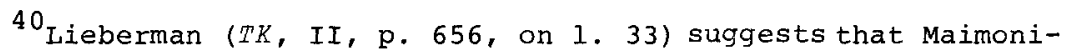
des' text of $T$. was probably similar to that of Rosh (who, in fact, cites Maim., Code, Diverse-Kinds 10:10 in support of his reading).

${ }^{41}$ We note that both Maimonides and Rosh omit reference to $B$ and $D$.

${ }^{42} \mathrm{Cf}$. also the version of Rabbenu Tam (presented by Lieberman [citing Ravyah] TK, II, p. 656, on 1. 33) which reads $A$ as follows:
A shirt [of wool] which was torn and he
fastened it [i.e., the shirt] [together] with a thread [of flax]--it [i.e., the shirt] is prohibited.

This version omits the phrase "if he sewed it," and so reads $A$ and $C$ as a single rule. According to this reading one is prohibited even from fastening together the torn ends of a woolen shirt with a thread of flax. The rule of this version thus clearly opposes that given by the version of Rosh.

$$
43 \mathrm{TZ}, \mathrm{p} .224 \text {, on } 1.36 \text {, and } T K, \mathrm{II}, \mathrm{p} .657 \text {, on } 1.36 \text {. }
$$

44 According to Lieberman ( $T K$, II, p. 657, on 1.36 ) this reading is found in the oldest printed edition and in the manuscripts of the code (in place of the present reading of $y k r w k$ ). The reading of Rosh is also cited by Lieberman.

${ }^{45}$ Following Lieberman, $T 2$, p. 224 , on 1.36 , who takes trp to be synonymous with krk.

$$
\begin{aligned}
& 46_{T Z,} \text { p. } 224 \text {, on } 1.36 \text {, and } T K, I I, p .657 \text {, on } 1.36 \text {. } \\
& 47_{T K}, I I, p .657 \text {, on } 1.36 \text {. } \\
& 48_{\text {We note that Finkelstein (p. 265, on } 1.11 \text { ) considers }}
\end{aligned}
$$
this pericope to be part of a marginal gloss of sifre.

${ }^{49} \mathrm{Cf}$. Sifre Dt. $230 \mathrm{k}$ for a similar exegesis of the word together in Dt. 22:10 (You shalt not plow with an ox and an ass together).

50 According to Sens' version of $Y$. the scroll-wrapper may also be placed on one's lap (under the scroll) and thus may serve to warm the lap.

$51_{T Z}$, p. 224 , on 1. 36. Cf. also $T K$, II, pp. $657 f$., on 11 . 36-37, where Lieberman describes bl'ry $n \bar{\varepsilon} y m$ as sheets, and identifies them with the Greek Badvapia or Bavıapla. 
52

Y. reads as follows:

R. Abbahu in the name of R. Yohanan says,

"Women's bath-towels (b $2 n r y$ n $y y m$ ) àre prohibited on account of [the laws of] diverse-kinds."

$Y$. thus disagrees with $A$, perhaps following Eliezer's view

(M. 9:3B) that bath-towels are subject to the laws of diverse-kinds.

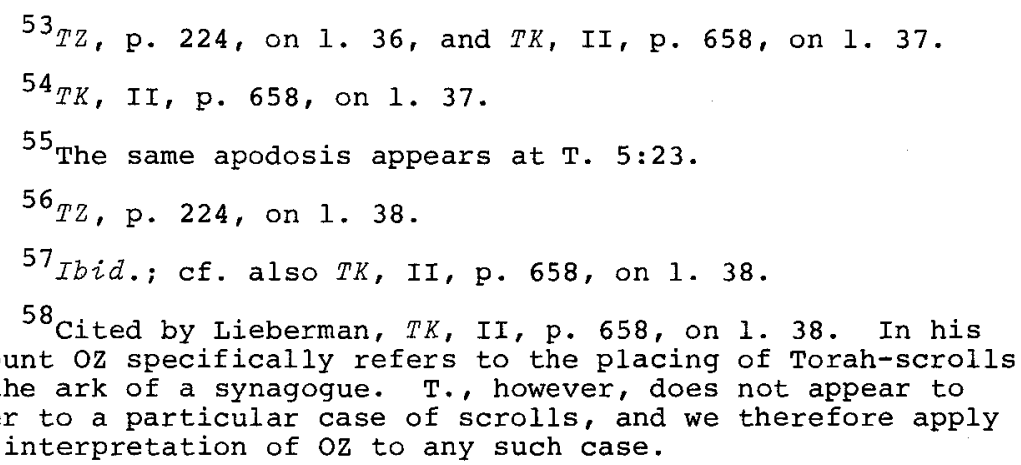

${ }^{59}$ We note that the dispute of $B-E$ attests that of $M .9: 3 A-B$ to Usha, so that the Eliezer of M. is clearly a Yavnean (Neusner, Eliezer, I, p. 39).

60 Alternatively, the rule of $B$ may be based on an exegesis of Lv. 19:19. According to Albeck B may take the phrase Nor shall there come upon you [a garment of cloth composed of two kinds of stuff (LV. 19:19) ] to mean that one may not bear diverse-kinds on his body in any manner at all. One may therefore not place a pack-saddle of diverse-kinds on his shoulder, even though the pack-saddle is not designed to be worn by man. This interpretation is somewhat difficult, however, for it does not allow for the importance of $\mathrm{C}$ (and for the force of ' $p$ ). If the point of $B$ is that one is not permitted to bear diverse-kinds at all, then C's point, that he may not put a pack-saddle on his shoulder even to carry out the dung, becomes obvious, and serves only to illustrate $B$. We therefore prefer the first interpretation given above, according to which $C$ refers to the intention of the bearer of the pack-saddle, and thus introduces a new consideration into the pericope.

${ }^{61}$ Cited by Lieberman, $T K$, II, p. 659, on 1.42.

62 Ibid.

$63_{T K}$, II, p. 659, on 1. 43.

${ }^{64}$ For other readings, cf. Zachs, $I$, p. 297 , on 1.17.

${ }^{65} \mathrm{Cf}$. his note to T. Kel. B.B. 5:Il, in Die Tosefta

(Stuttgart: Kohlhammer, 1960), VI.1, p. 172, n. 42.

${ }^{66}$ For other readings, cf. Zachs, I, p. 298, on 1. 17.

${ }^{67}$ In the Code Maimonides speaks simply of a shoe which is composed of diverse-kinds, and we therefore take him to refer to a cloth shoe. Cf. also Ridbaz, who cites Maimonides' reference to slippers in the latter's Commentary and maintains that Maimonides refers to the same type of slippers in the Code (for the citation of the passage in the Code, see below, n. 76). 
${ }^{68}$ For the list of manuscripts, cf. Zachs, I, p. 298, on 1.19.

${ }^{69}$ According to this interpretation, pynwn is derived from the Greek rivos, which means dirt or filth. In this instance pynwn refers to coarse wool which contains dirt or foreign substances (cf. S. Krauss, Talmudische Archaeologie [Leipzig: G. Fock, 1910], I, p. 628, n. 712). Alternatively, mncly hpynwn may refer to shoes made of pinna (cf. Krauss, ibid.), a fiber produced by the mollusk Pinna nobizis (cf. J.P. Wild, Textize Manufacture, p. 20). According to this explanation the point of $A$ apparently is that one must examine the shoes in order to be certain that they are actually composed of pinna, and not of a mixture of wool and flax. It is not clear, however, why these shoes in particular have to be examined for diverse-kinds. We therefore prefer the first interpretation given above, for according to that explanation (as we shall see), the reasoning behind the rule for the mncly hpynwn follows that of the rule for the birrus and bardaicus.

${ }^{70} \mathrm{Cf}$. T. Kel. B.B. 5:11, which states that the birrus and the bardaicus were composed of heavy or thick material. Cf. also T. Neg. 5:14, which also implies that these two types of cloaks were composed of heavy material.

$71_{\text {The birrus was a cloak which apparently also had a cowl }}$ (cf. L.M. Wilson, The Clothing of the Ancient Romans [Baltimore: Johns Hopkins Press, 1938], pp. 125ff. henceforth: Clothing). We assume that the bardaicus is identical with the bardocuculius, a hooded cloak named after the Bardaei, a people of Illyria (cf. wilson, ibid., p. 85; cf. also Krauss, Talmudische Archaeologie, I, p. 611, n. 586).

72 For the composition of the birrus, cf. Edict of Diocletian 19.25ff., which in fixing prices for different type of garments, lists the birri only among the woolen garments (cf. The Edict of Diocletian, trans. S.R. Graser, in Tenney Frank, ed., An Economic Survey of Ancient Rome [Baltimore: Johns Hopkins Préss, 1940], $\mathrm{v}$, pp. $374 \mathrm{ff.}$.). For the composition of the bardaicus, cf. Wilson, clothing, p. 95, who cites an epigram of Martial $(1,53)$ referring to a bardocuculius composed of greasy wool.

${ }^{73} \mathrm{Cf}$. Edict of Diocletian, 19.28-31 (trans. Graser, ibid., p. 374), which lists dalmatics of wool, and Edict, 26.5ff. (trans. Graser, pp. $390 \mathrm{ff}$.), which lists dalmatics composed of linen.

${ }^{74}$ Yose's saying clearly assumes that all of the garments of $A$, including the dalmatic (and the shoes of $A(4)$ ) were composed of wool. Alternatively, yosé may gloss an earlier version of the list which did not contain the dalmatic (or the shoes of $A(4)$, if these are taken to refer to shoes of pinna). Since the identities of the final two items of $A^{\prime}$ 's list are not certain, it is not possible to make a definite statement concerning the relationship between $\mathrm{A}-\mathrm{B}$ and $\mathrm{C}-\mathrm{D}$.

75 The extent to which this assumption accords with our knowledge of the clothing industry in the Roman Empire is not clear. While it is probably true that hemp was cheaper than flax in many places, it is also true that by the first century A.D., flax was grown even in the western provinces (cf. Pliny, Historia Naturalis $19.27 \mathrm{ff}$, who refers to flax which was grown in spain and Gaul). Our evidence thus does not give us reason to believe that hemp was regularly substituted for flax in the manufacture of clothing (for a survey of cloth manufacture in the Roman Empire, cf. A.H.M. Jones, "The Cloth Industry in the Roman Empire," 
reprinted in P.A. Brunt, ed., The Roman Economy [Oxford: Basil Blackwell, 1974], pp. 350-364). We note, however, that Egypt and syria were known for their fine linens, which were exported throughout the empire (cf. Wild, Textile Manufacture, p. 15). It is possible, then, that knowledge of such trade led to the supposition that flax was not readily available in distant lands. We repeat, however, that our evidence does not allow us to make an accurate judgment of this assumption.

${ }^{76} \mathrm{Cf}$. Ridbaz, who raises a similar consideration. Maimonides himself presents a different reason for $\mathrm{E}$ (Code, Diverse-Kinds $10: 15)$ :

A shoe which is [composed of] diverse-kinds and lacks a heel--it is permitted to wear it. For the skin of the [sole of the] foot is hard and does not receive comfort [from the shoe] like the rest of the body.

It is not clear, however, that the foot receives no comfort from the sole of the shoe (cf. Sirillo's comment [cited by Zachs, I, p. 298, n. 32]), and it is thus difficult to accept Maimonides' interpretation (cf. also the objections discussed by Ridbaz). We therefore prefer the interpretation given above in the text.

${ }^{77}$ Cf. T. Kil. 5:16, which states that a women's bath-towel is not considered a garment unless it is sewn together at the ends and thus designed to stay on the body.

78 Alternatively, following Y. Kil. 9:5, Ribmaș, Sens and Rosh maintain that $\mathrm{E}$ refers to a cloth-lined shoe. According to this interpretation the point of $\mathrm{E}$ is simply that one need not be concerned lest the lining of the shoe contain diverse-kinds. It is not clear, though, why one should assume that such a lining is free of diverse-kinds. We therefore prefer the interpretation of Maimonides given above.

${ }^{79}$ B. Yev. $5 b$ and B. Nid. 61 a discuss whether $B$ refers to three separate acts of combining diverse-kinds or to three parts of a single process (i.e., the wool and flax must be hackled, spun, and woven together in order to be prohibited as a mixture of diverse-kinds). We maintain that it is more likely that $B$ refers to three separate acts, for otherwise $A$ and $B$ would completely oppose one another. While A would maintain that wool and flax must be spun and woven together in order to be regarded as a mixture of diverse-kinds, $B$ would argue that these fibers must be hackled together as well. Now it is true that, according to our interpretation, $A$ and $B$ also disagree, but at the same time they also agree concerning wool and flax which is spun or woven. It is therefore possible to explain why B was placed after A. According to the alternative interpretation, however, no such explanation is possible, for A and B simply oppose one another. We therefore prefer the interpretation given above in the text (for a summary of the views of the commentaries, cf. Albeck, p. 372).

${ }^{80} \mathrm{Cf}$. Lieberman (TZ, p. 225, on 1.47), who explains that Simeon b. Eleazar reads śctnz as $\xi^{e} t z_{z}$ and so derives mlyz from the latter ( $I \omega z$ does not appear in T.). Alternatively, Albeck suggests that simeon b. Eleazar simply adds a $l$ to $n w z$ and so reads it as $n i w z$.

${ }^{81}$ Alternatively, most commentaries consider the subject of $n l w z$ and mlyz to be the wearer of diverse-kinds. We assume, however, that Simeon b. Eleazar simply continues $B$, and so depends on the latter for its subject, which is "something" composed of 
diverse-kinds. We therefore agree with the interpretation of Albeck (cf. also T. $5: 21 \mathrm{~b}$ ).

$$
82 T Z, \text { p. } 225 \text {, on } 1.46 \text {. }
$$

${ }^{83}$ This interpretation of $T$. assumes that the weaving described in $A$ is done on a warp-weighted loom. We note, however, that such looms were usually operated with weights (e.g., of stone), so that it is not clear whether our interpretation of $T$. accords with our knowledge of weaving techniques. We see no better explanation of $T$. , however, and therefore present this one as the most plausible explanation.

${ }^{84}$ The point of weighing down the wool is not only to keep it in place, but also to keep all of its threads under the same degree of tension, as Forbes explains (p. 198):

The spacing of the warp threads on the loom governs to a large degree the texture of the fabric to be woven. Their tension must be uniform or else the fabric will be uneven.

${ }^{85}$ Cited by Lieberman, $T K$, II, p. 660 , on 1. 46. Sens actually takes A to mean that one places both wool and flax on a warp of another kind so that the weaver ( $h^{\prime} w r g$ ) will not lose the threads of the warp (his language is somewhat difficult at this point). We maintain, however, that $A$ describes a case in which the wool is used for the warp, so that the flax is attached to it in order to weigh it down.

${ }^{86}$ Alternatively, Lieberman (ibid.) maintains that A concerns wool which is being combed in order to be spun. The point of $B$, then, is that in combing wool one may accidentally mix it with some of the flax which lies under it, and thus spin wool and flax together. Lieberman apparently takes A to mean that the wool is being prepared for weaving, i.e., it is being spun. The phrase thywt 'wrg clyw, though, implies that the wool has already been prepared for weaving, and thus has already been spun. We therefore prefer the interpretation given above in the text.

${ }^{87}$ It is not clear whether one pericope depends on the other. We have already shown (cf. Our discussion of M. 9:8) that $M$. does not provide the original context of the exegesis of shacatnez, so that it is possible that M. cites Sifré, to which an exegesis of a verse in Dt. is surely appropriate. It is not possible to prove such dependence, however, and it is therefore difficult to arrive at a definite conclusion concerning the relationship between $M$. and Sifre in this instance.

${ }^{88}$ We note that Sifra Qedoshim $4: 18$ a asks the same question as does A-B, but answers it by citing the word garment (Lv. 19:19), which it takes to exclude pieces of wool and flax from the prohibition.

$$
\begin{aligned}
& { }^{89} \text { For the list of manuscripts, cf. Zachs, I, p. } 301 \text {, on } 1.23 . \\
& { }^{90} \mathrm{Cf} \text {. Zachs, I, p. } 301 \text {, on } 1.24 . \\
& { }^{91} \text { our translation here follows that of Blackman. } \\
& 92 \text { y. presents E as an anonymous saying. }
\end{aligned}
$$

${ }^{93}$ Cf. Wild, Textize Manufacture, p. 60: "Felt consists of a sheet of compressed woollen or other fabrics, not spun, but held together by the surface irregularities of the fabric alone." 
94 Alternatively, Maimonides (Comm.) takes mwlz to mean "twisted" (CF. MR, M. MaCas. 4:5). He thus understands F to say that threads of wool would be gathered together and twisted with threads of flax in order to make the cord. The point of E-F, then, is that the cords of purple wool are prohibited because they would be twisted, or spun, together with the flax. According to this interpretation, E-F serves to illustrate M. 9:8A-B's prohibition against wearing wool and flax which have been spun together. This explanation of $F$, however, is not as plausible as the one presented above in the text. The term mwli appears to refer to an act which is done immediately before the cord is tied. It is thus more iikely that mwll refers to the basting of the cord, which holds the cord in place until it is tied, than to twisting the threads of the cord, which is not directly related to the act of tying. We therefore prefer the first interpretation given above.

${ }^{95}$ Some commentaries (e.g., Sens, Rosh, TYY) maintain that one may not attach strips of wool and linen to opposite ends of a leather strap because one must still connect the strips together in tying the belt. According to this interpretation, however, the gloss of $\mathrm{H}$ is pointless, for if the strips are to be connected when the belt is tied, it makes no difference whether or not they are directly connected when the belt is not tied (MS). We therefore prefer the first interpretation given above, according to which $\mathrm{H}$ introduces the issue of (indirect) connection.

${ }^{96}$ The reading of $s r q$ is also found in Ms. Munich of $\mathrm{M}$.

${ }^{97}$ We note that Finkelstein (p. 265, on 1. 11) considers $W-X$ to be a marginal gloss of sifre.

${ }^{98}$ We here follow the word order of the MT, rather than that of the RSV (Nor shall there come upon you a garment of cloth made up of two kinds of stuff).

${ }^{99}$ Cf. Sifre Dt. 232a, which bases the same rule concerning pieces of shorn wool and stalks of flax on the exegesis of shacatnez, maintaining that the pieces of wool and flax are neither hackled, spun, nor woven together.

100 The relationship between Sifra and $M$. here is not clear. We note that while Sifra at G-H presumably bases its exegesis of shacatnez on LV. 19:19, M. 9:8B cites Dt. 22:11 in its version of the same exegesis. It is thus not likely that $M$. here cites Sifra, for $M$. would have no reason to change the verse of the exegesis from Lv. 19:19 to Dt. 22:11. It follows, therefore, either that Sifra cites M. or that both Sifra and M. know the exegesis without one being dependent on the other. Now since Sifra knows M. 9:9A-B's rule concerning felted stuffs and links this rule to the exegesis of shacatnez, it is likely that sifra knows the exegesis as well from M., and that sifra has simply changed the verse of the exegesis from Dt. 22:11 to Lv. 19:19 (for the relationship between $M$. and Sifré Dt. $232 a$, cf. above n. 87).

${ }^{101} \mathrm{Cf}$. his translation of B. Shab. $54 \mathrm{a}$ in The Babylonian Talmud: Seder Moced (London: Soncino, 1938), I, p. 249.

${ }^{102}$ Cf. M. Shab. $7: 2,13: 2$.

${ }^{103}$ For the rule of I, cf. M. Shab. $7: 2$ (cited by Albeck). 
104 TZ, p. 225, on 1. 44. Both in $T Z$ and in $T K$ (II, p. 660, on 1. 44), however, Lieberman states that he does not know the meaning of $c_{y t}$, and that his identification of the item as a wrapper is only a suggestion.

105 We note that, whether T. complements M. 9:10B-I alone, or links the latter to M. $9: 9 \mathrm{C}-\mathrm{D}$, it is not clear why $T$. was redacted between $T$. 5:19, which complements $M .9: 4$, and T. 5:21, which comments on M. $9: 8$.

106 We here follow Lieberman's identification of pwqryt syph (TZ, p. 225, on 1. 49, and TK, II, p. 662, on 1.49). Alternatively, HD (following Rashi, B. Shab. 50a, s.v. pwqryn wsyph) maintains that pwqryt refers to pieces of combed flax, and that a syph is a piece of beaten wool. According to HD the point of $A$ is that one is permitted to wear a pwqryt and syph together on a wound, for the two items are not considered to be connected and to form a garment of diverse-kinds. (He also notes that the two strips now receive uncleanness as a utensil, for they were already considered garments before being joined.) We maintain, though, that $B$ refers to tying together the ends of each item (as in T. 5:16), and not to tying the two items together. We therefore prefer the first interpretation given above in the text.

on 1.5$)$.

${ }^{107} \mathrm{Cf}$. his comment to T. Shab. $5(6): 2$ (TK, III, p. 72,

${ }^{108}$ Cf. T. Shab. $5(6): 2$ (cited by Lieberman, $T K$, II, p. 662, on 1. 49), which states that one may bear tufts or strips of wool from one domain to the otheron the Sabbath only if the wool is dyed in oil (apparently to make it clear that it serves as a garment [cf. Rashi, B. Shab.50a, s.v. bamn șspn bsmn]) and tied together with a cord.

${ }^{109}$ We assume that, as in the case of $T .5: 16, T$. refers to midras-uncleanness, to which the tufts and strips are not susceptible because they are used only to cover wounds. Cf. Lieberman, $T K$, II, p. 658, on 1. 37 .

110 Alternatively, Lieberman (TK, II, p. 662, on $11.49,50)$, referring to Sifre, maintains that $A$ concerns pieces of wool which have not been hackled, and thus do not come under the laws of diverse-kinds (M. 9:8B), even if they are tied together with cords of flax. The point of B-D, then, is that pieces of wool which are sewn together are considered to form a garment, and thus are prohibited because of the flax which they contain. It is not clear, however, how unhackled wool can be subject to the laws of diverse-kinds at all. In addition, $T$. makes no mention of cords of flax which may be used to tie the pieces of wool together. We therefore maintain that the issue of $T$. concerns not whether or not the wool is hackled, but, as in the case of T. 5:16, whether the specified items are regarded as garments. 
SOURCE INDEX

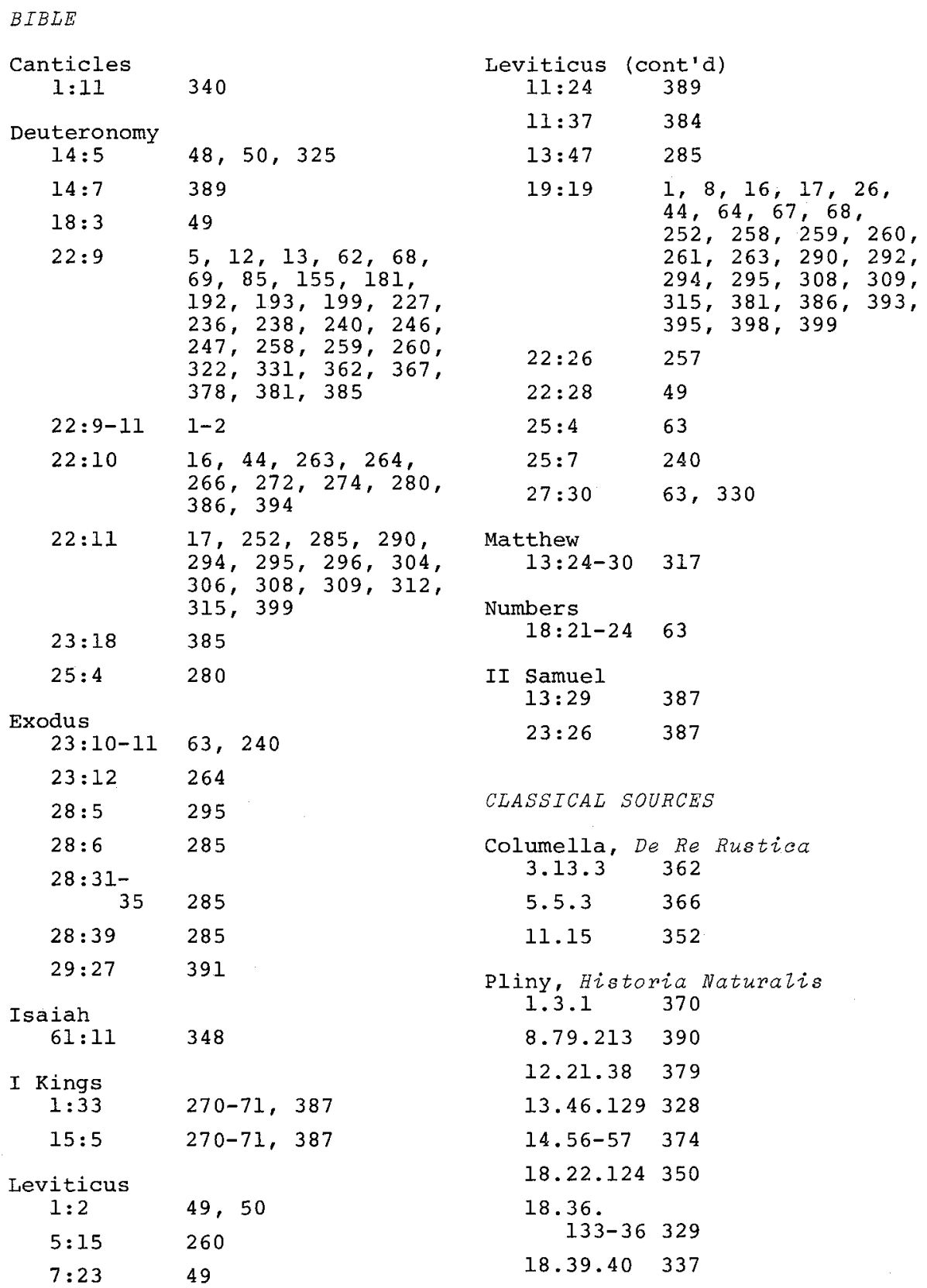




$\begin{array}{ll}\text { Historia Naturalis (cont'd) } \\ 18.49 .182- & 335 \\ 183 & \\ 19.16-18 & 391 \\ 19.24 .69 & 352 \\ 19.27 & 396 \\ 19.32 .105-7 & 352 \\ 19.54 .170 & 343 \\ 20.163 & 370\end{array}$

Theophrastus, Historia Planetarum

$\begin{array}{ll}1.3 .1 & 370 \\ 1.7 .3 & 329 \\ 2.5 .5 & 327 \\ 4.2 .1 & 374 \\ 4.7 .7 & 379 \\ 7.1 .2 & 352 \\ 8.5 .1 & 350 \\ 8.11 .8 & 329\end{array}$

Varro, Rerum Rusticarium 2.8 .6 338

MISHNAH

Baba' Batra'

$\begin{array}{ll}2: 3 & 333 \\ 6: 7 & 346\end{array}$

Baba' Mesica' $4: 11$

$7: 9$

368

Baba' Qamma' $5: 7$

46

Bekorot

$1: 2 \quad 389$

Bikkurim

$\begin{array}{ll}1: 1 & 343 \\ 1: 9 & 362 \\ 2: 4 & 362 \\ 2: 8 & 258 \\ 2: 8-11 & 388 \\ 2: 11 & 258\end{array}$

Demai

$\begin{array}{ll}1: 1 & 320 \\ 5: 10 & 383\end{array}$

$\begin{array}{rl}\begin{array}{c}\text { CEduyyot } \\ 5: 2\end{array} & 154 \\ \text { CErubin } & \\ 1: 8 & 343 \\ 1: 9 & 207,208,372 \\ 1: 10 & 207,213,214,372 \\ 2: 1 & 346 \\ 2: 5 & 111,112,346 \\ 7: 2 & 343 \\ 7: 3 & 343 \\ 10: 8 & 343,344 \\ \text { Hallah } & \\ 1: 3 & 255,382 \\ \text { Kelim } & \\ 1: 1 & 274 \\ 1: 2 & 273,274 \\ 1: 4 & 273 \\ 17: 14 & 389 \\ 23: 2 & 372\end{array}$

Kilayim

$1: 1$

$5,25,26,30,31$, $33,38,39,321$

$1: 1-3 \quad 25,26,27,30,34$, $35,38,39,321$

$1: 1-4 \quad 5$

$1: 1-5 \quad 25$

$1: 1-6 \quad 5,25,44$

$1: 1-7: 8 \quad 5$

$1: 2$

$5,25,28-29,30$, $31,32,38,39$, $40,41,316,318$, 321

$1: 3$

$25,32-33,34,39$, 319,329

$1: 4 \quad 5,25,35,36,37$, $38,319,326$

$1: 4-5 \quad 44$

$1: 4-6 \quad 6$

$1: 5 \quad 5,25,27,37,38$, $39,40,41,43$, $44,321,329$

$1: 5-6 \quad 25$

$1: 6 \quad 5,25,43-44,45$, $46,47,268,269$, $276,324,386$, 389 
Kilayim (cont'd)

$\begin{array}{ll}1: 7 & 6,25,35,50-51, \\ & 52,53,56,58, \\ & 59,60,61,62, \\ & 142,329 \\ 1: 7-8 & 25,51,61,62, \\ & 232,244 \\ 1: 7-9 & 6 \\ 1: 8 & 6,25,50,52-53, \\ & 56-58,60,61,69, \\ & 369,370 \\ 1: 9 & 6,8,25,26,61, \\ 1: 9-2: 2 & 79 \\ 1: 9-2: 5 & 6-7 \\ 1: 9-3: 7 & 6-8 \\ 2: 1 & 71,72,73,77, \\ & 334\end{array}$

$2: 1-2 \quad 6,8,71,73,74$, 78,80

$2: 2 \quad 74,77,78,127$, 333,334

$2: 3 \quad 78-79,81,82,83$, $84,85,336$

$2: 3-4 \quad 79,87$

$2: 3-5 \quad 7,9$

$2: 4 \quad 71,79,84-85,86$

$2: 5 \quad 71,87,89$

$2: 6 \quad 7,9,72,90,91$, $92,101,107,108$, $138,139,338,339$

$2: 6-9 \quad 72$

$2: 6-11 \quad 9$

$2: 6-3: 3 \quad 7$

$2: 7 \quad 7,9,72,94,99$, $100,101,102,103$, $113,121,342$

$2: 7-8 \quad 9,72$

$2: 8 \quad 7,72,102,103,104$, $105,106,107,108$, $216,338,346,356$, 363,379

$2: 9 \quad 7,9,72,103,107$, $108,110,111,339$

$2: 9-10 \quad 104$

$2: 10 \quad 7,9,72,109,111$, $112,113,115,117$, $119,124,133,134$, $135,139,339,355$

$2: 10-11 \quad 9,72,73$

$2: 11 \quad 7,41,43,72$,
Kilayim (cont'd)

$\begin{array}{ll}3: 1 & 7,116,119,120 \\ 3: 1-2 & 9,115 \\ 3: 1-3 & 115,116 \\ 3: 2 & 7,9,118-19,121, \\ & 126,127,141,179, \\ 3: 3 & 180,349 \\ & 719,115,116, \\ & 117,122-23,124, \\ & 125,135,137,138 \\ & 139,205\end{array}$

$3: 4 \quad 8,115,116,124$, $125,126,129 ; 141$, $338,347,351,356$, 370

$3: 4-5 \quad 9,32,115,116$, 129,318

$3: 4-7 \quad 8$

$3: 5 \quad 8,115,116,126$, $127,128,347$

$3: 6 \quad 8,115,116,128$, $129,131,132,133$, $134,135,137,138$, $139,205,338,356$

$3: 6-7 \quad 9,116$

$3: 7 \quad 8,9,43,110,115$, $116,133-34,137$, $138,139,140,141$, $154,352,356,358$

$4: 1 \quad 12,107,135,145$, $146-47,149,177$, $204,222,363,380$

$4: 1-2 \quad 222$

$4: 1-3 \quad 145,146,147,149$, 158

$4: 1-4 \quad 9,12$

$4: 1-5: 4 \quad 9$

$4: 1-7: 8 \quad 9$

$4: 2$

$147,149,150,177$, $204,222,360$

$4: 3 \quad 145,147,149,150$, $151,343,371$

4:4 145, 151, 153, 207, $208,209,211,213$, $360-61,362,372$

$4: 5 \quad 10,12,135,146$, $154,156,157,181$, $183,201,203,204$, $216,232,367$

$4: 5-6 \quad 145$

$4: 5-7 \quad 145,159,165$ 


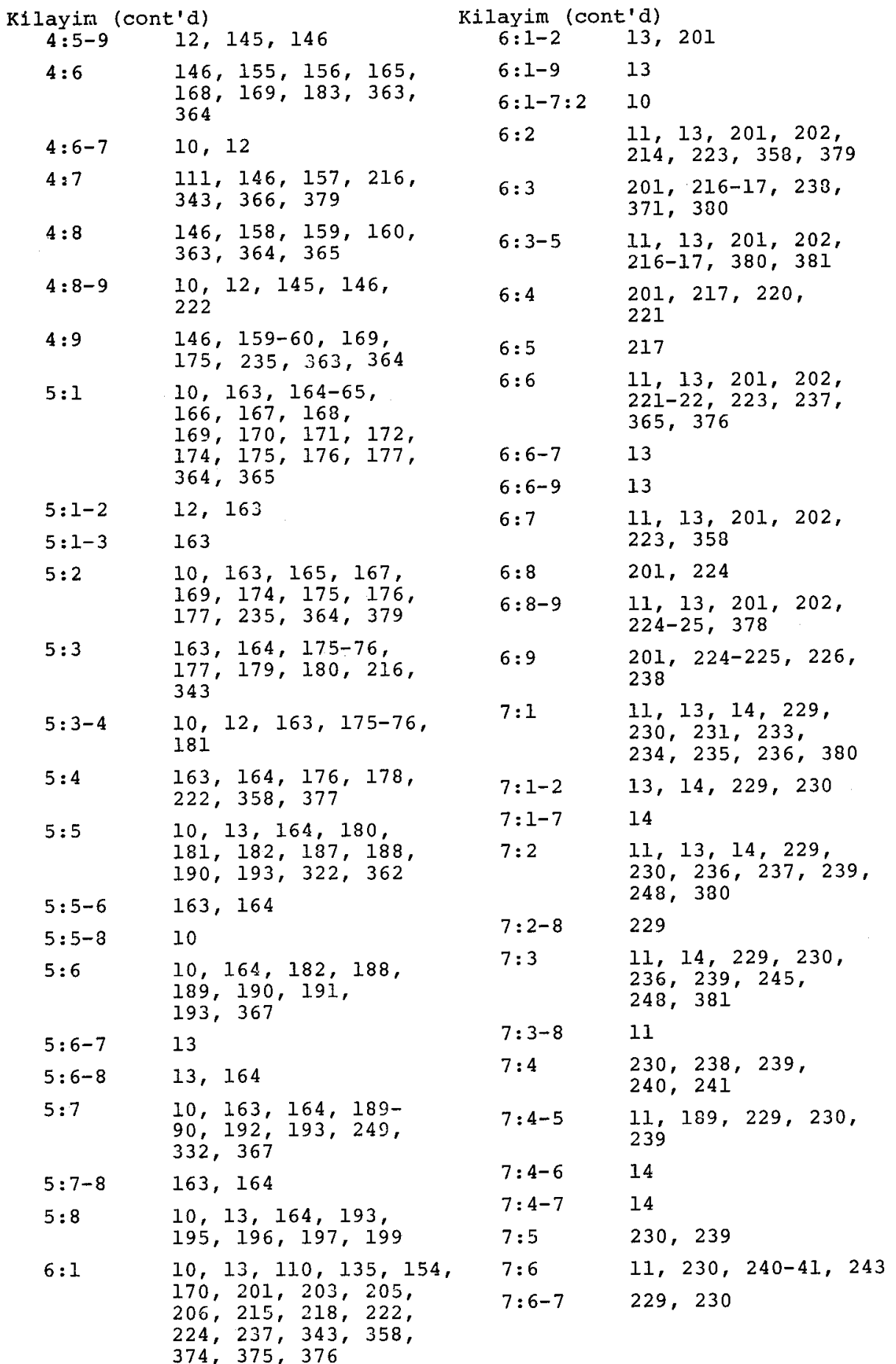




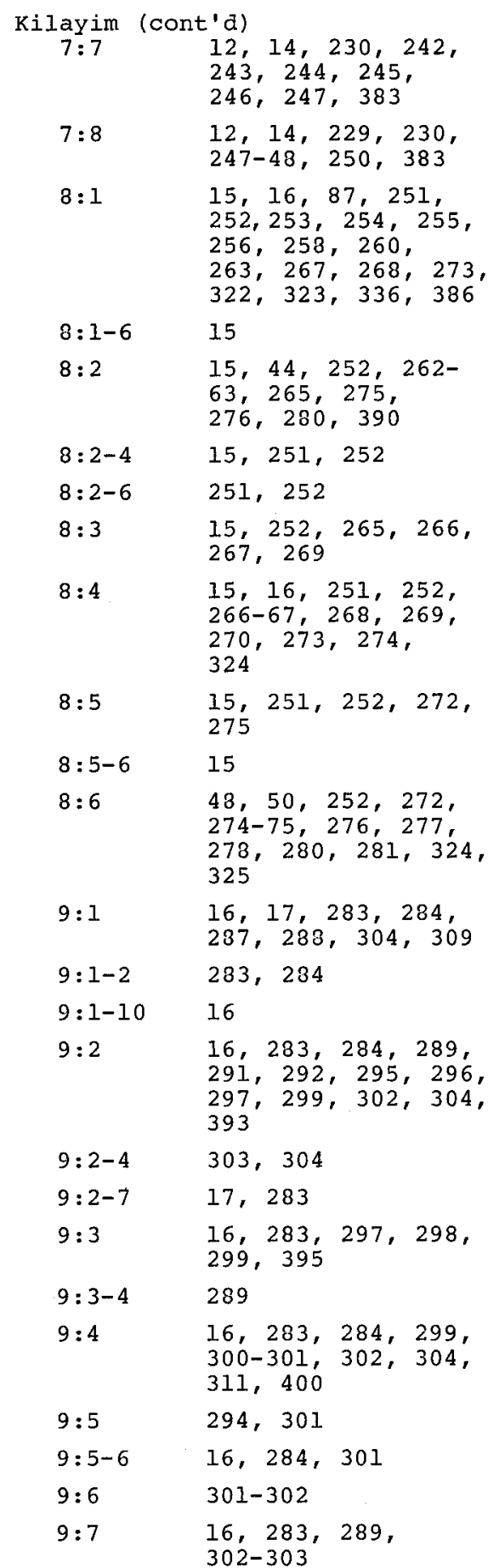

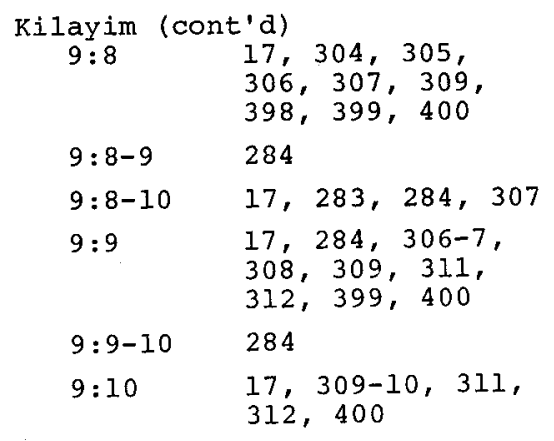

$\begin{array}{cl}\text { Macaserot } & \\ 1: 3 & 36,320,382 \\ 4: 5 & 399 \\ 5: 8 & 76\end{array}$

Ma ${ }^{C}$ aser Sheni

$1: 3-4 \quad 50,324$

Nazir

$7: 3 \quad 333$

NegaCim
$11: 2$

oholot

$1: 7 \quad 274$

$8: 1 \quad 42$

$8: 2 \quad 343,344$

$18: 2 \quad 110$

$18: 2-3 \quad 143$

$18: 3 \quad 375$

$18: 3-4 \quad 322$

${ }^{c}$ Orlah

$2: 1 \quad 249$

$3: 7 \quad 42,381$

Pe'ah

$2: 1 \quad 346$

$2: 3 \quad 363,366$

$2: 10 \quad 343$

Qiddushin

1:9

144,357

Shabbat

$1: 3 \quad 333$

$7: 2 \quad 399$

$9: 2 \quad 116,348$

$10: 4 \quad 333$ 


$\begin{array}{rr}\text { Shabbat } & \text { (cont'd) } \\ 10: 6 & 383 \\ 11: 2 & 343 \\ 13: 2 & 399 \\ \text { Shevi }^{c} \text { it } & \\ 1: 4 & 346 \\ 1: 6 & 346 \\ 1: 8 & 336 \\ 2: 8 & 351\end{array}$

Temurah $6: 1$

256

Terumot

333

$2: 6$

29,31

Tohorot

$1: 3$

389

Uqsin

$\dot{1}: 1$

322

$1: 6$

42,322

$2: 9$

383

$2: 10$

250

$3: 8$

250,384

Zebaḥim

$9: 3$

256

$14: 2$

256

TOSEFTA

'Ahilot

$15: 2$

187

$18: 4$

144

Baba' Meșica'

$$
8: 12 \quad 279
$$

Bekorot

$$
1: 9 \quad 278,389,390
$$

Erubin

$$
\begin{array}{rlrl}
2(3) & : 1 & 207,372 \\
2(3) & : 2 & 210 & \\
6(9) & : 13- & & \\
& 14 & 151,360-61
\end{array}
$$$$
7(10): 5 \quad 344
$$

Kelim, B. B.

$5: 11$

395,396

$6: 3$

391

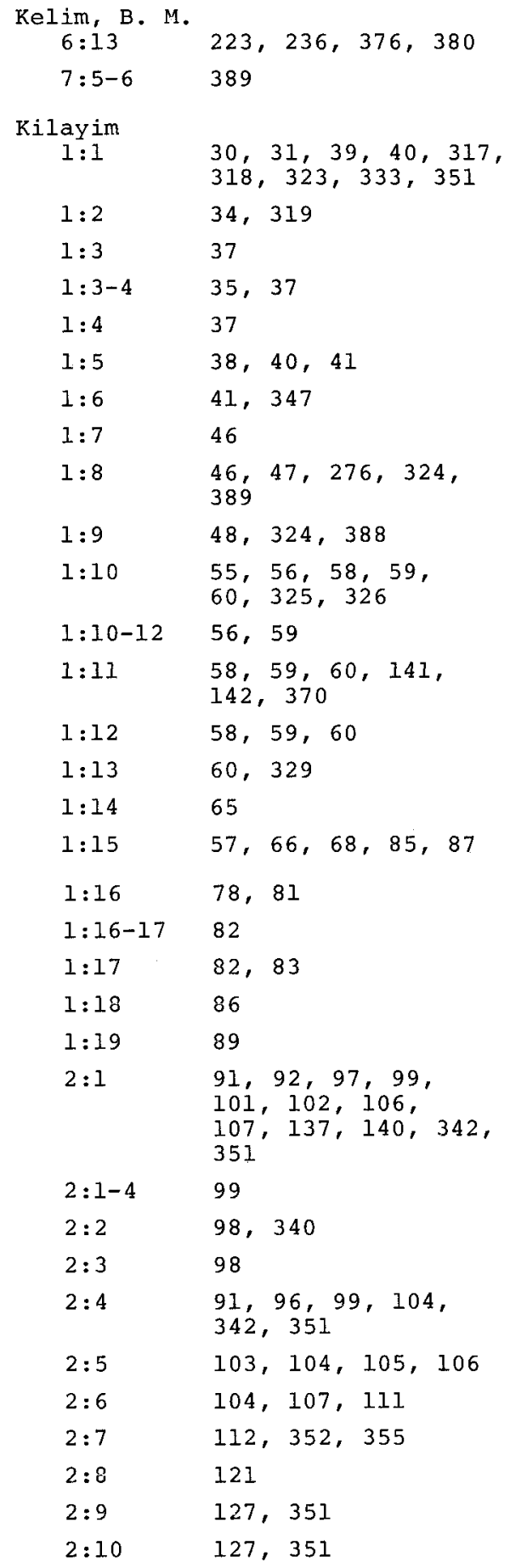




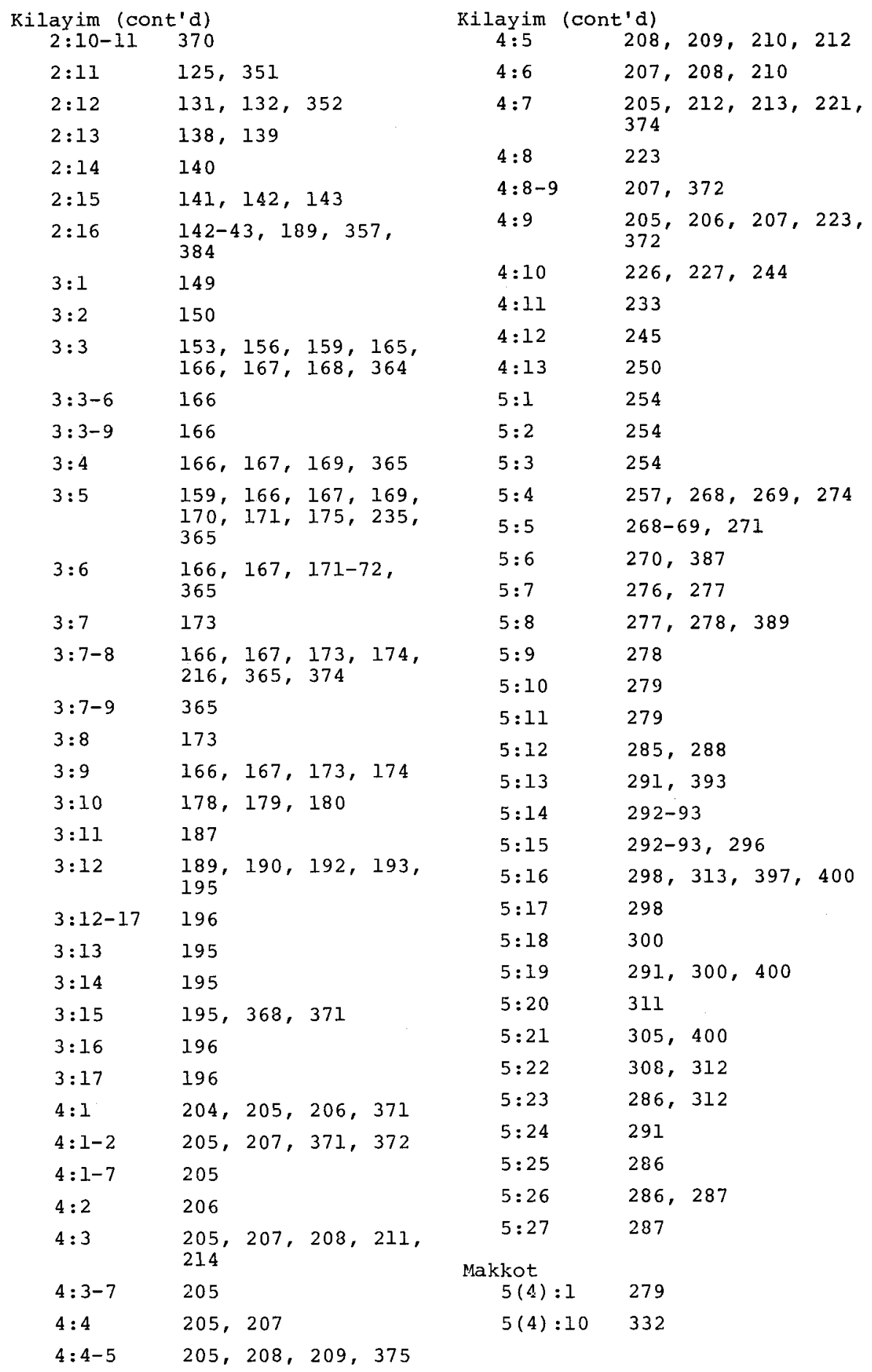




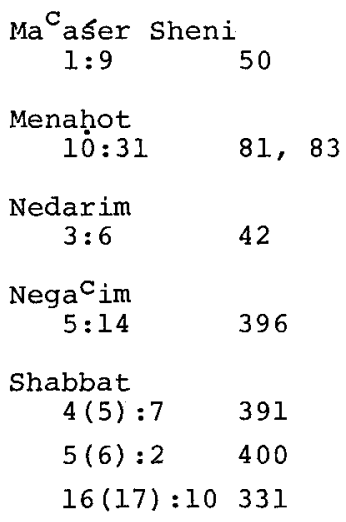

VIII : $8 \quad 325$

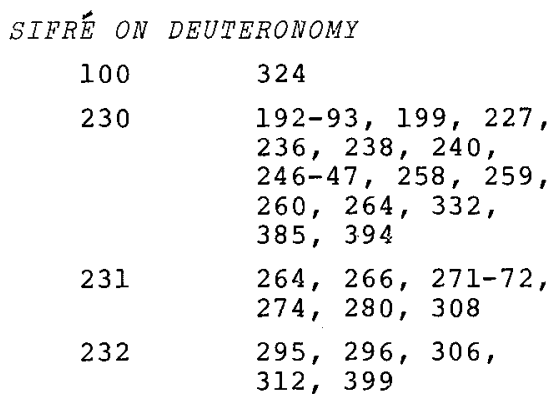




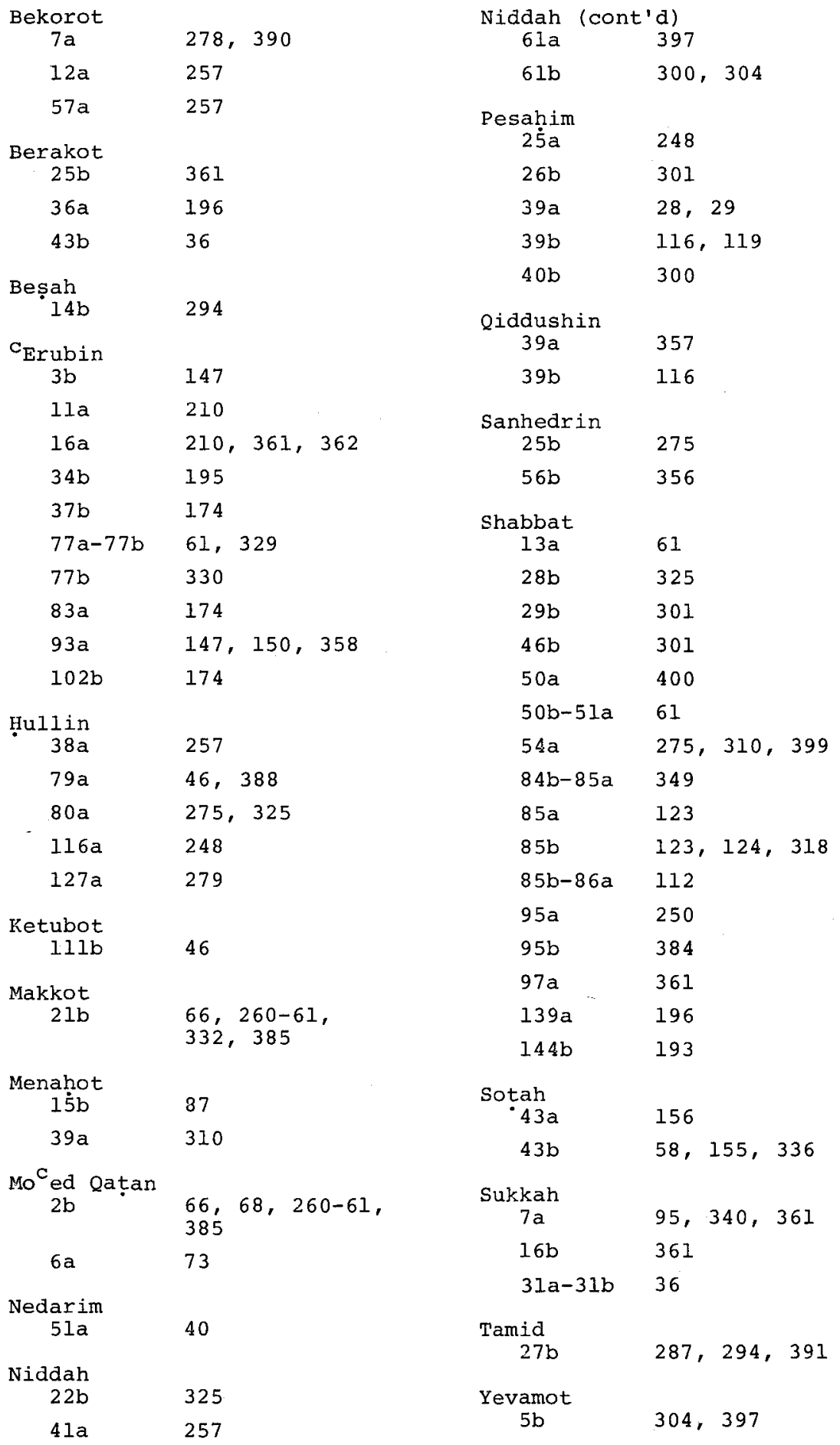




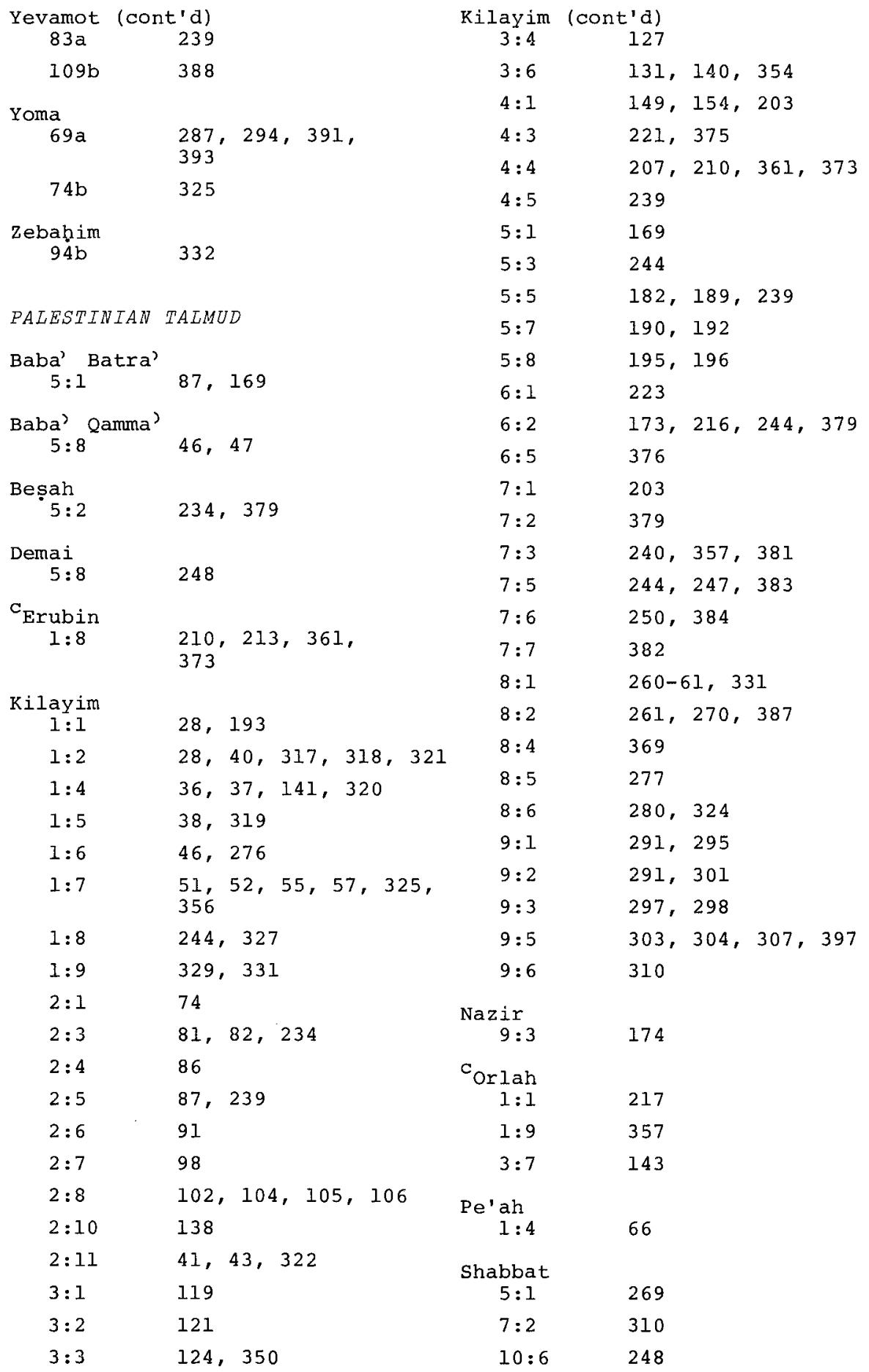




$\begin{array}{rr}\text { Shabbat } & \text { (cont'd) } \\ 13: 1 & 310 \\ 14: 1 & 279 \\ \text { Shevi }^{c} \text { it } & \\ 1: 3 & 174 \\ 3: 3 & 207\end{array}$

Sukkah

$1: 1 \quad 210,373$

\section{MAIMONIDES}

Diverse-Kinds

$1: 5 \quad 35$

$1: 6 \quad 68,370$

$2: 1 \quad 74$

$2: 7 \quad 76$

$2: 8-9 \quad 88$

$2: 10 \quad 88$

$2: 11 \quad 62,63,329$

$2: 13 \quad 80$

$3: 1-2 \quad 27$

$3: 3 \quad 317$

$3: 4 \quad 36$

$3: 5-6 \quad 321$

$3: 13 \quad 135,155$

$3: 15 \quad 102,103$

$3: 16 \quad 95$

$3: 17 \quad 101$

$4: 7 \quad 345$

$4: 9 \quad 347$

$5: 5 \quad 223$

$5: 7 \quad 322$

5:11 242

$5: 12 \quad 241$

$5: 17 \quad 367-68$

$5: 19 \quad 194,379$

$6: 1-2 \quad 182$

$6: 4 \quad 336$

$6: 14 \quad 225$

$6: 15 \quad 226$

$7: 1 \quad 135$

$7: 5 \quad 157$

$7: 6 \quad 214$

$\begin{array}{ll}\text { Diverse-Kinds (cont'd) } \\ 7: 7 & 156,362 \\ 7: 8 & 156,364 \\ 7: 9 & 166 \\ 7: 16 & 361 \\ 7: 22 & 176,366 \\ 8: 2 & 371 \\ 8: 8 & 215,374 \\ 8: 11 & 382 \\ 9: 4 & 44,45 \\ 9: 5 & 47,272 \\ 10: 1 & 289,290,393 \\ 10: 9 & 392 \\ 10: 10 & 293,394 \\ 10: 11 & 293 \\ 10: 15 & 303,304,397 \\ 10: 18 & 296 \\ 10: 19 & 391 \\ 10: 23 & 310 \\ \text { First-fruits } \\ 9: 1 & 49\end{array}$

Sabbath

25:14-15 64, 331 
GENERAL INDEX

Aaron Ibu Hayyim (QA), animals, commingling different kinds of, 261,386

Abbahu, fibers, commingling different kinds of, 395

Abba Saul, crops, sowing together different kinds of, 79,80 , 84,335 ;

vines, sowing crops among, 244, 245

Abba Yose b. Hanan of Vani, crops, sowing together different kinds of $91,92,93,99,101,339$

Abraham b. David of Posquières (Rabad), animals, commingling different kinds of, 386 ;

grafting, $62,63,329,330$;

vines, sowing crops among, $182,194,368$

Adeni, Solomon b. Joshua (MS), animals, commingling different kinds of, 44,275 ;

crops, sowing together different kinds of, 90, 94, 340, 352;

fibers, commingling different kinds of, 290,399 ;

vines, sowing crops among, 159, 190, 193, 214, 215, 238, 374,376

Albeck, H., animals, commingling different kinds of, 386 ;

crops, sowing together different kinds of, 107, 110,346, $349,351,356$;

fibers, commingling different kinds of, $304,305,395,397$;

plants, permitted or prohibited pairings of, 32 ;

vines, sowing crops among, $218,222,241,363,368$

Animals, commingling different kinds of, 15-16, 43-50, 251-31

$c_{\text {Aqiva, }}$ crops, sowing together different kinds of, 66-63, 123-24, $128-29,131-32,135,139,352,353$;

plants, permitted or prohibited pairings of, 32-35;

vines, sowing crops among, 190-92, 203, 205, 239-40, 244-45

Asher b. Yehiel (Rosh), animals, commingling different kinds of, 388 ;

crops, sowing together different kinds of, $94,96,340$, 352,355 ;

fibers, commingling different kinds of, 292, 293, 307, 397, 399; grafting, 325 ;

vines, sowing crops among, 214, 235, 366

Assi, crops, sowing together different kinds of, 340

Bar Qappara, crops, sowing together different kinds of, 350 ; plants, permitted or prohibited pairings of, 43,322

Ben 'Azzai, vines, sowing crops among, 244-45

Berlin, Naftali Șevi Yehudah (Neșiv), vines, sowing crops among, $1 \dot{9} 9,238,247,37 \dot{8}, 385$

Blackman, P., animals, commingling different kinds of, 43 vines, sowing crops among, 165

Bokser, B. M., crops, sowing together different kinds of, 354; vines, sowing crops among, 153, 154, 155, 239

Crops, sowing together different kinds of, 6-9, 61, 64-144

Danby, H., animals, commingling different kinds of, 253, 266, 272,386 ;

crops, sowing together different kinds of, 90, 94, 102, 107, $109,113,126$;

fibers, commingling different kinds of, 284, 289, 297, 306, 309; grafting, 61 ;

plants, permitted or prohibited pairings of, 32 ;

vines, sowing crops among, 146, 151, 153, 158, 160, 165, $176,180,188,190,193,212,214,216,217,221,222$, $223,224,231,234,236,240,242,363$ 
David b. Solomon Ibn Abi Zimra (Ridbaz), crops, sowing together different kinds of, 336 ;

fibers, commingling different kinds of, 395, 397;

grafting, 63;

vines, sowing crops among, 226, 368, 371

Deuteronomic Code, 2

Dosethai b. Judah, vines, sowing crops among, 195, 197

Eleazar (Amora), vines, sowing crops among, 190

Eleazar b. Simeon, crops, sowing together different kinds of, 91-93, $99,101,339$;

fibers, commingling different kinds of, 300

Eleazar b. Sadoq, vines, sowing crops among, 234-36, 380

Eliezer (or Eleazar), crops, sowing together different kinds of, $109,110,124,125,139,346,351,355$;

fibers, commingling different kinds of, 297, 298, 299, 395;

vines, sowing crops among, 176, 178, 179-80, 193-94, 199, $205,208-9,214-16,366$

Eliezer b. Jacob, crops, sowing together different kinds of, 97 , 99, 100, 107-8;

vines, sowing crops among, 158-59, 175-78, 180, 214-16

Elijah b. Solomon Zalman (GRA), animals, commingling different kinds of, 258, 259, 260, 261, 262, 263, 269, 270, 274, 276,386 ;

crops, sowing together different kinds of, $74,75,87,90$, $91,96,98,109,117,120,140,338,346,356$;

fibers, commingling different kinds of, 288;

grafting, 56, 63;

plants, permitted or prohibited pairings of, $26,28,35,40$, 319 ;

vines, sowing crops among, 152, 153, 155, 156, 159, 171, $187,192,193,194,199,204,206,227,244,245,361$, $363,366,375,378,380,381,382,385$

Ephraim Isaac of Premsyla (MR), animals, commingling different kinds of $45,267,276,388,389$;

crops, sowing together kinds of, $74,75,76,86,90,333$, 336,341 ;

fibers, commingling different kinds of, 285, 299, 399;

grafting, 62,325 ;

plants, permitted or prohibited pairings of, $33,38,321$;

vines, sowing crops among, 155-56, 218, 361, 362, 363, 364

Epstein, Y. N., crops, sowing together different kinds of, 344 ; plants, permitted or prohibited pairings of, 33

Estori Parhi (KP), animals, commingling different kinds of, 276; vines, sowing crops among, 190

Feldman, U., vines, sowing crops among, 369, 371

Feliks, J., animals, commingling different kinds of, 44-46;

crops, sowing together different kinds of, 75, 76, 78, 79, $90,91,92,103,105,106,107,120,332,333,334,336$, $337,339,342,344,345,350$;

grafting, $36,51,52,53,54,55,56,57,58,59,60,62$, $63,326,327,328,330$;

plants, permitted or prohibited pairings of, $28,29,33$, 39,316 ;

vines, sowing crops among, 375, 379

Fibers, commingling of, 16-17, 283-313

Gamaliel, vines, sowing crops among, 171, 206, 371

Gereboff, J. vines, sowing crops among, 371

Grafting, 6, 35-37, 50-64, 141-42

Green, W. S., vines, sowing crops among, 374 
Hai Gaon, grafting, 62,330

Hananiah b. Gamaliel, fibers, commingling different kinds of, 308,312

Hananiah b. Hakinai, vines, sowing crops among, 158

Heller, Yom Tov Lipman (TYT), animals, commingling different kinds of, 44,275 ;

crops, sowing together different kinds of, $80,95,96,110$, 345 ;

plants, permitted or prohibited pairings of, 26, 42;

vines, sowing crops among, 156, 366

Hillel b. Eliaqim (Hillel), animals, commingling different kinds of, $260,261,264,265$;

fibers, commingling different kinds of, 295, 309;

vines, sowing crops among, 192, 199, 227, 246, 378, 385

Hillel, House of, crops, sowing together different kinds of, $90-91,92,93$;

vines, sowing crops among, 146-48, 154-55, 157, 181, 183, $196,198,203-5,216,233-34,235,358,359,363,367$, $371,374,379,380$

Isaac b. Melchizedek of siponto (Ribmaș), animals, commingling different kinds of, 255;

crops, sowing together different kinds of, 95, 345, 352;

fibers, commingling different kinds of 307,397 ;

vines, sowing crops among, 154, 156, 159, 223, 232, 238, 361,376

Isaac b. Moses of Vienna (OZ), animals, commingling different kinds of, 255 ;

crops, sowing together different kinds of, 142 ;

fibers, commingling different kinds of, 299, 395

Ishmael, crops, sowing together different kinds of, 122-24, $128-33,134,136,137,141,353,354,356$;

vines, sowing crops among, 196, 198, 217, 219, 220, 221, 374

Is 1 the Babylonian, animals, commingling different kinds of, $270-71,387$

Israelstam, J., plants, permitted or prohibited pairings of, 32

Jastrow, M., animals, commingling different kinds of, 266;

fibers, commingling different kinds of, 291, 311;

vines, sowing crops among, 224

Jonah, grafting, 36 ;

plants, permitted or prohibited pairings of, 38, 317;

vines, sowing crops among, 227

Joshua, vines, sowing crops among, 217, 219, 220, 374

Joshua b. Levi, animals, commingling different kinds of, 390; grafting, 320

Josiah, crops, sowing together different kinds of, 331

Judah, animals, commingling different kinds of, 46-47, 266-70, 273,324 ;

crops, sowing together different kinds of, 61, 64, 104-5, $116-17,123-24,331,344,349$;

fibers, commingling different kinas of, 298-99, 310-11;

grafting, 51-52, 58-60;

plants, permitted or prohibited pairings of, 28-32, 317, 318;

vines, sowing crops among, 147-50, 157-58, 160-61, 208-9, $227,359,360$

Judah b. JAgra, grafting, 58-60, 328

Judah the Prince (Rabbi), crops, sowing together different kinds of, 104, 114

Kahane, crops, sowing together different kinds of, $340,352,354$ 
Karlin, Samuel Avigdor b. Abraham (MB), animals, commingling different kinds of, 255 ;

crops, sowing together different kinds of, 339, 356;

vines, sowing crops among, 153, 154, 214, 372

Karo, Joseph b. Ephraim (KM), vines, sowing crops among, 156, 371

Lieberman, S., animals, commingling different kinds of, 267, 268, $269,277,278,323,388$;

crops, sowing together different kinds of, $65,66,83,90$, $91,98,104,106,107,113,120,121,127,131,137$, $138,140,142,143,144,331,334,341,344,346,356$, 357 ;

fibers, commingling different kinds of, 286, 287, 288, 291, $293,298,300,301,311,313,392,394,397,398,400$; grafting, $36,57,61,141,325$;

plants, permitted or prohibited pairings of, $32,40,42$, 318,322

vines, sowing crops among, 149, 150, 153, 154, 169, 170, $171,173,179,180,193,195,196,197,206,208,209$, $210,222,226,232,233,234,250,264,360,365,372$, $375-76,379,382,383$

Lipschütz, Baruch Isaac b. Israel (TYB), vines, sowing crops among, 380

Lipschütz, Isaac b. Gedaliah (TYY), animals, commingling different kinds of, 272,388 ;

crops, sowing together different kinds of, 74, 90;

fibers, commingling different kinds of, 289, 290, 393, 399; grafting, 63, 64, 329, 330;

vines, sowing crops among, 151, 152, 156, 157, 214, 238, $241,361,377$

Löw, I., grafting, $36,57,326,328$;

plants, permitted or prohibited pairings of, 316 ;

vines, sowing crops among, 369

Maimonides, animals, commingling different kinds of, 44, 45, $47,49,273,386,388$;

crops, sowing together different kinds of, $68,74,76,80$, $87,88,90,94,95,101,102,103,125,126,129,134$, $135,340,341,342,344,345,347,349,350,352,353,355$;

fibers, commingling different kinds of, 284, 285, 289, $290,293,296,301,303,304,310,311,391,392,393$, $395,397,399$;

grafting, $35,36,62,63,64,329,330,331$;

plants, permitted or prohibited pairings of, $27,42,316,321$;

vines, sowing crops among, 151, 152, 153, 154, 155, 156, 157, $165,176,178,181,182,183,194,204,214,215,219$, $223,225,226,231,240,241,242,358,359,361,362,363$, $366,367,368,371,374,375,376,379,380,382$

Margoliot, Moses b. Simeon (PM), animals, commingling different kinds of, $268,273,387$;

crops, sowing together different kinds of, 85, 87, 137, 354;

plants, permitted or prohibited pairings of, 43, 319;

vines, sowing crops among, 156, 366, 381, 385

Meir, animals, commingling different kinds of, 265-66, 268, 269, 274-77;

crops, sowing together different kinds of, 104-5, 107-9, $114,134,136,338,345,346,357$;

fibers, commingling different kinds of, 298-99;

plants, permitted or prohibited pairings of, 30-32;

vines, sowing crops among, 160, 165-66, 169, 175, 217, 220, $223,233,234-35,376,379,380$

Meiri, Menahem b. Solomon, grafting, 62

Mena, vines, sowing crops among, 216 
Neha b. Sabbah, animals, commingling different kinds of, 393 Neh̆emiah, crops, sowing together different kinds of, 131-32; plants, permitted or prohibited pairings of, 38, 40-41

Neusner, J., crops, sowing together different kinds of, 346, 351; plants, permitted or prohibited pairings of, 42 ; vines, sowing crops among, 179, 187, 236, 366, 383

Obadiah of Bertinoro (Bert.), animals, commingling different kinds of, 272 ;

crops, sowing together different kinds of, 95, 117, 355;

fibers, commingling different kinds of, 289, 310; grafting, $63,64,325,329$;

vines, sowing crops among, 155, 156, 159, 190, 238, 241, $361,366,380$

Order, and creation, 2-4;

and holiness, 2-3;

human conception of, 1,3 ;

priestly understanding of, $2-4$

Pardo, David Samuel b. Jacob (HD), animals, commingling different kinds of, 255, 256;

crops, sowing together different kinds of, $66,81,82$, $98,104,140,336,399$;

fibers, commingling different kinds of, $286,393,394,400$; grafting, 56 ;

plants, permitted or prohibited pairings of, 322 ;

vines, sowing crops among, 173, 178, 187, 188, 208, 360, 372,384

Plants, permitted or prohibited pairings of, 5-6, 25-35, 37-43

Porton, G., crops, sowing together different kinds of, 131, 351; vines, sowing crops among, 217,374

Priestiy Code, 2-4

Primus, C., crops, sowing together different kinds of, 332; vines, sowing crops among, 190

Rav, crops, sowing together different kinds of, 340 ; plants, permitted or prohibited pairings of, 320 ; vines, sowing crops among, 384

Resh Laqish, crops, sowing together different kinds of, 331

Samson of Sens, animals, commingling different kinds of, 255 , $256,272,276,388$;

crops, sowing together different kinds of, 88, 90, 95, 96, $104,112,137,138,140,335,345,347,352,355$;

fibers, commingling different kinds of, 288, 290, 302, 303, $307,310,392,393,397,398,399$;

grafting, $54,62,63,64,325,327,329$;

plants, permitted or prohibited pairings of, 41 ;

vines, sowing crops among, 152, 153, 156, 159, 166, 223, $232,358,361,363,371,376$

Samuel, crops, sowing together different kinds of, 131, 354, 357

Shammai, House of, animals, commingling different kinds of, 272-74; crops, sowing together different kinds of, 90-93, 140; grafting, 37;

vines, sowing crops among, 146-48, 154-55, 181, 196, 198, $203-5,233,234,358,379,380$

simeon, animals, commingling different kinds of, 389 ;

crops, sowing together different kinds of, 73-77, 94, 96, $104,105,341,344$;

plants, permitted or prohibited pairings of, 30-31, 34-35, 319; vines, sowing crops among, 160-61, 169, 170, 174-75, 192, $196,235,239-41,248-49,250$ 
Simeon b. Eleazar, fibers, commingling different kinds of, 300-301, $304-6,309,397$;

vines, sowing crops among, 187-88, 221, 375

Simeon b. Gamaliel, crops, sowing together different kinds of, $81,83,104-5,344$;

grafting, 58-60;

vines, sowing crops among, 233

simeon b. Judah, vines, sowing crops among, 192

Sirillo, Solomon b. Joseph, crops, sowing together different kinds of $, 68,76,86,90,125,130,137,352$;

fibers, commingling different kinds of, 397; grafting, $54,327,330$;

vines, sowing crops among, 217

Sirkes, Joel, animals, commingling different kinds of, 387;

crops, sowing together different kinds of, 95

Solomon b. Isaac (Rashi), animals, commingling different kinds of, 280 ;

crops, sowing together different kinds of, 95, 332;

fibers, commingling different kinds of, 400 ;

grafting, $62,63,330$;

vines, sowing crops among, 156, 361, 384

Tarfon, vines, sowing crops among, 193-94, 196, 198, 368

Tosafot Anshé Shem (TAS), crops, sowing together different kinds of, 76 ;

vines, sowing crops among, 182-83, 367

Vines, sowing crops among, 9-15, 145-250

Yehosaf Ashkenazi, crops, sowing together different kinds of, 90

Yohanan, fibers, commingling different kinds of, 393, 395; vines, sowing crops among, 376

Yohanan b. Nuri, vines, sowing crops among, 203-5, 206, 237, 375,376

Yosé, animals, commingling different kinds of, 48-50, 272-76, 324,325 ;

crops, sowing together different kinds of, 73-74, 94-96, $101,104,111-12,134-36,346,355$;

fibers, commingling different kinds of, 303, 306-7, 396; grafting, 327 ;

plants, permitted or prohibited pairings of, 30 ;

vines, sowing crops among, 176, 178, 205, 208-9, 212, 217, $220,223-24,233,239-40,241,362,377$

Yosé b. Geali, vines, sowing crops among, 171

Yosé b. HaHotef, crops, sowing together different kinds of, 134,136

Yosé b. Judah, vines, sowing crops among, 205-6, 212-14

Zachs, N., crops, sowing together different kinds of, 126

ze'ira, fibers, commingling different kinds of, 393 
